
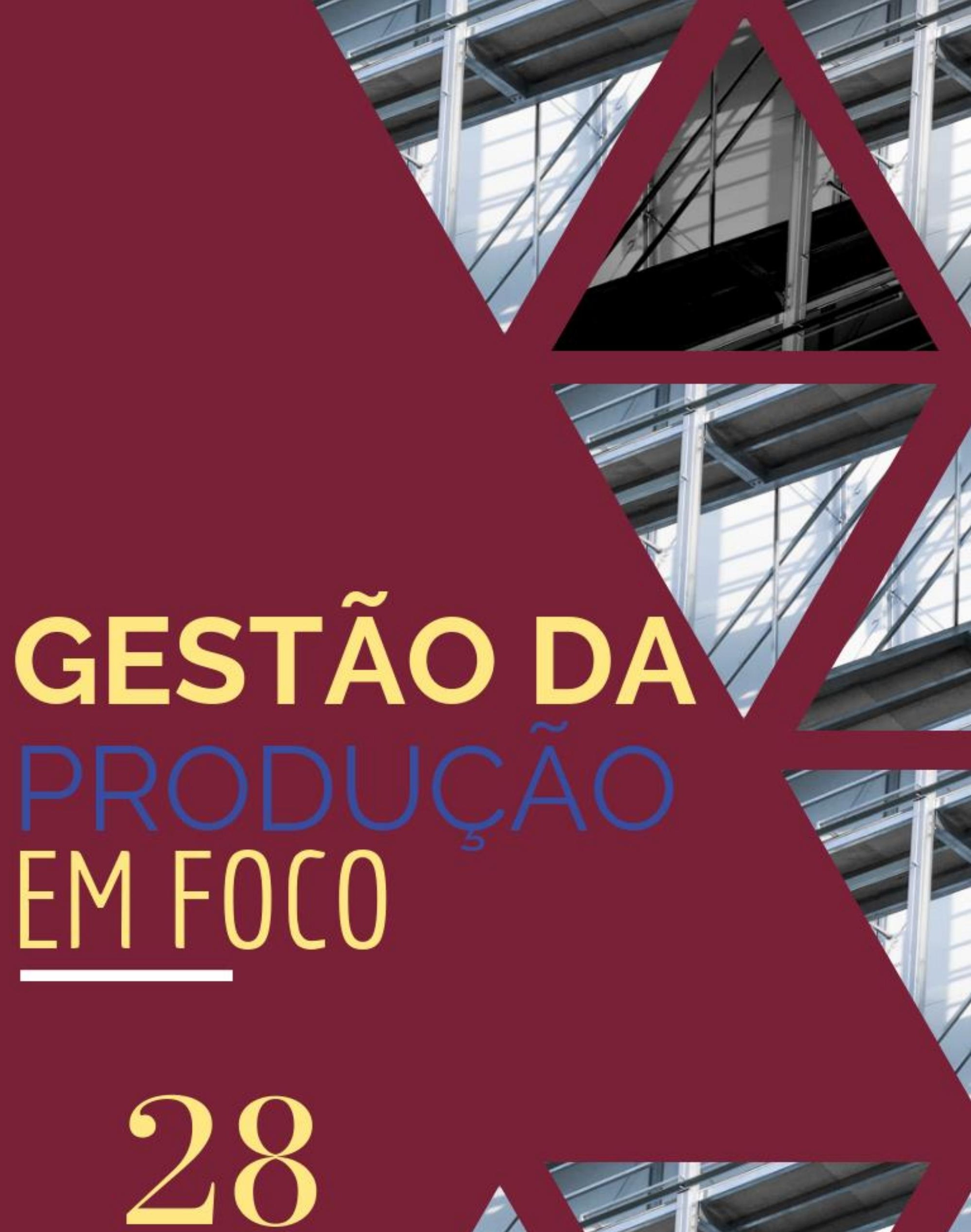

$<>$ Editora Poisson 
Editora Poisson

\section{Gestão da Produção em Foco Volume 28}

1ạ Edição

Belo Horizonte

Poisson

2019 
Editor Chefe: Dr. Darly Fernando Andrade

\section{Conselho Editorial}

Dr. Antônio Artur de Souza - Universidade Federal de Minas Gerais

Ms. Davilson Eduardo Andrade

Dr. José Eduardo Ferreira Lopes - Universidade Federal de Uberlândia

Dr. Otaviano Francisco Neves - Pontifícia Universidade Católica de Minas Gerais

Dr. Luiz Cláudio de Lima - Universidade FUMEC

Dr. Nelson Ferreira Filho - Faculdades Kennedy

Ms. Valdiney Alves de Oliveira - Universidade Federal de Uberlândia

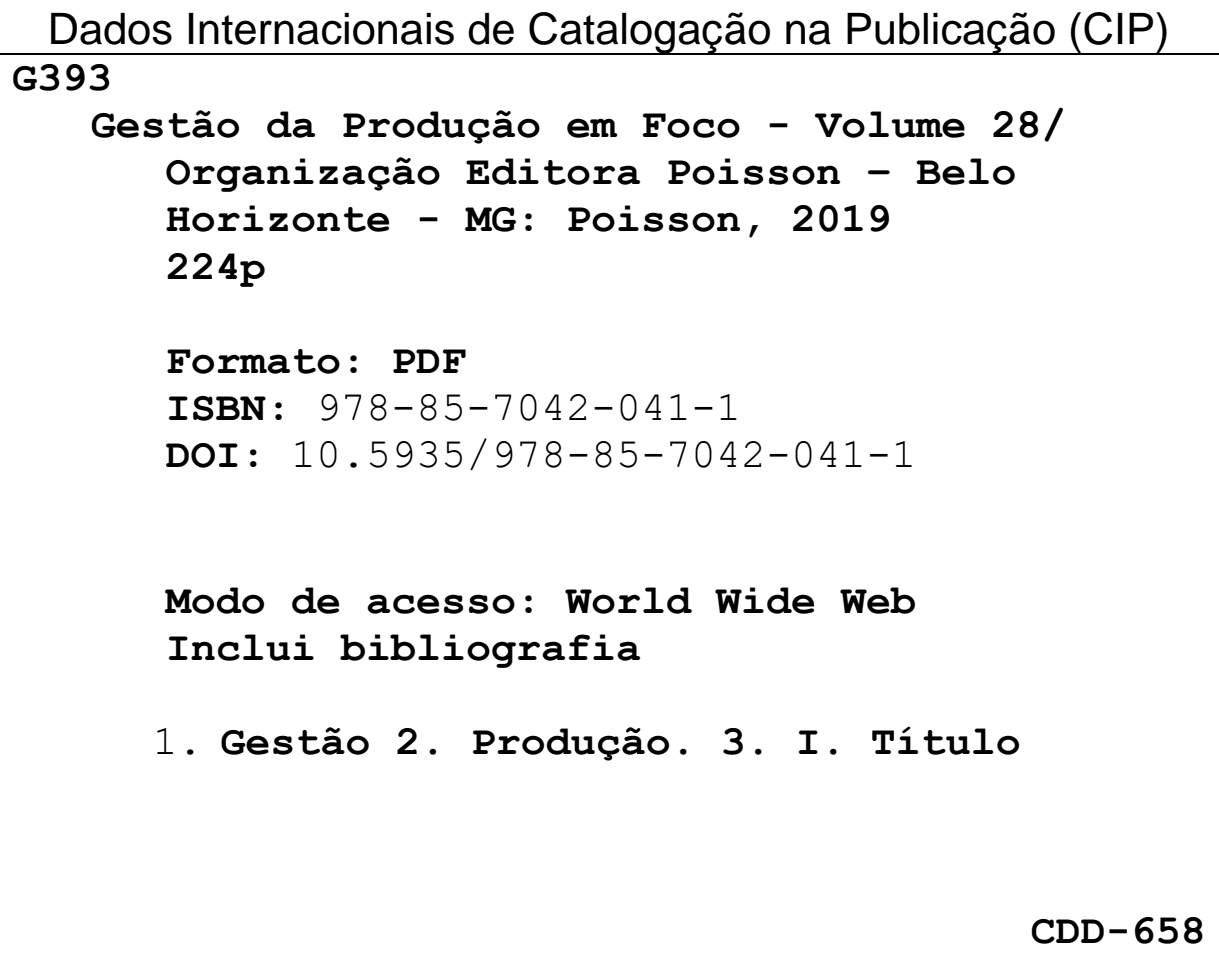

O conteúdo dos artigos e seus dados em sua forma, correção e confiabilidade são de responsabilidade exclusiva dos seus respectivos autores.

Baixe outros títulos gratuitamente em www.poisson.com.br

contato@poisson.com.br 


\section{Sumárīio}

Capítulo 1: Aplicação dos conceitos de engenharia de métodos: Estudo de caso em uma hamburgueria na cidade de Penedo, AL.

Nicolas Lennick Bomfim de Albuquerque, Maria Eduarda da Silva Nunes, Anderson Costa Ramos, Ana Carolina Lucena Christiano

Capítulo 2: Controle produtivo no gerenciamento de obras: O uso de aplicativos e sistemas em construtoras de Quixadá-CE

Francisco Rennan Mota Uchôa, Ranna Marques Felipe, Cintia Castelo Branco, Pedro Matheus Vieira Pinheiro, Paulo Rogério Freitas de Matos

Capítulo 3: Proposta de redução de tempo de setup em células de usinagem com o uso de conceitos da Metodologia SMED

Gabriela Moraes Simões Evangelista , Laura Keiko Arimitsu , André de Lima ,Ivan Correr

Capítulo 4: Barreiras ao uso da estatística como prática da gestão da qualidade em indústrias de transformação do Sul e Sudeste do Brasil.

Letícia Saggioratto, Adriana Barbosa Santos, Carolina Barbosa Gomes

Capítulo 5: Controle da variabilidade do processo de envase de biocombustível com o uso da Metodologia Seis Sigma.

Rafael Francisco Campos Pianno, Walther Azzolini Júnior, Jorge Alberto Achcar

Capítulo 6: Análise da capacidade de transporte do sal em uma salina do $\mathrm{RN}$, com base na teoria das restrições.

Dellano Jatobá Bezerra Tinoco

Capítulo 7: Propostas de melhorias com o uso da Metodologia Six Sigma em uma confecção paranaense.

Ana Carolina Kiener, Cássia Garcia Renó, Délvio Venanzi, Haroldo Lhou Hasegawa, Vidal Dias da Mota Junior

Capítulo 8: Desenvolvimento de um sistema de controle da velocidade de uma máquina de ensaios mecânicos.

Erick Cardoso Costa, Rodrigo de Carvalho Paes Loureiro, Rodrigo Bíscaro Nogueira, Reinaldo José Tonete, Max Adilson Lima Costa 


\section{Sumárīio}

Capítulo 9: Implementação da IATF 16949:2016 em uma indústria de grande porte.

Lorena Santos de Jesus, Samantha Nascimento Santana

Capítulo 10: Elaboração de procedimentos para uma empresa de pequeno porte com base na ISO 22716:2007.

Laís Gabriel Leandro Marilene Souza Gabriel, Valnei Carlos Denardin, Ivete de Fátima

Rossato, Ana Regina de Aguiar Dutra, Juliano Mazute

Capítulo 11: Evolução do rendimento e da área colhida da laranja e o deslocamento da cultura dentro do estado de São Paulo.

Gerônimo Guerreiro Neto, Leonardo Rezende Martins, Sérgio Rangel Fernandes Figueira

Capítulo 12: Proposta de aplicação da Ferramenta Kanban em uma indústria de ráfias.

Anderson Castagna, Stefan Antonio Bueno, Mara Lucia Grando, Cleusa Teresinha Anschau

Capítulo 13: Qualidade em serviços e satisfação de estudantes no ensino superior do Instituto Federal de São Paulo.

Jorge Henrique de Oliveira Silva, Glauco Henrique de Sousa Mendes, Gilberto Miller Devós Ganga, Solange Aparecida de Souza Monteiro

Capítulo 14: Aplicação de métodos multicritérios para apoio na tomada de decisão de investimentos em serviços tecnológicos oferecidos para a indústria nacional.

Alisson Marcelo Laurindo, Eduardo Rocha Loures

Capítulo 15: Aplicação de métodos de auxílio multicritério para seleção de fornecedores de serviço de transporte para empresas do segmento de óleo e gás.

Davidson de Almeida Santos, Mara Regina dos Santos Barcelos, Osvaldo Luiz Gonçalves Quelhas, Carlos Francisco Simões Gomes, Sheila da Silva Carvalho Santos

Capítulo 16: Avaliação ergonômica do trabalho do armador no ambiente fabril. 


\section{Sumárīo}

Capítulo 17: O valor colaborativo do usuário em um projeto de melhoria de um posto de trabalho em uma empresa de panificação.

Adonildo Marques da Silva Neto, Camilla Henrique de Araújo, Rodrigo Ribeiro Monteiro Gomes

Capítulo 18: Identificação do nível de inovação das empresas do APL de calçados da região do Cariri-CE.

Isis da Silva Vieira, Isydorio Alves Donato, Maria Keyllyany Rodrigues da Silva

Capítulo 19: Ecossistema de inovação: Um estudo acerca do incentivo ao desenvolvimento de startups no município de São Carlos/SP

Aiquinis Kellen Rosalis Fantuce, Ana Rita Gallo, Maria Amélia Silva dos Reis, Suellen

Cristina Balduino Lopes, Thiago Silva Polli Santos

Capítulo 20: A aprendizagem e o conhecimento como ferramentas para empoderamento de Mulheres: Relato de casos.

Irlanda Mayra Medeiros da Silva, Suellen Karolyne Silva Correia, Luana Kelly de Mendonça,

Ricardo Moreira da Silva, Josilene Aires Moreira 


\section{Capítulo 1}

\section{APLICAÇÃO DOS CONCEITOS DE ENGENHARIA DE METODOS: ESTUDO DE CASO EM UMA HAMBURGUERIA NA CIDADE DE PENEDO, AL}

\section{Nicolas Lennick Bomfim de Albuquerque}

\section{Maria Eduarda da Silva Nunes}

Anderson Costa Ramos

Ana Carolina Lucena Christiano

Resumo: O presente artigo busca propor a aplicação dos conceitos e técnicas exequíveis da Engenharia de Métodos no contexto micro empresarial, considerando sua importância no que concerne a determinação de padrões nos métodos e tempos nas atividades produtivas desenvolvidas por uma hamburgueria localizada no município de Penedo, AL. Ao estudar os tempos e movimentos realizados em cada tarefa da produção de um dos produtos, atestou-se os possíveis benefícios e aperfeiçoamentos gerados a partir do uso e elaboração dessas técnicas e documentos. Para tal, houveram acompanhamentos da rotina da empresa a fim de compreender o processo realizado e cronometrar o tempo despendido em cada micro processo, para análise e estudo posteriores. Desta forma, tornou-se possível o uso de algumas ferramentas e documentos como: planta baixa, fluxograma, mapofluxograma, layout e cálculos para encontrar o tempo padrão. A partir disso, foram identificados problemas referentes ao espaço físico, tempo de produção e fator de ritmo do operador. Logo, a presente proposta consiste na disponibilização de um conjunto de técnicas da Engenharia de Métodos que irão permitir aos gestores conduzir o negócio e tomar decisões de maneira mais incisiva.

Palavras-chave: Engenharia de métodos, Estudo de tempos, Estudo de movimentos, Tempo Padrão. 


\section{INTRODUÇÃO}

A engenharia de métodos ou o estudo dos tempos e movimentos, surgiu como fruto dos trabalhos de Frederick Taylor, bem como do casal Frank e Lillian Gilbreth, há mais de cem anos. Tais estudos desenvolveram maneiras de determinar, respectivamente, o métodopadrão e o tempo-padrão para a execução de tarefas. Slack (2015) entende que o estudo do método é uma abordagem sistemática para encontrar o melhor método, o que inclui: entender o trabalho em estudo; registrar os fatos importantes do método atual; examinar os fatos criticamente e em sequência; desenvolver um método mais prático, econômico e eficaz; instalar esse método; e manter o método a partir de avaliações constantemente no uso. Assim, percebe-se que a necessidade de métodos padronizados torna os conceitos, que compõem os estudos de métodos, movimentos e tempos, presentes no mais amplo contexto empresarial.

A engenharia de métodos foi criada para a melhoria do trabalho manual, por meio de determinações de um número-padrão de minutos que uma pessoa qualificada, treinada e experiente pode executar, em seu repertório de tarefas específicas, trabalhando normalmente. De acordo com Barnes (1977), toda empresa comercial ou organização industrial preocupa-se com a criação de bens e serviços de alguma forma, utilizando homens, máquinas e materiais. $\mathrm{Na}$ operacionalização de um processo de produção, pode-se abranger a entrada e processamento de matérias-primas e insumos, até entrega do produto acabado. No planejamento desse processo, deverão ser considerados tanto o sistema no seu conjunto, quanto cada operação individual, que forma o sistema ou processo.

Neste sentido, o objetivo deste trabalho foi, a partir da observação da rotina de uma hamburgueria localizada na cidade de Penedo/AL e da utilização dos conceitos e das ferramentas da engenharia de métodos, demonstrar a aplicabilidade e importância das mesmas no contexto micro empresarial. Dentre as vantagens e aplicabilidades tem-se a possibilidade do aumento da capacidade produtiva da organização, através da determinação de um tempo padrão no sistema produtivo e a disposição de documentos que possibilitam tomadas decisões empresariais, relativas às melhorias e sistematização do arranjo físico.

\section{FUNDAMENTAÇÃO TEÓRICA}

Neste tópico, procura-se desenvolver condições para uma maior compreensão dos principais conceitos referentes à Engenharia de Métodos, bem como às suas ferramentas utilizadas neste trabalho.

\subsection{A ENGENHARIA DE MÉTODOS}

A engenharia de métodos integra 0 subconjunto das áreas de estudo da Engenharia de Produção, segundo a Associação Brasileira de Engenharia de Produção (ABEPRO). Souto (2002) aborda a engenharia de métodos como sendo uma técnica que se empenha diretamente no ajuste e implantação de métodos, visando a melhor execução de tarefas partindo da implementação de técnicas eficazes para a padronização das operações e aumento da produtividade.

Seleme (2009) defende o uso da palavra 'melhor', em um meio competitivo, para definir engenharia de método o caminho para se chegar ao melhor resultado. Por outras palavras, um procedimento desenvolvido a partir das necessidades de simplificação e de padronização do trabalho humano para a redução do esforço despendido na execução das operações e tarefas.

Congruentemente, Peinado et al. (2007) afirma que engenharia de métodos ou 0 estudo de tempos, movimentos e métodos aborda técnicas que submetem a uma detalhada análise cada operação de uma dada tarefa, com o objetivo de eliminar qualquer elemento desnecessário à operação e determinar o melhor e mais eficiente método para executá-la.

\subsection{FERRAMENTAS DA ENGENHARIA DE MÉTODO}

Nessa seção, será discutido algumas técnicas e ferramentas da engenharia de métodos que subsidiarão o desenvolvimento deste trabalho.

\subsubsection{GRÁFICO DO FLUXO DO PROCESSO}

Para se ter uma investigação detalhada é preciso analisar as etapas que compõem o processo de fabricação, isto é, as operações. De acordo com Barnes (1977), o gráfico do fluxo do processo é uma técnica utilizada para se registrar um processo de maneira 
compacta, a fim de tornar possível sua melhor compreensão global e posterior elaboração da proposta de melhoria. O diagrama reproduz as etapas do processo, delineando seus passos, como os transportes, as esperas, armazenagens etc. e, para elaboração deste diagrama, utiliza-se a simbologia padronizada pela American Society of Mechanical Engenieers (ASME), descrita na figura 1.

Tálamo (2016) afirma que o gráfico deve ser adequado à realidade de cada empresa e pode ser executado tanto para o fluxo percorrido dos materiais quanto para a sequência de atividades de um operador. Ainda o mesmo autor, ao explicar os símbolos do diagrama de fluxo de processo, define operação como qualquer intervenção sobre um material ou produto por meio de uma ou mais operações; transporte é qualquer deslocamento do material dentro do processo, exceto quando a movimentação for parte integrante da operação; inspeção é toda avaliação quantitativa ou qualitativa sobre o material; espera é o intervalo de tempo entre a última operação e a seguinte; e armazenamento o controle físico de um material.

Figura 1- Símbolos da ASME para gráfico do fluxo de processo

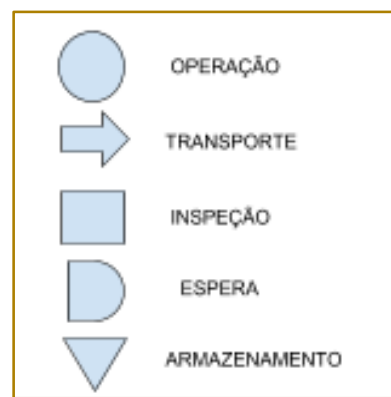

Fonte: adaptado pelos autores (BARNES, 1977)

\subsubsection{MAPEAMENTO DE PROCESSOS}

A literatura apresenta algumas metodologias de mapeamento com diferentes enfoques tornando a correta interpretação das técnicas fundamentais no processo de mapeamento, dentre eles, o presente trabalho utilizar-seá do fluxograma, que consiste em uma técnica que permite o registro das ações de algum tipo e pontos de tomada de decisão que ocorrem no fluxo real e; do mapofluxograma é o fluxograma desenhado sobre a planta ou layout das instalações da empresa para melhor visualização do processo. (BARNES, 1977)

De acordo a visão de Koschmider e Reijers (2015), o mapeamento de processos é o nível mais tangível e concreto da classificação do processo, pois pode ser utilizado como uma ferramenta de melhoria separada, bem como em combinação com a gestão por processo. Para os autores, ao identificar e mapear os processos, desenvolve-se um meio de entender a organização, e as oportunidades de melhoria são identificadas.

\subsubsection{CRONOMETRAGEM E TEMPO PADRÃO}

A cronometragem é a determinação do tempo médio da execução de uma atividade por meio de instrumentos que permitem a medição do tempo gasto, desta forma, essencial para o controle de uma produção de um produto ou de um serviço (TÁLAMO, 2016).

A execução da cronometragem tem por objetivo estabelecer o tempo padrão, que em uma abordagem mais clássica, Barnes (1977) propõe o cálculo do tempo padrão com a exigência de alguns dados preliminares importantes, dentre eles o fator de ritmo, o qual analisa $\mathrm{o}$ esforço empregado pelo trabalhador. Esse valor será empregado, assim como o tempo cronometrado, obtendo o tempo normal para operação, sendo este devendo ser somado às tolerâncias para contrabalancear os espaços de tempo não trabalhados e, desta forma, se obter o tempo padrão.

Logo, para verificar e propor um tempo padrão de uma operação, tem que se aferir o tempo pela cronometragem por diversas 
vezes, para se obter uma média aritmética dos dados coletados. Dentre as Regras gerais para determinação de um tempo cronometrado, os autores Peinado e Graeml (2007) pressupõem as seguintes etapas: 1 Separação do processo em partes, as quais possam ser as mais curtas possíveis, desde que não sejam inferiores a cinco segundos; 2Separação do trabalho realizado pelo operador e o trabalho realizado pela máquina quando forem interdependentes; 3Separação dos atrasos ocasionados pelo operador e pelos equipamentos.

Para calcular o tempo padrão, além de realizar várias aferições de cronometragem de tempo, demanda-se, também, alguns dados preliminares importantes, dentre eles o fator de ritmo, que analisa o esforço empregado pelo trabalhador, esse valor será empregado assim como o tempo cronometrado obtendo o tempo normal para cada operação (BARNES, 1997).

$\mathrm{TN}=\mathrm{TC} \times \mathrm{V}$

Denotando:

$\mathrm{TN}=$ Tempo normal

$\mathrm{TC}=$ Tempo cronometrado

$\mathrm{V}=$ Velocidade do operador

Consoante Barnes (1977), o tempo normal é o tempo requerido por um operário qualificado, trabalhando no ritmo normal dos operários em geral sob supervisão hábil, para completar um elemento, ciclo ou operação, seguindo um método preestabelecido. É também a soma de todos os tempos elementares normais que constituem um ciclo ou uma operação, desprovido de tolerâncias. Tolerâncias são os acréscimos de tempo incluídos no tempo normalizado de uma operação, a fim de compensar o operário pela produção perdida por causa de fadiga e das interrupções normalmente previstas, tais como as paradas pessoais e as inevitáveis. O tempo padrão deve possuir o tempo normal somado as tolerâncias para contrabalançar os espaços de tempo não trabalhados desta forma.

Tempo Padrão: TP = TN x FT

Em que:

TP = Tempo padrão

$\mathrm{TN}=$ Tempo normal

FR = Fator de Tolerância

\section{METODOLOGIA}

\subsection{CLASSIFICAÇÃO DA PESQUISA}

O presente trabalho pode ser classificado, quanto à aplicabilidade, como pesquisa aplicada, que, tomando como base os fundamentos de Silva e Menezes (2005), dizem gerar conhecimentos para aplicação prática, bem como conhecimentos dirigidos à solução de problemas específicos, envolvendo verdades e interesses locais. Quanto à forma de abordagem do problema, esse trabalho tem como foco a abordagem qualitativa do problema, que segundo Cauchick, (2010), Gressler (2004), Silva e Menezes (2005) tem como objetivo interpretar e dar significado aos fenômenos investigados, e não empregar métodos e técnicas estatísticas como base do processo de análise do problema. Quanto aos fins, com base em Vergara (2012), a pesquisa é exploratória, pois visa proporcionar maior familiaridade com o problema e possíveis descobertas, com vistas a torná-lo explícito ou a construir hipóteses e esclarecimentos com a utilização dessas ferramentas in loco para que assim se possa comprovar a eficiência das ferramentas utilizadas no desenvolvimento do estudo.

Em relação aos meios, esse trabalho se consolidou a partir da realização de um estudo de caso, bem como de uma pesquisa bibliográfica e de um levantamento de dados. A pesquisa é um estudo de caso, pois consiste no estudo profundo e exaustivo do objeto de estudo, permitindo seu extensivo e detalhado conhecimento (GIL, 2010, apud BARBOSA et al., 2017). É bibliográfica, haja visto que há a utilização de ferramentas já descobertas e desenvolvidas na literatura da área, além de ter todo o levantamento bibliográfico com base em materiais publicados em livros, revistas, anais de congressos e periódicos eletrônicos (VERGARA, 2012). Enfim, é um levantamento de dados porque envolve a interrogação direta das pessoas envolvidas com 0 processo produtivo, carecendo de elementos teóricos que justifiquem sua realidade coletada e analisada (SILVA; MENEZES, 2005; THUMS, 2003).

\subsection{UNIDADE DE ANÁLISE}

A empresa atua no setor alimentício fabricando sanduíches naturais, de chapa (hambúrgueres) e açaí na tigela, da mesma 
maneira prestam serviço de entrega, intitulada comercialmente de Fire burger, é localizada no município de Penedo-AL, onde foi fundada no ano de 2014, precisamente no mês de novembro. Atualmente, possui um quadro composto por 7 funcionários, alocados nos setores da produção e de administração, sendo 4 na produção e 3 na administração. A média de faturamento mensal é de 24.000 reais. A mão-de-obra trabalha sob o regime de uma jornada de trabalho de 7 horas trabalhada durante os 7 dias na semana, de 16 horas até 23 horas, tendo direito a 1 dia de folga semanal, e não é permitido horas extras. A rotatividade e absenteísmo na empresa é baixo, em que houvera nos últimos seis meses apenas uma demissão. A faixa etária dos funcionários é em torno de 21 anos, os quais são recrutados por meio de mídias sociais e, sem necessidade de experiência prévia, a capacitação é promovida pela empresa. A remuneração é efetuada quinzenalmente, e as refeições dos colaboradores são providas pela organização e as demais necessidades, como banheiros, vestiários, bebedouro, etc, são os mesmos utilizados pelos clientes, em função do ambiente ser pequeno.

\subsection{COLETA DOS DADOS}

As técnicas de coleta de dados adotadas foram: a observação do processo de produção dos sanduíches, em 5 visitas, onde foi cronometrando o tempo utilizado para o preparo dos mesmos, onde foi escolhido um sanduíche dentre os disponíveis no cardápio. Além disso também se elaborou e aplicou aos proprietários uma entrevista com um questionário semiestruturado, de modo a coletar dados para caracterização e análise organizacional.

\section{RESULTADOS E DISCUSSÕES}

\subsection{DESCRIÇÃO SUCINTA VERBAL DE CADA ETAPA DE FABRICAÇÃO}

Dentre o mix de produtos oferecidos pela hamburgueria, foi selecionado o x-burguer para análise do processo (figura 2) e elaboração do mapofluxograma (figura 5). Inicialmente é realizada a compra dos materiais necessários para a produção dos sanduíches, são eles: pão, queijo, hambúrguer bovino e salada. A compra do material é feita diariamente. Finalizada esta etapa o funcionário busca no estoque todos os materiais e os posicionam em cima do balcão em estoques separados por ingrediente. Após receber o pedido e ligar a chapa começa o processo de produção com aquecimento da parte inferior do pão. Em seguida o hambúrguer é assado, põe-se o queijo em cima do hambúrguer para esquentar, adiciona-se o hambúrguer e queijo na parte inferior do pão e depois a salada. A finalização do sanduíche se dá após ser fechado com a parte superior do pão e colocado na embalagem apropriada. Por fim é posicionado na bandeja e levado para balcão onde é feita a entrega aos clientes pelos garçons.

\subsection{CARACTERIZAÇÃO DAS SEÇÕES DA FÁBRICA E SUAS FƯNÇÕES}

Por ser uma empresa de pequeno porte, a mesma possui o setor administrativo, setor de produção dos sanduíches, o setor de pedidos e entregas e o setor de segurança. Os responsáveis pela administração são os proprietários da hamburgueria. Através desse setor são realizados os pagamentos de materiais e de fornecedores; para essas e demais atividades relacionadas contam com um computador e registros.

O setor de produção é onde ocorre todas as etapas de fabricação dos sanduíches, no qual existem quatro funcionários responsáveis pelas atividades de separar os materiais, esquentar e assar os mesmos, bem como finalizar o produto. E o setor de pedidos e entregas conta com 2 entregadores.

Número de empregados é distribuído nos setores com 3 na administração, entre eles, segurança, entregadores; e 4 pessoas na fabricação dos hambúrgueres, totalizando 7 funcionários. O maquinário e equipamentos para a confecção dos produtos são: 2 chapas, 1 freezer, 1 geladeira, 1 liquidificador. No estoque tem: 1 prateleira e a matéria prima armazenada.

\subsection{GRÁFICO DO FLUXO DE PROCESSO}

O gráfico do fluxo de processo (figura 2) é uma técnica que serve para representar toda a sequência de tarefas realizadas na empresa pelos seus funcionários. Seus símbolos têm por objetivo facilitar a visualização do processo e identificar atividades críticas. O fluxograma descrito abaixo foi analisado e descrito em relação ao produto escolhido para mostrar a aplicabilidade da engenharia 
de métodos foi a produção de x-burguer. $\mathrm{O}$ processo tem inicio com a busca dos materiais no estoque, com sua devida separação e disposição na bancada. O que facilita o processo e reduz tempo gasto com esperas e longos deslocamentos do funcionário. O fluxograma (figura 2) detalhado auxiliará o treinamento dos funcionários, uma vez que está descrita todas as operações, proporcionando a sugestão de um método de produção padrão.

Figura 2 - Gráfico do fluxo do processo de produção do x-burguer.

\begin{tabular}{|c|c|c|c|c|c|}
\hline \multicolumn{6}{|c|}{ FLUXOGRAMA DO PROCESSO } \\
\hline Etapa & Distância (m) & Tempo (min) & \multicolumn{2}{|c|}{ Processo } & Descrição do Processo \\
\hline 1.1 & & & $\Rightarrow$ & $D \nabla$ & Estoque dos materiais \\
\hline 1.2 & & & $\Rightarrow$ & $D \nabla$ & Busca dos materiais no estoque \\
\hline 1.3 & & & $\Rightarrow$ & $D \nabla$ & Pegar os materiais \\
\hline 1.4 & & & $\Rightarrow$ & $\nabla \nabla$ & Trazer os materiais para o balcão \\
\hline 1.5 & & & $\Rightarrow$ & $D \nabla$ & Separação dos materiais ao lado da chapa \\
\hline 1.6 & & & $\Rightarrow$ & $D \nabla$ & Ligar a chapa \\
\hline 1.7 & & & $\Rightarrow$ & $D \nabla$ & Estoque do pão \\
\hline 1.8 & & & $\Rightarrow$ & $D \nabla$ & Tansporte do pão para a chapa \\
\hline 1.9 & & & $\Rightarrow$ & $D \nabla$ & Esquenta o Pão \\
\hline 1.10 & & & $\Rightarrow$ & $D \nabla$ & Estoque do hamburguer \\
\hline 1.11 & & & $\Rightarrow$ & $D \nabla$ & Transporte do Hamburguer para a chapa \\
\hline 1.12 & & & $\Rightarrow$ & $D \nabla$ & Assar o hamburguer \\
\hline 1.13 & & & $\Rightarrow$ & $D \nabla$ & Estoque do queijo \\
\hline 1.14 & & & $\Rightarrow$ & $D \nabla$ & Transporte do Queijo para a chapa \\
\hline 1.15 & & & $\Rightarrow$ & $D \nabla$ & Coloca o Queijo em cima do Hamburguer \\
\hline 1.16 & & & $\Rightarrow$ & $D \nabla$ & Pôr o Hamburguer e o queijo em cima da parte inferior do pão \\
\hline 1.17 & & & $\Rightarrow$ & $D \nabla$ & Estoque da salada \\
\hline 1.18 & & & $\Rightarrow$ & $D \nabla$ & Busca Salada no estoque ao lado da chapa \\
\hline 1.19 & & & $\Rightarrow$ & $D \nabla$ & Coloca a salada junto ao hamburguer e queijo \\
\hline 1.20 & & & $\Rightarrow$ & $\nabla \nabla$ & Fecha o sanduíche com a parte superior do pão \\
\hline 1.21 & & & $\Rightarrow$ & $D \nabla$ & Coloca o sanduíche na embalagem própria \\
\hline 1.22 & & & $\Rightarrow$ & $D \nabla$ & Coloca o sanduíche embalado na bandeja \\
\hline 1.23 & & & $\Rightarrow$ & $D \nabla$ & Transporte da bandeja para o balcão \\
\hline
\end{tabular}

Fonte: Adaptado pelos autores (simbologia da ASME) (2018)

\subsection{PLANTA BAIXA DAS INSTALAÇÕES E ARRANJO FÍSICO (LAYOUT)}

As instalações da empresa (figura 3) apresentam limitações de espaço, e por isso há dificuldades de propor melhorias relacionadas ao arranjo físico e disposição de máquinas e equipamentos (figura 4). Portanto, como se pode observar no layout dos equipamentos da lanchonete, a utilização da planta baixa e arranjo físico servirá para melhor visualização das tarefas descritas no fluxograma (figura 2) sendo operacionalizadas no mapofluxograma (figura 5). Além de permitir os decisores planejarem possíveis reformas estruturais ou até mesmo razoáveis redimensionamentos do layout 
Figura 3 - Planta baixa da lanchonete Fire.

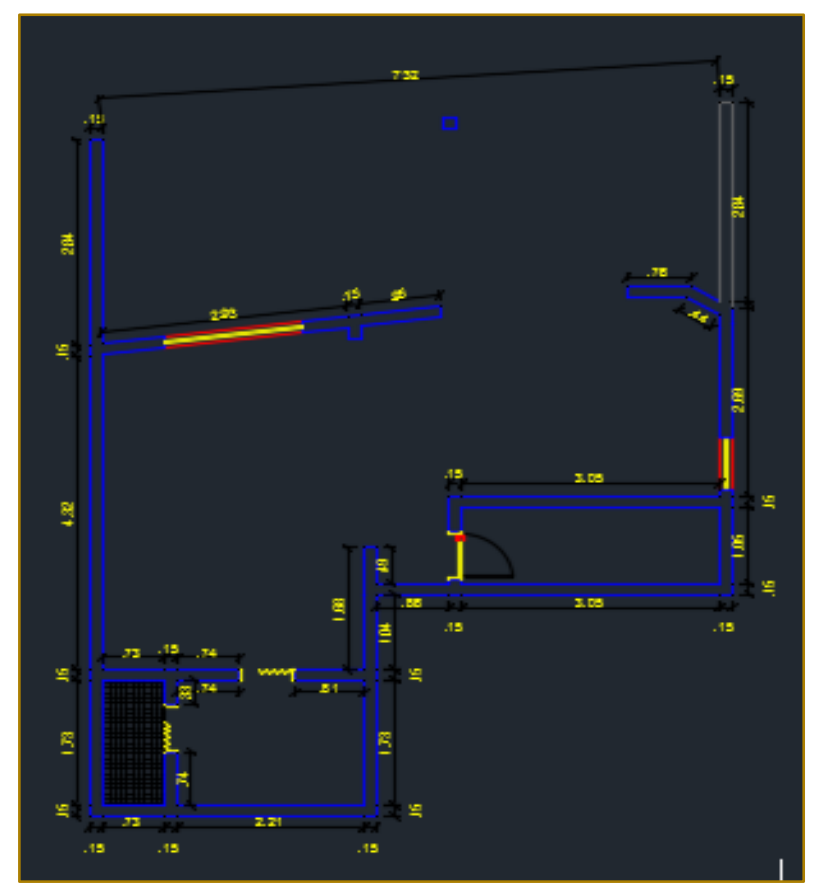

Fonte: Autores (2018)

Figura 4 - Layout dos equipamentos da lanchonete Fire

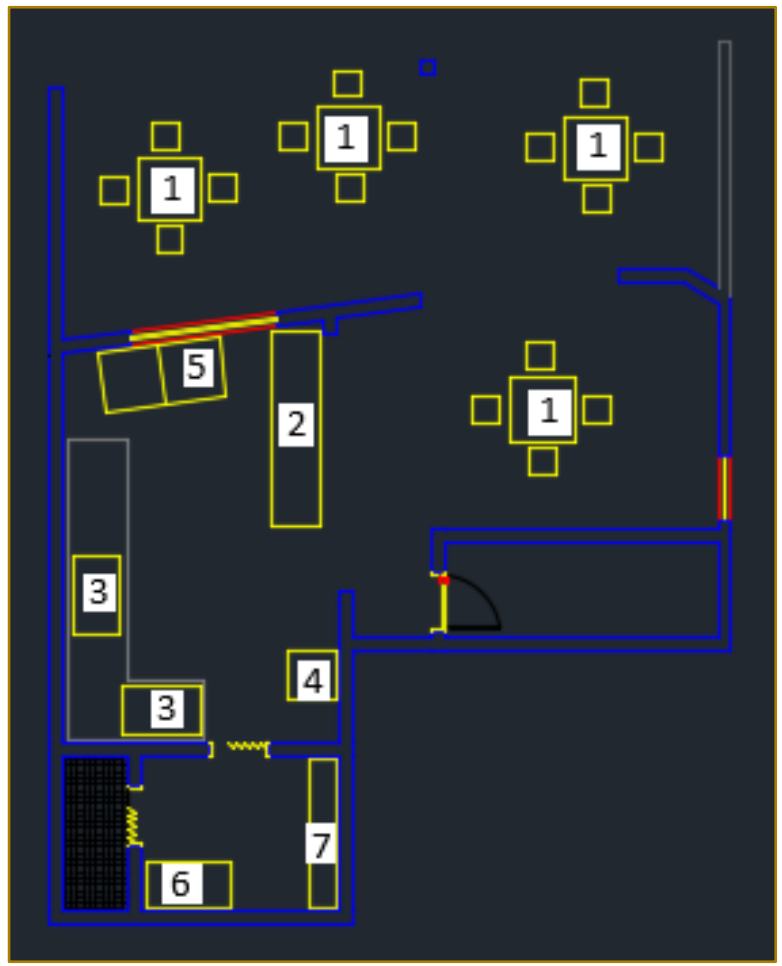

Fonte: Autores (2018)

Simbologia: 1 - Mesa refeição $(70 \times 70 \mathrm{~cm}) ; 2$ - Balcão da recepção $(54 \times 220 \mathrm{~cm}) ; 3$ Chapa de forno $(53 \times 88 \mathrm{~cm}) ; 4$ - Geladeira $(54 \times 54 \mathrm{~cm}) ; 5$ - Freezer $(66 \times 136 \mathrm{~cm}) ; 6$ -
Pia $(51 \times 96 \mathrm{~cm}) ; 7$ - Prateleira de estoque (30 $\times 164)$. 


\subsection{MAPOFLUXOGRAMA}

O mapoflugograma permitirá o delineamento de uma linha sequencial do processo produtivo junto ao fluxograma. Permitindo e auxiliando a exploração das possibilidades de mudanças no processo ao espaço físico presente. Apresentando todo o esforço despendido pelo executor das tarefas do processo e quais máquinas e/ou equipamentos serão de fato necessário, evitando gastos excessivos ou a subutilização de equipamentos que podem está ocupando espaços úteis e importantes.

Figura 5 - Mapoflugrama do processo

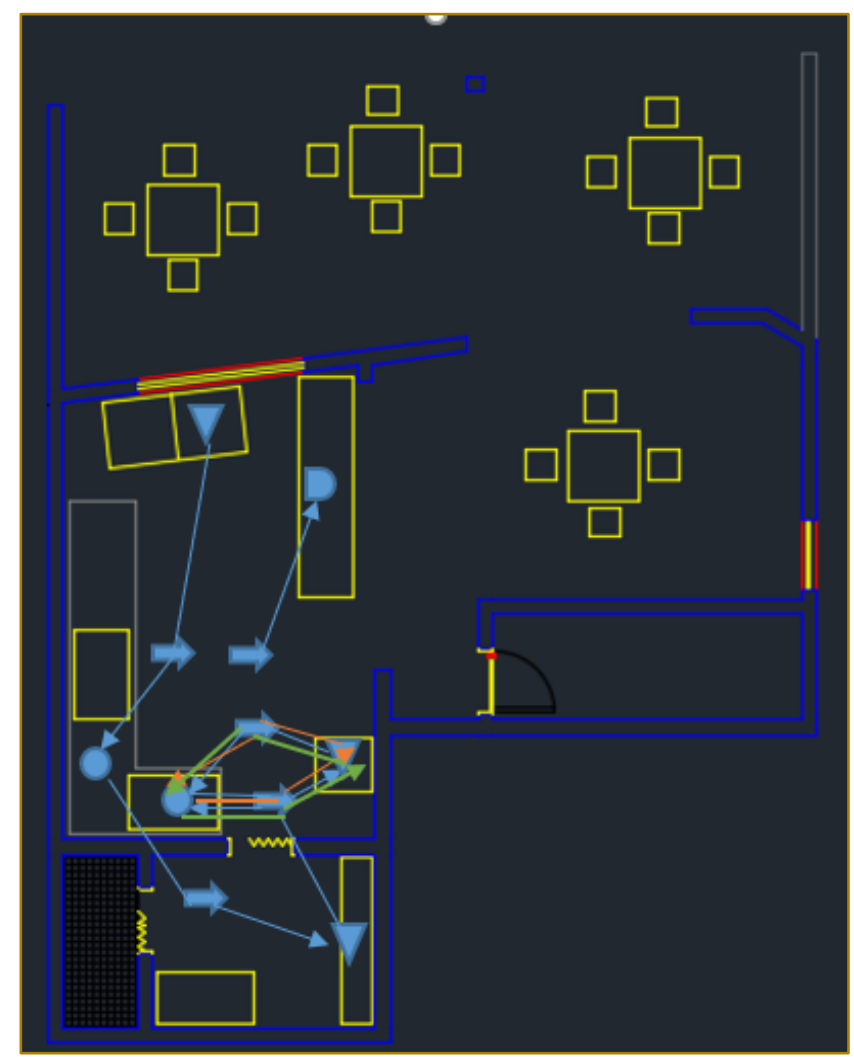

Fonte: Autores (2018)

Legenda: linha azul: pão; linha laranja: queijo; linha verde: salada.

\subsection{TEMPO PADRÃO}

Na busca de determinar um tempo padrão, os resultados foram obtidos a partir do acompanhamento da produção dos sanduiches, no intuito de coletar os dados para o cálculo de elementos necessários para chegar à proposta de padronização do tempo de produção. O processo de produção do $x$ burguer, produto escolhido dentre o mix de produtos da lanchonete. Dentro de oito processos realizados em cinco cronometragens para cada um, assim, verificou a velocidade de execução do operador, essa velocidade $V$ (também denominada de RÍTMO) do operador é determinada subjetivamente por parte do cronometrista, que a referência à assim denominada velocidade normal de operação, à qual é atribuído um valor 1,00 (ou 100\%); Onde velocidade normal ( $\mathrm{V}=100 \%)$, velocidade acelerada ( $V>100 \%$ ) e velocidade lenta $(\mathrm{V}<100 \%)$ (BARNES, 1977). Logo, após achar o tempo normal e tempo normal total, para encontrar o tempo padrão fez-se necessário achar 0 fator FT (Fator de Tolerância) é geralmente dado por: $F T=1 /(1$ p). O fator de tolerância é importante, já que não é possível trabalhar sem interrupções toda uma jornada de trabalho. Sendo previstas interrupções no trabalho para que sejam atendidas as denominadas necessidades fisiológicas e para proporcionar um descanso, aliviando os efeitos da fadiga no trabalho. De um modo geral, atribui-se tolerância de 5\% para necessidades fisiológicas, $10 \%$ para trabalhos leves, como é o presente caso; e mais de $50 \%$ para 
trabalhos árduos e/ou em condições precárias. Além disso, é possível observar (tabela 1) que o ritmo do operador, em determinadas fases na montagem, pode ser considerado lento, pois se perceber habilidade na execução das tarefas, porém seu nível de esforço não corresponde ao posto em que está inserido acrescentando um tempo maior para produção de uma unidade do produto na 4 cronometragem que soma $8,18 \mathrm{~min}$ em todo o processo, diferente das demais cronometragem, numa média de $6,6 \mathrm{~min}$.

Tabela 1 - tabela de cronoanálise.

\begin{tabular}{|c|c|c|c|c|c|c|c|c|}
\hline \multirow{2}{*}{ Operações } & \multicolumn{5}{|c|}{ Cronometragem (min.) } & \multirow{2}{*}{$\begin{array}{l}\text { Tempo } \\
\text { Cronometrado } \\
\text { Média(min.) }\end{array}$} & \multirow[t]{2}{*}{$\begin{array}{l}\text { Velocidad } \\
\quad \text { e (\%) }\end{array}$} & \multirow[t]{2}{*}{$\begin{array}{l}\text { Tempo normal } \\
\text { (min.) }\end{array}$} \\
\hline & 1 & 2 & 3 & 4 & 5 & & & \\
\hline Ouvir o pedido & 1,23 & 1,32 & 0,83 & 1,24 & 1,42 & 1,21 & $100 \%$ & 1,21 \\
\hline $\begin{array}{c}\text { Busca dos materiais } \\
\text { no estoque }\end{array}$ & 0,43 & 0,67 & 0,78 & 0,87 & 0,53 & 0,66 & $80 \%$ & 0,52 \\
\hline $\begin{array}{l}\text { Separar os } \\
\text { ingredientes }\end{array}$ & 1,56 & 1,23 & 1,43 & 1,61 & 1,36 & 1,44 & $80 \%$ & 1,15 \\
\hline Esquentar o pão & 0,54 & 0,51 & 0,63 & 0,48 & 0,54 & 0,54 & $85 \%$ & 0,46 \\
\hline Assar o hambúrguer & 1,5 & 1,3 & 1,46 & 2,55 & 1,58 & 1,68 & $95 \%$ & 1,59 \\
\hline $\begin{array}{l}\text { Montagem do } \\
\text { sanduíche }\end{array}$ & 0,6 & 0,76 & 0,59 & 0,64 & 0,72 & 0,66 & $80 \%$ & 0,53 \\
\hline Embalar & 0,3 & 0,43 & 0,32 & 0,43 & 0,34 & 0,36 & $95 \%$ & 0,35 \\
\hline Entrega no balcão & 0,3 & 0,38 & 0,41 & 0,36 & 0,42 & 0,37 & $95 \%$ & 0,36 \\
\hline \multicolumn{8}{|c|}{ Tempo normal total (min.) } & 6,17 \\
\hline \multicolumn{8}{|c|}{ Tolerância } & $10 \%$ \\
\hline \multicolumn{8}{|c|}{$\begin{array}{c}\text { Tempo padrão (min.) } \\
\left(\mathrm{TP}=\mathrm{TN} \times \mathrm{FT} \text { ITP }=6,17^{\star} 1,1\right) \\
\text { FT }=10 \%(1,10)\end{array}$} & 6,78 \\
\hline
\end{tabular}

Fonte: Autores (2018)

\section{CONSIDERAÇÕES FINAIS}

Com base nos resultados observados e discutidos, verifica-se a aplicabilidade e necessidade da utilização das técnicas e teorias da Engenharia de Métodos no micro empreendimentos, haja visto que, comumente, micro e pequenas empresas têm dificuldades de padronizar seus métodos e tempos ao operacionalizar seus serviços ou processos produtivos. Sendo assim, conhecer suas tarefas, processos e operações de modo holístico e amplo, por meio de plantas baixas, arranjos físicos, fluxo de processos e mapofluxogramas, é o primeiro passo para galgar novos passos em direção a padronização dos métodos produtos e posterior análise e determinação do tempo padrão de execução.
Não obstante, foram encontrados problemas em relação ao espaço físico onde está alocada a lanchonete, tais problemas são relacionados ao tamanho reduzido do local, o que reduz, por conseguinte, as possibilidades de propostas de mudanças junto ao arranjo físico.

Notou-se que o fator humano no procedimento estudado apresenta crucial importância na verificação de velocidade de produção e produtividade.

O presente trabalho não possui pretensão de acompanhar a execução ou praticabilidade das propostas sugeridas, ficando a critério da empresa o fazer.

Isto exposto, avalia-se que o estudo de tempos e movimentos, quando aplicada de 
maneira adequada potencializa as micro e pequenas empresas, em níveis de padronização de empresas de portes superiores, em razão das ferramentas

\section{REFERÊNCIAS}

[1] BARBOSA, T. A.et al. Aplicação de conceitos de Engenharia de métodos em um restaurante de comida japonesa. XXXVII Encontro Nacional de Engenharia de Produção, 2017.

[2] BARNES, R. M. Estudo de movimentos e de tempos: projeto e medida do trabalho. São Paulo: Edgard Blücher, 1977.

[3] CAUCHICK M, Paulo A. (coord.). Metodologia de pesquisa em engenharia de produção e gestão de operações. Rio de Janeiro: Elsevier, ABEPRO, 2010.

[4] GRESSLER, L. A. Introdução à pesquisa: projetos e relatórios. $2^{\underline{a}}$ ed. São Paulo: Loyola, 2004.

[5] GIL, A. C. Como elaborar projetos de pesquisa. 5. ed. São Paulo: Atlas, 2010.

[6] KOSCHMIDER, A.; REIJERS, H. A. Improving the Process of Process Modelling by the Use of Domain Process Patterns. Enterprise Information Systems, v. 9, n. 1, p. 29-57, jan. 2015.

[7] PEINADO, J.; GRAEML, A. Estudo de tempos, movimentos e métodos. In: Administração possibilitarem a identificação minuciosa de falhas e gargalos nos sistemas produtivos e consequentes intervenções, as quais geram aumentos de produtividade e rentabilidade.

da Produção: Operações Industriais e de Serviços. Curitiba: UnicenP, 2007. cap. 2.

[8] SELEME, ROBSON. Métodos e tempos: racionalizando a produção de bens e serviços. Editora Ibpex, 2009.

[9] SILVA, E. L; MENEZES, E. M. Metodologia da pesquisa e elaboração de dissertação. 4.ed. Florianópolis: Laboratório de Ensino à Distância da UFSC, 2005.

[10] SLACK, N. et al. Administração da Produção. 4. ed. São Paulo: Atlas, 2015.

[11] TÁLAMO, J. Roberto. Engenharia de métodos: o estudo de tempos e movimentos. Curitiba: Intersaberes, 2016.

[12] THUMS, J. Acesso à realidade: técnicas de pesquisa e construção do conhecimento. Canoas: ULBRA, 2003.

[13] VERGARA, S. C. Projetos e relatórios de pesquisa em administração. 11. ed. São Paulo: Atlas, 2012. 


\section{Capítulo 2}

\section{CONTROLE PRODUTIVO NO GERENCIAMENTO DE OBRAS: O USO DE APLICATIVOS E SISTEMAS EM CONSTRUTORAS DE QUIXADÁ-CE.}

\section{Francisco Rennan Mota Uchôa}

\section{Ranna Marques Felipe}

Cintia Castelo Branco

Pedro Matheus Vieira Pinheiro

Paulo Rogério Freitas de Matos

Resumo: A utilização de aplicativos e sistemas no processo de controle produtivo em empresas de construção civil ainda é um tabu. Durante o gerenciamento de uma obra, os sistemas podem auxiliar no processo de compra de materiais, vistorias, compartilhamento de informações, dentre outros inúmeros fatores. Por meio de uma pesquisa bibliográfica buscou-se unir os conceitos de controle produtivo, gerenciamento de obras e a utilização de sistemas e aplicativos nesse processo. Através de uma pesquisa de campo, os autores entrevistaram duas construtoras da cidade de Quixadá-CE no intuito de conhecer a metodologia de gerenciamento de obras empregada na empresa, identificar se foi utilizado algum sistema ou aplicativo que auxilie no gerenciamento das obras e quais as principais barreiras para a utilização desses softwares.

Palavras-chave: Gerenciamento de Obras. Sistemas de controle. Controle de Produção. 


\section{INTRODUÇÃO}

A construção de um empreendimento, uma obra civil, é um processo complexo e com diversos fatores que devem ser estruturados, planejados e executados com o maior rigor e atenção de todos os envolvidos.

Um projeto de Construção Civil deve seguir algumas etapas para a sua concepção. Essas etapas são caracterizadas como: "o estudo de viabilidade, o desenvolvimento do produto, desenvolvimento dos projetos executivos, desenvolvimento da obra e desligamento com liberação para Habite-se" (ASSUMPÇÃO e FUGAZZA, 2001, p. 01).

Das diversas etapas de uma construção o desenvolvimento prático da obra é uma etapa que necessita de muita atenção. O gerenciamento da obra requer que diversos fatores e departamentos estejam em sintonia e que, ao menor sinal de inconformidade, todos os setores sejam informados e ajustados para que o processo não tenha atrasos, desperdícios e prejuízos.

De modo geral, existem diversas particularidades, como as necessidades do cliente, os possíveis impactos em construções vizinhas, dentre outros que, durante a etapa de criação de um projeto, não são devidamente observadas ou são suprimidas por diversos fatores, desde 0 desconhecimento do projetista, análises mal realizadas, até problemas não identificados anteriormente à construção.

Pensando nesses pontos, o uma boa equipe de gestão é uma peça fundamental no andamento do empreendimento, pois todas as informações e detalhes devem ser supervisionados e verificados por essa equipe. Como são muitos fatores e particularidades em cada obra, há a necessidade de um processo de controle detalhado e coeso, para que as falhas possam ser as menores possíveis. Atribuições como organização, liderança e conhecimento profundo da obra e dos processos de controle produtivo, são fundamentais para essa função.

É necessário, também, que ocorra o compartilhamento de informações, plantas, dados, entre outros, com todos os envolvidos no processo da construção e que problemas de desorganização, perdas, ou métodos antigos não atrapalhem esse compartilhamento.
O auxílio da tecnologia é fundamental para a organização de diversos processos. A criação de sistemas e aplicativos para gerenciamento de obras cresce a cada ano, visto que a Indústria da Construção Civil ainda é uma área que a Tecnologia da Informação possui dificuldades de se inserir.

Então, como as construtoras de Quixadá-CE gerenciam as obras, como o uso de sistemas e aplicativos poderiam auxiliar o gerenciamento das obras, além disso, quais as barreiras para sua utilização nas construtoras de Quixadá-CE?

Por meio desse questionamento, este trabalho tem como objetivo promover um estudo obre a utilização de sistemas e aplicativos para controle de produção e gerenciamento de obras em construtoras de Quixadá-CE, visualizando seus benefícios no processo de construção civil local.

O desenvolvimento em tecnologias, sistemas e aplicativos que auxiliam e organizam os processos é crescente. Além desse crescimento, o número de adeptos a essas facilidades tecnológicas em diferentes áreas de atuação é visível. Agendas, lembretes, informações, entre outros, que até então eram acompanhados em meio físico (papel) tornam-se agora digitais, na palma da mão, ao alcance dos smartphones.

Em contrapartida, a área da Construção Civil é vista por muitos como conservadora. É uma área em que a Tecnologia da Informação ainda encontra diversas barreiras em mostrar seu potencial de facilitar os processos, organizar e guardar as mais diversas informações, assim como apresentá-las.

$\mathrm{Na}$ Construção Civil os estudos de tempo e custo são predominantes, logo, justifica-se o estudo de ferramentas que auxiliem na organização e aperfeiçoamento de processos de gerenciamento de obras.

As construtoras localizadas na cidade de Quixadá-CE são de pequeno porte, visto que as obras executadas por elas são apenas de construção de casas simples e reformas. Com isso, acentuam-se as principais causas de barreiras para utilização de ferramentas e sistemas tecnológicos de gestão de projetos e empreendimentos. O investimento nesses tipos de softwares completos é, normalmente, caro e requer um elevado nível de conhecimento e aptidão em Tecnologia da Informação e softwares. 


\section{REFERENCIAL TEÓRICO}

\subsection{PLANEJAMENTO E CONTROLE DA PRODUÇÃO}

Durante a produção, seja de um produto ou serviço, é necessário que se tenha um planejamento estruturado e coeso para que falhas e processos desnecessários sejam evitados.

O processo de Planejamento e Controle de Produção (PCP) foi evoluindo a partir de todos os estudos envolvendo a administração dos processos de produção, a administração científica de Taylor, a produção em massa de Ford e os demais estudiosos que, década pós década trabalharam com o PCP de acordo com as evoluções tecnológicas e processuais até a presente data.

Buscando apresentar as funções do PCP, Lustosa et al. (2008, p. 5) diz que "na busca por excelência, percebe-se a influência de três funções do PCP: o planejamento, a programação e o controle. Ao comandar, coordenar e controlar o processo produtivo tais funções são imprescindíveis para a sobrevivência da empresa".

Em uma empresa, o Planejamento e Controle de Produção (PCP) está inserido no setor administrativo/produtivo, junto aos demais setores que possuem funções de planejamento, compras, manutenção, qualidade e tecnologia.

É de fundamental importância entender onde o PCP está inserido e com que outras funções ele deve se comunicar para que exista uma unidade nas tomadas de decisão durante o processo produtivo, onde "O PCP é responsável pela coordenação e aplicação dos recursos produtivos de modo a atender da melhor forma possível aos planos estabelecidos nos níveis estratégico, tático e operacional" (LUSTOSA et al., 2008, p. 7).

Um planejamento deve ser pensado, descrito e elaborado para que haja um detalhamento das ações que serão executadas. Esse detalhamento possibilitará que, durante 0 processo de construção, critérios de controle sejam estabelecidos.

Os sistemas de planejamento e controle de produção devem seguir contextos cíclicos e de ajustes sempre que necessários. Essa visão processual é de extrema importância para a determinação das futuras tomadas de decisão.
Albertin e Pontes (2016, p. 124) dizem que:

O controle de produção garante que todas as decisões tomadas durante o planejamento e a programação sejam executadas nos prazos e com os volumes preestabelecidos. Para isso, precisamos dispor de um sistema de informações que relate periodicamente sobre: materiais em processo (produto semiacabado) existentes nos diversos setores de produção, estoques de matéria-prima e de produtos acabados, localização e progresso de cada OP, nível de utilização da capacidade dos equipamentos etc.

Com isso, percebe-se o quão importante é o processo de controle, visto que os prazos e ustos de um projeto não devem superar o programado pelo planejamento. Todo processo planejado deve apresentar ações de controle e monitoramento durante a produção.

Os diversos sistemas de controle de produção são baseados nos modelos e indicadores fixados pela empresa na programação da produção. Segundo Tironi (1993 apud LUSTOSA et al., 2008, p. 212) os indicadores são "a expressão da mensuração ou da medida da qualidade de um produto ou processo, ou da produtividade de um processo".

Quando se alinha os conceitos de Planejamento e Controle de Produção com a sua aplicação no gerenciamento de obras da construção civil necessita-se realizar uma análise detalhada em relação a indicadores de desempenho e os métodos utilizados.

Bernardes (2010, p. 59) apresenta alguns tópicos onde considera como deficiências nos sistemas de planejamento e controle de empresas de construção:

Dificuldade para organizar o próprio tempo de
trabalho; Ausência de integração vertical do
planejamento; Inexistência de um plano de
médio prazo; Falta de formalização e
sistematização na elaboração do plano de
curto prazo; Desconsideração da
disponibilidade financeira na fixação das
metas; Estabelecimento de metas impossíveis
de serem atingidas; Falta de envolvimento do
mestre de preparação nos planos de curto
prazo; Controle informal; Programação de
recursos realizada fora do período adequado
ou em caráter emergencial.

Considerando esses pontos, percebe-se que diversos problemas durante a viabilidade da obra e no planejamento são pontos que 
atrapalham os sistemas de controle, o gerenciamento da obra e, consequentemente, a sua finalização.

As entidades responsáveis pelo planejamento encontram dificuldades na atualização dos planos, visto que as mesmas não dispõem de informações do canteiro de obras para a retroalimentação do planejamento, como também devido ao excesso de trabalho que é exigido para atualizar planos muito detalhados (LAUFER; TUCKER, 1987 apud BERNARDES, 2010, p. 12).

$\mathrm{Na}$ Construção Civil, cada projeto deve ser tratado de forma única, com processos e problemas específicos. Isso mostra como o tratamento das informações deve sofrer uma análise mais detalhada e auxiliada por sistemas que facilitem o processo.

\subsection{SOFTWARES ERP E APS}

Uma atenção especial deve ser dada para os sistemas ERP (Enterprise Resources Planning) e APS(Advanced Planning \& Scheduling). Lustosa et al. (2008, p. 289) resume um sistema ERP como:

Um sistema capaz de receber, controlar e processar, de forma estruturada e on-line, os dados inerentes à maioria dos processos de negócios internos realizados em uma organização, integrando as áreas funcionais em uma base de dados única.

Enterprise Resources Planning ou Planejamento de Recursos Empresariais, em tradução direta, onde as principais características desse sistema são: usa uma base unificada de dados; permite a troca de informações on-line; Permite a integração entre as áreas funcionais afins da organização; são sistemas modulares, parametrizáveis que se adaptam às necessidades de cada empresa; são sistemas multiempresas; Podem ser integrados aos sistemas de outras empresas (LUSTOSA et. al 2008).

Os sistemas APS, de acordo com Faé e Ehrart (2005 apud SOUSA, 2012, p. 4), são uma evolução de vários sistemas onde:

A maioria dos softwares APS utilizam princípios de Theory of Constraints (TOC) ou Teoria das Restrições, sendo capazes de considerar praticamente todas as variáveis $e$ restrições inerentes ao ambiente produtivo, gerando planos de execução viáveis que necessitam de pouca ou nenhuma intervenção do programador, e funcionam de forma integrada aos ERPs.

Portanto, esses sistemas se integram para melhorar a produção, o controle produtivo e, consequentemente, os resultados obtidos pela empresa.

Os softwares voltados a gerenciamento e controle de obras disponíveis no mercado auxiliam a todo o processo de levantamento, atualização simultânea de informações e a sua disponibilidade facilitada para todos os componentes da empresa em qualquer hora e local, tornando todo o processo mais integrador.

A facilidade da internet e dos computadores pessoais permitem ainda que a interação seja mais popular e possível para todos.

A necessidade desses sistemas em uma empresa de construção civil fica evidenciada pela grande quantidade de dados e informações que são circuladas dentro da organização durante todo 0 processo de planejamento, programação, controle e construção de um empreendimento.

\section{METODOLOGIA}

Em posse dos conceitos descritos acima, além de uma base bibliográfica (BRENNER; JESUS, 2008) para a realização de uma pesquisa de abordagem quali-quantitativa, buscou-se alcançar os objetivos por meio de pesquisa exploratória e explicativa (GIL, 1999).

Buscando conhecer o potencial da construção civil da cidade de Quixadá-CE, fez-se uma busca através da internet e de informações com professores do curso de Engenharia de Produção Civil do Instituto Federal do Ceará, além de alguns profissionais da construção civil, com o intuito de identificar quais eram as principais empresas do ramo na cidade. A pesquisa resultou nos nomes de 04 empresas.

Metodologicamente, usamos a Pesquisa de Campo (LAKATOS; MARCONI, 2010) e coletamos dados em duas das construtoras citadas, buscando entender como é o processo de Gerenciamento de Obras adotado pela empresa e se eles utilizam sistemas e aplicativos de controle e gerenciamento.

Coletamos os dados por meio de entrevistas (BRENNER; JESUS, 2008) com os 
responsáveis pelo Gerenciamento de Obras de cada empresa, onde os proprietários assumiam essa função.

As entrevistas foram estruturadas em três partes. O foco da primeira parte era o conhecimento geral da empresa em relação a: porte, quantidade de funcionários, quantidade de obras por período, responsáveis do setor de planejamento e controle das obras.

$\mathrm{Na}$ segunda parte da entrevista buscou-se entender a metodologia de Gerenciamento de Obras adotado pela empresa nos seguintes aspectos: como é o processo de planejamento e controle de produção da obra, quantas pessoas são responsáveis por esse processo, como é feito o gerenciamento de informações e dados, e se a mesma utiliza de sistemas e aplicativos de gerenciamento de obras.

O questionamento sobre a utilização ou não de sistemas e aplicativos para gerenciamento das obras possibilitou ter-se duas vertentes de perguntas. Caso a empresa utilizasse aplicativos ou sistemas de gerenciamento de obras, as perguntas teriam o foco: saber quais eram esses sistemas, como funcionavam, que setores da empresa tinham acesso e utilizavam esse sistema e qual o tipo de armazenamento de dados.

Caso a empresa afirmasse que não usa nenhum sistema ou aplicativo, o foco das perguntas seria: entender o porquê da não utilização de sistemas, quais os principais empecilhos, informar o nome de alguns sistemas e aplicativos de gerenciamento de obras e questionar ao entrevistado se ele conhecia ou não esses sistemas.

\section{RESULTADOS E DISCUSSÃO}

Seguindo critérios de confidencialidade das informações, as construtoras entrevistadas serão nomeadas como: Construtora A, Construtora B.

A construtora A é uma microempresa com um proprietário e um sócio informal que atua no mercado formalmente há um ano, contudo, apresentava bastante tempo de serviços informais, o fluxo de obras era considerado bom de acordo com a demanda, possuindo normalmente entre duas e seis obras simultâneas. Os principais serviços apontados foram: Construção de casas e Reformas, já em relação ao efetivo de pessoal, possui seis funcionários fixos e os demais somente se houver demanda. Sobre investimento em qualificação, softwares e equipamentos a empresa se posiciona atualmente em definir prioridades, onde a menor prioridade são os softwares.

A construtora B é uma empresa de pequeno porte com 19 anos de mercado e atua na região do Sertão Central do Ceará e em algumas outras cidades do estado, como a capital Fortaleza. O fluxo de obras é considerado alto e possui atualmente 92 funcionários contratados dentre eles: administrativo, técnicos e trabalhadores das obras. Os principais serviços da empresa são construções e reformas de casas e empresas, fabricação de pré-moldados para consumo interno e, além disso, a empresa trabalha ainda no setor imobiliário.

Buscando conhecer como funciona o gerenciamento de obras de cada empresa, foi aplicado um questionário onde os entrevistados responderam como os setores funcionam e o Quadro 01 apresenta as respostas. 
Quadro 1 - Respostas dos entrevistados às perguntas de funcionamento da empresa na parte de Gerenciamento de Obras.

\begin{tabular}{|c|c|c|}
\hline Questionamento & Construtora A & Construtora B \\
\hline $\begin{array}{l}\text { Existe um funcionário ou setor } \\
\text { responsável pelo } \\
\text { Gerenciamento das obras? } \\
\text { Se sim, quem? }\end{array}$ & Sim, o proprietário. & $\begin{array}{c}\text { Sim, em cada obra tem um responsável } \\
\text { pela obra, além dos técnicos em } \\
\text { edificações e os engenheiros } \\
\text { supervisores. }\end{array}$ \\
\hline $\begin{array}{l}\text { Como é o processo de } \\
\text { planejamento e controle de } \\
\text { uma obra na sua empresa? }\end{array}$ & $\begin{array}{c}\text { Projeto estrutural e } \\
\text { arquitetônico; } \\
\text { Orçamento; } \\
\text { Fechamento de contrato; } \\
\text { Obra; } \\
\text { Entrega }\end{array}$ & $\begin{array}{c}\text { A empresa acredita que o planejamento é } \\
\text { a parte fundamental de toda a obra, por } \\
\text { isso há um foco nessa parte. Quando a } \\
\text { empresa é contratada por um cliente são } \\
\text { feitos os projetos estruturais e } \\
\text { arquitetônicos, e após a contratação, o } \\
\text { planejamento. }\end{array}$ \\
\hline $\begin{array}{l}\text { Como é o fluxo de } \\
\text { informações entre a obra e o } \\
\text { responsável pelo } \\
\text { planejamento? }\end{array}$ & $\begin{array}{l}\text { Existe um responsável na obra } \\
\text { pelo andamento da obra, que } \\
\text { passa as informações } \\
\text { informalmente para o } \\
\text { proprietário. Além disso, o } \\
\text { proprietário faz visitas } \\
\text { constantes à obra. }\end{array}$ & $\begin{array}{l}\text { Por meio de relatórios formais (planilhas e } \\
\text { relatórios digitais) e informais (por } \\
\text { telefone, em acontecimento urgente) e } \\
\text { visitas dos responsáveis técnicos que são } \\
\text { responsáveis pelo planejamento. }\end{array}$ \\
\hline $\begin{array}{l}\text { A empresa utiliza algum } \\
\text { sistema ou aplicativo para } \\
\text { gerenciamento de obras? }\end{array}$ & Não, apenas planilhas do Excel. & $\begin{array}{l}\text { Sim, atualmente, além dos softwares como } \\
\text { Excel e MS Project, eles utilizam um } \\
\text { software ERP para construção civil feito } \\
\text { por uma empresa especializada. }\end{array}$ \\
\hline
\end{tabular}

Fonte: Próprio Autor.

Após questionamentos comuns sobre o gerenciamento das obras, o entrevistado foi questionado sobre a utilização de softwares de gerenciamento, a empresa que respondeu negativamente sobre essa utilização foi direcionada a perguntas distintas àquela que respondeu positivamente na segunda etapa da pesquisa. O Quadro 02 apresenta as respostas da empresa que respondeu negativamente.

Quadro 2 - Respostas do entrevistado as perguntas caso a empresa não utilizasse softwares de gerenciamento.

\begin{tabular}{|c|c|}
\hline Questionamento & Construtora A \\
\hline $\begin{array}{l}\text { Por que vocês não utilizam nenhum } \\
\text { sistema ou aplicativo? }\end{array}$ & $\begin{array}{l}\text { Pelo fluxo de obras e porte da empresa não se vê a } \\
\text { necessidade de utilização. }\end{array}$ \\
\hline $\begin{array}{l}\text { Você conhece algum sistema de } \\
\text { gerenciamento de obras? }\end{array}$ & Sim, mas não soube citar nenhuma no momento. \\
\hline $\begin{array}{l}\text { Qual o grau de envolvimento da sua } \\
\text { equipe com tecnologias? }\end{array}$ & $\begin{array}{l}\text { O proprietário possui adaptabilidade com ferramentas } \\
\text { tecnológicas, mas os funcionários da obra não. }\end{array}$ \\
\hline Você conhece algum desses sistemas? & Nenhum dos apresentados. \\
\hline
\end{tabular}

Fonte: Próprio Autor.

As perguntas direcionadas ao entrevistado que respondeu negativamente à utilização de sistemas e aplicativos de gerenciamento nos leva a conhecer os motivos atuais da não utilização. Além disso, mostra como o entrevistado entende e é influenciado pelo uso de tecnologia durante todo o processo da obra.

O entrevistado que respondeu positivamente a utilização de sistemas de gerenciamento foi direcionado a outras perguntas. As respostas estão apresentadas no Quadro 03 a seguir. 
Quadro 3 - Respostas do entrevistado as perguntas caso a empresa utilizasse softwares de gerenciamento.

\begin{tabular}{|c|c|}
\hline Questionamento & Construtora B \\
\hline Como é o sistema utilizado? & $\begin{array}{c}\text { É um sistema com múltiplos acessos, onde cada funcionário } \\
\text { possui um login e senha e tem permissão para colocar as } \\
\text { informações referentes ao seu setor. Ele integra informações de } \\
\text { diversos setores da empresa e podem ser retirados relatórios } \\
\text { das atividades. Usado principalmente para acompanhamento } \\
\text { financeiro da obra e das necessidades e acompanhamento de } \\
\text { materiais. }\end{array}$ \\
\hline $\begin{array}{l}\text { Ele integra quais áreas da empresa e quais } \\
\text { informações são compartilhadas? }\end{array}$ & $\begin{array}{c}\text { Financeiro, orçamento, compras, gerenciamento. Praticamente } \\
\text { todos os setores da empresa. }\end{array}$ \\
\hline $\begin{array}{l}\text { Existe a possibilidade de acesso remoto ao } \\
\text { sistema? }\end{array}$ & Não. \\
\hline $\begin{array}{l}\text { O sistema é de fácil entendimento e } \\
\text { operação? }\end{array}$ & $\begin{array}{c}\text { Sim, pois a empresa sempre utilizou softwares ERP, mas a } \\
\text { empresa contratada deu cinco meses de treinamentos e } \\
\text { suporte aos funcionários. }\end{array}$ \\
\hline Você conhece algum outro sistema? & $\begin{array}{c}\text { Sim, ele se chama Arquimedes da empresa Multiplus } \\
\text { Engenharia. }\end{array}$ \\
\hline
\end{tabular}

Fonte: Próprio Autor.

A partir das respostas das entrevistas podemos tecer alguns comentários a cerca das metodologias de gerenciamento das obras nas empresas pesquisadas. A construtora A é relativamente nova, e o fluxo de obras é baixo. A mesma possui uma visão de não precisar de aparatos tecnológicos para gerenciar suas obras, o seu conhecimento técnico e na opinião do entrevistado suas visitas à obra suprem as necessidades de um planejamento e técnicas de controle. Perguntado se ele estava satisfeito com a atual forma de gerenciamento das obras ele informou que estava satisfeito.

Em relação a construtora $B$ percebeu-se que a mesma tem mais tempo de mercado, um fluxo de construção maior, possui uma visão de melhora contínua, mostrou que a etapa de planejamento da construção é de fundamental importância para que não haja retrabalhos e maior desgaste com o cliente. Perguntado se a atual forma de gerenciamento das obras da sua empresa era satisfatório, o entrevistado informou que não, ainda havia problemas nesse processo.

O responsável pela construtora $B$ informou ainda que a empresa já utiliza sistemas ERP há muitos anos e que estes auxiliam muito os processos burocráticos de uma obra. Antes havia muita perda de material, muito desperdício e informações desencontradas. $\mathrm{O}$ sistema, que ainda não é considerado perfeito, foi um agregador a empresa e acima de tudo um facilitador. No entanto, onde hoje o checklist de entrega é feito através de uma lista impressa, caso houvesse um sistema remoto com essa função poderia auxiliar o processo.

Pode-se listar alguns pontos sobre a utilização ou não de sistemas nas construtoras de Quixadá-CE:

A empresa ser de pequeno porte não interfere na utilização de softwares de gerenciamento de obras, seu uso irá depender da visão da empresa e a disponibilidade para investimento;

O procedimento de planejamento em uma obra é de fundamental importância, pois é nesse processo que se identificam, além de outros aspectos os possíveis problemas e critérios para controle da obra. Esses critérios, se aplicados a um sistema, auxiliam também no método de vistoria.

É necessária a intimidade dos responsáveis da empresa com a tecnologia, além de conhecer quais são os sistemas e aplicativos disponíveis no mercado para entender como esses sistemas podem ajudar sua empresa.

\section{CONSIDERAÇÕES FINAIS}

Em busca por entender como as construtoras da cidade de Quixadá-CE se posicionam no mercado e como elas enxergam a utilização de sistemas e aplicativos no processo de 
gerenciamento de obras em suas empresas, expôs-se neste trabalho pontos de grande discussão.

As empresas pesquisadas possuem visões diferentes de como o fluxo de informações pode influenciar no produto final. Os processos de controle de uma obra devem seguir critérios rígidos e de fácil acesso.

A utilização de sistemas auxilia no processo de conferencia, vistoria, antecipação de problemas, dentre outros fatores. Isso permite que custos extras sejam evitados além do

\section{REFERÊNCIAS}

[1] ASSUMPÇÃO, José Francisco Pontes; FUGAZZA, Antônio Emílio Clemente. Coordenação de projetos de edifícios: um sistema para programação e controle do fluxo de atividades do processo de projetos. In: WORKSHOP NACIONAL: gestão do processo de projeto na construção civil. Anais... 2001. Disponível em: < http://www.lem.ep.usp.br/gpse/es23/anais/COORD ENACAO_DE_PROJETOS_DE_EDIFICIOS.pdf>. Acesso em: 08 abr. 2018.

[2] ALBERTIN, Marcos Ronaldo; PONTES, Heráclito Lopes Jaguaribe. Administração da produção e operações. Curitiba: InterSaberes, 2016.

[3] BERNARDES, Mauricio Moreira e Silva. Planejamento e Controle de Produção para empresas de construção civil. Rio de Janeiro: RTC, 2010.

[4] BRENNER, Eliana de Moraes; JESUS, Dalena Maria Nascimento de. Manual de planejamento e apresentação de trabalhos retrabalho, que sempre deixam os clientes insatisfeitos.

A compra de um sistema deve ser tratada como investimento e não um custo para a empresa. Foi dessa forma que a construtora $B$ se mostrou sobre a utilização desses softwares.

Uma consultoria apresentando os diversos sistemas disponíveis no mercado e como eles podem auxiliar no processo de gerenciamento das obras é uma maneira de mostrar as empresas do mercado local e de outras regiões como as empresas podem evoluir.

acadêmicos: projetos de pesquisa, monografia e artigos. 2. ed. São Paulo: Atlas, 2008.

[5] GIL, Antonio Carlos. Métodos e técnicas de pesquisa social. São Paulo: Atlas, 1999.

[6] LAKATOS, Eva Maria; MARCONI, Marina de Andrade. Fundamentos de metodologia científica. 7. ed. São Paulo: Atlas, 2010.

[7] LUSTOSA, Leonardo. et. al Planejamento e Controle da Produção. Rio de Janeiro: Elsevier, 2008.

[8] SOUSA, Thales Botelho de. Referencial teórico sobre sistemas APS: um ponto de partida para futuras pesquisas. In: ENCONTRO NACIONAL DE ENGENHARIA DE PRODUÇÃO, 32., Rio Grande do Sul, Beto Gonçalves, Anais..., 2012. Disponível em: <http://www.abepro.org.br/biblioteca/enegep2012_ tn_sto_157_914_20595.pdf>. Acesso em: 08 abr. 2018. 


\section{Capítulo 3}

\section{PROPOSTA DE REDUÇÃO DE TEMPO DE SETUP EM CÉLULAS DE USINAGEM COM O USO DE CONCEITOS DA METODOLOGIA SMED}

\section{Gabriela Moraes Simões Evangelista}

Laura Keiko Arimitsu

André de Lima

Ivan Correr

Resumo: Com a instabilidade econômica e política atual, as empresas necessitam de formas para se manterem competitivas no mercado, por isso é necessário que sejam implementados métodos para obtenção de melhorias do processo e redução de custos. No ambiente produtivo, um dos principais causadores do aumento de desperdícios é a operação de preparação das máquinas (setup), por essa razão reduzir esse tempo é de extrema importância, já que permite melhorias relacionadas à flexibilidade, capacidade produtiva, atendimento ao cliente e redução de tempos, estoques, não conformidades, lead times e custos. Ademais, algumas empresas empregam metade do seu tempo produtivo realizando os setups. Perante esse fato, originou-se o método conhecido como SMED (Single Minute Exchange of Die), capaz de proporcionar a simplificação e redução do tempo do setup, por intermédio da separação das operações internas e externas, padronizações, uso de gabaritos, eliminação de ajustes, check lists, comunicação e treinamentos dos envolvidos, entre outras ações. Neste contexto, o presente trabalho visa apresentar uma proposta de melhoria para redução do tempo de setup no processo de usinagem em uma organização do ramo de autopeças do estado de São Paulo, baseado nos conceitos da metodologia SMED visando o uso de técnicas de separação, redução ou eliminação do tempo de setup, padronização das atividades, sistematização e melhorias do processo, treinamento e envolvimento da equipe. A metodologia utilizada para o desenvolvimento do estudo foi baseada em uma pesquisa explicativa do tipo pesquisa-ação correlacionada ao uso do método DMAIC. Com as melhorias sugeridas, pretendese reduzir $50 \%$ do tempo de setup, possibilitando o aumento de fatores, como produtividade, disponibilidade, flexibilidade e qualidade, além de minimizar os custos e desperdícios do processo de usinagem.

Palavras-chave: Usinagem, setup, SMED e DMAIC 


\section{INTRODUÇÃO}

No cenário mundial atual, as barreiras comerciais se expandem gradativamente, devido à globalização, tornando o ambiente industrial extremamente competitivo. Alguns dos desafios enfrentados pelas organizações são a alta concorrência, a exigência do mercado e a necessidade de atender o cliente (CALHADO et al., 2015).

Nos processos de usinagem, organizações buscam alternativas de aumentar a produtividade, reduzindo perdas de tempo em seu sistema produtivo, entre estas ações, realizar um melhor proveito do tempo de preparação de máquinas, eliminando o desperdício e consequentemente reduzindo o custo, aumentando a eficiência operacional (VIEIRA JR. et al., 2011).

Um dos métodos utilizados para a redução do tempo de preparação de máquinas, ou, setup, é o Single Minute Exchange Die (SMED). Sua aplicação visa a simplicidade e não exige altos custos de investimento, sendo muito utilizado por organizações que possuem um mix variados de produtos (SHINGO, 1985).

Como, as empresas fornecedoras de produtos para as indústrias automotivas, estão cada vez mais suscetíveis às influências de seus clientes, no que diz respeito às flutuações do mercado, aumento de produtividade das máquinas, viabilização de produção em lotes com tamanhos reduzidos, e em consequência, redução do estoque. A busca de metodologias, conceitos, sistemas e ferramentas que visam reduzir os custos organizacionais e eliminar os desperdícios são fundamentais (STRAPASSON; LEITE, 2012).

Portanto, o presente artigo tem como objetivo apresentar uma proposta de melhoria para redução do tempo de setup no processo de usinagem em uma organização do ramo de autopeças do estado de São Paulo, baseado nos conceitos da metodologia SMED visando o uso de técnicas de separação, redução ou eliminação do tempo de setup, padronização das atividades, sistematização e melhorias do processo, treinamento e envolvimento da equipe.

\section{REFERENCIAL TEÓRICO}

\subsection{TEMPO DE SETUP}

Anteriormente, a fabricação de produtos diversificados e com pequenos lotes eram considerados um grande empecilho para a gestão da produção. Acreditando ser caro preparar uma máquina para produzir apenas uma peça, as empresas optavam por diminuir a gama de produtos e produzir grandes lotes, além da implementação de células e máquinas dedicadas Porém, o mercado teve um largo crescimento e desenvolvimento, exigindo que as empresas se adaptassem as suas necessidades, dessa forma para atender os clientes com um número maior de produtos disponíveis e de forma que reduza os seus estoques, o cenário alterou-se, surgindo layouts flexíveis, mão de obra multifuncional, produção em baixa escala e elevação de mix de produtos. O cenário anterior possibilitava minimizar a importância dos tempos de setups, mas o atual exige que esse tempo seja tratado de forma relevante (GAITHER; FRAZIER, 2004; MAESTRELLI et al., 2014).

Segundo Satolo e Calarge (2008), o tempo de setup é o tempo de preparação que ocorre entre a última peça produzida no lote atual (lote A) até a produção da primeira peça boa do lote posterior (lote B), como apresentado na figura 1. 
Figura 1: Caracterização do tempo de setup

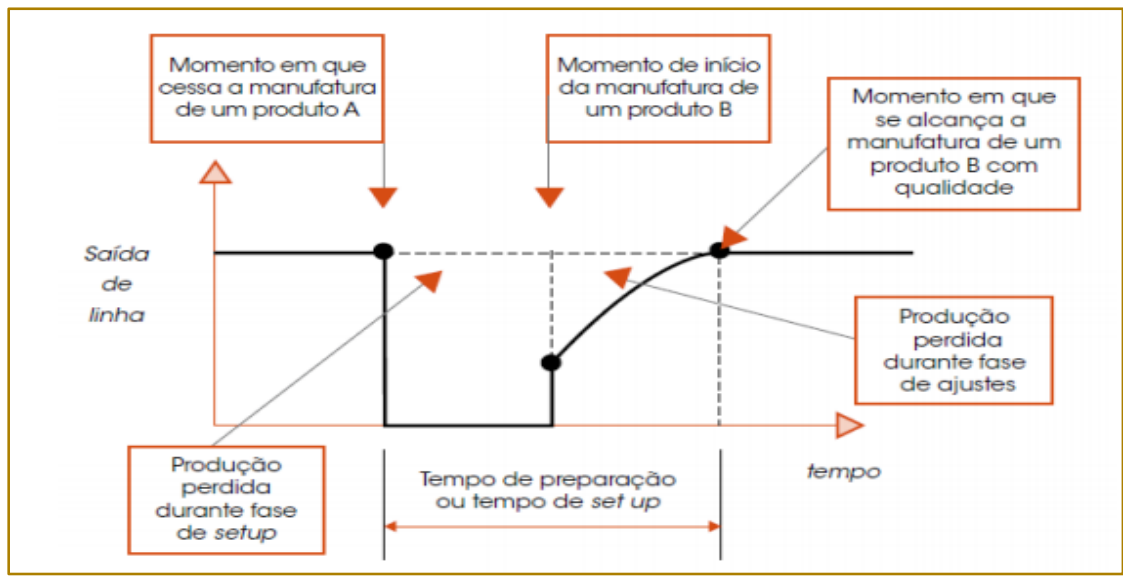

Fonte: Adaptado de Satolo e Calarge (2008)

Segundo Shingo (2000), as 4 etapas básicas de atividades de setup são mostradas no quadro 1.

Quadro 1: As principais etapas e atividades do setup

\begin{tabular}{|l|l|}
\hline Etapa & Atividade \\
\hline $\begin{array}{l}\text { Preparação da matéria- } \\
\text { prima, dispositivose } \\
\text { ferramentas }\end{array}$ & $\begin{array}{l}\text { Etapa que ocorre a preparação da matéria-prima, dispositivos e } \\
\text { ferramentas, sendo verificado se os materiais estão conformes para a } \\
\text { utilização e nos locais corretos, também está incluso as limpezas das } \\
\text { máquinas. }\end{array}$ \\
\hline $\begin{array}{l}\text { Montagemeremoção de } \\
\text { ferramentase } \\
\text { componentes }\end{array}$ & $\begin{array}{l}\text { Ocorre a remoção das ferramentas e componentes utilizados no lote } \\
\text { anterior a fixação das que serão utilizadas para atendimento ao novo } \\
\text { lote que será produzido. }\end{array}$ \\
\hline $\begin{array}{l}\text { Centrageme } \\
\text { determinação das } \\
\text { dimensões das } \\
\text { ferramentas: }\end{array}$ & $\begin{array}{l}\text { Consistenas atividades de posicionamento das ferramentas, medições } \\
\text { e calibrações, a fim de encontrar as condições ideias para o processo. }\end{array}$ \\
\hline $\begin{array}{l}\text { Processosiniciais e } \\
\text { ajustes: }\end{array}$ & $\begin{array}{l}\text { São realizados os testes e ajustes necessários para a iniciação do } \\
\text { processo, caso as etapas anteriores forem realizadas de forma } \\
\text { satisfatória e eficiente, menoro tempopara essa etapa será empregada, } \\
\text { já que a mesma é totalmente dependente das etapas anteriores. }\end{array}$ \\
\hline
\end{tabular}

Fonte: Adaptado de Shingo (2000)

Dentro do tempo de setup, relacionado ao processo de usinagem, existem inúmeras atividades, como requisição e transporte do ferramental, troca de ferramentas e dispositivos, ajustes, calibrações, programação das máquinas, preset de ferramentas, inspeções, aprovações, entre outras (BATELOCHI, 2007).

Com as transformações do mercado e com o desenvolvimento de diferentes modelos de produtos, a produção de lotes maiores é impulsionada, causando superprodução, desperdícios, estoques, elevando os custos de produção. Consequentemente há o aumento de ocorrências de setup, sendo assim é necessário que o tempo do mesmo seja reduzido. Já que um elevado tempo de setup impacta na disponibilidade da máquina. Por isso, a redução do tempo de setup é um dos principais focos das empresas de manufatura (SATOLO; CALARGE, 2008; CORAZZA, 2016). 


\subsection{IMPORTÂNCIA DA REDUÇÃO DO TEMPO DE SETUP}

A redução do tempo de setup é considerada um dos principais fundamentos de agregação à melhoria contínua de um processo, abrangendo melhorias nos sete desperdícios da Manufatura Enxuta (WILTSIE, 2012).

A melhoria no tempo de setup impacta várias esferas organizacionais (NICHOLAS, 1998; GOSS et al., 2010), conforme o quadro 2.

Quadro 2: Impactos nas esferas organizacionais

\begin{tabular}{|l|l|}
\hline \multicolumn{1}{|c|}{ Esferas organizacionais } & \multicolumn{1}{c|}{ Impactos } \\
\hline Qualidade & Redução de não conformidades de produto e processo \\
\hline Custo & $\begin{array}{l}\text { Redução de custos relacionados à estoque acabado, work in process, mão de obra } \\
\text { indisponibilidade das máquinas, entre outros }\end{array}$ \\
\hline Tempo & $\begin{array}{l}\text { Redução de tempo com movimentação dos operadores, calibração, ajustes, troca de } \\
\text { ferramentas, preset, entre outros }\end{array}$ \\
\hline Flexibilidade & $\begin{array}{l}\text { Setups àgeis proporcionam flexibilidade para atender as demandas variadas, seja } \\
\text { para ajustes das ferramentas e equipamentos ou na preparação como um todo }\end{array}$ \\
\hline $\begin{array}{l}\text { Melhor utilização da mão de } \\
\text { obra }\end{array}$ & $\begin{array}{l}\text { Com o setup simplificado e padronizado, todos os operadores podem ser } \\
\text { qualificados, sem necessidade de determinar pessoas especificas, reduzindo a } \\
\text { dependência do operador para a realização da operação }\end{array}$ \\
\hline Capacidade e lead time & $\begin{array}{l}\text { Maior utilização das máquinas, consequentemente maximizando a capacidade } \\
\text { produtiva e reduzindo o lead time }\end{array}$ \\
\hline
\end{tabular}

Fonte: Adaptado de Nicholas (1998) e Goss et al. (2010)

Outros autores descrevem benefícios adicionais aos citados anteriormente, Allahverdi e Soroush (2008) apresentam o impacto aos clientes, como melhoria no desempenho de entrega e na capacidade de resposta. Wiltsie (2012) ressalta melhorias na programação e controle de produção, quebras de ferramentas, programação das máquinas, redução de manutenção de equipamentos. Mardegan et al. (2006) expõe as vantagens da redução do tempo de setup, conforme figura 2.

Segundo McCarthy (2006), na maioria das empresas $50 \%$ do tempo de trabalho é empregado no processo de setup, dessa forma, reduzir o tempo de preparação tornase requisito de competividade no contexto empresarial mundial.

Figura 2: Vantagens da redução do tempo de setup

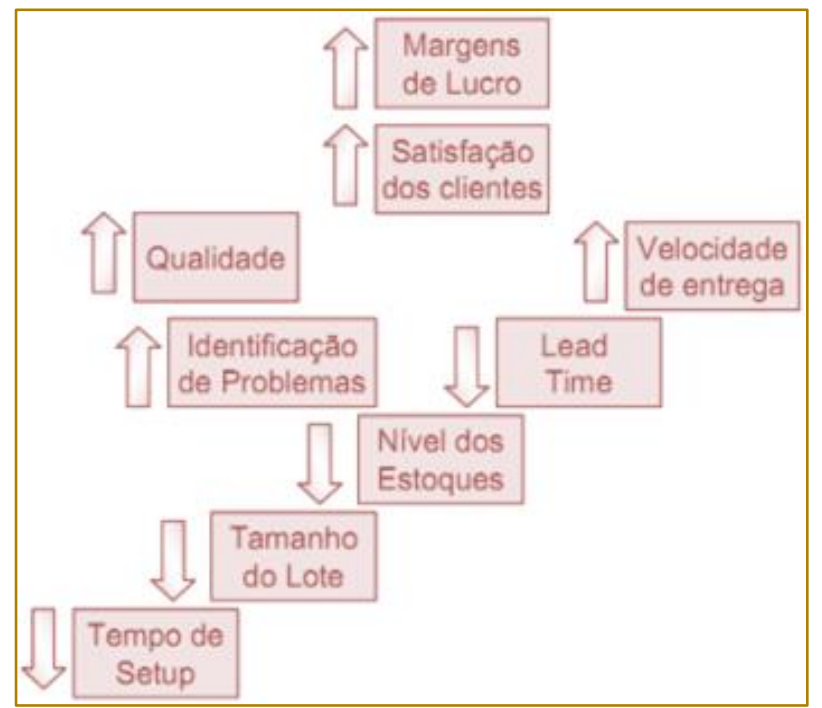

Fonte: Adaptado de Mardegan et al. (2006)

Para auxiliar nesses casos, a principal e mais difundida metodologia para a redução do tempo de setup é o SMED, uma das propostas sugeridas na filosofia Lean para a eliminação de desperdícios (MARDEGAN, 2006). 


\subsubsection{SMED}

SMED (Single Minute Exchange of Die) é uma metodologia criada para obter maior eficácia no tempo de troca e preparação das máquinas e equipamentos, tendo como meta obter a redução no tempo de setup para um dígito (SHINGO, 1985).

O SMED foi desenvolvido com o intuito de suprir as flutuações da demanda, proporcionando uma resposta rápida das organizações perante as mudanças. Podendo ser aplicado em qualquer segmento, qualquer máquina ou equipamento. Possibilitando a realização do nivelamento da produção e a redução dos tamanhos dos lotes (SHINGO, 1985).

Uma das principais finalidades do SMED é simplificar e reduzir o tempo de troca de ferramentas, minimizando ou eliminando as perdas associadas ao processo de setup (FAGUNDES; FOGLIATTO, 2003).

Segundo Cakmakci e Karasu (2007) as operações de setup são divididas em dois tipos:

Setup interno: são operações realizadas quando a máquina está desligada/parada;

Setup externo: são operações realizadas quando a máquina ainda está operando/funcionando.

Shingo (2000) definiu que a metodologia se compõe por quatro estágios conceituais e técnicas que são aplicadas em seu respectivo estágio, onde ambos são necessários para a obtenção da redução do setup, conforme mostra a figura 3 .

Figura 3: Estágios e técnicas da metodologia SMED

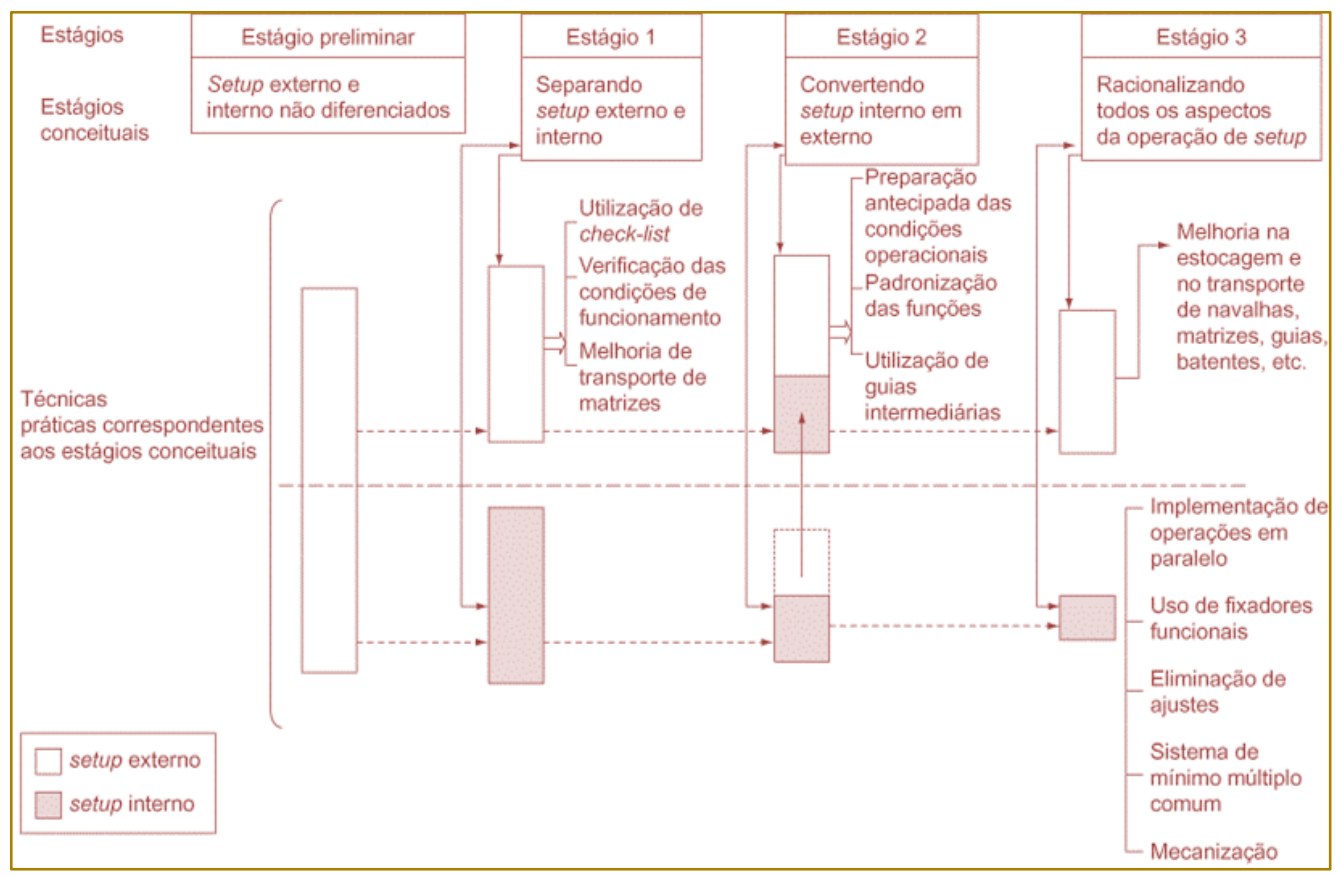

Fonte: Adaptado de Shingo (2000)

A metodologia SMED proporciona uma contribuição significativa para as organizações, fazendo com que as máquinas e equipamentos da área produtiva continuem em operação por um maior período de tempo, logo, obtendo um aumento no volume de produção (FOGLIATTO; FAGUNDES, 2003).

O precursor em estudar e aplicar as técnicas para redução do tempo de setup foi Shigeo Shingo (WERKEMA, 2006). Um dos objetivos principais da sua metodologia é converter o máximo possível do tempo de setup interno para externo (SHINGO, 2000).

Monden (1984) propõe uma metodologia semelhante à de Shingo, os aspectos que diferenciam é que o autor ressalta que etapa da conversão da operação do setup interno em externo como uma das mais importantes e recomenda uma análise mais detalhada, a padronização das funções direcionadas às 
operações de redução do tempo de setup, e a realização de uma avaliação dos investimentos ao retorno obtido com a redução do tempo de setup.

Já Moxham e GreatBanks (2001) defendem a essencialidade de "pré-requisitos" ou um estágio inicial denominado "SMED ZERO", onde se abrange os seguintes aspectos: trabalhar a comunicação e o envolvimento em equipe, controle visual da fábrica, analisar e medir o desempenho.

Por outro lado, Mclntosh et al. (2007) recomendam o uso de outros recursos atrelados a implementação do SMED, utilizando-se de checklist ou gabaritos, técnicas do Kaizen, etc. Onde o foco principal é a melhoria contínua, buscando sempre o aprimoramento dos métodos existentes.

O SMED não é uma técnica simples, mas sim um conceito que requer o comprometimento e mudanças da organização como um todo, pois o tempo de setup é relacionado frequentemente à área produtiva, porém ele reflete nas outras áreas da organização. A falta de fornecimento de infraestrutura apropriada, treinamento e a falta da conscientização da importância de reduzir o tempo de setup, pode ocasionar o fracasso na implementação, o bom gerenciamento e a divulgação da importância da metodologia influencia diretamente nos resultados da mesma (VAN GOUBERGEN, 2000).

Outros autores descrevem benefícios adicionais aos citados anteriormente relacionados ao setor de usinagem, Calhado et al. (2015) apresentam um aumento da flexibilidade dinâmica para poder acompanhar as variações do mercado, e a possibilidade de produção em lotes pequenos, Cechect et al. (2008) aponta a redução no lead time e redução nos níveis de estoque. Xavier et al. (2014) retrata o resultado perante os clientes, com um melhor no desempenho de entrega e na capacidade de resposta. Corazza (2016) destaca a organização, a padronização, pontualidade nos prazos de entrega e robustez na qualidade das atividades.

\section{METODOLOGIA DO DESENVOLVIMENTO DA PESQUISA}

O estudo foi realizado em uma empresa multinacional de grande porte no ramo de autopeças. A empresa possui 29 plantas distribuídas no mundo, a planta estudada é situada no interior do estado de São Paulo.

A metodologia do desenvolvimento do estudo foi baseada em uma pesquisa explicativa do tipo pesquisa-ação. Conforme Gil (2007), a pesquisa explicativa tem como principal objetivo identificar os fatores que contribuem ou causam as ocorrências do evento. Determinado como pesquisa-ação, visto que é baseado na resolução ou melhoria de problemas, havendo a necessidade do envolvimento e participação dos pesquisadores de forma colaborativa perante ao evento (ELLIOT, 1997; THIOLLENT, 2011). O estudo teve embasamento metodológico baseado na estruturação das etapas da pesquisa-ação formuladas por Thiollent (2011) e Mello (2012).

É notório a semelhança das etapas da pesquisa-ação com a metodologia DMAIC (definir, medir, analisar, implementar e controlar), sendo que ambas possuem o propósito de implementar melhorias. Usevicius (2004) ratifica que as principais equivalências entre as metodologias são o desenvolvimento de hipóteses, coletas de dados, planos de ação e as habilidades necessárias para conduzir um projeto pelo pesquisador da pesquisa-ação ou pelo Black Belt. O quadro 3 apresenta a correlação das etapas e objetivos da pesquisa-ação e DMAIC 
Quadro 3: Correlação entre as etapas e objetivos: pesquisa ação e DMAIC

\begin{tabular}{|c|c|c|c|}
\hline \multicolumn{2}{|c|}{ PESQUISA AÇÃO } & \multicolumn{2}{|r|}{ DMAIC } \\
\hline ETAPAS & OBJETIVOS & ETAPAS & OBJETIVOS \\
\hline Fase exploratória & $\begin{array}{l}\text { Determinação do campo de } \\
\text { pesquisa, os envolvidos e suas } \\
\text { expectativas }\end{array}$ & \multirow{4}{*}{ Definir } & \multirow{4}{*}{$\begin{array}{l}\text { Identificação do problema, tema, } \\
\text { área e constituição de um time } \\
\text { multifuncional }\end{array}$} \\
\hline Tema da pesquisa & Definiçãa do tema da pesquisa & & \\
\hline Colocação dos problemas & $\begin{array}{l}\text { Definição da problemática no qual } \\
\text { o tema da pes quis a será } \\
\text { des envolvido }\end{array}$ & & \\
\hline Seminário & $\begin{array}{l}\text { Constituição do grupo dos } \\
\text { pesquisadores }\end{array}$ & & \\
\hline Campo de obs ervação & $\begin{array}{l}\text { Delimitação do campo de } \\
\text { observação no qual o tema é } \\
\text { aplicável }\end{array}$ & \multirow{2}{*}{ Medir } & \multirow{2}{*}{$\begin{array}{l}\text { Levantamento dos dados e } \\
\text { mensuramento das variáveis do } \\
\text { processo }\end{array}$} \\
\hline Coleta de dados & $\begin{array}{l}\text { Aplicação de técnicas para coleta } \\
\text { de dados }\end{array}$ & & \\
\hline Hipótes es & $\begin{array}{l}\text { Formulação de suposições de } \\
\text { soluções para resolução do } \\
\text { problema }\end{array}$ & \multirow{2}{*}{ Analis ar } & \multirow{2}{*}{$\begin{array}{l}\text { Análise e identificação da causa } \\
\text { raíz }\end{array}$} \\
\hline Análise de dados & $\begin{array}{l}\text { A análise e interpretação dos } \\
\text { dados obtidos devem ser } \\
\text { realizados }\end{array}$ & & \\
\hline Plano de ação & Elaboração do plano de ação & Implementar & $\begin{array}{l}\text { Execução do plano de ação para } \\
\text { corrigir ou reduzir as variáveis }\end{array}$ \\
\hline Divulgação dos resultados & $\begin{array}{l}\text { Divulgação dos resultados aos } \\
\text { membros do grupo e externamente } \\
\text { para áreas interes sadas }\end{array}$ & Controlar & Padronização e conclusão \\
\hline
\end{tabular}

Fonte: Adaptado de Harry e Schroeder (2000), Thiollent (2011) e Mello (2012)

\section{DESENVOLVIMENTO, APLICAÇÃO E RESULTADOS}

Para a iniciação do projeto houve a necessidade da criação de um time multifuncional, para o desenvolvimento, acompanhamento e propostas de soluções.

A metodologia escolhida pelo time para o desenvolvimento das etapas do projeto foi o DMAIC, dessa forma os resultados serão apresentados nas fases: definir, medir, analisar e implementar.

\subsection{DEFINIR}

O estudo iniciou com a necessidade de identificação do processo gargalo, conforme Goldratt e Cox (1998) a prioridade da aplicação de melhorias deve ser perpetuada no processo gargalo, pois essas melhorias tendem solucionar a restrição de modo a aumentar a capacidade de toda a fábrica, melhorando o atendimento a demanda, não havendo a necessidade de aquisição de novos equipamentos e mão de obra.

Para identificar o processo gargalo foram considerados os índices do OEE, conforme Hansen (2006), o OEE (Eficiência Global dos Equipamentos) é um indicador baseado em três variáveis: disponibilidade, performance e qualidade.

Com o levantamento de dados do OEE de todos os processos produtivos foi identificado que 0 processo com menor índice apresentado é a usinagem com OEE de $71,88 \%$, sendo assim definido esse processo para aplicação da melhoria, demonstrado na Figura 4. 
Figura 4: OEE dos processos produtivos

\begin{tabular}{|c|c|c|}
\hline FUNDIÇÃO & USINAGEM & PINTURA \\
OEE: $\mathbf{7 8 , 1 5 \%}$ & OEE: $\mathbf{7 1 , 8 8 \%}$ & OEE: $\mathbf{7 3 , 9 3 \%}$ \\
\hline
\end{tabular}

Fonte: Os autores

O próximo passo foi a definição do projeto, com essa finalidade foram listados os maiores tempos empregados no processo de usinagem, os dois principais são relacionados à manutenção, tais como, manutenção elétrica e preventiva, porém são tempos não atuantes, já que são pertencentes à outra área, logo os outros três tempos consecutivos e relevantes foram considerados: ajuste, setup e parada não identificada, de acordo com a figura5.

Figura 5: Maiores tempos empregados nos processos de usinagem

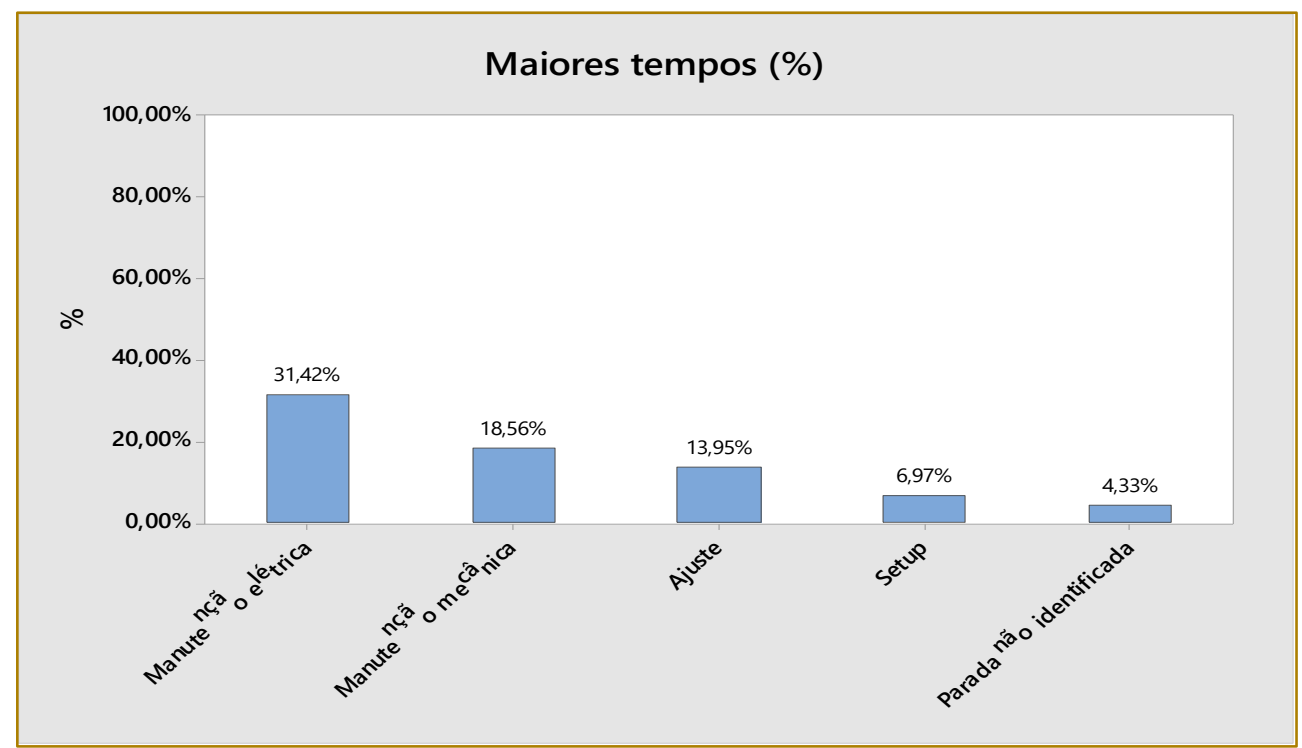

Fonte: Os autores

Ainda com o propósito de definição do projeto, baseado na VOC (voz do cliente), os envolvidos no processo produtivo constataram duas necessidades de melhorias, sendo: redução do tempo de setup e aumento do tempo de ciclo. O setup apresentou-se expressivo, já que foi demonstrado nas duas informações coletadas, resultando na definição do projeto.
Posteriormente, para um melhor resultado de implementação foi fundamental selecionar uma célula de trabalho, definida como escopo do projeto, consequentemente houve a necessidade de conhecer os tempos médios e quantidades de setups de todas as células. A partir do quadro 4 é possível obter a célula adequada. 
Quadro 4: Quantidade e tempo de setups por célula

\begin{tabular}{|r|r|r|r|}
\hline Célula & $\begin{array}{c}\text { Quantidade de } \\
\text { setup }\end{array}$ & $\begin{array}{c}\text { Tempo } \\
\text { médio }\end{array}$ & Tempo total \\
\hline 1 & 17 & 4,21 & 71,57 \\
\hline 2 & 21 & 2,73 & 57,33 \\
\hline 3 & 30 & 2,48 & 74,40 \\
\hline 4 & 24 & 3,49 & $\mathbf{8 3 , 7 6}$ \\
\hline 5 & 2 & 7,50 & 15,00 \\
\hline 6 & 16 & 3,00 & 48,00 \\
\hline 7 & 4 & 4,25 & 17,00 \\
\hline
\end{tabular}

Fonte: Os autores

Mesmo não apresentando a maior quantidade de setups e o maior tempo gasto para o processo, a célula 4 mostra-se vantajosa, por demonstrar o maior tempo total, além de conter duas células famílias, possibilitando a abrangência das ações para a célula 2 e 3.

\subsection{MEDIR}

Com a definição da célula 4 houve a estratificação dos dados para uma maior confiabilidade, com o objetivo de medir e verificar a dispersão de dados, verificando assim a variabilidade do processo, conforme mostrado na figura 6.

Figura 6: Tempos médios de setups na célula 4

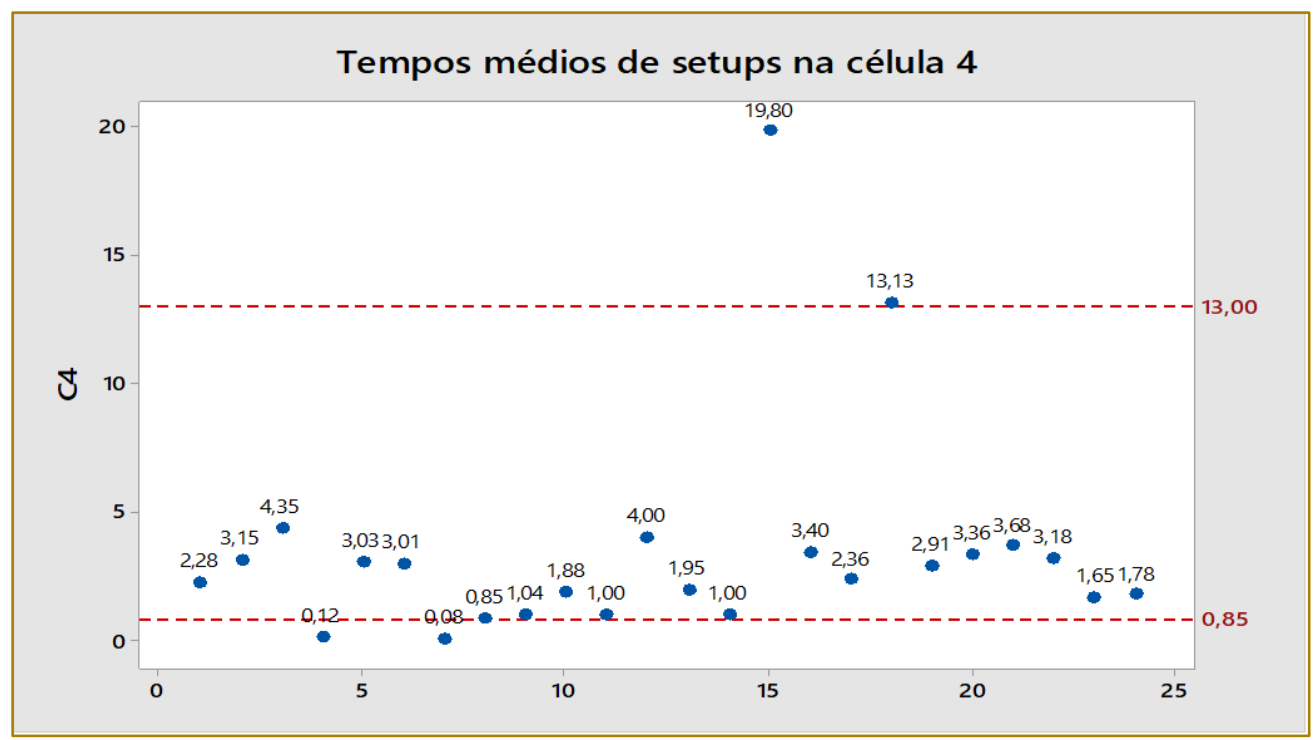

Fonte: Os autores

Pela existência de pontos dispersos e que não demonstram a realidade do tempo de setup, os dados abaixo dos limites inferiores e superiores foram desconsiderados, sucedendo na média real do tempo de setup de 2,60 horas.

A partir da medição da célula 4 foi realizado o cálculo de lacuna para propor a meta do projeto. No cálculo da lacuna é levado em consideração o valor da média de 2,60 horas, o melhor valor já encontrado de 0,85 horas e a proposta de redução de 50\%, resultando numa meta de 1,80 horas.

Em seguida, com o intuito de identificar possíveis variáveis entre turnos e produtos, a medição se fez necessária, assim sendo realizado as estratificações.

A empresa opera em três turnos, de acordo com a quadro 5, o turno 1 efetuou 9 setups com tempo médio de 2,53 horas, o turno 2 com 8 setups e tempo médio de 2,98 horas e o turno 3 com 2 setups e 1,45 horas. O turno 3 
demonstra diferença significativa perante aos turnos 1 e 2, seja na quantidade ou tempos médios de setups, porém a partir da realização de uma matriz de correlação foi identificado que no caso do turno 3 , os setups ocorridos nesse período eram de produtos da mesma família e quando ocorre setups entre produtos com polegadas semelhantes, as necessidades de trocas são menores e mais ágeis, justificando assim a discrepância.

Quadro 5: Quantidade e tempo médio de setups por turno

\begin{tabular}{|c|c|c|}
\hline Turno & $\begin{array}{c}\text { Quantidade de } \\
\text { setups }\end{array}$ & $\begin{array}{c}\text { Tempo médio de } \\
\text { setups }\end{array}$ \\
\hline 1 & 9 & 2,53 \\
\hline 2 & 8 & 2,98 \\
\hline 3 & 2 & 1,45 \\
\hline
\end{tabular}

Fonte: Os autores

Também foi levantado o tempo médio de setup por produto, conforme figura 7, para constatar se há relevância entre tipos de produto para determinação de um projeto especifico, mas como foi salientado pelo time, realizando melhorias na sistemática do processo de realização do setup, independente do produto haverá resultado.

Figura 7: Tempo médio de setup por produto

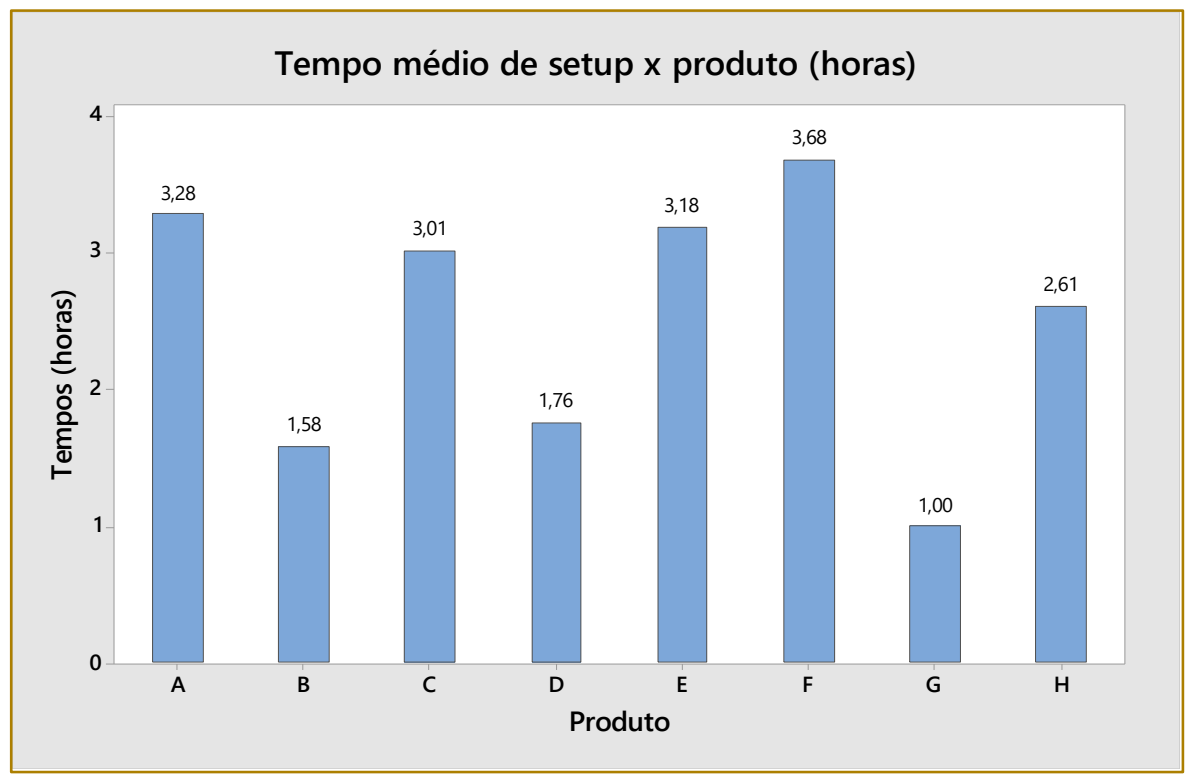

Fonte: Os autores

\subsection{ANALISAR}

$\mathrm{Na}$ etapa de analisar foi desenvolvido o mapeamento de processos (figura 8), por meio do mapa é possível identificar todas as etapas, atividades envolvidas e o impacto dessas atividades no aumento do tempo de setup.

Figura 8: Etapas do tempo de setup

\begin{tabular}{|l|l|l|l|l|}
\hline $\begin{array}{l}\text { 1) Programação e } \\
\text { pré-setup }\end{array}$ & $\begin{array}{l}\text { 2) Tomo: } \\
\text { operação 10 }\end{array}$
\end{tabular}$\quad$\begin{tabular}{l}
$\begin{array}{l}\text { 3) Torno: } \\
\text { operação 20 }\end{array}$ \\
\hline
\end{tabular}

Fonte: Os autores 
Houve a análise da composição das atividades de cada etapa para a efetivação do setup e sequentemente o levantamento das causas do impacto dessas atividades de forma a elevar o tempo de setup, conforme os quadros $6,7,8,9$ e 10.

\subsubsection{PROGRAMAÇÃO E PRÉ-SETUP}

A etapa de programação e pré-setup (Quadro

6) compreende sete atividades.

Quadro 6: Etapas e atividades da programação e pré-setup

\begin{tabular}{|l|l|}
\hline Atividades & $\begin{array}{l}\text { Causa do impacto da atividade no aumento do } \\
\text { tempo }\end{array}$ \\
\hline 1. Programação do PCP & $\begin{array}{l}1.1 \text { Mix de produtos na mesma célula } \\
1.2 \text { Programação não planejada }\end{array}$ \\
\hline 2. Separação dos componentes & $\begin{array}{l}2.1 \text { Componentes misturados } \\
2.2 \text { Falta de definição dos componentes para o uso } \\
\text { em cada setup } \\
2.3 \text { Falta de identificação dos componentes }\end{array}$ \\
\hline 3 Separação dos calibradores & $\begin{array}{l}3.1 \text { Calibradores misturados } \\
4 . \text { Montagem de brocas }\end{array}$ \\
\hline 5. Verificação da condição dos insertos & $\begin{array}{l}5.1 \text { Requisição de novos insertos } \\
5.2 \text { Necessidade de uma nova liberação após o setup }\end{array}$ \\
\hline 6. Verificação da programação da máquina & $\begin{array}{l}6.1 \text { Falta de programação para novos produtos } \\
6.2 \text { Separação do CNC data e o pen drive dos } \\
\text { programas }\end{array}$ \\
\hline 7. Separação dos instrumentos de medição & $\begin{array}{l}7.1 \text { Tempo de movimentação para a busca dos } \\
\text { instrumentos }\end{array}$ \\
\hline
\end{tabular}

Fonte: Os autores

\section{Torno (operação 10)}

A operação 10 abrange oito atividades (Quadro 7).

Quadro 7: Etapas e atividades do torno (operação 10)

\begin{tabular}{|c|c|}
\hline Atividades & $\begin{array}{l}\text { Causa do impacto da atividade no aumento do } \\
\text { tempo }\end{array}$ \\
\hline 1. Troca de garras & $\begin{array}{l}\text { 1.1 Falta de padronização de parafusos (diferença } \\
\text { entre unidades de medidas) }\end{array}$ \\
\hline 2. Verificação do travamento do centralizador & $\begin{array}{l}\text { 2.1 Entrada de cavaco no apoio do centralizador } \\
2.2 \text { Falta de planos de limpeza }\end{array}$ \\
\hline 3. Transferência do programa para CNC & $\begin{array}{l}\text { 3.1 Transferência durante o setup } \\
\text { 3.2 Unico } \mathrm{CNC} \text { data para dois setores da fäbrica }\end{array}$ \\
\hline 4. Edição do programa & $\begin{array}{l}\text { 4.1 Edição conforme a posição da ferramenta e o } \\
\text { corretor (diferentes entre células) }\end{array}$ \\
\hline 5. Ajustes dos parâmetros de pressão de aperto & $\begin{array}{l}5.1 \text { Falta de identificação e padronização das } \\
\text { garras }\end{array}$ \\
\hline 6. Troca dos insertos & 6.1 Falta de definição da vida útil dos insertos \\
\hline 7. Ajustes & 7.1 Falta de dispositivos de medição \\
\hline 8. Verificação dos apoios (fora do setup) & 8.1 Problema de oscilação axial \\
\hline
\end{tabular}

Fonte: Os autores 
A operação 20 contempla cinco atividades (Quadro 8).

Quadro 8: Etapas e atividades do torno (operação 20)

\begin{tabular}{|c|c|}
\hline Atividades & $\begin{array}{l}\text { Causa do impacto da atividade no aumento do } \\
\text { tempo }\end{array}$ \\
\hline 1. Troca de garras & $\begin{array}{l}\text { 1.1 Falta de padronização de parafusos (diferença } \\
\text { entre unidade de medidas) }\end{array}$ \\
\hline 2. Troca e a regulagem do pino centralizador & 2.1 Folga do pino centralizador \\
\hline $\begin{array}{l}\text { 3. Verificação dos parâmetros de pressão de } \\
\text { aperto }\end{array}$ & $\begin{array}{l}\text { 3.1 Falta de identificação e padronização das } \\
\text { garras }\end{array}$ \\
\hline 4. Ajustes & 4.1 Falta de dispositivos de medição \\
\hline 5. Verificação (fora do setup) & 5.1 Problema de oscilação axial \\
\hline
\end{tabular}

Fonte: Os autores

\section{Furadeira}

As etapas e atividades da furadeira (Quadro

9) consiste de oito atividades.

Quadro 9: Etapas e atividades da furadeira

\begin{tabular}{|c|c|}
\hline Atividades & $\begin{array}{l}\text { Causa do impacto da atividade no aumento do } \\
\text { tempo }\end{array}$ \\
\hline 1. Montagem das brocas & $\begin{array}{l}\text { 1.1 Dimensão errada na haste das brocas } \\
\text { 1.2 Defeito no cone }\end{array}$ \\
\hline 2. Preset & $\begin{array}{l}\text { 2.1 Programa parametrizado errado } \\
2.2 \text { Medição errada da altura da broca } \\
2.2 \text { Medição no ponto incorreto (variação entre } \\
\text { turnos) }\end{array}$ \\
\hline 3. Troca da flange & $\begin{array}{l}3.1 \text { Quebra da porca T } \\
3.2 \text { Montagem do conjunto (gera falha no air } \\
c h e c k \text { ) }\end{array}$ \\
\hline 4. Troca da pinça & 4.1 Excesso de cavaco \\
\hline 5. Alteração da posição das garras & 5.1 Demora na alteração \\
\hline 6. Centralização do furo de válvula & 6.1 Dificuldade para encontrar o centro \\
\hline 7. Transferência do programa para a furadeira & 7.1 Falta do cartão para transferência do programa \\
\hline 8. Ajustes & 8.1 Falha no preset/ou no programa \\
\hline
\end{tabular}

Fonte: Os autores 
Tridimensional

A etapa de tridimensional é composta de nove atividades (Quadro 10).

Quadro 10: Etapas e atividades da tridimensional

\begin{tabular}{|c|c|}
\hline Atividades & $\begin{array}{l}\text { Causa do impacto da atividade no aumento do } \\
\text { tempo }\end{array}$ \\
\hline 1. Movimentação para a tridimensional & 1.1 Equipamento afastado da usinagem \\
\hline 2. Espera pela medição & \multirow{4}{*}{$\begin{array}{l}2.1,3.1,4.1,5.1 \text { e } 6.1 \text { Equipamento lento, não } \\
\text { adequado ao processo e não dedicado apenas ao } \\
\text { setup (atende medição de part numbers da } \\
\text { produção) }\end{array}$} \\
\hline $\begin{array}{l}\text { 3. Preparação do equipamento (para } \circ \text { lado } \\
\text { interno do produto) } \\
\text { 4. Realização das medições (para o lado interno) }\end{array}$ & \\
\hline $\begin{array}{l}\text { 5. Preparação do equipamento (para } \circ \text { lado } \\
\text { externo do produto) }\end{array}$ & \\
\hline 6. Realização das medições (para o lado externo) & \\
\hline 7. Emissão dos relatórios & $\begin{array}{lccc}7.1 & \text { Necessidade de } & \text { preenchimento } & \text { de } \\
\text { especificações pelo inspetor } & & \end{array}$ \\
\hline 8. Movimentação de retorno para a célula & 8.1 Equipamento afastado da usinagem \\
\hline 9. Medição (inspeção) & 9.1 Método não adequado \\
\hline
\end{tabular}

Fonte: Os autores

\section{Implementar}

Inicialmente, com o uso dos conceitos SMED

foi proposto a separação das seguintes atividades de setup interno que são possíveis de serem realizadas de forma externa, conforme quadro 11.

Quadro 11: Atividades internas e externa de setup (cenário atual x proposto)

\begin{tabular}{|l|l|l|l|l|}
\hline \multicolumn{1}{|c|}{ Atividades } & \multicolumn{2}{c|}{ Atual } & \multicolumn{2}{c|}{ Proposto } \\
\hline & $\begin{array}{c}\text { Setup } \\
\text { Interno }\end{array}$ & $\begin{array}{c}\text { Setup } \\
\text { Externo }\end{array}$ & $\begin{array}{c}\text { Setup } \\
\text { Interno }\end{array}$ & $\begin{array}{c}\text { Setup } \\
\text { Externo }\end{array}$ \\
\hline Montagem de brocas & & & & \\
\hline Verificação da condição dos insertos & & & & \\
\hline Verificação da programação da maquina & & & & \\
\hline Transferência do programa para CNC & & & & \\
\hline Edição do programa & & & & \\
\hline Montagem das brocas & & & & \\
\hline Preset & & & & \\
\hline Transferência do programa para a furadeira & & & & \\
\hline Movimentacao para a tridimensional & & & & \\
\hline Aguardar medição da tridimensional & & & & \\
\hline
\end{tabular}


Em seguida, a partir da análise das causas que impactam no aumento do setup foram definidas propostas de solução para cada causa.
Com o intuito de ressaltar todas as propostas sugeridas, as mesmas foram segregadas e relacionadas em grupos, como mostrado no Quadro 12.

Quadro 12: Propostas para a melhoria do tempo de setup na usinagem

\begin{tabular}{|c|c|}
\hline Grupos & Propostas de melhorias \\
\hline Grupo 1 - Ferramentas & $\begin{array}{l}\text { 1.1 Montagem e presetting das brocas anteriomente ao setup } \\
\text { 1.2 Realização do estudo de vida útile padronização do tempo de uso dos insertos } \\
\text { 1.3 Sistematização e padronização do processo de montagem das brocas } \\
\text { 1.4 Verificação das condições e requisição dos insertos anteriormente ao setup } \\
\text { 1.5 Presetting extemo }\end{array}$ \\
\hline $\begin{array}{l}\text { Grupo 2- } \\
\text { Componentes }\end{array}$ & $\begin{array}{l}\text { 2.1 Separação e identificação dos componentes } \\
\text { 2.2 Criação de check list que determina todos os componentes que serão utilizados para a } \\
\text { operação por part number } \\
\text { 2.3 Padronização das especificações dos parafusos utilizados na troca das garras } \\
\text { 2.4 Criação de uma proteção para o centralizador } \\
\text { 2.5 Elaboração de plano de limpeza do centralizador para não ocorência do travamento } \\
\text { 2.6 Identificação e alinhamento entre o uso dos pinos guias e das garras } \\
\text { 2.7 Diminuuição da folga do pino centralizador } \\
\text { 2.8 Realização da montagem do conjunto da flange no pré-setup } \\
\text { 2.9 Engate rápido para a alteração da posição das garras }\end{array}$ \\
\hline $\begin{array}{l}\text { Grupo } 3 \text { - } \\
\text { Calibradores e } \\
\text { equipamentos de } \\
\text { medição }\end{array}$ & $\begin{array}{l}\text { 3.1 Separação dos calibradores por part number } \\
\text { 3.2 Utilização do equipamento de medição mais ágil, adequado e preciso para o processo de } \\
\text { setup (equipamento já existente na făbrica, porém não calibrado, por ter uma calibração mais } \\
\text { complexa, sendo neces sária ser realizada por um terceiro) } \\
\text { 3.3 Relatório de inspeção e medição automático, sem necessidade de preenchimento pelo } \\
\text { operador } \\
\text { 3.4 Padronização e mellhoria das inspeções }\end{array}$ \\
\hline \begin{tabular}{|l|} 
Grupo 4- \\
Programą̧ão CNC
\end{tabular} & $\begin{array}{l}\text { 4.1 Separação e trans ferência do CNC data e pen drive com antecedência } \\
\text { 4.2 Padronização das posições das ferramentas e corretores na programação da máquina }\end{array}$ \\
\hline Grupo 5-Ajustes & $\begin{array}{l}\text { 5.1 Equipamentos para ajustes especificos por célula } \\
\text { 5.2 Realização de presetting extemo, reduzindo as necess idades de ajustes }\end{array}$ \\
\hline \begin{tabular}{|l|} 
Grupo 6- \\
Movimentação
\end{tabular} & 6.1 Recolocação do principal equipamento na us inagem \\
\hline \begin{tabular}{|l|} 
Grupo 7- \\
Programacão
\end{tabular} & $\begin{array}{l}\text { 7.1 Programar produtos familias na mesma célula, eliminando a necessidade de inúmeras trocas e } \\
\text { ajustes }\end{array}$ \\
\hline
\end{tabular}

Fonte: Os autores

Para o levantamento das atividades, causas e sugestões de melhorias foi essencial a participação de todos os envolvidos no processo de usinagem para melhor entendimento e abrangência das ações. Após as implementações, os mesmos deverão ser treinados sobre as novas sistemáticas do processo.

\section{CONSIDERAÇÕES FINAIS}

Como apresentado, a metodologia SMED proporciona uma contribuição significativa para as organizações, visando a redução dos tempos de setup e aumentado o tempo produtivo de máquinas e equipamentos. Cenário este, que se apresenta na grande maioria das empresas atualmente, em especial empresas de manufatura, devido a necessidade de se obter resultados melhores, menores custos, menores tempos e maior flexibilidade para atender a demanda do mercado.
Para o presente projeto, foi possível apresentar uma proposta de melhoria para redução do tempo de setup no processo de usinagem, baseado nos conceitos da metodologia SMED.

Para o desenvolvimento, planejamento e execução do projeto, foram executadas as etapas: definir, medir, analisar e implementar, cujos resultados foram apresentados como propostas de melhorias como: separação de setup interno e externo, padronização de atividades, uso de dispositivos, eliminação de ajustes, melhoria organizacional, dentre outras melhorias apresentadas e que são melhor exemplificadas no Quadro 12.

A última etapa do projeto que é a checagem dos resultados, está em fase de conclusão e espera-se obter uma redução de 50\% do tempo de setup nos processos de usinagem estudados. Os resultados finais obtidos com a conclusão do presente projeto, serão apresentados e divulgados posteriormente em congressos da área. 


\section{REFERÊNCIAS}

[1] ALLAHVERDI, A.; SOROUSH, H. M. The significance of reducing setup times/setup costs. European Journal of Operations Research, 187, 978-984, 2008

[2] BATELOCHI, L. Fundamento do set up rápido. Revista $O$ mundo da Usinagem, p.6-11, $n^{\circ} 38,8^{\circ}$ ed., 2007.

[3] CALHADO, M. P. et al. Implantação do método de troca rápida de ferramentas no setor de usinagem em uma indústria de autopeças. In: XXXV ENCONTRO NACIONAL DE ENGENHARIA DE PRODUCAO. Fortaleza, 2015.

[4] CAKMAKCI, M.; KARASU, M. K. Set-up time reduction process and integrated predetermined time system MTM-UAS: a study of application in a large size company of automobile industry. The International Journal of Advanced Manufacturing Technology, v. 33, n. 3-4, p. 334344, 2007.

[5] CECHECT, L. A. et al. Implantação dos conceitos de TRF em uma empresa do setor de plásticos. In: SIMPÓSIO DE ENGENHARIA DE PRODUÇÃO. Bauru, 2008.

[6] CORAZZA, E. J. Otimização do tempo de setup no setor de usinagem, em uma empresa de processamento de alumínio de Joinville/SC - Brasil. In: XXXVI ENCONTRO NACIONAL DE ENGENHARIA DE PRODUCÃO. João Pessoa, 2016.

[7] ELLIOT, J. La investigación-acción en educación. $3^{\circ}$ ed. Madrid: Morata, 1997.

[8] FOGLIATTO, F. S.; FAGUNDES, P. R. M. Troca rápida de ferramentas: proposta metodológica e estudo de caso. Gestão e Produção, v. 10, n. 2, p. 163-181, 2003.

[9] GAITHER, N.; FRAZIER, G. Administração da produção e operações. $8^{\circ}$ ed. São Paulo: Pioneira Thomson Learning, 2004.

[10] GIL, A.C. Como elaborar projetos de pesquisa. 4를. São Paulo: Atlas, 2007.

[11] GOLDRATT, E. M.; COX, J. A Meta: um processo de melhoria contínua. $2^{\circ}$ ed. São Paulo: Nobel, 1998.

[12] GOSS, R.; MAXIM, C.; ADHIKARI, D.; ROTHE, J. Leveraging new SEMI standard to reduce waste and improve flow for semiconductor manufacturing. Robotics and Computer Integrated Manufacturing, 26, 658-664, 2010.

[13] HANSEN, R.C. Eficiência Global dos Equipamentos - uma poderosa ferramenta de produção/manutenção para o aumento dos lucros. Porto Alegre, Bookman, 2006.

[14] HARRY, M.; SCHROEDER, R. Six Sigma: The Breakthrough Management Strategy Revolutionalizing the World's Top Corporations. Currency/Doubleday, New York, NY, 2000.
[15] MAESTRELLI, N. Redução de tempos de preparação de máquinas (setup): um caso de aplicação. Revista Manufatura em foco, Prol Editora Gráfica, p.8-11, ano 2, n¹2, 2014.

[16] MARDEGAN, R. et al. Estudo de caso de implementação de troca rápida de ferramenta em uma empresa metal mecânica. In:XXVI Congresso de Engenharia de Produção. Fortaleza, 2006.

[17] MCCARTHY, R. Toolroom management: presetting increases profits and productivity. MoldMaking Technology, 2006.

[18] MCINTOSH, R. I.; SUGAI, M.; NOVASKI, O. Metodologia de Shigeo Shingo (SMED): análise crítica e estudo de caso. In: Revista Gestão e Produção. São Carlos, 2007.

[19] MELLO, C. H. P. et al. Pesquisa-ação na engenharia de produção: proposta de estruturação para sua condução. Production Journal. v. 22, n. 1 , p. $1-13,2012$

[20] MONDEN, Y. Produção sem estoques: uma abordagem prática ao sistema de produção da Toyota. São Paulo: IMAM, 1984.

[21] MOXHAN, C.; GREATBANKS, R. Prerequisites for the implementation of the SMED methodology. A study in the textile-processing environment. The International Journal of Quality \& Reliabilty Management. v.18, n. 4/5, p. 404-414, 2001.

[22] NICHOLAS, J. Competitive manufacturing management Irwin. McGraw-Hill, 181-186, 1998.

[23] SALOTO, E. G.; CALARGE, F. A. Troca Rápida de Ferramentas: estudo de casos em diferentes segmentos industriais. Exacta, p. 283296, v. $6, n^{\circ} 2,2008$.

[24] SHINGO, S. A revolution in manufacturing: the SMED system. Cambrigde: Product Press, 361p., 1985.

[25] SHINGO, S. Sistema de Troca Rápida de Ferramenta: uma revolução nos sistemas produtivos. Bookman, 2000.

[26] STRAPASSON, M.; LEITE,H. V. dos R. Troca rápida de ferramenta: estudo de caso em uma indústria do setor metal mecânico. In: XXXII ENCONTRO NACIONAL DE ENGENHARIA DE PRODUCAO. Bento Gonçalves, 2012.

[27] THIOLLENT, M. J. M. Metodologia da pesquisa-ação. 18 ed. São Paulo: Cortez, 2011.

[28] USEVICIUS, L. A. Implantação da metodologia seis sigma e aplicação da técnica estatística projeto de experimentos na resolução de problemas e otimização de processos de fabricação. Mestrado - Universidade Federal do Rio Grande do Sul. Porto Alegre, 2004.

[29] VAN GOUBERGEN, D. Set-up reduction as an organization-wide problem. In: SOLUTIONS 
2000

CONFERENCE,

2000. Proceedings... Cleveland: DRI Research e Publications, 2000.

[30] VIEIRA JUNIOR, M. et al. Statement of losses caused by the presetting of tools by the manual method. In: POMS 22nd Annual Conference, Anais... Reno, Nevada, U.S.A, 2011.

[31] WERKEMA, C. Lean Seis Sigmas: introdução às ferramentas do Lean Manufacturing. v.4. Belo Horizonte: Werkema Editora, 2006.
[32] WILTSIE, J. Setup reduction-one discipline you must master. Magazine Production Maching, 2012.

[33] XAVIER, C. A. R. et al. A melhoria do setup de uma empresa de usinagem: um estudo de caso em Porto Velho. Revista Interdisciplinar Científica Aplicada. Blumenau, v.8, n.2, p.12-34, TRI II, 2014. 


\section{Capítulo 4}

\section{BARREIRAS AO USO DA ESTATISTICA COMO PRÁTICA DA GESTÃO DA QUALIDADE EM INDÚSTRIAS DE TRANSFORMAĊÃO DO SUL E SUDESTE DO BRASIL}

\section{Letícia Saggioratto \\ Adriana Barbosa Santos \\ Carolina Barbosa Gomes}

Resumo: Este artigo trata de aspectos relevantes acerca da compreensão sobre certas barreiras ao uso da estatística como prática da gestão da qualidade no âmbito organizacional, as quais foram identificadas com base na literatura e encontram-se presentes nos diferentes níveis hierárquicos. Apesar do uso da Estatística na gestão e controle da qualidade ter uma história de sucesso há décadas, são escassos os trabalhos recentes que identificam as barreiras estratégicas, táticas e operacionais a partir de estudos empíricos com empresas do Brasil. Mais especificamente, esta pesquisa enfoca o entendimento sobre os princípios do pensamento estatístico, o uso efetivo de ferramentas e técnicas estatísticas com vistas à melhoria da qualidade e a avaliação das barreiras existentes nos diferentes níveis hierárquicos de atividade. Um conjunto de indústrias de transformação do Sul e Sudeste do Brasil compuseram a amostra do estudo empírico. Os resultados revelam que há uma expressiva proporção de concordância com os princípios do pensamento estatístico; que a falta de suporte da alta administração é um entrave significante para se utilizar o enfoque estatístico; que há um bom grau de conhecimento sobre ferramentas e técnicas estatísticas em nível gerencial, por outro lado, há deficiências substanciais de capacitação em tais ferramentas e técnicas entre os funcionários de nível operacional.

Palavras-chave: Pensamento estatístico, Barreiras operacionais, Barreiras estratégicas, Survey, Qualidade. 


\section{INTRODUÇÃO}

Nas últimas duas décadas, a utilização da Estatística teve grande impulso em diversas áreas tanto no meio acadêmico, das pesquisas científicas, como empresarial das organizações de manufatura ou serviços. A Internet permitiu conhecer teorias estatísticas já consolidadas há décadas, aplicações e novidades de pesquisas inéditas e promoveu o uso da Estatística acentuadamente nos ambientes empresariais, contribuindo para compor uma base de conhecimentos que dá melhores condições para operar sistemas produtivos e para assegurar decisões.

A partir dos anos 1980 ocorreu também uma difusão maior da importância do pensamento estatístico como fator que torna a gestão da qualidade mais efetiva, uma vez que enfoca a minimização da variabilidade, o monitoramento mais rígido dos processos e o foco em dados, sem, necessariamente, estar atrelado ao uso das ferramentas e técnicas, como se pode pensar (OAKLAND; SOHAL, 1987; BRITZ et al., 2000; GRIGG; WALLS, 2007; IGNÁCIO, 2010).

Com os avanços tecnológicos e acesso mais facilitado às tecnologias para armazenamento e análise de dados, as organizações se mobilizaram no sentido de capacitar melhor seus funcionários para que se tornem mais aptos a usarem ferramentas estatísticas, principalmente aqueles que atuam em nível gerencial e operacional, dedicados às atividades de projetos de melhoria da qualidade. No entanto, esta prática merece atenção dos executivos em dois pontos importantes. O primeiro é a crença que só o fato de usar ferramentas estatísticas resultará na melhoria organizacional desejada. Neste sentido, embora a aplicação de uma gama destas ferramentas seja um recurso valioso para diagnosticar e solucionar problemas nos processos, pela obtenção de estimativas, testes de hipóteses, modelagem de variáveis chaves, entre outros, cabe a quem gerencia os processos carentes de melhoria definir os meios e onde será aplicada a abordagem estatística. O segundo é a priorização da capacitação de operadores, supervisores e técnicos em geral, por meio de treinamentos intensivos de curta duração para se atualizarem sobre ferramentas, equipamentos, softwares, normas, etc, inferindo que deficiências dos processos possam ser sanadas apenas com a capacitação dos profissionais de nível operacional. Todavia, a visão estatística estreita de gerentes e executivos que atuam no nível tático ou estratégico pode ser uma barreira ainda maior a se transpor do que a referida capacitação (LEITNAKER; SANCHES; HILD, 1996; MAKRYMICHALOS et al., 2005; HOERL; SNEE, 2010).

Apesar do enfoque estatístico ser relevante em todos os tipos de negócios no século XXI, ainda se verificam barreiras para sua utilização adequada como prática da gestão da qualidade. Tais barreiras não são genuínas dos profissionais que atuam em empresas, haja vista que podem ser identificadas em outros ambientes produtivos, inclusive no meio acadêmico/científico, e podem ser encontradas nos três níveis de atividade organizacional (estratégico, tático e operacional); o que dificulta ou impede a difusão do pensamento estatístico e, por conseguinte, a aplicação dos métodos estatísticos diretamente voltados à melhoria da qualidade e do desempenho dos negócios de forma mais efetiva. Neste sentido, o desafio de se difundir o pensamento estatístico e não apenas o uso das ferramentas entre não estatísticos interfere em aspectos de cunho não teórico, que esbarram em questões mais complexas relativas à estrutura organizacional e a cultura, que aumentam a pressão e responsabilidade da alta administração para que o sucesso dessa difusão aconteça de fato.

Neste contexto, este artigo visa avançar no entendimento dessas barreiras encontradas nos diferentes níveis hierárquicos, bem como analisar o grau de concordância com os princípios do pensamento estatístico, a frequência de uso das ferramentas e técnicas estatísticas com vistas à melhoria da qualidade; e avaliar as referidas barreiras, a partir de um survey com indústrias de transformação do Sul e Sudeste do Brasil.

\section{PENSAMENTO ESTATÍSTICO NA MELHORIA DA QUALIDADE}

Não há como negar a existência de variação entre produtos, pessoas, serviços, processos, organizações, natureza, etc. Ela é parte intrínseca da vida e, em um ambiente produtivo, sua presença pode ocorrer por diferentes causas, assim como ocorre na natureza. Ao se priorizar este fato inerente ao pensamento estatístico, consequentemente, se fundamenta melhor as ações com intuito de reduzir custos associados com inspeção, desperdícios, retrabalho, insatisfação dos 
clientes, entre outros, os quais constituem propósitos relevantes para a estratégia competitiva de muitas organizações que buscam melhorar seus resultados e sua posição frente a concorrência (PFANNKUCH; WILD, 2004)

O pensamento estatístico é pré-requisito para o uso de ferramentas estatísticas, em razão de seu caráter mais conceitual, filosófico, universalmente aplicável, e de ter o conhecimento como principal benefício (COLEMAN, 2013). Há mais de duas década R. D. Snee definiu pensamento estatístico como "um processo de raciocínio que reconhece que variação está em tudo ao nosso redor e presente em tudo que fazemos, que todo trabalho é uma série de processos interligados; e que identificar, caracterizar, quantificar, controlar e reduzir variação fornece oportunidades de melhoria" (SNEE, 1990). Esta definição deriva do princípio fundamental da qualidade defendido por W. E. Deming: Reduce variation and you improve quality. De acordo com o glossário de termos da American Society for Quality (ASQ, 1996), o pensamento estatístico é uma filosofia de aprendizagem e ação respaldada por três princípios fundamentais:

- Princípio 1: Todo trabalho ocorre em um sistema de processos interconectados;

- Princípio 2: A variação está presente em todos os processos;

- Princípio 3: A chave do sucesso é entender e reduzir variação.

Para Dransfield e Fisher (1999), o sucesso de estratégias que busquem a melhoria da qualidade, com ações corretivas para aumentar a eficiência de processos, dependerá de elementos cruciais, como: grau de consciência que se tem de que a variação está sempre presente; gerar dados sobre a qualidade dos processos; extrair as informações relevantes com a utilização de ferramentas estatísticas apropriadas; e utilizar a informação para otimizar a tomada de decisão.

Mais recentemente, no contexto dos programas de qualidade, o pensamento estatístico apareceu como protagonista do Seis Sigma, tendo papel preponderante para compreensão da metodologia sistematizada de implementação de projetos de melhoria, focada em análise de dados e numa abordagem holística para a solução de problemas críticos em processos. Ainda, servindo de aporte para tornar a tomada de decisão mais eficiente (SANTOS; MARTINS, 2008; ANTONELLI; SANTOS, 2011) por seus efeitos positivos no desempenho operacional $(\mathrm{GOH}, 2011)$.

\section{BARREIRAS AO USO DE ESTATÍSTICA NAS ORGANIZAÇÕES}

Apesar dos aspectos positivos já atestados e relatados por executivos de grandes organizações, pesquisadores e consultores, é notório que há empresas de diversos setores que apresentam resistência ou dificuldades em adotar uma forma lógica de incorporar a abordagem estatística com clareza. Surgem, então, certas barreiras que entravam a difusão da importância e uso de estatística de forma ampla nessas organizações. Buscando compreender melhor tais aspectos, foi realizado um brainstorming com pesquisadores, consultores e um levantamento da literatura mais recente para compor uma lista de pontos que atualmente se configuram como tais barreiras. Cinco tipos se destacaram: recursos financeiros; visão estratégica; comprometimento da alta administração; visão gerencial; e capacitação, conforme sintetizado na Tabela 1 e mais detalhado na Tabela 2.

\subsection{BARREIRAS NO NÍVEL ESTRATÉGICO}

Dentre as principais barreiras no nível estratégico (BE) identificadas, destacam-se aquelas relacionadas às restrições financeiras, à falta de abrangência na visão estratégica e a falta de apoio da alta administração.

\section{Recursos Financeiros}

Em relação às barreiras relacionadas aos recursos financeiros, nota-se que as dificuldades na implementação de programas de qualidade, a falta de treinamentos e a escassez de investimentos em tecnologia para armazenamento e tratamento de dados tem constituído uma das BE.

No âmbito da gestão da qualidade, as BE impactam a implementação de programas de qualidade. Estudos com empresas de pequeno e médio porte da Malásia e de grande porte no Brasil retratam que a limitação gerada por restrições financeiras afetou sensivelmente $\mathrm{o}$ sucesso da implementação de programas de gestão da 
qualidade, como Six Sigma, ISO 9001 e Total Productive Maintenance (TPM) (AHMED; HASSAN, 2003; TJAHJONO, et al., 2010; ATTRI, et al., 2013; CARVALHO; LEE HO; PINTO, 2007).

\section{Visão estratégica}

Não se pode atingir altos níveis de qualidade sem o desenvolvimento de habilidades que contribuam continuamente para um direcionamento apropriado da implementação de programas de qualidade. Todavia, isso requer uma mudança de mindset que tira as pessoas de sua zona de conforto; o que pode desencadear resistências substanciais que expõem problemas relacionados à cultura organizacional que não favorecem a implementação dos programas de qualidade (SNEE, 1990; MAKRYMICHALOS et al., 2005; ABRAHAN, 2005; GRIG; WALLS, 2007). O medo de enfrentar o desconhecido assusta os executivos que buscam em sua experiência uma saída para não inovar partindo para uma nova filosofia e modo de pensar.

As $\mathrm{BE}$ relacionadas à abrangência da visão estratégica são caracterizadas pela falta do devido entendimento sobre as causas de variação que afetam os processos, dando lugar a soluções rápidas sem planejamento adequado, que despendem grande esforço em ações de contenção e que tornam a implementação dos programas de qualidade ineficiente no longo prazo por não atacarem a causa raiz dos problemas.

Tabela 1 - Barreiras ao uso do pensamento estatístico, ferramentas e das técnicas estatísticas

\begin{tabular}{|c|c|c|c|}
\hline $\begin{array}{c}\text { Nível } \\
\text { hierárquico }\end{array}$ & Característica & Barreira & Autores \\
\hline \multirow{3}{*}{ Estratégica } & $\begin{array}{l}\text { Recursos } \\
\text { Financeiros }\end{array}$ & $\begin{array}{l}\text { Restrições Financeiras } \\
\text { (capacitação e ferramentas } \\
\text { deficitárias e/ou não continuidade } \\
\text { dos programas de qualidade). }\end{array}$ & $\begin{array}{l}\text { Attri et al. (2013), Ahmed; Hassan } \\
\text { (2003), Carvalho; Lee Ho; Pinto (2007), } \\
\text { Žmuk (2015) }\end{array}$ \\
\hline & $\begin{array}{l}\text { Visão } \\
\text { Estratégica }\end{array}$ & $\begin{array}{l}\text { Existe uma grande resistência a } \\
\text { mudanças de mindset das } \\
\text { pessoas e cultura da empresa, } \\
\text { porque confronta o desconhecido } \\
\text { e a zona de conforto. }\end{array}$ & $\begin{array}{l}\text { Makrymichalos et al. (2005), Abrahan } \\
\text { (2005), Carvalho (2015), Tanco et al. } \\
\text { (2010). }\end{array}$ \\
\hline & $\begin{array}{c}\text { Alta } \\
\text { Administração }\end{array}$ & $\begin{array}{l}\text { Falta de suporte e envolvimento } \\
\text { da alta administração para } \\
\text { promover a aplicação e difusão } \\
\text { do pensamento estatístico e uso } \\
\text { das técnicas estatísticas. }\end{array}$ & $\begin{array}{l}\text { Ahmed; Hassan (2003), Carvalho } \\
\text { (2015), Attri et al. (2013), Abrahan } \\
\text { (2005), Carvalho; Lee Ho; Pinto (2007), } \\
\text { Grigg; Walls (2007), Vining (2011), } \\
\text { Tanco et al. (2010). }\end{array}$ \\
\hline \multirow[b]{2}{*}{ Tática } & \multirow[b]{2}{*}{ Capacitação } & $\begin{array}{l}\text { Falta de ênfase no uso dos } \\
\text { princípios do pensamento } \\
\text { estatístico para auxiliar na tomada } \\
\text { de decisões }\end{array}$ & \multirow{2}{*}{$\begin{array}{l}\text { Ahmed; Hassan (2003), Makrymichalos } \\
\text { et al. (2005), Carvalho (2015), John and } \\
\text { Johnson (2002), Grigg; Walls (2007), } \\
\text { Attri et al. (2013), Abrahan (2005), } \\
\text { Žmuk (2015), Tanco et al. (2010). }\end{array}$} \\
\hline & & $\begin{array}{l}\text { Ausência de conhecimento } \\
\text { estatístico adequado dos } \\
\text { gerentes, proveniente de } \\
\text { formação e/ou capacitação } \\
\text { defasada. }\end{array}$ & \\
\hline \multirow{3}{*}{ Operacional } & \multirow{3}{*}{ Capacitação } & $\begin{array}{l}\text { Falta de conhecimento e visão } \\
\text { clara do por que o treinamento é } \\
\text { requerido }\end{array}$ & $\begin{array}{l}\text { Ahmed; Hassan (2003), Carvalho; Lee } \\
\text { Ho; Pinto (2007) }\end{array}$ \\
\hline & & $\begin{array}{l}\text { Utilização das técnicas } \\
\text { estatísticas e/ou softwares de } \\
\text { maneira incorreta, em } \\
\text { desencontro as necessidades } \\
\text { reais da empresa }\end{array}$ & \multirow{2}{*}{$\begin{array}{l}\text { Makrymichalos et al. (2005), Carvalho; } \\
\text { Lee Ho; Pinto (2007), Grigg; Walls } \\
\text { (2007), Kumar et al. (2007), Tjahjono et } \\
\text { al. (2010), Tanco et al. (2010). }\end{array}$} \\
\hline & & $\begin{array}{l}\text { Complexidade dos treinamentos } \\
\text { sobre o uso das ferramentas } \\
\text { estatísticas }\end{array}$ & \\
\hline
\end{tabular}


Tabela 2 - Detalhamento das barreiras estratégicas, táticas e operacionais

\begin{tabular}{|c|c|}
\hline Nível & Barreira \\
\hline \multirow{3}{*}{ Estratégico } & $\begin{array}{l}\text { BE1: o apoio financeiro na continuidade de aplicação dos programas e ferramentas da } \\
\text { qualidade, em períodos de restrições financeiras da empresa se torna inadequado para } \\
\text { a difusão do pensamento estatístico }\end{array}$ \\
\hline & $\begin{array}{l}\text { BE2: a aprovação de algum projeto ou iniciativa ousada que vise à melhoria da } \\
\text { qualidade na empresa é pouco incentivada, devido à visão estratégica inadequada } \\
\text { para a difusão do pensamento estatístico }\end{array}$ \\
\hline & $\begin{array}{l}\text { BE3: O uso da estatística na empresa é pouco incentivado pela alta administração, } \\
\text { devido à visão estratégica e apoio financeiro inadequado }\end{array}$ \\
\hline \multirow{2}{*}{ Tático } & $\begin{array}{l}\text { BT1: o uso da estatística para as tomadas de decisões é pouco enfatizado, devido a } \\
\text { falta de entendimento da mesma para a capacitação adequada do gestor para a } \\
\text { melhoria da qualidade }\end{array}$ \\
\hline & $\begin{array}{l}\text { BT2: o grau de conhecimento estatístico do funcionário de nível tático/gerencial é } \\
\text { baixo/ausente devido à defasagem de capacitação para a melhoria da qualidade }\end{array}$ \\
\hline \multirow{3}{*}{ Operacional } & $\begin{array}{l}\text { BO1: o grau de compreensão do funcionário de nível operacional sobre a necessidade } \\
\text { da realização de capacitação no uso dos métodos, ferramentas e técnicas estatísticas } \\
\text { é baixo/ausente }\end{array}$ \\
\hline & $\begin{array}{l}\text { BO2: o grau de conhecimento dos funcionários de nível operacional para a aplicação } \\
\text { correta e adequada dos métodos, ferramentas, softwares e técnicas estatísticas é } \\
\text { baixo/ausente }\end{array}$ \\
\hline & $\begin{array}{l}\text { BO3: o enfoque principal dado para a capacitação dos funcionários em relação à } \\
\text { aplicação das ferramentas e técnicas estatísticas é inadequado, sendo muito complexo } \\
\text { e teórico }\end{array}$ \\
\hline
\end{tabular}

Fonte: Elaborado pelos autores

\section{Comprometimento da alta administração}

O comprometimento da alta administração tem sido registrado como um dos fatores críticos de sucesso para implementação de programas como o Six Sigma, os quais contemplam um enfoque mais intenso em redução de variação e eliminação de desperdícios, uso de dados e medição para subsidiar a tomada de decisão (ABRAHAN, 2005; GRIG; WALLS, 2007; TJAHJONO et al., 2010; VINING, 2011). A falta de apoio da alta administração foi notória no topo da lista em empresas da Índia e do Brasil em relação às barreiras para implementação do TPM (TJAHJONO et al., 2010; ATTRI, 2013). Em contrapartida, empresas renomadas como Motorola, General Electric, Allied Signal, entre outras, tiveram grande sucesso na implementação do programa Six Sigma como resultado do forte apoio de seus CEOs que reconheciam a sistemática metodológica para implementar projetos com forte ênfase estatística como trajetória para alcançar a excelência em qualidade e que compreendem que qualidade é inversamente proporcional a variabilidade (MONTGOMERY, 2010).

Além disso, o comprometimento da alta administração é fundamental para o alinhamento estratégico e para alcance das metas de longo prazo, sobretudo para se ter os subsídios necessários para a resolução de problemas e melhorias nos processos que aumentam a satisfação dos clientes (AHMED; HASSAN, 2003; ABRAHAN, 2005; GRIG; WALLS, 2007). Neste sentido, a aplicação do pensamento estatístico em nível estratégico estabelece a criação e disseminação de uma gramática comum de comunicação, a qual favorece o alinhamento estratégico, a integração e a mudança de cultura organizacional; dimensões estratégicas que compõem a espinha dorsal da implementação de programas como o Six Sigma.

\subsection{BARREIRAS NO NÍVEL TÁTICO/GERENCIAL (BT)}

Educação/Treinamento 
A falta de preparo dos profissionais é uma das principais barreiras no nível tático (BT), tanto pela formação deficiente na graduação como pela carência de treinamentos ou cursos extracurriculares sobre estatística com enfoque teórico-prático (ATTRI, 2013). Em alguns casos, o apelo teórico de alguns treinamentos torna-se uma barreira, haja vista que o método tradicional de ensino da estatística enfatiza as técnicas estatísticas, teorias matemáticas e detalhamento de cálculos, logo, gera ensinamento ineficiente do valor das ideias estatísticas e suas aplicações, despertando até mesmo medo nos profissionais (MAKRYMICHALOS et al., 2005; WILKS, 2006). Neste sentido, percebese uma barreira educacional decorrente do nível de formação em estatística durante a universidade. Parcerias entre universidades e indústrias poderiam contribuir para minimizar certas deficiências encontradas atualmente nas empresas (ABRAHAN, 2005; WILKS, 2006).

A qualidade dos treinamentos também é citada em estudo com indústrias de alimentos por Grig; Walls (2007) destacando a influência significativa da capacitação, principalmente, quanto ao uso das ferramentas estatísticas mais avançadas, que exigem mais aprofundamento teórico-prático antes que possam ser rotineiramente aplicadas; fato que restringe seu uso. A ausência de desenvolvimento teórico para resolver problemas reais usando design of experiments é apontada por Tanco et al. (2009) como uma barreira técnica enfrentada por engenheiros. Outros estudos recentes também discutem essa limitação técnica vivenciada nas empresas e identificam uma tendência na utilização de conceitos, ferramentas e técnicas mais básicas no contexto da gestão da qualidade, apenas com intuito de se tentar reduzir defeitos e propiciar um monitoramento mais satisfatório dos processos de manufatura (GRIG; WALLS, 2007; TANCO et al., 2009; MAKRYMICHALOS et al., 2005; CARVALHO; LEE HO; PINTO, 2007). Com a variedade de softwares estatísticos disponíveis e foco em resultados rápidos, a atenção demasiada na aplicação das ferramentas estatísticas deixa de lado uma discussão prévia importante sobre a finalidade dessas ferramentas, ou seja, sobre quais são as reais funções delas para conhecimento mais profundo dos processos.
Outra BT também observada é a falta de visualização dos processos com foco na variabilidade, de modo que há dificuldade em distinguir causas comuns e especiais de variação nos processos-chave de negócio (MAKRYMICHALOS et al., 2005). Neste caso, falta uma clareza maior sobre a utilização dos princípios do pensamento estatístico nas atividades do dia-a-dia e no nível de profundidade com que as ferramentas foram estudadas para dar segurança sobre sua aplicação. A BT fica evidente quando se configura a dificuldade de mostrar liderança e direcionar as ações para que a melhoria da qualidade aconteça (BRITZ, 2000). Atividades de melhoria incluem trabalho direcionado para as causas de variação especiais e comuns, mas cabe atentar ao fato de que não são as mesmas pessoas que atuam nestas duas frentes e nem sempre os gerentes conseguem lidar com essa situação.

\subsection{BARREIRAS NO NÍVEL OPERACIONAL (BO)}

\section{Educação/Treinamento}

Problemas atrelados à capacitação aparecem como a mais relevante barreira de nível operacional (BO) que traz uma grande preocupação para o desenvolvimento individual e coletivo. A falta de entendimento da importância do aprimoramento técnico pelos funcionários pode gerar uma limitação substancial para se alcançar níveis de excelência na qualidade de produtos, serviços ou processos.

Ao examinar mais especificamente a agenda de cursos de capacitação sobre estatística, verifica-se que certas lacunas na formação básica podem despertar resistência dos profissionais, principalmente, ao considerarem os cursos complexos, teóricos de difícil entendimento. Acham difícil saber como aplicar a teoria na solução dos problemas que eles enfrentam diariamente. A discussão desta BO de âmbito educacional não é recente na literatura e os resultados de estudos empíricos revelam sua relevância ainda hoje nas industrias (ANTONY; KAYE; FRANGOU, 1998; AHMED; HASSAN, 2003; BERGQUIST; ALBING, 2006). Exemplo disso, é o survey realizado com empresas envolvidas com a implantação do Six Sigma no Brasil em que a complexidade dos treinamentos internos e o manuseio das ferramentas da qualidade estiveram entre as dificuldades mais assinaladas por 
engenheiros da área de qualidade (CARVALHO; LEE HO; PINTO, 2007).

O uso incorreto na aplicação dos métodos estatísticos é outra BO presente devido a uma lacuna de conhecimento teórico-prático, de falta de embasamento de como interpretar conceitos cruciais para entendimento dos resultados computacionais (MAKRYMICHALOS et al., 2005; TJAHJONO et al., 2010; NUNES et al, 2015). Este problema se acentua porque a questão tecnológica está diretamente ligada ao uso otimizado da estatística. Diante disso, algumas pessoas "escorregam" na hora de manipular interpretar os outputs dos softwares estatísticos.

Com os benefícios do avanço tecnológico, notados principalmente nos ganhos em tempo para se realizar as tarefas e no leque de opções colocados à disposição, atualmente, se consegue rapidamente armazenar dados, extrair dados, realizar cálculos precisos e análises. Isso atrai cada vez mais usuários para as ferramentas computacionais. Por consequência, a ênfase nas evidências estatísticas é cada vez mais valorizada. Por outro lado, o risco de erros por falta de embasamento teórico é crescente e fator limitante da validade e confiabilidade dessas evidências.

\subsection{AÇÕES QUE PODEM SER APRIMORADAS COM UMA VISÃO AMPLA DA ABORDAGEM ESTATÍSTICA}

Para mitigar as barreiras discutidas acima, recomenda-se que um conjunto de ações sejam aprimoradas em cada nível de atividade, as quais demonstrem consistência de propósito e uma cultura e visão organizacional mais ampla e madura.

Em nível estratégico: Fixar metas; reconhecer que estatística é indispensável para tomada de decisão; melhorar o suporte ao planejamento, coleta de dados, modelagem e analises; e constância de propósito.

Em nível tático/gerencial: Criar métricas de desempenho que reflitam a eficiência e eficácia das atividades; quebrar barreiras interfuncionais, por meio de uma linguagem comum; estimular o trabalho em equipe para reduzir as fontes de variação sobre as atividades das pessoas; Tomar decisões baseadas em fatos e dados; aumentar a robustez no gerenciamento; assegurar uma efetiva apresentação das informações gerenciais para que a mesma seja recebida e interpretada da forma correta, a fim de direcionar quando e qual ação deve ser priorizada.

Em nível operacional: focar na melhoria contínua dos processos internos; estudar constantemente as fontes de variabilidade visando minimizá-las; padronizar atividades e procedimentos; estimular a quantificação da incerteza; planejar a coleta de dados, análise e apresentação apropriada das informações.

\section{MÉTODO DE PESQUISA}

Com base no referencial teórico, duas hipóteses foram formuladas, a saber: $\mathrm{H} 1$ : Os princípios do pensamento estatístico são pouco difundidos dentre as ações da alta administração; H2: A falta de capacitação e conhecimento sobre ferramentas e técnicas estatísticas básicas ou intermediárias retarda o avanço do uso da estatística com vistas à melhoria da qualidade.

Para avaliar tais hipóteses, a abordagem de pesquisa quantitativa foi adotada, baseada num levantamento tipo survey exploratóriodescritivo como método de pesquisa.

A população objeto de estudo foi delimitada tendo como base informações em diferentes fontes de dados primários e secundários, sendo eles, o contato de ex-universitários; listas atualizadas das maiores empresas divulgada pela Revista Época Negócios, 360ㅡㅡำ Empresas, edição de 2016; das 500 maiores empresas do Brasil, divulgada pela Exame, edição 2017; das 1000 maiores empresas do Brasil, divulgada pela Revista Valor Econômico e o Linkedin. Esse último para visualizar de maneira ilimitada o perfil de profissionais que trabalham nas empresas listadas. No total, a população considerada foi de 290 empresas.

\subsection{INSTRUMENTO DE COLETA}

Utilizou-se como instrumento de coleta de dados um questionário auto preenchido, ou seja, que seja lido e respondido diretamente pelo respondente, contendo quatro tópicos principais. São eles:

- Parte 1: Caracterização do entrevistado;

- Parte 2: Caracterização da empresa;

- Parte 3: Difusão da estatística na empresa; 
- Parte 4: Ferramentas, Técnicas e Softwares Estatísticos.

Para a construção do questionário buscou-se realizar questões objetivas e fáceis de serem entendidas, utilizando-se a plataforma Survey Monkey, visando também maior personalização do layout, pela preocupação com a comunicação visual (cores, formas e disposição das questões) e taxa de resposta (SYNODINOS, 2003; TOOURANGEAU, 2000; FOX; CRASK; KIM, 1998; COUPER, 2001; READLINE; DILLMAN, 2002; COUPER, 2005). Além disso, essa plataforma possibilitou programar a obrigatoriedade das respostas, evitando respostas incompletas ou esquecidas (SHMIDT, 1997) e também a programação de pergunta filtro para obter respostas do público alvo desejado.

No início do questionário foi inserida uma tela inicial, contendo uma descrição breve da pesquisa, objetivos, tempo estimado para preenchimento, esclarecimento em relação à confidencialidade e sigilo das informações fornecidas, instruções gerais e destaque para a importância da participação do respondente (SHMIDT, 1997; FREITAS et al., 2000;
DILLMAN, 2000; FREITAS et al., 2004; AHMED; HASSAN, 2003; FORZA, 2002).

\subsubsection{AVALIAÇÃO PRÉVIA QUESTIONÁRIO}

DO

A avaliação prévia do questionário foi realizada com a finalidade de aprimorá-lo, antes do envio final aos respondentes. Os avaliadores foram três Master Black Belts, que responderam a uma ficha de avaliação, com questões abertas sobre: descrição da pesquisa; layout e design do questionário, entre outros. Dessa forma, foram realizados os ajustes considerados pertinentes.

Além disso, também foram realizados testes em três diferentes navegadores: Firefox, Chrome e Internet Explorer em tela de computador e de celular, visando reduzir a ocorrência de problemas de conexão de tecnologia (SHMIDT, 1997; SOLOMON, 2001; DILLMAN et al., 2001; LINK et al., 2014; TINGLING et al., 2003), de modo que todos apresentaram bom desempenho de processamento dos dados, como exemplificado na Figura 1.

Figura 1 - Tela inicial do questionário em computador e celular

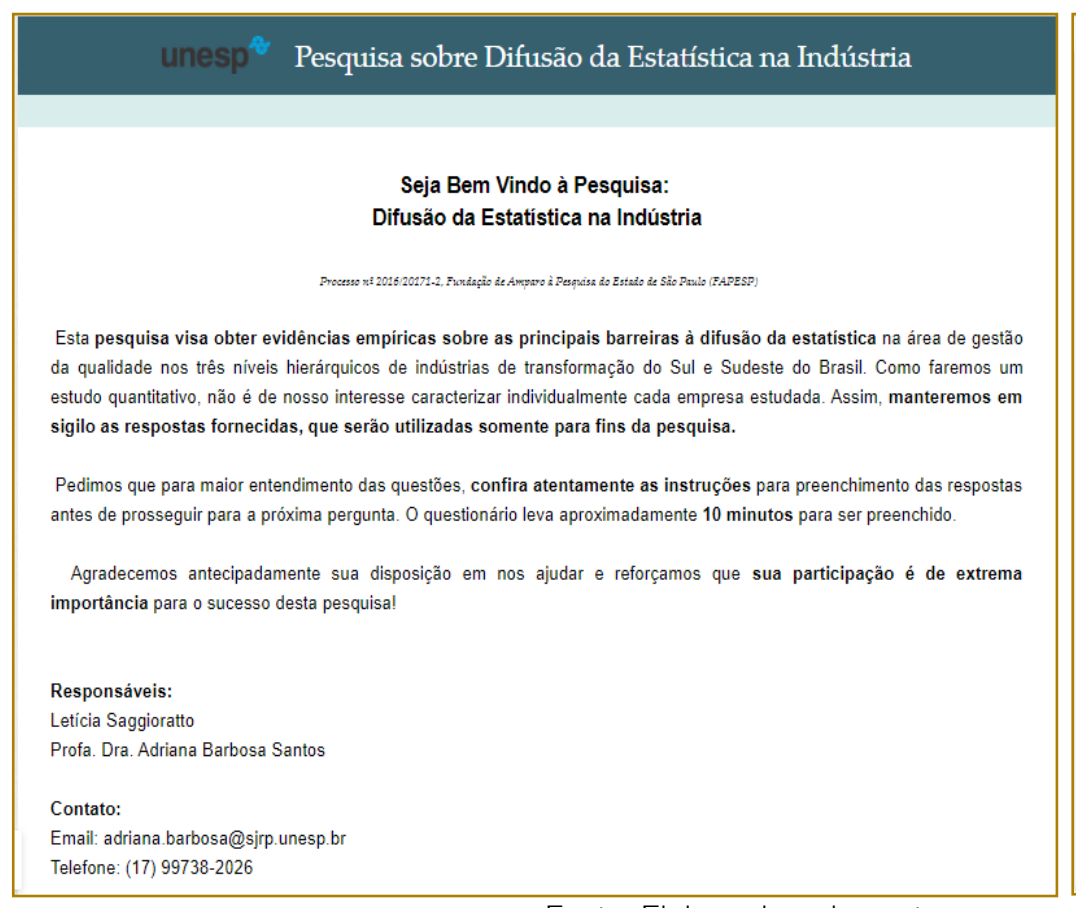

Fonte: Elaborado pelos autores

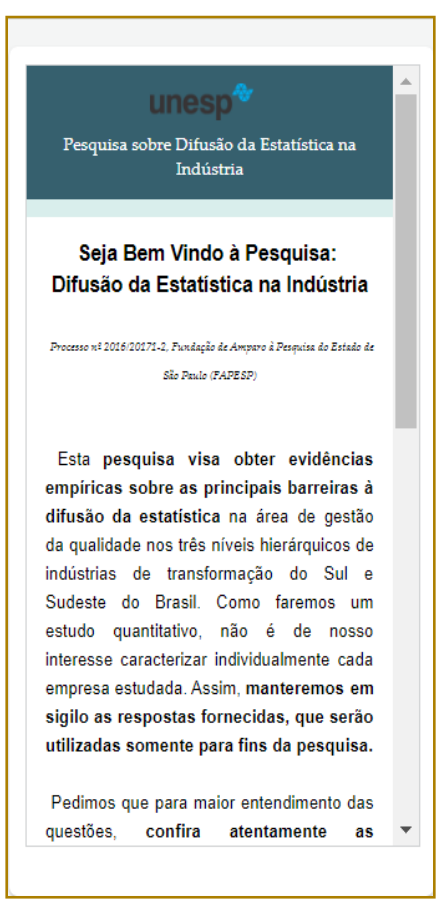

empiricas sobre as principais barreiras à difusâo da estatistica na área de gestão da qualidade nos três niveis hierárquicos de Pedimos que para maior entendimento das uestões, confira atentamente as 


\subsection{COLETA DE DADOS, TAXA DE RESPOSTA E MÉTODO DE ANÁLISE DOS DADOS}

Para a coleta e armazenamento dos dados, o questionário foi acessado e preenchido via Web entre 12 de março e 12 de abril de 2018, por meio da plataforma Survey Monkey com o endereço de acesso personalizado, visando promover relevância e limitar acesso ao survey.

O procedimento de coleta de dados consistiu, primeiramente do contato prévio por meio das redes sociais, WhatsApp, Facebook e Linkedin, já que o seu uso, segundo Couper (2017) e Nelson et al. (2014), tem sido associado a uma forma eficiente e econômica de recrutamento nas pesquisas. O SAC/e-mail institucional obtido do site da empresa foi usado quando não se dispunha do contato das redes sociais. O contato prévio foi realizado para melhorar as taxas de resposta da pesquisa (COOK et al., 2000; SILLS; SONG, 2002) e obter o contato direto do responsável da qualidade da empresa.

Em seguida foram enviadas mensagens personalizadas com o link da pesquisa para os e-mails obtidos no contato prévio, desenvolvidas por meio da plataforma gratuita MailChimp, a fim de minimizar os problemas de segurança contra spam. No caso de contatos que tiveram insucesso na abordagem do contato prévio, o link da pesquisa foi enviado por meio das redes sociais ou SAC/e-mail institucional obtido do site da empresa.

Por fim, três ondas de mensagens foram realizadas de modo que quando enviadas por e-mail também foram personalizados por meio da plataforma MailChimp. As ondas visaram reforçar a participação e motivar o respondente que ainda não havia respondido a pesquisa a fazê-lo. O uso das redes sociais também foi realizado para reforçar a taxa de resposta, donde se notou grande efetividade.

A taxa de resposta da pesquisa foi de 18,3\%. Estudos com a aplicação de survey em indústrias, como por exemplo, o estudo da implementação de programas da qualidade em empresas de grande porte do Brasil foi de 19,8\% (CARVALHO; LEE HO; PINTO, 2007) e o estudo da aplicação da abordagem estatística em indústrias de alimentos de São Paulo foi de 18,3\% (ANTONELLI; SANTOS, 2011). Dessa forma, percebe-se que a taxa de resposta se encontra semelhante ao obtido por estudos recentes da literatura.

A Figura 2 resume a sequência de coleta de dados e a Figura 3 a representatividade amostral em termos geográficos.

Figura 2 - Detalhamento da estratégia de coleta de dados

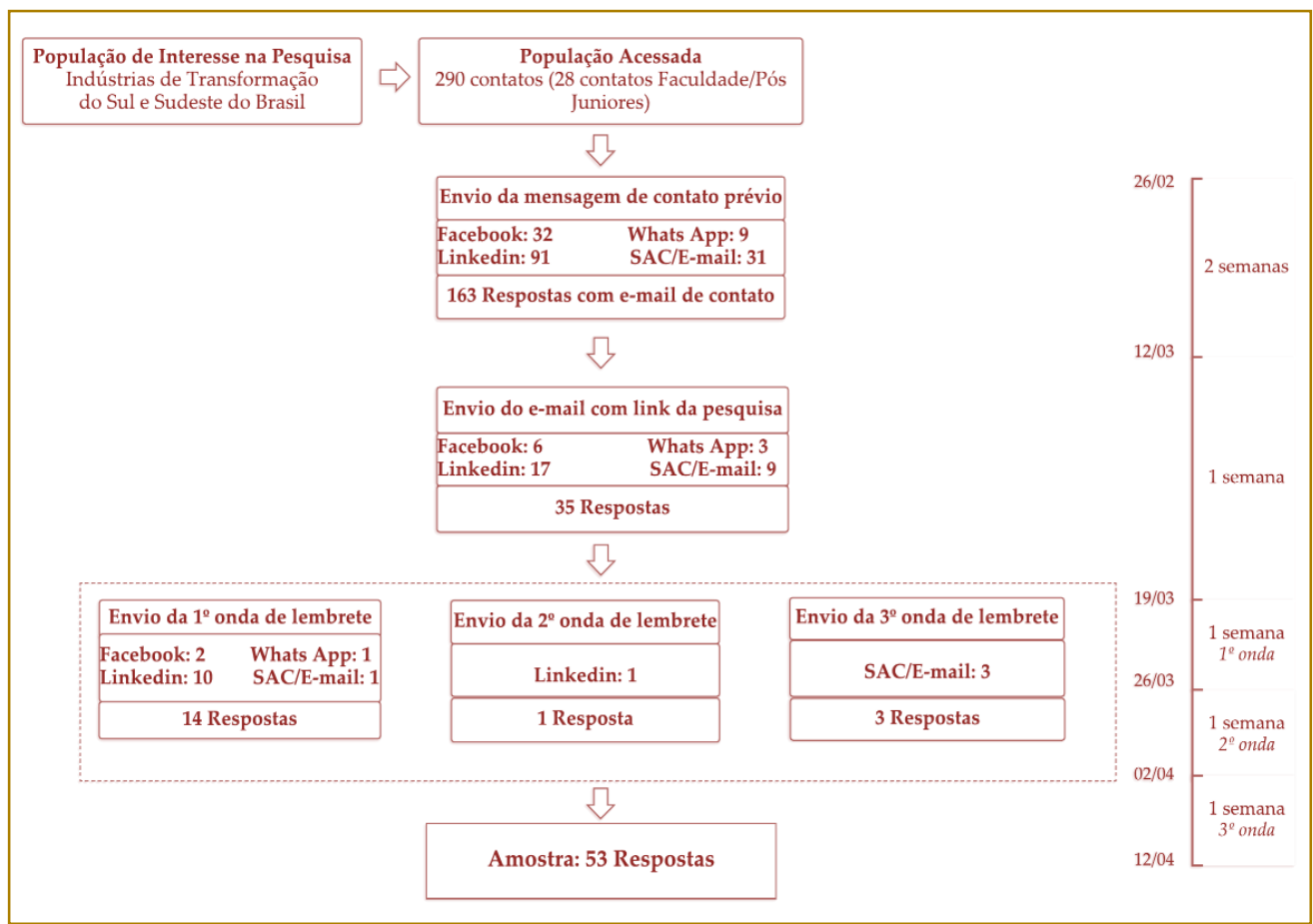

Fonte: Elaborado pelos autores 
Figura 3 - Representatividade amostral em termos geográficos

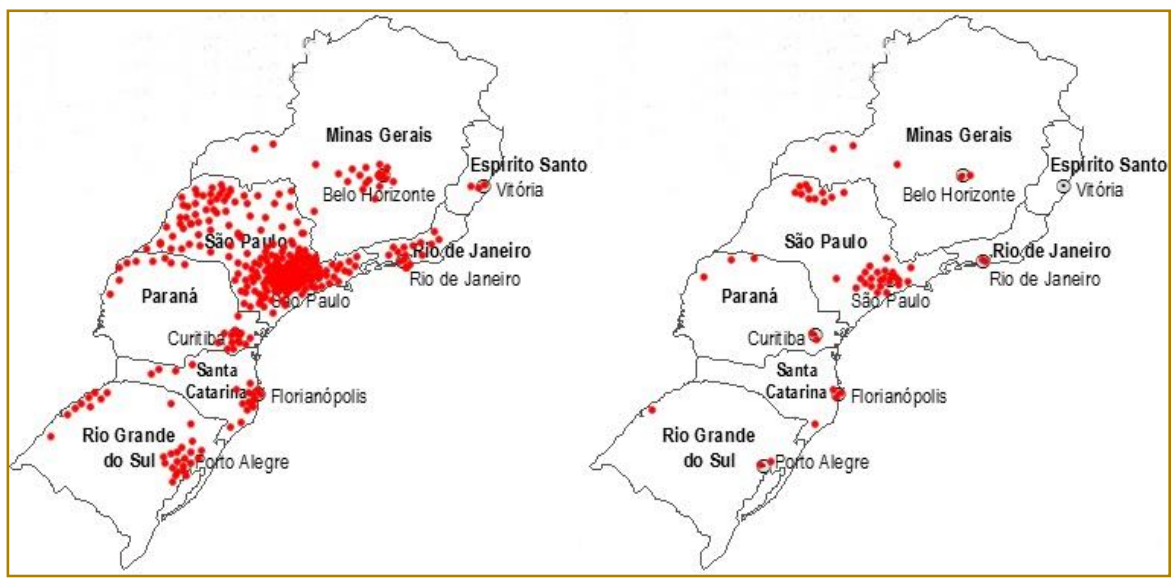

Fonte: Pesquisa de campo desenvolvida pelos autores

As respostas obtidas da aplicação do questionário foram organizadas e analisadas estatisticamente com a utilização de métodos estatísticos univariados - análises de frequências e percentuais, proporção de concordância, gráficos básicos e teste para proporção. Adotou-se para os testes estatísticos um nível de significância de 5\%. 0 coeficiente $\alpha$-Cronbach foi calculado para analisar a consistência das respostas do questionário (HAIR JUNIOR et al., 2005).

Como recursos computacionais utilizaram-se os softwares MS Excel 2013 e Minitab v. 16.

\section{RESULTADOS E DISCUSSÃO}

\subsection{CARACTERIZAÇÃO GERAL DA} AMOSTRA
O questionário online foi respondido por 53 indústrias de transformação pertencentes ao grupo amostral, de forma que a 42 (79\%) são de grande porte, 8 (15\%) são de médio porte, $2(4 \%)$ são microempresas e $1(2 \%)$ é de pequeno porte.

O setor de atuação das indústrias participantes está exemplificado na Tabela 3, na qual se pode perceber a grande maioria presente no setor de alimentos (S1), 46,2\%, seguida pelo setor de produtos químicos (S2), $7,7 \%$, metalurgia (S3), 7,5\%, bebidas (S4), $5,8 \%$, farmoquímicos (S6), 5,8\%, produtos de metal (S7), 5,8\%, produtos de papel (S8), $3,8 \%$, minerais não metálicos (S9), 3,8\%, máquinas, aparelhos e materiais elétricos (S10), $3,8 \%$ e outros, $\quad 10 \%$.

Tabela 3 - Setores de atuação das indústrias participantes da pesquisa

\begin{tabular}{|l|c|}
\multicolumn{1}{|c|}{ Setor } & $\%$ \\
\hline S1: Fabricação de Produtos Alimentícios & 46,2 \\
\hline S2: Fabricação de Produtos Químicos & 7,7 \\
\hline S3: Metalurgia & 7,5 \\
\hline S4: Fabricação de Bebidas & 5,8 \\
\hline S6: Fabricação de Produtos Farmoquímicos e Farmacêuticos & 5,8 \\
\hline S7: Fabricação de Produtos de Metal, exceto Máquinas e Equipamentos & 5,8 \\
\hline S8: Fabricação de Celulose, Papel e Produtos de Papel & 3,8 \\
\hline S9: Fabricação de Produtos de Minerais Não-Metálicos & 3,8 \\
\hline S10: Fabricação de Máquinas, Aparelhos e Materiais Elétricos & 3,8 \\
\hline Outros & 10 \\
\hline
\end{tabular}

Fonte: Pesquisa de campo 
Essa elevada representação do setor S1, pode ser justificada pelo plano amostral da pesquisa, já que 94 empresas (32\%) estão presentes nesse setor.

Em relação às certificações que as indústrias possuem, verificam-se percentuais altos para a implantação da ISO 9001:2000 (60,4\%), BPF $(45,3 \%)$ e do sistema APPCC $(39,6 \%)$, o que condiz com a maioria delas atuarem no setor de alimentos e bebidas. Na Figura 4 estão expostas todas as certificações levantadas no estudo.

Figura 4 - Certificações das Indústrias participantes da pesquisa.

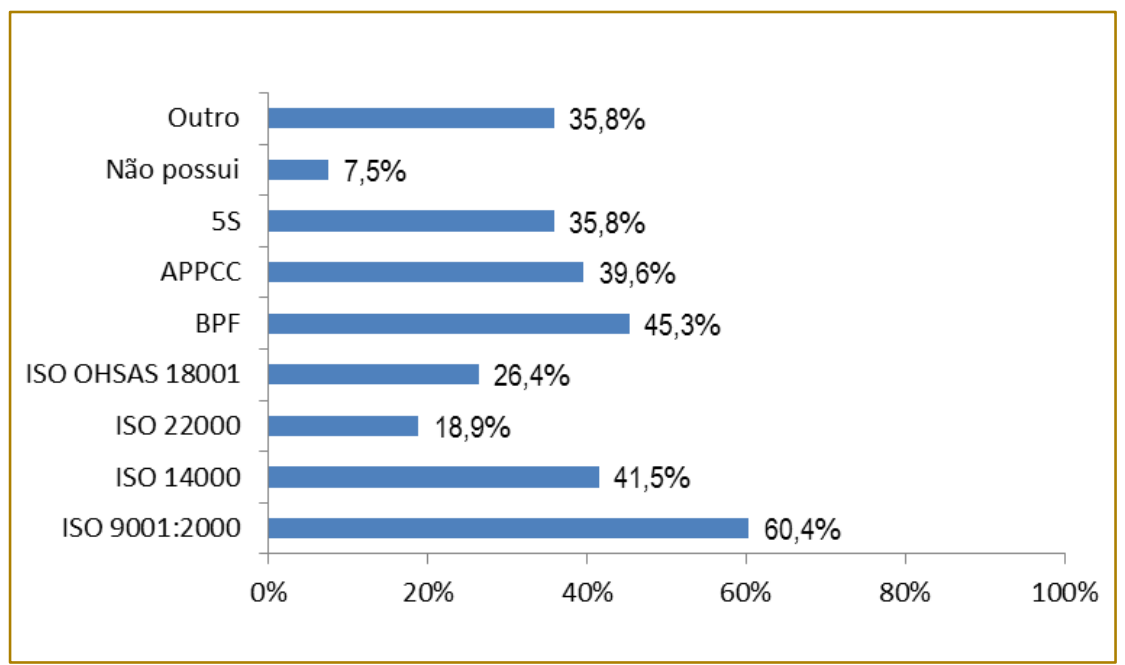

Fonte: Pesquisa de campo

Na Tabela 4 é exibido um panorama sobre a posição das indústrias de transformação quanto à implantação de programas da qualidade e o seu tempo de aplicação. Notase que os programas mais utilizados são medidas mais básicas para controle e melhoria da qualidade, como as iniciativas de melhoria no dia a dia $(69,8 \%)$ e 0 gerenciamento por processos (66,0\%), apesar dos programas Gestão da Qualidade Total (TQM) e Lean Manufacturing terem apresentado valores expressivos, de 45,3\% e $37,8 \%$, respectivamente. Pode-se perceber também que a grande maioria dos programas é recente nas empresas, com menos de 5 anos, apesar da grande relevância já constatada na literatura acerca desses programas há mais de 10 anos.

Tabela 4 - Presença dos programas da qualidade de acordo com tempo de implantação

\begin{tabular}{|c|c|c|c|}
\hline Programa & $<5$ anos & 5 a 10 anos & $>10$ anos \\
\hline Iniciativas de melhoria no dia a dia & $14(37,8 \%)$ & $9(24,3 \%)$ & $14(37,8 \%)$ \\
\hline Gerenciamento por processos & $18(51,4 \%)$ & $5(14,3 \%)$ & $12(34,3 \%)$ \\
\hline TQM & $11(45,8 \%)$ & $4(16,7 \%)$ & $9(37,5 \%)$ \\
\hline Lean Manufacturing & $15(75,0 \%)$ & $4(20,0 \%)$ & $1(5,0 \%)$ \\
\hline Seis Sigma & $8(53,3 \%)$ & $1(6,7 \%)$ & $6(40,0 \%)$ \\
\hline Eventos Kaizen & $9(60,0 \%)$ & $3(20,0 \%)$ & $3(20,0 \%)$ \\
\hline TPM & $8(53,3 \%)$ & $2(13,3 \%)$ & $5(33,3 \%)$ \\
\hline Lean Sigma & $5(55,6 \%)$ & $1(11,1 \%)$ & $3(33,3 \%)$ \\
\hline
\end{tabular}




\subsection{DIFUSÃO DO PENSAMENTO} ESTATÍSTICO

Os resultados referentes à parte 3 do questionário se referem aos princípios do pensamento estatístico e às barreiras que difundem a sua difusão na organização, mais especificamente, abordam as estratégicas BE1, BE2 e BE3 e a tática BT1.

\subsubsection{PRINCÍPIOS DO PENSAMENTO ESTATÍSTICO}

Os princípios do pensamento estatístico são apresentados na Tabela 5, de acordo com a proporção de concordância dos respondentes, de modo que se percebe que mais de $80 \%$ dos respondentes conseguem compreender bem os três princípios, o que pode ser atribuído à disseminação na literatura dos resultados positivos gerados por essa boa compreensão. Como constatado por Antonelli e Santos (2011), em survey com profissionais de indústrias de alimentos de grande porte de São Paulo, há benefícios diretos dessa compreensão, não apenas para aplicação de ferramentas e técnicas estatísticas de forma ampla, como para priorização de foco em processos e ganhos de produtividade. Além disso, ao se realizar o teste exato para a proporção de concordância com cada princípio $\left(H_{0}: p=0,7\right.$ vs $\left.H_{1}: p>0,7\right)$, os valores $P$ relativos a cada teste fornecem evidência de que $H_{0}$ deve ser rejeitada, ao nível de 0,05 de significância $(P<0,05)$; reforçando evidências de que há uma proporção expressiva de empresas em que há compreensão dos princípios.

Tabela 5 - Resultados do teste da proporção de concordância com cada princípio do pensamento estatístico

\begin{tabular}{|l|c|c|c|}
\multicolumn{1}{|c|}{ Princípio } & $\begin{array}{c}\text { Proporção } \\
\text { Amostral }\end{array}$ & $\begin{array}{c}\text { Intervalo de } \\
\text { Confiança (95\%) }\end{array}$ & Valor P \\
\hline $\begin{array}{l}\text { Acredita-se que todo o trabalho realizado é } \\
\text { um sistema de processos conectados }\end{array}$ & 0,83 & $(0,70 ; 0,92)$ & 0,037 \\
\hline $\begin{array}{l}\text { Acredita-se que a variação existe em todos } \\
\text { os processos da empresa }\end{array}$ & 0,88 & $(0,77 ; 0,96)$ & 0,020 \\
\hline $\begin{array}{l}\text { Reduzir a variação dos processos é } \\
\text { considerado importante para o sucesso da } \\
\text { empresa }\end{array}$ & 0,98 & $(0,90 ; 0,99)$ & $<0,001$ \\
\hline
\end{tabular}

Fonte: Pesquisa de campo

\subsubsection{BARREIRAS ESTRATÉGICAS}

Os resultados da proporção de empresas cujas barreiras se fizeram presentes na visão dos respondentes estão expostos na Tabela 6. A proporção de empresas cujas barreiras estratégicas, BE1 e BE2 são entraves fundamentais para a maior difusão da estatística e melhoria da qualidade da empresa não foi estatisticamente significativa pelo teste exato para a proporção, tendo ambos os valores $P>0,05$. Por outro lado, no caso da BE3 a situação se mostrou mais crítica e com uma proporção significativa de respostas afirmativas à presença da barreira. Do total de empresas, 43 (81,1\%) identificaram a presença de BE3. Além disso, o valor $P$ de 0,048 , relativo ao teste da proporção, é um indicativo da significância da barreira BE3, de modo que a hipótese de pesquisa $\mathrm{H} 1$ não deve ser rejeitada. Ademais, deve-se salientar que a falta de apoio da administração é um entrave importante para a difusão da estatística e melhoria da qualidade da empresa, muito embora haja uma expressiva proporção de concordância com os princípios do pensamento estatístico (Tabela 5). De forma similar, Attri et al. (2013), que realizaram survey com empresas da Índia sobre barreiras para implementação do programa TPM, encontraram que a falta de apoio da alta administração foi considerada como a mais importante no ranking das barreiras levantadas. 
Tabela 6 - Resultados do teste da proporção de empresas cujas barreiras estratégicas estão presentes

\begin{tabular}{|c|c|c|c|c|}
\hline Nível & Barreira & $\begin{array}{l}\text { Proporção } \\
\text { amostral }\end{array}$ & $\begin{array}{l}\text { Intervalo de Confiança } \\
\qquad(95 \%)\end{array}$ & Valor P \\
\hline \multirow{3}{*}{ Estratégico } & BE1 & $32(60,4 \%)$ & $(0,46 ; 073)$ & 0,951 \\
\hline & BE2 & $40(75,5 \%)$ & $(0,62 ; 0,86)$ & 0,239 \\
\hline & BE3 & $43(81,1 \%)$ & $(0,68 ; 0,90)$ & 0,048 \\
\hline
\end{tabular}

\subsubsection{BARREIRAS TÁTICAS}

Verifica-se na Tabela 7 que a BT1 relacionada com falta de ênfase do uso do pensamento estatístico para a tomada de decisões foi considerada uma barreira somente por 24 $(45,3 \%)$ dos respondentes. Tal aspecto pode estar associado à boa compreensão dos princípios do pensamento estatístico. Para BT2, relacionada com a ausência de conhecimento estatístico adequado gerado por capacitação e/ou formação defasada por parte dos gerentes, foi observado que em 38 $(71,7 \%)$ das empresas esse aspecto é uma barreira tática que dificulta a melhoria da qualidade. Neste estudo, não se evidencia que a proporção de empresas em que as barreiras táticas se verificam seja estatisticamente significativa (Valor $P>0,05$ ), verificando que em nível tático a hipótese $\mathrm{H} 2$ não se confirma.

Tabela 7 - Resultados do teste da proporção de empresas cujas barreiras táticas estão presentes

\begin{tabular}{|c|c|c|c|c|}
\hline Nível & Barreira & $\begin{array}{l}\text { Proporção } \\
\text { amostral }\end{array}$ & $\begin{array}{l}\text { Intervalo de Confiança } \\
(95 \%)\end{array}$ & Valor P \\
\hline \multirow{2}{*}{ Tático } & BT1 & $24(45,3 \%)$ & $(0,31 ; 0,59)$ & 0,999 \\
\hline & BT2 & $38(71,7 \%)$ & $(0,58 ; 0,83)$ & 0,460 \\
\hline
\end{tabular}

\subsubsection{BARREIRAS OPERACIONAIS}

Verifica-se na Tabela 8 a forte presença identificada das barreiras operacionais, de modo que a $\mathrm{BO}$, relacionada com a falta de conhecimento do porque o treinamento é requerido, foi descrita por $49(92,5 \%)$ dos respondentes e a $\mathrm{BO} 2$, relacionada com a utilização das ferramentas e softwares estatísticos de maneira incorreta foi descrita por $50(94,3 \%)$ dos respondentes, sendo considerada a maior barreira observada dentre todas as demais, de modo que o valor $\mathrm{P}<0,001$ relativo ao teste da proporção constitui evidência de que, em nível operacional, a hipótese $\mathrm{H} 2$ é corroborada, presumindo-se daí a existência dessa barreira. Este resultado ratifica a falta de preparo dos profissionais como uma barreira que se deve tanto a deficiência de conceitos estatísticos, mesmo básicos de formação de graduação, como também à carência de treinamentos ou cursos extracurriculares sobre estatística. Tal aspecto foi reforçado no estudo de Carvalho (2015), ao estudar empresas do setor de bens de capital do estado de São Paulo e também no estudo de Attri et al. (2013). Tal barreira foi uma das principais barreiras ao uso de estatística por profissionais da área de gestão da qualidade neste setor. 
Tabela 8 - Proporção de empresas cujas barreiras operacionais estão presentes

\begin{tabular}{|c|c|c|c|c|}
\hline \multirow{2}{*}{ Nível } & Barreira & $\begin{array}{c}\text { Proporção } \\
\text { amostral }\end{array}$ & $\begin{array}{c}\text { Intervalo de Confiança } \\
(95 \%)\end{array}$ & Valor P \\
\cline { 2 - 5 } Operacional & BO1 & $49(92,5 \%)$ & $(0,82 ; 0,98)$ & $<0,001$ \\
\cline { 2 - 5 } & BO2 & $50(94,3 \%)$ & $(0,84 ; 0,99)$ & $<0,001$ \\
\hline
\end{tabular}

Fonte: Pesquisa de campo

O uso incorreto ou dificuldade no manuseio das ferramentas e técnicas estatísticas é outro ponto, atribuído à existência de uma lacuna de formação dos funcionários (MACKRYMICHALOS et al., 2005). Segundo Carvalho; Lee Ho; Pinto (2007), no levantamento realizado sobre as dificuldades relacionadas à implantação do Seis Sigma, $30,4 \%$ das respostas foram afirmativas para a dificuldade de manuseio das ferramentas da qualidade.

A Figura 5 sintetiza os resultados relativos a essa percepção sobre todas as barreiras levantadas na pesquisa, as quais estão concentradas para uma proporção de empresas estatisticamente superior a $0,7 \mathrm{em}$ nível estratégico e operacional (BE3, BO1 e $\mathrm{BO} 2)$.

Figura 5- Percentual de concordância com a presença de cada tipo de barreira à difusão da estatística.

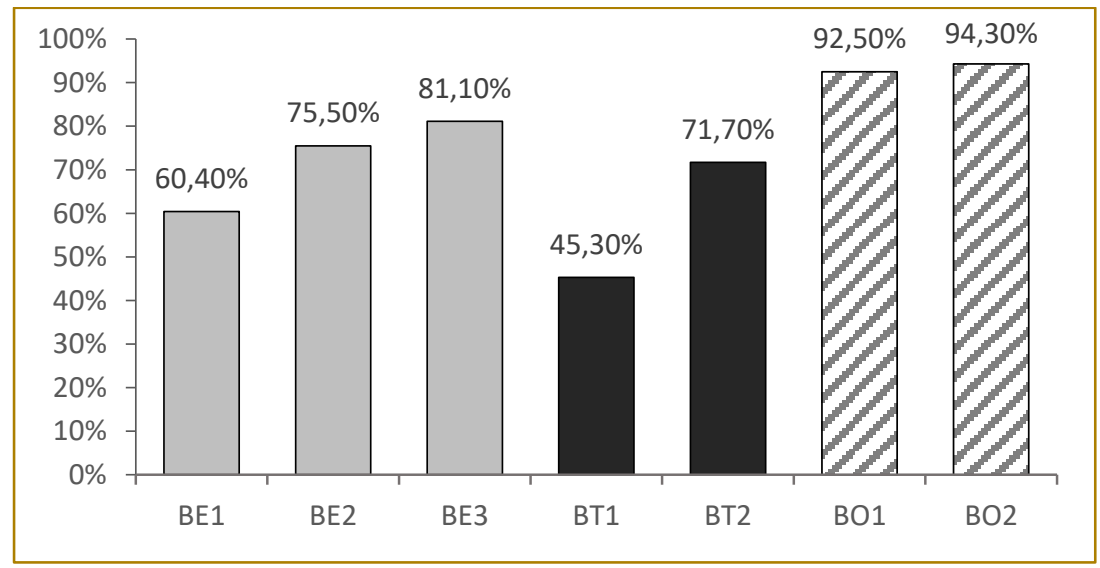

Fonte: Pesquisa de campo

\subsection{USO DE FERRAMENTAS E TÉCNICAS ESTATÍSTICAS}

Baseado na frequência de uso das ferramentas estatísticas, foi possível construir as Tabelas 9 e 10, as quais contêm o percentual de uso intenso das ferramentas básicas/intermediárias e avançadas. Nelas está quantificada a porcentagem de empresas que fazem uso mais intenso das ferramentas, ou seja, que utilizam sempre ou frequentemente. A medida de confiabilidade e consistência das respostas $\alpha$-Cronbach calculada para as ferramentas básicas/intermediárias foi 0,83, considerada muito boa, de acordo com Hair Junior et al. (2005). O mesmo foi feito para as ferramentas avançadas cujo valor foi de 0,91.

Conforme os resultados das referidas tabelas, a maioria das empresas costuma usar as ferramentas básicas/intermediárias, sendo notória a diferença com a distribuição da frequência para as avançadas, que apresentam baixa frequência de uso (máximo de $18,9 \%)$.

Neste sentido, em estudo com indústrias de alimentos, Grigg e Walls (2007) destacam que - uso das técnicas estatísticas mais avançadas exige nível de qualidade razoável nos treinamentos, antes que possam ser rotineiramente aplicadas; ao contrário das técnicas estatísticas básicas, que não demandam conhecer conceitos mais complexos profundamente para a sua aplicação.

Outros estudos recentes também discutem essa limitação técnica vivenciada nas empresas e identificam uma tendência na utilização de conceitos, ferramentas e 
técnicas mais básicas no contexto da gestão da qualidade, apenas com intuito de se tentar reduzir defeitos e propiciar um monitoramento mais satisfatório dos processos de manufatura (KUMAR et al., 2007; GRIGG; WALLS, 2007; TJAHJONO et al., 2010; MAKRYMICHALLOS et al., 2005).

Acerca da capacitação em relação ao uso das ferramentas e técnicas estatísticas, a maior parte do enfoque dado é na resolução de problemas com o uso do pensamento estatístico $(47,17 \%)$ e em estimular a capacidade analítica do funcionário, promovendo a maior participação possível (16,98\%). Assim, percebe-se que os treinamentos realizados podem ser considerados de qualidade, haja vista que o método tradicional envolve ênfase nas técnicas estatísticas e matemáticas (MACKRYMICHALOS et al., 2005; JOHN; JOHNSON, 2002). Contudo, a frequência de aplicação é baixa, com $24(45,28 \%)$ das empresas aplicando no máximo 1 vez ao ano, $13(24,53 \%)$ de 1 a 3 vezes ao ano e 3 $(5,66 \%)$ mais de 3 vezes ao ano, o que pode justificar a grande proporção amostral da $\mathrm{BO} 2$.

Tabela 9 - Frequência de uso das ferramentas básicas/ intermediárias nas empresas e medida de confiabilidade das respostas

\begin{tabular}{|l|c|}
\hline \multicolumn{1}{|c|}{ Ferramentas Básicas/Intermediárias } & $\begin{array}{c}\text { Uso intenso } \\
\text { (\% de empresas) }\end{array}$ \\
\hline Mapeamento dos Processos & 73,6 \\
\hline Diagrama de Causa e Efeito & 67,9 \\
\hline Amostragem para Aceitação & 67,9 \\
\hline Diagrama de Pareto & 66,0 \\
\hline Folha de Verificação & 58,5 \\
\hline Gráficos de Controle & 56,6 \\
\hline Medição e análise da capacidade do & 56,6 \\
\hline processo & 56,6 \\
\hline Medição da Variação do Processo & 54,7 \\
\hline Controle estatístico dos processos & 43,4 \\
\hline Histograma & 34,0 \\
\hline Conceito/Princípio de Estratificação & 20,8 \\
\hline Diagrama de Correlação & 15,1 \\
\hline Análise de Regressão Simples & \\
\hline
\end{tabular}

Fonte: Pesquisa de campo

Tabela 10 - Frequência de uso das ferramentas avançadas nas empresas e medida de confiabilidade das respostas

\begin{tabular}{|c|c|c|}
\hline Ferramentas Avançadas & $\begin{array}{c}\text { Uso intenso } \\
\text { (\% de empresas) }\end{array}$ & $\alpha$-Cronbach \\
\hline Teste de Hipóteses & 18,9 & \\
\hline Análise do Sistema de Medição & 17,0 & \multirow{6}{*}{0,91} \\
\hline Planejamento de Experimentos & 15,1 & \\
\hline Análise de Variância (ANOVA) & 15,1 & \\
\hline Técnicas de Simulação de Processos e Fluxos & 13,2 & \\
\hline Análise de Regressão Múltipla & 9,4 & \\
\hline Técnicas de Análise Multivariada & 7,5 & \\
\hline
\end{tabular}

Fonte: Pesquisa de campo 


\section{CONCLUSÃO}

O estudo empírico exposto neste trabalho contribuiu para mostrar que apesar da boa compreensão dos princípios do pensamento estatístico, ainda se verificam certas barreiras para uma aplicação efetiva da estatística como prática da gestão da qualidade em empresas do Brasil de diversos setores industriais. A hipótese de que o pensamento estatístico não se difunde na organização sem o suporte adequado da alta administração foi corroborada, a partir das evidências de que o uso da estatística na empresa é considerado pouco incentivado pela alta administração, devido à visão estratégica e apoio financeiro inadequado. A falta de capacitação em estatística dos funcionários de nível operacional, consiste numa barreira para o avanço do uso da estatística com vistas à melhoria da qualidade de produtos, serviços e processos, e ressalta um problema atual da carência de educação estatística já ressaltado na introdução deste trabalho. Isso ocorre tanto em teoria como prática, sobretudo diante da forte pressão existente na atualidade para que os profissionais tomem decisões baseadas em análise de dados. Assim, a existência das barreiras identificadas

\section{REFERÊNCIAS}

[1] ABRAHAN, B. Statistics in Business and Industry: Implementation. International Statistical Review. v.73, n. 2, p.173า-176, 2005.

[2] AHMED, Shamsuddin; HASSAN, Masjuki. Survey and case investigations on application of quality management tools and techniques in SMls. International Journal of Quality \& Reliability Management, v. 20, n. 7, p. 795-826, 2003

[3] ANTONELLI, S. C.; SANTOS, A. B. Aplicação da abordagem estatística no contexto da gestão da qualidade: um survey com indústrias de alimentos de São Paulo. Gestão \& Produção. São Carlos, v. 18, n. 3, p. 509-524, 2011.

[4] ANTONY J, KAYE, M, FRANGOU, A. A strategic methodology to the use of advanced statistical quality improvement techniques. TQM Magazine. v.10, p. 168-176, 1998.

[5] ASQ. Glossary and tables for statistical quality control - ASQ Statistics Division. 3 ed. Milwaukee: ASQ Quality Press, 1996.

[6] ATTRI, Rajesh et al. Analysis of barriers of total productive maintenance (TPM). International Journal of System Assurance Engineering and Management, v. 4, n. 4, p. 365-377, 2013. pode justificar a predominância do uso das ferramentas básicas/intermediárias e a baixa frequência com que são feitos cursos de capacitação.

Além dos pontos relevantes derivados dos resultados do survey e do embasamento para melhor compreensão das barreiras estratégicas, táticas e operacionais identificadas, buscou-se detalhar os aspectos metodológicos inerentes ao plano de coleta de dados. Houve uma preocupação com a definição adequada do instrumento de coleta, adoção de estratégias para aumento das taxas de resposta e com os procedimentos de coleta para que outras pesquisas com propostas semelhantes priorizem recomendações da literatura que versa sobre como conduzir um survey eletrônico, os quais aumentam a credibilidade dos resultados.

\section{AGRADECIMENTO}

Os autores agradecem à FAPESP pelo suporte financeiro fornecido para o desenvolvimento desta pesquisa - Processo (2016/20171-2).
[7] BERGQUIST, B., ALBING, M. Statistical methods: does anyone really use them? Total Quality Management Bussiness Excelence, v. 17, p. 961-972, 2006.

[8] BRITZ, Galen C. et al. Improving performance through statistical thinking. Milwaukee: ASQ Quality Press, 2000. 171 p.

[9] Carvalho M. M.; Lee Ho L.; Pinto, S. H. B. Six Sigma program implementation and diffusion in Brazil. Production Journal, v. 17, n. 3, p. 486-501, 2007.

[10] CARVALHO, N. G. Avaliação do uso do pensamento estatístico e técnicas estatísticas em empresas de bens de capital seriados do estado de São Paulo. Dissertação (Mestrado em Engenharia de Produção) - Universidade Federal de São Carlos, São Carlos, 2015. $165 f$.

[11] COLEMAN, S.Y. Statistical thinking in the quality movement \pm 25 years. The TQM Journal. $v$. 25, n. 6, p. 597-605, 2013.

[12] COOK, Colleen; HEATH, Fred; THOMPSON, Russel L. A meta-analysis of response rates in web or Internet based surveys. Educational and Psychological Measurement, 2000. 
[13] COUPER, Mick P. Web surveys: the Questionnaire Design Challenge. In: INTERNATIONAL STATISITICAL INSTITUTE - ISI, 53, Seoul, Korea. Anais... Seoul, Korea, 2001.

[14] COUPER, Mick P. Technology Trends in Survey Data Collection. Social Science Computer Review, v. 23, p. 486-501, 2005.

[15] COUPER, Mick P. New Developments in Survey Data Collection. Annual Review of Sociology, Michigan, v. 43, n. 1, p.1 21-145, 31 jul. 2017.

[16] DILLMAN, Don A. Mail and Internet Surveys: The Tailored Design Methods. New York: Wiley, 2 ed., 2000.

[17] DILLMAN, Don A.; BOWKER, Dennis K. The Web questionnaire challenge to survey methodologists. See Reips \& Bosnjak, 2001.

[18] DRANSFIELD, S. B.; FISHER NI, VOGEL, N. J. Using statistics and statistical thinking to improve organizational performance. International Statistical Revew, v. 67, n. 2, p. 99-150, 1999.

[19] FORZA, Cipriano. Survey research in operations management: a process-based perspective. International Journal of Operations \& Production Management, v. 22, n. 2, p. 152-194, 2002

[20] FOX, Richard J., CRASK, Melvin R.; KIM, Jonghoon. Mail survey response rate: A metaanalysis of selected techniques for inducing response. Public Opinion Quarterly, 52, p. 467-491, 1998.

[21] FREITAS, Henrique et al. O método de pesquisa survey. Revista de Administração, São Paulo, v. 35, n.3, p. 105-112, 2000.

[22] FREITAS, Henrique; JANISSEK-MUNIZ, Raquel; MOSCAROLA, Jean. Dinâmica do processo de coleta e análise de dados via web. CIBRAPEQ-1a Conferência internacional do Brasil de Pesquisa Qualitativa, 24 a 27 de março, Taubaté/SP, 2004

[23] GOH, T.N. Six sigma in industry: some observations after twenty-five years. Quality and Reliability Engineering International. v.27, n.2, p.221-227, 2011.

[24] GRIGG, Nigel Peter, WALLS, Lesley. The role of control charts in promoting organizational learning: new perspectives from a food industry study. The TQM Magazine, v. 19, n. 1, p. 37-49, 2007 .

[25] HAIR JUNIOR, Joseph F. et al. Análise multivariada de dados. 5th ed. Porto Alegre: Bookman, 2005. 593 p.

[26] HOERL, R. W.; SNEE, R. D. Statistical Thinking and Methods in Quality Improvement: a look to the future. Quality Engineering, v.22, n.3, p.119-129, 2010.
[27] IGNÁCIO, Sérgio Aparecido. A importância da estatística para o processo de conhecimento e tomada de decisão. Revista Paranaense de Desenvolvimento, n.118, p.175-192, 2010.

[28] JOHN, J.A.; JOHNSON, D.G. Statistical Thinking for Effective Management. Proceedings of the 6th International Conference on Teaching Statistics (ICOTS-6), South Africa, 2002.

[29] KUMAR, U. Dinesh et al. Six sigma project selection using data envelopment analysis. The TQM Magazine, v. 19, n. 5, p. 419-441, 2007.

[30] LEITNAKER, M. G., SANDERS, R. D., HILD, C. The power of statistical thinking: improving industrial processes. Reading: Addison-Wesley Publishing Company, 1996.

[31] LINK, Michael W. et al. Mobile technologies for conducting, augmenting and potentially replacing surveys: report of the AAPOR task force on emerging technologies in public opinion research. Deerfield, IL: AAPOR, 2014.

[32] MAKRYMICHALOS, Miltiadis et al. Statistical thinking and its role for industrial engineers and managers in the 21st century. Managerial Auditing Journal, v.20, n.4, p.354-363, 2005

[33] MONTGOMERY, D. C. A modern framework for achieving enterprise excellence. International Journal of Lean Six Sigma, v.1, n.1, p.56-65, 2010.

[34] NELSON, Erik J. et al. Estimation of Geographic Variation in Human Papillomavirus Vaccine Uptake in Men and Women: An Online Survey Using Facebook Recruitment. Journal Medical Internet Research, v.16, n. 9, 2014.

[35] NUNES, C. A.; ALVARENGA, V. O.; SANT'ANA, A. S.; SANTOS, A. S.; GRANATO, D. The use of statistical software in food science and technology: advantages, limitations and misuses. Food Research Intertional, v. 75: p. 270-280, 2015.

[36] OAKLAND, John S.; SOHAL, Amrik. Production Management Techniques: A Proposed Methodology for Overcoming Barriers to Acceptance. International Journal of Operations \& Production Management, v. 7, n. 4 p. 23 - 34, 1987.

[37] PFANNKUCH, M.; WILD, C. Towards an understanding of statistical thinking (17-46). In: Ben-Zvi, D., \& Garfield, J. B. (Eds.). The challenge of developing statistical literacy, reasoning and thinking. Dordrecht, The Netherlands: Kluwer Academic Publishers, 2004

[38] REDLINE, Cleo D.; DILLMAN, Don A. The influence of alternative visual designs on respondents' performance with branching instructions in self-administered questionnaires. New York: John Wiley, 2002.

[39] SANTOS, A. B.; MARTINS, M. F. Modelo de referência para estruturar o Seis Sigma nas 
organizações. Gestão \& Produção, v.15, n.1, p.4356, 2008.

[40] SCHMIDT, William C. World-Wide Web survey research: Benefits, potential problems and solutions. Behavior Research Methods, Instruments \& Computers, 1997.

[41] SILLS, Stephen J.; SONG, Chunyan. Innovations in survey research: An application of Web-based surveys. Social Science Computer Review, 2002.

[42] SOLOMON, David J. Conducting webbased surveys. Practical Assessment, Research \& Evaluation, 2001.

[43] SNEE, R. D. Statistical thinking and its contribution to total quality. JASA. v. 44, n. 2, p. 116-121, 1990.

[44] SYNODINOS, Nicolaos. E. The "art" of questionnaire construction: some important considerations for manufacturing studies. Integrated Manufacturing Systems, v.14, n.3, p.221-237, 2003.

[45] TANCO M, VILES E, ILZARBE L, ALVAREZ M.J. Barriers faced by engineers when applying design of experiments. TQM Journal. v. 21, n.6, p.565-75, 2009.

[46] TINGLING, Peter; PARENT, Michael; WADE, Michael. Extending the capabilities of Internet-based research: lessons from the field. Internet Research, p. 223-35, 2003.

[47] TJAHJONO, B. et al. Six Sigma: a literature review. International Journal of Lean Six Sigma, v. 1, n. 3, p. 216-233, 2010

[48] TOURANGEAU, Roger; RIPS, Lance J.; RASINSKI, Kenneth. The Psychology of Survey Response. New York: Cambridge University Press, 2000.

[49] VINING, G. Technical advice: essential elements for quality improvement programs. Quality Engineering, v.23, n.4, p.395ᄀ-397, 2011.

[50] ZMUK B. Business sample survey measurement on statistical thinking and methods adoption: the case of Croatian small enterprises. INDECS. v. 13, n. 1, p. 154-166, 2015.

[51] Wilks, S. S. Undergraduate statistical education. American Statistician. v. 60, n.1, p. 3945 ,

2006. 


\section{Capítulo 5}

\section{CONTROLE DA VARIABILIDADE DO PROCESSO DE ENVASE DE BIOCOMBUSTIVEL COM O USO DA METODOLOGIA SEIS SIGMA}

\section{Rafael Francisco Campos Pianno}

Walther Azzolini Júnior

Jorge Alberto Achcar

Resumo: Perda nos processos industriais compreende diferentes tipos, os principais são: tempo e material. Em um processo de envase de combustível a perda de material pode ocorrer não somente com relação ao descarte por vazamento ou por evaporação natural, mas também por descontrole da vazão no fluxo, o que pode representar maior ou menor volume transferido tanto em "beneficio" do cliente quanto em do fabricante ou distribuidor, o que não condiz com os princípios das boas práticas corporativas. O presente trabalho trata do controle da variabilidade no envase de biocombustível com o uso da metodologia Seis Sigma. Como resultado do projeto de controle da variabilidade descrito neste trabalho os autores dão ênfase a redução da média de variação do processo de envase de 351,2 I, e respectivo desvio padrão de 404,8 I para um valor médio de 72,2 I com desvio padrão de 92,2 I, caracterizando boa normalidade do processo de envase de biocombustível objeto do estudo após o uso da metodologia Seis Sigma.

Palavras-chave: Metodologia Seis Sigma, Processo de envase de biocombustível. 


\section{INTRODUÇÃO}

A partir do século XIX a revolução industrial intensificou o uso de combustíveis fósseis, inserindo no cenário mundial a necessidade da concepção de novas alternativas de combustível e de projetos de controle com o propósito de contenção dos prejuízos causados ao meio ambiente, o que evoluiu para um conjunto de princípios definido por sustentabilidade. Uma das alternativas é o uso de biocombustíveis que embora emita CO2(g) durante a combustão este gás carbônico é reabsorvido na fotossíntese durante a produção das fontes renováveis utilizadas (MOTA; MONTEIRO, 2013).

O biocombustível etanol vem sendo utilizado no Brasil desde 1920 e se firmou a partir de novembro de 1975 com o Proálcool. O Programa Nacional de Produção de Biodiesel foi lançado em 06 de dezembro de 2004 e regulamentado pela Lei no- 11.097, de 2005. Inicialmente ficou estabelecido a obrigatoriedade do uso de $2 \%$ em volume de biodiesel misturado ao óleo diesel(LEITE, 2007).

Contudo, é um processo. Segundo Werkema (1995) um processo é a combinação de equipamentos, pessoas, informações, insumos e procedimentos, tendo como intuito a fabricação de um bem ou prestação de serviço e, portanto, apresenta variabilidade. Manter a variabilidade nos limites mínimo e máximo aceitáveis para um determinado processo é um requisito de qualidade.

De acordo comMontgomery (2004)a qualidade é inversamente proporcional a variabilidade. A melhoria da qualidade está relacionada com a redução de variabilidade, onde produtos e serviços podem ser produzidos num processo estável de modo que a variabilidade seja pequena em torno de um valor desejado.Entre os programas de controle da variabilidade mais citados na literatura encontra-se a metodologia Seis Sigma.

Na visão de Gross (2001) qualquer empresa pode utilizar a metodologia Seis Sigma para redução da variabilidadede seus processos e - sucesso de um programa Seis Sigma depende do comprometimento da equipe para com as etapas do projeto.

O pacote de ferramentas DMAIC é o mais utilizado no programa Seis Sigma. A sigla DMAIC signfica: Define (definir), Measure (medir), Analyze (analisar), Improve (melhorar) e Control (controlar) (MERGULHÃO, 2003).O programa Seis Sigma vem ao encontro da redução de variabilidade através de ações que se traduzem em ganhos financeiros através do controle e monitoramento estatístico, aumentando a capacidade de resolução de problemas com foco na satisfação do cliente (SANTOS, 2006).

O objetivo deste trabalho é aplicar e avaliar um estudo da metodologia DMAIC em uma empresa fabricante de biodiesel, que para fins de faturamento do biocombustível na unidade litro (I) a $20^{\circ} \mathrm{C}$ gera uma variação entre os volumes obtidos da massa da balança $(\mathrm{kg})$ e do volume da capacidade do tanque do caminhão.

A empresa é de grande porte, teve inicio de suas atividades na décaca de 2.000 e atualmente contempla 85 colaboradores, dos quais 55 atuam na área industrial e 30 funcionários no setor administrativo. O universo são os setores de embarque e faturamento. Os carregamentos são agendados pelas distribuidoras através do site da Petrobrás www.canalcliente.com.br conforme disponibilidade de horários da usina produtora.

O artigo contempla cinco seções: 1. Introdução, 2. Revisão da literatura, 3. Estudo de Caso, 4. Resultados e 5. Considerações Finais.

\section{REVISÃO DA LITERATURA}

\subsection{CONCEITOS SEIS SIGMA}

A metodologia Seis Sigma tem sido utilizada como estratégia de negócios e implantada com sucesso em muitas organizações como a Motorola, General Eletric (GE), Honeywell, Bombardier, ABB, Sony. Teve inicio no final da década de 1.980 na Motorola com os prinicipios baseados nas teorias japonesas TQM e uso da estatistica,como objetivo dediminuir falhas nos seus produtos (ANTONY, et. al, 2007).

Há, de acordo com a literatura, algumas definições quanto ao termo Seis Sigma. $\mathrm{Na}$ Motorola o Seis Sigma é um programa de melhoria de qualidade com o intuito de diminuir os defeitos para 3,4 ppm (partes por milhão) de oportunidades. (ANTONY, et. al, 2012).

A literatura indica que a metodologia Seis Sigma apresenta as abordagens estatística e estratégica para as organizações priorizando 
o foco em processos, a partir da compreenção dos fatores que impulsionam o aumento da variabilidade e do conhecimento da variação para propor ações nas atividades diárias de gestão de processos (SANTOS, 2006).

\subsection{DMAIC}

Geralmente os projetos Seis Sigma são derivados de objetivos estratégicos a partir da redução de variabilidade nos processos. As etapas do DMAIC são aplicadas para identificar as causas raízes no programa da metodologiaSeis Sigma a fim de reduzir falhas no processo edefeitos nos produtos, convergindo para a minimização da variabilidadenos processos (ANTONY et. al, 2012).

Os autores Antony et. al (2007) sugerem como aplicação da metodologia DMAIC para processos de serviços as fases:

- Defirnir:

Definir o problema do projeto;

Compreender o problema a partir da perspectiva dos clientes;

Realizar mapeamento do processo para identificar o problema,

Identificar as entradas e saídas do processo;

Definir carta do projeto com escopo e limites do projeto, recursos, prazos e responsabilidades da equipe;

Identificar o patrocinador do projeto;

Identificar todos os clientes (internos e externos);

- Medir:

Determinar o desempenho atual;

Medir a capacidade de curto e longo prazo;

Decidir o que medir;
Identificar os pontos para melhorias;

- Analisar:

Identificar as causas raízes dos defeitos dos processos;

Investigar as causas de variabilidade;

Compreender a natureza e a distribuição dos dados;

Determinar as variáveis de processo que podem estar ligadas aos defeitos;

Quantificar os ganhos financeiros;

- Melhorar:

Desenvolver soluções para melhorar os problemas e evitar que se repitam;

Avaliar o impacto de cada solução potencial usando matriz de decisão de critérios;

Avaliar os riscos associados a soluções;

Reduzir a taxa de defeitos e validar melhorias;

Reavaliar o impacto da solução potencial;

- Controlar:

Desenvolver ações corretivas para sustentar o desempenho do processo;

Elaborar e revisar procedimentos operacionais;

Identificar um dono do processo e estabelecer sua função;

Implementar planos de controle de processo e determinar a capacidade do processo;

Fechar o projeto e compartilhar as principais lições aprendidas;

Divulgar os resultados internamente ou externamente;

Reconhecer os membros da equipe.

Segundo Damasceno (2009) e representado na Figura 1 a metodologia DMAIC é semelhante ao ciclo PDCA. 
Figura 1: Metodologia DMAIC.

\begin{tabular}{|c|l|}
\hline DEFINIR & Identificar o problema \\
& Definir Requisitos \\
\hline MEDIR & $\begin{array}{l}\text { Validar o problema } \\
\text { Redefinir o prolema / objetivo } \\
\text { Medir entradas e saídas } \\
\text { (chaves) }\end{array}$ \\
\hline ANALISAR & $\begin{array}{l}\text { Hipóteses e Causas } \\
\text { Identificar causa-raiz }\end{array}$ \\
\hline MELHORAR & $\begin{array}{l}\text { Ideias para eliminar a causa } \\
\text { raiz } \\
\text { Testar soluções }\end{array}$ \\
\hline Padronizar e medir \\
\hline CONTROLAR & $\begin{array}{l}\text { Medidas Padrão de Controle } \\
\text { Corrigir as anomalias }\end{array}$ \\
\hline
\end{tabular}

Fonte: Pande (2007) apud Damasceno (2009).

\subsection{NORMAS PARA CARREGAMENTO DE BIODIESEL}

Nos editais públicos dos leilões de biodiesel constam informações e referências que devem serem atendidas pelas unidades produtoras. No contexto deste artigo é importante salientar os itens 6.3 e 7.2.2 do edital do leilão de biodiesel L59:

6.3 A quantificação do carregamento de BIODIESEL será efetuada pela capacidade volumétrica do caminhão-tanque ou do vagão-tanque, tomando como referência a seta indicativa desta capacidade ou o medidor volumétrico de vazão devidamente aferido e instalado no sistema de bombeamento do FORNECEDOR, sendo que o faturamento será baseado na apuração do volume em litros a $20^{\circ}$ C. 7.2.2. Será facultado ao MOTORISTA ou outro representante indicado pelo PREPOSTO ou pela ADQUIRENTE, acompanhar as operações de carregamento de caminhões-tanques e vagões-tanque, sem aviso prévio. (BRASIL, 2018 p. 13-85).

Oórgão INMETRO é responsável pela aferição da capacidade volumétrica dos tanques que transportam líquidos a granel. A Portaria 208 de 06 de maio de 2016 diz no item 7:

ERROS MÁXIMOS ADMISSÍVEIS -Os volumes determinados e os erros máximos admissíveis nas verificações são referidos a temperatura de $20{ }^{\circ} \mathrm{C}$. O erro máximo admissível na verificação e de 0,25 \% para mais ou para menos, da capacidade nominal de cada nível materializado no tanque ou compartimento (BRASIL, 2016 p11).

\section{ESTUDO DE CASO}

A metodologiadesenvolvidaneste trabalho foi a aplicação das etapas do DMAIC para a redução de variabilidade em litros (I) de biodiesel carregado em caminhões tanques com o intuito de identificar, compreender e controlar a variabilidade do volume de biodiesel expedido nos caminhões tanques. Para aplicação destas ferramentas foram levantadas informações no setor de carregamento. A Figura 2 representa a estrutura metodológica do DMAIC desenvolvida neste trabalho. 
Figura 2: Estrutura do Projeto.

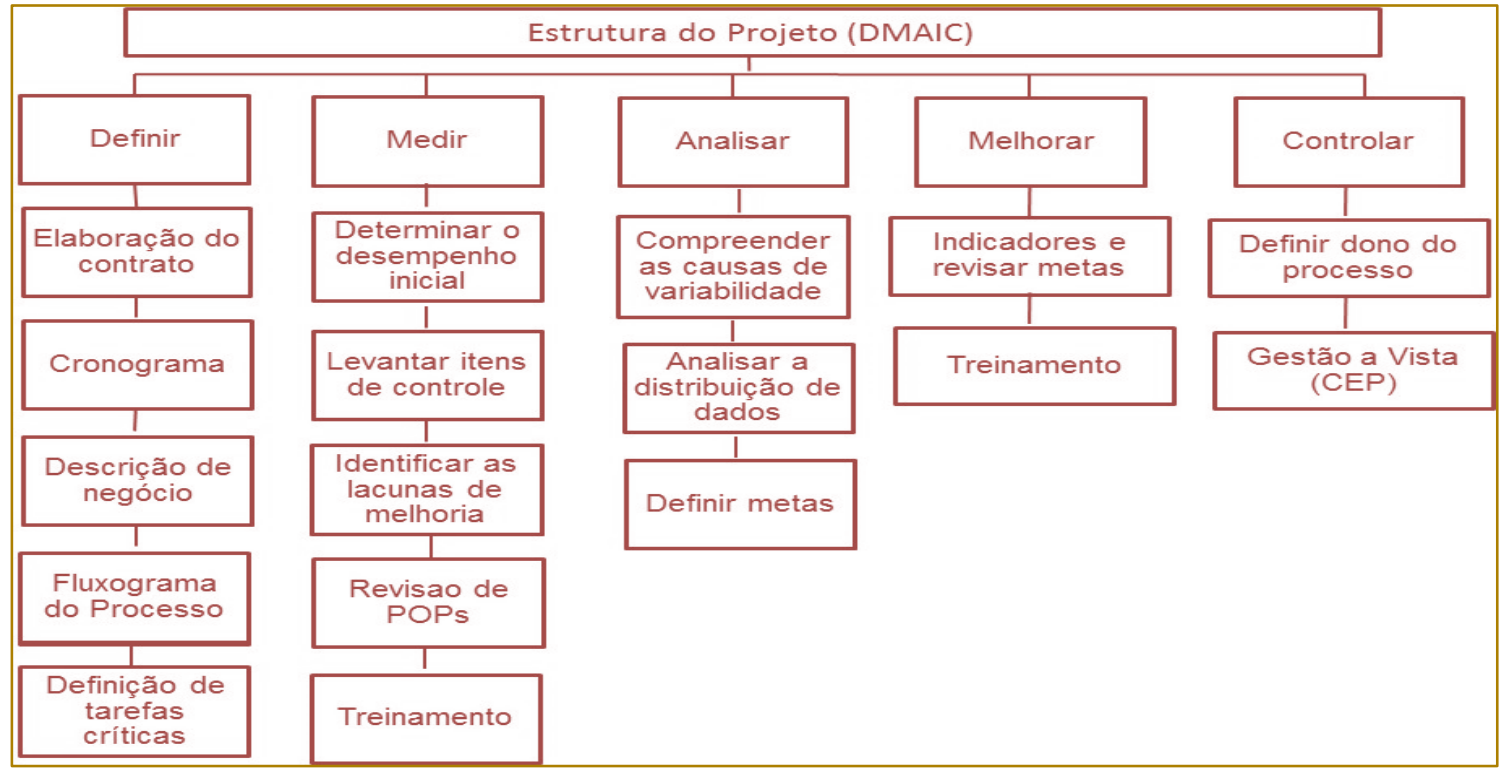

Fonte: Elaborado pelo autor.

A quantificação do volume para emissão da nota fiscal é baseado na conversão do volume em litros (I) a $20^{\circ} \mathrm{C}$. Para isso é utilizado o conversor fornecido pela Agência Nacional do Petróleo (ANP) onde são inseridos os seguintes dados: volume de capacidade do tanque do caminhão, temperatura de carregamento, temperatura da amostra, densidade do produto e massa liquida da balança.

O conversor fornece o resultado do volume convertido a $20^{\circ} \mathrm{C}$ em relação a capacidade do tanque do caminhão tanque e compara com o volume convertido a $20^{\circ} \mathrm{C}$ referente a massa liquida da balança. Antes do projeto de controle da variabilidadedescrito neste trabalhoera considerado correto para fins desta comparação a variação de 500 litros.

\section{RESULTADOS}

$\mathrm{Na}$ fase definir foi elaborado o contrato, o cronograma do projeto, a descrição do negócio, formação da equipe, mapeamento de entradas e saídas do processo, macro fluxograma e fluxograma do carregamento. $\mathrm{Na}$ Figura 3 está representado o macro fluxograma do processo.

$\mathrm{Na}$ fase definir foi elaborado o macro fluxograma e determinadas as tarefas criticas:

Emissão da Autorização de embarque: esta atividade é executada pelo faturamento na entrada do veículo para a pesagem inicial. Este documento contém a informação do volume a ser transferido para o caminhão. Para efeitos de multa por execesso de peso este volume deve ser a capacidade volumétrica mínima (primeira seta) do tanque do caminhão.

- Carregar Biodiesel: O operador deve carregar a quantidade em volume (I) informada na autorização de embarque através de bombeamento do biodiesel que passa por um medidor de vazão. No término o operador deve checar a quantidade volumétrica carregada visualmente até a esfera da seta ficar parcialmente coberta com o movimento do liquido.

- Converter o volume a $20^{\circ} \mathrm{C}$ : Esta tarefa tem maior criticidade, onde o faturista deve converter a massa liquida da balança $(\mathrm{kg})$ para a unidade litro (l) afim de faturar a nota fiscal. Para isso, utiliza o conversorfornecido pela Agência Nacional do Petróleo (ANP) onde são inseridos o volume de capacidade do tanque do caminhão, temperatura de carregamento, densidade do biodiesel medido no ato de carregamento e a massa liquida da balança. O conversor transformaa massa da balança $(\mathrm{kg})$ para o volume $(\mathrm{I})$ na temperatura padrão de $20^{\circ} \mathrm{C}$. Este volume é comparado com o volume da capacidade do caminhão.Antes do projeto era considerado normal a variação comparativa até 500 I.

- Alimentar planilha do indicador: O faturista deve preencher a variação obtida do 
Figura 3: Macrofluxograma do Processo.

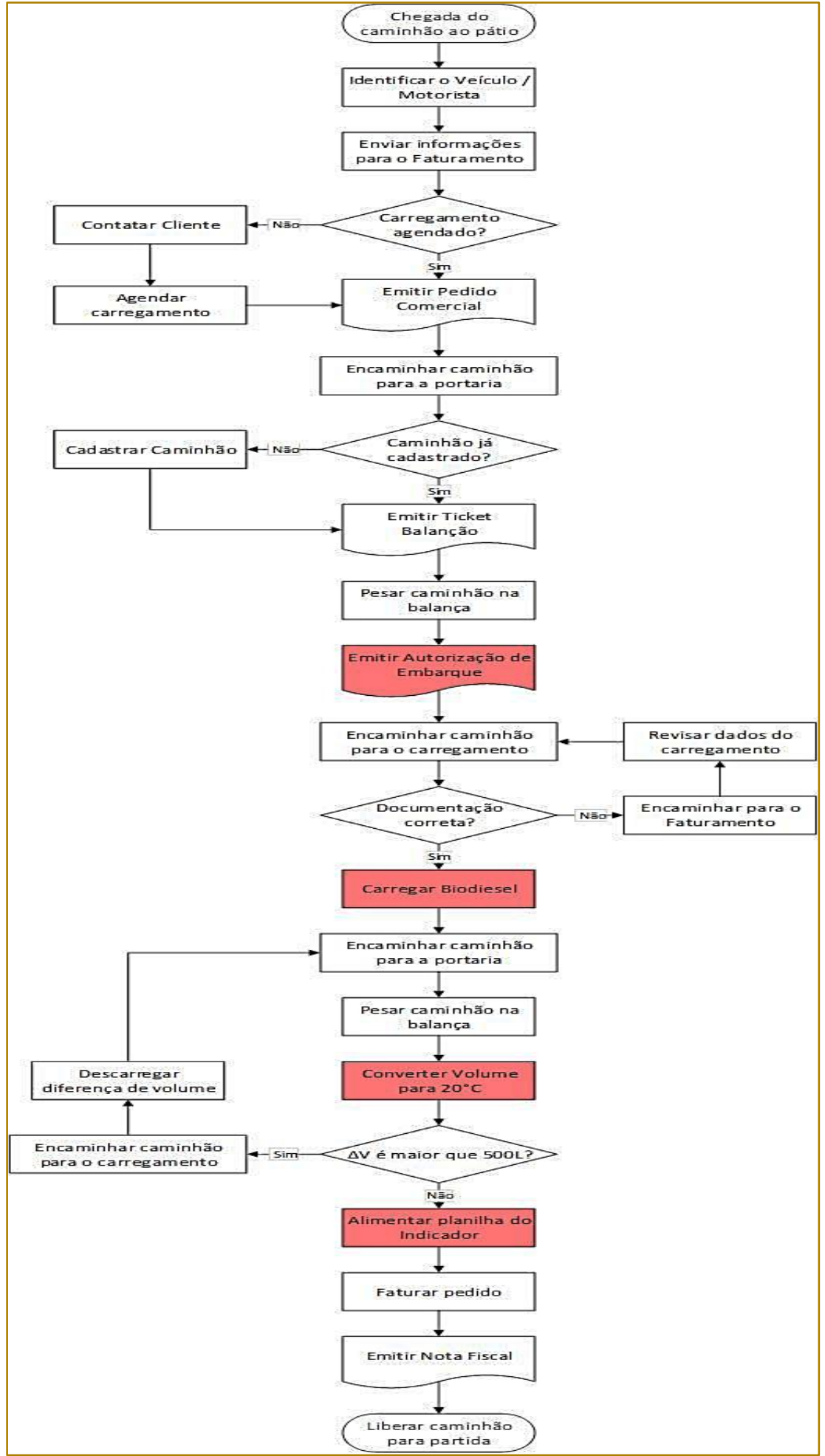

Fonte: Elaborado pelo autor.

$\mathrm{Na}$ fase medir foi levantado o desempenho inicial do processo referente aos dados fornecidos pelo conversor. O período de junho a outubro do ano de 2017 corresponde aos dados antes do projeto e a partir de novembro do mesmo ano teve início a padronização do processo. A Tabela1ilustra os dados obtidos no período de junho a dezembro de 2017, a variação média mensal em (I) significa variação mensal média em (I) por 
carregamento e seus respectivos desvio padrão.

Tabela 1: Dados dos carregamentos de junho a dezembro de 2017.

\begin{tabular}{|l|c|c|c|c|c|c|c|}
\hline \multicolumn{1}{|c}{ Dados / Mês (2017) } & Jun & Jul & Ago & Set & Out & Nov & Dez \\
\hline Variação mensal média (I) & 293 & 273 & 303 & 518 & 298 & 106 & 39 \\
\hline Desvio padrão & 372 & 339 & 403 & 430 & 367 & 87 & 85 \\
\hline Número de Carregamentos & 236 & 151 & 149 & 297 & 318 & 177 & 177 \\
\hline
\end{tabular}

Fonte: Dados da Variabilidade dos Carregamentos.

Na tabela-1 observa-se que a maior média de variação ocorreu no mês de setembro com 518 litros de biodiesel carregados além da seta mínima da capacidade do tanque do caminhão. Além das médias altas foi observado elevado desvio padrão no período de junho a outubro de 2017 devido a falta de padronização do processo de carregamento.

$\mathrm{Na}$ fase analisar a equipe discutiu os motivos das variaçõese identificou como causa principal a falha no método devido a falta de procedimento para este controle. A partir do mês de novembro/2017 foi criado o indicador da variação média mensal (I) por caminhão e definiu a meta de variação do conversor de 200 litros, desta forma se o volume carregado apresentasse variação positiva acima do permitido o veículo retornava ao carregamento para retirada de produto e quando ocorria variação negativa inferior a (200litros) o veículo retornava para completar o volume de biodiesel. O faturamento passou a alimentar a planilha do indicador variação média mensal (I) no final do dia e enviar a planilha por e-mail ao supervisor do carregamento que repassa as informações a equipe operacional.

A Figura 4 corresponde a distribuição normal dos dados no período anterior ao projeto, meses de junho a dezembro de 2017. Neste período não há normalidade, média de variação de 351,2 I e desvio padrão de 404,8 I.

Figura 4:Histograma da variabilidade dos meses de junho a outubro de 2017.

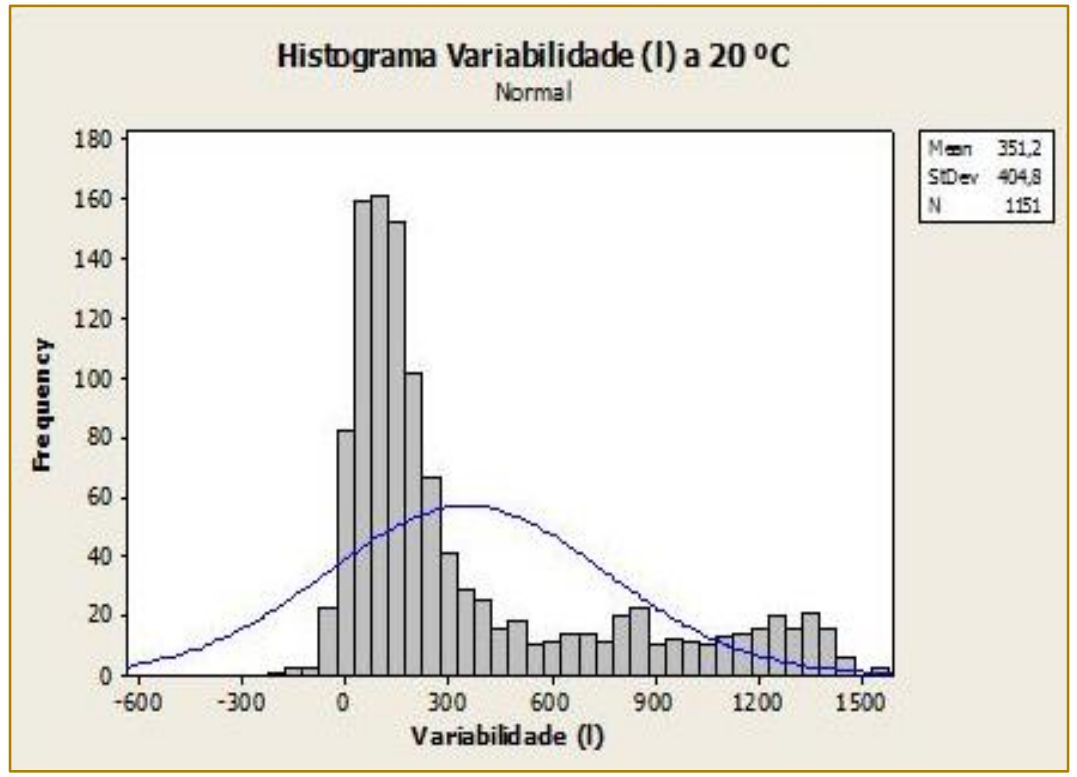

$\mathrm{Na}$ etapa melhorar foi criado o indicador índice de reprocesso de carretas que retornavam para o setor para acrescentar ou retirar produto. A meta inicial do índice de reprocesso foi $5 \%$. Posteriormente foram definidas as responsabilidades e treinamentos para as equipes do carregamento e faturamento. 
A Figura 5 corresponde a distribuição normal dos dados referente aos meses de novembro e dezembro. Neste período observa-se boa normalidade dos dados, média 72,2 I e desvio padrão de 92,2 I.

Figura 5:Histograma da variabilidade referente aos meses de novembro e dezembro de 2017.

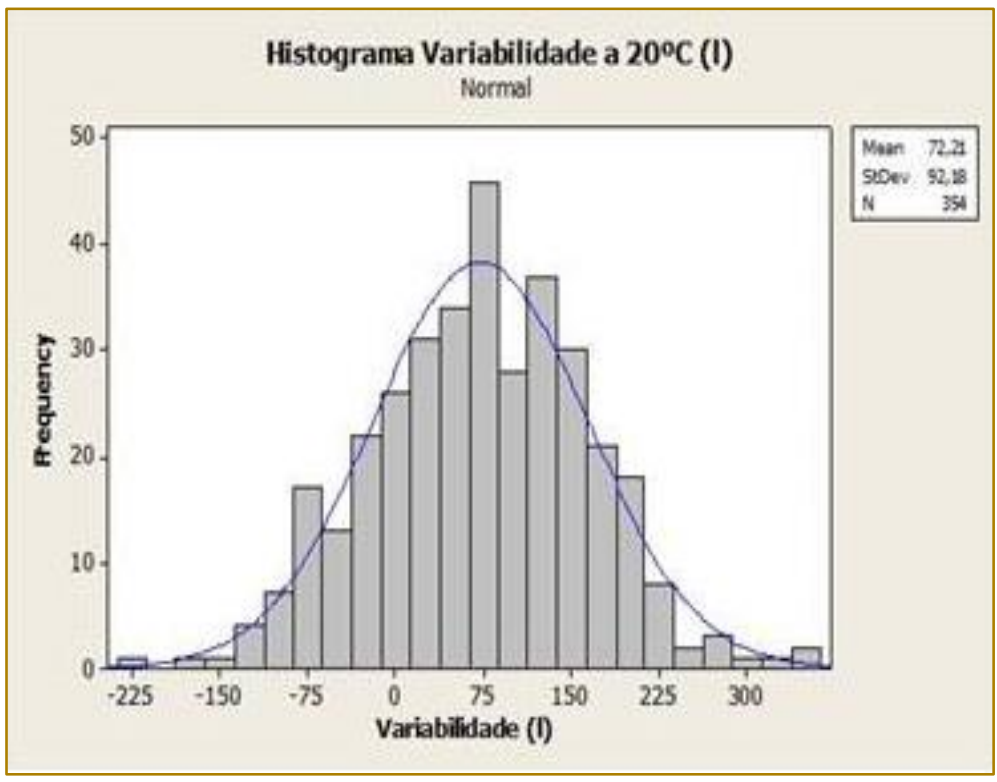

Na etapa controlar, a última da metodologia DMAIC foi feito um quadro de gestão a vista no setor de carregamento, onde os operadores passaram a anotar diariamente a variação média de volume (I) dos carregamentos do dia anterior. Desta forma os operadores passaram a observar a tendência de variabilidade que ocasionou em menor média de variabilidade mensal com valores mais próximos de zero, de acordo com a Tabela 2.

Tabela 2: Dados dos carregamentos de janeiro a março de 2018.

\begin{tabular}{|c|c|c|c|}
\hline Dados / Mês (2018) & Janeiro & Fevereiro & Março \\
\hline Variação mensal média (L) & -1 & -12 & 1 \\
\hline Desvio padrão & 59 & 64 & 59 \\
\hline Número de Carregamentos & 281 & 269 & 361 \\
\hline
\end{tabular}

Fonte: Dados da Variabilidade dos Carregamentos.

\section{CONSIDERAÇÕES FINAIS}

Analisando os dados antes e após o projeto conclui-se que a padronização do processo de carregamento de biodiesel se mostrou eficiente e alcançou o objetivo proposto da redução de variabilidade comparativa dos volumes obtidos e convertidos a $20^{\circ} \mathrm{C}$ da massa da balança e capacidade do tanque do caminão.

Com a finalidade de evidenciar a aplicação das etapas da metodologia DMAIC - definir, REFERÊNCIAS

[1] ANP, AGÊNCIA NACIONAL DO PETRÓLEO, GÁS NATURAL E BIOCOMBUSTíVEL. medir, analisar, melhorar e controlar foi possivel identificar fatores de influencia no processo, assim como mensurar dados com o propósito de quantificar a redução de variabilidade em volume (I) no carregamento de biocombustível, comprovando a eficiência da metodologia DMAIC e a importância do sistema de medição com base nos parâmetros do processo de envase definidos na legislação vigente.

Edital do leilão público ํo 001/18 59ำ leilão de biodiesel (I59) 
[2] ANTONY, J. ANTONY, F. J.; KUMAR, M.; $\mathrm{CHO}, \mathrm{B} . \mathrm{R}$. Six sigma in service organizations: benefits, challenges and difficulties, common myths, empirical observations and success factors. International Journal of Quality \& Reliability Management, v. 24, p. 294-311, 2007.

[3] ANTONY, J. et al. Application of six-sigma DMAIC methodology in a transactional environment. International Journal of Quality \& Reliability Management, v. 29, p. 31-53, 2012.

[4] BRASIL. Inmetro, Instituto nacional de metrologia qualidade e tecnologia. Portaria no 208 de 06 de maio de 2016.

[5] DAMASCENO, H. E. M. et al. Aplicação da estratégia seis sigma à uma unidade de saúde. In: Encontro Latino Americano de Iniciação Científica, 13; Encontro Latino Americano de Pós-Graduação, 9, 2009, Universidade do Vale do Paraíba. Anais... Disponível em: www.inicepg.univap.br/cd/INIC_2009/anais/arquivo s/RE_0881_0439_01.pdf, Acesso em 25 de junho de 2018

[6] GROSS, J. M. A road map to Six Sigma Quality. Quality Progress, v. 34, p. 24-29, 2001.
[7] LEITE, R. C. C.; LEAL, M. R.L.V.; O biocombustível no Brasil. Novos Estudos CEBRAP no 78, São Paulo, p. 15-21, 2007.

[8] MERGULHÃO, R. C. Análise da implementação do Seis Sigma em empresas de manufatura no Brasil. 104 páginas. Dissertação de Mestrado. Universidade Federal de Itajubá UNIFEI, 2003

[9] MONTGOMERY, D. C. Introdução ao Controle Estatístico da Qualidade. 4aㅡ ed. LTC; ISBN 9788521614005; 2004

[10] MOTA, C. J. A.; MONTEIRO, R. S. Química e Sustentabilidade: Novas Fronteiras em Biocombustíveis. Química Nova, v. 36, p. 14831490, 2013.

[11] SANTOS, A. B. Modelo de referência para estruturar o programa de qualidade Seis Sigma: proposta e avaliação. 2006. 312 p. Tese (Doutorado em Engenharia de Produção) Universidade Federal de São Carlos

[12] WERKEMA, M. C. C.; Ferramentas Estatísticas Básicas para o Gerenciamento de Processos, Vol.2, Belo Horizonte - MG, 1995. 


\section{Bapítulo 6}

\section{ANÁLISE DA CAPACIDADE DE TRANSPORTE DO SAL EM UMA SALINA DO RN, COM BASE NA TEORIA DAS RESTRIÇÕES}

\section{Dellano Jatobá Bezerra Tinoco}

Resumo: Este artigo tem como objetivo investigar a forma como está atualmente organizado o fluxo de caminhões que realiza o transporte do sal numa indústria salineira do RN. Assim, foi realizada uma pesquisa exploratória de campo, que utiliza alguns conceitos da ferramenta Teoria das Restrições - TOC aplicados na empresa estudada. O estudo tem como foco a análise e exploração dos Recursos de Capacidade Restrita - CCR e gargalos, com o intuito de auxiliar nas decisões relacionadas à gestão da capacidade. Primeiramente foi mapeado e analisado o processo produtivo, em seguida houve a coleta dos dados de tempos e cálculo das capacidades. Iniciou-se, então, a análise e exploração dos recursos limitantes do sistema produtivo, com o intuito de apontar as possíveis causas dessas restrições de capacidade. Ao fim, foi possível identificar quais os pontos críticos, recomendando ações de melhorias para elevar o nível de gestão do fluxo de caminhões.

Palavras Chave: Gestão da Capacidade, Processo, TOC, Gargalo, Caminhão 


\section{INTRODUÇÃO}

São notáveis, sobretudo na manufatura, frequentes transformações nos sistemas produtivos em virtude do processo de globalização, da ameaça de novos concorrentes, da busca incessante da qualidade e redução de custos de produção como meio para incrementar o lucro e fortalecer a posição competitiva das empresas. Os meios para estabelecer esse fortalecimento variam em função das características de cada empresa, do segmento em que atuam, bem como dos produtos que comercializam (UMBLE E SRIKANTH, 1995).

A capacidade produtiva de uma empresa é dada pela máxima produção possível a ser obtida em condições normais de trabalho e em determinado período de tempo. (SLACK et al., 2008) Portanto entende-se que a produtividade de uma empresa está diretamente relacionada à sua capacidade, devendo então ser medida corretamente, analisada e melhorada.

Segundo Souza e Pires (1999), é uma prática comum nas empresas de manufatura a procura constante pela gestão das capacidades produtivas dos seus recursos, ou seja, uma situação em que a capacidade de todos os recursos esteja aproximadamente equilibrada entre si e com a demanda do mercado. Essa prática é justificada pela tentativa de se manter todos os recursos continuamente ativados, amortizando os investimentos realizados e procurando estabelecer um fluxo uniforme de materiais pela fábrica.

Deste modo, a Teoria das Restrições ganha relevância nessa problemática, uma vez que auxilia a tomada de decisão na empresa, quanto a otimização do processo produtivo. De acordo com Souza (2005), essa nova sistemática gerencial tem como premissa básica, gerenciar através das limitações a fim de gerar ganhos monetários. Permitindo uma análise focalizada em pequenos pontos que têm influência global. Com isso, a Teoria das Restrições é uma metodologia para identificação dos gargalos, ou seja, qualquer elemento ou fator que impede que um sistema conquiste um nível melhor produtividade. (GOLDRATT E COX, 2000).

Gargalo e CCRs - Recursos de Capacidade Restrita são limitações de recursos responsáveis pela maioria dos problemas ligados a gestão da capacidade, que geralmente são causadas por variabilidades do processo e/ou demanda. Neste contexto, o objetivo do artigo centrou-se na utilização dos conceitos da teoria das restrições, para a identificação e exploração do recurso restritivo do processo de uma salina. E utilizar essas informações para então subsidiar as propostas de melhorias e decisões para empresa a fim de gerar maiores ganhos para a mesma.

\section{GESTÃO DA CAPACIDADE}

Capacidade é o nível máximo que um processo pode atingir ao operar, sob condições normais, em determinado período de tempo (SLACK et al., 2008). O intuito de gerenciar essa capacidade é atender a demanda de maneira eficiente.

Davis et al., (2001) separam em internos e externos os fatores que interferem na capacidade. Dentre os fatores externos, incluem-se: legislação governamental, acordos com sindicatos, e capacidades do fornecedor. Dentre os fatores internos, incluem-se: projeto de produto e serviço, pessoal e empregos, layout de planta e fluxo de processo, capacidades e manutenção de equipamento, administração de materiais e sistemas de controle de qualidade.

Outra questão que deve ser considerada em operações de manufatura, é que algumas partes trabalham abaixo da sua capacidade e outras em seu limite máximo. A esse respeito Slack et al. (2008), registra que "(...) dependendo da natureza da demanda, o uso de diferentes partes de uma operação pode atingir sua capacidade máxima e atuar como uma restrição para toda a operação".

Logo, Heizer e Render (2001) acrescentam mais um fator à lista supracitada, o fator gargalo. A maioria dos processos envolve múltiplas operações com capacidades distintas e um gargalo é a operação com a menor capacidade efetiva no processo, limitando a produção final. Neste caso, a melhoria da capacidade de um processo ocorre somente quando a capacidade do gargalo é aumentada por meio de melhorias no processo.

\section{TEORIA DAS RESTRIÇÕES}

A Teoria das Restrições (Theory of Constraints - TOC) foi desenvolvida na década de 80 pelo físico Eliyahu Goldratt e revelou-se uma 
metodologia eficaz, que apresenta soluções para os problemas de produtividade $e$ variações na demanda. O TOC foi aplicado pela primeira vez no planejamento e programação de produção para maximizar os lucros e a eficácia das empresas em relação aos requisitos do mercado, identificando e explorando recursos de restrição. Para maximizar os lucros, o TOC pode ser usado para desenvolver um programa mestre de produção (MPS) que maximize o rendimento das restrições do sistema (isto é, explora as restrições), (GOLMOHAMMADI, 2015).

Para tanto a Teoria das Restrições enumera cinco passos, pelos quais pode-se determinar que restrições estão delimitando o desempenho e ganho da empresa, mantendo ainda um processo de melhoria contínua (GARDINER et al., 1994):

Identificar a(s) restrição(ões) do sistema, decidir como explorar a(s) restrição(ões) do sistema, subordinar tudo à decisão acima, elevar a(s) restrição(ões) do sistema e se uma restrição for quebrada, voltar ao passo inicial para que a inércia não cause uma restrição no sistema.

O mérito desta metodologia está em enfatizar a importância do gargalo de uma forma estruturada e abrangente, segundo o pressuposto da racionalização. Ou seja, de não se investir recursos e esforços no que não agrega valor, mas tão somente despesas. Uma vez que, em um processo tudo agrega custo, mas nem tudo agrega valor. (OLIVEIRA et al., 2009).

\subsection{GARGALO E CCRS}

Para que um sistema produtivo opere eficientemente, todas as operações integrantes do processo devem possuir a mesma capacidade. No entanto, caso sejam distintas, a capacidade total será definida pela operação mais lenta. (SLACK et al., 2008)

Antunes et al., (2008) definem gargalo como sendo constituído de recursos cuja capacidade disponível é menor do que a capacidade necessária para atender às ordens demandadas pelo mercado. $\mathrm{Na}$ atribuição de gargalos envolvendo trabalhadores, empregos e máquinas, se os produtos excedentes tiverem que ser totalmente empregados, então os produtos em falta naturalmente exigirão trabalho adicional, mas sujeito a restrições de capacidade inerentes, (GEETHA E VARTAK, 1994).

Essas restrições podem ser classificadas em internas, quando provem de algum recurso da empresa, e externas, se o mercado for a restrição, impedindo a empresa de trabalhar em sua capacidade total. Ou ainda, no caso de haver restrição de fornecimento de materiais, fazendo com que o mercado fornecedor limite a capacidade de produção da empresa por não poder atender a demanda completamente, (COGAN, 2007).

Os CCRs surgem devido às variabilidades do sistema produtivo ou variações significativas de demanda, que geralmente são problemas relacionados à sequenciamento das ordens de produção, manutenção, tempos de preparação acima dos programados, fornecimento de materiais, qualidade de produtos, variabilidade e sazonalidades da demanda (ANTUNES et al., 2008).

Hopp e Spearman (2000) dizem que a variabilidade causa grandes impactos na performance do sistema produtivo, postulando que segundo a lei da variabilidade: "o aumento de variabilidade sempre resulta em perda de performance do sistema produtivo". Dessa forma, faz-se necessária a preocupação com o gerenciamento desses recursos ser tão importante quanto à preocupação com a restrição em si, para se reduzir as variabilidades do sistema e obter um planejamento mais completo e eficiente.

\section{SETOR SALINEIRO}

O cloreto de sódio, ou sal, é uma das substâncias mais abundantes na natureza e oferece mais de 14.000 aplicações em suas diversas formas, a maior parte delas na indústria química. O sal é empregado na fabricação de cloro, soda cáustica, ácido clorídrico, vidro, alumínio, plásticos, têxteis, borracha, hidrogênio e celulose, entre outros itens, além de ser utilizado na indústria alimentícia (humana e animal e na preservação de alimentos).

De acordo com o Departamento Nacional de Produção Mineral - DNPM, Sumário Mineral de 2017, a produção mundial de todos os tipos de sal para o ano de 2016 foi estimada em torno de 255 milhões de toneladas, representando um decréscimo de cerca de $6 \%$ em relação ao ano anterior. A China contribuiu com 22,74\% da produção e 
continuou na liderança, seguida pelos Estados Unidos da América (EUA), com $16,46 \%$. No Brasil, a produção de sal foi estimada em 7,5 milhões de toneladas, destas 6 milhões de toneladas foram de sal por evaporação solar.

No Brasil, os principais estados produtores são o Rio Grande do Norte, no chamado Pólo Costa Branca; e o Rio de Janeiro, na chamada Região dos Lagos. E, de acordo com a SIESAL - Sindicato das Indústrias de Extração do Sal o Estado do RN, o estado produz cerca de 5 milhões de toneladas de sal por ano, o que representa mais de 95\% da produção nacional de sal marinho.

\section{METODOLOGIA}

A presente pesquisa é de natureza aplicada, objetivo exploratório descritivo, abordagem quantitativa e qualitativa. Quanto ao método, a pesquisa pode ser classificada como pesquisa-ação, uma vez que um dos pesquisadores é parte integrante da empresa estudada.

Para o desenvolvimento do artigo, o procedimento de pesquisa está dividido em três etapas: revisão bibliográfica, coleta de dados e proposta de melhorias para a empresa estudada.

Primeiramente foi realizada uma pesquisa bibliográfica em fontes como livros, dissertações, monografias e artigos científicos, de modo a reunir elementos para uma abordagem na área de gestão da capacidade, TOC, CCR e gargalos.

A segunda etapa contempla a coleta de dados em campo, aonde permitiu identificar quais pontos críticos a empresa estudada se encontrava. Para isso, a coleta de dados foi realizada por meio de busca documental e cronoanálise realizado pelos pesquisadores.

Por fim, na terceira etapa, foram sugeridas propostas de melhorias baseadas nos pontos críticos observados in loco.
6. AVALIAÇÃO DA CAPACIDADE DE TRANSPORTE DO PROCESSO PRODUTIVO DA SALINA

\subsection{CARACTERIZAÇÃO DA EMPRESA}

A empresa estudada foi fundada em 1996, e em 2003 passou a ser a maior empresa privada do setor salineiro a nível mundial, hoje faz parte de um dos grupos mais importantes do mundo. Sua unidade de produção se localiza no Rio Grande do Norte, emprega cerca de 160 funcionários, e produz em torno de 500.000 toneladas de sal por ano.

Seus produtos estão classificados como os seguintes tipos de sal: Sal Industrial: Sal grosso, sal moído e sal triturado (com ou sem adição de iodo, consumo industrial e humano). Sal Pecuária: Sal moído iodado (consumo animal).

Para a obtenção do produto, a produção do sal se inicia num "braço de mar", onde a água salgada é captada e bombeada para os tanques evaporadores. A evaporação é um processo natural, provocado pelo sol e pelo vento, aumentando gradativamente a concentração dos sais presentes na água, onde a água extremamente concentrada é transferida, por meio da gravidade, para os tanques até o ponto em que a salmoura está quase saturada de sal.

A partir dessa fase, inicia-se a cristalização do sal, ocorrendo a precipitação do sal e evaporação quase que total da água. O sal cristalizado é colhido através de uma máquina colheitadeira (CS) e transferido para os caminhões, onde será transportado até a área onde se localiza o funil, conforme demonstrado na Figura 1. Nesse momento, os caminhões aguardam por sua vez para que possam descarregar o sal cristalizado no funil. Logo após passar pelo funil, o sal entra no lavador por meio de uma esteira rolante, para a operação de lavagem. Ao sair do lavador, o produto passa novamente por uma esteira, onde acontece manualmente a inspeção de insolúveis, até o pátio de secagem onde o mesmo permanece estocado. 
Figura 1 - Planta baixa dos cristalizadores e lavador. Fonte: Google Earth.

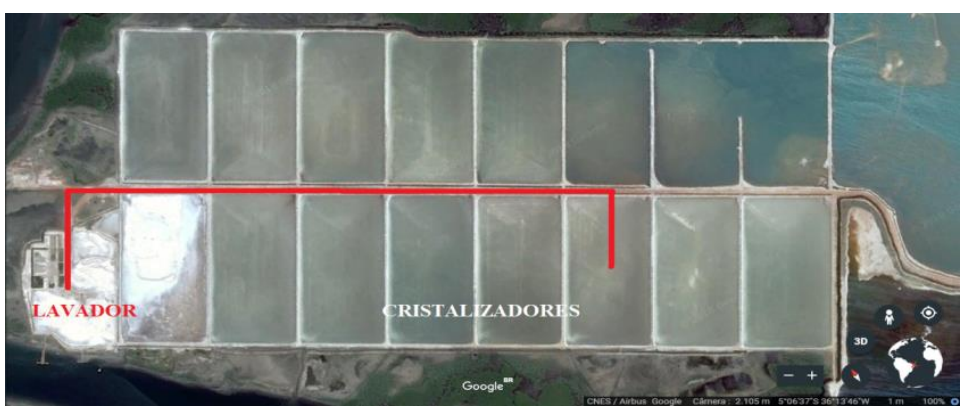

Em relação aos recursos que suportam seu processo produtivo, temos que na empresa estudada a colheita do sal é própria, o transporte do sal por caminhões da colheita até o lavador é 100\% terceirizado e a lavagem/estocagem do sal é própria. Assim, temos que parte do seu processo produtivo, apesar da proximidade com as empresas terceirizadas no alinhamento da necessidade de caminhões para a colheita, a empresa estudada não consegue manter um fluxo contínuo de caminhões, durante os dias produtivos.

\subsection{COLETA DE DADOS}

A coleta de dados iniciou com a indicação da classificação da capacidade dos caminhões que a empresa terceirizada disponibilizou. A empresa estudada tinha a sua disposição Caminhões (CB) e Caminhões Trucados (CBT), para o transporte de sal de CB 7, CBT 14 e CBT 18 toneladas. Para checar se o peso teórico estava próximo ao peso informado de que os caminhões suportavam transportar do cristalizador (CR) até o lavador, a checagem do peso de cada caminhão foi realizada aleatoriamente num período de 20 dias. A Tabela 1 abaixo, informa a tara do caminhão, o peso bruto do caminhão carregado, o peso líquido, o peso líquido transformado em toneladas, o peso teórico que cada caminhão suportava e o desvio padrão.

TABELA 1 - Amostras do peso dos caminhões.

\begin{tabular}{|c|c|c|c|c|c|c|}
\hline Dia & Tara (kg) & $\begin{array}{l}\text { Bruto } \\
(\mathrm{kg})\end{array}$ & Líquido (kg) & Ton & Teórico (ton) & $\begin{array}{l}\text { Desvio } \\
\text { Padrão }\end{array}$ \\
\hline 1 & 6.950 & 15.330 & 8.380 & 8,38 & 7 & 1,38 \\
\hline 2 & 6.800 & 14.930 & 8.130 & 8,13 & 7 & 1,13 \\
\hline 3 & 7.090 & 14.070 & 6.980 & 6,98 & 7 & $-0,02$ \\
\hline 4 & 6.950 & 15.740 & 8.790 & 8,79 & 7 & 1,79 \\
\hline 5 & 6.800 & 16.690 & 9.890 & 9,89 & 7 & 2,89 \\
\hline 6 & 7.090 & 16.930 & 9.840 & 9,84 & 7 & 2,84 \\
\hline 7 & 5.730 & 14.570 & 8.840 & 8,84 & 7 & 1,84 \\
\hline 8 & 5.760 & 13.160 & 7.400 & 7,40 & 7 & 0,40 \\
\hline 9 & 6.950 & 15.740 & 8.790 & 8,79 & 7 & 1,79 \\
\hline 10 & 6.800 & 16.010 & 9.135 & 9,14 & 7 & 2,14 \\
\hline 11 & 7.090 & 15.930 & 8.985 & 8,99 & 7 & 1,99 \\
\hline 12 & 5.530 & 13.450 & 7.920 & 7,92 & 7 & 0,92 \\
\hline 13 & 6.360 & 13.320 & 6.960 & 6,96 & 7 & $-0,04$ \\
\hline 14 & 9.270 & 25.230 & 15.960 & 15,96 & 14 & 1,96 \\
\hline 15 & 10.110 & 26.030 & 15.920 & 15,92 & 14 & 1,92 \\
\hline 16 & 14.110 & 30.380 & 16.270 & 16,27 & 14 & 2,27 \\
\hline 17 & 9.880 & 28.480 & 18.600 & 18,60 & 18 & 0,60 \\
\hline 18 & 8.090 & 25.870 & 17.780 & 17,78 & 18 & $-0,22$ \\
\hline 19 & 11.510 & 32.330 & 20.820 & 20,82 & 18 & 2,82 \\
\hline 20 & 14.860 & 34.140 & 19.280 & 19,28 & 18 & 1,28 \\
\hline & & & & & & 29,67 \\
\hline
\end{tabular}

Fonte: $\mathrm{O}$ autor. 
Foi informado também a distância de cada cristalizador ao lavador, o ponto médio do cristalizador $(280 \mathrm{~m})$, a capacidade de produção de uma colheitadeira e a do lavador que também é de 400 tons/h para os pesquisadores realizarem seus cálculos.

Após aferido o peso dos caminhões, o pesquisador seguiu para a cronoanálise dos tempos de cada parte do transporte dos caminhões, desde a colheita, até o lavador. Na tabela 2, temos uma análise do tempo que os caminhões vazios levam para chegar na colheitadeira e serem carregados de sal, para aí sim prosseguir para o lavador. Vale ressaltar que o exemplo das tabelas de 2 a 6 , estão levando em consideração a distância de um cristalizador a 2.200 metros do lavador, conforme destacado em vermelho na Figura 1. No processo da colheita, o caminhão leva um determinado tempo para entrar no cristalizador e se deslocar até o seu ponto médio, que é de 280 metros.

TABELA 2 - Análise do tempo que os caminhões vazios levam para chegar na colheitadeira.

\begin{tabular}{|c|c|c|c|c|c|}
\multicolumn{5}{|c}{} & \multicolumn{5}{c|}{ Caminhões Vazios } \\
Caminhões & Vel. (m/s) & $\begin{array}{c}\text { T. p/ chegar } \\
\text { CS }\end{array}$ & Vel. CR (m/s) & T. p/ chegar & $\begin{array}{c}\text { Tempo p/ } \\
\text { CS }\end{array}$ \\
CB 7 ton & 4,17 & 528,00 & 2,78 & 100,62 & 85,00 \\
\hline CBT 14 ton & 5,56 & 396,00 & 2,78 & 100,62 & 155,00 \\
\hline CBT 18 ton & 6,94 & 316,80 & 4,17 & 67,08 & 199,00 \\
\hline
\end{tabular}

Fonte: $\mathrm{O}$ autor.

$\mathrm{Na}$ tabela 3, observa-se as mesmas informações da tabela 2, só que levando em consideração o caminhão preenchido de sal e na última coluna o tempo deste caminhão descarregando todo o sal no funil do lavador.

TABELA 3 - Análise do tempo que os caminhões carregados levam para chegar no lavador.

\begin{tabular}{|c|c|c|c|c|c|}
\hline \multirow[b]{2}{*}{ Caminhões } & \multicolumn{4}{|c|}{ Caminhões Carregados } & \multirow{2}{*}{$\begin{array}{l}\text { Descarga } \\
\text { Lavador }\end{array}$} \\
\hline & $\begin{array}{l}\text { Velocidade } \\
\text { (m/s) }\end{array}$ & $\begin{array}{c}\text { T. p/ chegar } \\
\text { CS }\end{array}$ & $\mathrm{CR}(\mathrm{m} / \mathrm{s})$ & $\begin{array}{c}\text { T. p/ chegar } \\
\text { CS }\end{array}$ & \\
\hline CB 7 ton & 2,78 & 792,00 & 1,39 & 201,25 & 53,00 \\
\hline CBT 14 ton & 4,17 & 528,00 & 2,78 & 100,62 & 63,00 \\
\hline CBT 18 ton & 5,56 & 396,00 & 4,17 & 67,08 & 59,00 \\
\hline
\end{tabular}

Fonte: $\mathrm{O}$ autor.

Já na tabela 4, obtemos os dados referente ao somatório do tempo total das tabelas 2 e 3, na terceira coluna o cálculo desse tempo em viagens por hora, consequentemente 0 cálculo da capacidade de carga por hora e por último, a frota necessária se a empresa estudada tivesse a sua disposição somente caminhões CB 7 ton, CBT 14 ton e CBT 18 ton.

TABELA 4 - Análise do tempo total, da capacidade e da frota necessária para o processo.

\begin{tabular}{|c|c|c|c|c|}
\hline Caminhões & Total (s) & Viagens/h & $\begin{array}{l}\text { Capacidade } \\
\text { (ton/h) }\end{array}$ & $\begin{array}{c}\text { Frota } \\
\text { Necessária }\end{array}$ \\
\hline CB 7 ton & $1.759,87$ & 2,05 & 14,32 & 28 \\
\hline CBT 14 ton & $1.343,25$ & 2,68 & 37,52 & 11 \\
\hline CBT 18 ton & $1.104,96$ & 3,26 & 58,64 & 7 \\
\hline
\end{tabular}

Fonte: $\mathrm{O}$ autor.

Foi possível verificar a disponibilidade em determinado dia de caminhões no processo produtivo da empresa estudada, sem levar em consideração caminhões parados por motivos de quebras e/ou ausência de motoristas, dentre outros. Assim, temos na tabela 5 a disponibilidade real de caminhões no processo. 
TABELA 5 - Análise da disponibilidade de caminhões no processo.

\begin{tabular}{|c|c|c|}
\hline Processo atual & QTD & Capacidade Tons/h \\
\hline CB 7 ton & 6 & 64,44 \\
\hline CBT 14 ton & 2 & 56,28 \\
\hline CBT 18 ton & 3 & 131,95 \\
\hline Total & 11 & 252,67 \\
\hline
\end{tabular}

Fonte: $\mathrm{O}$ autor.

Em relação ao processo otimizado, temos que na tabela 6 , os dados estão dispostos de forma a atender a demanda da colheitadeira e do lavador (400 tons/h). Dados teóricos em relação à tabela 5, para chegarmos próximo à capacidade do lavador e da colheitadeira e assim manter o fluxo em regime.

TABELA 6 - Análise otimizada dos caminhões no processo.

\begin{tabular}{|c|c|c|}
\hline Processo Otimizado & QTD & Capacidade Tons/h \\
\hline CB 7 ton & 8 & 85,92 \\
\hline CBT 14 ton & 4 & 112,56 \\
\hline CBT 18 ton & 5 & 219,92 \\
\hline Total & 17 & 418,40 \\
\hline \multicolumn{3}{|c}{} \\
\hline
\end{tabular}

\subsection{ANÁLISE DOS DADOS}

Ao iniciar a análise do gargalo do processo produtivo do sal, pode-se visualmente identificar que há uma variabilidade relacionada à incapacidade da empresa terceirizada em atender de forma plena em números de caminhões o processo produtivo. Aonde acontece a não utilização da sua eficiência máxima. Nessa situação descrita, vale salientar que a estrutura disponibilizada pela empresa estudada (colheitadeira, sal e lavador), os gargalos são minimizados da seguinte maneira: a colheitadeira não se torna um gargalo devido a ter equipamentos reservas de prontidão para entrar em ação caso algum haja alguma parada, o sal é abundante e tem à disposição para colheita e o lavador, caso deixe de funcionar, o sal é colocado em outra área para posterior processamento. Dessa forma, o gargalo crítico se torna a disponibilidade de caminhões.

Temos que na tabela 1, apesar dos dados sofrerem alterações a cada pesagem, devido a densidade do sal, ao fator humano que nem sempre conseguem repetir a ação de carregar de forma plena o caminhão, o desperdício de sal durante o trajeto do cristalizador até o lavador, dentre outros, temos que no final a diferença entre o peso bruto e a tara dos caminhões não refletem um desvio negativo e sim positivo minimizando as perdas para a empresa estudada.
Já o relacionamento entre a tabela 2 e a tabela 3 , em relação à diferença de tempo, se justifica devido ao caminhão estar vazio, consumindo menos tempo para se deslocar e no seu retorno o caminhão já carregado gasta mais tempo para se deslocar.

Avaliando os números dos caminhões, na tabela 4, temos que para o sistema entrar em regime somente com caminhões de um tipo, como CB 7 tons, seriam necessárias 28 unidades. Para CBT 14 tons, seriam necessárias 11 unidades de caminhões. E, para CBT 18 tons, seriam necessárias 7 unidades para o sistema entrar em regime.

$\mathrm{Na}$ tabela 5 foram coletadas as informações de um determinado dia/horário. Assim, o processo de transporte naquele momento só teria à sua disposição 11 caminhões e teria uma capacidade de transporte de 252,67 tons. Em contrapartida, temos os dados informados na tabela 6 , referente a análise dos caminhões em relação à otimização do processo para atingir sua capacidade plena de 400 tons $/ \mathrm{h}$. Assim, com 17 caminhões à disposição para o transporte de sal, teríamos uma capacidade de transporte de 418,40 tons $/ \mathrm{h}$.

Diante do exposto, relacionando a não produtividade devido a falta de caminhões com a estrutura da empresa, montada e ociosa aguardando o sal, temos o seguinte resultado: capacidade real de 400 tons/h, capacidade utilizada (no caso medido) de 252,67 tons/h temos uma diferença de 147,33 
tons/h que foram deixadas de ser colhidas pela ineficiência na disponibilidade dos caminhões pela empresa terceira. Adotando como base a tonelada de sal a granel vendida a $\mathrm{R} \$ 35,00$ temos os resultados do valor financeiro deixado de ser processado pela ineficiência do transporte do sal, que está representado na tabela 7 .

TABELA 7 - Análise dos gastos diante da ineficiência do transporte de sal.

\begin{tabular}{|c|c|rr|}
\hline \multicolumn{3}{|c|}{ Toneladas } & \multicolumn{2}{c|}{ Valor } \\
\hline 1h & 147,33 & $\mathrm{R} \$$ & $5.156,61$ \\
\hline 1 dia & $1.178,65$ & $\mathrm{R} \$$ & $41.252,91$ \\
\hline 1 mês & $23.573,09$ & $\mathrm{R} \$$ & $825.058,26$ \\
\hline 1 ano & $282.877,12$ & $\mathrm{R} \$$ & $9.900 .699,09$ \\
\hline
\end{tabular}

A tabela 7 reflete uma relação quantitativa dos dados apresentados em relação a sua ineficiência. Podemos destacar principalmente toda a estrutura da empresa estudada à disposição daquele setor de produção, como por exemplo a quantidade de funcionários que foi contratada para processar 400 tons/h de sal, a energia elétrica desperdiçada com equipamentos parados devido a instabilidade de caminhões à disposição, depreciação dos equipamentos, custo fixo aumentado, dentre muitos outros fatores que poderiam ser minimizados somente pelo fato de o transporte não cumprir com a sua eficiência na totalidade.

\section{CONCLUSÕES}

Adotar decisões gerenciais que considerem o fluxo do processo produtivo com determinadas práticas típicas de gestão da capacidade, conforme aqui discutido, podem contribuir para elevar o ganho global da empresa. Uma das alternativas para continuar as discussões pautadas neste artigo, é a de tentar preencher as lacunas que emergiram durante a pesquisa, tais como pesquisas que considerem as implicações e extensão da TOC ao se considerar o fator humano, não só na manufatura como também nas diversas áreas da empresa.

O estudo demonstrou então, que a Teoria das Restrições pode ser utilizada não só para encontrar os gargalos do processo e formas para explorá-lo, mas pode ser base para apoiar a justificativa de uma operação crítica que estava mascarada em meio às diversas operações dentro do processo. Comprovando, com uma análise prévia de resultados financeiros, que as mudanças em um CCR justificam o investimento na contratação de mais caminhões e refletem em um ganho significativo para toda a indústria, como mostra o cálculo da economia mensal de cerca de $\mathrm{R} \$ 825.058,26$ em toneladas de sal que deixaram de ser colhidas, mesmo tendo a estrutura necessária para tal.

Buscou-se então deixar clara a necessidade da existência de um melhor aproveitamento da sua capacidade produtiva, através do apoio do referencial teórico que subsidiou o estudo e a análise dos resultados. O objetivo do estudo foi alcançado, com a indicação da empresa em relação a seu baixo nível de eficiência de capacidade produtiva. Onde, a organização reconhece a importância da melhoria contínua da Gestão da Capacidade Produtiva, fazendo necessário aprofundar o estudo nos pontos levantados na pesquisa.

Numa perspectiva de futuro é preciso que a empresa em questão utilize a gestão da capacidade de produção, como um degrau para busca da melhoria contínua dos procedimentos e dos processos e após implementação de novos processos de gestão, capacitações da equipe, melhoria contínua, dentre outros.

Pelos resultados obtidos, conclui-se que a empresa avaliada utiliza métodos e procedimentos ultrapassados em relação aos conhecimentos das melhores práticas atuais. Faz-se necessário a evolução da gestão da capacidade produtiva e um melhor controle de suas restrições para que a empresa estudada passe a se utilizar do fácil acesso a modernas técnicas e práticas da teoria apresentada, ganhando assim em competitividade. 


\section{REFERÊNCIAS}

[1] ANTUNES, J.; ALVAREZ, R.; KLIPPEL, M.; BORTOLOTTO, P.; DE PELLEGRIN, I. Sistemas de Produção - Sistemas e Práticas para Projeto e Gestão da Produção Enxuta. Porto Alegre: Bookman, 2008.

[2] DAVIS, M.; AQUILANO, N.; CHASE, R. Fundamentos da Administração da Produção. Porto Alegre: Bookman, 2001.

[3] DNPM - DEPARTAMENTO NACIONAL DE PRODUÇÃO MINERAL. Sumário Mineral 2017.

[4] GARDINER, S. C.; BLACKSTONE, J. H.; GARDINER, L. R. The evolution of the Theory of Constraints. Industrial Management. v. 36, n. 3, p. 13-16, Mai/Jun 1994.

[5] GEETHA, S.; VARTAK, M. N., (1994). The three-dimensional bottleneck assignment problem with capacity constraints. European Journal of Operational Research, Vol.73(3), pp.562-568, 1994.

[6] GOldRATT, E. M. COX, J. A meta. São Paulo: Educator, p.366, 2000.

[7] GOLMOHAMMADI, D. A study of scheduling under the theory of constraints. International Journal of Production Economics, July 2015, Vol.165, pp.38-50, 2015.

[8] HEIZER, J.; RENDER, B. Administração de Operações. Rio de Janeiro: LTC, 2001.
[9] HOPP, W. J.; SPEARMAN, M. L. Factory Physics: foundations of manufacturing management. $2^{\underline{a}}$ ed. New York: McGraw-Hill, 2000.

[10] OLIVEIRA, U. R.; MARINS, F. A. S.; ALMEIDA, D. A. Integrando técnicas e procedimentos de gestão de operações: uma aplicação em um banco comercial brasileiro de grande porte. Prod., São Paulo, 2010.

[11] Sindicato das Indústrias de Extração de Sal do Rio Grande do Norte - SIESAL. Anuário de informações 2009.

[12] SLACK, N.; CHAMBERS, S.; JOHNSTON, R. Administração da Produção. 2. ed. São Paulo: Atlas, 2008.

[13] SOUZA, F. B. Do OPT à Teoria das Restrições: mitos e avanços. Revista Produção, São Paulo: maio/ago. 2005, v. 15, n. 2, p. 184-197, 2008.

[14] SOUZA, F. B.; PIRES, S. R. I. Análise e Proposições Sobre o Balanceamento e Uso de Excesso de Capacidade em Recursos Produtivos. Gestão \& Produção. V.6, p. 111-126, ago. 1999.

[15] UMBLE, M. M.; SRIKANTH, M. L. Synchronous Manufacturing: principles for world class excellence. Cincinnati: South-Western, 1995. 


\section{Capítulo 7}

\section{PROPOSTAS DE MELHORIAS COM O USO DA METODOLOGIA SIX SIGMA EM UMA CONFECÇ̃̃O PARANAENSE}

\section{Ana Carolina Kiener}

\section{Cássia Garcia Renó}

\section{Délvio Venanzi}

\section{Haroldo Lhou Hasegawa}

\section{Vidal Dias da Mota Junior}

Resumo: Este projeto tem como intuito analisar os principais problemas de uma empresa do ramo de vestuário utilizando a metodologia Seis Sigma. Esta análise permitiu analisar as localidades da calça que estavam foram dos padrões, obtendo como resultado o quadril e entrepernas. O desdobramento e classificação dos problemas permitiram a tomada de decisões a fim de melhorar não somente a qualidade mas também o processo produtivo sendo que as principais ações resultantes deste estudo de caso foram: Implementação do PDCA e realização de reformas e o concerto e a compra de novas máquinas. Portanto, é possível concluir que a metodologia seis sigma é viável para identificar, analisar e propor melhorias no processo produtivo.

Palavras-Chave: Metodologia Six sigma. Qualidade, produtividade, confecção. 


\section{INTRODUÇÃO}

Atualmente o setor têxtil vem se recuperando no mercado brasileiro. De acordo com a Associação Brasileira da Indústria Têxtil (Abit), este setor fechou, em 2017, com aumento de $3,5 \%$ na produção de vestuário, totalizando 5,9 bilhões de peças. Enquanto que a produção têxtil encerrou 2017 com crescimento de 4,2\%, com 1,77 milhão de toneladas.

Para 2018, a expectativa da Abit é de crescimento de 2,5\% na produção de vestuário, $4 \%$ na produção têxtil e de $5 \%$ no varejo de vestuário. A entidade também estima que o faturamento chegue a $R \$ 152$ bilhões e que sejam investidos $R$ \$ 2,25 milhões.

Conforme Plath, Kachba e Dias (2011) e Cardoso, Biégas e Moro (2009), o mercado têxtil brasileiro tem como requisito de competitividade a qualidade de seus produtos, visto que há uma disputa com o mercado. Logo, há a necessidade de uma melhor gestão dos processos para gerar produtos em conformidade com os padrões estabelecidos. Para alcançar a excelência nos processos de forma estratégica, facilitando assim, a sobrevivência do mercado frente a seus concorrentes, uma das estratégias utilizadas é a aplicação da metodologia seis sigma.

Tal metodologia é bastante utilizada no setor têxtil e pode ser apontado como uma mola impulsionadora para o renascimento deste ramo industrial. Como exemplo, Lima (2016) e Teles (2015) utilizaram algumas ferramentas da qualidade para identificar problemas e propor soluções voltadas à redução de desperdícios, Nogueira (2015) utilizando-se da metodologia DMAIC (Definir, Medir, Analisar, Melhorar e Controlar) conseguiu aumentar a lucratividade da empresa estudada e por fim Dioseghi et al (2015) estudou a redução de estoques e organização de almoxarifado de um empresa de moda adulta, agregando as ferramentas da Qualidade com a metodologia do PDCA (Planejar, fazer, checar e agir).

Partindo destes princípios, o objetivo deste estudo, portanto, foi utilizar a metodologia Seis Sigma como base no DMAIC para o estudo de uma empresa do ramo têxtil. O foco principal foi identificar possíveis problemas desta empresa e priorizá-los. Em seguida, atacar os principais problemas utilizando-se de ferramentas da qualidade, a fim de definir suas causas e propor um plano de melhorias para aperfeiçoar o desempenho da empresa pesquisada.

O estudo foi realizado em uma empresa do ramo de vestuário localizado no interior do estado do Paraná que possui cerca de 250 funcionários e atua no mercado de bottons (calças, shorts e bermudas) no modelo: marca própria e private label, ou seja, neste último fornecer produtos rotulados com marcas de terceiros, sendo a sua produção mensal de aproximadamente 50.000 peças e na sua maioria para o setor private label.

\section{REFERENCIAL TEÓRICO}

\subsection{SEIS SIGMA NO SETOR TÊXTIL}

Conforme dados disponibilizados pela Associação Brasileira da Indústria Têxtil (Abit), o setor fechou em 2017 com incremento de $3,5 \%$ na produção de vestuário, totalizando 5,9 bilhões de peças. Enquanto que a produção têxtil encerra com crescimento de $4,2 \%$, com 1,77 milhão de toneladas. Ainda segundo a Abit, no ano de 2018 espera-se recuperar 20mil vagas de empregos, uma vez que entre os anos de 2015 e 2016 foram fechadas aproximadamente 130 mil vagas. Contudo devido ainda às desconfianças com relação à crise econômica e política que se instalou no Brasil nos últimos anos, as indústrias se mantém conservadoras com relação a investimentos e expansões.

Por outro lado, o mercado brasileiro é bastante exigente, uma vez que exige de seus fabricantes qualidade e competitividade, ou seja, preços atraentes. Dentro deste contexto Plath, Kachba e Dias (2011) e Cardoso, Biégas e Moro (2009), afirmam que uma boa gestão a fim de gerar produtos em conformidade com os padrões estabelecidos e também uso de ferramentas e práticas de modo a diminuir os desperdícios e a ocorrência de produtos não conformes e maximizar o valor são os fatores chaves para garantir a sobrevivência de empresas neste ramo. Dentro deste contexto, o seis sigma (six sigma) é uma alternativa bem vista neste meio.

Para autores como Toledo et al (2014, p. 309) e Carpinetti (2008, p.138), o seis sigma surgiu na Motorola na década de 1980, sua estratégia para melhorar a qualidade dos produtos, foi tentar aumentar o nível de qualidade dos processos produtivos, dessa forma implicaria diretamente na qualidade dos 
produtos finais, sendo que Rotondaro (2006, p. 18) complementa que:

Esta metodologia utiliza ferramentas e métodos estatísticos para definir os problemas e situações a melhorar, medir para obter as informações e os dados, analisar a informação coletada, incorporar e empreender melhorias nos processos e, finalmente, controlar os processos ou produtos existentes.

O seis sigma, basicamente trabalha com o rastreamento e identificação de erros e suas respectivas causas visando em eliminá-los e com isso traz um importante avanço ao sistema operacional à medida que direciona toda a organização ao mesmo fim: atender aos requisitos do cliente. Para tal, devem-se alinhar os processos com rigor analítico somado à execução de uma metodologia de melhoria rigorosa, cujo princípio fundamental é o foco no cliente. Logo, a sua definição abrange desde erros de processos até a satisfação do cliente nos processos aonde como resultado final, visa se a otimização das operações (VENANZI, et al, 2017).

Embora o seis sigma utilize ferramentas já consolidadas há muito tempo em outras aplicações como o do setor de qualidade (mais especificamente em programas de qualidade total), a metodologia a ser seguida é distinta, sendo que para este caso se baseia no método DMAIC (Define, Measure, Analyze, Improve and Control) cujo foco predominante, conforme aponta Jacobs e Chase (2009,p.158) é o "entendimento e alcance do que o cliente quer, porque isso é considerado chave para rentabilidade de um processo de produção". Ainda para Jacobs e Chase (2009, p. 158), o diferencial do seis sigma é a integração das ferramentas da qualidade em um sistema coorporativo, sendo as ferramentas mais comuns: Fluxograma, Diagrama de dispersão, Diagrama de Pareto, Lista de Verificação Diagrama de Causa e Efeito, entre outros.

As ferramentas de qualidade, supracitadas já foi objeto de estudo de Okoshi et al (2006) na primeira metade da década dos anos 2000, em empresas de pequeno e médio porte situadas em cidades do norte do estado do Paraná, no setor de vestuários. Este trabalho permitiu as empresas diagnosticadas a detectarem de modo efetivo os pontos negativos e as principais melhorias a serem efetuadas de modo a agregar valor aos seus modelos de negócios e também ganhar em competitividade.

Atualmente, a metodologia seis sigma é bastante utilizada e difundida para determinar e propor soluções às empresas do ramo dos têxteis. Lima (2016) e Teles (2015) utilizaram algumas ferramentas da qualidade para identificar problemas e propor soluções voltadas à redução de desperdícios. Ambos relatam que a partir da análise deste método, foi possível elaborar planos de ações visando à melhoria contínua dos processos.

Por outro lado, Nogueira (2015), além de visar à redução de desperdícios, também utilizou a metodologia seis sigma para aumentar o faturamento dos negócios da empresa estudada. Sua ideia foi utilizar ferramentas da qualidade juntamente com a metodologia DMAIC (Definir, Medir, Analisar, Melhorar e Controlar) para atingir seu objetivo e dessa forma, a empresa conseguiu aumentar em $37,38 \%$ seu faturamento e reduzir 9\% do estoque de matéria-prima no período de tempo estudado. Estes estudos, mostram que a metodologia quando aplicada de forma efetiva vem a contribuir com o processo de melhoria e agregação de valor ao modelo de negócio.

\section{METODOLOGIA DE PESQUISA}

Para o presente trabalho, foi realizada uma pesquisa de abordagem qualitativa para uma pesquisa exploratória, baseado em uma pesquisa em campo resultando em um estudo de caso, com análise dos resultados in loco estratificada de dados reais de produção e observações realizadas dentro da linha de produção e no setor do controle de qualidade.

Conforme aponta Gil (2008) a pesquisa exploratória a criação de hipóteses de uma problemática, sendo que a abordagem qualitativa permite a interpretação dos fenômenos do ambiente de pesquisa. Os meios de investigação podem ser classificados como pesquisa de campo e pesquisa bibliográfica resultando em um estudo de caso, onde são investigados os fenômenos contemporâneos, inseridos em algum contexto da vida real onde foram utilizadas múltiplas fontes de evidências (YIN, 1994). 


\section{RESULTADOS E DISCUSSÕES}

A pesquisa se iniciou com a elaboração de um roteiro destacando as principais etapas a serem desenvolvidas para a aplicação sensata e lógica das ferramentas a fim de garantir um melhor aproveitamento e interpretação dos resultados. Para tanto, foi elaborado um roteiro metodológico, conforme indica a Figura 1.

FIGURA 1- Roteiro metodológico utilizado para o desenvolvimento do trabalho.

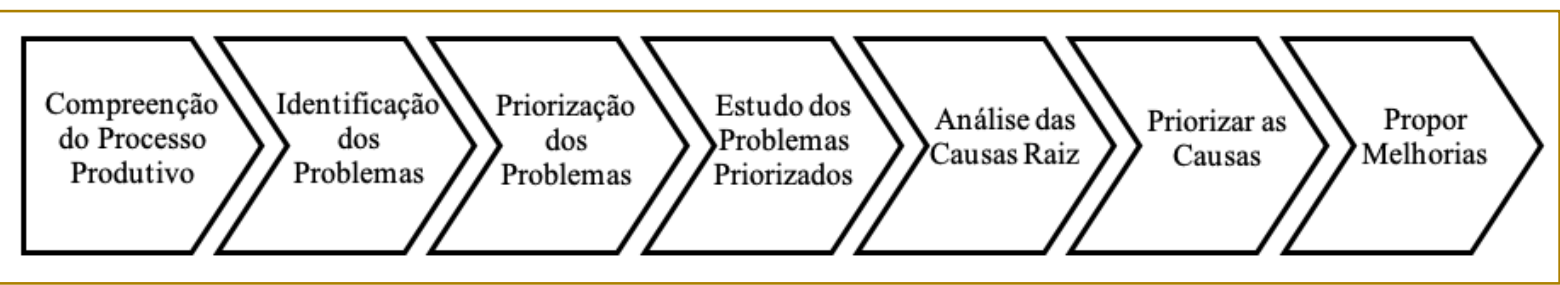

Fonte: Elaboração própria

Para identificar os principais problemas e priorizá-los foram necessárias levantamento de dados do SAC (Serviço de Atendimento ao Cliente), folhas de verificação, análise de probabilidade estatística amostral, alguns indicadores de processo e análise estatística. $\mathrm{Na}$ etapa de análise da causa raiz, empregouse o Diagrama de Causa e Efeito (diagrama de Ishikawa ou espinha de peixe). Enquanto que para priorizá-las, foi utilizado o diagrama de dispersão, novamente o gráfico de Pareto, a FMEA (Análise de Modos de Falhas e Efeitos) e o QFD (Desdobramento da função qualidade). Por fim, utilizou-se o $5 \mathrm{~W} 2 \mathrm{H}$, que é uma ferramenta utilizada para complementar o ciclo de melhoria contínua a fim de auxiliar o plano de ação e que significa em inglês: What, Why, Where, When, Who, How e How Much (O que, Porque, Onde, Quando, Quem, Como e Quanto).

Dentro do "chão de fábrica", ou seja, "in loco" foi coletado informações referentes à identificação dos problemas perante o SAC e o controle de qualidade e o resultado indicou que a falta da padronização das medidas das calças foi a que obteve $33 \%$ das reclamações seguido do atraso nas entregas com 19\%. Neste caso optou-se por analisar mais afundo este primeiro problema, para tanto foi levantado um teste com 30 amostras de um modelo de calça de numeração 42 destinado ao mercado private label, para realizar as medições e constatar a existência ou não e o grau de padronização do produto. A análise dos resultados, também mostrou que os principais pontos com a tolerância fora do padrão estabelecido pela empresa, que é de $\pm 0,5 \mathrm{~cm}$ em sua medida, foram às medidas de: cintura, quadril, joelho, bainha e entrepernas, sendo que a figura 2 ilustra as posições das medidas no vestuário e a tabela 1 os valores dos pontos medidos nas amostras.

FIGURA 2- As medidas de uma calça estudadas no trabalho.

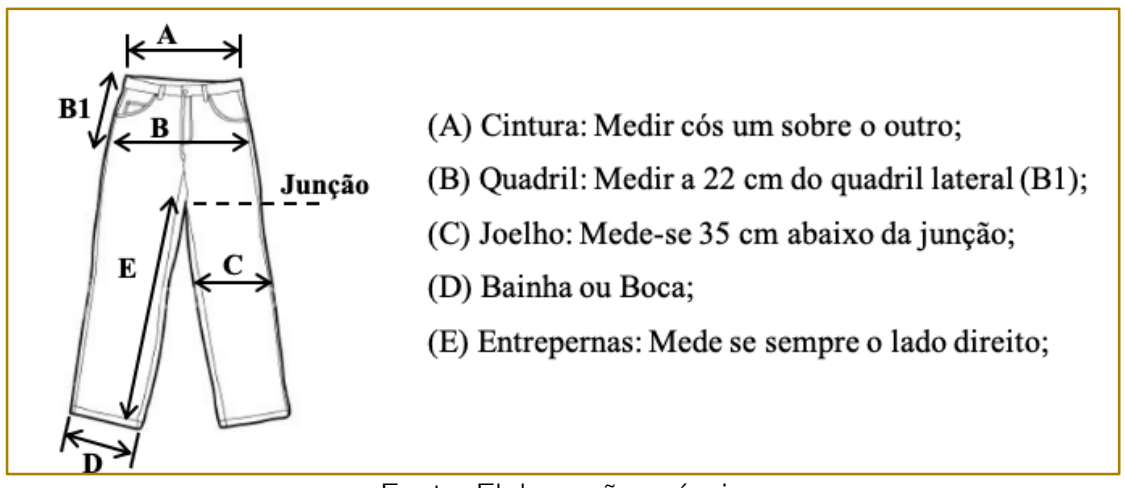

Fonte: Elaboração própria 
TABELA 1- Média simples e desvio padrão das medidas obtidas durante o processo de amostragem e checagem.

\begin{tabular}{|c|c|c|c|c|}
\hline Descrição & Padrão & Média Simples & Amplitude & Desvio Padrão \\
\hline Cintura & $43 \mathrm{~cm}$ & $41,5 \mathrm{~cm}$ & $0,9 \mathrm{~cm}$ & 0,6 \\
\hline Quadril & $54 \mathrm{~cm}$ & $51,6 \mathrm{~cm}$ & $0,9 \mathrm{~cm}$ & 0,8 \\
\hline Joelho & $21 \mathrm{~cm}$ & $19,7 \mathrm{~cm}$ & $1,5 \mathrm{~cm}$ & 1,1 \\
\hline Bainha ou Boca & $20 \mathrm{~cm}$ & $19,0 \mathrm{~cm}$ & $0,5 \mathrm{~cm}$ & 0,6 \\
\hline Entrepernas & $88 \mathrm{~cm}$ & $90,6 \mathrm{~cm}$ & $0,5 \mathrm{~cm}$ & 0,7 \\
\hline
\end{tabular}

Fonte: Elaboração própria

Para a interpretação e estudo dos dados com o uso dos intervalos de confiança em função dos testes de equivalência. Este teste foi realizado utilizando-se do software Minitab ${ }^{\circledR}$ onde foi considerado um intervalo de confiança de 95\% e uma análise bilateral, ou seja, as margens superior e inferior possuem um intervalo de rejeição de $2,5 \%$ cada. A análise final pode ser observada na Tabela 2.

TABELA 2- Resultados das análises dos dados fornecidas pelo Minitab®.

\begin{tabular}{|c|c|c|c|c|c|}
\hline \multirow{2}{*}{ Descrição } & \multirow{2}{*}{ Padrão } & \multirow{2}{*}{ Média Simples } & \multirow{2}{*}{ Desvio Padrão } & \multicolumn{2}{|c|}{ Tolerância } \\
\hline & & & & Mínimo & Máximo \\
\hline Cintura & $43 \mathrm{~cm}$ & $41,5 \mathrm{~cm}$ & 0,6 & $41,8 \mathrm{~cm}$ & $44,2 \mathrm{~cm}$ \\
\hline Quadril & $54 \mathrm{~cm}$ & $51,6 \mathrm{~cm}$ & 0,8 & $52,4 \mathrm{~cm}$ & $55,6 \mathrm{~cm}$ \\
\hline Joelho & $21 \mathrm{~cm}$ & $19,7 \mathrm{~cm}$ & 1,1 & $18,9 \mathrm{~cm}$ & $23,1 \mathrm{~cm}$ \\
\hline Bainha ou Boca & $20 \mathrm{~cm}$ & $19,0 \mathrm{~cm}$ & 0,6 & $18,9 \mathrm{~cm}$ & $21,1 \mathrm{~cm}$ \\
\hline Entrepernas & $88 \mathrm{~cm}$ & $90,6 \mathrm{~cm}$ & 0,7 & $86,6 \mathrm{~cm}$ & $89,4 \mathrm{~cm}$ \\
\hline
\end{tabular}

Fonte: Elaboração própria

Apesar de todas as medidas se encontram fora do padrão, ficou bastante evidente que as medidas de "quadril" e "entrepernas" foram as que apresentaram as maiores discrepâncias fazendo com que estes parâmetros fossem os pontos a serem melhorados. Para a análise detalhada foi escolhida a análise de Pareto, para tanto foi realizado um estudo durante o mês de abril do ano de 2018. Os dados foram tabulados apresentados na tabela 3 e tabela 4 . 
TABELA 3- Análise de Pareto em relação às principais ocorrências de problemas na parte do Quadril.

\begin{tabular}{|c|c|c|c|}
\hline \multicolumn{4}{|c|}{ Estratificação dos Principais Problemas encontrada na parte do "Quadril" } \\
\hline Causas & Total de Peças com problemas & $\%$ Relativa & \% Acumulada \\
\hline Má Qualidade das peças finais & 13.845 & $36,2 \%$ & $36,2 \%$ \\
\hline Tecidos com falha no "urdume"* & 9.685 & $25,3 \%$ & $61,5 \%$ \\
\hline Erro na montagem das peças & 7.480 & $19,6 \%$ & $81,1 \%$ \\
\hline Molde com Defeito & 1.800 & $4,7 \%$ & $85,8 \%$ \\
\hline Falha do Operador & 1.500 & $3,9 \%$ & $89,7 \%$ \\
\hline Má Qualidade da linha de costura & 900 & $2,4 \%$ & $92,1 \%$ \\
\hline Máquina de costura com defeito & 780 & $2,0 \%$ & $94,1 \%$ \\
\hline Outros & 2270 & $5,9 \%$ & $100,0 \%$ \\
\hline
\end{tabular}

*Urdume (ou teia) é o nome que se dá aos fios do tecido no sentido do comprimento;

Fonte: Elaboração própria

TABELA 4- Análise de Pareto em relação às principais ocorrências de problemas na parte da Entreperna.

\begin{tabular}{|c|c|c|c|}
\hline \multicolumn{2}{|c|}{$\begin{array}{c}\text { Estratificação dos Principais Problemas encontrada na parte da "Entreperna" } \\
\text { Causas }\end{array}$} & $\begin{array}{c}\text { Total de Peças com problemas } \\
\text { Mélativa }\end{array}$ & \% Acumulada \\
\hline Má Qualidade das peças finais & 10.335 & $30,1 \%$ & $30,1 \%$ \\
\hline Falha do Operador & 9.800 & $28,5 \%$ & $58,6 \%$ \\
\hline Costura de 2 pesponto\# & 8.150 & $23,7 \%$ & $82,3 \%$ \\
\hline Tecidos com falha na "trama"\$ & 1.800 & $5,2 \%$ & $87,5 \%$ \\
\hline Mesa de Apoio para Trabalho & 980 & $2,8 \%$ & $90,3 \%$ \\
\hline Lavagem com pino no quadril & 820 & $2,4 \%$ & $92,7 \%$ \\
\hline outros & 2.515 & $7,3 \%$ & $100,0 \%$ \\
\hline
\end{tabular}

\#Pesponto é um tipo de costura que forma uma linha de pontos consecutivos nos dois lados do tecido;

\$ Trama é o nome dado aos fios do tecido no sentido transversal da largura

Fonte: Elaboração própria

Com os dados em mãos fica evidente que nos dois casos a "qualidade final das peças", que englobam vários outros problemas são as principais causas dos problemas em ambos os casos. Para tanto a segunda análise foi verificar se existe uma correlação entre os principais problemas que compõem os $80 \%$ da distribuição de Pareto. Chama a atenção ao fato de nos dois casos o quesito de "Má Qualidade das peças finais" estarem destacados como os principais problemas com mais de $30 \%$ do total de peças com algum tipo de divergência.

A fim de descobrir a origem do problema da qualidade não adequada dos produtos, foram desenhados dois diagramas de Ishikawa (causa e efeito ou espinha de peixe), no qual foi realizado um levantamento histórico dos principais motivos de erros de medida em relação aos dois problemas estudados. Tal levantamento foi realizado in loco com o acompanhamento e discussão detalhada a fim de caracterizar de forma mais realistica possível a situação.

Para o problema do "Quadril", foi notado que a alta rotatividade de funcionários e a falta de padronização que leva a montagem errada das peças, os moldes com defeitos são as causas origem do problema de qualidade e ao realizar uma análise mais minuciosa 
descobriu-se que o tecido além do problema da qualidade do urdume existe também o problemas relacionados com a má qualidade da linha de costura do tecido o que leva a problemas de qualidade. A figura 3 ilustra o detalhamento do diagrama de Ishikawa para o "quadril".

FIGURA 3- Diagrama de Ishikawa explorando a causa raiz dos problemas referentes a parte do "Quadril".

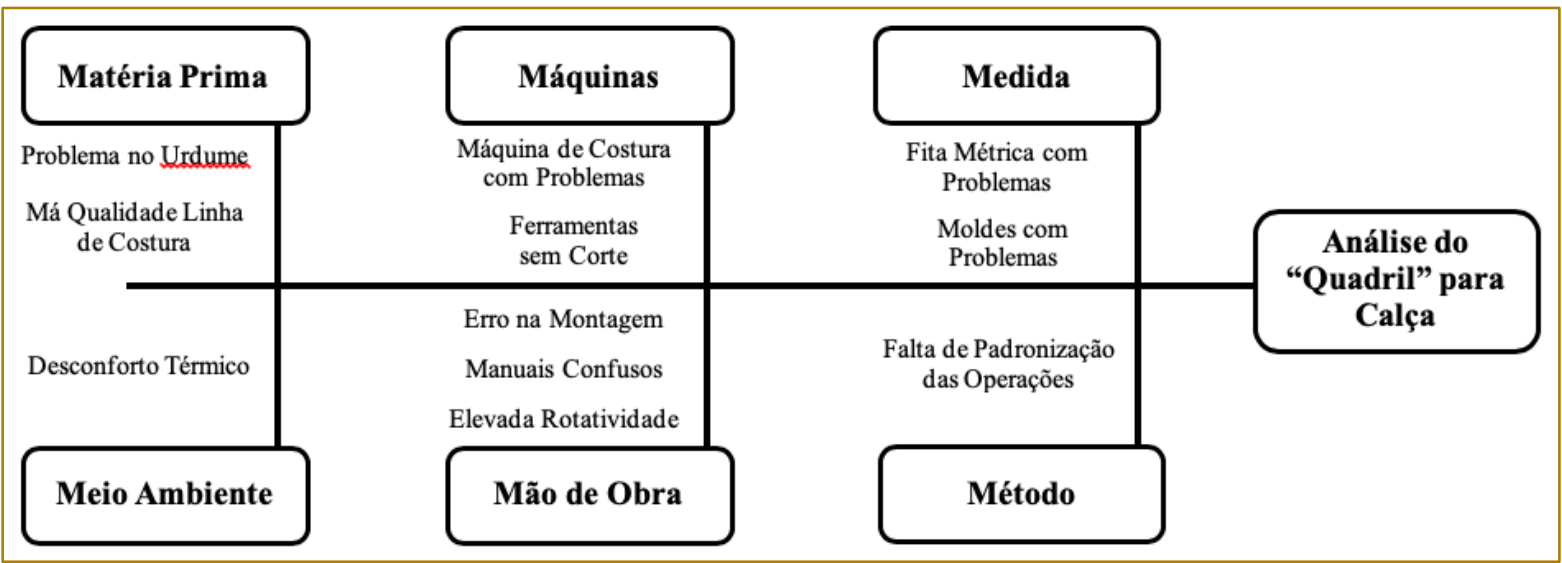

Fonte: Elaboração Própria

Com relação ao problema da "Entrepernas", conforme ilustra o diagrama de Ishikawa da figura 4, analogamente ao resultado do tecido com falhas no urdume, neste caso também ocorre além da falha no trema a má qualidade da costura do tecido, em resumo basicamente os problemas desta parte do vestuário possuem a mesma causa raiz da outra parte estudada. Neste estudo também foi verificado que a mesa de trabalho, conhecido como mesa de apoio, não possuía dimensões adequadas para realização de um trabalho adequado que em partes facilita o processo de correção.

FIGURA 4- Diagrama de Ishikawa explorando a causa raiz dos problemas referentes a parte do "Entrepernas".

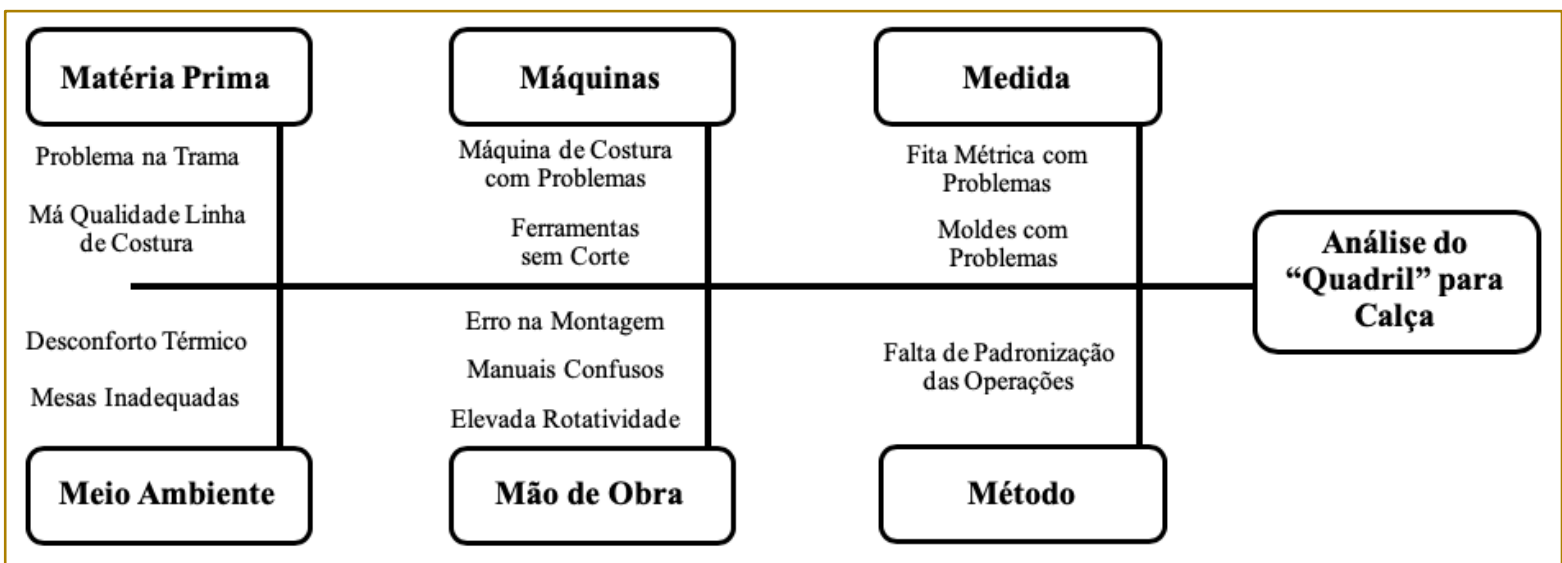

Fonte: Elaboração Própria

Estes levantamentos, principalmente o diagrama de Ishikawa, permitiu elucidar de forma clara a necessidade de intervenções a fim de diminuir a incidência dos problemas referentes a qualidade final das peças, para tanto foi realizado um levantamento minucioso a fim de descobrir o que realmente engloba a falta de qualidade e os resultados mostraram que mais de $50 \%$ dos problemas de qualidade são originados no setor de costura seguido por aproximadamente 35\% dos problemas envolvendo o setor de lavanderia. 
Sendo assim decidiu-se a utilização do FMEA (Análise de Modo de Falha e Efeitos) tendo como intuito definir quais são os efeitos para o cliente relacionados com o problema em questão e quais as causas que precisam de uma ação corretiva imediata. O resultado desta análise está apresentado no modelo disponível no quadro 1.

Quadro 1- Modelo de quadro de FMEA utilizado para o estudo dos defeitos nas calças.

\begin{tabular}{|c|c|c|c|c|c|c|c|c|c|}
\hline \multicolumn{10}{|c|}{ Análise da Calça Jeans Numeração 42} \\
\hline \multirow[b]{2}{*}{ Item } & \multirow[b]{2}{*}{ Descrição } & \multirow[b]{2}{*}{ Função } & \multicolumn{7}{|c|}{ Possíveis Falhas } \\
\hline & & & Modo & D & Efeito & S & Causa(s) & O & RPN \\
\hline \multirow{6}{*}{1} & \multirow{6}{*}{ Quadril } & \multirow{3}{*}{$\begin{array}{l}\text { Dar Caimento a } \\
\text { Peça no } \\
\text { tamanho correto }\end{array}$} & \multirow{6}{*}{$\begin{array}{l}\text { Fora de } \\
\text { Medidas e } \\
\text { Tolerâncias }\end{array}$} & \multirow{6}{*}{2} & $\begin{array}{l}\text { Tamanho fora do } \\
\text { Padrão }\end{array}$ & 9 & Controle Dimensional & 10 & 180 \\
\hline & & & & & Problema no Elastano & 10 & Problema no Urdume & 8 & 160 \\
\hline & & & & & Rasgos & 8 & Problema no Urdume & 8 & 128 \\
\hline & & \multirow{3}{*}{$\begin{array}{l}\text { Estar de acordo } \\
\text { com o tamanho } \\
\text { da Cintura }\end{array}$} & & & Zíper Inadequado & 5 & $\begin{array}{l}\text { Falta de Controle de } \\
\text { Qualidade }\end{array}$ & 10 & 100 \\
\hline & & & & & Peça Enrugada & 6 & Erro de Montagem & 7 & 84 \\
\hline & & & & & Bolso Torto & 4 & Erro de Montagem & 7 & 56 \\
\hline \multirow{6}{*}{2} & \multirow{6}{*}{ Entreperna } & \multirow{3}{*}{$\begin{array}{l}\text { Atender } \\
\text { Comprimento } \\
\text { da Perna }\end{array}$} & \multirow{6}{*}{$\begin{array}{l}\text { Fora de } \\
\text { Medidas e } \\
\text { Tolerâncias }\end{array}$} & \multirow{6}{*}{2} & Peça Descosturada & 10 & Falta de Treinamento & 9 & 180 \\
\hline & & & & & $\begin{array}{l}\text { Aparência não } \\
\text { desejada }\end{array}$ & 8 & Falta de Treinamento & 9 & 144 \\
\hline & & & & & Peça Curta & 7 & $\begin{array}{c}\text { Falta de Controle de } \\
\text { Qualidade }\end{array}$ & 10 & 140 \\
\hline & & \multirow{3}{*}{$\begin{array}{l}\text { Comprimento } \\
\text { dentro das } \\
\text { Especificações }\end{array}$} & & & Peça Franzida & 8 & $\begin{array}{l}\text { Costura de } 2 \\
\text { pesponto }\end{array}$ & 8 & 128 \\
\hline & & & & & Problema no Elastano & 6 & $\begin{array}{c}\text { Falta de Controle de } \\
\text { Qualidade }\end{array}$ & 10 & 120 \\
\hline & & & & & Costura Grossa & 5 & $\begin{array}{c}\text { Costura de } 2 \\
\text { pesponto }\end{array}$ & 8 & 80 \\
\hline
\end{tabular}

Fonte: Elaboração Própria

Logo, é possível concluir que as causas que necessitam de ação corretiva com maior urgência são: Falta de controle da qualidade e tecido com problema no urdume, para o quadril, e Falta de controle de qualidade e de treinamentos aos operadores e a costura com dois pespontos, para a entrepernas. Vale lembra que a classificação e a atribuição dos pontos foram realizadas em conjunto com a alta direção da empresa e os responsáveis dos setores.

Esta análise permitiu a implementação de programas de melhoria contínua na empresa incluindo a agregação de treinamentos, revisão de padrões e manuais assim como procedimentos operacionais e também com os cálculos financeiros e de análise econômica, que por motivos de confidencialidade o balancete completo não pode ser publicado, a empresa decidiu fazer um investimento de mais de vinte mil reais a fim de fazer pequenas reformas e também substituir ou reparar máquinas de costura de modo a diminuir as variações que levam a costura de dois pespontos na entreperna das calças.

\section{CONSIDERAÇÕES FINAIS}

Este estudo teve como intuito analisar uma indústria de confecção e identificar os principais problemas ocorridos durante 0 processo de produção de calça jeans. Para que a empresa possa se posicionar perante ao mercado, assegurando a qualidade de seu produto.

Com base nos resultados obtidos é possível identificar que a empresa possui alguns problemas relevantes para seus clientes, entretanto o principal é a calça fora de tolerância de medidas. Logo, a análise deste estudo foi aprofundada nas medidas 
especificas da peça, com base na tabela padrão.

Dentro das medidas especificadas, foram identificadas com maior número de anomalias as partes do quadril e entrepernas. Assim, o objeto de estudo se voltou especificamente para estas localidades. Após diversas análises, foram encontradas as causas para tais problemas e identificados quais seriam as respectivas ações corretivas.

Sendo assim, julgou-se mais viável a implantação do PDCA e a compra de novas máquinas para diminuir ou sanar os

\section{REFERÊNCIAS}

[1] AGUIAR, S. Integração das Ferramentas da Qualidade ao PDCA e ao Programa Seis Sigma. Nova Lima: INDG Tecnologia e Serviços Ltda., 2006. 234 p.

[2] CARDOSO, P. M. M.; BIÉGAS, S.; MORO, S. R. Qualidade na Indústria de Confecções: Abordagem de Ensino e Prática. Maringá, p. 4, Junho, 2009. Disponível em: <http://www.dep.uem.br/simepro/3

/Artigos/qualidade_industria.pdf>. Acesso em: 28 Out 2017.

[3] CARPINETTI, L. C. R. Gestão da Qualidade: Conceitos e Técnicas. 2 ed São Paulo: Atlas, 2012. 239 p.

[4] COLENGHI, V. M. O \& M e qualidade total: Uma integração Perfeita. Uberaba: V. M. Colenghi, 2007. $272 \mathrm{p}$

[5] DIOSEGHI, C.N et al. Utilização de ferramentas da qualidade para proposta de melhorias no almoxarifado de uma indústria de confecção. Fortaleza, p. 18, Out, 2015. Disponível em: $<\mathrm{http}: / /$ www. abepro.org.br/biblioteca/TN_STP_206_219_27765. pdf>. Acesso em: 28 Out 2017.

[6] GUPTA, P.; SRI A. Seis Sigma: Virtualmente sem estatística. Porto: Vida Econòmica. 2012. 136 p.

[7] JACOBS, R.; CHASE, R.; Administração da Produção e Operações: O essencial. Porto Alegre: Bookman, 2009.

[8] LIMA, L. C. Aplicação das ferramentas da qualidade para solução de problemas no processo produtivo com ênfase nos princípios da produção enxuta. Dourados, p. 85, 2016. Disponível em: <https://dspace.ufgd.edu.br/jspui/bitstream/123456 789/361/1/LARISSALIMA.pdf>. Acesso em: 28 Out 2017

[9] NOGUEIRA, R. R. Análise da implementação de Lean Seis Sigma com foco na problemas de falta de qualidade e costura de 2 pespontos.

A partir destas ações e das análises dos resultados, deduz-se que os demais problemas também serão reduzidos ou eliminados devido suas correlações. Portanto, conclui-se que é viável a aplicação da metodologia baseada no seis sigma para identificar, analisar e propor melhorias cabíveis ao problema levantado, quando há um histórico de dados para correlaciona-lo com os problemas, visto que esta metodologia se baseia em análises estatísticas.

ferramenta DMAIC em uma indústria de fios. Maringá, v.11, n. 1, p. 99, 2015. Disponível em: http://www.dep.uem.br/gdct/index.php/dep_tcc/arti cle/view/73/pdf>. Acesso em: 28 Out 2017.

[10] OKOSHI, C.Y., FRACAROLLI, R.L., ALTOE,E.S.F.M., $\quad$ CARNELOSSI,A.C.N., CARDOZA,E. Aplicação das ferramentas da qualidade em um arranjo produtivo local-indústria de vestuário. In: Encontro nacional de Engenharia de Produção XXX. São Carlos-SP. Anais. Disponível em: $\quad<$ http://www.abepro.org.br /biblioteca/enegep2010_tn_sto_119_779_15571.pdf >. Acesso em: 02 de maio de 2018

[11] PALADINI, E. P. Qualidade total na prática: Implantação e avaliação de sistemas de qualidade total. São Paulo: Atlas, 1994. 214 p.

[12] PLATH, A. M. S.; KACHABA, Y. R.; DIAS, M.C. Gestão da qualidade em empresas de diferentes segmentos do mercado têxtil: Um estudo multicaso. Belo Horizonte, p. 10, Out 2011. Disponível em: <http://www.abepro.org.br/biblioteca/enegep2011 tn_wic_136_866_18032.pdf>. Acesso em: 28 Out 2017.

[13] ROTONDARO, R.G et al. Seis Sigma: Estratégia gerencial para a melhoria de processos, produtos e serviços. São Paulo: Atlas, 2006. 375 p.

[14] RUMSEY, Deborah. Estatística II para leigos. Rio de Janeiro: RJ. Alta Bookes, 2014. 391 p.

[15] SELEME, R.; STADLER, H. Controle da qualidade: as ferramentas essenciais. Curitiba: InterSaberes, 2012

[16] TELES, R. R. Análise de desperdício de matéria-prima no setor de corte em uma Indústria de Confecção: Estudo de caso. Maringá, v.11, n. 1, p. 62, 2015. Disponível em: <http://www.dep.uem.br /gdct/index.php/dep_tcc/article/view/78/pdf>. Acesso em: 28 Out 2017. 
[17] TOLEDO, J. C. et al. Qualidade: Gestão e Métodos. Rio de Janeiro: LTC, 2014. 398 p.

[18] VENANZI .D., SILVA, O.R., FAUSTINO, D.L., HASEGAWA, H.L. Aplicação do lean-six sigma: estudo de caso na empresa xyz. In:
ANDRADE, D.F. Seis Sigma: Coletânia de Artigos Volume I. Belo Horizonte-MG. Editora Poisson, 2017. p.175-187.

[19] YIN, R. K. Case study research, design and methods. 2. ed. London: Sage, 1994. 


\section{Capítulo 8}

\section{DESENVOLVIMENTO DE UM SISTEMA DE CONTROLE DA VELOCIDADE DE UMA MÁQUINA DE ENSAIOS MECANICOS}

\section{Erick Cardoso Costa}

Rodrigo de Carvalho Paes Loureiro

Rodrigo Bíscaro Nogueira

Reinaldo José Tonete

Max Adilson Lima Costa

Resumo: As máquinas de ensaios mecânicos são empregadas para auxiliar na obtenção de características intrínsecas aos materiais de engenharia sob condições de esforços conhecidas. Essa máquina submete um corpo de prova a uma carga de tração, compressão ou flexão mensurando a deformação resultante para quantificar as propriedades mecânicas do material. Essa condição de esforço imposta é promovida por um sistema de movimentação. Para tanto, devido as desconformidades intrínsecas ao sistema, o controle da velocidade real de ensaio deve ser monitorado e corrigido para garantir a confiabilidade e reprodutibilidade dos ensaios. Dessa forma, este trabalho apresenta o desenvolvimento e implementação de um sistema de malha fechada para corrigir a velocidade real de ensaio utilizando uma plataforma de fonte aberta em uma máquina de ensaios mecânicos. Para o projeto da máquina empregou-se a metodologia de Processo de Desenvolvimento Integrado de Produtos para auxiliar na fase de desenvolvimento do conjunto mecânico e eletrônico. Para o sistema de controle da velocidade real de ensaio foi desenvolvido um projeto de software para garantir o funcionamento do sistema de movimentação de acordo com as normas. Para avaliar o desempenho da máquina foram executados testes de deslocamento da plataforma móvel. A validação do sistema de malha fechada foi efetuada através de testes com método convencional de movimentação comparando-o com o método desenvolvido neste trabalho. A máquina apresentou estabilidade e rigidez permitindo efetuar ensaios de tração e compressão. O sistema de controle desempenhou papel fundamental, proporcionando ajuste da velocidade de ensaio e da taxa de deformação mantendo-as próximas aos valores estabelecidos pelas normas vigentes.

Palavras-chave: velocidade de ensaio, taxa de deformação, máquina de ensaios mecânicos, PRODIP, automação e controle. 


\section{INTRODUÇÃO}

No decorrer dos anos, com o intuito de aumentar a confiabilidade e eficiência de projetos estruturais, deu-se maior importância às características dos materiais utilizados como matéria-prima, tanto aqueles já existentes quanto novos. Dentro dessa realidade, para garantir a qualidade e otimizar os projetos e produtos desenvolvidos pela engenharia, aumentou-se às exigências quanto aos testes para avaliar as propriedades e o comportamento mecânico destes materiais (REBOUÇAS, 2007; GARCIA et al., 2013).

A obtenção destas propriedades e comportamento mecânico dos materiais é realizada com 0 auxílio dos ensaios mecânicos que consiste em submeter estruturas a condições de esforços conhecidas (CALLISTER, 2013; BOYCE e DILMORE, 2008). Estes ensaios são empregados com objetivo de avaliar o desempenho mecânico de materiais que constituirão peças estruturais dos mais diversos produtos como máquinas, ferramentas, estruturas de edifícios, dentre outros (GERE, 2003). A partir destes ensaios é possível obter as características intrínsecas aos materiais pela análise da relação entre a tensão gerada e a deformação produzida. Este método possibilita expressar, de forma quantitativa e qualitativa, as propriedades mecânicas necessárias para aplicação, certificação de produtos, controle de qualidade, seleção de materiais, pesquisa e desenvolvimento de novos materiais (SOUZA, 1982; BLANCO, 2006).

Para execução destes testes, geralmente, é utilizada uma máquina de ensaios mecânicos que submete um corpo de prova (amostra com dimensões normatizadas) do material a solicitação mecânica (tração, compressão ou flexão), mensurando a deformação resultante da condição de esforço. A geração de carga é efetuada por um sistema de movimentação que proporciona o deslocamento da plataforma móvel na direção vertical induzindo uma carga axial ao corpo de prova (CP) resultando na deformação deste até sua ruptura (ASKELAND e PHULÉ, 2008; GRUPO CIMM, 2016).

Para gerar esta carga, deve haver um sistema que acione o movimento linear da plataforma móvel. Além disso, as velocidades reais de ensaio devem atender faixas de valores de acordo com o tipo de material a ser analisado, sendo estas estabelecidas por normas técnicas (LEMOS et al., 2013). Dessa forma, o sistema de movimentação deve possibilitar velocidade variável e interagir com uma unidade controladora para que os parâmetros de entrada de ensaio possam ser definidos através de uma interface com o operador, de forma que o ensaio possa ser monitorado concomitante a operação (DE FAVERI, 2015).

O presente trabalho faz parte de um conjunto de projetos que têm por finalidade desenvolver uma máquina de ensaios mecânicos. O desenvolvimento da máquina é extremamente complexo por envolver diversos sistemas responsáveis pelo seu funcionamento, tais como estrutura mecânica, eletrônica envolvida, acessórios e sensores que auxiliam na aquisição dos dados de ensaio, como célula de carga e extensômetro. Devido sua extensão, o desenvolvimento deste projeto foi executado em etapas complementares de acordo com os trabalhos de Costa e Nogueira (2018), Fonseca e Nogueira (2018) e Loureiro (2017).

Neste sentido, este trabalho teve como objetivo desenvolver a estrutura mecânica, o sistema de acionamento e de controle da máquina de ensaios mecânicos. Um diferencial desta máquina é a relação custobenefício, no que concerne à eletromecânica envolvida, uma vez que os componentes usados são de fonte aberta, de baixo custo e atribuem funcionalidade e modularidade ao sistema.

\section{DESENVOLVIMENTO E FABRICAÇÃO DA MÁQUINA DE ENSAIOS MECÂNICOS}

O desenvolvimento de um equipamento envolve diversas áreas de conhecimento da engenharia, principalmente aqueles relacionados ao dimensionamento estrutural, fabricação, eletrônica envolvida, elementos mecânicos, integração de CLP, automação, interação homem-máquina (IHM), dentre outros (BACK et al., 2008; BETRÁN, 2009). Essas variedades de campos tendem a gerar uma barreira para a determinação das possíveis soluções a serem empregadas durante a elaboração do projeto de produto. Para isso, podem ser usadas abordagens metodológicas que auxiliem desde a etapa preliminar à execução, não somente para a escolha de soluções individuais, mas também no que diz respeito à compatibilidade entre os elementos (SBRAVATI et al., 2013; SILVEIRA, 2015). 
Neste contexto, o presente trabalho apresenta os componentes utilizados e os métodos empregados para o desenvolvimento da máquina de ensaios mecânicos. Para tanto, o modelo adotado para este projeto foi o Processo de Desenvolvimento Integrado de Produtos (PRODIP), apresentado por Back et al. (2008), com destaque as três fases iniciais da macrofase intitulada de Processo de Projeto: projeto informacional, projeto conceitual e projeto preliminar.

\subsection{PROJETO INFORMACIONAL}

A máquina de ensaios mecânicos é um equipamento utilizado para submeter uma amostra (CP) de um determinado material a condições de esforços para mensurar a tensão imposta e a deformação gerada no material. Devido à característica de geração de esforço, as propriedades de rigidez e estabilidade da máquina são fatores de suma importância para manter as condições de trabalho de acordo com as especificações. Além da imposição dessa condição de esforço sobre o CP, os dados relativos a taxa de deformação do CP resultante da velocidade real de ensaio deve ser adquirida.
No que concerne a velocidade do ensaio, sabe-se que esta variável é função das características do sistema de geração de carga. Neste sentido, o sistema de acionamento deve apresentar princípios de movimentação que promova o controle da velocidade do ensaio. Os princípios de movimentação amplamente usados são: hidráulico, pneumático e eletromecânico. Comumente são empregados sistemas hidráulicos e eletromecânicos, devido à possibilidade de geração de maiores cargas de ensaio com relativo controle.

Para o desenvolvimento da máquina, a primeira etapa é a definição da função global do equipamento, sendo esta a geração da carga de ensaio e aquisição de dados de deformação. Dessa forma, a determinação da função global permitiu visualizar um cenário mais claro com relação às possíveis soluções. Ademais, é necessária a implementação de um sistema de controle da velocidade real de ensaio por meio da integração entre o extensômetro resistivo e o sistema motriz. A partir disso, foram elencados os principais requisitos de funcionalidade que a máquina deveria atender, conforme apresentado na Tabela 1.

Tabela 1 - Requisitos de funcionalidade.

\begin{tabular}{l} 
REQUISITOS DE FUNCIONALIDADE \\
\hline Rigidez e estabilidade da estrutura mecânica \\
\hline 2 Controle e variação da velocidade de ensaio \\
\hline 3 Sistema de movimentação modular \\
\hline 4 Permitir ensaio de tração e compressão \\
\hline 5 Proporcionar carga suficiente para materiais poliméricos \\
\hline 6 Integração do sistema de movimentação e do extensômetro com malha fechada \\
\hline 7 Controle da taxa de deformação do CP \\
\hline 8 Interface em um microcomputador
\end{tabular}

Fonte: Autor

\subsection{PROJETO CONCEITUAL}

Para elaboração do projeto conceitual, a primeira etapa para o desenvolvimento da máquina foi a concepção da estrutura mecânica de maneira que esta atendesse aos requisitos supracitados. Como requisito, foi necessária a determinação do princípio de movimentação a ser empregado e os respectivos componentes, uma vez que o design deve prever $\mathrm{O}$ alojamento destes elementos. Dentre as possíveis soluções, apesar dos atributos dos sistemas hidráulico e eletromecânico, ambos serem amplamente empregados neste tipo de equipamento e atenderem as principais características, o sistema eletromecânico foi escolhido, pois permitiu elevado controle, modularidade dos componentes mecânicos e eletrônicos e variedade de elementos a serem empregados.

A partir desse ponto, o projeto da máquina foi dividido em dois subgrupos: 1 - estrutura mecânica; e 2 - sistema eletrônico. Esta ramificação proporcionou uma visualização sistemática da função de cada subgrupo e facilitou a determinação dos componentes necessários, sendo estes descritos a seguir. 


\subsubsection{ESTRUTURA MECÂNICA}

Para manter a confiabilidade dos ensaios, o desenvolvimento da máquina deve prever uma estrutura mecânica com rigidez e estabilidade suficiente que impossibilite introduções de erros oriundos de deformações da mesma. Além disso, para possibilitar a execução dos ensaios mecânicos, o sistema está restrito a um grau de liberdade devido à geração de carga ser na direção axial ao CP, ou seja, deslocamento em um único eixo cartesiano. Portanto, foram usados elementos de máquina para conversão do movimento rotativo em linear. Os componentes empregados no subgrupo intitulado de "estrutura mecânica" são mostrados na Tabela 2.

Tabela 2 - Componentes da estrutura mecânica

\begin{tabular}{|c|c|}
\hline \multirow{7}{*}{ 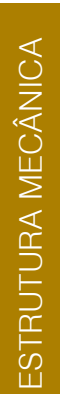 } & Estrutura base \\
\hline & Eixo para deslocamento \\
\hline & Plataformas fixas e móvel \\
\hline & Acoplamento do motor elétrico \\
\hline & Parafuso de potência com castanha \\
\hline & Sistema de transmissão \\
\hline & Rolamentos \\
\hline
\end{tabular}

Fonte: Autor

Após a definição dos principais componentes foi elaborado um modelo CAD 3D da máquina de ensaios mecânicos, conforme Figura 1. A máquina foi fabricada com estrutura metálica de forma a apresentar rigidez e estabilidade. Foi empregado um único parafuso de potência sendo necessário o uso de dois eixos guias verticais. Foram feitas três plataformas fixas, sendo as plataformas 1 e 2 para acoplar o sistema de transmissão e as plataformas 2 e 3 para manter fixos os eixos guias. O motor elétrico foi fixado na parte traseira do equipamento. O sistema de transmissão implementado é constituído de um conjunto pinhão, corrente e coroa agregado a uma castanha rosqueada ao parafuso de potência. A castanha rosqueada conta com dois rolamentos acoplados nas extremidades inferior e superior.

Figura 1 - CAD 3D da máquina de ensaios mecânicos.
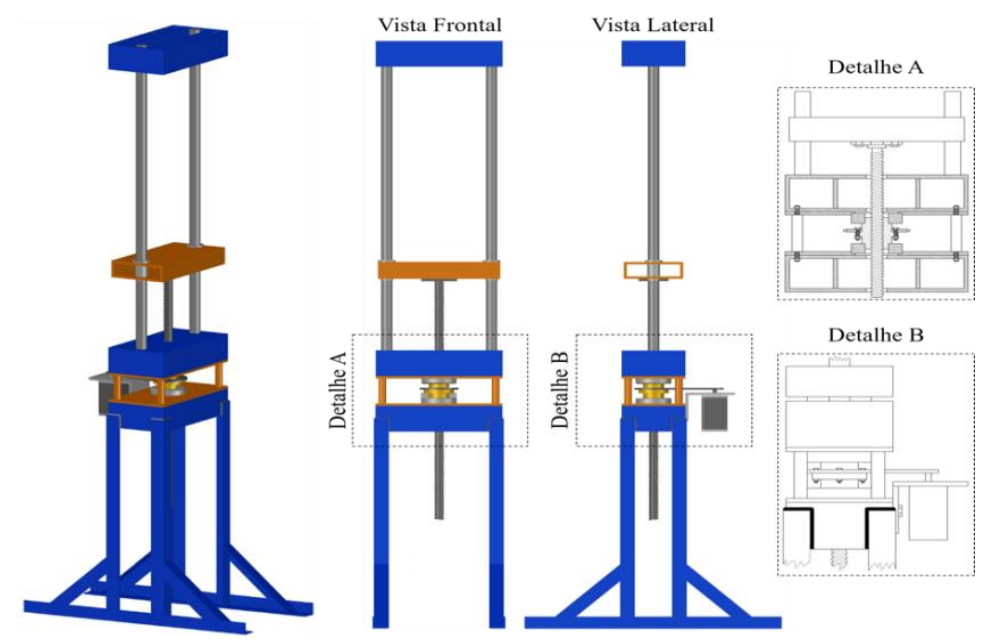

Fonte: Autor 


\subsubsection{SISTEMA ELETRÔNICO}

O sistema eletrônico a ser implementado deve atender aos requisitos de funcionalidade elencados na fase do projeto informacional. Conforme apresentado na Tabela 3, para compor o sistema eletrônico optou-se em utilizar a plataforma de prototipagem arduino modelo UNO, devido este ser de fonte aberta, possibilitar interação com operador por meio de um microcomputador e permitir aquisição de dados.

O componente motriz escolhido foi um motor de passo NEMA 37. Apesar de ser um elemento de acionamento, o mesmo foi alocado neste subgrupo devido às características de controle serem possibilitadas pela eletrônica envolvida. Em decorrência de este motor de passo requerer maior potência para movimentação, empregou-se um driver de controle modelo HY-DIV268N-5A. Para comunicação entre os instrumentos eletrônicos foram utilizados jumpers. Como fonte de alimentação usou-se uma fonte chaveada de $24 \mathrm{~V}$ e $5 \mathrm{~A}$. O sistema de controle foi implementado por meio de um microcomputador agregado a interface de programação do arduino (IDE).

Tabela 3 - Componentes do sistema eletrônico.

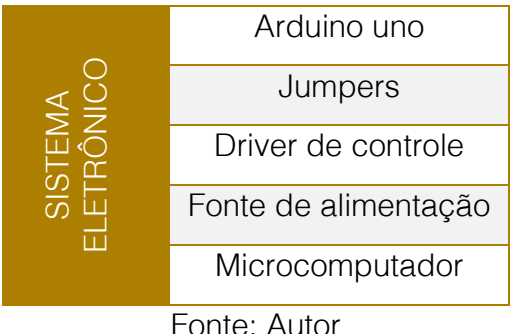

Agregado ao sistema de acionamento, foi implementado um sistema de controle de malha fechada para correção da velocidade real de ensaio por meio da rotação do motor de passo a partir de dados relativos à taxa de deformação, obtidos por um extensômetro resistivo fixado ao $\mathrm{CP}$. A eletrônica envolvida, dedicada a esta função, conta com strain gages acoplados a uma estrutura mecânica que funciona como um extensômetro resistivo, que também foi desenvolvido. Utilizando a ponte de Wheatstone e um amplificador de sinal, o extensômetro foi conectado ao arduino. A Tabela 4 mostra os componentes utilizados no sistema de controle de velocidade de ensaio.

Tabela 4 - Componentes para controle de malha fechada

\begin{tabular}{|c|c|}
\hline \multirow{4}{*}{ 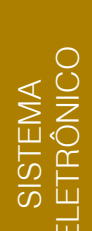 } & Strain gages (BF350-3AA) \\
\hline & Módulo amplificador de sinal HX711 \\
\hline & Resistores de $350 \Omega$ \\
\hline & Botão táctil \\
\hline & Placa protoboard \\
\hline
\end{tabular}

Fonte: Autor

O circuito do sistema eletrônico é ilustrado pela Figura 2. Este esquema foi empregado para atuar como conjunto responsável pelo gerenciamento e comando do sistema motriz da máquina de ensaios mecânicos e auxiliar na aquisição dos dados relativos ao ensaio mecânico, tais como: deformação, velocidade de ensaio e taxa de deformação. 
Figura 2 - Circuito do sistema de controle de velocidade de ensaio

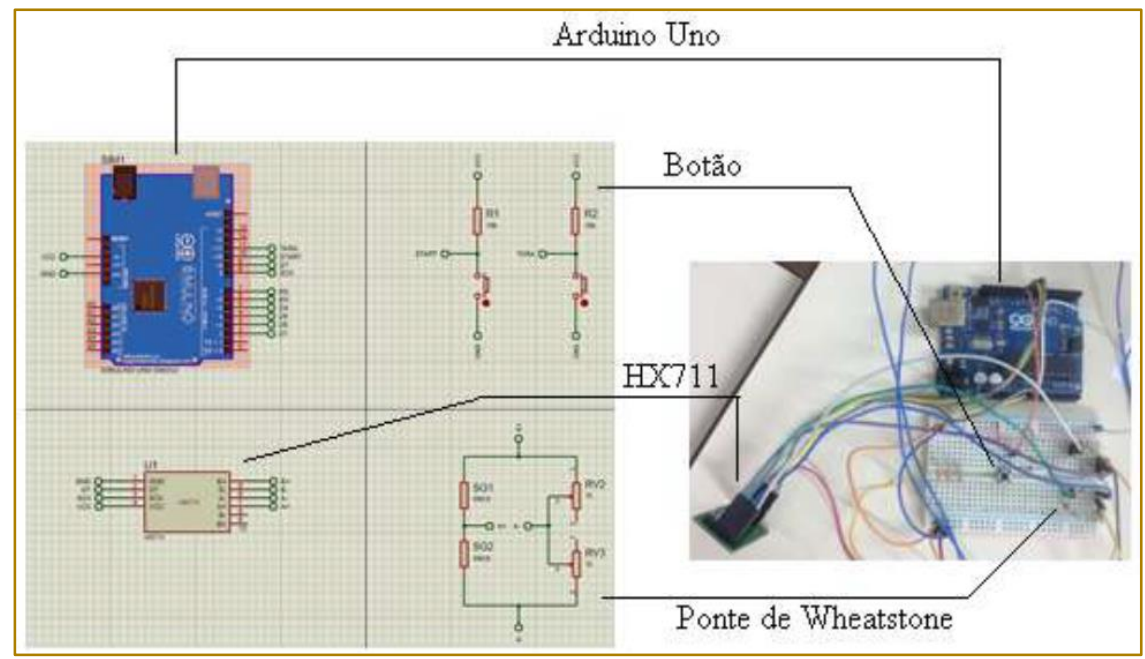

Fonte: Autor

Agregado ao sistema eletrônico, foi implementado um algoritmo capaz de controlar a taxa de deformação do CP. O algoritmo permitiu imprimir na tela do microcomputador os ciclos de aquisição de dados como: variação do tempo, deslocamento, velocidade do ensaio, deformação, taxa de deformação e velocidade de rotação do motor de passo. A Equação 1 foi utilizada no algoritmo para efetuar o controle da velocidade do motor de passo.

$$
n_{\text {motor }}=\frac{i V}{p} \quad \text { Equação } 01
$$

A equação implementada considerou a relação de transmissão (i), o passo do parafuso de potência ( $p$ ) e a velocidade de ensaio $(V)$.

\subsection{PROJETO PRELIMINAR}

A etapa do projeto preliminar consistiu na fabricação, adaptação e montagem dos componentes da máquina de ensaios mecânicos. No que diz respeito à fabricação, foram feitas bases metálicas com cantoneiras de duas polegadas para sustentar a estrutura mecânica de movimentação do equipamento. As plataformas fixas e móvel são de chapa de aço com $10 \mathrm{~mm}$ de espessura, sendo duas fixas para acoplar o sistema motriz (conjunto de transmissão de movimento e motor de passo), uma fixa na parte superior do equipamento e uma plataforma móvel para executar o movimento na direção vertical. Fabricou-se também uma castanha rosqueada para ser agregada ao parafuso de potência. Foram usados dois eixos com buchas de Teflon $\AA$ de forma a restringir 0 movimento da plataforma móvel. A Figura 3 mostra a máquina de ensaios mecânicos. 
Figura 3 - Máquina de ensaios mecânicos desenvolvida

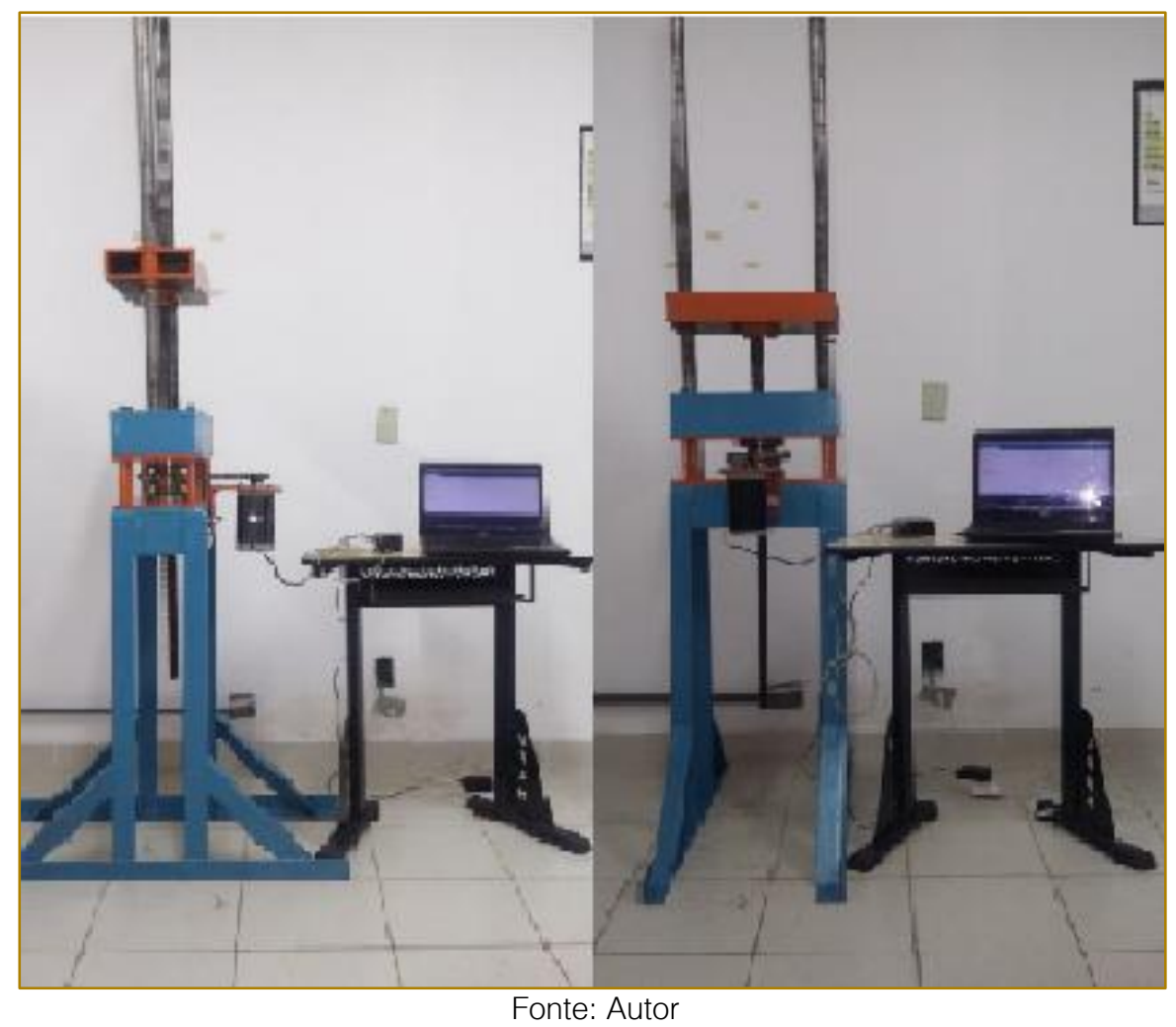

Para o sistema de controle de velocidade de ensaio foi desenvolvido um projeto de software com intuito de garantir o funcionamento do equipamento. Nesta etapa, foi usado a interface de desenvolvimento (IDE) do Arduino para implementar as funções em um fluxo lógico. A Figura 4 ilustra o fluxograma da programação para sistematizar a lógica base de execução do controle do sistema de movimentação.

Inicialmente foram configurados os dispositivos de entrada e saída utilizados no Arduino. Foram configurados nas portas do arduino: motor de passo, módulo amplificador (HX711) e botão de inicialização. $\mathrm{Na}$ sequência, definiu-se a velocidade inicial do motor de passo de acordo com a velocidade de ensaio desejada, sendo adotado $5 \mathrm{~mm} / \mathrm{min}$. Posteriormente, foi definida a inicialização da porta serial para comunicar-se com software ExcelTM.

Após a inicialização da lógica, uma função loop é executada a partir da leitura dos dados de entrada. Concomitante ao início do fluxo de informações analógicas, um evento trigger (intertravamento) é disparado para adquirir os primeiros dados. Em seguida, é realizada a verificação do estado do disparo de início. Caso seja efetuado este início, o software é conduzido à rotina de inicialização das leituras e cálculos, na qual uma flag interna é iniciada.

Esta flag (start_flag) é importante para fechamento dos cálculos e limpeza das variáveis internas. Havendo início da aquisição e leitura de dados, a lógica start_flag ainda é 1 (nível lógico alto), para que seja registrado o tempo de início da aquisição de dados. Caso a start_flag já tenha sido iniciada, o processador já não encontrase no primeiro ciclo de aquisição. Deste modo, o software é encaminhado para as rotinas realizando o cálculo de variação de tempo, deslocamento, velocidade convencional de ensaio, taxa de deformação e obtenção do ajuste da rotação do motor de passo para diferentes tipos de velocidade de ensaio. 
Figura 4 - Fluxograma de software base no Arduino

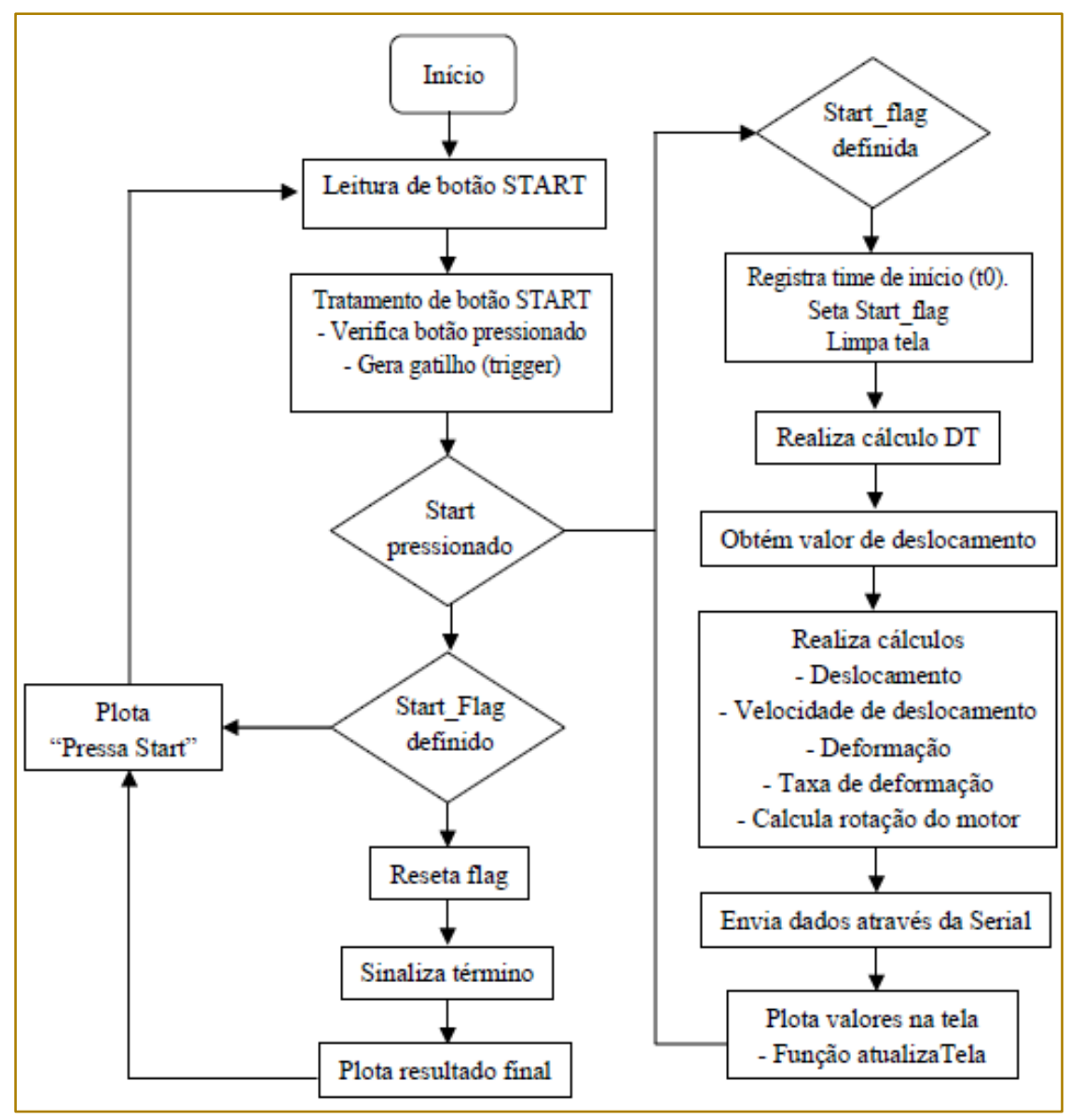

Fonte: Autor

Para sistematizar o fluxo de informações do sistema eletromecânico de geração de carga de ensaio, a Figura 5 mostra esquematicamente a correlação entre os subsistemas 1 e 2 para que a função global definida no projeto informacional seja atingida. A distribuição de informações é iniciada com a entrada de dados em uma IHM que permite a configuração da velocidade de ensaio inicial, bem como da porta serial de comunicação com o ExcelTM. Dado o início do deslocamento, a IDE manda informações digitais para o arduino UNO. Este, alimentado pela porta USB, converte estas informações em sinais analógicos para o driver de controle do sistema motriz, sendo estes alimentados pela fonte chaveada. A partir disso, o motor de passo inicia rotação e, por meio dos elementos de conversão, a plataforma móvel é deslocada com movimento linear.

Por conseguinte, o software é iniciado e a função loop é executada para que os dados oriundos da velocidade de ensaio atual sejam adquiridos, conforme a lógica supracitada pela Figura 5. Neste novo estado, o sistema eletromecânico de geração de carga de ensaio é constantemente alterado com novas informações referentes a rotação do motor de passo, afim de corrigir a velocidade real de ensaio e permanecer na magnitude determinada inicialmente na interface contida no microcomputador. 
Figura 5 - Esquema do sistema eletromecânica de geração de carga de ensaio.

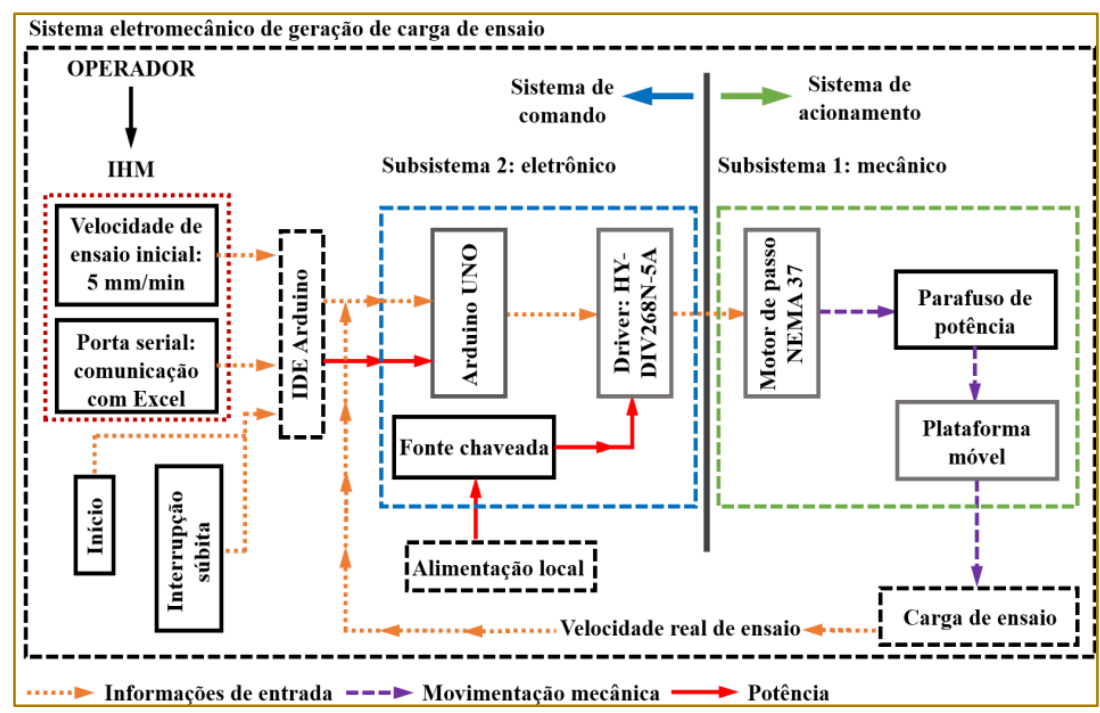

Fonte: Autor

\section{TESTES DA MÁQUINA DE ENSAIOS MECÂNICOS}

Na sequência, são apresentados os principais resultados obtidos nos testes realizados a máquina de ensaios mecânicos desenvolvida neste trabalho e as potencialidades do sistema de controle da velocidade de ensaio que engloba a instrumentação deste equipamento.

\subsection{SISTEMA DE CONTROLE DA MÁQUINA DE ENSAIOS MECÂNICOS}

Com intuito de avaliar o sistema de movimentação, seu respectivo desempenho e evidenciar as principais diferenças entre o método tradicional de movimentação e o desenvolvido neste trabalho foram efetuados testes referentes ao controle da velocidade real de ensaio e da taxa de deformação do CP.

Devido ao sistema de controle ser responsável por gerenciar e processar os dados adquiridos por meio da plataforma arduino, este foi o principal elemento avaliado. Concomitante a esta validação, a verificação da atuação dos elementos que compõem a máquina foi feita a partir dos respectivos desempenhos. No primeiro passo, o deslocamento da plataforma móvel foi iniciado para executar o ensaio mecânico. Em seguida, o motor de passo desloca a plataforma móvel no sentido longitudinal, tracionando o CP. O extensômetro, por estar em contato direto com o $\mathrm{CP}$ que se encontra sob deformação, é excitado por meio do deslocamento das suas hastes móveis, possibilitando a captura de dados referente a deformação. O algoritmo recebe os dados, efetua os cálculos e plota na interface do microcomputador, com auxílio do ExcelTM, as variáveis de velocidade convencional, deslocamento, variação do tempo, taxa de deformação, deformação e controle do motor.

Para a configuração dos testes, estabeleceuse velocidade do ensaio de $5 \mathrm{~mm} / \mathrm{min}$, de acordo com a norma ASTM D638-02a. Os testes foram executados em duas etapas distintas, sendo estas: 1 - com controle da velocidade de deformação do CP; e 2 - sem o ajuste da velocidade de deformação do CP.

Conforme ilustrado pela Figura 6, referente à etapa 1, o comportamento da deformação, com a utilização do sistema de controle, mostrou que o ajuste da velocidade de deformação do $\mathrm{CP}$ atingiu uma maior deformação em um intervalo de tempo relativamente curto. Isto ocorreu porque o sistema proporciona estabilidade à velocidade de deformação, nesse caso específico estabelecida em $5 \mathrm{~mm} / \mathrm{min}$, ocasionando um alongamento mais acelerado do CP. Para o teste executado sem o ajuste da velocidade, a deformação do CP ocorreu de forma mais lenta quando comparado com o ajuste da velocidade de deformação. 
Figura 6 - Gráfico de deformação em função do tempo.

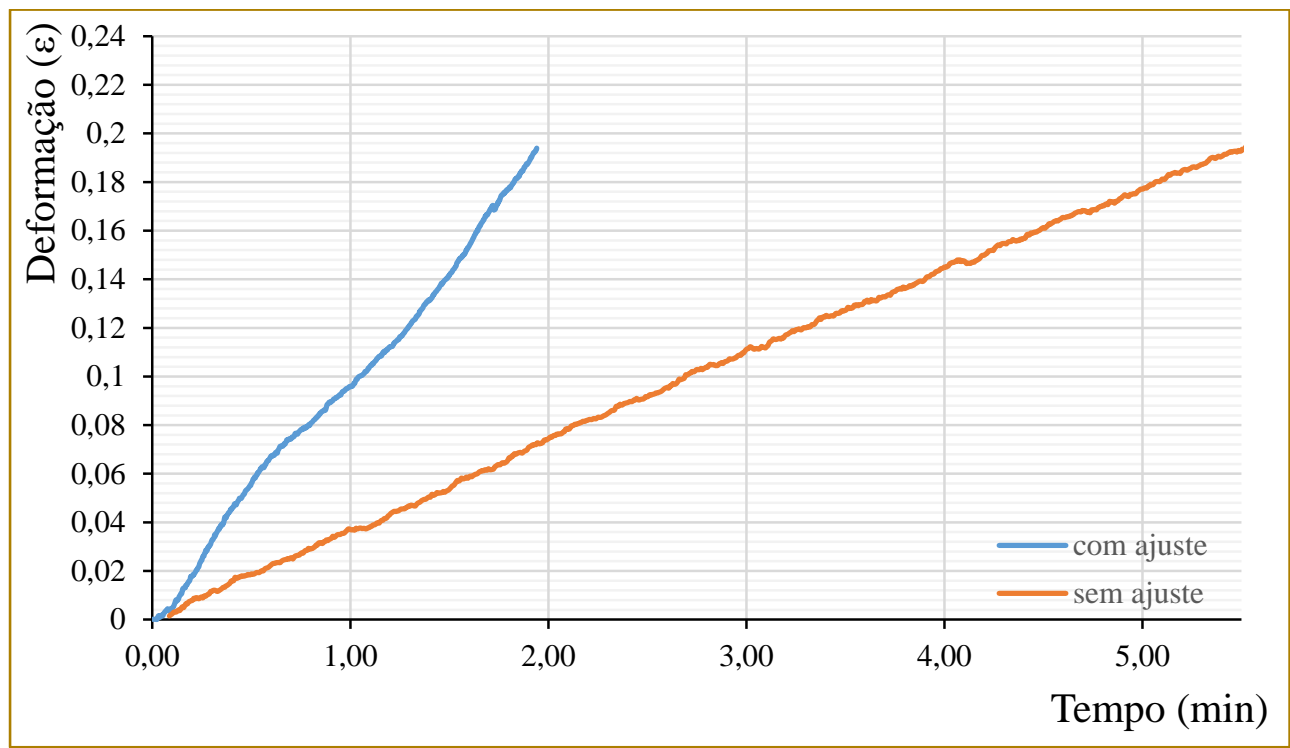

Fonte: Autor

Similar ao teste de velocidade de deformação, a velocidade convencional foi avaliada em duas etapas: 1 - com ajuste; e 2 - sem ajuste. A Figura 7 mostra a velocidade real de ensaio em função do tempo. Para manter o ajuste da velocidade de deformação o algoritmo apresentou um tempo de resposta lento ao tentar manter a velocidade de ensaio constante, conforme pré-estabelecido em 5 $\mathrm{mm} / \mathrm{min}$. Sem o ajuste da velocidade de deformação, a velocidade convencional permaneceu constante, com média de 1,8 $\mathrm{mm} / \mathrm{min}$. Entretanto o teste sobre o $\mathrm{CP}$ foi realizado com velocidade convencional inferior ao proposto pela norma ASTM D63802a (5 mm/min), mostrando grande diferença do sistema com e sem ajuste de velocidade.

Figura 7 - Gráfico de velocidade real de ensaio em função do tempo.

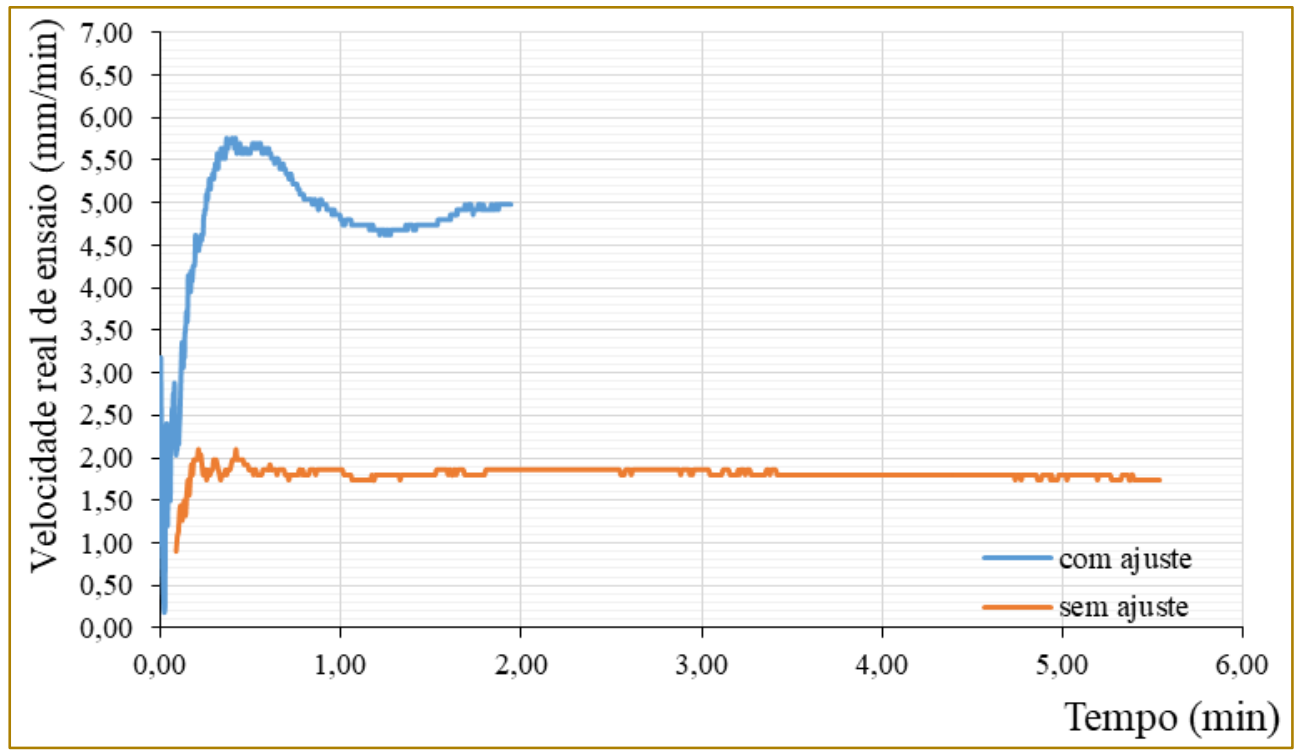

Fonte: Autor

A Figura 8 mostra o ajuste da velocidade aproximando a taxa de deformação para 0,1 min-1, próximo ao especificado pela norma ASTM D638-02a. Entretanto, para a taxa de 
deformação sem o ajuste de velocidade, permaneceu próximo a 0,04 min-1. Isto indica que o desempenho do sistema sem o devido controle de movimentação torna o ensaio desconforme à norma. Além disso, evidencia que a taxa de deformação do CP é influenciada diretamente pelo sistema de acionamento, uma vez que este efetua e submete o CP a uma carga axial.

Figura 8 - Gráfico taxa de deformação em função do tempo.

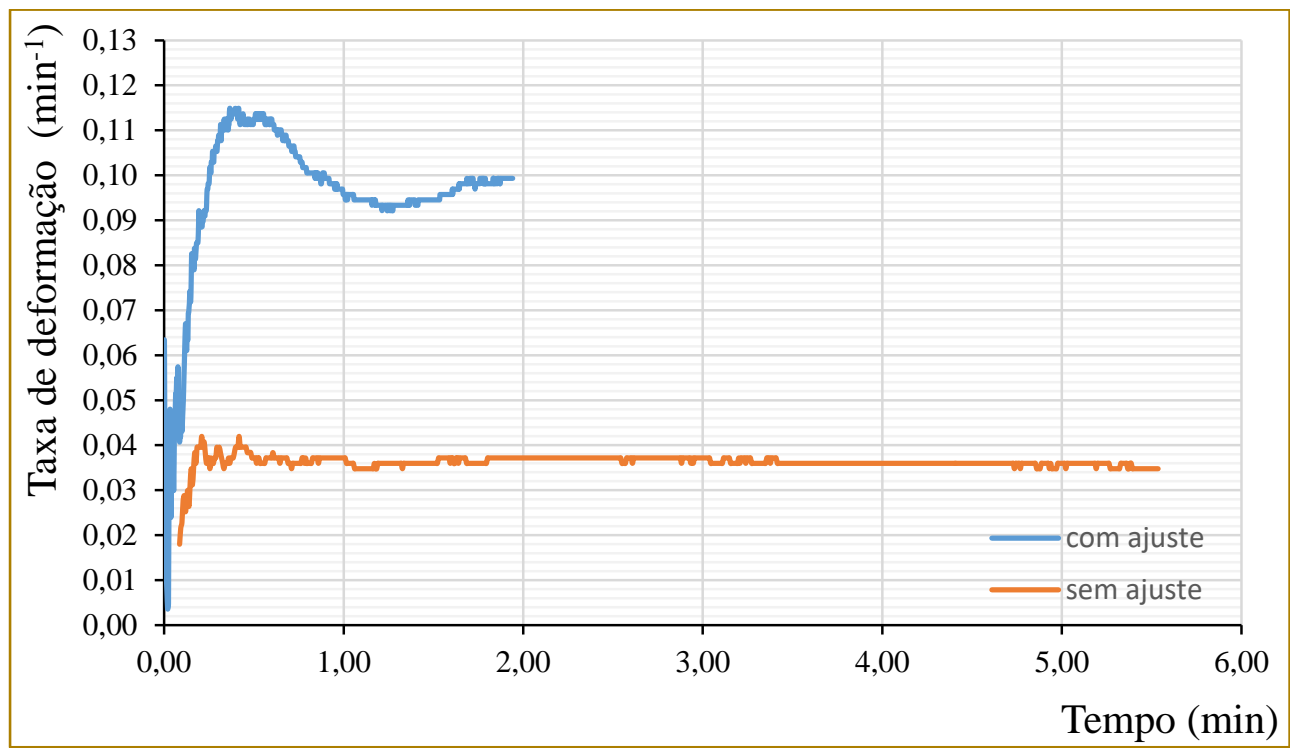

Fonte: Autor

\section{CONCLUSÕES}

Neste trabalho foi possível desenvolver parcialmente uma máquina de ensaios mecânicos enfatizando a estrutura mecânica e eletrônica de acionamento e geração de carga, com sistema de controle e componentes mecânicos de fácil aquisição e de simples fabricação com funcionalidade adequada para esta finalidade.

O desenvolvimento do sistema eletrônico possibilitou efetivo controle da taxa de deformação, velocidade real de ensaio e deformação aplicada ao CP. O desenvolvimento e testes do extensômetro em conjunto com o sistema eletrônico possibilitou controlar a velocidade do motor de passo em função da velocidade de deformação que ocorreu no CP durante o ensaio de tração.

Os resultados proporcionaram analisar o funcionamento da máquina e do sistema de controle através de comparações e análises das discrepâncias entre os parâmetros: velocidade real de ensaio, deformação e taxa de deformação de um ensaio de tração, mensurados diretamente no CP ou apenas pela movimentação da plataforma móvel da máquina.
A utilização do sistema de controle desenvolvido permitiu o ajuste da velocidade real de ensaio e da taxa de deformação mantendo-as próximas aos valores estabelecidos pela norma ASTM D638-02a a partir de dados obtidos pelo extensômetros concomitante ao ensaio de tração.

Apesar da eficiência da máquina, o sistema de controle apresentou tempo de resposta relativamente lento para estabilizar a variação da velocidade de deformação, devido à resposta do motor de passo para controlar as oscilações ocorridas durante o ensaio de tração.

\section{AGRADECIMENTOS}

Os autores agradecem a Fundação de Amparo à Pesquisa do Estado do Amazonas (FAPEAM) pelo auxílio financeiro, ao Programa de Educação Tutorial (PETEngenharias) do Instituto de Ciências Exatas e Tecnologias - UFAM e a todos os membros do Laboratório de Pesquisa do ICET - UFAM que colaboraram para o desenvolvimento deste trabalho. 


\section{REFERÊNCIAS}

[1] ASKELAND, D. R.; PHULÉ, P. P., Ciência e Engenharia dos Materiais. 1 ed.- São Paulo: Cengage Learning, 2008.

[2] BACK, N.; OGLIARI, A.; DIAS, A.; SILVA, J. C. DA. Projeto integrado de produtos. Planejamento, Concepção e Modelagem. São Paulo: Manole, 2008.

[3] BETRÁN, J. A. R. Sistematização do processo de projeto em automação de máquinas cartesianas com acionamento eletromecânico ênfase no posicionamento. Dissertação (Mestrado em Engenharia Mecânica) - Universidade Federal de Santa Catarina, 2009

[4] BLANCO, C., Mecânica dos Materiais. 4aㅗ Edição ed. 2006: Fundação Calouste Gulbenkian.

[5] BOYCE, B. L.; DILMORE, M.F. The dynamic behavior of tough, ultrahigh-strength steels at strain-rates from $0.0002 \mathrm{~s}-1$ to $200 \mathrm{~s}-1$. International Journal oflmpact Engineering, 2008.

[6] CALLISTER, WILLIAM D. JR., Ciência e Engenharia de Materiais: Uma Introdução. 8 ed. Rio de Janeiro: LTC: Livros Técnicos e Científicos Editora S.A, 2013.

[7] COSTA, E. C.; NOGUEIRA, R. B. Máquina universal de ensaios mecânicos: Projeto de acionamento e controle. 1 ed., p. 84. Editora: Novas Edições Acadêmicas, 2018.

[8] DE FAVERI, G. Projeto de máquina de ensaios universais para materiais poliméricos. Dissertação (Mestrado em Ciências e Engenharia dos Materiais) - Universidade do Estado de Santa Catarina, 2015

[9] FONSECA, J. H. L.; NOGUEIRA, R. B. Extensômetro eletromecânico: máquina universal de ensaios mecânicos. 1 ed., p.80. Editora: Novas Edições Acadêmicas, 2018.

[10] GARCIA, A.; SPIM, J. A. E DOS SANTOS, C., A. Ensaios dos Materiais - $2^{\underline{a}}$ ed. - Rio de Janeiro: LTC, 2013.
[11] GERE, J. M. Mecânica dos materiais. São Paulo: Thomson, 2008.

[12] GRUPO CIMM. Máquina de Ensaios Universais. Disponível em: http://www.cimm.com.br/portal/material_didatico/65 45-maquinas-de-ensaio-universais\#.VvOuEE_N3_g. Acessado em 31 de janeiro de 2016.

[13] LEMOS, G. V. B.; VIEIRA, D. M. M.; dos SANTOS, B. P.; HAAG, J.; COSTA, V. M.; MEINHARDT, C. P.; FABRÍCIO, D. A. K.; CHIOSSI, T. P.; STROHAECKER, T. R. O efeito da velocidade de deformação no ensaio de tração em aço SAE 4340. 68음 Congresso anual da ABM. Belo Horizonte, Minas Gerais - BR, 2013.

[14] LOUREIRO, R. C. P. Desenvolvimento de sistema para controle da taxa de deformação no corpo de prova em ensaio de tração. Trabalho de Conclusão de Curso (Graduação em Engenharia de Produção) - Universidade Federal do Amazonas, 2017.

[15] REBOUÇAS, P. P. Desenvolvimento de sistema de aquisição de dados para cálculos automáticos das propriedades mecânicas em um ensaio de tração. VII Congresso Norte Nordeste de Pesquisa e Inovação - CONNEPI. Fortaleza: 2007.

[16] SBRAVATI, B; MORENO, D. A. N.; SCHROETER, R. B. Desenvolvimento de um dispositivo de parada súbita para processos de furação. $7^{\circ}$ Congresso Brasileiro de Engenharia de Fabricação - COBEF, 2013

[17] SILVEIRA, C. A. Integração de um sistema de impressão 3D em uma arquitetura modular de posicionamento cartesiano. Dissertação (Mestrado em Engenharia Mecânica) - Universidade Federal de Santa Catarina, 2015.

[18] SOUZA, S. A. Ensaio mecânicos de materiais metálicos. Fundamentos teóricos e práticos. São Paulo: Edgard Blücher, 1982. 


\section{Capítulo 9}

\section{IMPLEMENTAÇÃO DA IATF 16949:2016 EM UMA INDÚSTRIA DE GRANDE PORTE}

\section{Lorena Santos de Jesus}

Samantha Nascimento Santana

Resumo: As empresas buscam cada vez mais aumentar sua vantagem competitiva promovendo, dentre outros fatores, a maior satisfação dos seus clientes. Para os fornecedores da indústria automotiva possuir um Sistema de Gestão da Qualidade (SGQ), como forma de garantir a conformidade de seus produtos e serviços, é um requisito mandatório que promove a melhoria continua dos seus processos e mantêm o padrão de excelência exigida por este seguimento de mercado. Por este motivo, o presente artigo tem como objetivo descrever por meio da metodologia de estudo de caso a transição do antigo SGQ automotivo baseado na norma ISO/TS 16949:2009 para a IATF 16949:2016 em uma indústria de autopeças multinacional localizada no nordeste brasileiro. Aqui seram destacados as etapas iniciais da transição e a adequação completa da empresa de um dos dez capítulos da norma (de número 6), denominado Planejamento. Como resultados alcançados temos a apresentação da sistemática utilizada para a implementação de uma norma de alta complexidade, como a IATF 16949:2016, em uma indústria com experiência e know how, que pode vir a ser multiplicada por outras empresas que tenham a mesma necessidade de certificação em padrões internacionais.

Palavras-chave: IATF; SGQ; ISO; Automotiva. 


\section{INTRODUÇÃO}

As grandes montadoras do setor automotivo internacional (em especial as alemãs, italianas, francesas e americanas) demandam, entre outras exigências, que os membros da sua cadeia de fornecimento possuam um sistema de gestão da qualidade com base em normas internacionais. Para tanto, estas se uniram para desenvolvimento de um padrão internacional com base nos requisitos da ISO 9001 e seus requisitos específicos, por não acreditarem que apenas a certificação na norma ISO seria suficiente para garantir a qualidade dos seus produtos e serviços providos pelos seus fornecedores.

Para o grupo criado pelas montadoras foi dado o nome de International Automobile Task Force, mais conhecido por IATF, que desenvolveu o padrão internacional para sistema de qualidade automotivo denominado inicialmente como QS-9000 e, atualmente IATF 16949:2016. Esta última foi estruturada de forma similar a ISO, chamada de estrutura de alto nível, o que facilita sua implementação junto as demais normas do sistema de gestão.

Desta forma, o presente artigo tem como objetivo descrever por meio da metodologia de estudo de caso, a transição do antigo SGQ automotivo baseado na norma ISO/TS 16949:2009 para a IATF 16949:2016 em uma indústria de autopeças multinacional localizada no nordeste brasileiro. Aqui são destacadas as etapas iniciais da transição e a adequação completa da empresa do capítulo 6 da norma denominado planejamento.

Os objetivos específicos referem-se à apresentação da etapa inicial da transição bem como sua importância para a empresa alcançar a nova certificação. São descritos também as ações necessárias para que os sub requisitos do capítulo 6 sejam implementados e como este processo aconteceu.

A escolha desta temática adveio da importância da certificação no SGQ automotivo para as empresas que fornecem para este seguimento de mercado, sendo esta mandatória para permanecer na posição de provedora de produtos e serviços. Devido a esta premissa, a implementação da IATF 16949:2016 é um fator crucial para estas organizações, visto que, caso estas não sejam certificadas, serão gerados consideráveis prejuízos financeiros devido à perda de negócios com seus clientes: as montadoras.

\section{REVISÃO DA LITERATURA}

\subsection{SETOR AUTOMOTIVO}

A indústria automobilística mundial é constituída de dois grandes complexos responsáveis pela produção de veículos automotivos: as montadoras e os fornecedores de autopeças (ROTTA e BUENO, 2000).

Sako (2005 apud Sakuramoto e DiSerio 2004, 2005) ao estudar a indústria automobilística explicita que:

A sua atual estrutura, no mundo, apresenta-se globalizada e modularizada. Os fabricantes de equipamentos originais (OEM's), responsáveis pelo desenvolvimento de veículos, transferiu para os fornecedores a responsabilidade da produção de componentes, subsistemas e até mesmo sistemas completos, para serem entregues na linha de montagem da montadora (SAKO 2005 apud SAKURAMOTO E DISERIO, 2004, 2005, p. 10).

Sendo assim, as OEM's, como forma de garantir a qualidade dos seus fornecedores de componentes (também chamados de tier 1), desenvolveu um Sistema de Gestão da Qualidade baseado na ISO 9001 e nos requisitos específicos dos principais OEMs do mundo.

\subsection{ISO 9001}

A organização responsável pelo desenvolvimento de inúmeras normas difundidas em escala mundial é a Organização Internacional de Normatização (ISO). Entre as mais populares é a série ISO 9000 que é a responsável por fornecer as direções de como estabelecer um SGQ. No Brasil as diretrizes dessas normas são regidas pela Associação Brasileira de Normas Técnicas - ABNT (AGUIAR, SALOMON E MELLO, 2015).

As normas ISO passam por constante atualização sendo a mais recente a ISO 90001:2015. De acordo com a ISO 9001: 2015 (2015) a grande mudança da ISO 9001 versão 2015 em detrimento da versão anterior 2008 é o pensamento baseado no risco. O conceito de pensamento baseado no risco estava implícito nas edições desta norma internacional, incluindo, por lidar com ações preventivas para eliminação de não 
conformidades, analisar qualquer não conformidade ocorrida e tomar ações para evitar reincidência.

De acordo com a Associação Brasileira de Normas Técnicas a norma ISO 9001:2015 (2015, p.1) está estruturada em 10 capítulos: 0.Introdução, 1. Escopo, 2.Referências normativas, 3.Termos e definições, 4.Contexto da organização, $5 . \quad$ Liderança, 6. Planejamento, 7. Suporte, 8. Operações, 9. Avaliação de performance, 10. Melhoria. Essa estrutura serviu como base para implantação da IATF 16949:2016 na empresa estudada.

\subsubsection{INTERNATIONAL AUTOMOBILE TASK FORCE (IATF)}

Segundo International Automotive Task Force (2017, p.1, tradução autoras), a IATF "é um grupo ad hoc de montadoras automotivas e suas respectivas associações, formadas para fornecer produtos de qualidade para clientes automotivos em todo o mundo". O Quadro 1 a seguir apresenta os requisitos referente ao capitulo 6 da IATF 16949:2016 que contempla as premissas para o planejamento eficiente da norma, baseado nas obras de Araújo (2017, p. 1 e 2) e da ABNT NR ISO 9001 (2015, p.17 e 18).

\section{QUADRO 1 - Requisitos da IATF 16949:2016. Fonte: ABNT NR ISO 9001 2015, p.17 e 18 e Araújo} (2017, p.1-2).

\section{Riscos e Oportunidades}

\begin{tabular}{|c|c|c|}
\hline \multicolumn{3}{|c|}{ Riscos e Oportunidades } \\
\hline 6.1 .1 & $\begin{array}{l}\text { Quando do planejamento do Sistema de Gestão da Qualidade, a organização deve } \\
\text { considerar questões referenciadas em } 4.1 \text { e os requisitos referenciados em } 4.2 \text { e } \\
\text { determinar os riscos e oportunidades que precisam ser abordados para: a) dar } \\
\text { segurança para que o Sistema de Gestão da Qualidade, possa atingir os resultados } \\
\text { esperados; b) aumentar os efeitos desejáveis; c) prevenir ou reduzir efeitos } \\
\text { indesejados; d) alcançar melhoria. }\end{array}$ & Item novo \\
\hline 6.1 .2 & $\begin{array}{l}\text { A organização deve planejar: a) ações para abordar os riscos e oportunidades; b) } \\
\text { como: 1) integrar e implementar ações em seus processos do Sistema de Gestão da } \\
\text { Qualidade; 2) avaliar a eficácia dessas ações. Ações tomadas para abordar os } \\
\text { riscos e oportunidades, devem ser proporcionais ao impacto potencial sobre a } \\
\text { conformidade de produtos e serviços. }\end{array}$ & Item novo \\
\hline 6.1.2.1 & $\begin{array}{l}\text { A organização deve incluir na sua análise de risco, no mínimo, as lições aprendidas } \\
\text { com o recall de produto, auditorias de produto, reparos e retornos de campo, } \\
\text { reclamações, sucata e retrabalho. A organização deve reter informações } \\
\text { documentadas como evidência dos resultados da análise de risco }\end{array}$ & $\begin{array}{c}\text { Item } \\
\text { modificado }\end{array}$ \\
\hline \multicolumn{3}{|c|}{ Ações preventivas } \\
\hline 6.1 .2 .2 & $\begin{array}{l}\text { A organização deve determinar e implementar ações para eliminar as causas de não } \\
\text { conformidades potenciais, a fim de evitar a sua ocorrência. As ações preventivas } \\
\text { devem ser apropriadas à severidade dos problemas potenciais. Araújo }(2017, \text { p.2) }\end{array}$ & $\begin{array}{c}\text { Item } \\
\text { modificado }\end{array}$ \\
\hline \multicolumn{3}{|c|}{ Planos de contingência } \\
\hline 6.1.2.3 & $\begin{array}{l}\text { A organização deve: a) identificar e avaliar os riscos internos e externos para todos } \\
\text { os processos de manufatura e equipamentos de infraestrutura essenciais para } \\
\text { manter as saídas da produção e assegurar que os requisitos do cliente sejam } \\
\text { atendidos; b) definir planos de contingência de acordo com o risco e o impacto ao } \\
\text { cliente; c) preparar planos de contingência para continuidade do fornecimento em } \\
\text { caso de qualquer um dos seguintes eventos: falhas em equipamentos chave; } \\
\text { interrupção dos produtos, processos e serviços providos externamente; desastres } \\
\text { naturais recorrentes; fogo; interrupções das utilidades; falta de mão de obra; ou } \\
\text { rupturas na infraestrutura; d) incluir, como um suplemento para os planos de } \\
\text { contingência, um processo de notificação ao cliente e outras partes interessadas da } \\
\text { extensão e da duração de qualquer situação que impacte as operações do cliente; } \\
\text { e) testar periodicamente os planos de contingência em relação a sua eficácia (por } \\
\text { exemplo, simulações, conforme apropriado); f) conduzir análise crítica do plano de } \\
\text { contingência (no mínimo anualmente) usando uma equipe multidisciplinar incluindo } \\
\text { a alta direção e atualizar conforme necessário; g) documentar os planos de } \\
\text { contingência e reter informações documentadas descrevendo quaisquer revisões, } \\
\text { incluindo a(o) pessoa(l) que autorizou a(s) mudança(s). }\end{array}$ & $\begin{array}{c}\text { Item } \\
\text { modificado }\end{array}$ \\
\hline
\end{tabular}


QUADRO 1 - Requisitos da IATF 16949:2016. Fonte: ABNT NR ISO 9001 2015, p.17 e 18 e Araújo (2017, p.1-2). (continuação)

\begin{tabular}{|c|c|c|}
\hline \multicolumn{3}{|c|}{ Objetivos da qualidade e o planejamento para alcançá-los } \\
\hline 6.2 .1 & $\begin{array}{l}\text { A organização deve estabelecer objetivos da qualidade nas funções, níveis e } \\
\text { processos pertinentes necessários para o sistema de gestão da qualidade. Os } \\
\text { objetivos da qualidade devem ser: a) coerentes com a política da qualidade; b) } \\
\text { mensuráveis; c) levar em conta requisitos aplicáveis; d) pertinentes para a } \\
\text { conformidade de produtos e serviços e para aumentar a satisfação dos clientes; e) } \\
\text { ser monitorados; f) comunicados; g) atualizados como apropriados. A organização } \\
\text { deve manter a informação documentada sobre os objetivos da qualidade. }\end{array}$ & $\begin{array}{l}\text { Item não } \\
\text { modificado }\end{array}$ \\
\hline 6.2 .2 & $\begin{array}{l}\text { Ao planejar como alcançar seus objetivos da qualidade, a organização deve } \\
\text { determinar: a) O que será feito; b) quais recursos serão requeridos; c) Quem será } \\
\text { responsável; d) quando isso será concluído; e) como os resultados serão avaliados. }\end{array}$ & $\begin{array}{c}\text { Item } \\
\text { modificado }\end{array}$ \\
\hline 6.2.2.1 & $\begin{array}{l}\text { A alta direção deve assegurar que os objetivos da qualidade para atender os } \\
\text { requisitos dos clientes estejam definidos, estabelecidos e mantidos para funções, } \\
\text { processos e níveis relevantes por toda a organização. }\end{array}$ & Item novo \\
\hline \multicolumn{3}{|c|}{ Planejamento de mudanças } \\
\hline 6.3 & $\begin{array}{c}\text { Quando a organização determina a necessidade de mudanças no sistema de } \\
\text { gestão de qualidade, as mudanças devem ser realizadas de maneira projetada e } \\
\text { sistemática. A organização deve considerar: a) o propósito das mudanças e suas } \\
\text { potenciais consequências; b) a integridade do sistema de gestão de qualidade; c) a } \\
\text { disponibilidade de recursos; d) a alocação ou realocação de responsabilidades e } \\
\text { autoridades. }\end{array}$ & Item novo \\
\hline
\end{tabular}

\subsubsection{TRANSIÇÃO ISO/TS 16949 PARA IATF 16949:2016}

Segundo a IATF (2017, tradução autoras) a ISO/TS 16949 é uma especificação técnica para o sistema de gestão da qualidade no setor automotivo que foi inicialmente desenvolvido em 1999 pelo o IATF em conjunto com a Comité técnico ISO para gestão da qualidade, ISO/TC 176. Desde então, esta vem crescendo se tornando uma das normas internacionais mais utilizadas na indústria automotiva, que objetiva harmonizar diferentes avaliações e sistemas de certificação dentro da cadeia de fornecimento automotiva global.

Ainda segundo esta fonte, em outubro de 2016 a IATF 16949:2016 foi publicada e substituiu a ISO/TS 16949, definindo os requisitos para Sistema de Gestão da Qualidade para organizações da indústria automotiva. Este está alinhado e faz referência a mais recente versão da norma ISO de Sistema de Gestão da qualidade, ISO 9001:2015 a qual a IATF 16949:2016 respeita sua estrutura e seus requisitos. "A IATF 16949:2016 não é uma norma de sistemas da qualidade isolada, mas sim complementa, como um suplemento, a ISO 9001:2015" (IATF, 2017, tradução autoras).

\subsubsection{PLANEJAMENTO - CAPÍTULO 6}

O capítulo 6 da ISO 9001:2015 tem entre suas principais novidades a necessidade de abordar os riscos e oportunidades, para que o SGQ possa alcançar seus resultados pretendidos; aumentar efeitos desejáveis; mitigar, os efeitos indesejáveis; e alcançar melhoria.

Uma das formas de mitigar os riscos que é mencionada pelo SGQ é através dos Planos de Contingência. Dessa forma, a organização deve:

Preparar planos de contingência para fornecimento continuo caso qualquer um dos eventos seguintes ocorra: equipamento chave; interrupção de fornecimento de fontes externas de produtos, processos e serviços, desastres naturais recorrentes, fogo, interrupção de utilidades, falta de mão de obra ou rupturas de infraestruturas (FISCHER,2017,p.5).

Segundo a BSI group (2015), definir objetivos de qualidade mensuráveis é um dos elementos chaves da norma e presente no capítulo. "Os objetivos de qualidade devem ser consistentes com a política de qualidade, pertinente para a conformidade de produtos e serviços, bem como melhorar a satisfação do cliente" (BSI GROUP, 2015, p.16). 
Além disso, no capítulo sobre planejamento é preciso identificar as potenciais consequências de alterações no SGQ, determinar quem estará envolvido, quando as mudanças irão acontecer e quais recursos precisam ser alocados (BSI GROUP, 2015).

\section{METODOLOGIA}

No desenvolvimento deste projeto a técnica utilizada é a do estudo de caso que segundo Yin (2001 apud Oliveira 2011, p.27) é caracterizado pelo "estudo profundo e exaustivo dos fatos objetos de investigação, permitindo um amplo e pormenorizado conhecimento da realidade e dos fenômenos pesquisados".

De acordo com Triviños (1987 apud Oliveira 2011, p.28) o estudo de caso é "uma categoria de pesquisa cujo objeto é uma unidade que se analisa profundamente". Nesse sentido, Yin (2001, p.31 apud Oliveira 2011, p.27) evidencia que a essência de um estudo de caso está relacionada ao esclarecimento de "uma decisão ou um conjunto de decisões: o motivo pelo qual foram tomadas, como foram implementadas e com quais resultados".

O ponto forte dos estudos de casos, segundo Hartley (1994 apud Oliveira 2011, p.28) "reside em sua capacidade de explorar processos sociais à medida que eles se desenrolam nas organizações, permitindo uma análise processual, contextual e longitudinal das várias ações e significados que se manifestam e são construídas dentro delas".

Quanto ao objetivo da pesquisa o artigo pode ser classificado como descritivo que de acordo com Gil (1999 apud Oliveira 2011, p.21) têm como finalidade principal "a descrição das características de determinada população ou fenômeno, ou o estabelecimento de relações entre variáveis". Neste projeto será descrito a etapa 6 da norma da IATF 16949:2016 que está relacionada ao planejamento do processo de implantação da norma.

No que se refere a coleta de dados foi utilizada a observação que de acordo com Marconi \& Lakatos (1996) e Selltiz et al. (1965) apud Oliveira (2011, p.38) pode ser classificada segundo "os meios utilizados: assistemática e sistemática; a participação do observador: não-participante e participante; o número de observações: individual e em equipe e o lugar onde se realiza: na vida real e em laboratório".

Nesta pesquisa a observação é classificada quanto à participação do observador na qual o mesmo se envolve com o grupo, transformando-se em um de seus membros, consequentemente fazendo parte do objeto de pesquisa e é realizada na vida real na qual os dados são obtidos à medida que o sistema é implementado ( MARCONI \& LAKATOS, 1996 apud OLIVEIRA 2011).

\section{RESULTADOS E DISCUSSÃO \\ 4.1 ESTUDO DE CASO - A EMPRESA}

A organização estudada é de capital fechado e pertencente ao seguimento automotivo, sendo classificada como de grande porte e localizada no nordeste brasileiro. Reconhecida pela qualidade em seus produtos e serviços, está é certificada nas normas de qualidade ISO/TS 16949 e ISO 9001, bem como nas normas de meio ambiente, ISO 14001, e de saúde ocupacional OHSAS 18001.

A principal atividade da unidade estudada é relacionada à fabricação e desenvolvimento de autopeças para o mercado de reposição e fornecimento direto (tier 1) para algumas montadoras (OEM). Sendo assim, esta necessita manter a certificação no SGQ automotivo (antes ISO/TS 16949:2009 e agora IATF 16949:2016), para continuar a prover para este seguimento de mercado, já que a certificação é uma exigência para toda a cadeia de fornecedores automotivos.

\subsubsection{ETAPA INICIAL DA IMPLEMENTAÇÃO DO SGQ AUTOMOTIVO}

Devido a estrutura e conhecimento organizacional da empresa adotada no presente estudo de caso quanto aos processos de migração entre normas SGQ, foi realizada, inicialmente, um treinamento sobre a norma IATF 16949:2016 para todos os "colaboradores chave" da organização, que são os profissionais responsáveis por implementar as mudanças da norma dentro da empresa. São eles os donos dos processos (gestores de departamento, incluindo o diretor da planta), supervisores, engenheiros e planejadores de qualidade, manufatura e manutenção. Neste treinamento foram explicados todos os requisitos da norma associando-os sempre com o dia-a-dia 
industrial. Este serviu também como uma análise inicial dos gaps entre a nova norma e as adaptações necessárias para atende-la.

Após esta etapa, a empresa contratou uma consultoria externa renomada para levantamento de gaps da organização em relação à nova norma do Sistema de Gestão da Qualidade. Esta análise foi realizada em formato de uma Auditoria de Sistema com base na norma IATF 169494:2016.

Com o término da "auditoria", foram propostas algumas ações pela consultoria para a adequação dos pontos identificados os quais foram discutidos e consolidados com a área de planejamento de segurança da qualidade da empresa, definindo assim um plano de ação e um cronograma macro para transição. O resultado da análise de gaps foi apresentado em reunião de análise crítica com a alta gestão, que validou o planejamento definido.

Uma das primeiras ações necessárias no plano consistiu na implementação do capítulo 6 da norma na organização, visto que uma das mudanças mais discrepantes em relação a norma antiga se encontram neste requisito.

\subsection{IMPLEMENTAÇÃO DO CAPÍTULO 6 - PLANEJAMENTO}

\subsubsection{RISCOS, OPORTUNIDADES E PLANEJAMENTO DAS MUDANÇAS}

Os requisitos 6.1.1, 6.1.2 e 6.1.2.1, apresentados no Quadro 1, estão relacionados a determinação de ações para mitigar os riscos e aumentar as oportunidades dos processos do sistema da qualidade da organização. Essa avaliação já era realizada nos processos produtivos (manufatura) e o de logística (física e planejamento) no qual a metodologia P-FMEA se encontrava estabelecida na organização.

Para os processos de suporte (referentes as atividades dos departamentos de qualidade, controladoria, recursos humanos, segurança, meio ambiente, manutenção, etc.) e alta direção foi determinado, como forma de atendimento desses itens a adoção de uma Matriz de Riscos e Oportunidades, apresentado na Figura 01.

FIGURA 01- Matriz de avaliação de riscos e oportunidades.

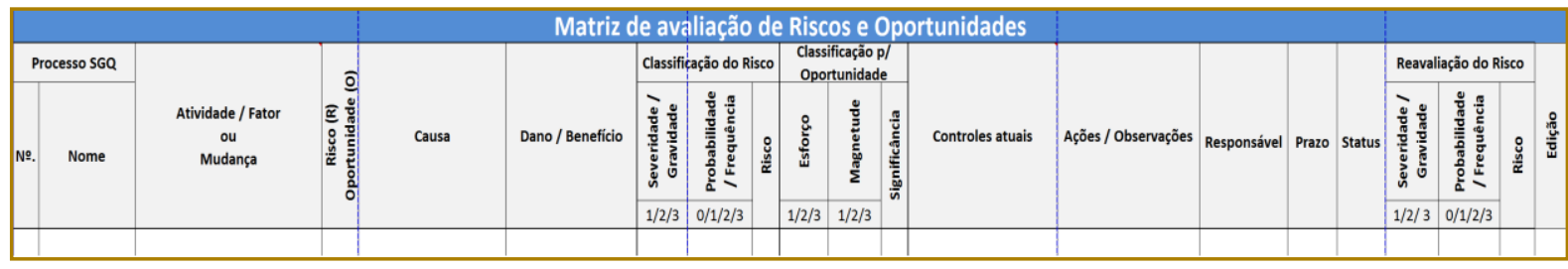

Fonte: A empresa (2017)

Para a utilização da matriz, foram realizadas reuniões entre os donos de processos e o planejador da qualidade responsável pela moderação das avaliações de riscos e oportunidades possibilitando uma visão mais abrangente quanto seus referidos processos. Como resultado de cada uma das análises foi a definição de ações para mitigar eliminar risco e alcançar as oportunidades com base nos critérios previamente estabelecidos.

A matriz se assemelha com a metodologia FMEA, onde são adotados critérios com base em pontuações para os riscos (severidade $x$ frequência) para determinar para qual deste seria necessário adotar ações de mitigação ou, no caso das oportunidades (esforço $x$ magnitude), determinar a significância da oportunidade para verificar se para estas serão definidas ações para alcança-las ou não.

\subsubsection{AÇÕES PREVENTIVAS}

Em relação ao item 6.1.2.2, apresentado no Quadro 1, não ocorreram mudanças significativas em relação à antiga versão da norma. A única modificação realizada é referente ao uso de lições aprendidas como forma de impedir recorrência de não conformidades em processos similares.

No entanto, não foram necessárias determinar e nem executar ações para este item, já que a organização possui uma sistemática a nível mundial para compartilhamento de lições apendidas dentro do que ela chama de IPN (International Production Networks). 


\subsubsection{PLANOS DE CONTINGÊNCIA}

O requisito 6.1.2.3, indicado no Quadro 1, foi modificado na nova versão da IATF 16949:2016. Para adequação, foi necessário a criação de novos planos de contingências (PC) obrigatórios (como, por exemplo, o para interrupção de produtos e serviços providos externamente e desastres naturais recorrentes) e modificação dos PCs existentes, como por exemplo, o para interrupção de utilidades e de equipamentos chave.

Dentre as novas diretrizes para planos de contingências, segundo a norma, incluem a revisão anual dos referidos PCs por uma equipe multifuncional através de simulações e sua análise crítica pela alta direção.

Para garantir a implementação desse requisito, ocorreram reuniões com times multidisciplinares responsáveis por implementar e manter esses PCs, para definição de cronogramas anuais para garantir que estes sejam reavaliados segundo periodicidade requerida por norma.

Outra ação necessária, foi à necessidade da criação de uma sistemática documentada de notificação (interna e externa a organização) quando qualquer das situações descritas no PCs ocorram e possam impactar na continuidade do fornecimento dos produtos ou gerar não conformidades nos produtos e lou processos

\subsubsection{OBJETIVOS DA QUALIDADE PLANEJAMENTO PARA ALCANÇA-LOS}

Os itens 6.2.1, 6.2.2 e 6.2.2.1, indicados no Quadro 1, já se encontravam na versão anterior da norma na qual mencionava que os objetivos de qualidade devem ser mensuráveis e consistentes com a política da qualidade. Sendo assim, essa sistemática se encontrava estabelecida na organização, não sendo necessário nenhuma ação adicional. A novidade relacionada a estes itens é o planejamento, ou seja, definição do plano de ação, para alcançar os objetivos definidos.

Para isso a organização definiu um template para o plano, onde as ações necessárias para alcançar os objetivos da qualidade serão descritas, monitoradas e mantidas como evidências, destacando, mais uma vez, a preocupação da norma em relação a prevenção do risco, agora relacionado ao não atingimento de metas.
Os objetivos da qualidade passarão a ser definidos anualmente, conforme especificado em norma.

\subsubsection{PLANEJAMENTO DE MUDANÇAS}

O requisito 6.3, apresentado no Quadro 1, é um item novo da IATF 16949:2016, que estabelece que deve existir uma sistemática para mudanças realizadas no Sistema de Gestão da Qualidade da organização.

Para isso, a empresa criou um procedimento documentado onde definiu que mudanças no Sistema de Gestão da Qualidade devem ser avaliadas com a matriz de riscos e oportunidades, descrito no item 4.2.2 para avaliar seus impactos positivos ou negativos, antes que as mudanças sejam efetuadas.

\section{CONSIDERAÇÕES FINAIS}

A certificação e manutenção do Sistema de Gestão da Qualidade automotivo é mandatória para os fornecedores do mercado OEM e para sua cadeia de fornecimento. Dessa forma, sua implementação é um fator crítico para estas organizações e que pode, se não concretizada, provocar a geração de produtos e processos não conformes além de prejuízos financeiros através da perda de negócios.

No presente trabalho foi apresentado a sistemática de transição entre as normas de SGQ automotiva ISO/TS 16949:2009 para a IATF 16949:2016 em uma organização de grande porte. Com isso, foi possível observar a maturidade da organização estudada sobre a implementação de normas internacionais, como pôde ser verificado nas etapas iniciais, através da realização de treinamentos dos colaboradores, inclusive com o envolvimento da alta gestão da empresa, o que, sem dúvidas, ajudou a impulsionar o projeto.

A disseminação do mindset sobre a importância da implementação da IATF 16949:2016 para a melhoria contínua dos processos e para a manutenção da provisão de produtos para as montadoras para os colaboradores sempre foi a chave de sucesso para a certificação nas edições antigas da SGQ automotiva e foi repetido nesse novo período de transição.

Mesmo com toda essa experiência, a empresa optou por trazer "um olhar de fora" da organização, empresa de consultoria, para 
auxiliar na elaboração do seu plano de ação para adequação, o que eliminou o conflito de interesses e possíveis vícios caso essa análise de gaps fosse feita por um colaborador da empresa.

Por ser a grande novidade da IATF 16949:2016, as ações necessárias para atendimento aos requisitos do capítulo 6, foram as primeiras a serem implementadas no período de transição. A ideia do "pensamento baseado em risco" trouxe uma nova visão sobre os processos mapeados na empresa onde ações para melhoria contínua destes

\section{REFERÊNCIAS}

[1] ABNT NR ISO 9001:2015. Sistemas de gestão da qualidade - Requisitos. Disponível em < http://associacaodeinspetores.com.br/arquivos/arq uivo_informativo/c2c76186249e40f1f5da5c8b09582 702.pdf>. Acesso em 15 out 2017.

[2] ABNT. Sistema de gestão da qualidade: Fundamentos e vocabulários. Disponível em < http://www.standardconsultoria.com/f/files/814048c e04d8cdfe2b1ba9438be31009791895463.pdf> Acesso em 04 set 2017.

[3] ABNT. ABNT NBR ISO 9001:2015. Disponível em < http://www.abnt.org.br/publicacoes2/category/145abnt-nbr-iso-9001>. Acesso em 06 set 2017.

[4] ABNT. Sistema de Gestão da Qualidade: Requisitos. Disponível em $<$ http://www.logfacilba.com.br/iso/iso2015_versao_ completa.pdf>. Acesso em 06 set 2017

[5] ACT. Os novos requisitos da ISO 9001:2015 - Capitulo 3: Interpretação da clausula 6 (Planejamento). Disponível em < http://www.actconsultoria.com.br/os-novosrequisitos-da-iso-90012015-capitulo-3interpretacao-da-clausula-6-planejamento-dosistema-de-gestao-da-qualidade/>. Acesso em 16 nov 2017.

[6] AGUIAR, D. C.; SALOMON, V.; MELLO, C. An ISO9001 based approach for the implementation of process FMEA in the Brazilian automotive industry International Journal of Quality \& Reliability Management, Vol. 32 Iss 6 pp, 2015

[7] BRUM; Tarcísio Costa. Oportunidades da aplicação de ferramentas de gestão na avaliação de políticas públicas: O caso da politica Nacional de resíduos sólidos para a construção civil. Disponível

em <http://www.ufjf.br/ep/files/2014/07/2012_3_Tarcisio .pdf>. Acesso em 03 set 2017.

[8] BSI GROUP. Mudando da ISO 9001:2008 para a ISO 9001:2015: Guia de transição. Disponíve foram definidas e implementadas. Antes, estas análises dos riscos e oportunidades estavam apenas voltadas aos processos de manufatura e logística, mas agora estão presentes em todos os processos da organização, incluindo os de suporte e os de gestão.

Por fim, vale ressaltar que este trabalho pode ser utilizado como um modelo de boas práticas ou referência para implementação ou transição desta ou outras normas de sistema de gestão, do qual outras organizações possam ter como base.

<http://www.cursosonlinecursos.com.br/curso/apos tila/7147e3df28fc8ee27c225a18d03bfa2d58de891 756c33. pdf > . Acesso em 07 set 2017.

[9] FISCHER, Ricardo. Gestão de produtos sob a ótica da IATF 16949:2016. Disponível em< http://slideplayer.com.br/slide/11847344/>. Acesso em 17 nov 2017

[10] IATF. A new evolution for quality management in the automotive industry. Disponível em <http://www.iatfglobaloversight.org/wp/wpcontent/uploads/2016/12/IATF-Press-release-v708082016_CLEAN_IATF.pdf>. Acesso em 03 set 2017

[11] IATF. About IATF. Disponivel em <http://www.iatfglobaloversight.org/about-iatf/>. Acesso em 04 set 2017.

[12] OLIVEIRA; Otávio; GOBBO; José; CESAR; Mônica. Implantação do sistema de gestão da qualidade ISO 9000 em uma empresa de transporte rodoviário. Disponível em < http://www.abepro.org.br/biblioteca/enegep2006_tr 470321_7208.pdf>. Acesso em 06 set 2017.

[13] OLIVEIRA; Maxwell Ferreira. Metodologia científica: um manual para a realização de pesquisas em administração. Disponível em < https://adm.catalao.ufg.br/up/567/o/Manual_de_met odologia_cientifica_-_Prof_Maxwell.pdf>. Acesso em 10 out 2017 .

[14] ROSPI; Leonardo; VENDRAMETTO; Oduvaldo; NETO; Pedro. As perspectivas dos sistemas de gestão da qualidade baseados na norma ISO 9001:2000. Disponível em < http://www.abepro.org.br/biblioteca/ENEGEP2006_ TR470319_7462.pdf>. Acesso em 06 set 2017.

[15] ROTTA, I. S.; BUENO, F. Análise setorial da indústria automobilística: principais tendências. Disponível em www.abepro.org.br/biblioteca/ENEGEP2000_E0064 .PDF>. Acesso em 06 set 2017. 
[16] SAKURAMOTO; Carlos; DISERIO; Luiz Carlos. Indústria Automobilística no Brasil: Protagonista no palco de uma eminente transformação global. Disponível em < http://bibliotecadigital.fgv.br/dspace/bitstream/han
dle/10438/16340/Industria_automotiva_no_Brasil_Pr otagonista_no_palco_de_uma_eminente_transform a\%C3\%A7\%C3\%A3o_global.pdf?sequence=1 $\mathrm{P}$. Acesso em 03 set 2017. 


\section{Bapítulo 10}

\section{ELABORAÇÃO DE PROCEDIMENTOS PARA UMA EMPRESA DE PEQUENO PORTE COM BASE NA ISO 22716:2007}

\section{Laís Gabriel Leandro Marilene Souza Gabriel}

Valnei Carlos Denardin

Ivete de Fátima Rossato

Ana Regina de Aguiar Dutra

Juliano Mazute

Resumo: O presente estudo propõe uma metodologia para elaboração de procedimentos para uma empresa de pequeno porte conforme a ISO 22716:2007, uma norma baseada em requisitos de boas práticas de fabricação para indústria cosmética. A implementação de um sistema de qualidade na empresa que chamaremos de PL surgiu a partir da exigência do seu principal cliente, além da necessidade de padronização e controle dos seus processos, evitando erros operacionais básicos, bem como reclamações de clientes. Atualmente as indústrias de cosméticos passam por auditorias de órgãos governamentais, estas exigências são repassadas a toda cadeia de fornecimento, a PL é um fornecedor indireto de grandes empresas de cosméticos, desta forma a adequação de regras de boas práticas de fabricação se tornou um requisito para se manter no mercado. O trabalho traz quais são as etapas necessárias para a adequação da organização além dos resultados atingidos, como a redução de reclamação de clientes, padronização dos processos da empresa e ferramentas para elaboração de controles e indicadores de desempenho.

Palavras-chave: ISO 22716:2007, Boas práticas de fabricação, Gestão da qualidade. 


\section{INTRODUÇÃO}

A vaidade feminina e masculina alimenta um mercado em ascensão que movimenta mais de $R \$ 38$ bilhões por ano no país, segundo a Associação Brasileira da Indústria de Higiene Pessoal, Perfumaria e Cosméticos (ABIHPEC). O Brasil é o terceiro maior mercado consumidor mundial de produtos de beleza, atrás apenas da China e dos Estados Unidos. De acordo com um estudo realizado pelo SPC Brasil, em um cenário de crise, o brasileiro opta por cortar atividade de lazer em vez de gastos com a beleza, este comportamento, favorece a "indústria da beleza" que voltou a crescer em 2016. Mesmo em épocas de recessão econômica, como a atual, os consumidores, sobretudo as mulheres não param de investir em produtos de estética e beleza, nem que para isso precisem substituir uma marca tradicional por outra mais acessível.

O mercado global de cosméticos cresceu, em 2016, segundo The Statistics Portal, aproximadamente $4 \%$ em relação ao ano de 2015. Os produtos para os cuidados com a pele, cabelos e corpo representam os principais itens do mercado de cosméticos. Produtos para a pele representaram a maio parte das vendas, perfazendo $36 \%$ do mercado global. Os produtos capilares representaram mais 23\%, enquanto a maquiagem representou 18,2\% em 2016. Prevê-se que os cuidados com a pele permaneçam como a categoria de produto mais lucrativa, já que seu valor de mercado deverá crescer 20,1 bilhões de dólares entre 2014 e 2019. A partir de 2016, a Ásia e a Oceania eram líderes do setor, respondendo por aproximadamente $40 \%$ do mercado global. Entre 2016 e 2021, o mercado de beleza na Ásia-Pacífico deverá crescer 14,9 bilhões de dólares em vendas.

No Brasil a ANVISA (Agência Nacional de Vigilância Sanitária) é responsável pela fiscalização das empresas relacionadas à área de cosmético e farmacêutico baseados nos atos normativos publicados. Devido a rigorosa fiscalização sofrida pelas empresas da área de cosmético e farmacêutico, alguns requisitos exigidos pelo órgão regulamentador como padronização das amostras, rastreabilidade, entre outros são repassados a toda cadeia de fornecimento. Desta forma, estas empresas atuam rigorosamente no processo de qualificação de seus fornecedores, realizando auditorias anuais, com base nos requisitos das normas ISO
9001, ISO 22716, além de legislações específicas. Reforça-se a importância da ANVISA, a partir de um estudo exploratória bibliográfica e documentária realizado por Garbossa e Campos, 2016, onde se mostrou que a criação da ANVISA foi necessária porque não havia sido publicada nenhuma resolução sobre a segurança e eficácia na indústria dos cosméticos.

Este estudo será aplicado ao desenvolvimento de procedimentos para implementação de um sistema de qualidade em uma empresa de pequeno porte, com base nos requisitos da ISO 22716:2007, focando as Boas Práticas de Fabricação (BPF) para empresas da área de cosméticos, além de atender requisitos relacionados a toda a sua documentação. A ferramenta das BPF possui requisitos similares à legislação brasileira, como a RDC 48/2013 (Regulamento Técnico de Boas Práticas de Fabricação para Produtos de Higiene Pessoal, Cosméticos e Perfumes). Para a EFMHACA (2014), a ferramenta das BPF garante que a qualidade seja incorporada à organização e aos processos envolvidos na fabricação dos produtos.

No presente estudo será realizado um diagnóstico da empresa por meio do mapeamento de processos para definição, elaboração e implementação dos procedimentos operacionais, visando atender as exigências do mercado, satisfação dos clientes e melhoria do sistema de gestão da empresa, com a padronização dos processos.

\section{REFERENCIAL TEÓRICO}

O referencial do presente estudo versa sobre os conteúdos da ISO 22716:2007, do planejamento da qualidade e das boas práticas de fabricação.

A ISO 22716:2007 é uma norma elaborada pelo Comitê Técnico ISO/TC 217, que apresenta uma abordagem abrangente para o sistema de gestão da qualidade da cadeia produtiva envolvida na fabricação, embalagem, testes, armazenamento e transporte de produtos cosméticos acabados, alinhada a outros sistemas de gestão da qualidade, o que assegura fácil integração a esses sistemas, tais como ISO 9001.

No contexto da ..encontra-se a ferramenta das Boas Práticas de Fabricação (BPF) de Cosméticos (ISO 22716), que definem requisitos primordiais para os processos de produção de cosméticos, os quais buscam 
estabelecer padrões e registros dos processos produtivos, bem como um sistema de garantia de qualidade (MASAND ET AL, 2014; YAPAR 2017). Em 2009, Moore já escreveu em seu livro intitulado "Manufacturing Cosmetic Ingredients according to Good Manufacturing Practice Principles", que os princípios chaves da ferramenta das BPF eram: o produto não deve prejudicar o usuário final; o produto deve ser puro e livre de contaminantes; deve haver procedimentos de fabricação definidos para garantir eficácia na fabricação de produtos de qualidade; deve haver registros do processo de fabricação que demonstrem que o produto foi feito de acordo com o planejamento; os trabalhadores devem ter competência para tais processos; o equipamento de fabricação deve ser adequado à finalidade e mantido adequadamente; a qualidade não deve ser inspecionada no final do processo, e sim produzida ao longo do mesmo.

O planejamento da qualidade é uma das etapas mais importantes para um processo de implementação de um SGQ (sistema de gestão da qualidade).

Planejar a qualidade significa tomar decisões gerenciais antes que as máquinas parem por defeitos, antes que montanhas de refugo sejam gerados, antes que os fornecedores nos deixem sem abastecimento, antes que nossos consumidores reclamem, antes que os custos disparem. (Paladini, 2004, p 105).

Para as organizações, a qualidade é uma grande preocupação, pois possuir bens e serviços de alta qualidade pode dar a uma organização considerável vantagem competitiva. A qualidade, na medida certa, reduz custos com retrabalho, refugo, reclamações e devoluções, entre outros benefícios. Os entendedores do assunto acreditam que, em longo prazo, a qualidade é o diferencial no desempenho de uma organização em relação a seus concorrentes. (SLACK, CHAMBERS e JOHNSTON, 2009; ).

Segundo Paladini (2009) um modelo usualmente empregado para o planejamento da qualidade envolve um esquema de atividades especificas. Esse esquema deve atender aos requisitos gerais do processo de gerenciamento da qualidade em praticamente todo tipo de empresa, já que há certo mito de que os sistemas de gestão da qualidade não se adequam a empresas de pequeno porte. O seguinte modelo possui seis etapas: política da qualidade; diagnóstico; organização e administração; planejamento propriamente dito; definição e estruturação do plano de ação, que viabiliza a política da empresa e a implantação.

Nesta etapa cada uma das atividades planejadas deverá ser executada e é conveniente dividir sua execução em três áreas distintas: projeto, processo e produto. Os resultados da implementação devem ser todos documentados, é importante definir um procedimento de gestão de treinamento para padronização da forma de registro dos resultados e relatórios padrões da organização, levando em consideração a realização de manuais para facilitar o entendimento de todas as áreas.

Segundo Toledo e outros (2012), o planejamento estratégico nas organizações é desenvolvido, geralmente, por meio de uma sequência de etapas e atividades, sendo elas:

- Diagnóstico estratégico: é considerado uma das etapas iniciais do planejamento, considera-se nessa etapa a análise do ambiente externo e interno da organização;

- Ambiente externo: devem ser observados fatores, situações e mudanças que podem ter um impacto positivo (oportunidades) ou negativo (ameaças) em seu desempenho, devem ser analisadas as questões relacionadas à economia, à tecnologia, à demografia, à legislação que incide sobre a organização, ao meio ambiente, à concorrencial, ao mercado-alvo etc.;

- Ambiente interno: observados fatores relacionados as suas competências, recursos e atividades, o objetivo é identificar seus pontos fortes e fracos, e, por isso, sendo analisados fatores como: estrutura, suprimentos, tecnologia, mão de obra, recursos financeiros etc.;

- Rever visão, missão e valores: os valores representam as crenças que traduzem os princípios que orientam sua atuação em termos de decisões e comportamentos, ou seja, formam a ideologia da organização, trazendo qual a estratégia será definida pela empresa;

- Definição de objetivos: com base nos resultados das etapas de diagnóstico e intenção estratégica, a organização deve formular um conjunto de objetivos e estratégias para alcança-los, em formato 
de plano de ação, com ações a curto e longo prazo.

\section{LEVANTAMENTO DE CAMPO}

\subsection{MAPEAMENTO DOS PROCESSOS}

$\mathrm{Na}$ figura 1, demonstra-se o mapa do processo da empresa, onde se inicia com a entrada do pedido do cliente, definição do tipo de serviço, e caso o orçamento seja aprovado pelo cliente, este será enviado a empresa com a lista dos insumos necessários para realização do serviço, as etapas seguintes serão realizadas com a produção, faturamento e entrega do material.

As áreas de recursos humanos, qualidade e administrativo trabalham dando apoio a processos como: contratação, inspeção de qualidade e emissão da nota fiscal.

Figura 1- Macroprocesso da produção.

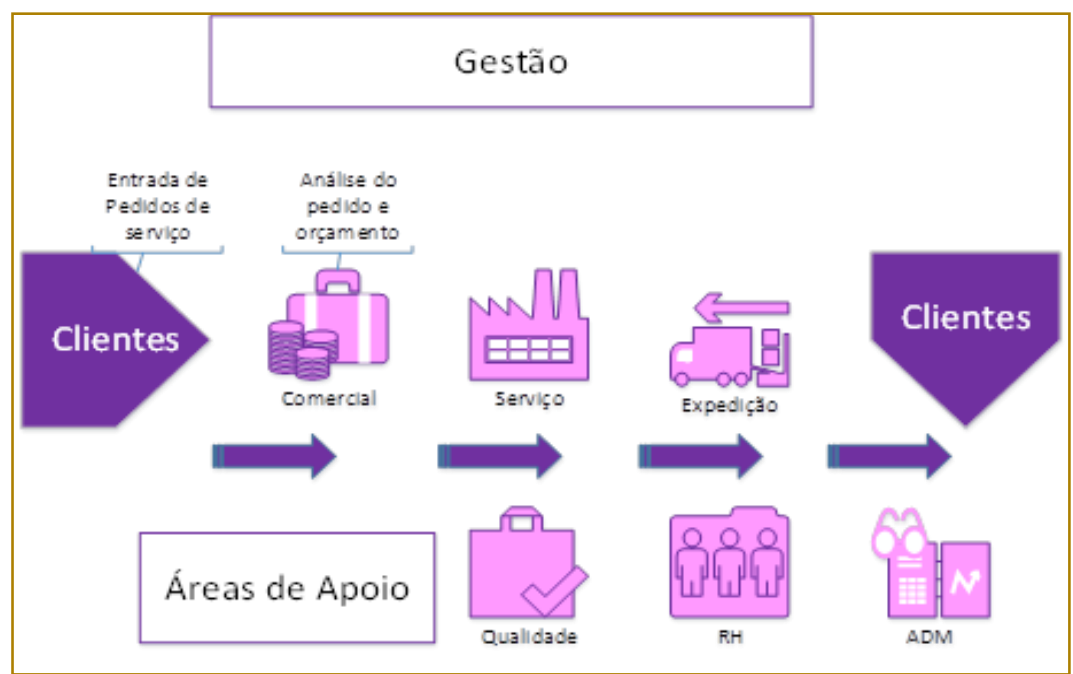

Fonte: elaborado pelo autor, (2017).

\subsection{CULTURA DA QUALIDADE NA} ORGANIZAÇÃO

A empresa PL possui diretrizes organizacionais definidas e implementadas como Missão, visão e valores que buscam atender as normas e as necessidades dos clientes.

Todos os valores, diretrizes, regras de BPF (boas práticas de fabricação) e organograma da empresa estão descritos no Manual do colaborador, o qual é entregue durante a integração de novos funcionários.

Observamos que pelo fato de não estar estruturada uma política com objetivos da qualidade definidos pela empresa, os mesmos poderão acarretar na ausência de metas e resultados em relação a qualidade do produto (serviço) oferecido pela organização.

O grau de exigência da qualidade dos serviços prestados é muito elevado, pois a empresa é um terceiro indireto de indústrias de cosméticos, as quais possuem regras de limpeza, estrutura de planta e controle de processo. Mesmo não sendo um fornecedor direto destas empresas, as cobranças são similares, pois os requisitos sofrem um desdobramento, atingindo a cobrança de toda a cadeia que fornece materiais para este mercado, a seguir na figura 2 apresentaremos a cadeia de exigência dos requisitos de qualidade. 
Figura 2: Desdobramento dos requisitos de qualidade de indústrias de cosméticos.

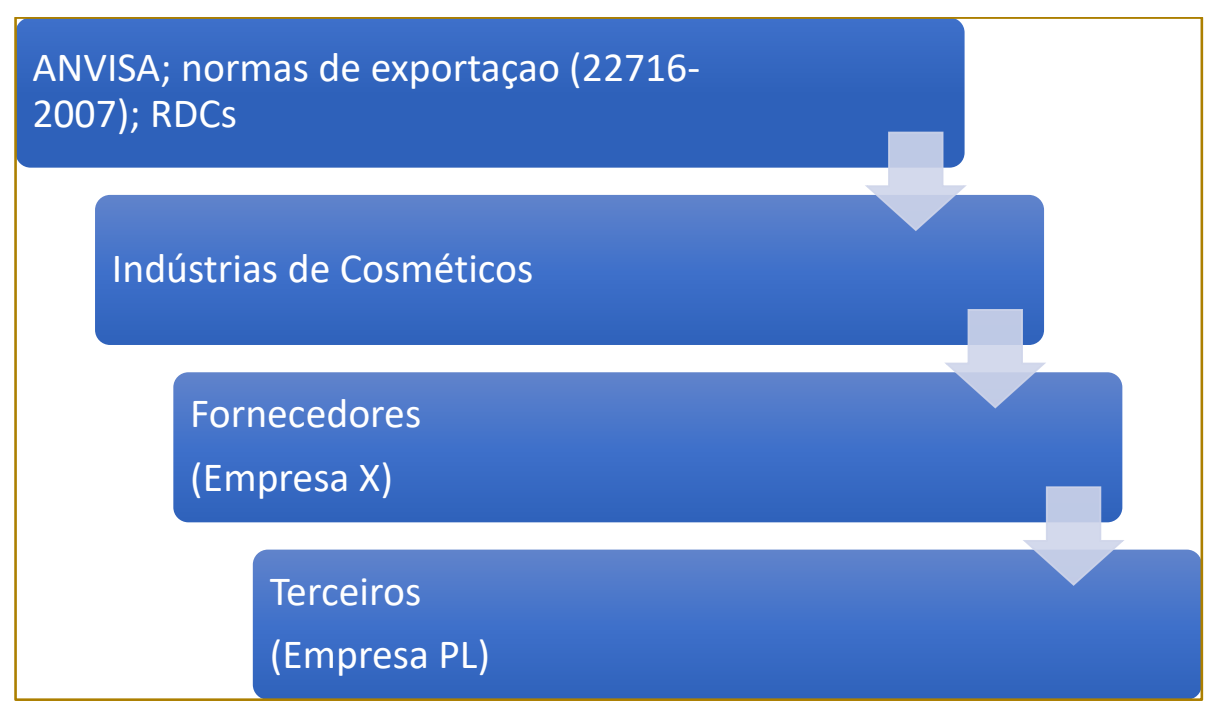

Fonte: elaborado pelo autor, (2017).

\subsection{ANÁLISE DO SISTEMA DE QUALIDADE}

Atualmente a empresa não possui um sistema documental definido, ou seja, não há uma sistemática padronizada para a elaboração de procedimentos. Os processos de inspeção são baseados em procedimentos enviados pelos clientes. Para os registros das atividades realizadas são utilizados checklists específicos, como as inspeções e testes.

\subsection{APLICAÇÃO DA METODOLOGIA PARA IMPLEMENTAÇÃO DO SGQ}

A ISO 22716:2007 é uma norma voltada as Boas Práticas de Fabricação para a área de cosmético, desta forma muitas requisitos estão voltados ao controle de limpeza dos equipamentos, que são utilizados para envase dos produtos cosméticos, ou seja, há requisitos da norma que não se aplicam ao processo da PL. Para facilitar o processo de adequação foram elaborados dois esquemas, o primeiro trata a ordem de planejamento para a adequação a norma e o outro, quais os processos que necessitam estar documentados. A figura 3 a seguir demonstra a ordem de planejamento para adequação a norma.

Figura 3: Planejamento para a adequação aos requisitos da norma

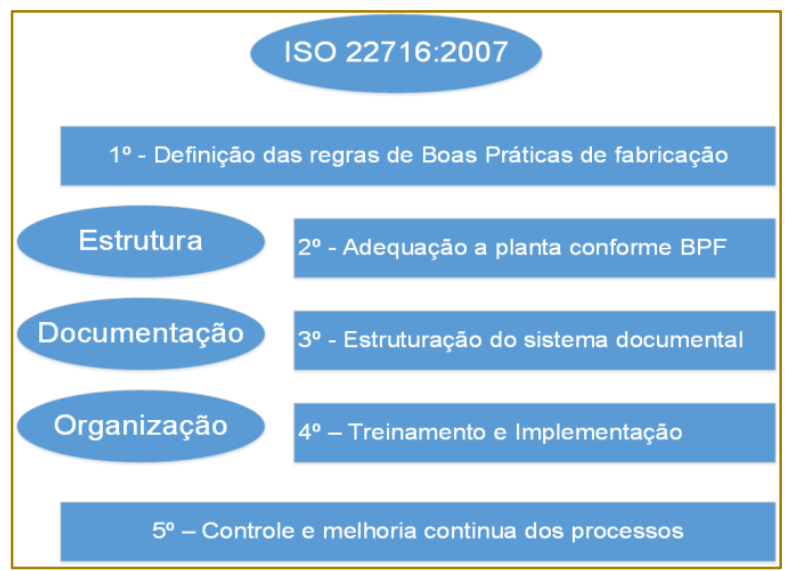

Fonte: elaborado pelo autor, (2017). 
A primeira fase da adequação da empresa é baseada na definição das regras de BPF. Em indústrias de cosméticos há necessidade de utilizar a legislação como base, por exemplo, a RDC 48/2013 Boas práticas de fabricação para produtos de higiene pessoal, cosméticos e perfumes, pois este tipo de indústria é auditado por órgãos governamentais. Como a empresa a ser estudada é um fornecedor indireto, serão utilizados requisitos enviados por clientes e a própria ISO 22716:2007.

Após definir-se quais serão as regras de BPF, a empresa poderá seguir para a segunda etapa, que é dimensionar sua planta, conforme os seguintes requisitos: áreas de acesso; áreas de produção; estruturas e luminárias; evitar cruzamentos nos fluxos de materiais, pessoas e resíduos, ou seja, definir - layout de fábrica; definir local para o armazenamento de alimentos.

$\mathrm{Na}$ terceira fase é iniciada a estruturação da documentação, a qual é um dos requisitos das BPF. A própria ISO 22716:2017 referencia em seus requisitos a necessidade de documentação padronizada. A documentação deverá fazer parte da rotina de todos os colaboradores, deve ser "vista" como uma metodologia de auxílio na padronização das atividades e não na burocratização do negócio. Na figura 4, é possível visualizar a necessidade básica de documentação em casos de indústrias com o mesmo foco da PL, ou seja, um fornecedor indireto da indústria de cosméticos. Nesta etapa deverá ser avaliado o organograma da empresa, frisando que a norma solicita que a área de qualidade seja independente das demais. Já a quarta etapa é composta pela implementação de todos os procedimentos através dos treinamentos as áreas envolvidas. A quinta e última etapa trata do controle de todos os processos, através de auditorias, indicadores de processo, lembrando que o processo de melhoria contínua deve girar constantemente, para o progresso da organização.

\subsection{DEFINIÇÃO DAS NORMAS DE BPF}

As Boas Práticas de Fabricação não são apenas regras de higienização, elas tratam de toda a estrutura da empresa, como: organograma, procedimentos e regras de acesso a planta industrial. Nos próximos tópicos serão apresentadas as primeiras etapas para a definição das BPF como a organização e estrutura, as regras de acesso a planta e o seguimento aos procedimentos padrões serão realizados durante a etapa de elaboração da documentação da empresa.

\subsection{ORGANIZAÇÃO}

Foi indicado a empresa fazer a alteração do organograma conforme a figura 4 , dando independência da área de qualidade a de produção, dessa forma a área reportará diretamente ao diretor da planta, evitando o conflito de interesses.

Figura 4: Proposta de alteração do organograma

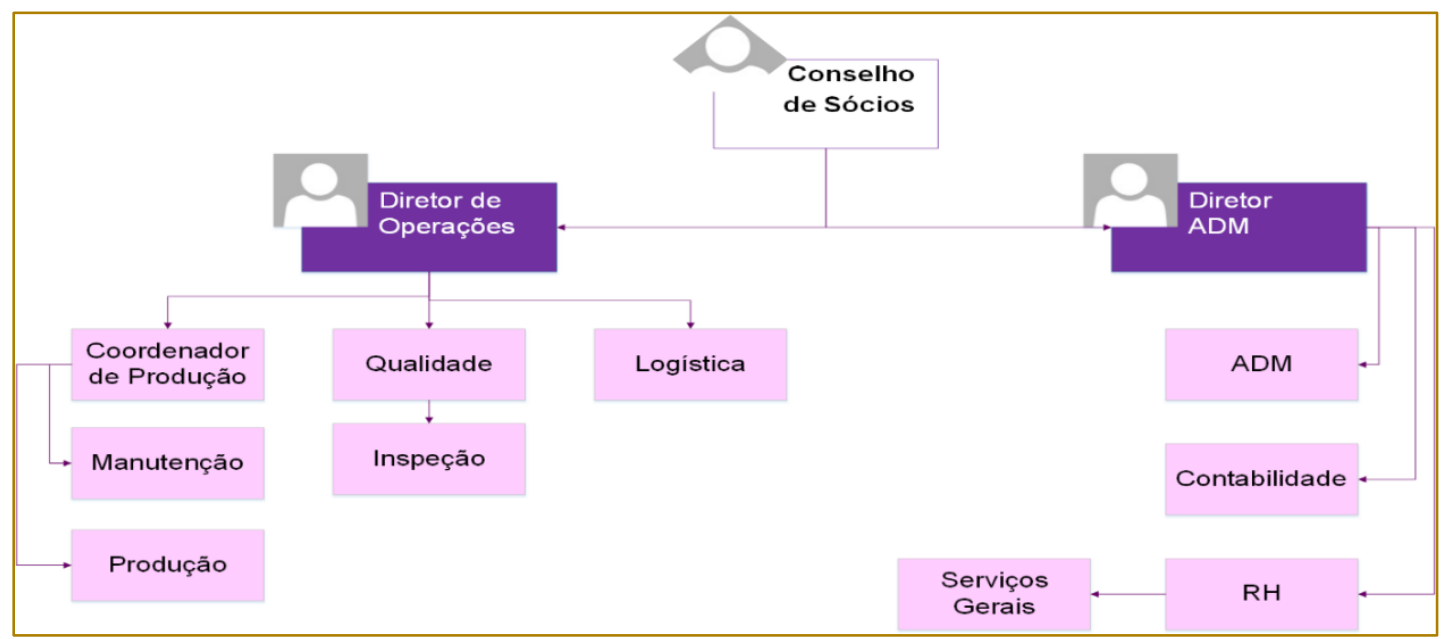

Fonte: elaborado pelo autor, (2017). 


\subsection{INSTALAÇÃO}

A ISO 22716:2007 traz no item "4 - instalação" todos os requisitos que precisam ser analisados. A seguir serão abordados cada tópico apresentado na norma e interpretação do mesmo na adaptação da planta.

Instalações devem ser localizadas, designadas, construídas e utilizadas para assegurar a proteção dos produtos; a limpeza eficiente; o armazenamento adequado; o espaço de circulação; a ventilação; a iluminação e o fluxo em todas as áreas, além de facilitar a visualização das operações a serem executadas. Alguns processos podem exigir diferentes níveis de iluminação, ou seja, podem necessitar de maior potência de lâmpadas ou luminárias especiais para execução efetiva das tarefas.

O requisito "instalação" também aborda a localização física onde será recebido, produzido, armazenado e expedido o produto.

A planta deve ter tamanho adequado para realizar movimentação de materiais, sendo que extintores, equipamento e corredores não devem ser obstruídos, nesta etapa é importante a definição e construção de um mapa de fluxo de materiais, resíduos e pessoas, sendo possível avaliar possíveis cruzamentos de fluxos e se necessário a definição de um plano de ação preventivo, como identificação e separação de materiais. Será importante definir e identificar cada uma das áreas, como recebimento, produção, estoque e banheiros, isso ajuda a garantir que as regras de BPF sejam cumpridas de acordo com o local. Tubulações, drenos e dutos devem ser mantidos limpos de acordo com procedimentos definidos.

No início do projeto a empresa PL já estava em processo de mudança para uma planta que atenderia as necessidades das boas práticas de fabricação, as quais já eram de conhecimento da alta direção. A mudança foi realizada no final do ano de 2016. Foram realizadas apenas algumas adequações ao prédio, para garantir cada uma das exigências apresentadas.

\subsection{ESTRUTURA DOCUMENTAL DO SISTEMA DE GESTÃO DA QUALIDADE}

A primeira tratativa em relação ao $S G Q$ (Sistema de Gestão da Qualidade) da PL foi a definição da política e objetivos da qualidade, formulada em conjunto com a alta direção. A política da qualidade possui grande importância, pois ela expressa o que a organização define como qualidade, ou seja, a tomada de decisão em relação a qualidade de produtos e processos é baseada na sua política. Os objetivos são os itens de controle que a organização irá ter, ou seja, devem ser mensuráveis para orientação nas tomadas de decisão da gestão estratégica. A empresa PL define sua política e objetivos como:

Política da qualidade: Estabelecer um processo de melhoria continua dos serviços prestados com a garantia de excelência aos requisitos de qualidade e consequentemente satisfação dos clientes, atuando com colaboradores motivados e capacitados e respeito ao meio ambiente.

\section{Objetivos:}

- Padronizar processos para medir a excelência dos serviços prestados;

- Aprimorar processos para diminuir erros operacionais e número de reclamações de clientes;

- Aumentar o envolvimento dos colaboradores nos processos da empresa;

- Garantir a satisfação do cliente;

- Aumentar o reconhecimento externo.

Todos os colaboradores da empresa foram capacitados na política e objetivos da qualidade, a fim de iniciar o processo de implementação do SGQ da empresa. Foram colados cartazes nas áreas para dar ênfase a importância da definição da política, outro ponto importante foi a presença da alta direção em todos os treinamentos, mostrando o envolvimento direto no projeto.

Para iniciar o processo de construção dos documentos foi realizado um mapeamento de todos os processos atuais da empresa. Conforme a norma ISO 22716:2007, foram definidos quais procedimentos iriam ser construídos em cada uma das áreas. O foco do projeto será na área de operações, a qual tem impacto direto na qualidade do produto fornecido. A figura 6 apresenta o mapeamento da área industrial, com seus respectivos documentos. 
Figura 5: Mapeamento módulo de operações.

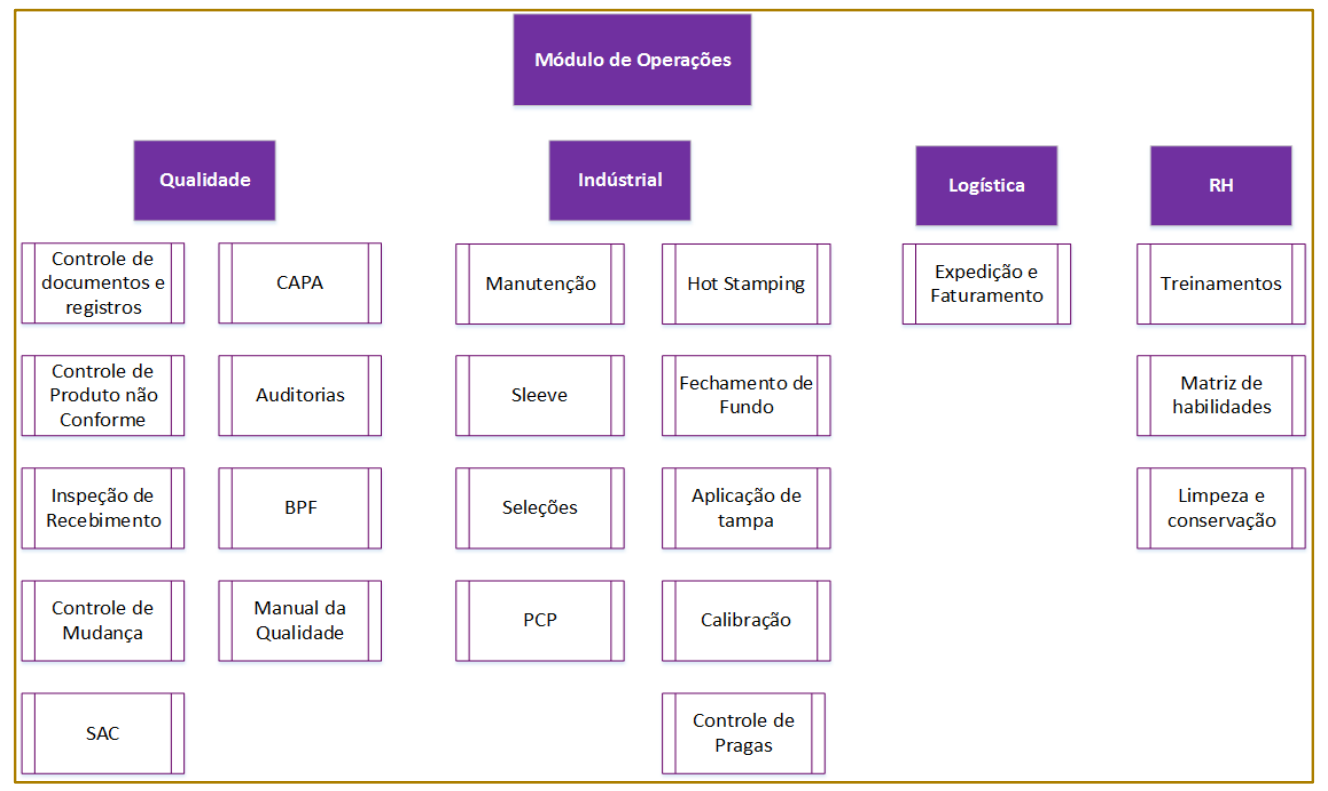

Fonte: elaborado pelo autor, (2017).

A ordem de construção e implementação de cada um dos documentos é importante, pois cada um representa um processo com entradas, execuções e saídas, estas atividades podem envolver mais de uma área, a exemplo da área de "Controle de documentos e registro", que tem objetivo de definir a sistemática de construção, execução e obsolescência de qualquer documento da empresa.

Para facilitar o acompanhamento de construção dos procedimentos foi definido um cronograma para as datas de treinamento, os mesmos foram executados pelo responsável da área de qualidade da empresa PL. Todos os documentos são arquivados em um sistema de Dropbox, o que facilita o acesso para todas as áreas da empresa. A fim de dar importância a cada procedimento em todas as áreas foi disponibilizado uma cópia dos seus procedimentos, onde ficou claro que cada atividade deve ser padronizada, evitando erros operacionais.

A última e mais importante etapa do processo de planejamento e implementação dos requisitos da norma demonstrados na figura 6 é o "controle e melhoria contínua dos processos". É nesta etapa que a cultura de seguimento dos procedimentos e práticas das regras de BPF devem ser enraizadas na rotina dos colaboradores, tornando-se um hábito. Para isso é importante a apresentação dos resultados obtidos a todos colaboradores mensalmente, tornando todos como uma engrenagem fundamental para a manutenção e sucesso do SGQ (sistema de gestão da qualidade), adotando que auditorias deverão acontecer mensalmente nos primeiros seis meses e posteriormente semestralmente.

\section{CONSIDERAÇÕES FINAIS}

O comprometimento da alta direção em relação à implementação dos processos é fundamental para o sucesso do projeto de elaboração de procedimentos conforme a ISO 22716:2007, já que serão sugeridos processos que não são executados pelos colaboradores e exigem uma mudança cultural na rotina de todos. Este comprometimento foi o principal motivo do sucesso na implementação de cada procedimento na empresa $\mathrm{PL}$, ajudando a área de qualidade na manutenção de cada atividade e regras sugeridas.

A primeira melhoria realizada é importante para a adequação da empresa e está presente na alteração do organograma, para que a qualidade reporte direto a alta direção evitando assim o conflito de interesses entre as áreas. A segunda etapa foi o start do projeto, através da divulgação da política da qualidade aos colaboradores e calendário de treinamento dos procedimentos, lembrando que cada treinamento foi acompanhado pela alta direção, dando importância e força na implementação de cada procedimento. 
Através da etapa de mapeamento de processos foi possível identificar quais processos já estavam de acordo com a norma e quais os procedimentos que deveriam ser criados e implementados. Com base em cada processo foi realizado um cronograma de elaboração e implementação dos procedimentos.

O grande desafio encontrado durante a elaboração dos procedimentos foi em como adequar os processos aos requisitos da norma ISO 22716:2007 sem "engessar" a rotina dos colaboradores, ou seja, evitar que os tempos de repostas aos clientes internos e externos não diminuíssem, de forma a atender a norma. Para isso foram efetuadas simulações dos processos, acompanhamento contínuo dos resultados, conversas com os colaboradores para identificação das principais dúvidas, e quando necessário, alteração dos procedimentos. O grande diferencial na implementação correta dos procedimentos é a qualidade de treinamento e entendimento de todos no procedimento.

\section{REFERÊNCIAS}

[1] ABNT. ISO 90012015, Sistema de Gestão da Qualidade.

[2] CARPINETTI, Luiz Ribeiro, GEROLAMO, Mateus Cecílio. Gestão da Qualidade - ISO 9001:2015. Atlas. São P/2016.

[3] CUSTÓDIO, Marcos Franqui. Gestão da Qualidade e Produtividade. São Paulo, Person Education do Brasil, 2015.

[4] DEMING, W. E. Saia da crise: as 14 lições definitivas para controle de qualidade. São Paulo: Futura, 2003.

[5] EFMHACA. Ethiopian Food, Medicine \& Healthcare Administration \& Control

[6] Authority. Good manufacturing practice guideline for harmaceutical products main principles, First Edition, 2014. Available in:< http://apps.who.int/medicinedocs/documents/s2235 7en/s22357en.pdf> Accessed in: 12 dec.2018.

[7] FEIGENBAUM, Armand V. Controle da qualidade total: Gestão e Sistemas. Editora: Makron Books. São Paulo. 1994.

[8] GARBOSSA, W. A. C.; CAMPOS, P. M. B. G. M. Evaluation of the Brazilian Cosmetic Legislation and its impact on the industries during the 20th century. Brazilian Journal of Pharmaceutical Sciences, 52(2), p. 319-328, 2016. DOI:10.1590/s1984-82502016000200010
A partir dos treinamentos e implementação dos procedimentos foram observados os primeiros resultados como:

- Padronização da rotina de trabalho entre os dois turnos de produção;

- Diminuição dos erros operacionais;

- Mudança cultural em relação a rotina das regras de boas práticas de fabricação;

Após um mês da implementação do procedimento de inspeção de recebimento o número de reclamações do mês seguinte foi zerado. Realizando análises foi identificado que o principal motivo das reclamações eram "sujidade na tampa", sendo este o defeito com incidência correspondente a $71 \%$ na inspeção de recebimento dos materiais enviados pelo cliente para a execução de serviços pela PL, ou seja, as sujidades dos materiais eram de origem do cliente e não da empresa PL. Através dos números foi possível mostrar ao cliente a verdadeira causa raiz do desvio.

[9] ISO 22716:2007, Cosméticos - Boas Práticas de Fabricação (GMP) - Diretrizes das Boas Práticas de Fabricação

[10] MASAND, S; MADAN, S; BALIAN, S. K. Modern concept of storage and packaging of raw herbs used in Ayurveda. Int J Res Ayurveda Pharm.; 5(2), p.242-5, 2014. DOI: 10.7897/22774343.05249

[11] MOORE, I. Manufacturing Cosmetic Ingredients according to Good Manufacturing Practice Principles. Global Regulatory Issues for the Cosmetics Industry, p. 79-92, 2009. DOI:10.1016/b978-0-8155-1569-2.50011-7

[12] PALADINI, Edson Pacheco. Gestão estratégica da qualidade: princípios, métodos e processos, $2^{\underline{a}}$ edição. Atlas, São Paulo .2009.

[13] SLACK, Nigel; CHAMBERS, Stuart; JOHNSTON, Robert. Administração da produção. São Paulo: Atlas, 2009.

[14] TOLEDO, José de, BORRÁS, Miguel Aires, MERGULHÃO, Ricardo Coser, MENDES, Glauco Henrique. Qualidade - Gestão e Métodos. LTC. São Paulo 2012.

[15] THE STATISTICS PORTAL. Available in:< https://www.statista.com/topics/3137/cosmeticsindustry> Accessed in: 12 dec.2018.

[16] YAPAR, EVREN. Herbal Cosmetics and Novel Drug Delivery Systems. Indian Journal of Pharmaceutical Education and Research. 51. s152s158, 2017. DOI: 10.5530/ijper.51.3s.3. 


\section{Bapítulo 11}

\section{EVOLUCÃO DO RENDIMENTO E DA ÁREA COLHIDA DA LARANJA E O DESLOCAMENTO DA CULTURA DENTRO DO ESTADO DE SÃO PAULO}

\section{Gerônimo Guerreiro Neto}

\section{Leonardo Rezende Martins}

\section{Sérgio Rangel Fernandes Figueira}

Resumo: Os indicadores de produção da laranja no estado de são paulo passaram por mudanças importantes nos últimos anos. Em análise exploratória baseada em dados primários e secundários da fao, ibge e fundecitrus, foi identificado que entre 1997 e 2016 ocorreu uma retração de 45,4 \% da área colhida em hectares e de 15, $4 \%$ do volume produzido em toneladas. Contudo, o rendimento em $\mathrm{kg}$ por hectare evoluiu 55,9 \% atenuando a perda da produção. Adoção de maior densidade em plantas por hectare teve contribuição no aumento da produtividade. Concomitantemente ocorreu um deslocamento da produção da laranja dentro do estado de são paulo, onde regiões tradicionais ao norte e centro do estado perderam área colhida em detrimento ao sudoeste do estado. Neste período a cana de açúcar evoluiu 128, 4 \% em área colhida no estado e avançou em áreas ao centro e norte que tradicionalmente eram cultivadas com a cultura da laranja. Condições climáticas favoráveis e menor incidência de pragas e doenças em municípios ao sudoeste de são paulo foram atrativos apontados pela literatura como possíveis responsáveis por este deslocamento da produção.

Palavras-chave: Iaranja; evolução; área ; rendimento; deslocamento. 


\section{INTRODUÇÃO}

A laranja é uma cultura de fácil adaptabilidade às condições variadas de solo e clima do País, presente em quase todo o território brasileiro (OSORIO et al., 2018).

Em São Paulo, a partir da década 1960, com o desenvolvimento da indústria de suco concentrado, o crescimento da demanda pela matéria-prima provocou expansão da área plantada e da produção de laranja, até fins da década de 1990, passando a se constituir numa das principais atividades agrícolas paulista (AMARO; CASER, 2004). A partir da implantação da agroindústria citrícola nos anos 1960, houve um incrível impulso na expansão da área plantada com pomares de laranja e efetivamente em produção no Brasil e, particularmente, em São Paulo. Contudo, houve um arrefecimento nos anos 2000. (BOECHAT, 2015).

Entre 2000 e 2010, houve crescimento da produção de cana-de-açúcar em 8 Estados brasileiros, inclusive São Paulo, onde verificou-se a tendência de avanço da lavoura canavieira em substituição a outras culturas, como a laranja em terras paulistas (AGUIAR; SOUZA, 2014). A cana-de-açúcar, não só está em pleno desenvolvimento no Estado de São Paulo, como é um dos prováveis motivos para o deslocamento dos citros ou até mesmo sua redução na parcela produtiva agrícola paulista (MAÇORANO 2017).

Entre 1995 e 2015 ocorreu grande elevação na produção canavieira paulista, passando de aproximadamente 158 milhões de toneladas na safra 1995/96 para aproximadamente 368 milhões de toneladas na safra 2015/2016 (OLIVEIRA, 2017).

Segundo Camargo et al. (2008), a expansão da cultura da cana-de-açúcar vem determinando novas configurações regionais das explorações agropecuárias no Estado de São Paulo, gerando concentração da posse da terra, pois o arrendamento de pequenas e médias propriedades, tem como característica a destruição das benfeitorias existentes, o que praticamente inviabiliza o retorno à terra dos seus proprietários, gerando impactos sociais.

\section{OBJETIVO}

O objetivo geral do trabalho é fazer uma análise comparativa entre a evolução da área colhida da laranja no Estado de São Paulo, para com a cana-de-açúcar entre 1997 e 2016.

Para atingir o objetivo geral é proposto os seguintes objetivos específicos:

i) Identificar a evolução da área colhida da cana-de-açúcar e da laranja entre 1997 e 2016 no Estado de São Paulo;

ii) Fazer a proporção da área colhida da laranja pela área de cana-de-açúcar entre 1997 e 2016;

iii) Identificar a evolução de área colhida de laranja e da cana nos 20 maiores municípios produtores de laranja em 1996 e em 2016.

\section{JUSTIFICATIVA}

O trabalho se justifica pela enorme relevância da produção da laranja no Estado. A cadeia produtiva da citricultura tem um papel relevante para a sociedade brasileira: pela contribuição econômica e social. Por ano movimenta cerca de US\$ 15 bilhões e exporta US\$ 2,5 bilhões, enquanto a sua produção agrícola, junto com a agroindústria, gera 230 mil postos de trabalho (NEVES; KALAKI, 2015). No demais, o respectivo estudo é relevante na medida que fornece resultados importantes para futuros trabalhos acadêmicos.

\section{REVISÃO DE LITERATURA}

\subsection{PANORAMA DA PRODUÇÃO DE LARANJA NO BRASIL E EM SÃO PAULO}

De todas as frutas cítricas cultivadas no Brasil, a laranja é a mais importante. O País foi responsável pela produção de 17,25 milhões de toneladas no ano de 2016, sendo o maior produtor mundial (FAO, 2018). Rio Grande do Sul, Sergipe, Paraná, Minas Gerais, Bahia e São Paulo, respondem por 92,8\% da área colhida e $96 \%$ da produção brasileira. Apesar do protagonismo, São Paulo, o maior produtor com 12,8 milhões de toneladas em 2016, perdeu 334.144 mil hectares de laranja entre 1997 a 2016, principalmente em municípios localizados ao centro e norte do Estado, como Araraquara, Bebedouro, Olímpia e Itápolis (IBGE, 2018). 


\subsection{PRINCIPAIS REGIÕES PRODUTORAS DE LARANJA DO ESTADO DE SÃO PAULO}

O Fundo de Defesa da Citricultura (Fundecitrus) classifica as regiões produtoras de laranja dentro do "Cinturão Citrícola" em: Norte, Noroeste, Centro, Sul e Sudoeste, conforme Figura 1. Pela classificação municípios importantes em área colhida como: Bebedouro, Barretos, Colômbia,
Olímpia, Tabapuã, Monte Azul Paulista e Itajobi pertencem a região Norte. Araraquara, Itápolis, Tabatinga, Taquaritinga e Borborema, região Centro. Limeira, Tambaú, Casa Branca e Mogi Guaçu, região Sul. Buri, Angatuba, Avaré, Itapetininga, laras e Botucatu, região Sudoeste.

FIGURA 1 - Cinturão Citrícola dividido por regiões

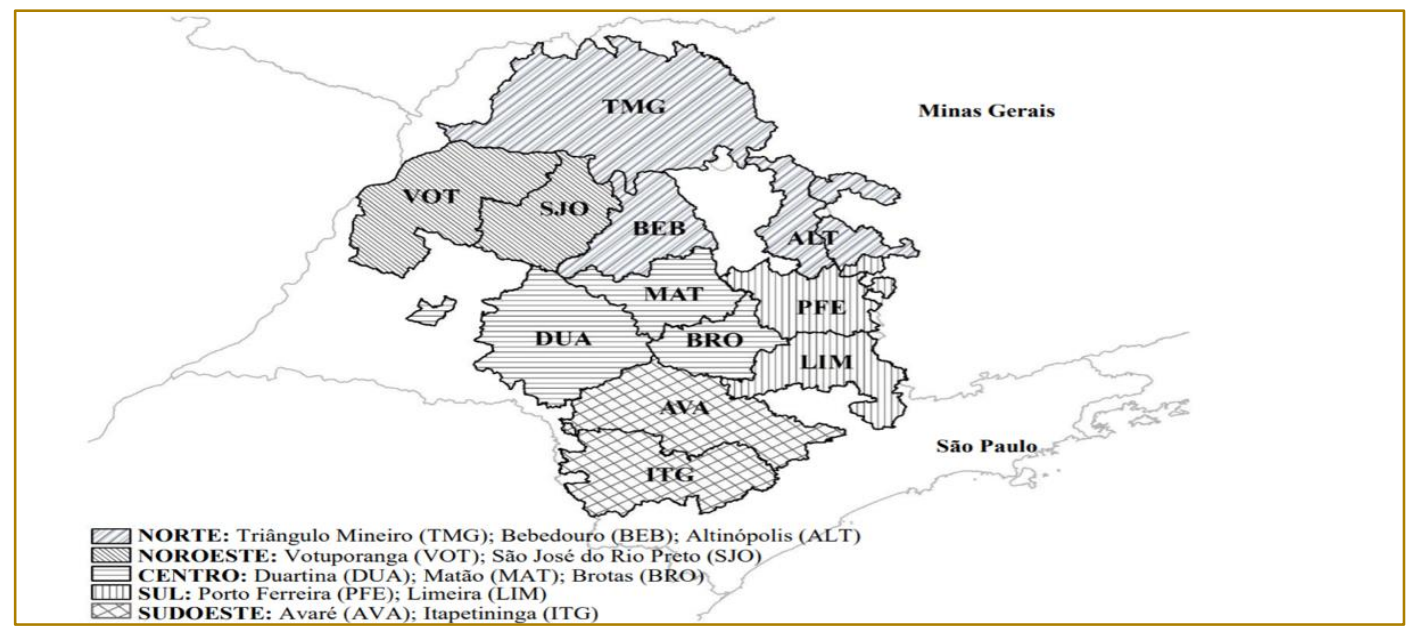

Fonte: Fundecitrus (2018)

\subsection{REDUÇÃO NO NÚMERO DE PROPRIEDADES COM LARANJA NO} ESTADO DE SÃO PAULO

Assim como ocorre a retração na área colhida de laranja, o número de propriedades destinadas à produção da laranja no Estado de São Paulo cai drasticamente ao longo dos anos, conforme Tabela 1. De 35.883 propriedades que produziam laranja na safra 1995/1996, ao máximo, 5.882 restaram na safra 20017/2018. Em cenário de concentração, dado a perda de área, as propriedades ficam maiores, em média com 70,4 hectares cada (CATI, 2018; FUNDECITRUS, 2018).

TABELA 1 - Área total com laranja, número de propriedades com laranja e área média por propriedade.

\begin{tabular}{|c|c|c|c|}
\hline Ano Safra & $\begin{array}{c}\text { Área total com laranja } \\
\text { (hectares) }\end{array}$ & Número de propriedades & $\begin{array}{c}\text { Área média/propriedade } \\
\text { (hectares) }\end{array}$ \\
\hline $1995 / 96^{*}$ & 865.801 & 35.883 & 24,1 \\
\hline $2007 / 08^{*}$ & 741.316 & 20.720 & 35,8 \\
\hline $2017 / 18^{\star \star}$ & 414.353 & 5.882 & 70,4 \\
\hline
\end{tabular}

Fonte: *CATI (2018), Secretaria de Agricultura e Abastecimento, CATI/IEA, Projeto LUPA. Somente São Paulo; ** Fundecitrus (2018), Pesquisa de estimativa de safra 2018. São Paulo e Triângulo/Sudoeste Mineiro.

\subsection{DENSIDADE DE PLANTIO COMO MECANISMO DE AUMENTO DE PRODUTIVIDADE}

A produtividade ou rendimento é um importante indicador de eficiência técnica das lavouras. O adensamento em citros é uma boa alternativa para aumentar produção sem a necessidade de aumentar a área de plantio, porém fatores como variedades e portaenxertos e região de cultivo são fatores que devem ser considerados (TROMBIN, 2018). O 
adensamento de novos plantios de citros é uma estratégica adotada para ampliação da produtividade, sendo que a cultura apresenta boa resposta de produção quando cultivada sob maiores densidades - mais plantas por hectare (STUCHI; GIRARDI, 2011).

A técnica do adensamento tem se intensificado na citricultura, onde ganhos de rendimento (produtividade) por hectare, podem ocorrer por maior densidade de plantas por área. A produtividade na citricultura, pode ser expressa em termos de: caixa por planta; em tonelada por unidade de área (hectare); em caixas por hectare cultivado; ou em caixas por área com plantas em produção (AMARO; CASER, 2004).

Dados do Fundecitrus, conforme Gráfico1, apontam um crescimento na densidade média de plantas por ano de plantio no Cinturão Citrícola (São Paulo e Triângulo/Sudoeste Mineiro) (FUNDECITRUS, 2018).

GRÁFICO 1 - Densidade média (plantas por hectare) por ano de plantio

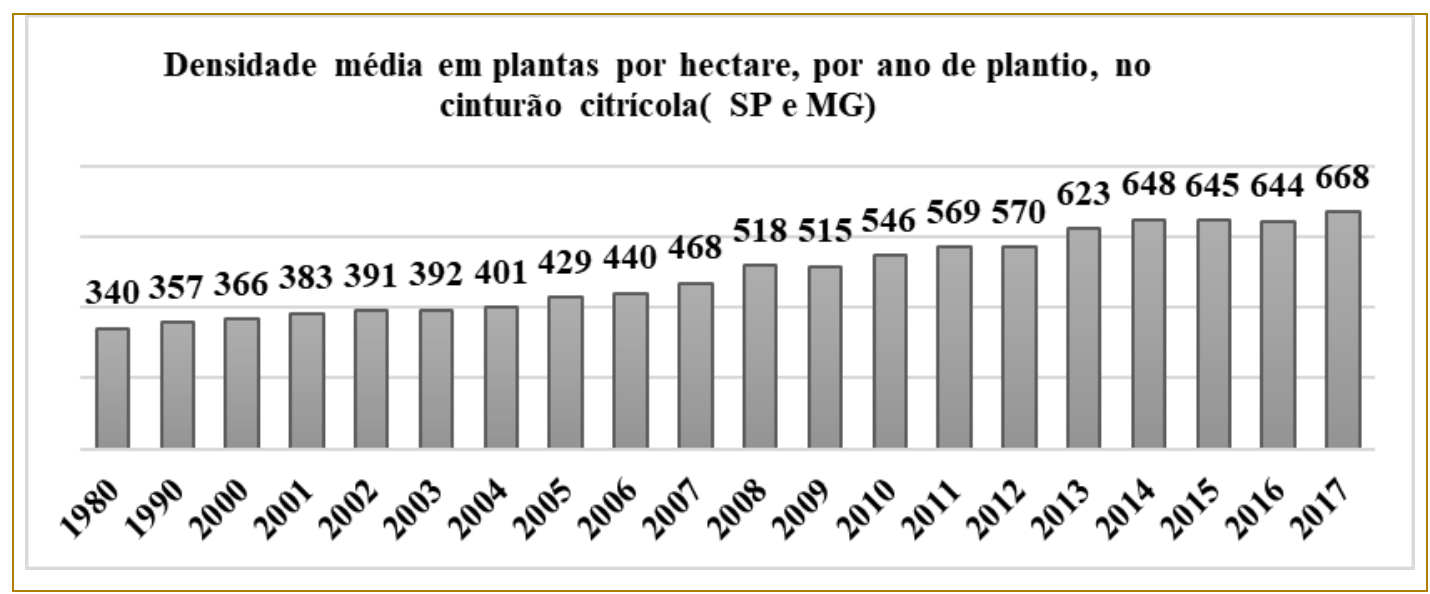

Fonte: Elaboração própria a partir de dados do Fundecitrus (2018)

O adensamento de laranjeiras valência em 727 plantas por hectare produziu 2 vezes a mais que o plantio com 615 plantas por hectare, na primeira colheita (GRIZOTTO et al., 2012). A maior concentração de plantas por área (adensamento) é uma tecnologia que tende cada vez a ser mais adotada na realidade atual da citricultura paulista e brasileira, visto a necessidade de obtenção do máximo retorno no menor tempo possível (AZEVEDO et al., 2015). O aumento de produtividade nos pomares paulista, está relacionado a melhores práticas agrícolas, melhorias na implantação, ao manejo correto do pomar e também ao maior adensamento de plantas por hectare (ERPEN et al., 2018).

\subsection{PANORAMA E CONTEXTUALIZAÇÃO DA PRODUÇÃO DA CANA-DE-AÇÚCAR EM SÃO PAULO}

A cana-de-açúcar é uma das principais lavouras cultivadas no Brasil, em especial no Estado de São Paulo, o principal produtor, com 5,6 milhões de hectares em área colhida em 2016 (IBGE, 2018).
Esta relevância é fruto de alguns movimentos importantes na cadeia produtiva. Criado em 1975, o Programa Nacional do Álcool (Proálcool), estimulava o desenvolvimento de um combustível alternativo ao petróleo, tendo papel importante na expansão da cana-deaçúcar no Brasil (GUIMARÃES, 2008). Entre 1980 a 1985, o Proálcool teve forte evolução, seja por guerras no Oriente Médio, com consequente aumento nos preços do petróleo, seja pelo incentivo no uso e na fabricação de álcool hidratado como combustível, o que acelerou o avanço da cultura da cana-de-açúcar e a instalação de destilarias autônomas (SHIKIDA; BACHA, 1999).

As tecnologias produzidas no mercado do etanol têm sido catalisadoras de demanda, como o desenvolvimento do veículo Flex Fuel, que teve sua introdução efetiva no mercado brasileiro a partir de 2003. Este cenário permitiu a consolidação no mercado nacional de veículos bicombustíveis, gerando maior demanda por etanol hidratado no País, por consequência a expansão da produção canavieira (LIMA; DE SOUSA, 2015). 
Entre 1995 e 2013, expansão canavieira em São Paulo foi impulsionada, principalmente, pelo aumento da área cultivada e preços, com baixa contribuição do efeito rendimento, evidenciado pela elevada contribuição do efeito substituição na expansão da área cultivada. Nesse período, a lavoura canavieira expandiu em 2,49 milhões de hectares no Estado de São Paulo, substituindo lavouras temporárias, permanentes e pastagens (CAMARA; CALDARELLI, 2016). A lavoura da cana-de-açúcar, vem se expandindo até mesmo sobre áreas do Estado de São Paulo que tradicionalmente desenvolviam a citricultura, fazendo com que essa lavoura (citros) venha a se deslocar do centro-norte paulista para as regiões sul-sudeste desse Estado, que apresentam melhores condições para o desenvolvimento dessa atividade (GUIMARÃES, 2008).

Segundo Neves et al. (2007), os antigos pomares do norte e nordeste do Estado de São Paulo, foram substituídos principalmente pela cana-de-açúcar. Em 2001, a área plantada de cana no norte do cinturão citrícola era o dobro da área de laranja e, em 2005 , essa relação passou a ser praticamente 3 vezes superior.

\section{MATERIAL E MÉTODOS}

A pesquisa foi desenvolvida com um viés de exploração, em uma revisão de literatura fundamentada em uma bibliografia, bem como, sobre um levantamento documental de dados primários estatísticos de domínio público.

O primeiro desafio do trabalho aqui apresentado, foi a pesquisa bibliográfica, através da fundamentação teórica e coleta de dados secundários. O intuito foi buscar em revistas, teses, sites, artigos científicos, livros e outras fontes, estudos e pesquisas relacionados ao tema desenvolvido no artigo, procurando familiaridade com o contexto da pesquisa.

O levantamento de dados, é a primeira iniciativa de qualquer pesquisa, podendo ser efetuado de maneira documental, através de fontes primárias, ou por pesquisa bibliográfica, quando no uso de fontes secundárias (MARCONI; LAKATOS, 2010). Segundo Gil (2010), a pesquisa bibliográfica, além da fundamentação teórica sobre o tema tratado, permite a obtenção de dados que estão muito dispersos no espaço ou que pertencem a séries históricas.

O segundo passo do estudo foi efetuar um levantamento de dados primários em órgãos governamentais, como o IBGE e a CATI, órgãos intergovernamentais como a $F A O$ e Associações, como o Fundecitrus. A terceira etapa consistiu na estruturação dos dados dos indicadores de produção paulista das culturas da laranja e cana-de-açúcar em software Excel 2016, fazendo as devidas evoluções de área colhida, produção e produtividade. Após a tabulação e estruturação dos dados, procurou-se em consonância, ou não, com a literatura, analisar as evoluções dos indicadores de produção e levantar hipóteses sobre as possíveis variáveis que podem estar provocando a mudança na geografia da produção da laranja no Estado de São Paulo.

\section{RESULTADOS E DISCUSSÕES}

Ao se analisar as evoluções dos indicadores de área colhida, produção e produtividade da laranja, e a respectiva comparação com a área colhida da cana, é importante considerar: o Estado de São Paulo perdeu $45,4 \%$ de sua área colhida com laranja em 20 anos (1997 a 2016), retrocedendo para 402,6 mil hectares (Ha), conforme Tabela 2. Entretanto, a produção em toneladas recua, não proporcionalmente e perde somente $15,4 \%$ do volume produzido. Isto é explicado pela elevação na produtividade (rendimento em quilogramas por hectare), que o Estado adquiriu, passando de 20,6 mil toneladas por hectare em 1997, para 31,9 mil toneladas por hectare em 2016, em evolução de 54,9\% na produtividade. Ou seja, a área que sofreu retração foi compensada pelo aumento de produtividade, que mitigou a perda em volume de toneladas produzido. 
TABELA 2 - Área colhida da cana de açúcar e da laranja em hectares $(\mathrm{Ha})$ e o rendimento (Kg/Ha) e a produção (Toneladas) da laranja no Estado de São Paulo, entre 1997 e 2016.

\begin{tabular}{|c|c|c|c|c|c|}
\hline Ano & $\begin{array}{l}\text { Cana-de- } \\
\text { Área colhida } \\
(\mathrm{Ha})\end{array}$ & $\begin{array}{c}\text { Laranja } \\
\text { Área colhida } \\
(\mathrm{Ha})\end{array}$ & $\begin{array}{c}\text { Proporção da área } \\
\text { da laranja pela } \\
\text { cana }\end{array}$ & $\begin{array}{c}\text { Laranja } \\
\text { Rendimento } \\
(\mathrm{Kg} / \mathrm{Ha})\end{array}$ & $\begin{array}{c}\text { Laranja } \\
\text { Produção } \\
\text { (Toneladas) }\end{array}$ \\
\hline 1997 & 2.446 .300 & 736.770,00 & $30,1 \%$ & $20.604,48$ & 15.180 .800 \\
\hline 1998 & 2.564 .950 & $766.640,00$ & $29,9 \%$ & $17.774,40$ & 13.626 .680 \\
\hline 1999 & 2.555 .000 & 776.690,00 & $30,4 \%$ & $19.968,00$ & 15.508 .960 \\
\hline 2000 & 2.484 .790 & $609.475,00$ & $24,5 \%$ & 23.359,84 & 14.237 .331 \\
\hline 2001 & 2.567 .178 & $581.487,00$ & $22,7 \%$ & $23.267,00$ & 13.529 .892 \\
\hline 2002 & 2.660 .950 & $586.837,00$ & $22,1 \%$ & $25.150,00$ & 14.759 .067 \\
\hline 2003 & 2.817 .604 & $600.060,00$ & $21,3 \%$ & $22.242,00$ & 13.347 .090 \\
\hline 2004 & 2.951 .804 & $587.935,00$ & $19,9 \%$ & $25.033,00$ & 14.717 .790 \\
\hline 2005 & 3.084 .752 & $574.510,00$ & $18,6 \%$ & $25.005,00$ & 14.366 .030 \\
\hline 2006 & 3.495 .893 & $571.532,00$ & $16,3 \%$ & $25.137,00$ & 14.367 .011 \\
\hline 2007 & 3.890 .414 & 584.096,00 & $15,0 \%$ & $25.517,00$ & 14.904 .621 \\
\hline 2008 & 4.530 .784 & $592.566,00$ & $13,1 \%$ & $24.533,00$ & 14.537 .610 \\
\hline 2009 & 4.781 .465 & $551.901,00$ & $11,5 \%$ & 24.718,00 & 13.642 .165 \\
\hline 2010 & 4.986 .634 & $548.103,00$ & $11,0 \%$ & $26.034,00$ & 14.269 .383 \\
\hline 2011 & 5.205 .841 & $563.952,00$ & $10,8 \%$ & $27.118,00$ & 15.293 .506 \\
\hline 2012 & 5.150 .461 & 470.082,00 & $9,1 \%$ & $28.433,00$ & 13.365 .983 \\
\hline 2013 & 5.399 .235 & $446.043,00$ & $8,3 \%$ & $29.187,00$ & 13.018 .878 \\
\hline 2014 & 5.566 .084 & 423.987,00 & $7,6 \%$ & 28.988,00 & 12.290 .567 \\
\hline 2015 & 5.527 .560 & 412.635,00 & $7,5 \%$ & 29.758,00 & 12.279 .253 \\
\hline 2016 & 5.588 .566 & 402.626,00 & $7,2 \%$ & $31.908,00$ & 12.847 .146 \\
\hline $\begin{array}{c}\text { Variação } \\
\%\end{array}$ & $128,40 \%$ & $-45,40 \%$ & $-35,4 \%$ & $54,90 \%$ & $-15,40 \%$ \\
\hline
\end{tabular}

Fonte: Elaboração própria a partir dos dados do IBGE (2018).

O resultado corrobora com o estudo sobre os indicadores de produção da laranja paulista, em que as elevadas produtividades atingidas, foram compensando a perda de área colhida de laranja entre 2001 a 2015, de maneira que o recuo na produção total em toneladas fosse atenuado (ERPEN et al., 2018). Em contrapartida, no mesmo período, a cana-deaçúcar evoluiu 128,4\% em área colhida, alcançando 5,58 milhões de hectares. Nesta evolução, a área da laranja que representava $30,1 \%$ da de cana em 1997, retroage para apenas $7,2 \%$ em 2016. Em consonância com Erpen et al. (2018), que avaliou a evolução da cana-de-açúcar de 2001 a 2015 em 115\% no Estado de São Paulo, seguindo a mesma tendência.
Em estudo sobre a citricultura brasileira, de 1990 a 2005, no que diz respeito a indicadores de produção, a variável de área colhida, tem uma retração em que, pode- se concluir apressadamente por uma estagnação do setor, entretanto, com um olhar mais detido nos dados da produção citrícola, sobretudo para o caso paulista, revelam uma manutenção nos últimos anos dos patamares de produção, sugerindo um aumento na produtividade (BOECHAT, 2015).

\subsection{DESLOCAMENTO E PROTAGONISMO NA ÁREA COLHIDA DA LARANJA NO ESTADO DE SÃO PAULO}

Na medida que ocorreu uma diminuição na área total de laranja em hectares no Estado 
de São Paulo, alguns municípios foram perdendo o protagonismo em detrimento a outros, conforme Tabela

3.

TABELA 3 - 20 maiores municípios em área colhida de laranja, em São Paulo, em 1996 e 2016.

\begin{tabular}{|c|c|c|c|c|c|c|c|}
\hline Ano & Posição & Município & Hectare & Ano & Posição & Município & Hectare \\
\hline 1996 & 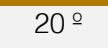 & Santa R. Passa Quatro & 8.800 & 2016 & 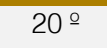 & Taquaritinga & 4.538 \\
\hline 1996 & $19 \stackrel{\circ}{2}$ & Colina & 8.960 & 2016 & $19 \stackrel{0}{2}$ & Monte Azul Paulista & 4.788 \\
\hline 1996 & 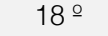 & Borborema & 9.200 & 2016 & 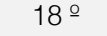 & Buri & 4.800 \\
\hline 1996 & $17^{\circ} \stackrel{\circ}{ }$ & Boa Esperança do Sul & 10.000 & 2016 & $17 \stackrel{\circ}{-}$ & Brotas & 4.980 \\
\hline 1996 & 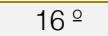 & Tabapuã & 10.400 & 2016 & 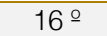 & Angatuba & 5.000 \\
\hline 1996 & $15 \circ$ & Itajobi & 10.520 & 2016 & 15 & Conchal & 5.500 \\
\hline 1996 & $14^{\circ}$ & Colômbia & 10.712 & 2016 & $14^{\circ}$ & Bebedouro & 6.250 \\
\hline 1996 & $13^{\circ}$ & Itapetininga & 11.200 & 2016 & $13^{\circ}$ & Pirassununga & 6.667 \\
\hline 1996 & $12^{\circ}$ & Tabatinga & 11.800 & 2016 & 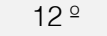 & Avaré & 6.700 \\
\hline 1996 & 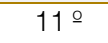 & Brotas & 12.000 & 2016 & $11^{\circ}$ & Mogi Mirim & 7.000 \\
\hline 1996 & $10^{\circ}$ & Limeira & 12.800 & 2016 & $10^{\circ}$ & Aguaí & 7.350 \\
\hline 1996 & $9 \stackrel{\circ}{9}$ & Monte Azul Paulista & 14.000 & 2016 & $9 \stackrel{\circ}{9}$ & Barretos & 7.449 \\
\hline 1996 & 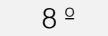 & Taquaritinga & 14.400 & 2016 & 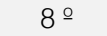 & Botucatu & 8.000 \\
\hline 1996 & $7 \stackrel{\circ}{=}$ & Araraquara & 16.000 & 2016 & $7 \stackrel{\circ}{=}$ & laras & 8.000 \\
\hline 1996 & $6 \div$ & Barretos & 16.800 & 2016 & 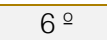 & Tambaú & 8.400 \\
\hline 1996 & 50 & Casa Branca & 18.400 & 2016 & 5 & Itápolis & 10.504 \\
\hline 1996 & $4 \stackrel{\circ}{=}$ & Olímpia & 22.000 & 2016 & 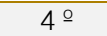 & Itapetininga & 11.400 \\
\hline 1996 & $3 \stackrel{\circ}{\circ}$ & Bebedouro & 29.800 & 2016 & $3 \stackrel{\circ}{ }$ & Casa Branca & 13.000 \\
\hline 1996 & 20 & Itápolis & 32.000 & 2016 & $2 \circ$ & Mogi Guaçu & 13.720 \\
\hline 1996 & $1 \stackrel{\circ}{=}$ & Mogi Guaçu & 40.800 & 2016 & $1 \stackrel{\circ}{=}$ & Colômbia & 14.553 \\
\hline Total & & Total hectares & 320.592 & Total & & Total hectares & 158.599 \\
\hline
\end{tabular}

Fonte: Elaboração própria com dados do IBGE (2018).

Municípios localizados ao norte, centro e sul do Estado, com elevada representatividade em área colhida de laranja em 1996, como: Araraquara, Olímpia, Limeira, Tabatinga, Itajobi, Tabapuã e Borborema, não figuraram entre os 20 maiores em área no ano de 2016. Por outro lado, municípios com pouca tradição no cultivo da laranja na década de 90, e localizados mais ao sudoeste do Estado, como Buri, Angatuba, laras, Botucatu e Avaré, aparecem com relevância em 2016.

A literatura cita possíveis causas do deslocamento dos laranjais do norte e centro de São Paulo para a região sudoeste do Estado. Condições de clima mais favorável, menor incidência de doenças e pragas e menor preço das terras ao sudoeste, além da demanda por terras por parte das usinas de cana-de-açúcar no centro norte do Estado, estariam provocando este fenômeno. Sobre o efeito do clima em Itápolis (região centro), deve ser questionado se antes de grandes cultivos de citros se estabelecerem na região, houve uma organização ao nível de prever que mudanças climáticas poderiam apontar para um cenário futuro em que essa região já não apresentasse mais um contexto climático favorável aos citros (MAÇORANO, 2017).

Em função dos sérios problemas fitossanitários da citricultura, existe tendência de transposição de parte da área plantada da região tradicional (compreendida entre as regiões Norte e Centro-Sul do Estado de São Paulo) para diversos municípios do sudoeste paulista, tais como: Buri, Itapetininga, Avaré, Angatuba, Paranapanema (SAA, 2009).

Segundo Neves et al. (2010), a citricultura que até então se concentrava ao norte do cinturão citrícola (São Paulo e Triângulo/Sudoeste Mineiro), se deslocou para regiões com menos tradição, no sudoeste paulista, nas proximidades da rodovia Castelo Branco em São Paulo. Condições climáticas mais favoráveis, menor pressão de pragas e doenças e menor valor das terras na região da "Castelo", e pressão das Usinas de canade-açúcar por áreas mais ao norte e centro do 
Estado tiveram influência nesta dinâmica. Nos últimos anos, as áreas de laranja situadas nas regiões tradicionais do norte e centro-sul do Estado de São Paulo vêm apresentando redução. No entanto, a região sudoeste caracteriza-se por maior incremento tanto na área plantada como na produção de frutos. 0 deslocamento da citricultura para esta região, além de possuir condições adequadas ao plantio, foi uma alternativa para minimizar o efeito das doenças que oneram o processo produtivo (CAPUTO, 2012).

\subsection{AVANÇO DA CULTURA DA CANA-DE- AÇÚCAR NO ESTADO DE SÃO PAULO}

A Tabela 3, evidenciou o protagonismo em 20 municípios (maiores) paulistas na área colhida de laranja em 1996, e suas evoluções em 2016. Paralelo a esta dinâmica, estes mesmos municípios tiveram uma forte evolução positiva na cultura de cana-de-açúcar de 1996 para 2016, exceção ao município de Limeira, conforme Tabela 4.

TABELA 4 - Evolução da área colhida (hectares) de cana-de-açúcar em 20 municípios paulistas.

\begin{tabular}{|l|c|c|c|}
\multicolumn{1}{|c|}{ Município } & Hectares em 1996 & Hectares em 2016 & $11,8 \%$ \\
\hline Araraquara (SP) & 34.000 & 38.000 & $445,8 \%$ \\
\hline Barretos (SP) & 12.000 & 65.500 & $79,5 \%$ \\
\hline Bebedouro (SP) & 20.000 & 35.900 & $40,0 \%$ \\
\hline Boa Esperança do Sul (SP) & 25.000 & 35.000 & $665,0 \%$ \\
\hline Borborema (SP) & 4.000 & 30.600 & $78,7 \%$ \\
\hline Brotas (SP) & 15.000 & 26.800 & $214,3 \%$ \\
\hline Casa Branca (SP) & 7.000 & 22.000 & $233,3 \%$ \\
\hline Colina (SP) & 8.100 & 27.000 & $434,5 \%$ \\
\hline Colômbia (SP) & - & 38.000 & $400,0 \%$ \\
\hline Itajobi (SP) & 5.500 & 29.400 & $105,6 \%$ \\
\hline Itapetininga (SP) & 2.200 & 11.000 & $-36,4 \%$ \\
\hline Itápolis (SP) & 18.000 & 37.000 & $144,4 \%$ \\
\hline Limeira (SP) & 22.000 & 14.000 & $1050,6 \%$ \\
\hline Mogi Guaçu (SP) & 4.500 & 11.000 & $332,7 \%$ \\
\hline Monte Azul Paulista (SP) & 1.195 & 13.750 & $107,0 \%$ \\
\hline Olímpia (SP) & 10.400 & 45.000 & $321,4 \%$ \\
\hline Santa Rita do Passa Quatro (SP) & 7.970 & 16.500 & $167,5 \%$ \\
\hline Tabapuã (SP) & 4.770 & 20.100 & $86,7 \%$ \\
\hline Tabatinga (SP) & 4.070 & 10.889 & $151,7 \%$ \\
\hline Taquaritinga (SP) & 15.000 & 28.000 & \\
\hline
\end{tabular}

Fonte: Elaboração própria a partir de dados do IBGE (2018).

\section{CONSIDERAÇÕES FINAIS}

A produção de laranja no Estado de São Paulo sofreu mudanças profundas nos últimos anos. De 1997 a 2016, a área colhida recuou em $45,4 \%$ e a produção $15,4 \%$, contudo, o rendimento (produtividade) em $\mathrm{kg} /$ hectare cresceu 54,9\%. O uso de tecnologia, melhores práticas culturais, o avanço de áreas irrigadas, o correto manejo fitossanitário e nutricional das plantas, melhor genética das variedades e porta-enxertos dos pomares de laranja, mas sobretudo a adoção de uma maior densidade de plantas por hectare, foram variáveis fundamentais no avanço da produtividade nos pomares de São Paulo. Em evolução negativa, o número de propriedades com laranja recuou 6 vezes, de 35.883 em 1995, para ao máximo 5.882 em 2017, saindo de 20,1 para 70,4 hectares de área média por propriedade, ou seja, uma concentração na área colhida e na produção. Paralelo a esta dinâmica, a cana-de-açúcar evoluiu 128,4\% em área colhida no Estado de São Paulo (1997 a 2016), avançando em regiões que tradicionalmente cultivavam a citricultura, sobretudo na região norte e centro do Estado de São Paulo, deslocando a produção de 
laranja para regiões menos tradicionais, em especial no sudoeste paulista.

Essa movimentação ocorre de maneira complementar na medida que as áreas tradicionais da citricultura ao norte e centro são assediadas por usinas de cana-de-açúcar ali presentes, como também as condições climáticas (temperatura amena no florescimento e maior regularidade nas chuvas), atraíram a citricultura para o sudoeste paulista. Ademais, no início da migração da citricultura para o sudoeste paulista, existia uma menor pressão de pragas e doenças na região, como também

\section{REFERÊNCIAS}

[1] AGUIAR, J.; SOUZA, P.M. Impactos do crescimento da produção de cana-de-açúcar na agricultura dos oito maiores Estados, produtores. Revista Ceres, v.61, n.4, p.482-493, 2014.

[2] AMARO, A.A.; CASER, D.V. Evolução da produtividade na citricultura paulista. Informações Econômicas, v.34, n.10, p.6-12, 2004.

[3] AZEVEDO, F.A.; PACHECO, C.A.; SCHINOR, E.H. CARVALHO, S.A.; CONCEIÇÃO, P.M. Produtividade de laranjeira Folha Murcha enxertada em limoeiro Cravo sob adensamento de plantio. Bragantia, v.74, n.2, p.184-188, 2015.

[4] BOECHAT, C.A. A questão agrária e a crise da citricultura brasileira. Teoria e Cultura, v.10, n.2, p.76-93, 2015.

[5] CAMARA, M.R.G.; CALDARELLI, C.E. Expansão canavieira e o uso da terra no Estado de São Paulo. Estudos Avançados, v.30, n.88, p.93116, 2016

[6] CAMARGO, A.M.A.P.; CASER, D.V.; CAMARGO, F.P.; OLIVETTE, M.P.A.; SACHS, R.C.C.; TORQUATO, S.A. Dinâmica e tendência da expansão da cana-de-açúcar sobre as demais atividades agropecuárias, Estado de São Paulo, 2001-2006. Informações Econômicas, v.38, n.3, p.47-66, 2008.

[7] CAPUTO, M.M. Estudo avalia cultivares de laranja de maturação precoce. Agência USP de Notícias. 2012. Disponível em: $<$ http://www.usp.br/agen/?p=107981>. Acesso em: 3 jul. 2018.

[8] CATI - Coordenadoria de Assistência Técnica Integral. Levantamento censitário das unidades de produção agropecuária do Estado de São Paulo - LUPA. 2018. Disponível em: $<$ http://www.cati.sp.gov.br/projetolupa/>. Acesso em: 29 maio 2018.

[9] ERPEN, L.; MUNIZ, F.R.; MORAES, T.S.; TAVANO, E.C.R. Análise do cultivo da laranja no as terras eram menos valorizadas que ao centro e norte do Estado de São Paulo.

A pesquisa em caráter exploratório, sugere modificações importantes no cenário geográfico da produção da laranja e da canade-açúcar no Estado de São Paulo, que podem desencadear mudanças relevantes de caráter social e econômico, merecendo estudos mais profundos sobre o tema. Como restrição à pesquisa, a falta de mais estudos relacionados ao recente fenômeno da produção paulista de laranja, limitou uma maior compreensão do contexto estudado.

Estado de São Paulo de 2001 a 2015. Revista IPecege, v.4, n.1, p.33-43, 2018.

[10] FAO - Food and Agriculture Organization of the Unite Nations. Orange production. Rome: FAO, 2018. Disponível em: <http://www.fao.org/faostat/en/\#data/QC>. Acesso em: 25 fev. 2018.

[11] FUNDECITRUS - Fundo de Defesa da Citricultura. Inventário de árvores e estimativa da safra de laranja no Cinturão Citrícola de São Paulo e Triângulo/Sudoeste Mineiro. 2018. Disponível em: <http://www.fundecitrus.com.br/pdf/pes_relatorios/ 2018_05_21_Invent\%C3\%A1rio_e_Estimativa_do_C inturao_Citricola_2018-20191.pdf>. Acesso em: 13 jul. 2018.

[12] GIL, A.C. Como elaborar projetos de pesquisa. 5. ed. São Paulo: Atlas, 2010.

[13] GRIZOTTO, R.K.; SILVA, J.A.A.; MIGUEL, F.B.; MODESTO, R.T.; VIEIRA JÚNIOR, J.B. Qualidade de frutos de laranjeira Valência cultivada sob sistema tecnificado. Revista Brasileira de Engenharia Agrícola e Ambiental, v.16, n.7, p. 784789, 2012

[14] GUIMARÃES, L.S.P. Dinâmica espacial da cana-de-açúcar no Brasil contemporâneo. 2008. Disponível

em: <http://www.mma.gov.br/estruturas/PZEE/_arquivos 128_10122008091059.pdf>. Acesso em: 9 jul. 2018.

[15] IBGE - Instituto Brasileiro de Geografia e Estatística. Sistema IBGE de recuperação automática. Produção agrícola municipal. 2018. Disponível em <https://sidra.ibge.gov.br/pesquisa/pam/tabelas>. Acesso em: 12 fev. 2018

[16] LIMA, N.C.; DE SOUZA, G.H.S. A demanda do etanol e sua caracterização no mercado brasileiro de combustíveis. Organizações Rurais \& Agroindustriais, v.16, n.4, p.532-544, 2015. 
[17] MAÇORANO, R.P. Impacto das mudanças climáticas na dinâmica na citricultura no Estado de São Paulo. 88 f. Dissertação (Mestrado em Engenharia Agrícola) - Faculdade de Engenharia Agrícola, Universidade Estadual de Campinas, Campinas, 2017

[18] MARCONI, M.A.; LAKATOS, E.M. Fundamentos de metodologia de científica. 7. ed. São Paulo: Atlas, 2010.

[19] NEVES, M.F.; KALAKI, R.B. Citricultura: perspectivas para a produção brasileira. Agroanalysis, v.35, n.6, p.26-27, 2015.

[20] NEVES, M.F.; LOPES, F.F.L.; TROMBIN, V.G.; AMARO, A.A.; NEVES, E.M.; JANK, M.S. Citros: Mudanças geográficas. Agroanalysis, v.7, n.7, p.12-16, 2007.

[21] NEVES, M.F.; TROMBIN, V.G.; MILAM, P.; LOPES, F.F.; CRESSONI, F.; KALAKI, R. O retrato da citricultura brasileira. 1. ed. São Paulo: FEA/USP, 2010.

[22] OLIVEIRA, A.F.M. Impactos dos preços sobre a oferta canavieira no Estado de São Paulo entre 1995 a 2015. 77 f. Dissertação (Mestrado em
Administração) - Universidade Estadual Paulista, Jaboticabal, 2017.

[23] OSORIO, R.M.L.; LIMA, S.M.V.; SANT'ANNA, R.L.S.; CASTRO, A.M.G. Demandas tecnológicas da cadeia produtiva de laranja no Brasil. Latin American Journal of Business Management, v.8, n.2, p.40-66, 2017.

[24] SAA - Secretaria de Agricultura e Abastecimento. Encontro de citricultura movimenta o Sudoeste Paulista. 2009. Disponível em: $<$ http://www.agricultura.sp.gov.br/noticias/encontro -de-citricultura-movimenta-o-sudoeste-paulista/> Acesso em: 2 jul. 2018.

[25] SHIKIDA, P.F.A.; BACHA, C.J.C. Evolução da agroindústria canavieira brasileira de 1975 a 1995. RBE, v.53, n.1, p.69-89, 1999.

[26] STUCHI, E.S.; GIRARDI, E.A. Adensamento de plantio deve ser o quarto elemento no manejo do HLB. Citricultura Atual, v.14, n.81, p.12-16, 2011.

[27] TROMBIN, V. Inventário de árvores. Revista Citricultor, ano IX, n.45, p.13-15, 2018. 


\section{Gapítulo 12}

\section{PROPOSTA DE APLICACÃO DA FERRAMENTA KANBAN EM UMA INDÚSTRIA DE RÁFIAS}

\section{Anderson Castagna}

\section{Stefan Antonio Bueno}

\section{Mara Lucia Grando}

\section{Cleusa Teresinha Anschau}

Resumo: Este artigo apresenta os resultados de uma pesquisa quali-quantitativa que teve a finalidade de identificar, analisar e propor melhorias no processo de fabricação de big bags de uma indústria de ráfia. Foram analisados todos os processos desde a chegada da matéria-prima para o setor de laminação da empresa até o setor de acabamento utilizando a ferramenta de mapeamento de fluxo de valor (MFV). Como resultado é proposto um mapa de fluxo de valor futuro onde através da implementação de um kanban entre o processo fornecedor e o processo cliente resultou em uma redução do lead time em 0,20 dias, aumento do giro de estoque em 0,90 vezes, e redução do estoque existente em 55.410 peças. Com isso, uma economia mensal de 69,89\%, além de um retorno de investimento para implementação do projeto a partir do segundo mês. Todos os resultados implicam em um processo mais organizado e mais rentável.

Palavras-chave: Mapa de fluxo de valor; Kanban; Otimização; Logística lean. 


\section{INTRODUÇÃO}

A competitividade existente em todos os ramos industriais, faz com que todas as empresas dispostas a andarem em sintonia ou a frente de seus concorrentes, adotem filosofias e/ou ferramentas para melhorar fatores como, aumento da produtividade, padronização dos processos, melhoria da qualidade, segurança, precisão, monitoramento remoto e otimização de recursos. Diante das pressões estabelecidas pelos clientes e com o cenário econômico instável, produzir com o menor custo possível é o diferencial para conseguir se manter competitivo no mercado.

O Sistema Toyota de Produção (STP) ou Produção Enxuta é uma das filosofias que auxiliam na melhoria desses fatores. O termo enxuto, segundo Moreira (2015) tem a ver com a quantidade produzida certa, as coisas certas, no tempo certo, no lugar certo, e ao mesmo tempo diminuindo desperdícios, sendo flexível e estando aberto a mudanças, esperando como resultado um maior sucesso em longo prazo.

O Kanban é uma das ferramentas utilizadas para realizar o controle do sistema puxado. De acordo com Moreira (2015, p. 17) "kanban é uma ferramenta simples de controle por meio da qual o sistema puxado de produção é gerenciado. "Planejando e controlando a ferramenta é possível criar um sistema que o processo posterior pode solicitar ao processo anterior um material específico, de acordo com a necessidade, evitando assim o acúmulo de estoque em processo.

O presente trabalho tem como tema apresentar a proposta da aplicação de um Kanban desenvolvido através de uma oportunidade de melhoria observada após a elaboração do mapeamento do fluxo de valor completo de uma linha de produção, mais precisamente no setor de Corte de Big Bag de uma indústria de ráfia localizada no Oeste de Santa Catarina.

O estudo visa o melhoramento do fluxo, otimizando o espaço físico utilizado pelo estoque entre um processo e outro, apresentando novos equipamentos de armazenagem e produzindo apenas na quantidade necessária através da produção puxada, proporcionando assim a redução dos desperdícios e aumento da eficiência.

\section{FUNDAMENTAÇÃO TEÓRICA}

\subsection{LEAN MANUFACTURING}

O termo Lean Manufacturing surgiu na década de 1980, através de pesquisas realizadas pelo Massachussetts Institude of Technology (MIT) e pela divulgação do livro mundialmente conhecido, escrito por James Wokmack, Daniel Jones e Daniel Ross, "A Máquina que Mudou O Mundo". A metodologia lean, logo se tornou uma das maneiras para se referir ao STP, já que tinha os mesmos princípios, a redução dos desperdícios.

O foco do lean manufacturing é a produção enxuta, e visa a eliminação dos sete desperdícios identificado por Ohno, sendo eles: excesso de produção, defeitos, espera, superprocessamento, movimentação desnecessária, estoque e transporte (WERKEMA, 2011).

Ademais, Werkema (2011) cita cinco princípios básicos do lean:

- Especificar o Valor: Entender o que é valor para o cliente;

Identificar o Fluxo de Valor: Visualizar as etapas do processo produtivo, e eliminar as que não geram valor e são desnecessárias para a qualidade do produto.

Criar Fluxos Contínuos: O fluxo deve ocorrer naturalmente com a puxada do processo seguinte.

Produção Puxada: O cliente puxa a produção, e não a empresa empurra os materiais para o estoque.

Buscar a Perfeição: Os processos devem ser claros, e os colaboradores devem ter em mente a busca pela perfeição.

Assim entende-se que o lean busca entregar ao cliente apenas o que ele entende como valor, eliminando tarefas e processos, que ocorrem de forma desnecessária, não acrescentando valor ao produto.

A agregação de valor é qualquer atividade exercida que seja entendida pelo cliente como valor, por exemplo, as etapas do processo de fabricação. Já a não geração de valor, são atividades que geram custos e não atribuem valor ao serviço ou produto, por exemplo, retrabalho (LEAN INSTITUTE BRASIL, 2011). 


\subsection{MAPA DE FLUXO DE VALOR}

O mapa de fluxo de valor (MFV) inicia-se com o entendimento da cadeia de valor. A cadeia de valor são todas as ações realizadas para o atendimento do valor pleno ao cliente, sendo formada por todos os processos para a geração de determinado bem ou serviço até a chegada ao cliente final. Todos os processos possuem sua cadeia de valor interna, que trabalham para gerar valor ao cliente interno, que faz parte da cadeia de valor do cliente externo até a chegada ao cliente final (RODRIGUES, 2016).

Por seguinte, Conto, et al., (2013, p. 6) ensina que "cadeia de valor pode ser definida como um conjunto de atividades e operações, de modo a criar valor desde as matérias primas até o produto ou serviço final." Desta forma, cadeia de valor é uma forma que as organizações se organizam para manter sua competitividade no mercado, gerando valor ao cliente com o mínimo de desperdícios possíveis.

A ferramenta de mapeamento de fluxo de valor (MFV) é uma ótima alternativa para destacar as perdas ocorridas nos processos produtivos de uma organização, auxiliando na visualização de futuros ajustes da rede para tornar o fluxo mais enxuto. O mapa oferece uma visão de linguagem comum, o que facilita a compreensão, de modo que todos possuam a mesma visão do assunto abordado (LIKER; MEIER, 2007).

Após desenvolvimento do MFV do estado atual, é necessário a elaboração do seu estado futuro. A meta do mapa de fluxo de valor futuro é criar uma articulação entre cliente e fornecedor, transformando em produção puxada ou contínua, e onde cada processo produzir apenas o quando a cliente precisa e o que precisam, através da aproximação dos dois (ROTHER; SHOOK, 2003).

De acordo com Lean Institute Brasil (2011) o mapa de fluxo de valor futuro, é realizado para apontar as melhorias propostas nos processos, baseado no mapa de fluxo de valor atual, ilustrando o estado futuro que deseja chegar, aonde é almejado um aumento de produtividade e uma redução de desperdícios, melhorando os resultados.

\subsection{KANBAN}

O termo kanban, significa "quadro de sinais" ou simplesmente "sinais", e é um dispositivo utilizado para autorizar ou dar instruções para a produção ou retirada de materiais em um sistema puxado (LEAN INSTITUTE BRASIL, 2011)

Segundo Martins; Laugeni (2005, p. 408) "o objetivo do kanban é assinalar a necessidade de mais material e assegurar que tais peças sejam produzidas e entregues a tempo de garantir a fabricação ou montagem subsequentes. Isso é obtido puxando-se as partes na direção da linha de montagem final".

Para realização do cálculo do kanban, existem algumas variáveis que podem ser utilizadas para se chegar ao resultado, e segundo Shingo (1996) é a quantidade diária consumida, o tempo para as peças serem fornecidas (lead time), o estoque mínimo e o tamanho do lote.

O número de kanbans é algo a ser levado muito a sério, pois é ele que resultará no limite máximo de itens que terá no estoque. Como exemplo, se existem cinco contêineres ou carrinhos com dez unidades cada, o limite máximo de estoque será de cinquenta unidades, e isso ocorrerá somente quando os cinco contêineres ou carrinhos estiverem completamente cheios, e dessa forma o kanban estará preso, e nenhuma unidade deve ser produzida, já que não há cartão kanban disponível que autorize tal produção (MOREIRA, 2015).

A quantidade de kanbans corresponde ao número de containers no sistema de ponto de pedido descrito anteriormente. Esse número pode ser calculado pela seguinte fórmula (SHINGO, 1996):

$$
\text { Número de Kanban }=\frac{\text { Estoque Máximo }(D+C)}{\text { Capacidade de } 1 \text { Container }}
$$

A principal natureza do sistema é de ser visual, e o kanban pode diminuir significativamente a quantidade de produtos ou peças em estoque, porém, não é uma ferramenta que irá reduzir o estoque a zero, com ela é possível controlar perfeitamente 
esse estoque, trabalhando com o mínimo possível, de forma que a linha não pare por falta de material.

\subsection{PAYBACK SIMPLES}

O cálculo do payback simples, possui uma fórmula aparentemente fácil de ser calculada, porém, é necessário o cuidado de incluir todos os custos do investimento. Segundo Alves (2014) a formulada é dada pelo valor do investimento inicial dividido pelo ganho do período, conforme fórmula:

$$
\text { Payback Simples }=\frac{\text { Investimento }}{\text { Ganho do Período }}
$$

Se utilizado o ganho do período mensal, o payback apresentará o resultado em meses, se utilizado o ganho do período anual, o payback apresentará o resultado em anos, e assim sucessivamente. As principais vantagens segundo Alves (2014) é que ele oferece uma ideia do risco do projeto e de sua liquidez, aumenta a segurança dos negócios, além de ser simples e de fácil compreensão.

\section{METODOLOGIA}

Com o intuito de explorar a temática descrita neste artigo, escolheu-se como metodologia a pesquisa bibliográfica, juntamente com a pesquisa de campo. De maneira geral a pesquisa se mostra do tipo quali-quantitativa, de modo que, a quantitativa busca mostrar opiniões e informações a partir de números e a abordagem qualitativa caracterizou o setor de corte de big bags através da ferramenta de mapeamento de fluxo de valor (MFV).

Nessa perspectiva, o primeiro passo para o estudo de campo foi observar o processo do setor produtivo escolhido na empresa e identificar através do mapa de fluxo de valor as atividades que agregam valor ao processo. Por conseguinte, foi realizado uma amostra a partir da coleta de dados referentes ao funcionamento atual do processo produtivo que é apresentado no mapa de fluxo de valor atual. Após definição do mapa de fluxo de valor futuro onde constam todas as melhorias propostas, foi realizado o tratamento dos dados de forma estatística, calculando e comparando os resultados propostos com os resultados obtidos atualmente pelo processo na empresa. A análise dos resultados é mostrada no tópico a seguir.

\section{APRESENTAÇÃO E ANÁLISE DOS RESULTADOS}

\subsection{DIAGNÓSTICO DA ÁREA}

O setor de Corte de Big Bag abastece quatro unidades de acabamento, denominadas como Fábrica 3, XYZ, ZYX e YXZ, sendo que as últimas três também são conhecidas como terceiras. Essas quatro unidades fazem o trabalho de costura, unindo os acessórios ao corpo do big bag. As terceiras produzem big bags descartáveis, conhecidos como one way, já a Fábrica 3 produz os reutilizáveis, conhecidos como multi way, aonde muitos são produzidos de acordo com a necessidade específica do cliente. Neste trabalho, será abordado somente o corte e abastecimento de acessórios as terceiras.

Diante do exposto, foi elaborado o MFV da família de produtos de acessórios para big bag, com início no envio do tecido pela fábrica 1, e tendo como final o envio desses componentes cortados para o acabamento em outras fábricas. Após o levantamento de dados, nos processos por onde esses produtos passam, foi desenvolvido o mapa de fluxo de valor atual, que é apresentado na Figura 
Figura 1 - Mapa de fluxo de valor do estado atual

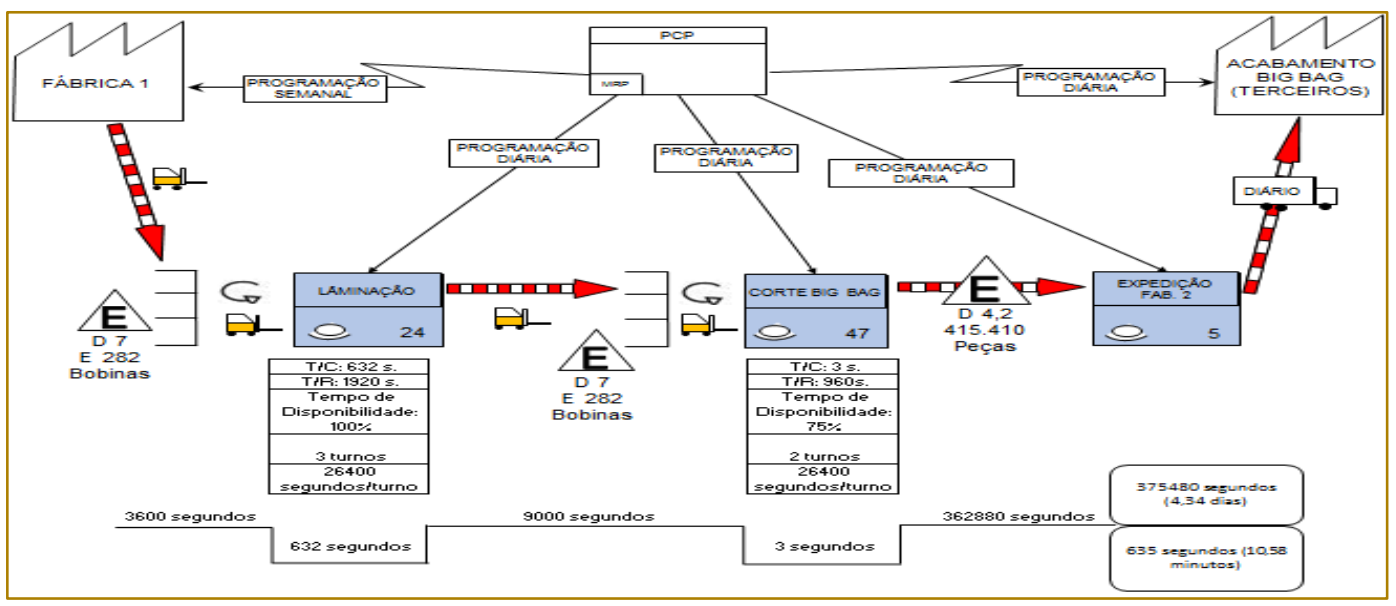

Fonte: O autor (2018)

Após realização do mapa, constatou-se que o tempo de processamento deste fluxo de produção é de 10 minutos e 35 segundos (635 segundos), já o lead time de produção é de 4,34 dias. Verificou-se também a grande movimentação de bobinas para abastecimento dos processos, e o alto nível de estoque contido no supermercado e pós cortem dos componentes.

Foi realizado o levantamento de quantidade de peças em estoque, tanto dentro do setor de corte quanto nas terceiras, quais são apresentados na Tabela 1.

Tabela 1 - Estoque Atual

\begin{tabular}{|c|c|c|}
\hline Componente & Estoque & Estoque em dias \\
\hline Topo & 76560 & 4,3 \\
\hline Fundo & 86700 & 4,8 \\
\hline Válvula de enchimento & 79900 & 4,4 \\
\hline Válvula de descarga & 76050 & 4,2 \\
\hline Flap & 96200 & 5,3 \\
\hline
\end{tabular}

Fonte: O autor (2018)

A meta de cada terceira é produzir 6.000 big bags por dia, sendo assim no pior dos casos que é o componente flap, dentro do setor de corte, existe estoque para 5,3 dias de produção das três terceiras, e no melhor caso, da válvula de descarga tem estoque para 4,2 dias.

\subsection{PROPOSTA DE MELHORIA}

Através da análise do mapa de fluxo de valor do estado atual, foi levantado pontos que podem ser melhorados a fim de trazer resultados positivos ao fluxo, esses foram apresentados na Figura 2. 
Figura 2 - Mapa de fluxo de valor do estado futuro.

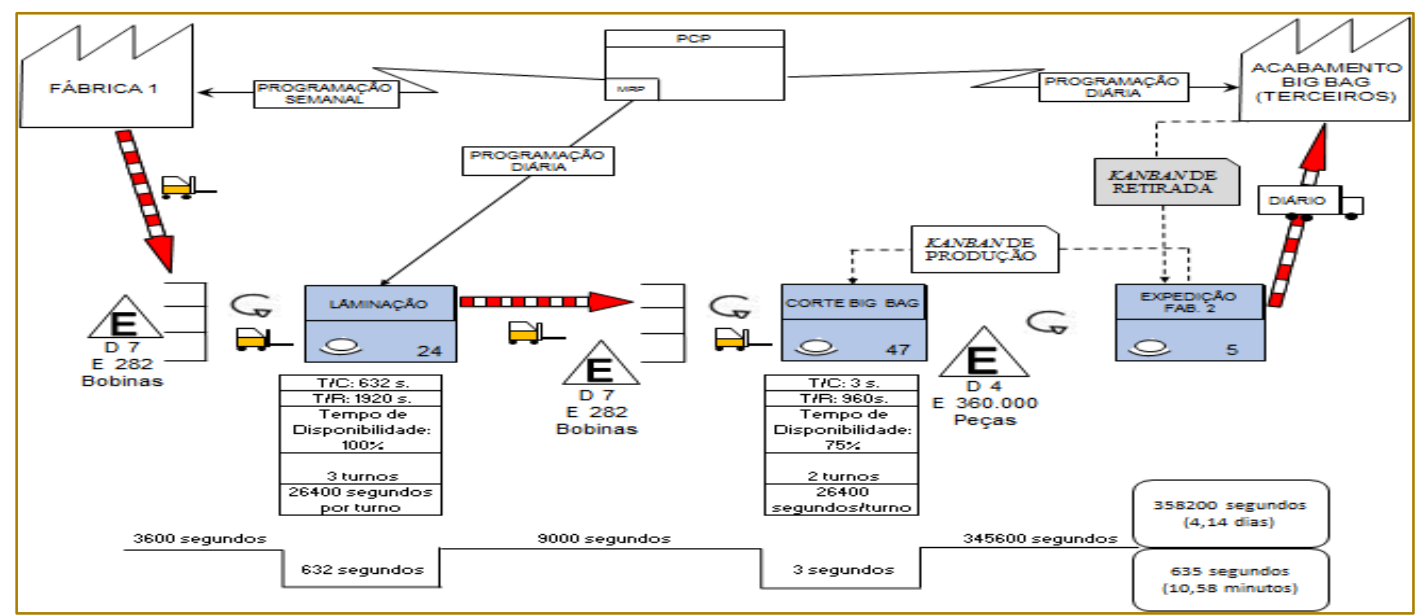

Fonte: O autor (2018)

No mapa de fluxo de valor atual, o estoque entre o setor de corte e as terceiras era de 415.410 peças, já no estado futuro, o almejado após aplicação do kanban, o estoque irá reduzir a 360.000 unidades. Além disso, o lead time de produção que era de 4,34 dias, tende a cair para 4,14 dias.

Ainda mais, a programação realizada pelo PCP e repassada ao setor de corte de big bag e expedição deixaria de existir, sendo assim o setor de PCP passaria a programação só para as terceiras, e a ordem para realização do corte e transporte se daria pelo kanban, transformando assim uma produção empurrada em produção puxada.

\subsection{RESULTADOS OBTIDOS}

A implementação do Kanban entre processo fornecedor e cliente foi fundamental para o alcance dos resultados do estudo. Para realização do cálculo do kanban, algumas variáveis foram analisadas, tais elas como histórico de consumo, quantidade projetada, lead time e capacidade de embalagem. Esses dados foram compilados e apresentados na Figura 3, qual apresenta o cálculo do dimensionamento do kanban.

Figura 3 - Cálculo kanban.

\begin{tabular}{|c|c|c|c|c|c|c|c|c|c|c|c|c|c|c|}
\hline & \multicolumn{4}{|c|}{ Produtos } & \multicolumn{3}{|c|}{ FornecedoriCliente } & \multicolumn{4}{|c|}{ Histórico Consumo } & \multicolumn{2}{|c|}{$\begin{array}{l}\text { Projeção } \\
\text { Demanda }\end{array}$} & \\
\hline & \multicolumn{2}{|c|}{$\begin{array}{c}\text { Código } \\
\text { Manufatu. }\end{array}$} & \multicolumn{2}{|c|}{ Descrição } & \multicolumn{2}{|c|}{ Fornecedor } & Cliente & Fev & \multicolumn{2}{|c|}{ Mar } & Abr & \multirow{2}{*}{$\begin{array}{l}\text { Mai } \\
6.000\end{array}$} & \multicolumn{2}{|c|}{ Jun } \\
\hline & & 0001 & Topo & & & orte & $\mathrm{ACl}$ & 5.350 & 5.6 & & 5.800 & & 6.0 & \\
\hline & & 002 & Fundo & & & orte & $\mathrm{AC1}$ & 5.350 & 5.6 & & 5.800 & 6.000 & 6.0 & \\
\hline \multicolumn{2}{|c|}{ Embalagem } & \multicolumn{6}{|c|}{ Lead Time Aberto [dias] } & & & & $\begin{array}{l}\text { Lead } \\
\text { Time }\end{array}$ & \multicolumn{3}{|c|}{ Dimensionamento } \\
\hline \multicolumn{2}{|c|}{ Capacidade } & \multicolumn{2}{|c|}{ Fluxo Imp. } & \multicolumn{2}{|c|}{ Subcontr. } & \multicolumn{2}{|c|}{$\begin{array}{c}\text { Tempo } \\
\text { Produção }\end{array}$} & \multicolumn{2}{|c|}{ Supermer. } & Le: & ad Time & \multicolumn{2}{|c|}{$\begin{array}{c}\text { Qtde } \\
\text { Cartő́es }\end{array}$} & $\begin{array}{l}\text { Estoque } \\
\text { Máx. }\end{array}$ \\
\hline \multicolumn{2}{|l|}{6000} & \multicolumn{2}{|c|}{1} & \multicolumn{2}{|c|}{1} & \multicolumn{2}{|c|}{1} & \multicolumn{2}{|l|}{1} & & 4 & \multicolumn{2}{|c|}{4} & 24.000 \\
\hline \multicolumn{2}{|l|}{3000} & \multicolumn{2}{|c|}{1} & \multicolumn{2}{|c|}{1} & \multicolumn{2}{|c|}{1} & \multicolumn{2}{|l|}{1} & & 4 & \multicolumn{2}{|c|}{8} & 24.000 \\
\hline
\end{tabular}

Fonte: O autor (2018)

Na Figura 3 foi apresentado o cálculo para a demanda de apenas uma das fábricas terceiras, porém as outras duas seguem o mesmo modelo, pois possuem capacidades e demandas iguais. Foram utilizados como base dois componentes, topo e fundo, pois a quantidade na embalagem de cada um é diferente, do topo 6.000 unidades e do fundo
3.000 unidades por embalagem. Os componentes flaps, válvula de enchimento e válvula de descarga, seguem a mesma proporção do topo. A demanda projetada foi estipulada como base a meta estipulada de produção das unidades, que é de 6.000 unidades por dia. 
Na Tabela 2 é apresentado como ficou o dimensionamento do kanban de todos os componentes da família de produtos escolhida para cada uma das fábricas de acabamento.

Tabela 2 - Dimensionamento do Kanban Por Componente

\begin{tabular}{|c|c|c|c|c|c|c|}
\hline & \multicolumn{4}{|c|}{ Meka } & \multicolumn{4}{c|}{ São Gabriel } \\
\hline Componente & $\begin{array}{c}\text { Estoque } \\
\text { Máx. }\end{array}$ & $\begin{array}{c}\text { Cartões } \\
\text { Kanban }\end{array}$ & $\begin{array}{c}\text { Estoque } \\
\text { Máx. }\end{array}$ & $\begin{array}{c}\text { Cartões } \\
\text { Kanban }\end{array}$ & $\begin{array}{c}\text { Estoque } \\
\text { Máx. }\end{array}$ & $\begin{array}{c}\text { Cartões } \\
\text { Kanban }\end{array}$ \\
\hline Topo & 24.000 & 4 & 24.000 & 4 & 24.000 & 4 \\
\hline Fundo & 24.000 & 8 & 24.000 & 8 & 24.000 & 8 \\
\hline Válvula de enchimento & 24.000 & 4 & 24.000 & 4 & 24.000 & 4 \\
\hline Válvula de descarga & 24.000 & 4 & 24.000 & 4 & 24.000 & 4 \\
\hline Flap & 24.000 & 4 & 24.000 & 4 & 24.000 & 8 \\
\hline
\end{tabular}

Fonte: O autor (2018)

Para implantar a ferramenta kanban, é necessário substituir o palete de madeira por uma gaiola que comportaria a quantidade de materiais dimensionada no kanban. Como cada cartão significa uma gaiola, serão necessárias 72 gaiolas para atender a demanda. O dimensionamento da gaiola deverá ter dimensões de 1,30 metros de altura $\times 1,45$ metros de comprimento $\times 1,20$ metros de largura.
A fabricação da gaiola tem como objetivo maximizar a capacidade de carga transportada no caminhão, além de proporcionar melhor armazenamento, possibilitando a verticalização através do empilhamento das mesmas. Na Figura 4 é apresentado o armazenamento dos paletes e gaiolas no caminhão.

Figura 4 - Armazenamento para transporte

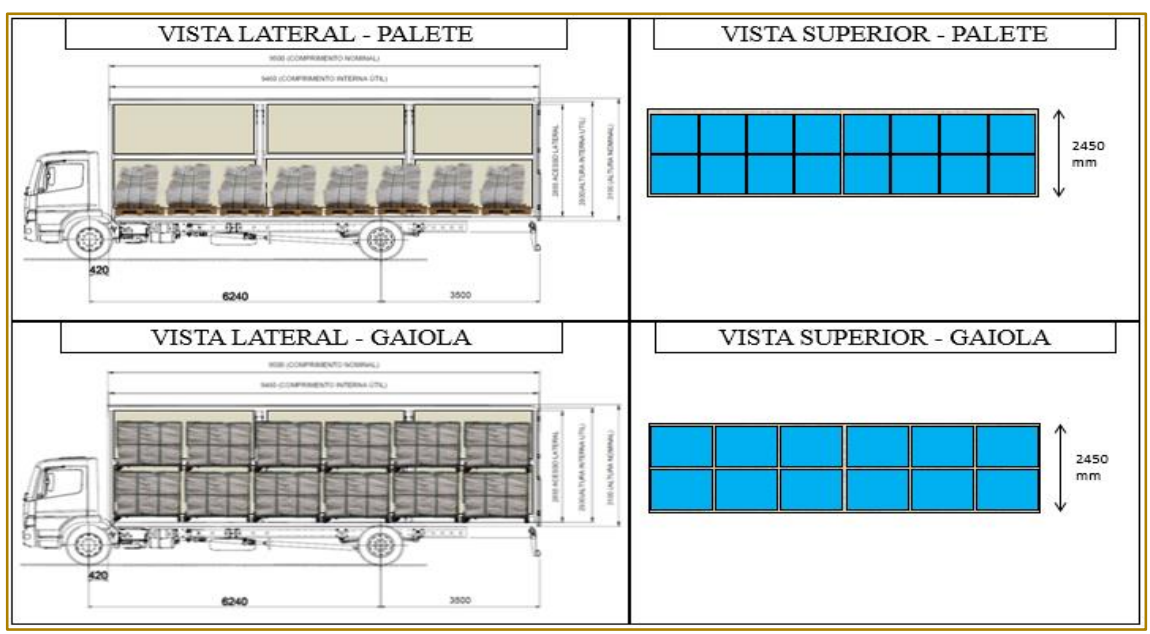

Fonte: O autor (2018)

Como apresentado na Figura 4, é possível colocar 16 paletes de Topo no caminhão, já com as gaiolas é possível colocar 24. Atualmente, a média por ordem de produção para as terceiras é de 1.750 big bags, logo a média de todos os acessórios é a mesma, já que se utiliza uma unidade de cada acessório para produzir um big bag. Com este dado, é possível estipular o custo por milheiro das peças enviado as terceiras, conforme Tabela 3. 
Tabela 3 - Custo por milheiro transportado

\begin{tabular}{|c|c|c|}
\hline & Aumento da capacidade de carga & Redução do custo por milheiro \\
\hline Gaiolas & $321,43 \%$ & 69,89\% \\
\hline
\end{tabular}

Com a realização do estudo, foi possível obter

resultados satisfatórios, quais estão apresentados na Tabela 4.

Tabela 4 - Resultados obtidos

\begin{tabular}{|c|c|c|c|}
\hline & Atual & Proposto & Descrição \\
\hline Estoque de Acessórios & 415.410 & 360.000 & Peças \\
\hline Dias em Estoque Acessórios & 4,2 & 4 & Dias \\
\hline Capacidade de Carga & 28.000 & 90.000 & Peças \\
\hline Custo Transporte & $\mathrm{R} \$ 18,93$ & $\mathrm{R} \$ 5,89$ & Por Milheiro Transportado \\
\hline Giro de Estoque & 1,3 & 1,5 & Mensal \\
\hline Lead Time & 4,34 & 4,14 & Dias \\
\hline
\end{tabular}

Fonte: O autor (2018)

Com a aplicação do kanban o estoque de acessórios diminuiria de 415.410 peças, para 360.000, logo o tempo em dias do estoque passaria de 4,2 para 4 dias. A gaiola de transporte, possibilitaria o transporte de 90.000 peças, enquanto utilizando paletes é enviado 28.000 peças por carga, com essa otimização, traz uma economia de $R \$ 13,04$ a cada mil peças transportadas. O lead time também reduziria, passando de 4,34 dias para 4,14, devido a diminuição do estoque na área de corte de big bag, e o giro de estoque aumentaria de 1,3 para 1,5 mensais.

A fabricação das gaiolas necessita de um investimento por parte da empresa, no valor de $R \$ 500,00$ por gaiola, resultando num total de $R \$ 36.000,00$ para compra de 72 gaiolas. A Tabela 5 apresenta o custo mensal de transporte.

Tabela 5 - Custo mensal

\begin{tabular}{c|c|c|c|c|}
$\begin{array}{c}\text { Milheiros } \\
\text { Mês }\end{array}$ & $\begin{array}{c}\text { Valor Total } \\
\text { Paletes }\end{array}$ & $\begin{array}{c}\text { Valor Total } \\
\text { Gaiola }\end{array}$ & Economia Mês & Investimento \\
\hline 2.340 & $\mathrm{R} \$ 100,00$ & $\mathrm{R} \$ 30,11$ & $\mathrm{R} \$ 69,89$ & $\mathrm{R} \$ 82,46$ \\
\hline & & & \\
\hline & Fonte: O autor (2018)
\end{tabular}

Conforme Tabela 5, a quantidade de milheiros transportados foi baseada em um mês com 26 dias, já descontando quatro domingos no mês, ficando assim em 2.340 milheiros
mensais.Com isso, é possível aplicar o payback desse investimento, apresentado na Tabela 6. 
Tabela 6 - Payback

\begin{tabular}{|c|c|c|}
\hline \multicolumn{3}{|c|}{ Análise de Retorno de Investimento } \\
Mês & Fluxo & Saldo \\
\hline 0 & $-\mathrm{R} \$ 82,46$ & $-\mathrm{R} \$ 82,46$ \\
\hline 1 & $\mathrm{R} \$ 69,89$ & $-\mathrm{R} \$ 12,57$ \\
\hline 2 & $\mathrm{R} \$ 69,89$ & $\mathrm{R} \$ 57,32$ \\
\hline
\end{tabular}

Fonte: O autor (2018)

Conforme Tabela 6, o investimento terá retorno a partir do segundo mês, tornando esse um projeto viável.

\section{CONSIDERAÇÕES FINAIS}

Esse trabalho teve como principal objetivo propor melhorias em uma indústria do setor de ráfia do oeste catarinense, qual apresenta problemas em seus processos produtivos, principalmente no setor de corte de big bags e envio de materiais para acabamento. Com estoques elevados, a desorganização no ambiente físico e dificuldades de controle do estoque, há uma notável necessidade de uma melhoria.

Dado o exposto, foi utilizando a ferramenta de mapeamento de fluxo de valor para diagnosticar locais de possíveis ganhos através da eliminação dos desperdícios, onde através dele foi possível propor a aplicação da ferramenta kanban entre o processo de corte de big bag e as fábricas de acabamento, transformando assim uma

\section{REFERÊNCIAS}

[1] CONTO, Samuel Martin et al. Proposta de Modelo de Cadeia de Valor Para um Centro Universitário. Revista GUAL, Florianópolis, v. 6, n. 2, p. 143-159, abr. 2013.

[2] LAUGENI, Fernando Piero; MARTINS, Petronio G; Administração da Produção. 2ª ed. rev. São Paulo: Saraiva, 2005

[3] LEAN INSTITUTE BRASIL. Lexico Lean: Glossário Ilustrado para praticantes do pensamento Lean. 4. ed. São Paulo: Lean Institute Brasil, 2011. $130 \mathrm{p}$.

[4] Sistema Toyota de produção. Disponivel em: $<$ https://www.lean.org.br/conceitos/117/sistematoyota-de-producao-(toyota-production-system--tps).aspx> Acesso em: Março, 2018. produção empurrada em puxada. Os dados foram coletados através de observações realizadas no processo, além de uma pesquisa no sistema operacional da empresa, para levantamento de dados como a quantidade de estoque e custos de transporte.

Com a coleta e análise desses dados, foi possível chegar a resultados satisfatórios, como a redução do lead time em 0,20 dias, aumento do giro de estoque em 0,90 vezes, redução do estoque em 55.410 peças, um aumento de capacidade de carga em $321,43 \%$, qual resulta em uma economia financeira no transporte de peças de 69,89\%.

Os objetivos do trabalho foram alcançados, visto que, os números apontam ser um investimento viável, com retorno a partir do segundo mês, além da empresa passar a ter o kanban como uma ferramenta de simples gerenciamento para controle de seu estoque e seu processo de corte e envio de materiais para as terceiras.

[5] LIKER, Jeffrey K.; MEIER, David.; O Modelo Toyota: manual de aplicação; trad. Lene Belon Ribeiro. Porto Alegre: Bookman, 2007.

[6] MOREIRA, Daniel Augusto; Administração da Produção e Operações. 2. ed. rev. ampl. São Paulo: Cengage, 2015.

[7] OHNO, T. O Sistema Toyota de Produção: além da produção em larga escala; trad. Cristina Schumacher - Porto Alegre: Bookman, 1997.

[8] RODRIGUES, Marcus Vinicius; Entendendo, aprendendo e desenvolvendo sistema de Produção Lean Manufacturing. $2^{2}$ ed. Rio de Janeiro: Elsevier, 2016

[9] ROTHER, Mike.; SHOOK, John. Aprendendo a enxergar: mapeando o fluxo de valor para agregar valor e eliminar o desperdício. São Paulo: Lean Institute Brasil, 2003. 
[10] SHINGO, Shigeo. O Sistema Toyota de Produção do ponto de vista da Engenharia de Produção; trad. Eduardo Schaan - 2. ed. - Porto Alegre: Artmed, 1996.
[11] WERKEMA, Cristina; Lean Seis Sigma: Introdução as ferramentas Lean Manufacturing. $2^{\text {a }}$ ed. Rio de Janeiro: Elsevier, 2011. 


\section{Gapítulo 13}

\section{QUALIDADE EM SERVICOS E SATISFACÃO DE ESTUDANTES NO ENSINO SUPERIOR DO INSTITUTO FEDERAL DE SÃO PAULO}

\section{Jorge Henrique de Oliveira Silva}

Glauco Henrique de Sousa Mendes

Gilberto Miller Devós Ganga

Solange Aparecida de Souza Monteiro

Resumo: Este artigo apresenta uma survey conduzida com o objetivo de avaliar a qualidade em serviços, os resultados na aprendizagem, a empregabilidade, a imagem, o valor percebido e a satisfação de estudantes no Ensino Superior do Instituto Federal de Educação, Ciência e Tecnologia de São Paulo. A partir da amostra obtida de 505 participantes, utilizou-se a análise de quartis para classificar os indicadores avaliados em níveis de prioridade de intervenção pela instituição. Observou-se que a grande maioria dos indicadores de qualidade em serviços situase no nível crítico de prioridade. Recomenda-se que a instituição de ensino concentre esforços para melhorar a qualidade nos serviços, especialmente por meio da formação continuada dos docentes; investimentos em melhorias na infraestrutura; e treinamentos com o pessoal que trabalha no apoio pedagógico e administrativo. 


\section{INTRODUÇÃO}

No Brasil, a partir de meados da década de 1990, houve um aumento expressivo no número de matrículas e de instituições ofertantes de Ensino Superior (BARROS, 2015). Em 2015, embora apenas 18,1\% da população brasileira de 18 a 24 anos tenha cursado o Ensino Superior, o número de matrículas em cursos presenciais $e$ a distância cresceu de aproximadamente 3,93 milhões, em 2003, para 8,02 milhões (INEP, 2016).

Contudo, esta expansão não foi perfeitamente ajustada à demanda por vagas de Ensino Superior no país. Desde 2003, existem mais vagas disponíveis do que alunos para preenchê-las, devido ao fato de que o Ensino Médio brasileiro, cuja responsabilidade é prioritariamente atribuída à esfera estadual de governo, não forma pessoas em quantidade suficiente para alimentar o sistema educacional (BARROS, 2015).

Neste cenário, muitas Instituições de Ensino Superior (IES) públicas e privadas vivenciam uma ociosidade de vagas e uma consequente concorrência por alunos (COUTINHO, 2007). Esta situação é uma realidade nos Institutos Federais de Educação, Ciência e Tecnologia (IFs), que são autarquias federais de Educação Profissional e Tecnológica (EPT) presentes em todos os estados brasileiros, com autonomia administrativa, financeira e pedagógica, distribuídos em 40 reitorias (INEP, 2016). Os IFs são subordinados ao Ministério da Educação (MEC), por intermédio da Secretaria de Educação Tecnológica (SETEC), e dedicam $50 \%$ de suas vagas ao Ensino Superior (BRASIL, 2008).

No caso dos IFs, a ociosidade de vagas no Ensino Superior está associada a altas taxas de evasão, indicando que muitos de seus alunos abandonam o curso ou transferem as matrículas para outras IES. Um Relatório do Tribunal de Contas da União, publicado em 2012, apontou que a taxa de conclusão de $80 \%$ prevista no Termo de Acordo de Metas para os IFs, situava-se em $25,4 \%$ para a licenciatura, 27,5\% para $\mathrm{O}$ bacharelado e $42,8 \%$ para os cursos de tecnólogo (BRASIL, 2012).

Além de representar prejuízos em relação à utilização dos recursos públicos, a ociosidade de vagas compromete a sustentabilidade dos IFs, uma vez que, no processo de distribuição das receitas orçamentárias pelo MEC, O número de matrículas é considerado um dos principais indicadores de desempenho e está proporcionalmente relacionado aos recursos disponibilizados para compor o orçamento de cada unidade organizacional da rede (SEI/MEC, 2016).

Dentre as causas relacionadas à ociosidade de vagas nos IFs, além de contingências com o aumento na oferta de Ensino Superior no país e do desajuste em relação à demanda, Andrade (2014) aponta dificuldades na aprendizagem dos alunos, devido a uma formação pregressa precária; a falta de identificação dos alunos com o curso; e um baixo nível de satisfação com a qualidade nos serviços educacionais recebidos. No que diz respeito à satisfação de estudantes com os serviços educacionais, pesquisas apontam que alunos mais satisfeitos são menos propensos à evasão (DOURADO; OLIVEIRA, 2009).

Tendo em vista que, no contexto do Ensino Superior, a satisfação de estudantes está relacionada a diversos construtos como a qualidade nos serviços, os resultados na aprendizagem, a empregabilidade promovida pela IES, a imagem institucional e o valor percebido pelos alunos (SILVA, 2017), o presente artigo apresenta uma survey conduzida com o objetivo de reconhecer as percepções dos alunos do Ensino Superior no IFSP sobre a qualidade nos serviços e outros construtos relacionados à satisfação de estudantes.

Nesta Introdução, contextualizam-se a problemática, o objetivo e a relevância da pesquisa. Na Seção 2, são apresentados os fundamentos teóricos. Na Seção de Métodos, descrevem-se os procedimentos adotados na condução da survey. A Seção 4 traz os resultados da pesquisa. E, por último, são apresentadas Considerações finais.

\section{FUNDAMENTAÇÃO TEÓRICA}

Nesta Seção são apresentadas as bases teóricas utilizadas na realização da pesquisa.

\subsection{QUALIDADE EM SERVIÇOS}

$\mathrm{Na}$ década de 1980, o crescimento expressivo do setor de serviços, fez surgir uma onda de estudos sobre a qualidade em serviços. A partir de conhecimentos adquiridos sobre a qualidade de produtos e considerando as particularidades dos serviços, desenvolveram-se linhas de 
pesquisas sobre a qualidade em serviços e, desde então, ela é reconhecida como um determinante crítico da satisfação de clientes e da competitividade das organizações (GRÖNROOS; GUMMERUS, 2014).

De acordo com Parasuraman, Zeithaml e Berry (1988), a qualidade em serviços é definida como o resultado de um processo de comparação entre as expectativas dos clientes e a percepção que eles têm em relação ao desempenho nos serviços. Além disso, os autores afirmam que, independentemente do tipo de serviço, os clientes utilizam basicamente critérios similares para avaliar a qualidade, os quais correspondem às dimensões da qualidade em serviços (Parasuraman; Zeithaml; Berry, 1988).

Parasuraman, Zeithaml e Berry (1988) construíram uma escala para medir as percepções dos clientes em relação à qualidade em serviços, denominada SERVQUAL, a qual é largamente referenciada na literatura e utilizada para avaliar a qualidade em serviços no setor privado e público. Na escala SERVQUAL, as dimensões da qualidade em serviços são as cinco seguintes:

a) Tangíveis: instalações físicas, equipamentos e aparência do pessoal;

b) Confiabilidade: habilidade para desempenhar o serviço prometido de forma confiável e precisa;

c) Responsividade: disposição da equipe para ajudar os clientes e prover pronto-atendimento;

d) Segurança: conhecimento da equipe e sua habilidade para inspirar confiança;

e) Empatia: cortesia e atenção individualizada que a organização oferece aos clientes.

Embora o caráter multidimensional da qualidade em serviços seja amplamente aceito, há divergências quanto ao uso das expectativas na avaliação da qualidade. Desenvolveu-se uma linha de pesquisa na qual a percepção dos clientes em relação ao desempenho no serviço, por si só, traduz uma medida apropriada da qualidade. Cronin e Taylor (1992) são as principais referências nesta linha, tendo inclusive adaptado a escala SERVQUAL a esta abordagem, a qual ficou conhecida como escala SERVPERF.

\subsection{SATISFAÇÃO DE CLIENTES}

A definição de satisfação de clientes não é consensual na literatura (GIESE; COTE, 2000). Grande parte define a satisfação com base no paradigma da desconfirmação de expectativas, descrevendo-a como um sentimento de prazer resultante da comparação entre as expectativas dos clientes e o desempenho percebido por eles em relação a um produto ou serviço (KOTLER; KELLER, 2006; OLIVER, 1980). No entanto, embora este paradigma seja considerado a teoria dominante, existem diferentes abordagens conceituais que conduzem a diferentes definições da satisfação de clientes (GIESE; COTE, 2000).

Após uma extensa revisão da literatura, Giese e Cote (2000) propuseram uma definição de satisfação baseada nos elementos comuns identificados em diversos estudos. Nesta definição, a satisfação de clientes é definida como uma resposta afetiva a aspectos relacionados à aquisição e/ou ao consumo de produtos ou serviços, com um ponto temporal específico de determinação e duração limitada.

Quando o cliente se sente satisfeito, a organização usufrui de benefícios, sendo reconhecido que melhorias nos níveis de satisfação conduzem a aumentos na lealdade dos clientes, reduzem a elasticidade de preço, baixam custos de transação, reduzem custos de falhas, atraem novos consumidores e ajudam a construir uma boa reputação da organização no mercado (HOFFMAN, 2005).

Além da qualidade em serviços, a satisfação relaciona-se a outros construtos, dentre os quais destaca-se o valor percebido, que, tradicionalmente, pode ser definido como "a avaliação geral pelo consumidor da utilidade de um produto ou serviço, baseada em percepções do que é recebido e do que é dado" (ZEITHAML, 1988, p.14).

Para Balmer e Greyser (2006), outro importante construto relacionado à satisfação é a imagem, que pode ser definida como as percepções sobre uma organização que são fixadas na memória dos clientes. Em muitos casos, a imagem não se relaciona apenas com o produto principal oferecido, mas com a conduta ética e com outras ações que a organização desempenha (BALMER; GREYSER, 2006). 


\subsection{QUALIDADE EM SERVIÇOS E SATISFAÇÃO DE ESTUDANTES NO ENSINO SUPERIOR}

Para Elliot e Healy (2001), a satisfação de estudantes é definida como uma resposta afetiva do aluno à avaliação feita por ele sobre diversos aspectos relacionados à experiência educacional durante o seu curso na IES. Esta avaliação inclui vários construtos como a qualidade nos serviços; o valor atribuído pelo aluno à educação recebida; a imagem da IES; os relacionamentos com os colegas, professores e funcionários; e as oportunidades de crescimento pessoal e profissional (ELLIOTT; HEALY, 2001).

Dentre os construtos relacionados à satisfação de estudantes no Ensino Superior, a qualidade em serviços é o mais explorado pela literatura. Embora varie a forma como a qualidade é mensurada, pode-se concluir que todos os instrumentos compreendem elementos importantes da educação, que incluem aspectos do ensino, instalações e serviços de apoio (ABDULLAH, 2006).

Além da qualidade em serviços, os resultados na aprendizagem e a empregabilidade promovida pela IES também são considerados relevantes para a satisfação de estudantes (SILVA, 2017). Os resultados na aprendizagem abrangem uma gama de aspectos cognitivos e afetivos que são uma medida de como a experiência na universidade têm apoiado o desenvolvimento pessoal dos alunos. (DUQUE, 2013; FRYE, 1999). Já o conceito de empregabilidade considera que as IES devem preparar seus alunos para serem indivíduos empregáveis, adotando estratégias que reforçam a empregabilidade (EURICO; SILVA; VALLE, 2015; HARVEY, 2010).

A partir desta fundamentação teórica, realizou-se uma pesquisa com o propósito de reconhecer as percepções dos alunos no Ensino Superior do IFSP em relação aos construtos relacionados à satisfação.

\section{MÉTODO}

Nesta Seção, caracteriza-se a pesquisa realizada e descrevem-se os procedimentos adotados em sua condução.

\subsection{CARACTERIZAÇÃO DA PESQUISA}

Esta pesquisa adota abordagem quantitativa e trata-se de uma survey, que é um tipo de pesquisa caracterizada pela obtenção de informações sobre características, ações ou opiniões de um determinado grupo de pessoas, representativo de uma população, por meio de um instrumento de pesquisa (FORZA, 2002).

\subsection{POPULAÇÃO}

A população desta pesquisa é constituída por alunos matriculados nos cursos de Ensino Superior do IFSP, que ingressaram nos anos de 2014 e 2015. Segundo dados do sistema de gestão acadêmica da IES, esta população distribui-se em 28 campi localizados no Estado de São Paulo e corresponde a 4.168 alunos, regularmente matriculados em cursos de nível superior nas modalidades de tecnologia, bacharelados tecnológicos e licenciaturas.

Considerando a população identificada, foi determinado um processo de amostragem não probabilística. Para um erro amostral de $5 \%$ e nível de confiança de 95\%, dado o tamanho da população, calculou-se uma amostra-alvo de 352 participantes.

\subsection{INSTRUMENTO DE PESQUISA}

A partir do objetivo da pesquisa e da fundamentação teórica, definiu-se um questionário estruturado em duas partes: a primeira relacionada à caracterização sociodemográfica da amostra, e a segunda, à avaliação da qualidade em serviços e demais construtos relacionados à satisfação de estudantes.

Na segunda parte do questionário, utilizou-se uma escala do tipo likert de 7 pontos, variando de "discordo totalmente" (1) a "concordo totalmente" (7), para reconhecer o grau de concordância dos respondentes em relação a 36 afirmativas referentes aos construtos pesquisados. Para minimizar respostas automáticas, as afirmativas foram embaralhadas de modo aleatório. A Tabela 1 apresenta os resultados de confiabilidade do instrumento de pesquisa. 
Tabela 1 - Confiabilidade do questionário

\begin{tabular}{|l|c|}
\multicolumn{1}{|c|}{ Construto } & Alfa de Cronbach \\
\hline Qualidade em Serviços & 0,91 \\
\hline $\begin{array}{l}\text { Resultados na } \\
\text { aprendizagem }\end{array}$ & 0,94 \\
\hline Empregabilidade & 0,85 \\
\hline Imagem & 0,81 \\
\hline Valor & 0,80 \\
\hline Satisfação & 0,86 \\
\hline
\end{tabular}

Fonte: Dados da Pesquisa.

A confiabilidade foi avaliada por meio do Alfa de Cronbach, que é um critério tradicional de consistência interna baseado nas intercorrelações das variáveis observáveis. Os resultados variam de 0 a 1 , com valores mais altos indicando maior confiabilidade. Especificamente, os valores devem ser superiores a 0,7 (NUNALLY; BERNSTEIN, 1994). De acordo com os resultados da Tabela 1, o questionário utilizado apresenta confiabilidade.

\subsection{PRÉ-TESTE}

Um pré-teste foi realizado com colegas pesquisadores, dois especialistas na área educacional e 18 alunos matriculados em cursos de Ensino Superior no câmpus Araraquara do IFSP, com o objetivo de testar se o questionário consegue atingir os objetivos do estudo, prevenir questões óbvias, validar o conteúdo e avaliar a clareza e a coerência da linguagem. Após as avaliações, o questionário recebeu algumas adaptações, que resultaram na versão final utilizada.

\subsection{COLETA DE DADOS}

Por e-mail, durante as duas primeiras semanas do mês de junho de 2017, 4.168 alunos matriculados no Ensino Superior do IFSP foram convidados para participar da pesquisa, respondendo ao questionário disponibilizado na internet por meio do software LimeSurvey. A taxa de retorno foi de $12,5 \%$ (524 respostas), superior à amostraalvo prevista de 352 participantes.

\subsection{ANÁLISE DOS DADOS}

Para analisar os dados coletados, aplicou-se a análise de quartis, conforme proposto por Freitas, Manhães e Cozendey (2006). Esta análise consiste em utilizar as medidas de posição denominadas quartis para classificar os indicadores avaliados pelos estudantes em níveis de prioridade de intervenção pela IES. Os quartis são medidos a partir dos resultados médios de cada indicador e representam valores de fronteira que delimitam quatro níveis de prioridade. Em cada nível integram-se $25 \%$ dos indicadores, os quais são classificados em prioridade de intervenção crítica (primeiro quartil), alta (segundo quartil), moderada (terceiro quartil) e baixa (quarto quartil).

\section{RESULTADOS}

Nesta Seção, descrevem-se o tratamento realizado nos dados, os resultados de caracterização da amostra e os resultados da avaliação realizada com os alunos.

\subsection{TRATAMENTO DOS DADOS}

Nesta pesquisa, para a etapa de tratamento dos dados foram observados: valores faltantes; padrões de respostas suspeitas e outliers. Do total de 524 questionários respondidos, permaneceram 505 casos válidos para as análises posteriores.

\subsection{CARACTERIZAÇÃO DA AMOSTRA}

A Tabela 2 apresenta os resultados de caracterização da amostra: 
Tabela 2 - Caracterização da amostra

\begin{tabular}{|c|c|c|}
\hline Gênero & Frequência & Percentual (\%) \\
\hline Feminino & 212 & 41,9 \\
\hline Masculino & 293 & 58,1 \\
\hline Total & 505 & 100 \\
\hline \multicolumn{3}{|l|}{ Idade } \\
\hline $18-24$ & 292 & 57,8 \\
\hline $25-30$ & 68 & 13,5 \\
\hline$>30$ & 145 & 28,7 \\
\hline Total & 505 & 100 \\
\hline \multicolumn{3}{|l|}{ Renda Familiar } \\
\hline$\leq 4$ salários mínimos & 301 & 59,6 \\
\hline > 4 salários mínimos & 175 & 34,6 \\
\hline Não informado & 29 & 5,8 \\
\hline Total & 505 & 100 \\
\hline \multicolumn{3}{|l|}{ Trabalhando } \\
\hline Sim & 258 & 51,1 \\
\hline Não & 247 & 48,9 \\
\hline Total & 505 & 100 \\
\hline \multicolumn{3}{|l|}{ Se trabalha } \\
\hline $\begin{array}{c}\text { Na área de } \\
\text { aprendizagem }\end{array}$ & 126 & 48,8 \\
\hline Fora da área & 132 & 51,2 \\
\hline Total & 258 & 100 \\
\hline
\end{tabular}

Fonte: Dados da pesquisa.

Os dados indicam que quase $60 \%$ dos estudantes de Ensino Superior no IFSP são jovens na faixa etária considerada ideal para o Ensino Superior, em sua maioria, provenientes de família com baixa renda. Neste sentido, o IFSP cumpre um importante papel social, pois proporciona maior igualdade ao Ensino Superior, que é um nível de ensino historicamente associado às classes econômicas superiores.

Os resultados também revelam que pouco mais da metade dos alunos $(51,1 \%)$ trabalha e estuda, ao mesmo tempo. No entanto, dentre os alunos que desenvolvem alguma atividade profissional, apenas $48,8 \%$ atua na área de aprendizagem. Neste sentido, os dados sinalizam que o IFSP deve concentrar esforços para desenvolver uma melhor articulação entre os estudantes e os arranjos produtivos locais, com vistas a promover maior integração de seus alunos ao mercado de trabalho e fornecer mão de obra qualificada para os empregadores.

\subsection{ANÁLISE DE QUARTIS}

A Tabela 3 apresenta os resultados da avaliação realizada com os alunos, classificando os indicadores de acordo com o nível de prioridade de intervenção da IES, por meio da análise de quartis. 
Tabela 3 - Resultados das percepções dos alunos

\begin{tabular}{|c|c|c|c|}
\hline Prioridade & \multicolumn{2}{|r|}{ Indicador } & Média \\
\hline \multirow{9}{*}{$\begin{array}{c}\text { Crítica } \\
\mathrm{Q} 1=4,678\end{array}$} & QUA2 & Conteúdo, carga horária e encadeamento das disciplinas & 4,36 \\
\hline & QUA3 & Práticas pedagógicas dos professores & 4,38 \\
\hline & QUA5 & Fornecimento de feedbacks sobre o desempenho dos alunos & 4,53 \\
\hline & QUA6 & Condições das salas de aulas apropriadas para a aprendizagem & 4,55 \\
\hline & QUA7 & Laboratórios e biblioteca apropriados para a aprendizagem & 4,56 \\
\hline & QUA8 & Espaço físico bem projetado, sinalizado e acessível & 4,56 \\
\hline & QUA9 & Desempenho da coordenação de curso & 4,57 \\
\hline & QUA10 & Desempenho do apoio pedagógico & 4,65 \\
\hline & SAT1 & Instituição de ensino próxima do ideal & 4,673 \\
\hline \multirow{10}{*}{$\begin{array}{c}\text { Alta } \\
\mathrm{Q} 2=5,147\end{array}$} & QUA11 & Desempenho do apoio administrativo & 4,679 \\
\hline & APR2 & Habilidade em lidar com incertezas e trabalhar sob pressão & 4,69 \\
\hline & APR3 & Capacidade para trabalhar em equipe & 4,85 \\
\hline & APR8 & Habilidades para analisar e interpretar gráficos e estatísticas & 4,91 \\
\hline & APR10 & Adoção de práticas de consumo consciente e sustentável & 4,93 \\
\hline & EMP1 & Formação que garante o ingresso no mercado de trabalho & 5,02 \\
\hline & EMP5 & Estímulo à formação continuada & 5,06 \\
\hline & IMA2 & Reputação acadêmica reconhecida pela sociedade & 5,08 \\
\hline & VAL2 & $\begin{array}{l}\text { Esforços realizados para concluir a formação são compensados } \\
\text { pelos benefícios recebidos }\end{array}$ & 5,147 \\
\hline & SAT2 & Satisfação com as competências profissionais adquiridas & 5,147 \\
\hline \multirow{8}{*}{$\begin{array}{l}\text { Moderada } \\
\text { Q3 }=5,251\end{array}$} & QUA1 & Qualidade geral do curso & 5,15 \\
\hline & APR1 & $\begin{array}{l}\text { Comportamento inovador, empreendedorismo, pensamento } \\
\text { crítico e ações criativas }\end{array}$ & 5,16 \\
\hline & APR5 & Habilidades de planejamento e organização & 5,18 \\
\hline & APR6 & $\begin{array}{l}\text { Habilidades para lidar com informações e com tecnologias de } \\
\text { comunicação }\end{array}$ & 5,18 \\
\hline & APR9 & $\begin{array}{l}\text { Consciência ética, exercício da cidadania e respeito à } \\
\text { diversidade na sociedade }\end{array}$ & 5,20 \\
\hline & EMP4 & Formação profissional esperada pelo mercado de trabalho & 5,21 \\
\hline & IMA4 & Reputação positiva no mercado de trabalho & 5,21 \\
\hline & VAL3 & Conquistar emprego e desenvolver uma carreira profissional & 5,24 \\
\hline \multirow{9}{*}{ Baixa } & QUA4 & Domínio do conteúdo pelos professores & 5,29 \\
\hline & APR4 & $\begin{array}{l}\text { Disposição para aprender, aceitar responsabilidades e resolver } \\
\text { problemas }\end{array}$ & 5,32 \\
\hline & APR7 & Competências de comunicação & 5,41 \\
\hline & EMP2 & Instituição de ensino valorizada pelos empregadores & 5,42 \\
\hline & EMP3 & Perspectiva de melhoria profissional & 5,43 \\
\hline & SAT3 & Satisfação familiar com a instituição de ensino & 5,45 \\
\hline & IMA1 & Imagem positiva & 5,59 \\
\hline & IMA3 & Responsabilidade ética e social & 5,69 \\
\hline & VAL1 & Satisfação com a escolha da instituição & 5,84 \\
\hline
\end{tabular}
Fonte: Dados da Pesquisa.

Os resultados informam que os dois indicadores com pior avaliação são QUA2 (Conteúdo, carga horária e encadeamento das disciplinas) e QUA3 (Práticas pedagógicas dos professores). Já os dois indicadores com melhor avaliação relacionam-se, respectivamente, ao valor percebido (VAL1: Satisfação com a escolha da instituição) e à imagem institucional (IMA3: Responsabilidade ética e social).

A grande maioria dos indicadores utilizados para avaliar a qualidade em serviços situa-se no nível crítico de prioridade. Neste nível, concentram-se todos os indicadores relacionados à qualidade na infraestrutura (QUA6, QUA7 e QUA8), o indicador de desempenho dos profissionais de apoio 
pedagógico (QUA9) e também do desempenho da coordenação de curso (QUA9). Apenas o desempenho dos técnicoadministrativos teve melhor avaliação na percepção dos alunos, mas ainda baixa, visto que se localiza no segundo pior nível de classificação conforme a análise de quartis.

Dentre os indicadores relacionados ao desempenho dos professores, somente QUA4 (Domínio do conteúdo pelos professores) não está no nível crítico e, pelo contrário, integra o quartil melhor avaliado. Este resultado indica que, na percepção dos alunos, os professores têm excelente domínio do conteúdo, mas não sabem transmiti-lo, nem fornecem um feedback considerado adequado na percepção dos estudantes.

A imagem do IFSP foi bem avaliada pelos alunos, já que todos os indicadores se situam nos melhores níveis de classificação. O mesmo pode ser afirmado em relação ao valor percebido pelos alunos, considerando-se que um dos indicadores teve a melhor média global na avaliação dos alunos, e os outros dois situam-se na fronteira do nível de prioridade alta e no nível de prioridade moderada.

Em relação à satisfação dos estudantes, os dados revelam que os alunos fizeram uma avaliação positiva quanto à satisfação familiar com a IES e com as competências profissionais adquiridas. Mas, quando

\section{REFERÊNCIAS}

[1] ABDULLAH, F. The development of HEdPERF: a new measuring instrument of service quality for the higher education sector. International Journal of Consumer Studies, v. 30, n. 6, p. 569581, nov. 2006

[2] ANDRADE, A. Expansão dos Institutos Federais: causas e consequências. 2014. $149 \mathrm{f}$. Dissertação (Mestrado) - Programa de PósGraduação em Educação, Universidade Cidade de São Paulo. 2014.

[3] BALMER, J.M.T.; GREYSER, S.A. Corporate marketing - Integrating corporate identity, corporate branding, corporate communications, corporate image and corporate reputation, European Journal of Marketing, v. 40, n.7-8, p.730-741, 2006.

[4] BARROS, A. S. X. Expansão da Educação Superior no Brasil: limites e possibilidades. Educ. Soc., Campinas, v. 36, n. 131, p. 361-390, abr.-jun., 2015 questionados se o IFSP está próximo a uma instituição considerada ideal, os resultados foram piores e a média situa-se no nível crítico de prioridade.

Por fim, quanto aos resultados na aprendizagem e à percepção de empregabilidade promovida, observa-se que a avaliação dos alunos oscila e que os resultados dos indicadores estão dispersos entre o segundo e o quarto quartis.

\section{CONSIDERAÇÕES FINAIS}

A análise dos resultados permitiu identificar que o IFSP cumpre um importante papel social na promoção de igualdade de acesso ao Ensino Superior, atendendo predominantemente jovens de baixa renda. Isto parece refletir-se numa avaliação positiva pelos alunos em relação à imagem institucional da IES e ao valor percebido pelos estudantes.

Recomenda-se à IES que concentre esforços para melhorar a qualidade nos serviços, especialmente por meio da formação continuada dos docentes com ênfase no desenvolvimento de melhores práticas pedagógicas; investimentos em melhorias na infraestrutura, como salas de aula, laboratórios e bibliotecas; e treinamentos com o pessoal que trabalha no apoio pedagógico e administrativo.

[5] BRASIL. Lei $n$ ํ 11.892, de 29 de dezembro de 2008. Institui a Rede Federal de Educação Profissional, Científica e Tecnológica, cria os Institutos Federais de Educação, Ciência e Tecnologia, e dá outras providências. Disponível em:

<http://www.planalto.gov.br/ccivil_03/_ato20072010/2008/lei/l11892.htm>. Acesso em out. 2016.

[6] BRASIL. Tribunal de Contas da União. Relatório de Auditoria Operacional em Acões da Rede Federal de Educação Profissional, Científica e Tecnológica. TC 026.062/2011-9. Brasília, 2012. Disponível em http://portal2.tcu.gov.br/portal/page/portal/TCU/co munidades/programas_governo/areas_atuacao/ed ucacao/Relatorio\%20de\%20Auditoria\%20\%20Educacao\%20Profissional.pdf . Acesso em 30 out. 2016.

[7] COUTINHO, F. C. C. Avaliação da qualidade dos serviços de uma instituição de ensino superior. 2007. 123 f. Dissertação 
(Mestrado) - Escola de Administração, Universidade Federal da Bahia, 2007.

[8] CRONIN, J.; TAYLOR, S. Measuring service quality: A reexamination and extension. Journal of Marketing, Chicago, v. 56, n. 3, p. 55-68, 1992.

[9] DOURADO, L. F.; OLIVEIRA, J. F. A qualidade da educação: perspectivas e desafios. Cadernos Cedes, Campinas, v. 29, n. 78, p. 201215, 2009.

[10] DUQUE, L. C. A framework for analysing higher education performance: students' satisfaction, perceived learning outcomes, and dropout intentions. Total Quality Management, v. 25, n. 1, p. 1-21, 2013.

[11] ELLIOTT, K. M.; HEALY, M. A. Key factors influencing student satisfaction related to recruitment and retention. Journal of Marketing for Higher Education, v. 10, n. 4, p. 1-11, 2001.

[12] EURICO, S. T; SILVA, J. A. M; VALLE, P. $O$. A model of graduates' satisfaction and loyalty in tourism higher education: The role of employability. Journal of Hospitality, Leisure, Sport \& Tourism Education, v. 16, p.30-42, 2015.

[13] FORZA, C. Survey research in operations management: a process-based perspective. International Journal of Operations \& Production Management, v.22, n.2, p.152-194, 2002.

[14] FREITAS, A. L. P.; MANHÃES, N. R. C.; COZENDEY, M. I. Emprego do SERVQUAL na avaliação da qualidade de serviços de tecnologia da informação: uma análise experimental. Encontro Nacional de Engenharia de Produção, 2006, 26.

[15] FRYE, R. Assessment, accountability, and student learning outcomes. Dialogue, v.2, p.2-11, 1999.

[16] GIESE, J. L.; COTE, J. A. Defining Consumer Satisfaction. Academy of Marketing Science Review, v. 2000, n. 1, 2000.

[17] GRÖNROOS, C; GUMMERUS, J. The service revolution and its marketing implications: service logic vs service-dominant logic. Managing Service Quality, v. 24, n. 3 p. 206-229, 2014

[18] HARVEY, L. New realities: The relationship between higher education and employment. Tertiary Education and Management, v. 6, n.1, p317, 2010.

[19] HOFFMAN, K. D. Marketing principles and best practices. Thomson South-Western, 2005.
[20] INEP. INSTITUTO NACIONAL DE PESQUISAS EDUCACIONAIS ANÍSIO TEIXEIRA. Ministério da Educação (INEP/MEC). Sinopse Estatística da Educação Superior 2015. Brasília: INEP/MEC, 2016. Disponível em: http://portal.inep.gov.br/web/guest/sinopsesestatisticas-da-educacao-superior. Acesso em dez. 2016.

[21] KOTLER, P.; KELLER, K. L. Administração de marketing. São Paulo: Pearson Prentice Hall, 2006. $750 \mathrm{p}$.

[22] MARCHETTI, R.; PRADO, P. H. M. Um tour pelas medidas de satisfação do consumidor. Revista de administração de empresas, v. 41, n. 4, p. 56-67, 2001.

[23] MARK, E. Student satisfaction and the customer focus in higher education. Journal of Higher Education Policy and Management, v.35, n.1, p.2-10, 2013.

[24] NUNNALLY, J. C.; BERNSTEIN, I. $\mathrm{H}$. Psychological theory. New York, NY: MacGraw-Hill, 1994.

[25] OLIVER, R. L. A cognitive model of the antecedents and consequences of satisfaction decisions. Journal of Marketing Research, p. 460469, 1980

[26] PARASURAMAN, A.; ZEITHAML, V. A.; BERRY, L. L. A conceptual model of service quality and its implications for future research. Journal of Marketing, Chicago, v. 49, p 41-50, 1985.

[27] PARASURAMAN, A.; ZEITHAML, V. A.; BERRY, L. L. Servqual. Journal of Retailing, v. 64, n. 1, p. 12-40, 1988.

[28] SEI/MEC. Nota Técnica № 32/2016/GAB/SETEC/SETEC. Disponível em: < http://portal.mec.gov.br/index.php?option=com_do $\mathrm{cman} \&$ view $=$ download\&alias $=40971-\mathrm{nt}-32$ metodologia-comp-matriz-orc-setec-conifpdf\&ltemid=30192>. Acesso em jun. 2016.

[29] SILVA, J. H. O. Modelo de satisfação de estudantes na Educação Profissional e Tecnológica: integrando qualidade em serviços, resultados na aprendizagem, empregabilidade, imagem, valor e lealdade. 2017. 130f. Dissertação (Mestrado Profissional em Gestão de Organizações e Sistemas Públicos). Universidade Federal de São Carlos, 2017.

[30] ZEITHAML, V. A. Consumer Perceptions of Price, Quality, and Value: A Means-End Model and Synthesis of Evidence. Journal of marketing, v. 52
n.
3
p.
$2-22$,
1988. 


\section{Gapítulo 14}

\section{APLICAÇÃO DE MÉTODOS MULTICRITÉRIOS PARA APOIO NA TOMADA DE DECISÃO DE INVESTIMENTOS EM SERVICOS TECNOLÓGICOS OFERECIDOS PARA A INDÚSTRIA NACIONAL}

\section{Alisson Marcelo Laurindo}

\section{Eduardo Rocha Loures}

Resumo: Métodos de decisão multicritérios MCDA/MCDM permitem analisar diversas variáveis nos mais diferentes pontos, criando uma integração entre sí e objetivando resultados satisfatórios. O objetivo deste artigo é demonstrar a utilização de um modelo para priorização de investimentos e ações de marketing e vendas em institutos de tecnologia. Propõe-se então o Método de Mudge, utilizado para definir critérios e gerar os pesos destes e posterior aplicação do método PROMETHEE para priorização dos resultados. Foi identificado como vantagem deste modelo um resultado explícit que facilita o acompanhamento dos indicadores e o aumento da compreensão do negócio por parte da organização 


\section{INTRODUÇÃO}

O ambiente competitivo nas organizações é marcado por mudanças e transformações decorrentes de novas metodologias de gestão e fenômenos da globalização da economia. Entretanto, o registro histórico demonstra que, o desenvolvimento econômico e social pertencia a quem detinha a matéria prima para o desenvolvimento, ou seja, a informação. Ainda em um contexto histórico evolutivo, as organizações são mais abertas, aprendendo com seus clientes, e não se limitam a barreiras físicas, sendo necessário repensar como se dará a criação de novas estratégias (CHESBROUGH, 2006; LAURINDO, 2013).

As organizações brasileiras, por sua vez, buscam padrões para tomada de decisão com qualidade e confiabilidade, visando então, eliminar incertezas em relação a indicadores ou informações isoladas em decorrência do aumento da velocidade das mudanças, dos elevados volumes de investimentos e do posicionamento dinâmico da organização em ambientes competitivos. Definir estratégias organizacionais utilizando ferramentas tradicionais como análise SWOT, Matriz GUT, Ferramentas SMART ou Balance Scorecard são favoráveis quando a complexidade das informações não é apresentada. Portanto, a tomada de decisões estratégicas, em situações de incerteza nas organizações, exige dos seus decisores análises confiáveis em um curto espaço de tempo.

Problemas envolvendo diversidade de critérios (multicritério) e incertezas caracterizam um cenário de complexidade confrontado pelas empresas em diferentes esferas. O processo de decisão multicritério, com foco na estratégia organizacional, envolve compreender e analisar opções de escolhas para condições e variáveis diferentes, para situações que extrapolam a rotina organizacional por meio do crescimento de decisões mais complexas. Colaborando com a temática, Saaty (1996; 2008) defende que todos os indivíduos tomam decisões, e que tudo o que fazemos, consciente ou não é resultado de alguma decisão voluntária ou involuntária.

Neste cenário de requisitos decisionais mais robustos, e com o fim da Terceira Revolução Industrial (KAGERMANN et al., 2013), o setor industrial caminha a passos largos em direção ao que está sendo chamado de Indústria 4.0, a Quarta Revolução Industrial. Assim, o uso de um método de análise multicritério é estratégico para as organizações, principalmente as que atuam com o desenvolvimento industrial.

O Serviço Nacional de Aprendizagem Industrial, face aos novos desafios de posicionamento junto ao setor industrial, a partir do Programa de Apoio à Competitividade da Indústria Brasileira (PAC da Indústria), organizou seus departamentos regionais (Estado), na área de atuação que presta serviços tecnológicos e fomenta a inovação industrial em Institutos de Tecnologia para se preparar para essa revolução industrial.

O presente trabalho tem por finalidade analisar os indicadores existentes na área de serviços tecnológicos e inovação, em um conceito estratégico, tendo como universo os Institutos de Tecnologia existentes em um Estado do Sul do Brasil. Como objetivo, busca-se definir qual instituto deverá ter prioridade no que tange novos investimentos e a intensificação nas ações de marketing e vendas, de forma a minimizar custos desnecessários e atendendo as diretrizes do PAC da Indústria.

Neste contexto, a utilização de métodos multicritério de apoio à tomada de decisão se faz importante no uso de técnicas e ferramentais capazes de auxiliar os gestores no direcionamento de suas ações. Esta escolha leva em conta diversos critérios para uma decisão menos intuitiva e mais assertiva. Como resultado espera-se a priorização dos institutos utilizando o método Promethee com base em critérios consensuados com especialistas via técnica de Mudge.

\section{MÉTODOS MULTICRITÉRIO MCDA/MCDM}

Em um posicionamento histórico, até a década de 70 , os métodos de otimização voltadas aos processos de tomada de decisão foram baseados em equações de programação matemática que buscavam solucionar apenas uma função objetivo (MOREIRA, 2007). Frente a isso, Gomes; Araya; Carignano (2004) destacou em seu estudo que a avaliação pela otimização clássica não tinha nenhuma possibilidade de aliar todos os critérios em uma única resposta. Desta forma, antes do final da mesma década, os métodos multicritérios começaram a surgir de forma clara e objetiva frente a 
necessidade de analisar problemas multivariados sobre diferentes perspectivas.

Os Métodos Multicritério de Apoio a Decisão (MMAD ou, em inglês, MCDM - Multicriteria Decision Making) e os Métodos de Análise Multicritérios (MAM ou, em inglês, MCDA Multicriteria Decision Analysis) apresentam similaridade de significado conceitual, e representam a forma como as ferramentas auxiliam a decisões difíceis devido as alternativas disponíveis apresentarem critérios de julgamento complexos e conflitantes entre si, o que geralmente impossibilita uma análise imediata. Neste contexto, a Análise Multicritério auxilia pessoas e/ou organizações em situações nas quais é necessário identificar prioridades, considerando, ao mesmo tempo, diversos aspectos (BOAS, 2005; SANTOS, et al. 2017).

Essa técnica quali-quantitativa reúne em um mesmo cenário de decisão abordagens exploratórias pouco estruturadas com modelos quantitativos modelados de forma estruturada e voltados para otimização dos objetivos propostos. Desta forma, o resultado é a solução do consenso de variáveis ponderadas frente a soluções de multicritérios. Em resumo, a ponderação de pesos para os critérios destes métodos contribui para a solução do problema.

Destacam-se os agrupamentos dos métodos frente a definição de pesos em quatro categorias, neste caso, ordenadas pela referência bibliográfica: escalas de pontos (OSGOOD, et al., 1957); distribuição de pontos (EASTON, 1973); comparação de critérios par a par (SAATY, 1980); e métodos baseados em ordenação de critérios (STILLWELL, et al., 1981).

O Apoio Multicritério à Decisão ganhou identidade e termologia própria a partir dos trabalhos de Bernardo Roy e de Thomas L. Saaty. A partir do trabalho de Roy se desenvolveram os Métodos ELECTRE e se consolidou a Escola Francesa de Auxílio Multicritério à Decisão. Com base nos trabalhos de Saaty desenvolveram-se os métodos AHP (Analytic Hierarquic Process) e suas variações, que se tornam referências da Escola Americana de Apoio Multicritério à Decisão (COSTA, 2006).

Diversos métodos MCDM são apresentados na literatura. Marttuten, Jenert e Belton (2017) apresentam uma revisão literária de métodos específicos para MCDA como AHP (HO, 2008), MCDM e MAUT (WALLENIUS, et al.,
2008), PROMETHEE (BEHZADIAN, KAZEMZADEH, ALBADVI, \& AGHDASI, 2010), TOPSIS (BEHZADIAN, KHANMOHAMMADI OTAGHSARA, YAZDANI, \& IGNATIUS, 2012) e VFT (PARNELL et al., 2013). Em algumas revisões, as combinações de MCDA com outros métodos foram abordadas ( $\mathrm{HO}, 2008$; WANG \& POH, 2014). No entanto, para o espaço de avaliação e decisão deste estudo, os métodos Mudge e Promethee revelam-se adequados pela facilidade de ponderação consensual de pesos e metodologia de priorização.

\subsection{DIAGRAMA DE MUDGE}

O Diagrama de Mudge é uma técnica que permite realizar uma avaliação cruzada e comparativa das funções de um produto ou serviço, e produz como resultado a priorização das funções selecionadas.

Entende-se por priorização das funções selecionadas o ranking com os pesos atribuídos aos critérios apresentados. A aplicação do diagrama Mudge demonstra que embora todas as características sejam necessárias, algumas apresentam grau de importância diferenciado.

O Diagrama de Mudge permite comparar entre si todas as funções que são desempenhadas por um recurso, estabelecendo-se valores a serem creditados a uma função, todas as vezes que esta demonstrar ser mais importante ou prioritária em relação a cada uma das demais. Ao final das comparações, apura-se o total dos pontos obtidos por cada função, aparecendo como prioritária aquela que mais pontos obtiver (GUIMARAES et al., 2014).

Essa avaliação que compara as funções aos pares tem início com o relacionamento da função "A" com a função "B" para determinar qual é a mais importante. Neste método a letra-chave da função escolhida como mais importante é colocada na parte superior esquerda do quadro "AB". A lógica dos números se dá pela escala: 1 - pouca importância superior; 2 - média importância superior; 3 - alta importância superior.

Após a função "A" ter sido comparada e avaliada com a função "B" e a letra-chave da função mais importante e o seu fator-peso anotados no quadro, repete-se o procedimento para a comparação "AC", "AD", "AE", "AF", seguindo até a última função. Após a finalização da comparação da linha A, 
é iniciada a comparação na linha abaixo, e compara-se "B" com as outras funções, até comparar todas as funções. Esse processo de comparação e avaliação finaliza até que todas as funções tenham sido individualmente comparadas e avaliadas com todas as outras funções relacionadas. Por fim, a avaliação se dá por completa com a soma dos fatorespeso para cada função com o total na coluna de peso da função. Como resultado, a que possui maior fator-peso se destaca (BASSO, 1991).

\subsection{MÉTODO PROMETHEE}

O método Promethee, Preference Ranking Organization Method for Enrichment Evaluation, teve seus primeiros estágios desenvolvidos por Brans e apresentado em 1982 na Université Laval, Québec, Canada. O método cria um ranking de resultados, baseado em critérios anteriormente inseridos, que auxilia na tomada de decisão. A possibilidade de tomar decisão baseada em multicritério diminui o risco e a incerteza na escolha do resultado. Este método é desenvolvido continuamente, e recebe melhorias desde 1988, quando pode ser visualizado graficamente. Seu sucesso se dá pelo fácil manuseamento e pelas suas capacidades matemáticas. (BRANS, MARESCHAL, 2005).

Cada uma das variantes dos métodos PROMETHEE (I, II, III, IV, V e VI) tem suas especificidades, sendo as principais diferenças e peculiaridades relacionadas ao uso de alternativas infinitas, estrutura de preferência por intervalos e a consideração da hipótese de incomparabilidade (GOMES; ARAYA; CARIGNANO, 2004).

Brans e Mareschal descrevem 0 procedimento de PROMETHEE II como:

Etapa 1. Definição dos índices de preferência agregados.

$$
\left\{\frac{\pi(a, b)=\sum_{j=1}^{k} \mathcal{P}_{j}(a, b) \mathcal{W}_{j}}{\pi(b, a)=\sum_{j=1}^{k} \mathcal{P}_{j}(b, a) \mathcal{W}_{j}}\right.
$$

Onde A é um conjunto finito de alternativas possíveis $\{a 1, a 2, \ldots, a n\}, k$ representa 0 número de critérios de avaliação e wj é o peso de cada critério. Os números são atribuídos arbitrariamente e os pesos são normalizados.

Etapa 2. Calcular $\pi(a, b)$ e $\pi(b, a)$ para cada par de alternativas de A.

Etapa 3. Definir o fluxo de superação positivo e negativo:

Fluxo positivo de superação:

$\emptyset^{+}(a)=\frac{1}{n-1} \sum_{x \in A} \pi(a, x)$

Fluxo negativo de superação:

$\emptyset^{-}(a)=\frac{1}{n-1} \sum_{x \in A} \pi(x, a)$

Etapa 4. Calcular o fluxo de superação líquida para cada alternativa da seguinte forma:

$\emptyset(a)=\emptyset^{+}(a)-\emptyset^{-}(a)$

Desta forma, descobre-se se o critério está mais superado, ou superando as alternativas.

\section{METODOLOGIA}

Este estudo foi realizado no SENAI de um Estado do Sul do Brasil, como informação do ano de 2017. O modelo proposto por este trabalho se aplica em um ambiente estratégico (Gerência de serviços tecnológicos) que detêm a governança para tomada de decisão nas áreas de consultoria, serviços metrológicos e PDI. Os indicadores de cada área são retirados dos Institutos que executam os serviços para o mercado conforme sua área foco de atuação (figura 1). 
Figura 1 - Governança

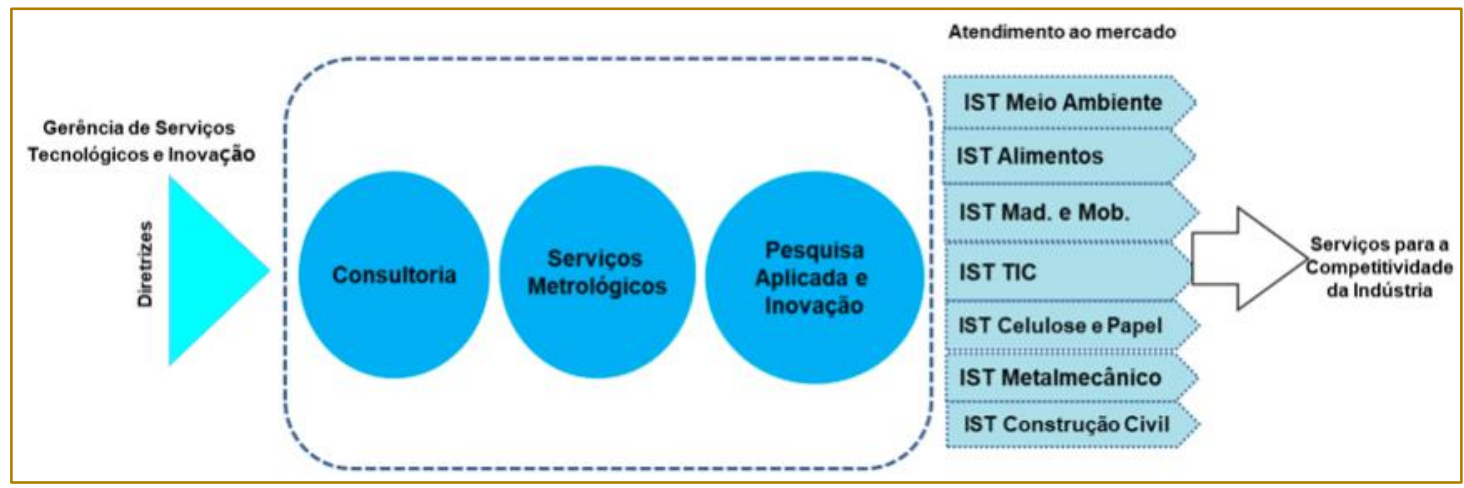

Fonte: Autores (2018)

O propósito de avaliação não é a definição de qual a área de serviço prioritária (PDI, consultoria ou metrologia), mas sim, demonstrar de forma prática a multidimensionalidade dos dados para tomada de decisão apoiado em diversos indicadores existentes nas áreas de serviços.

Desta forma, buscou-se priorizar qual é o Instituto de melhor resultado. Para isso foi analisado a composição de indicadores das áreas de negócios. A metodologia foi modelada em 5 etapas:

1 - Delimitação de referencial teórico para balizamento de conteúdo; 2 - análise e tabulação dos indicadores existentes nas três áreas de prestação de serviço; 3 - utilização do diagrama de Mudge para definição dos pesos dos critérios; 4 - seleção dos principais critérios; 5 - análise dos critérios na ferramenta visual Promethee.

Figura 2 - Modelo proposto

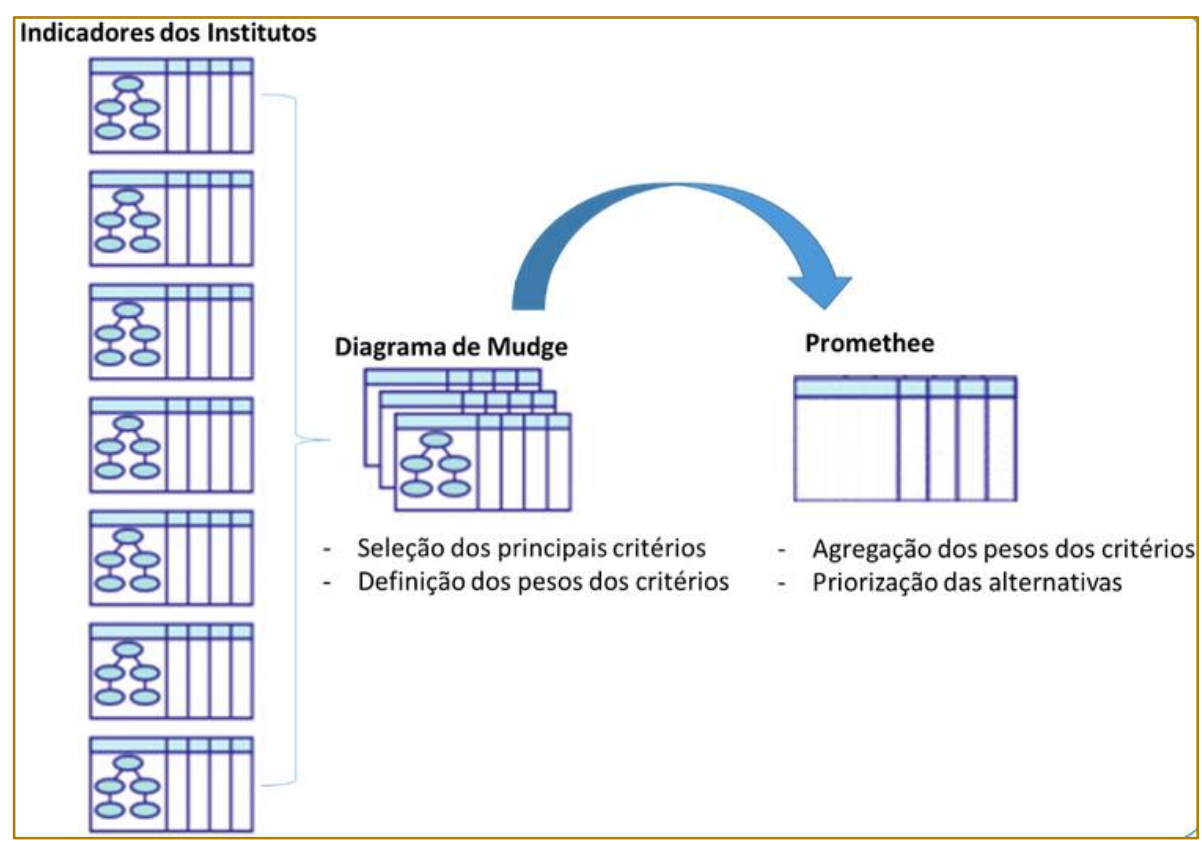

Fonte: Autores (2018)

A aplicação do Método de Mudge foi utilizada para filtrar critérios com base na redundância de indicadores pré-estabelecidos e inferir um peso aos mesmos que serão consumidos pela matriz de avaliação Promethee conforme apresenta o modelo proposto na figura 2.

A escolha do Método de Mudge foi baseada na facilidade de entendimento, praticidade de 
aplicação e eficácia além de que o estudo apresenta mais de 3 critérios, e com isso, é necessário o trabalho com uma aplicação sistematizada (ROZENFELD et al., 2006). Nele, os critérios são comparados par a par buscando definir qual é o mais importante e inserindo posteriormente o seu valor frente ao grau de importância. Também se objetivou excluir valores com baixa, ou nenhuma significância.

O resultado desta aplicação possibilitou a hierarquização dos critérios utilizando os percentuais da taxa de substituição.

Posteriormente, foram utilizados os critérios e pesos levantados para modelagem do método Promethee através da ferramenta Visual Promethee. O método permitiu uma análise de cenário sobre os critérios utilizados e sua influência na decisão, visto que nele foram detalhados os valores e números tabulados no relatório do conselho diretor do ano de 2018 para cada instituto executor dos serviços no Estado. Como resultado, obtevese o ranking dos institutos, não apresentando relação de incomparabilidade e considerando que os critérios estão interligados, de forma que um determinado indicador pode refletir parcialmente em outro.

\section{APLICAÇÃO E RESULTADOS}

Os modelos de análise multicritério, Mudge e Promethee, foram utilizados no entendimento de dados que investigam um novo modelo para tomada de decisão de novos investimentos e intensificação em ações de marketing e vendas de Institutos de tecnologia. Os critérios adotados surgiram de uma análise de 19 indicadores, para os quais foram considerados os 14 critérios mais utilizados, em 7 institutos de tecnologia.

\subsection{DEFINIÇÃO DOS CRITÉRIOS}

Os indicadores utilizados foram extraídos de bases homologadas pela organização estudada, considerando o objetivo para a presente análise, o de compreender frente aos indicadores usados isoladamente, quais não geram valor de forma agrupada. A lista com os indicadores foi gerada a partir de planilhas utilizadas pelos responsáveis das linhas de ação, que são: consultoria, serviços metrológicos e PDI.

Para determinar a hierarquia dos critérios existentes neste estudo, Keeney e Raiffa (1993) sugerem a "taxas de substituição", ou seja, o valor relativo que o sponsor atribui a cada um dos critérios. Utilizou-se então para esta definição o diagrama de Mudge. Para tal comparação, adotou-se o procedimento de análise par a par, questionando a importância do critério frente ao outro. Após a definição de qual foi o mais importante, definiu-se um valor. No Diagrama de Mudge, realizou-se a comparação das funções selecionadas, duas a duas, permitindo a classificação de acordo com o grau de importância. Conforme já descrito no estudo, utilizou-se a escala: 1 pouca importância superior; 2 - média importância superior; 3 - alta importância superior.

Durante as comparações feita com os stakeholders foram apresentadas as seguintes perguntas para aplicação da escala: "Qual requisito é mais importante?"; "Quanto mais importante é esse requisito?" (ROZENFELD et al., 2006, p. 222).

Especificamente na Tabela 1, a combinação de número/letra nos campos centrais representa qual objetivo é predominante e a sua intensidade de importância. No estudo, tem-se o entendimento que onde aparece ' $A 3$ ' no primeiro campo, apresenta que o critério $A$ - Receita prevalece sobre critério B Despesa, com uma intensidade 3 que representa alta importância superior, conforme a escala. Na última coluna obtém-se o ranking dos critérios, ou seja, seus respectivos graus de importância.

Estes graus de importância passam a ser entendidos como 'taxas de substituição' na medida em que se obtêm os valores percentuais dos critérios. O critério "J" é o mais importante, seguido do critério "H". 
Tabela 1: Diagrama de Mudge

\begin{tabular}{|c|c|c|c|c|c|c|c|c|c|c|c|c|c|c|c|c|c|}
\hline & & B & C & D & $E$ & $\mathrm{~F}$ & G & H & 1 & $\mathrm{~J}$ & K & L & M & $\mathrm{N}$ & Total & $\%$ & Colocação \\
\hline Receita & A & $\mathrm{A} 3$ & $\mathrm{~A} 2$ & $\mathrm{~A} 2$ & $\mathrm{~A} 1$ & $\mathrm{~A} 1$ & $\mathrm{~A} 3$ & $\mathrm{~A} 2$ & 12 & $\mathrm{~J} 3$ & $\mathrm{~A} 2$ & $\mathrm{~A} 1$ & $\mathrm{~A} 1$ & $\mathrm{~A} 1$ & 19 & $12 \%$ & 3 \\
\hline Despesa & & $B$ & C3 & B1 & B2 & B2 & B1 & $\mathrm{H} 2$ & 12 & $\mathrm{J3}$ & K2 & B1 & B1 & N1 & 8 & $5 \%$ & 10 \\
\hline Resultado Operacional & & & $\mathrm{C}$ & $\mathrm{C} 3$ & C1 & $\mathrm{C} 2$ & $\mathrm{C} 3$ & $\mathrm{C} 2$ & 11 & C1 & $\mathrm{C} 2$ & C1 & C1 & N1 & 19 & $12 \%$ & 3 \\
\hline n. colaboradores & & & & $\mathrm{D}$ & E1 & E1 & E2 & $\mathrm{H3}$ & 13 & $\mathrm{~J} 2$ & K2 & L2 & M1 & N1 & 0 & $0 \%$ & 12 \\
\hline Valor Equipamentos & & & & & $E$ & E2 & E1 & $\mathrm{H} 2$ & 12 & $\mathrm{~J} 2$ & K3 & L3 & M3 & N3 & 7 & $4 \%$ & 11 \\
\hline Valor Equipamentos depreciado & & & & & & $\mathrm{F}$ & G1 & $\mathrm{H} 2$ & 12 & $\mathrm{~J} 3$ & $\mathrm{~K} 2$ & L1 & M1 & N1 & 0 & $0 \%$ & 12 \\
\hline Metragem & & & & & & & G & $\mathrm{H3}$ & I1 & $\mathrm{J3}$ & K3 & L3 & M1 & N1 & 0 & $0 \%$ & 12 \\
\hline Itens Vendidos & & & & & & & & $\mathrm{H}$ & $\mathrm{H} 1$ & $\mathrm{H} 1$ & $\mathrm{H} 2$ & $\mathrm{H} 3$ & $\mathrm{H} 1$ & $\mathrm{H} 1$ & 20 & $13 \%$ & 2 \\
\hline Ticket Médio & & & & & & & & & 1 & $\mathrm{J1}$ & I1 & 12 & 11 & 11 & 17 & $11 \%$ & 5 \\
\hline Receita por colaborador & & & & & & & & & & $\mathrm{J}$ & $\mathrm{J} 2$ & $\mathrm{~J} 2$ & M3 & N3 & 21 & $13 \%$ & 1 \\
\hline Receita por equipamentos & & & & & & & & & & & $\mathrm{K}$ & K3 & M1 & N1 & 15 & $9 \%$ & 6 \\
\hline Receita por metro & & & & & & & & & & & & $\mathrm{L}$ & M1 & N1 & 9 & $6 \%$ & 9 \\
\hline Laudo & & & & & & & & & & & & & $M$ & N1 & 11 & $7 \%$ & 8 \\
\hline Ensaio & & & & & & & & & & & & & & \multirow[t]{2}{*}{$\mathrm{N}$} & 13 & $8 \%$ & 7 \\
\hline & & & & & & & & & & & & & & & 159 & $100 \%$ & \\
\hline
\end{tabular}

Fonte: Autor (2018)

Ordenados por relevância, os critérios apresentados no diagrama de Mudge (tabela 1) tem-se: Receita por colaborador, Itens vendidos, receita, resultado operacional, ticket médio, receita por equipamentos, ensaio, laudo, receita por metro, despesa, valor equipamento, número de colaboradores, valor equipamento depreciado, metragem. Os critérios "B", "D", "E", "F" e "G" (despesa, número de colaboradores, valor do equipamento, valor do equipamento depreciado e metragem) tiveram um grau de menor significância no estudo, sendo estes desqualificadas para a fase seguinte.

\subsection{APLICAÇÃO NO VISUAL PROMETHEE}

Para a modelagem do problema foram utilizadas 7 soluções propostas e 8 critérios. Os critérios modelados foram os selecionados a partir do diagrama de Mudge assim como seus pesos, que após análise dos critérios mais relevantes, foram inseridos na matriz de avaliação Promethee. Destes 8 critérios, 5 apresentaram escala de valor monetário, e outros 3 apresentaram escala numérica.

O suporte ao método Promethee I e II foi dado pelo software Visual Promethee. A função de preferência foi mantida padrão no primeiro modelo - (dizer qual função!). Após a modelagem do problema, observou o ranking inicial dos institutos na figura 3 , sendo o de TIC como melhor opção de priorização. Neste modelo, o instituto com menor aderência foi o de Metalomecânica.

Figura 3: Ranking (ordenamento da solução proposta)

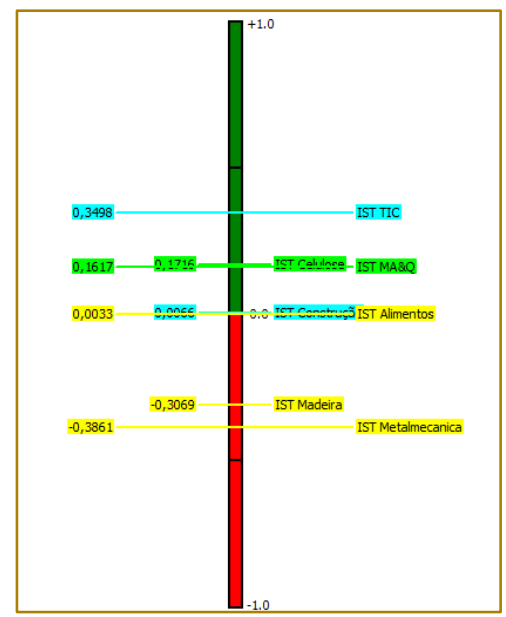

Fonte: autor (2018) 
Os fluxos de preferência dos Institutos são apresentados na Tabela 2, indicando o fluxo positivo (Phi+), o fluxo negativo (Phi-) e o fluxo líquido (Phi) obtido pela diferença entre os institutos analisados. O fluxo líquido de Phi que apresenta diretamente qual alternativa possui as melhores vantagens em relação às outras. Neste caso, O instituto de TIC. O fluxo Phi positivo apresenta o quanto a solução proposta possui de vantagem em relação às outras e o Phi negativo traduz o quanto à solução proposta possui de desvantagem em relação às outras.

Tabela 2: Tabela Phi - cenário 1

\begin{tabular}{|c|c|c|c|c|}
\hline Ranking & Instituto & Phi & Phi + & Phi- \\
\hline 1 & TIC & 0,3498 & 0,6749 & 0,3251 \\
\hline 2 & Celulose & 0,1716 & 0,5858 & 0,4142 \\
\hline 3 & MA\&Q & 0,1617 & 0,5809 & 0,4191 \\
\hline 4 & Construção & 0,0066 & 0,5033 & 0,4967 \\
\hline 5 & Alimentos & 0,0033 & 0,4868 & 0,4835 \\
\hline 6 & Madeira & $-0,3069$ & 0,3465 & 0,6535 \\
\hline 7 & Metalmecânica & $-0,3861$ & 0,2921 & 0,6782 \\
\hline \multicolumn{5}{|c|}{ Fonte: Autores (2018) } \\
\hline
\end{tabular}

Como segundo cenário foram parametrizadas as funções de preferência de acordo com o desempenho de cada critério da matriz de avaliação. Também foram revistos o limite de indiferença e limite de preferência. Assim, todos os critérios foram modelados como uma função linear com variação de seus limites de preferência.

O fluxo líquido de Phi que apresenta diretamente qual alternativa possui as melhores vantagens em relação às outras continuou sendo TIC, porém, o ordenamento se alterou entre os institutos de MA\&Q que subiu de $3^{\circ}$ para $2^{\circ}$, Alimentos que saiu da $5^{\circ}$ posição para a 3o posição, Celulose desceu duas posições comparada ao ordenamento anterior e Construção que saiu da $4^{\circ}$ posição para a $5^{\circ}$ posição neste cenário. Mesmo com a alteração do valor Phi para Madeira e Metalmecanica, estes continuaram no final do ranking.

É compreensivo a priorização de $M A \& Q$ pois tal instituto apresentou o maior número de itens vendidos, o maior número de laudos e o maior número de ensaios. O critério Receita por colaborador, que obteve o maior peso, tem o instituto de TIC como o maior número na avaliação, contribuindo para o entendimento da sua priorização em primeiro lugar no ranking.

Tabela 3: Tabela Phi - cenário 2

\begin{tabular}{|c|c|c|c|c|}
\hline Ranking & Instituto & Phi & Phi + & Phi- \\
\hline 1 & TIC & 0,1326 & 0,2546 & 0,122 \\
\hline 2 & $M A \& Q$ & 0,1222 & 0,4082 & 0,286 \\
\hline 3 & Alimentos & 0,1147 & 0,2448 & 0,1301 \\
\hline 4 & Celulose & 0,0312 & 0,1226 & 0,1539 \\
\hline 5 & Construção & 0,0459 & 0,1703 & 0,2163 \\
\hline 6 & Madeira & 0,1247 & 0,0728 & 0,1975 \\
\hline 7 & Metalmecanica & 0,1677 & 0,0717 & 0,2394 \\
\hline
\end{tabular}

Fonte:Autores (2018) 
Na Figura. 4 é possível notar o ordenamento dos institutos para investimento em marketing (vendas) ou investimento em infraestrutura, juntamente com o gráfico de barras que demonstra os pesos de cada critério.

Figura 4: Ordenamento e Pesos

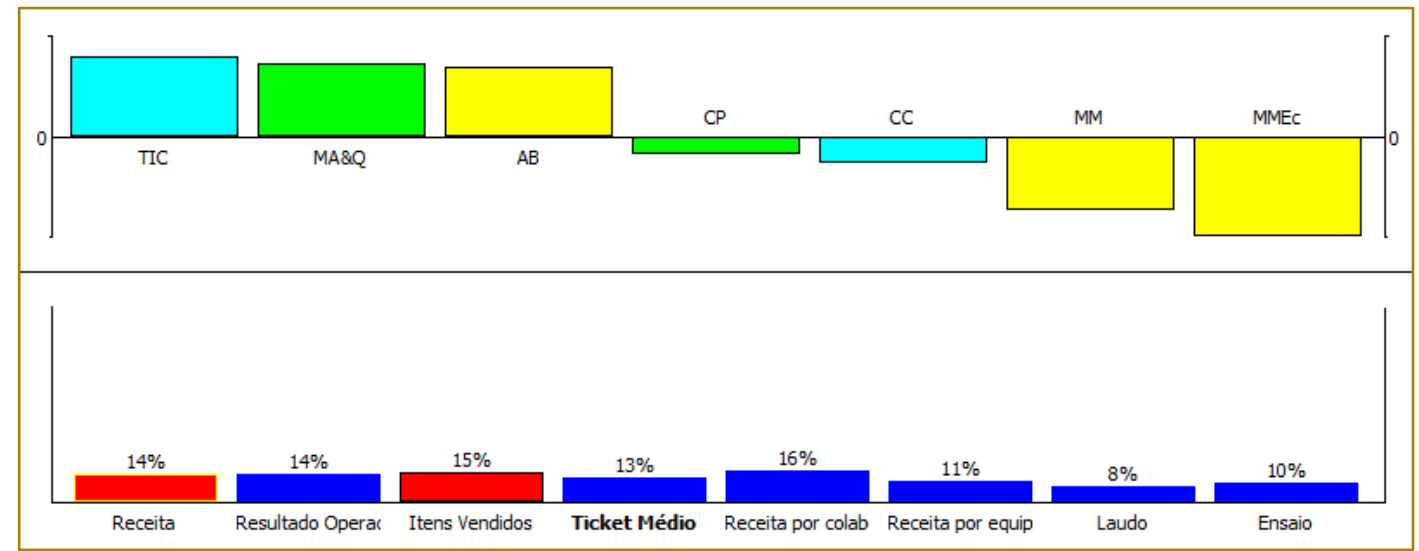

Fonte: Autores (2018)

\section{CONCLUSÃO}

Considerando o objetivo proposto pelo estudo, sob ótica de tratativa multicritério de priorização, obteve-se um resultado satisfatório com a definição dos critérios utilizando no método de Mudge, e posterior, a aplicação das informações existentes no modelo Promethee.

Foi possível determinar, desta forma, os institutos que melhor se destacam frente a uma análise multicritério de indicadores os quais eram utilizados separadamente pelas áreas de negócios. O estudo fornece uma metodologia estratégica para visualizar os rendimentos destes, facilita então ao decisor mais assertividade na escolha de investimento futuro.

O método Promethee apresentou como vantagem a transparência quanto aos critérios escolhidos e suas preferências de da decisão. A solução satisfatória encontrada foi o Instituto de TIC, o qual apresentou um valor de 0,1326 no ranking do cenário estabilizado (cenário 2). Mostrando assim, dentre as soluções existentes que este se adequou melhor aso critérios e valores inseridos.

Este trabalho apresentou a aplicabilidade da Análise Multicritério no auxílio à tomada de decisão em um problema de decisão de investimento dando maior assertividade na escolha de uma solução através da integração dos métodos Mudge e Promethee. Percebe-se que que o número de horas trabalhadas e número de clientes ativos podem compor um novo cenário de estudo, alterando assim o peso dos critérios. Pode-se também incluir uma análise com o método AHP e verificar se há ou não distorções quanto aos resultados, e/ou composição de um novo modelo de análise multicritério.

\section{REFERÊNCIAS}

[1] BASSO, J. Engenharia e análise do valor. São Paulo: Instituto IMAM, 1991. 140 p.

[2] BEHZADIAN Majid., KAZEMZADEH R.B., ALBADVI A., AGHDASI M. PROMETHEE: A comprehensive literature review on methodologies and applications. European Journal of Operational Research. v. 200, p. 198-215, 2010.

[3] BEHZADIAN Majid. KHANMOHAMMADI OTAGHSARA, S. YAZDANI, Morteza. IGNATIUS, Joshua. A state-of the-art survey of TOPSIS applications. Expert Systems with Applications. v. 39, n. 1, p. 13051-13069, 2012.

[4] BOAS, C. L. V. Análise da aplicação de métodos multicritérios de apoio à decisão (MMAD) na gestão de recursos hídricos. Simpósio Brasileiro De Recursos Hídricos, v. 16, 2005.

[5] BRANS, J.P.; MARESCHAL, B. PROMETHEE methods. In: Multiple criteria decision analysis: state of the art surveys. Springer, New York, NY, 2005. p. 163-186. 
[6] CHESBROUGH, H. Open Innovation: The new imperative for creating and profiting. Boston: Harvard Business Press, 2006.

[7] COSTA, H. G. Auxílio multicritério à decisão: método AHP. Rio de Janeiro: ABEPRO, 2006.

[8] EASTON, B.H. A Needs Index, Canterbury: Mimeograph - University of Canterbury, 1973.

[9] GOMES, L. F. A. M.; ARAYA, M. C. G.; CARIGNANO, C. Tomada de Decisão em Cenários Complexos: Introdução aos Métodos Discretos do Apoio Multicritério à Decisão. Tradutora Técnica Marcella Cecília Gonzáles Araya. São Paulo: Pioneira Thomson Learning, 2004, p. 168.

[10] GUIMARAES, A et al. Um estudo no setor de vitivinicultura no Brasil e em Portugal. Rev. Portuguesa e Brasileira de Gestão., Lisboa , v. 13, n. 4, p. 56-72, dez. 2014. Disponível em $<$ http://www.scielo.mec.pt/scielo.php?script=sci_art text\&pid=S1645-

44642014000400006\&lng=pt\&nrm=iso >. Acesso em: 03 mai. 2018.

[11] $\mathrm{HO}$, Wilian. Integrated analytic hierarchy process and its applications - A literature review. European Journal of Operational Research. v. 186, n. 1, p. 211-228, abril. 2008.

[12] KAGERMANN H.; et al. Securing the future of German manufacturing industry: recommendations for implementing the strategic initiative industrie 4.0: final report of the industrie 4.0 working group. Acatech: Alemanha, 2013.

[13] KEENEY, R. L. RAIFFA, H. Decision with multiple objectives, preferences and value tradeoffs. Cambridge: Cambridge University Press, 1993.

[14] LAURINDO, A. M. Gestão Estratégica Do Conhecimento: Investigação das práticas de gestão do conhecimento nas ações de planejamento de indústrias paranaenses. 2013. Dissertação (Mestrado) - Programa de pós graduação em engenharia de produção, Universidade Federal do Paraná, Curitiba, 2013.

[15] MARTTUNEN, Mika; LIENERT, Judit; BELTON, Valerie. Structuring problems for MultiCriteria Decision Analysis in practice: A literature review of method combinations. European Journal of Operational Research, v. 263, n. 1, p. 1-17, 2017.

[16] MOREIRA, R. A. Análise Multicritério dos Projetos do Sebrae/RJ através do Electre IV. 2007. Dissertação (Mestrado) - Programa de Pós-
Graduação e Pesquisa em Administração e Economia, Faculdade de Economia e Finanças IBMEC, Rio de Janeiro, 2007.

[17] OSGOOD, C.E.; Suci, G.J. \& Tannenbaum, P.H. The Measurement of Meaning. University of Illinois Press: Urbana, IL. 1957.

[18] PARNELL, Gregory S. HUGHES, David W. BURK, Roger Chapman. DRISCOLL, Patrick J. KUCIK, Paul D. Invited Review-Survey of ValueFocused Thinking: Applications, Research Developments and Areas for Future Research. Journal of Multi-Criteria Decision Analysis. v. 20, n. 1, p. 49-60, janeiro-abril. 2012.

[19] ROZENFELD, $H$. et al. Gestão de Desenvolvimento de Produtos: uma referência para a melhoria do processo. São Paulo: Saraiva, 2006. 542p.

[20] SAATY, T. L. The Analytic Hierarchy Process. New York: McGraw-Hill, 1980

[21] SAATY, Thomas L. Decision making with the analytic hierarchy process. International journal of services sciences, n. 1.1. 2008. P. 83-98.

[22] SAATY, Thomas L. Multicriteria Decision Making: The Analytic Hierarchy Process; Planning, Priority Setting, Resource Allocation. 2. Ed. Pittsburgh : R W S Publications, 1996.

[23] SANTOS, C. F. ; PIECHNICKI, F. ; ROCHA LOURES, EDUARDO ; SANTOS, E. A. P. . Mapping the Conceptual Relationship Among Data Analysis, Knowledge Generation and Decision-Making in Industrial Processes. In: 27th International Conference on Flexible Automation and Intelligent Manufacturing, 2017, Modena. Procedia Manufacturing, v. 11, p. 1751-1758, 2017.

[24] STILLWELL, W.G.; SEAVER, D.A. \& EDWARDS, W. A Comparison of Weight Approximation Techniques. In: Multiattribute Utility Decision Making, Organization Behavior and Human Performance. 28., Anais... 1981. 62-77.

[25] WALLENIUS, Jyrki DYER, James. S. FISHBURN, Peter. C. STEUER, Ralph. ZIONTS, Stanley. DEB, Kalyanmoy. Multiple Criteria Decision Making, Multiattribute Utility Theory: Recent Accomplishments and What Lies Ahead. Management Science. v. 54, n. 7, p. 1336-1349, julho. 2008.

[26] WANG, Q. POH, K. L. A survey of integrated decision analysis in energy and environmental modeling. Energy. v. 77, n. 1, p. 691702. 2008 


\section{Gapítulo 15}

\section{APLICAÇÃO DE MÉTODOS DE AUXÍLIO MULTICRITERIO PARA SELECÃO DE FORNECEDORES DE SERVICOO DE TRANSPORTE PARA EMPRESAS DO SEGMENTO DE ÓLEO E GÁS}

\section{Davidson de Almeida Santos}

\section{Mara Regina dos Santos Barcelos}

Osvaldo Luiz Gonçalves Quelhas

Carlos Francisco Simões Gomes

Sheila da Silva Carvalho Santos

Resumo: As empresas do segmento de óleo e gás necessitam escoar sua produção através da contratação de fornecedores de serviços de transporte. Nesse contexto, devido à importância desta ação para os resultados da empresa, o presente trabalho tem como objetivo a aplicação dos métodos de auxílio multicritério AHP, Electre I, e TODIM no processo de seleção de fornecedores de serviço de transporte para uma empresa do segmento de óleo e gás. O método AHP foi utilizado para gerar os pesos dos critérios, enquanto os métodos Electre I e TODIM foram usados para a seleção de fornecedores com base nos critérios estabelecidos. Especialistas determinaram os critérios mais relevantes. Os resultados demonstram que o método AHP gerou os pesos dos critérios de maneira consistente, conforme corroborado pelos valores de IC. O método Electre I selecionou o fornecedor 1como melhor opção. O método TODIM também selecionou o fornecedor 1 como melhor opção, mas, realizando a análise de sensibilidade o fornecedor 2 é o selecionado.

Palavras-chave: AHP; Electre I; TODIM; AMD. 


\section{INTRODUÇÃO}

O processo de tomada de decisão é a condicionante principal que determinará o grau de sucesso ou fracasso nas escolhas realizadas por seus gestores e está presente na essência de toda e qualquer organização, independentemente do porte ou da finalidade (ALVES; ALVES, 2015). A escolha de um fornecedor de serviço de transporte é um dos exemplos de decisão a serem realizadas pelos gestores nas empresas que poderá impactar de forma significativa (positiva ou negativamente) nos resultados das empresas.

Este trabalho objetiva auxiliar no processo de escolha de fornecedores de serviço de transporte para uma empresa do segmento de óleo e gás através da utilização dos métodos AHP (Analytic Hierarchy Process), ELECTRE I (Elimination Et Choice Traidusaint la Realitè), e TODIM (Tomada de Decisão Interativa Multicritério).

\section{REFERENCIAL TEÓRICO}

Nos últimos anos, a vertente de desenvolvimento metodológico na tomada de decisão tem se caracterizado por abordar a solução de problemas decisórios à luz de vários critérios (NEVES; PEREIRA; COSTA, 2013). Isso justifica o crescimento da demanda por abordagens baseadas em Multicriteria Decision Making (MCDM) ou Multicriteria Decision Aid (MCDA) e explica o aumento na adoção de modelos para suportar as decisões que ocorrem em situações de incerteza e risco (KLUCZEK; GLADYSZ, 2015).

De acordo com Oztaysi (2014), os métodos MCDA/MCDM permitem que a decisão seja regulada com base nos critérios ponderados mais relevantes ao problema a ser respondido pelos agentes de tomada de decisão, onde a importância dos critérios é definida por eles, em um processo interativo com outros atores técnico-políticos. É importante ressaltar que as mesmas consideram a influência de uma multiplicidade de critérios e incorporam subjetividade ao considerar os julgamentos de valor dos decisores (GOMES; GOMES, 2014).

\subsection{MÉTODO AHP (ANALYTIC HIERARCHIC PROCESS)}

O Método AHP objetiva a seleção de alternativas em um processo que considere diferentes critérios de avaliação e se baseia em três princípios do pensamento analítico: construção de hierarquias, definição de prioridades e consistência lógica (LIMA JUNIOR; CARPINETTI, 2015). A construção de hierarquias compreende melhor o problema em questão, a definição de prioridades compara as alternativas em relação a determinados critérios e a consistência lógica avalia o modelo de priorização com relação a sua consistência.

Para Subramanian e Ramanathan (2012), na construção de um modelo para estabelecer prioridades com o uso do AHP são desenvolvidas as seguintes etapas: construção de hierarquia identificando: foco principal, critérios, subcritérios e alternativas; aquisição de dados ou coleta de julgamentos de valor emitidos por especialistas; síntese dos dados obtidos dos julgamentos, calculando-se a prioridade de cada alternativa em relação ao foco principal; análise da consistência do julgamento identificando o quanto o sistema de classificação (composto por: hierarquia, métodos de aquisição dos julgamentos de valor e avaliadores) é consistente no ordenamento das alternativas viáveis.

A seguir apresenta-se a pontuação das alternativas do método AHP. 
TABELA 1 - Escala fundamental de Saaty.

\begin{tabular}{|c|c|c|}
\hline INTENSIDADE & PONTUAÇÃO & FORMA DE AVALIAÇÃO \\
\hline 1 & Igual importância & $\begin{array}{c}\text { As duas atividades contribuem igualmente para o } \\
\text { objetivo. }\end{array}$ \\
\hline 3 & $\begin{array}{l}\text { Importância pequena de uma } \\
\text { sobre a outra }\end{array}$ & $\begin{array}{c}\text { A experiência e o juízo favorecem uma atividade em } \\
\text { relação à outra. }\end{array}$ \\
\hline 5 & $\begin{array}{l}\text { Importância grande ou } \\
\text { essencial }\end{array}$ & $\begin{array}{l}\text { A experiência e o juízo favorecem fortemente uma } \\
\text { atividade em relação à outra. }\end{array}$ \\
\hline 7 & $\begin{array}{l}\text { Importância muito grande ou } \\
\text { demonstrada }\end{array}$ & $\begin{array}{l}\text { Uma atividade é muito fortemente favorecida em } \\
\text { relação à outra. Pode ser demonstrada na prática. }\end{array}$ \\
\hline 9 & Importância absoluta & $\begin{array}{l}\text { A evidência favorece uma atividade em relação à } \\
\text { outra, com o mais alto grau de segurança. }\end{array}$ \\
\hline $2,4,6,8$ & Valores intermediários & $\begin{array}{c}\text { Quando se procura uma condição de compromisso } \\
\text { entre duas definições. }\end{array}$ \\
\hline
\end{tabular}

Fonte: Adaptado de SAATY e VARGAS (2013).

Outro ponto importante em relação ao AHP é a verificação de consistência em relação aos julgamentos realizados pelo grupo de especialistas, feito através da Razão de Consistência $(R C)$, que permite avaliar a inconsistência em função da ordem da matriz de julgamentos (RATNAYAKE; MARKESET, 2010). Neste caso o valor deve ser inferior a 0,1 para que não haja a necessidade de revisão do modelo e/ou dos julgamentos. A razão de consistência é calculada pela fórmula descrita na Equação 1.

$$
R C=\frac{I C}{I R} \quad \text { (Equação 1) }
$$

O IC corresponde ao índice de consistência, já o IR é um índice consistência obtido para uma matriz recíproca, com elementos nãonegativos e gerada de forma randômica. (Alves e Alves, 2015). A Tabela 1 ilustra os resultados apresentados por Saaty para 0 valor de IR.

TABELA 2 - Índices de consistência randômicos (IR).

\begin{tabular}{|c|c|}
\hline Ordem da matriz & Valores de IR \\
\hline 2 & 0,00 \\
\hline 3 & 0,58 \\
\hline 4 & 0,90 \\
\hline 5 & 1,12 \\
\hline 6 & 1,24 \\
\hline 7 & 1,32 \\
\hline 8 & 1,41 \\
\hline 9 & 1,45 \\
\hline
\end{tabular}

Fonte: Alves e Alves (2015).

\subsection{MÉTODO ELECTRE I (ELIMINATION ET CHOICE TRADUSÀINT LA REALITÈ)}

O Electre I, é um dos métodos da família ELECTRE (Elimination Et Choix Traduisant la Réalité). Esses métodos utilizam o conceito de sobreclassificação, verificando as relações de subordinação entre as alternativas consideradas, são três as relações de preferência: indiferença, preferência fraca e preferência estrita (COSTA, 2016).

Os métodos da família ELECTRE são aplicados em duas etapas: (1) construção da relação de sobreclassificação; (2) selecionar, ordenar, ou classificar um conjunto de 
alternativas de acordo com a sua dominância. Os conceitos de concordância e discordância estabelecem os limites para validação ou não da relação de sobreclassificação. Ou seja, nos métodos ELECTRE, a relação de sobreclassificação está sujeita a cortes que são estabelecidos por níveis de concordância mínima (p) e de discordância máxima (q), que são estabelecidos pelo decisor (GOMES; GOMES, 2014; GOMES; COSTA, 2015).

Primeiramente é necessário calcular os índices de concordância e de discordância para cada par de alternativas em relação a cada critério estabelecido, conforme apresenta as Equações 2 e 3 (COSTA, 2016).

$$
\begin{aligned}
& \left\{C_{(a, b)=\frac{1}{w} \sum_{\forall j g_{i}(a) \geq g_{j(b)}} w_{j}} \text { onde } W=\sum_{J=1}^{m} w_{J}\right. \\
& \text { (Equação 2) } \\
& D_{(a, b)}=\max \left[\frac{g_{j}(b)-g_{j}(a)}{\delta_{j}} ; 0\right] \quad \text { onde } \delta_{j}=g_{j(x)}-g_{j(y)} \\
& \text { (Equação 3) }
\end{aligned}
$$

Nas equações, wj é o peso do critério j, enquanto que $X$ e $Y$ são, respectivamente, as alternativas com melhor e pior desempenho no mesmo critério j (COSTA, 2016). A afirmação aSb (a não é pior que b) será válida se $a \mathrm{C}(\mathrm{a}, \mathrm{b}) \geq \mathrm{p}$ e $\mathrm{D}(\mathrm{a}, \mathrm{b}) \leq \mathrm{q}$ (GOMES; GOMES, 2014).

\subsection{MÉTODO TODIM (TOMADA DE DECISÃO INTERATIVA MULTICRITÉRIO)}

O método TODIM, é um método multicritério de análise de decisão cujo resultado é representado pelas alternativas já sequenciadas por ordem de preferência e utiliza modelagem matemática baseada em matrizes de comparações por pares. O TODIM descreve o comportamento do ser humano em face ao risco (RIBEIRO; PASSOS; TEIXEIRA, 2012). O diferencial do método TODIM é a utilização de uma medida global calculável através da aplicação da Função de Valor da Teoria dos Prospectos (SILVA; BRANDALISE; CARNEIRO, 2011).

Inicia-se com um conjunto de $n$ alternativas a serem ordenadas com $m$ critérios quantitativos ou qualitativos, no qual um destes critérios é considerado como o de referência. Após a definição dos critérios, os especialistas estimam para cada um dos critérios qualitativos c, a contribuição de cada alternativa i para o objetivo associado ao critério. Este método requer que os valores das avaliações dos critérios em relação às alternativas sejam numéricos e normalizados transformando a escala verbal em uma escala cardinal (RANGEL; SILVA; SILVÉRIO, 2006).

Destaca-se que os pesos atribuídos aos critérios também deverão ser normalizados. 0 critério de referência arc representa a taxa de substituição do critério em análise c em relação ao critério de referência $r$, (RANGEL; SILVA; SILVÉRIO, 2006).

Os tomadores de decisão devem indicar qual critério r é para ser escolhido como critério de referência para os cálculos. De acordo com a importância relativa atribuída a cada critério, o critério com maior valor atribuído a sua importância será geralmente escolhido como critério de referência. $\mathrm{O}$ peso de cada critério é determinado pelos tomadores de decisão em uma escala numérica e é então normalizado. Assim, arc é o peso do critério c dividido pelo peso do critério de referência $r$ (GOMES; RANGEL, 2009).

A medida de dominância de cada alternativa i sobre cada alternativa j, incorporada a Teoria da Perspectiva, é expressa pela Equação 4 (RANGEL; SILVA; SILVÉRIO, 2006).

$$
\delta(i, j)=\sum_{c=1}^{m} \Phi(i, j), \forall(i, j)
$$


Onde:

$$
\Phi C_{i, j}=\left[\begin{array}{ll}
\sqrt{\frac{a_{r c}\left(w_{i c}-w_{j c}\right)}{\sum_{c} a_{r c}}} & \text { Se } \mathrm{w}_{\mathrm{ic}}-\mathrm{w}_{\mathrm{ic}}>0 \\
0 & \text { Se } \mathrm{w}_{\mathrm{ic}}-\mathrm{w}_{\mathrm{ic}}=0 \\
-\frac{1}{\Theta} \sqrt{\frac{\left.\sum_{c} a_{r c}\right)\left(w_{j c}-w_{i c}\right.}{a_{r c}}} & \text { Se } \mathrm{w}_{\mathrm{ic}}-\mathrm{w}_{\mathrm{ic}}<0
\end{array}\right.
$$

sendo que, $\delta(i, j)$ representa a medida de dominância da alternativa i sobre a alternativa j; $m$ representa o número de critérios; c é um critério qualquer, para $\mathrm{c}=1, \ldots, \mathrm{m}$; arc representa a taxa de susbstituição do critério $c$ pelo critério r; wic e wij são respectivamente, os pesos das alternativas i e j em relação ao critério c; $\theta$ é o fator de atenuação das perdas.

O fator $\Phi \mathrm{c}(\mathrm{i}, \mathrm{j})$ representa a parcela de contribuição do critério $c$ à função $\delta(i, j)$, quando se compara a alternativa i com a j. Caso o valor de wic - wjc seja positivo, representará um ganho para a função $\delta(\mathrm{i}, \mathrm{j})$ e, portanto, será usada a expressão de $\Phi \mathrm{c}(\mathrm{i}, \mathrm{j})$ correspondente, isto é, a equação (1a). Caso wic - wjc seja nulo, será atribuído o valor nulo para $\Phi c(i, j)(1 b)$, e se wic - wjc for negativo, $\Phi \mathrm{c}(\mathrm{i}, \mathrm{j})$ será representado pela equação (1c) (RANGEL; SILVA; SILVÉRIO, 2006).

A Equação 5 é usada para determinar o valor geral da alternativa i através da normalização das medidas de dominância correspondentes. A classificação de cada alternativa se origina da ordenação de seus respectivos valores (ZYOUD et al, 2016).

$$
\xi_{i}=\frac{\sum_{j=1}^{n} \delta(i, j)-\min \sum_{j=1}^{n} \delta(i, j)}{\max \sum_{j=1}^{n} \delta(i, j)-\min \sum_{j=1}^{n} \delta(i, j)}
$$

(Equação 5)

Portanto, as medidas globais obtidas calculadas por (2) permitem a classificação completa de todas as alternativas. Uma análise de sensibilidade deve ser aplicada para verificar a estabilidade dos resultados com base nas preferências dos tomadores de decisão. A análise de sensibilidade pode ser realizada em $\theta$, nos pesos dos critérios, na escolha do critério de referência e nas avaliações de desempenho (GOMES; RANGEL, 2009).

\section{METODOLOGIA}

As avaliações dos especialistas, que definiram os critérios mais importantes, foram feitas com base no trabalho de Bastos et al (2010). O método AHP foi utilizado para calcular os pesos dos critérios, pesos esses que foram empregados pelos métodos ELECTRE I e TODIM. Apesar do AHP ser um método compensatório, no presente trabalho o mesmo foi utilizado para permitir o estabelecimento das preferências.

Em seguida os métodos de auxílio multicritério ELECTRE I e TODIM foram aplicados a fim de selecionar a alternativa (fornecedor) que se mostra como melhor opção de acordo com os parâmetros estabelecidos.

Por fim, uma comparação entre os resultados obtidos pelos dois métodos foi realizada para testar se os métodos de auxílio multicritério podem ser, ou não, utilizados no problema em questão. Assim, o decisor possuirá duas alternativas de análise, a ordenação por um método não compensatório, no caso Electre I e um método compensatório o TODIM.

\section{ESTUDO DE CASO}

O presente estudo foi realizado em uma empresa do segmento de óleo e gás com o objetivo de auxiliar no processo de decisão relacionado a escolha de um fornecedor de serviço de transporte.

\subsection{IDENTIFICAÇÃO DOS CRITÉRIOS}

O processo de identificação dos critérios de seleção dos fornecedores de serviço de transporte foi estruturado com base no trabalho de Bastos et al (2010). Esse trabalho 
apresenta uma diversidade de critérios de seleção avaliados por um grupo de especialistas da área de logística. Após essa avaliação foram selecionados quatro critérios, a saber: custo, qualidade, inovação e flexibilidade.

\subsection{ESTRUTURAÇÃO DOS NÍVEIS HIERÁRQUICOS}

Para o segmento de óleo e gás foram consideradas três transportadoras como alternativas no processo de seleção. Essas transportadoras foram selecionadas com base em conversas realizadas com os gestores logísticos da empresa contratante. A estrutura hierárquica para a seleção do fornecedor é apresentada na Figura 1.

Figura 1 - Estrutura hierárquica para a seleção do fornecedor ideal

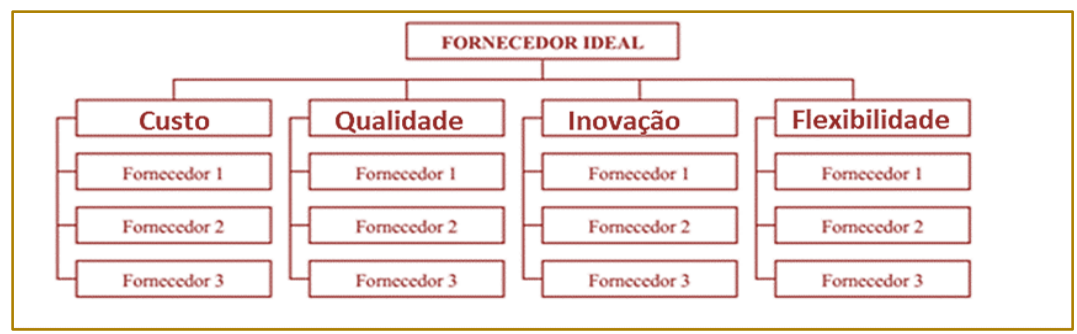

Fonte: Adaptado de Bastos et al (2010).

\subsection{ATRIBUIÇÃO DE PESOS PARA ALTERNATIVAS E CRITÉRIOS UTILIZANDO O AHP}

Primeiramente foi realizada a avaliação dos fornecedores de serviço de transporte junto aos especialistas em logística (grupo de profissionais que atuam ou atuaram no segmento de óleo e gás). As Tabelas 2, 3, 4, e 5 apresentam os resultados das avaliações em relação aos critérios adotados, ressaltando que as intensidades descritas no tabela 1 foram utilizadas nesta etapa.

Tabela 3 - Avaliação dos especialistas para o critério custo.

\begin{tabular}{|c|c|c|c|}
\hline Custo & Fornecedor 1 & Fornecedor 2 & Fornecedor 3 \\
\hline Fornecedor 1 & 1,00 & 5,00 & 1,00 \\
\hline Fornecedor 2 & 0,20 & 1,00 & 0,33 \\
\hline Fornecedor 3 & 1,00 & 3,00 & 1,00 \\
\hline
\end{tabular}

Tabela 4 - Avaliação dos especialistas para o critério qualidade.

\begin{tabular}{|c|c|c|c|}
\hline Qualidade & Fornecedor 1 & Fornecedor 2 & Fornecedor 3 \\
\hline Fornecedor 1 & 1,00 & 7,00 & 3,00 \\
\hline Fornecedor 2 & 0,14 & 1,00 & 0,33 \\
\hline Fornecedor 3 & 0,33 & 3,00 & 1,00 \\
\hline
\end{tabular}

Tabela 5 - Avaliação dos especialistas para o critério inovação.

\begin{tabular}{|c|c|c|c|}
\hline Inovação & Fornecedor 1 & Fornecedor 2 & Fornecedor 3 \\
\hline Fornecedor 1 & 1,00 & 5,00 & 1,00 \\
\hline Fornecedor 2 & 0,20 & 1,00 & 0,20 \\
\hline Fornecedor 3 & 1,00 & 5,00 & 1,00 \\
\hline
\end{tabular}

Tabela 6 - Avaliação dos fornecedores para o critério flexibilidade. 


\begin{tabular}{|c|c|c|c|}
\hline Flexibilidade & Fornecedor 1 & Fornecedor 2 & Fornecedor 3 \\
\hline Fornecedor 1 & 1,00 & 5,00 & 1,00 \\
\hline Fornecedor 2 & 0,20 & 1,00 & 0,20 \\
\hline Fornecedor 3 & 1,00 & 5,00 & 1,00 \\
\hline
\end{tabular}

Após a avaliação dos especialistas com base nos critérios estabelecidos, foi gerada uma matriz com os resultados, conforme ilustra a Tabela 7.

Tabela 7 - Mariz de resultados das avaliações.

\begin{tabular}{|c|c|c|c|c|}
\hline & Custo & Qualidade & Inovação & Flexibilidade \\
\hline Custo & 1,00 & 5,00 & 7,00 & 1,00 \\
\hline Qualidade & 0,20 & 1,00 & 5,00 & 0,20 \\
\hline Inovação & 0,14 & 0,20 & 1,00 & 0,20 \\
\hline Flexibilidade & 1,00 & 5,00 & 5,00 & 1,00 \\
\hline
\end{tabular}

Com base nos pesos atribuídos na comparação das alternativas em relação a cada um dos critérios e os pesos atribuídos na comparação entre os critérios, foi realizada a normalização dos mesmos (divisão do valor da coluna pelo somatório dos valores dessa coluna). As Tabelas 8, 9, 10, 11, e 12 apresentam os resultados dos cálculos realizados nesse processo.

Tabela 8 - Normalização dos pesos para o critério custo.

\begin{tabular}{|c|c|c|c|c|}
\hline Custo & Fornecedor 1 & Fornecedor 2 & Fornecedor 3 & Média \\
\hline Fornecedor 1 & 0,45 & 0,56 & 0,43 & 0,48 \\
\hline Fornecedor 2 & 0,09 & 0,11 & 0,14 & 0,11 \\
\hline Fornecedor 3 & 0,45 & 0,33 & 0,43 & 0,41 \\
\hline
\end{tabular}

Tabela 9 - Normalização dos pesos para o critério qualidade.

\begin{tabular}{|c|c|c|c|c|}
\hline Qualidade & Fornecedor 1 & Fornecedor 2 & Fornecedor 3 & Média \\
\hline Fornecedor 1 & 0,68 & 0,64 & 0,69 & 0,67 \\
\hline Fornecedor 2 & 0,10 & 0,09 & 0,08 & 0,09 \\
\hline Fornecedor 3 & 0,23 & 0,27 & 0,23 & 0,24 \\
\hline
\end{tabular}

Tabela 10 - Normalização dos pesos para o critério inovação.

\begin{tabular}{|c|c|c|c|c|}
\hline Inovação & Fornecedor 1 & Fornecedor 2 & Fornecedor 3 & Média \\
\hline Fornecedor 1 & 0,45 & 0,45 & 0,45 & 0,45 \\
\hline Fornecedor 2 & 0,09 & 0,09 & 0,09 & 0,09 \\
\hline Fornecedor 3 & 0,45 & 0,45 & 0,45 & 0,45 \\
\hline
\end{tabular}


Tabela 11 - Normalização dos pesos para o critério flexibilidade.

\begin{tabular}{|c|c|c|c|c|}
\hline Flexibilidade & Fornecedor 1 & Fornecedor 2 & Fornecedor 3 & Média \\
\hline Fornecedor 1 & 0,45 & 0,45 & 0,45 & 0,45 \\
\hline Fornecedor 2 & 0,09 & 0,09 & 0,09 & 0,09 \\
\hline Fornecedor 3 & 0,45 & 0,45 & 0,45 & 0,45 \\
\hline
\end{tabular}

Tabela 12 - Normalização dos pesos entre os critérios.

\begin{tabular}{|c|c|c|c|c|c|}
\hline & Custo & Qualidade & Inovação & Flexibilidade & Média \\
\hline Custo & 0,43 & 0,45 & 0,39 & 0,42 & 0,42 \\
\hline Qualidade & 0,09 & 0,09 & 0,28 & 0,08 & 0,13 \\
\hline Inovação & 0,06 & 0,02 & 0,06 & 0,08 & 0,05 \\
\hline Flexibilidade & 0,43 & 0,45 & 0,28 & 0,42 & 0,39 \\
\hline
\end{tabular}

Os resultados exibidos na Tabela 13 apresentam os pesos extraídos das tabelas anteriores. Desta forma os pesos definitivos para cada critério ficaram definidos da seguinte forma: 0,42 para custo; 0,13 para qualidade; 0,05 para inovação e 0,39 para flexibilidade.

Tabela 13 - Pesos fornecedor $x$ critério.

\begin{tabular}{|c|c|c|c|c|}
\hline \multirow{2}{*}{ Fornecedor } & \multicolumn{4}{c|}{ Critérios } \\
\cline { 2 - 5 } & Custo & Qualidade & Inovação & Flexibilidade \\
\hline Fornecedor 1 & 0,48 & 0,67 & 0,45 & 0,45 \\
\hline Fornecedor 2 & 0,11 & 0,09 & 0,09 & 0,09 \\
\hline Fornecedor 3 & 0,41 & 0,24 & 0,45 & 0,45 \\
\hline
\end{tabular}

Outro ponto importante no desenvolvimento do AHP é a possibilidade de verificação de consistência $(R C)$ nos julgamentos realizados pelos especialistas em logística. A razão de consistência encontrada para cada um dos critérios foi de: 0,03 para custo; 0,01 para qualidade; -0,02 para inovação e -0,02 para flexibilidade. Enfatizando que, de acordo com a metodologia, os julgamentos foram considerados como consistentes.

\subsection{UTILIZAÇÃO DO MÉTODO ELECTRE I}

O método ELECTRE I foi aplicado com o objetivo de auxiliar o processo de escolha do fornecedor de serviço de transporte de uma empresa do segmento de óleo e gás. Os pesos utilizados foram obtidos mediante à utilização do método AHP e a matriz de julgamentos demonstrada na Tabela 14 obtida através das avaliações dos especialistas.

Tabela 14 - Desempenho das alternativas.

\begin{tabular}{|c|c|c|c|c|}
\hline & Custo & Qualidade & Inovação & Flexibilidade \\
\hline W (peso) & 0,42 & 0,13 & 0,05 & 0,39 \\
\hline F1 & 0,48 & 0,67 & 0,45 & 0,45 \\
\hline F2 & 0,11 & 0,09 & 0,09 & 0,09 \\
\hline F3 & 0,41 & 0,24 & 0,45 & 0,45 \\
\hline
\end{tabular}


O método ELECTRE I foi aplicado mediante à utilização do sistema computacional J-Electre (PEREIRA; COSTA; NEPOMUCENO, 2014), que permite a execução dos algoritmos de alguns métodos multicritério da escola francesa, já tendo sido testado e validado para a execução dos métodos: ELECTRE I; I_S; I_V; II; III; IV; TRI e TRI-ME.

Os dados apresentados na Tabela 13 foram inseridos no software J-Electre e os valores para concordância mínima (p) e de discordância máxima (q), também foram inseridos, a saber: $p=0,8$ e $q=0,6$.

O sistema J-Electre calcula as matrizes de concordância, discordância e credibilidade, conforme ilustrado nas Tabelas 15, 16, e 17 respectivamente. Feito isso, a alternativa que representa a melhor opção é indicada, de acordo com os parâmetros estabelecidos. No caso, o fornecedor 1 foi selecionado como melhor opção.

Tabela 15 - Matriz de concordância.

\begin{tabular}{|c|c|c|c|}
\hline & $\mathrm{F} 1$ & F2 & F3 \\
\hline F1 & 0,00 & 1,00 & 1,00 \\
\hline F2 & 0,00 & 0,00 & 0,00 \\
\hline F3 & 0,44 & 1,00 & 0,00 \\
\hline
\end{tabular}

Tabela 16 - Matriz de discordância.

\begin{tabular}{|c|c|c|c|}
\hline & $\mathrm{F} 1$ & F2 & F3 \\
\hline $\mathrm{F} 1$ & 0,00 & 0,00 & 0,00 \\
\hline F2 & 1,00 & 0,00 & 0,62 \\
\hline F3 & 0,74 & 0,00 & 0,00 \\
\hline
\end{tabular}

Tabela 17 - Matriz de credibilidade.

\begin{tabular}{|c|c|c|c|}
\hline F1 & 0,00 & 1,00 & 1,00 \\
\hline F2 & 0,00 & 0,00 & 0,00 \\
\hline F3 & 0,00 & 1,00 & 0,00 \\
\hline
\end{tabular}

F2 domina F1. F3 domina F1. F2 domina F3

\subsection{MÉTODO TODIM}

O método TODIM foi aplicado com o objetivo de auxiliar no processo de escolha do fornecedor de serviço de transporte. No entanto, é importante mencionar que as duas primeiras etapas do método foram suprimidas, já que os pesos foram extraídos dos resultados obtidos com o AHP.

O critério referência para o problema proposto foi o custo, pois apresenta o maior peso dentre os critérios. Diante disso os resultados obtidos para o cálculo do arc foram os seguintes: 1,00 para custo; 0,32 para qualidade; 0,13 para inovação e 0,93 para flexibilidade.

O arc é calculado pelo valor do peso do critério dividido pelo valor do peso do critério de referência. A comparação das alternativas (par a par) em relação a cada critério foi realizada, conforme apresentado nas Tabelas $18,19,20$ e 21. 
Tabela 18 - Comparação par a par para o critério custo.

\begin{tabular}{|c|c|c|c|}
\hline Custo & Fornecedor 1 & Fornecedor 2 & Fornecedor 3 \\
\hline Fornecedor 1 & - & 0,39 & 0,18 \\
\hline Fornecedor 2 & 0,93 & - & 0,83 \\
\hline Fornecedor 3 & 0,42 & 0,35 & - \\
\hline
\end{tabular}

Tabela 19 - Comparação par a par para o critério qualidade.

\begin{tabular}{|c|c|c|c|}
\hline Qualidade & Fornecedor 1 & Fornecedor 2 & Fornecedor 3 \\
\hline Fornecedor 1 & - & 0,28 & 0,24 \\
\hline Fornecedor 2 & 2,08 & - & 1,08 \\
\hline Fornecedor 3 & 1,78 & 0,14 & - \\
\hline
\end{tabular}

Tabela 20 - Comparação par a par para o critério inovação.

\begin{tabular}{|c|c|c|c|}
\hline \multicolumn{1}{|c|}{ Inovação } & Fornecedor 1 & Fornecedor 2 & Fornecedor 3 \\
\hline Fornecedor 1 & - & 0,14 & - \\
\hline Fornecedor 2 & 2,58 & - & 2,58 \\
\hline Fornecedor 3 & - & 0,14 & - \\
\hline
\end{tabular}

Tabela 21 - Comparação par a par para o critério flexibilidade.

\begin{tabular}{|c|c|c|c|}
\hline Flexibilidade & Fornecedor 1 & Fornecedor 2 & Fornecedor 3 \\
\hline Fornecedor 1 & - & 0,38 & - \\
\hline Fornecedor 2 & 0,96 & - & 0,96 \\
\hline Fornecedor 3 & - & 0,38 & - \\
\hline
\end{tabular}

$\mathrm{Na}$ presente pesquisa o fator de atenuação de perdas $(\theta)$ foi igual a 1 , ou seja, as perdas contribuíram com seu valor real para o valor global. Após os cálculos realizados, os mesmos foram agrupados conforme apresentadas nas Tabelas 22, 23 e 24, sendo que as siglas F1, F2, e F3 se referem, respectivamente, aos fornecedores 1,2 , e 3 .

Tabela 22 - Comparação par a par dos fornecedores, com foco no fornecedor 1.

\begin{tabular}{|c|c|c|c|c|}
\hline \multirow{2}{*}{ Fornecedores } & \multicolumn{4}{|c|}{ Critérios } \\
& Custo & Qualidade Inovação & Flexibilidade \\
\hline F1, F1 & - & - & - & - \\
\hline F1, F2 & 0,39 & 0,28 & 0,14 & 0,38 \\
\hline F1, F3 & 0,18 & 0,24 & - & - \\
\hline
\end{tabular}


Tabela 23 - Comparação par a par dos fornecedores, com foco no fornecedor 2.

\begin{tabular}{|c|c|c|c|c|}
\multirow{2}{*}{ Fornecedores } & \multicolumn{4}{|c|}{ Critérios } \\
& Custo & Qualidade & Inovação & Flexibilidade \\
\hline F2, F1 & 0,93 & 2,08 & 2,58 & 0,96 \\
\hline F2, F2 & - & - & - & - \\
\hline F2, F3 & 0,83 & 1,08 & 2,58 & 0,96 \\
\hline
\end{tabular}

Tabela 24 - Comparação par a par dos fornecedores, com foco no fornecedor 3.

\begin{tabular}{|c|c|c|c|c|}
\hline \multirow{2}{*}{ Fornecedores } & \multicolumn{4}{|c|}{ Critérios } \\
& Custo & Qualidade & Inovação & Flexibilidade \\
\hline F3, F1 & 0,42 & 1,78 & - & - \\
\hline F3, F2 & 0,35 & 0,14 & 0,14 & 0,38 \\
\hline F3, F3 & - & - & - & - \\
\hline
\end{tabular}

Com base no somatório dos resultados obtidos a ordenação das alternativas de fornecedor de serviço de transporte foi realizada. Com a aplicação do método TODIM foram alcançados os seguintes valores normalizados: Fornecedor $1(1,00)$; fornecedor $2(0,00)$ e fornecedor $3(0,79)$. Diante dos resultados o fornecedor 1 alcançou a primeira posição.

A análise de sensibilidade pode ser realizada em algumas variáveis: no fator de atenuação das perdas $\theta$, nos pesos dos critérios, na escolha do critério de referência e nos pesos atribuídos as alternativas. Caso o fator de atenuação de perdas $(\theta)$ fosse alterado para 1 o fornecedor 2 passaria a ocupar a primeira posição com valor normalizado de 1,00.

Outro ponto importante em relação a análise de sensibilidade dos resultados obtidos, refere-se à alteração na escolha do critério de referência. Nesse caso, mesmo com a alteração do critério de referência, permanecendo 0 fator de atenuação de perdas $(\theta)$ em -1 , o resultado não é alterado. Com relação ao peso dos critérios, verifica-se que mesmo com a mudança nos mesmos o resultado não sofre alteração, ou seja, permanece com o fornecedor 2 como a alternativa a ser selecionada pela empresa contratante. Conclui-se com os argumentos expostos anteriormente, que a alteração no fator de atenuação de perdas $(\theta)$ é o que determina a modificação no resultado para a seleção de fornecedor pela empresa contratante.

\section{CONSIDERAÇÕES FINAIS}

A utilização dos métodos AHP, ELECTRE I e TODIM, de forma conjugada, no processo de seleção de alternativas de fornecedores de serviço de transporte apresentou um resultado final que se encontra alinhado com as expectativas dos especialistas em logística.

O método AHP atribui pesos de maneira consistente, com a preferência do decisor e ambos os métodos (ELECTRE I, e TODIM) selecionam a mesma alternativa como melhor opção: o fornecedor 1. Considerando que um método é compensatório e o outro não, há mais segurança na escolha.

Sendo assim, é possível concluir que os métodos de auxílio multicritério podem auxiliar os gestores de empresas no que diz respeito à tomada de decisões em relação a contratação de fornecedores, permitindo a explicitação de preferencias, tornando transparente $\mathrm{O}$ processo decisório e permitindo o continuo conhecimento do problema com a aplicação dos métodos.

Como proposta de estudos futuros poderiam ser avaliadas algumas possibilidades como: a inserção de mais alternativas de fornecedores de serviço de transporte; a retirada da alternativa com pior desempenho geral, com o objetivo de avaliar os impactos exercidos sob as demais alternativas; a utilização de outros critérios de avaliação das alternativas de fornecedores de serviço de transporte e o desenvolvimento de algumas análises de sensibilidade (variação do fator de atenuação de perdas e do critério de referência). 


\section{REFERÊNCIAS}

[1] ALVES, J. R. X.; ALVES, J. M. Definição de localidade para instalação industrial com o apoio do método de análise hierárquica (AHP). Production Journal, v. 25, n. 1, p. 13-26, 2015.

[2] BASTOS, A. et al. Caracterização das relações de parceria nas cadeias de suprimentos das empresas do setor metal mecânico do vale do Itajaí-SC. Anais do XVII Simpósio de Engenharia de Produção, SIMPEP, 2010.

[3] COSTA, H. G. Graphical interpretation of outranking principles: Avoiding misinterpretation results from ELECTRE I. Journal of Modelling in Management, v. 11, n. 1, p. 26-42, 2016.

[4] GOMES, C. F. S.; COSTA, H. G. Aplicação de métodos multicritério ao problema de escolha de modelos de pagamento eletrônico por cartão de crédito. Production, v. 25, n. 1, p. 54-68, 2015.

[5] GOMES, L. F. A. M.; RANGEL, L. A. D. An application of the TODIM method to the multicriteria rental evaluation of residential properties. European Journal of Operational Research, v. 193, n. 1, p. 204-211, 2009.

[6] GOMES, L. F. A. M.; GOMES, C. F. S. Tomada de decisão gerencial: enfoque multicritério. Editora Atlas SA, 2014.

[7] KLUCZEK, A.; GLADYSZ, B. Analytical Hierarchy Process/Technique for Order Preference by Similarity to Ideal Solution-based approach to the generation of environmental improvement options for painting process e Results from an industrial case study. Journal of Cleaner Production, v. 101, p. 360-367, 2015.

[8] LIMA JUNIOR, F. R.; CARPINETTI, L. C. R. A comparison between TOPSIS and Fuzzy-TOPSIS methods to support multicriteria decision making for supplier selection. Gestão \& Produção, v. 22, n. 1, p. 17-34, 2015.

[9] NeVES, R. B.; PEREIRA, V.; COSTA, H. G. Auxílio multicritério à decisão aplicado ao planejamento e gestão na indústria de petróleo e gás. Revista Produção, 2013.

[10] OZTAYSI, B. A decision model for information technology selection using AHP integrated TOPSIS-Grey: The case of content management systems. Knowledge-Based Systems, v. 70, p. 44-54, 2014.

[11] PEREIRA, V., COSTA, H. G.; NEPOMUCENO, L. D. O. (2014). Software JELECTRE-v1.0. Disponível em: https://sourceforge.net/projects/j-electre/files/.

[12] RANGEL, L. A. D.; SILVA, S. D.; SILVÉRIO, L. B. Ordenação de imóveis residenciais empregando o método TODIM. SIMPÓSIO BRASILEIRO DE PESQUISA OPERACIONAL, v. 38, 2006.

[13] RATNAYAKE, R. M. C.; MARKESET, T. Technical integrity management: measuring HSE awareness using AHP in selecting a maintenance strategy. Journal of Quality in Maintenance Engineering, v. 16, n. 1, p. 44-63, 2010.

[14] RIBEIRO, L. S.; PASSOS, A. C.; TEIXEIRA, M. G.. Seleção de tecnologias de comunicações no exército brasileiro utilizando os métodos multicritério de análise hierárquica, TODIM e software Sapiens. Production, v. 22, n. 1, p. 132141, 2012.

[15] SAATY, T. L.; VARGAS, L. G. The logic of priorities: applications of business, energy, health and transportation. Springer Science \& Business Media, 2013.

[16] SILVA, R. T.; BRANDALISE, N.; CARNEIRO, C. A. Utilizando o método TODIM para avaliar as melhores empresas para trabalhar. Independent Journal of Management \& Production, v. 2, n. 1, p. 1-7, 2011.

[17] SUBRAMANIAN, N.; RAMANATHAN, R. A review of applications of Analytic Hierarchy Process in operations management. International Journal of Production Economics, v. 138, n. 2, p. 215-241, 2012.

[18] ZYOUD, S. H. et al. A framework for water loss management in developing countries under fuzzy environment: Integration of Fuzzy AHP with Fuzzy TOPSIS. Expert Systems with Applications, v. 61, p. 86-105, 2016. 


\section{Capítulo 16}

\section{AVALIAÇÃO ERGONÔMICA DO ARMADOR NO AMBIENTE FABRIL \\ Laísa Cristina Carvalho \\ Ana Laura dos Reis}

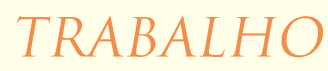

Resumo: A construção civil é umas das áreas que mais se emprega no país, entretanto ainda possui métodos construtivos artesanais, mão de obra desqualificada e com pouco uso de inovações tecnológicas. Ressaltando-se que a quantidade de colaboradoress nessa área é bem significativa, devido à variedade de atividades a serem executadas. Em sua maioria, as tarefas são executadas manualmente e solicitam diferentes graus de esforço e este quando aplicado de maneira recorrente, com materiais impróprios e postos de trabalho inadequados ao colaborador, geram doenças e distúrbios osteomusculares, em função dos riscos ergonômicos no qual estão expostos. Este estudo tem como objetivo diagnosticar os riscos ergonômicos associados à execução de armaduras no ambiente fabril. Para tanto, empregou-se a análise ergonômica do trabalho (aet), auxiliada pelo ewa e met. Ponderando tais fatores analisados, com registros fotográficos e acompanhamentos "in loco", foram estudadas as reais condições do posto de trabalho, buscando compreender as situações cotidianas de trabalho, saúde e segurança dos trabalhadores e caracterizando, assim, as condições do ambiente de trabalho durante a confecção das armaduras. Diante dos resultados encontrados fica evidente a existência de posturas inadequadas, elevado esforço e desgaste do colaborador durante a execução das atividades.

Palavras-chave: armaduras; riscos ergonômicos; posto de trabalho. 


\section{INTRODUÇÃO}

A construção civil é uma das áreas que mais se emprega no país, considerado um setor de destaque com grande expansão, porém se comparado a outros países possui métodos construtivos artesanais, mão de obra desqualificada, que resultam em baixa produtividade, ineficiência na produção, desperdícios e desconforto físico aos colaboradores (IIDA, 2005).

A situação do mercado de 2016 até o presente momento esteve em declínio devido à crise econômica que afetou a economia brasileira, porém por possuir um campo amplo com diversas áreas de atuação, a construção civil se mantém estável, podendo ser considerado como um fator positivo, entretanto a maioria das tarefas exigem dos colaboradores grandes esforços físicos comprometendo a saúde dos mesmos. Desse modo é indispensável a realização de estudos aprofundados nesse setor, com o objetivo de reavaliar e melhorar as condições de trabalho, oferecendo-lhes benefícios e soluções as propostas ofertadas.

Uma das preocupações da NR-17 é que a ergonomia auxilie como ferramenta de avaliação para que se alcance a organização no ambiente de trabalho e elevar as condições de conforto e segurança (BRASIL,2007). Porém, a ergonomia é pouco aplicada na construção civil, sobretudo em canteiro de obras, local onde são utilizados os equipamentos manuais e ferramentas, alguns inadequados e danificados para a realização de suas tarefas.

No serviço de armação as atividades são executadas manualmente e requerem diferentes graus de esforços, que quando aplicados de maneira recorrente, com ferramentas, equipamentos e postos de trabalho inadequados, desaceleram a produtividade. Considerando esse parâmetro a ergonomia se torna essencial durante o processo de desenvolvimento das tarefas, trazendo consigo aumento na produtividade e oferecendo bem-estar aos colaboradores no ambiente profissional.

O grande desafio da construção civil consiste em elevar a produtividade e simultaneamente garantir a segurança de seus colaboradores, dado que os processos de construção são oscilantes e as atividades possuem durações irregulares. A cobrança por altos índices de produtividade pode acarretar a um ritmo de trabalho intenso, propiciando ao surgimento de distúrbios osteomusculares, podendo levar a afastamentos por períodos indefinidos e incapacidade perdurável (INYANG et. al, 2012).

\subsection{OBJETIVO}

O objetivo geral dessa pesquisa é analisar as condições ergonômicas do posto de trabalho no processo de produção de armaduras associando este fator à produtividade.

\section{MÉTODO DE PESQUISA}

A pesquisa pode ser caracterizada como um estudo exploratório, com uma abordagem qualitativa, obtendo-se informações reais a respeitoda situação vivenciada pelos colaboradores. Na Figura 1 apresenta-se o fluxograma das etapas desenvolvidas para se atingir o objetivo proposto neste artigo. 
FIGURA 1 - Etapas da Pesquisa

Revisão Bibliográfica

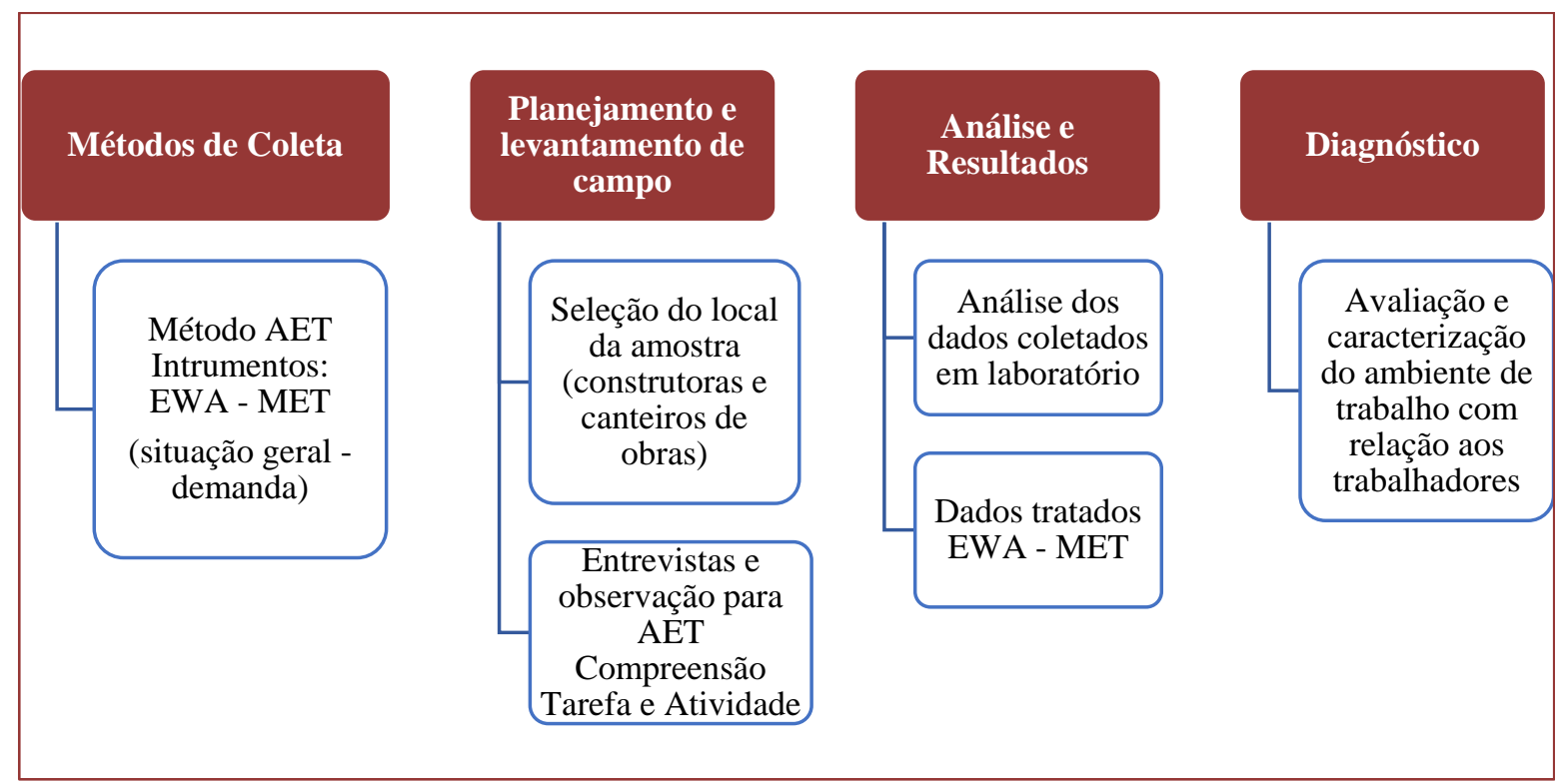

Fonte: Autores

A metodologia empregada na pesquisa fundamenta-se na Análise Ergonômica do Trabalho (AET) que sucede numa abordagem para a modificação e a concepção dos meios técnicos e organizacionais de trabalho, evidenciando novas questões sobre a interação homem-trabalho (GUÉRIN et al., 2001). A AET pode ser apresentada como uma intervenção no posto de trabalho para estudo das dificuldades causadas pelas tarefas decorrentes da execução das atividades no processo de produção de armaduras, propondo compreender o ambiente de trabalho, confrontando competências e limitações do colaborador, a fim de diagnosticar as situações críticas, e estabelecer sugestões de melhoria ao posto de trabalho (WISNER, 2003).

Sendo assim, a análise ergonômica no posto de trabalho é compreendida com a utilização da AET, buscando entender a demanda, o trabalho prescrito, condições físicas e organizacionais e como a atividade é realmente executado pelo colaborador (DUL; WEERDMEESTER, 2004).

Para obter-se os dados e avaliações foram utilizados dois instrumentos de análise ergonômica: ErgonomicWorkplaceAnalysis (EWA) e o Equivalente Metabólico (MET). O EWA é um instrumento que tem como foco a atividade do trabalho, e tem como finalidade diagnosticar, propor e implementar melhorias, buscando alternativas que atendam as demandas essenciais às situações produtivas. Em trabalhos manuais e atividades que envolvam movimentação manual de materiais, sua aplicação é mais eficiente. É um manual bem completo e contém uma estrutura sistemática, deste modo, pode ser utilizado para avaliar a qualidade das melhorias feitas no posto de trabalho ou nas atividades, e também para verificar os riscos ergonômicos. Todo desenvolvimento deste instrumento foi fundamentado "na fisiologia do trabalho, biomecânica ocupacional, aspectos psicológicos, higiene ocupacional e em um modelo participativo da organização do trabalho" (OLIVEIRA; FONTES, 2011; SHIDA; BENTO, 2012).

O MET é um instrumento empregado para descrever o gasto energético das atividades, sendo este apresentando em forma de tabelas (SMITH, 1997). O cálculo do gasto energéticobusca eliminar, principalmente, os riscos biomecânicos e se utiliza do compêndio de atividades físicas traduzidas por Farinatti (2003), com base na amostra da população brasileira, contemplando 605 atividades cotidianas (lazer, laboral e desportivas) executadas com diferentes intensidades. Assim, a intensidade física é determinada analisando a relação de Kcal/hora e, a partir desse parâmetro, é possível identificar a atividade como trabalho leve, moderado e pesado de acordo com o 
quadro $\mathrm{n}^{\circ} 03$ da "NR 15 - Atividades e operações insalubres".

\section{COLETA DE DADOS}

Necessariamente, contatou-se uma empresa solicitando permissão para a coleta de dados. Foram coletados dados a respeito da organização da empresa, jornada de trabalho dos funcionários, rotinas de trabalho e informações necessárias para sua caracterização.

Após compreensão das atividades, estas foram observadas "in loco", filmadas e fotografadas para posterior análise em laboratório. Ao findar a coleta em campo e com posse das filmagens, foram empregados os instrumentos ergonômicos para identificação dos principais riscos que os trabalhadores estão acometidos.

\section{RESULTADOS E DISCUSSÕES}

\subsection{CARACTERIZAÇÃO DA EMPRESA}

A empresa apresenta uma demanda de obras relativamente alta, produzindo armaduras para toda região Sul de Minas. As tarefas não possuem procedimentos de execução de serviço e/ou fichas para verificação do serviço e, de acordo com o responsável. Os funcionários são contratados pela empresa, devidamente registrados e treinados, recebem um salário mensal, sendo que as tarefas são distribuídas verbalmente e por etapas. Estes não apresentam uma demanda significativa de afastamento e/ou absenteísmo, e todos possuem um rendimento satisfatório de acordo com seu supervisor. As armaduras produzidas na fábrica no período visitado eram para uma edificação do município de Paraguaçu-MG.

\subsection{CARACTERIZAÇÃO DA ATIVIDADE}

A tarefa analisada constitui na montagem de armaduras de vigas de fundação com barras de aço com diâmetro de 10 mm, amarradas com arame recozido $\mathrm{n}$ - 18. Como condição técnica para a atividade montagem da armadura, é necessário que o serviço seja executado por trabalhador treinado, capaz de manusear e trabalhar com os equipamentos e ferramentas necessárias à execução desta atividade e equipamentos de proteção individual, obrigatórios ao cumprimento da atividade. As impressões gerais diante das observações in loco e também realizadas por meio das filmagens e fotos são que os trabalhadores possuem habilidades para execução da tarefa e que eles mesmos realizam a inspeção de qualidade do serviço conforme descrito no projeto.

Para realização da tarefa os equipamentos e ferramentas utilizados são: torquês, trena metálica e bancada para montagem. Os materiais/componentes manipulados foram as barras de aço já cortadas e dobradas com diâmetro de $10 \mathrm{~mm}$ e $0,617 \mathrm{~kg} / \mathrm{m}$ e o arame recozido $\mathrm{n}^{-}$18, estribos com diâmetro de $5 \mathrm{~mm}$ e $0,154 \mathrm{~kg} / \mathrm{m}$. Para determinar como a tarefa é executada, os trabalhadores foram observados ao longo de sua jornada de trabalho por cinco dias, verificando o modo operatório apresentado em cada dia. Diante do observado, foi possível compreender a tarefa e sua sequência de operações conforme apresentada no Quadro 1. O tempo médio de ciclo para confecção de uma armadura foi determinado por meio das filmagens, realizando-se uma média de todos os dias observados em relação aos quatro trabalhadores. 


\section{2}

QUADRO 1 - Sequência das operações da tarefa realizada pelos trabalhadores (armadores).

\begin{tabular}{|c|c|c|c|c|c|}
\hline 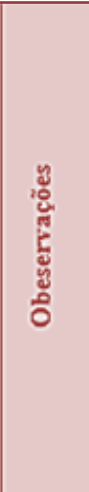 & 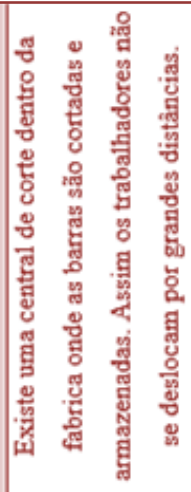 & 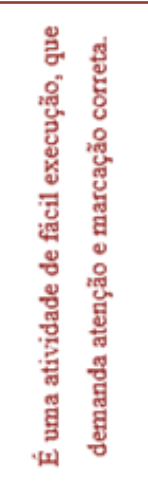 & 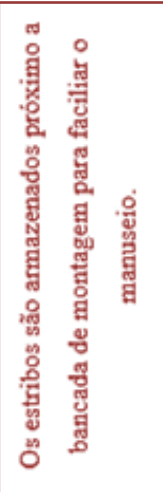 & 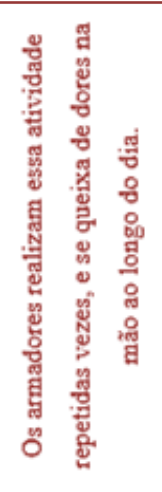 & 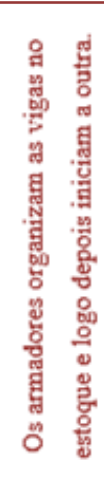 \\
\hline 苂 & 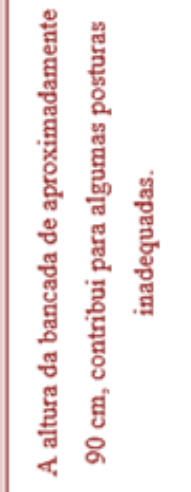 & 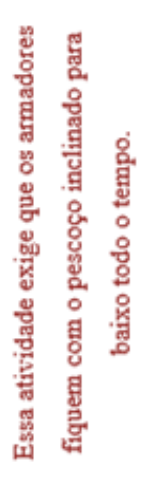 & 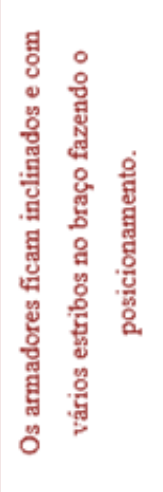 & 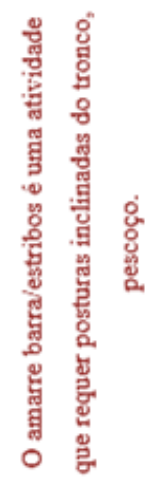 & 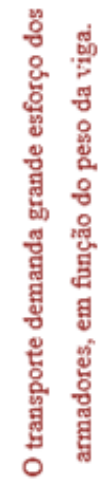 \\
\hline$\stackrel{g}{g}$ & 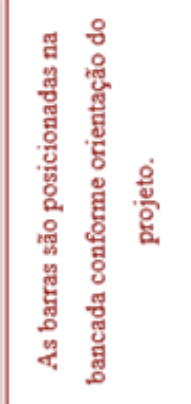 & 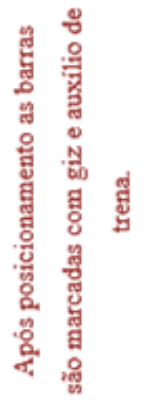 & 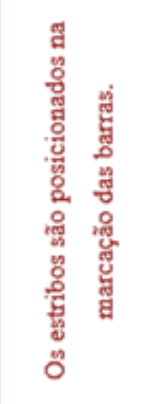 & 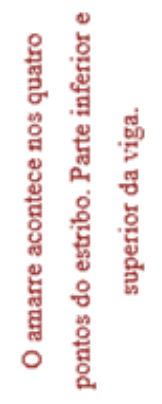 & 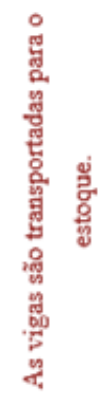 \\
\hline : & $\hat{n}$ & 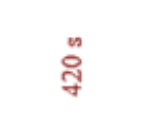 & ๕్రి & 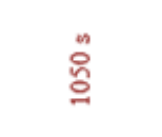 & $\approx$ \\
\hline 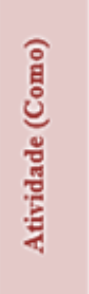 & 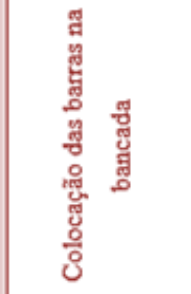 & 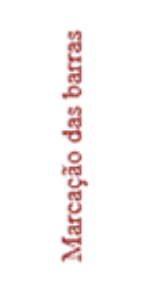 & 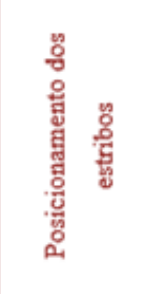 & 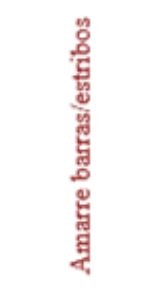 & 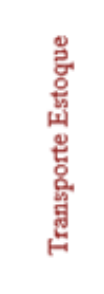 \\
\hline 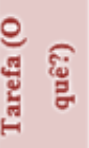 & \multicolumn{5}{|c|}{ 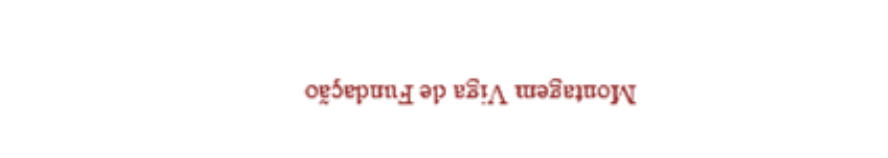 } \\
\hline
\end{tabular}

Fonte: Autor 


\section{RESULTADOS}

Para análise da tarefa foi utilizado o EWA, já descrito anteriormente, levando em consideração as entrevistas informais, o registro fotográfico e as observações in loco durante a execução do serviço. O pesquisador classifica os vários fatores em uma escala, geralmente de 1 a 5 , onde o valor 1 é dado quando a situação apresenta o menor desvio em relação a condição ótima ou aceitável para as condições e arranjo espacial do trabalho. Os valores 4 e 5 indicam que a condição de trabalho ou o ambiente podem causar danos à saúde dos trabalhadores.
$\mathrm{Na}$ análise da tarefa realizada pelos armadores observou-se que o fator de avaliação Levantamento de Cargas requer atenção, uma vez que resultou na classificação 3. De acordo com o julgamento do trabalhador, o levantamento de carga na execução da atividade é leve, os mesmos informam que já se acostumaram com o peso.

O fator Posturas de Trabalho e Movimentospode ser evidenciado na Figura 2. As posturas de trabalho e movimentos foram analisadas separadamente e foram seguidas as orientações contidas no EWA para se obter os resultados (QUADRO 2).

QUADRO 2 - Classificação Posturas de Trabalho e Movimento

\begin{tabular}{|c|c|}
\hline Posturas e movimentos & Classificação \\
\hline Pescoço - ombros & 3 \\
\hline Cotovelo - punho & 4 \\
\hline Costas & 3 \\
\hline Quadril - pernas & 3 \\
\hline
\end{tabular}

FIGURA 2 - Posturas do trabalhador
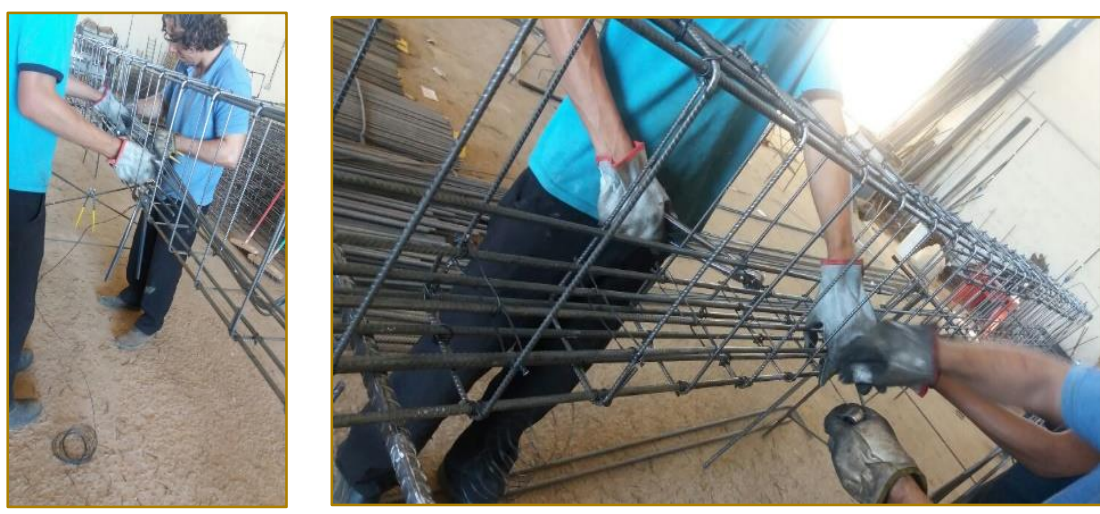

Fonte: Autor
O Risco de Acidente para tarefa em questão apresenta um risco de acidente pequeno, podendo o trabalhador evitar acidentes seguindo as instruções e orientações do mestre de obras e técnico de segurança. A severidade pode ser considerada grave, pois caso haja um acidente o armador pode perder parte do membro superior como dedos e mãos. De acordo com o julgamento do trabalhador, o risco de acidente na execução da tarefa é pequeno. Como o julgamento do trabalhador não diverge do julgamento do pesquisador, para o risco de acidente essa tarefa recebe classificação 2 .
Para análise do fator Atenção levou-se em consideração as atividades que o armador precisa de nível de atenção maior; neste caso, o somatório do tempo aproximado das atividades que demandam maior atenção é de 24,5 minutos, representando $66,5 \%$ da tarefa, sendo assim, classificado em 3.

Para melhor elucidar os resultados do EWA, o Quadro 3, a seguir, demonstra esquematicamente as classificações encontradas. 
QUADRO 3 - Resultados EWA. Fonte: Autor.

\begin{tabular}{|c|c|c|c|c|c|}
\hline \multicolumn{1}{|c|}{ EWA } \\
\hline OBRA & TAREFAS & $\begin{array}{c}\text { Levantamento } \\
\text { de carga }\end{array}$ & $\begin{array}{c}\text { Posturas de } \\
\text { Trabalho e } \\
\text { Movimento }\end{array}$ & $\begin{array}{c}\text { Risco de } \\
\text { acidente }\end{array}$ & $\begin{array}{c}\text { Nível de } \\
\text { atenção }\end{array}$ \\
\hline $\begin{array}{c}\text { Estudo } \\
\text { Exploratório }\end{array}$ & Montagem de Armaduras Vigas & 3 & 4 & 2 & 3 \\
\hline
\end{tabular}

Fonte: Autor

a) Resultados MET

Utilizou-se o MET para o cálculo do gasto energético (Kcal/hora) da sequência de operações da atividade, conforme apresentado no Tabela 1.

TABELA 1 - Resultados obtidos no MET

\begin{tabular}{|c|c|c|c|c|c|}
\hline Sequência das etapas & 1 & 2 & 3 & 4 & 5 \\
\hline $\begin{array}{l}\text { Tempo diário no ciclo } \\
\text { (h) }\end{array}$ & 0,15 & 0,93 & 1,38 & 2,33 & 0,12 \\
\hline Código & 11610 & 11610 & 11610 & 11630 & 11050 \\
\hline MET & 3,0 & 3,0 & 3,0 & 4,0 & 8,0 \\
\hline Kcal & 30,35 & 196 & 289,35 & 653,33 & 68,41 \\
\hline \multicolumn{6}{|c|}{ Determinação da relação Kcal/ hora = 1237,44/8,8 = 140,62 } \\
\hline
\end{tabular}

Fonte: Autor

De acordo com o resultado apresentado (Tabela 1), a operação que demanda mais esforço físico durante a jornada de trabalho é a de número 4 (consumo 653,33 kcal). Comparando-se os resultados com os prescritos na "NR-15 - Atividades e Operações Insalubres", conclui-se que para um trabalhador de porte médio a atividade montagem de armadura da viga pode ser considerada um trabalho leve do ponto de vista da taxa de metabolismo.

\section{CONSIDERAÇÕES FINAIS}

De acordo com as condições de trabalho a que estão sujeitos os colaboradores da construção civil, o foco desse estudo é diagnosticar as condições de trabalho dos armadores, através das análises de situações reais e cotidianas de trabalho, identificando os fatores determinantes e constrangimentos que podem acarretar danos à saúde dos operadores.

A análise da atividade na produção de armaduras permitiu adquirir informações e conhecimentos por meio de observações dos colaboradores, tornando-se possível identificar a rotina de trabalho e os fatores positivos ou negativos que interferem processo, permitindo que as informações e dados coletados em campo fossem checadas e em seguida analisadas em laboratório, confirmando pontos vulneráveis no posto de trabalho que prejudicam a saúde, segurança e conforto do colaborador.

Os instrumentos ergonômicos EWA e MET contribuíram de forma significativa para análise das posturas auxiliando a AET da atividade, portanto há uma contribuição para o setor da construção civil, com os riscos ergonômicos deste posto de trabalho. 


\section{REFERENCIAS}

[1] BRASIL. Ministério do Trabalho e Emprego. NR 17: Ergonomia. Brasília: Ministério do Trabalho e Emprego, 2007. Disponível em: <http://portal.mte.gov.br/data/files/FF8080812BE91 4E6012BEFBAD7064803/nr_17.pdf> Acesso em: 28 fev. 2018.

[2] DUL, J.; WEERDMEESTER, B. Ergonomia prática. São Paulo: Edgard Blucher, 2004.

[3] GUÉRIN, F. et al. Compreender o trabalho para transformá-lo: a prática da ergonomia. São Paulo: Edgard Blucher, 2001.

[4] IIDA, I. Ergonomia, projeto e produção. São Paulo: Edgard Blucher, 2005

[5] NORMA REGULAMENTADORA. NR 17: Ergonomia. 1978

[6] OLIVEIRA, J.; FONTES, A. Aplicação da Análise Ergonômica do Trabalho no Posto de Embalamento em uma Microempresa do Setor de
Brinquedos. In: XXXI Encontro Nacional de Engenharia de Produção, 2011, Belo Horizonte, MG. Anais do XXXI Encontro Nacional de Engenharia de Produção - ENEGEP, 2011

[7] SHIDA, G. J.; BENTO, P. E. G. Método e Ferramentas Ergonômicas que Auxiliam na Análise de Situação de Trabalho. In: CONGRESSO NACIONAL DE EXCELÊNCIA EM GESTÃO, n. 8, 2012, Rio de Janeiro, Niterói. Anais eletrônicos... Disponível em: <http://www.excelenciaemgestao.org/Portals/2/doc uments/cneg8/anais/T12_0496_3097.pdf>. Acesso em: 25 abril. 2018.

[8] SMITH. L. K. Cinesiologia Clínica de Brunnstrom. Editora manole. Ed 5. São Paulo. 1997.

[9] WISNER, A. A inteligência no trabalho: textos selecionados de ergonomia. Roberto Leal Ferreira (Trad.). São Paulo: FUNDACENTRO, 2003. $190 \mathrm{p}$. 


\section{Bapítulo 17}

\section{O VALOR COLABORATIVO DO USUÁRIO EM UM PROJETO DE MELHORIA DE UM POSTO DE TRABALHO EM UMA EMPRESA DE PANIFICAÇ̃̃O}

\section{Adonildo Marques da Silva Neto}

\section{Camilla Henrique de Araújo}

\section{Rodrigo Ribeiro Monteiro Gomes}

Resumo: A concepção de um projeto de melhoria de um posto de trabalho, é essencial a participação dos usuários em conjunto com os projetistas. Dessa forma, as condições e as definições das premissas são identificadas com maior propriedade. Nesse sentido, este estudo apresenta o valor que o usuário teve em um projeto de melhoria do posto de trabalho de um forneiro, numa empresa de pequeno porte do ramo da panificação, localizada na cidade de João Pessoa, Paraíba. Os dados foram coletados a partir de visitas à empresa e entrevistas realizadas com o colaborar, o proprietário e com a gerente de produção. Além disso, foram realizadas observações no ambiente em estudo, e em seguidas tratados de forma qualitativa, colocando em prática o conceito de projeto participativo. Para as propostas finais, seguiu-se uma abordagem bottom up, onde foi realizada a reunião de construção social com a participação e interação dos integrantes do grupo, sendo essencial para a obtenção dos resultados. Estes mostram que a reunião de construção social promove mais aceitação quanto ao processo de mudança e adequação, com destaque para o forneiro que soube com discernimento definir o que de fato era relevante para o escopo do projeto.

Palavras-chave: Posto de Trabalho, Projeto de Trabalho, Projeto Participativo, Indústria de panificação, Construção social 


\section{INTRODUÇÃO}

Ao elaborar um projeto de trabalho em uma unidade produtiva, uma análise acerca dos ambientes e fatores externos e internos à organização deve ser realizada. Ou seja, devem ser levados em consideração o mercado em que a empresa está inserida, os produtos e serviços produzidos, as atividades e operações realizadas, os funcionários envolvidos, os ambientes de trabalho, os níveis de produtividade e eficiência, o arranjo físico da mesma, entre outros.

Nesse estudo adotou-se a abordagem bottom-up para a elaboração do projeto de melhoria, que visa a elaboração de soluções de problemas e propostas de melhoria, relacionados ao ambiente de trabalho e atividades executadas por um forneiro em uma empresa do ramo da panificação de pequeno porte localizada na cidade de João Pessoa - PB.

A ABIP - Associação Brasileira da Indústria de Panificação e Confeitaria, conta que a panificação teve início na pré-história, quando os homens passaram a ser sedentários e dedicaram-se à agricultura. Há cerca de seis mil anos, no Mundo Antigo, os egípcios descobriram a fermentação e deram origem ao pão. Este, passou a ser visto não só como comida, mas também como moeda de compra, símbolo religioso e de poder. Hoje, esse alimento é item comum na mesa e seu processo produtivo sofreu grande evolução, porém ainda é possível encontrar aqueles que se dedicam ao modelo artesanal.

A concepção deste projeto contou com o envolvimento dos autores deste trabalho no papel de projetistas, do forneiro, do proprietário e da gerente de produção, colocando em prática o conceito de projeto participativo.

\section{FUNDAMENTAÇÃO TEÓRICA}

\subsection{PROJETO}

As definições para Projeto são diversas, por se tratar de um conceito aplicado em diversos âmbitos, sejam eles acadêmicos ou profissionais.

Segundo a ISO 10006, um projeto é um processo único, consistindo de um grupo de atividades coordenadas e controladas com datas para início e término, empreendido para alcance de um objetivo conforme requisitos específicos, incluindo limitações de tempo, custo e recursos. Já para o PMBok (2016), um projeto é um empenho temporário para se criar um produto, serviço ou resultado único. É comum entre esses dois conceitos que o projeto possui um ciclo de vida bem definido com início, meio e fim. Porém, a definição dada pela ISO 10006 também aponta para as limitações encontradas durante o processo de planejamento e execução de um projeto.

\subsection{PROJETO DE TRABALHO}

De acordo com Sell (1995), para a melhoria das condições de trabalho, tanto de forma corretiva - melhorias em sistemas já existentes - quanto de maneira prospectiva - melhorias nos sistemas de trabalho em fase de concepção e projeto - é necessário avaliar o trabalho humano existente, por critérios bem definidos, aceitos e que obedeçam a uma hierarquia de níveis de valoração relacionados com o trabalhador.

Segundo Slack (2009), o projeto de trabalho diz respeito a como estruturamos cada trabalho individual, o ambiente de trabalho e a interface com a tecnologia usada. Portanto, faz-se sempre necessário a realização de um projeto de trabalho, analisando o exercício da atividade desempenhada, os movimentos, o local de trabalho e os artefatos utilizados na execução da tarefa e no projeto de concepção ou de melhoria de um espaço de trabalho.

\subsection{PROJETO PARTICIPATIVO}

De acordo com Lana (2007), no processo participativo, o usuário possui um papel ativo durante a elaboração do projeto. Não apenas é fornecedor das necessidades a serem atendidas ou provedor de recursos, mas possui uma participação presente ao longo de todo o desenvolvimento do projeto. E no caso de um projeto de trabalho o usuário passa a ser o trabalhador.

A concepção e desenvolvimento de um projeto de trabalho participativo contam com o envolvimento de diferentes agentes, a fim de garantir a coerência entre os diferentes pontos de vista, percepções, experiências e necessidades de todos os colaboradores e stakeholders com o resultado final do projeto (Cordeiro, 2003). Tal integração viabiliza a proposição de melhorias e soluções para o ambiente de trabalho que se deseja analisar, contribuindo também o conforto ambiental, 
nível de qualidade, funcionalidade, redução de custos, aumento da eficiência e nível de produtividade das operações e trabalhadores.

\section{METODOLOGIA}

\subsection{CARACTERIZAÇÃO DA EMPRESA, DA SITUAÇÃO E DA PESSOA ESTUDADA}

Para a realização desse trabalho foi escolhida uma empresa de pequeno porte do ramo de panificação, localizada na cidade de João Pessoa - PB. O cargo escolhido como objeto de análise foi $\mathrm{O}$ Forneiro. O funcionário ocupante do cargo é do sexo masculino, possui 26 anos e ensino médio completo. Seu ambiente de trabalho consiste na sala de preparo e seu posto de trabalho é definido pela área onde o forno se encontra.

As atividades do forneiro se iniciam com a inserção das formas preenchidas com a massa do bolo no forno. Em seguida este os organiza dentro da máquina com o auxílio de um bastão e tablado de metal. Ao longo da jornada de trabalho, o funcionário regula a temperatura do forno e verifica o ponto de assadura dos bolos, retirando-os quando prontos.

À medida que são removidos do forno, os bolos são carregados em estantes móveis e transportados para o local em que são desenformados e organizados na estante, que em seguida é inserida no elevador de carga e segue para o setor de embalagens.

\subsection{LEVANTAMENTO E ANÁLISE DOS DADOS}

Para realização do projeto, fez-se o levantamento e análise dos dados acerca do forneiro e seu posto de trabalho, fazneo uso de diversas ferramentas. Foi realizada uma observação do processo produtivo, seguindo o fluxo de produção do macro para o micro, fazendo registros fotográficos e anotações com as informações mais relevantes do processo. Também se utilizou o método de observação indireta, através de uma entrevista com o próprio forneiro. Por fim, uma breve entrevista com o proprietário do estabelecimento para que houvesse um entendimento do processo a partir da visão de outra pessoa que tem conhecimento, mas não participa diretamente na atividade.

\subsection{PROBLEMAS}

A fim de identificar todos os problemas e riscos associados ao posto de trabalho escolhido, foi realizado o registro e análise do posto por meio de observações in loco em visitas técnicas. Para elaborar propostas de solução de problemas e melhorias, todos os dados e informações que já haviam sido coletadas foram revisados e novas visitas técnicas à empresa foram realizadas.

Em seguida, foi elaborada uma lista contendo não só os problemas identificados, mas também pontos considerados relevantes para aperfeiçoar e facilitar a realização do trabalho.

Com o intuito de realizar uma priorização inicial a respeito dos problemas e pontos iniciais que compuseram o pré-projeto, a equipe avaliou os pontos de acordo com sua gravidade, urgência e tendência, que resultou em uma Matriz GUT, mostrada a seguir (Tabela 1):

Tabela 1 - Matriz Gut

\begin{tabular}{|c|c|c|c|c|c|}
\hline Risco/Problema & Gravidade & Urgência & Tendência & GXUXT & Prioridade \\
\hline Exposição ao calor & 3 & $\overline{4}$ & 3 & 36 & 2 \\
\hline $\begin{array}{l}\text { Inexisttência de pausas e } \\
\text { intervalos }\end{array}$ & 2 & 3 & 2 & 12 & 3 \\
\hline $\begin{array}{l}\text { Desgastes de borracha do } \\
\text { tablado }\end{array}$ & 4 & 5 & 3 & 60 & 1 \\
\hline Espera do elevador de carga & 2 & 1 & 2 & 4 & 4 \\
\hline Posturas Inadequadas & 2 & 3 & 2 & 12 & 3 \\
\hline $\begin{array}{ll}\text { Movimentação excessiva } \\
\text { para alcançar materiais } \\
\text { distantes }\end{array}$ & 2 & 3 & 2 & 12 & 3 \\
\hline
\end{tabular}

Fonte: Autoria Própria 
A avaliação feita na matriz GUT deu-se baseada na Tabela 2. Aqueles com a maior pontuação requerem maior atenção e são preferíveis na composição da proposta de projeto final.

Tabela 2 - Avaliação da matriz GUT

\begin{tabular}{|c|c|c|c|}
\hline Nota & Gravidade & Urgência & Tendência \\
\hline 5 & Extremamente grave & $\begin{array}{l}\text { Precisa de atenção } \\
\text { imendiata }\end{array}$ & ...irá piorar rapidamente \\
\hline 4 & Muito grave & É urgente & ..irá piorar em pouco tempo \\
\hline 3 & Grave & O mais rápido possivel & ...irá piorar \\
\hline 2 & Pouco grave & Pouco urgente & ..irá piorar a longo prazo \\
\hline 1 & Sem gravidade & Pode esperar & ...não irá mudar \\
\hline
\end{tabular}

Fonte: Autoria Própria

\section{RESULTADOS}

\subsection{CONSTRUÇÃO SOCIAL}

As reuniões de construção social realizadas tiveram como objetivo reunir os diferentes níveis de conhecimento, percepções e informações acerca do posto analisado e problemas existentes. Dito isso, a participação e interação dos integrantes do grupo, proprietário, gerente de produção e funcionário foram essenciais.

$\mathrm{Na}$ primeira reunião, que contou com o forneiro e os projetistas, foram listados todos os equipamentos e máquinas utilizados por ele durante a execução das atividades (Figura $1)$.

Figura 1 - Checklist de equipamentos utilizados

\begin{tabular}{|l|l|}
\hline \multicolumn{2}{|c|}{ Checklist de Equipamentos Utilizados } \\
\hline Forno & \\
\hline Barra de Metal & \\
\hline Tablado & \\
\hline Formas & \\
\hline Estante Móvel & \\
\hline EPI's & \\
\hline Elevador de Carga & \\
\hline Interfone & \\
\hline Equipamentos de Limpeza & \\
\hline
\end{tabular}

Fonte: Autoria Própria

As atividades cíclicas e não-cíclicas também foram listadas pelos projetistas (Figura 2). 
Figura 2 - Checklist de atividades

\begin{tabular}{|c|c|}
\hline Checklist de Atividades & \\
\hline Paramentar-se com EPI's & \\
\hline Limpeza do formo & \\
\hline Ligar o forno & \\
\hline Higienizar as mãos & \\
\hline Inserir os bolos no formo & \\
\hline Organizar os bolos no forno & \\
\hline Verificar a temperatura do formo & \\
\hline Verificar se os bolos estio assados & \\
\hline Retirar a barra de metal do suporte & \\
\hline Retirar os bolos do forno & \\
\hline Abastecer as estantes móveis com os bolos & \\
\hline Desenformar bolos & \\
\hline Empilhar formas vazias & \\
\hline Retirar bandejas do armário & \\
\hline Retirar o papel manteiga do armário & \\
\hline Revestir as prateleiras das estantes com papel manteiga & \\
\hline Abastecer as estantes móveis com os bolos desenformados & \\
\hline Aguardar a chegada do elevador & \\
\hline Retirar estantes vazias do elevador de carga & \\
\hline Inserir estantes abastecidas no elevador de carga & \\
\hline Comunicar o envio da carga para o setor de embalagem & \\
\hline
\end{tabular}

O Layout do ambiente de trabalho, realizado no início do projeto, também foi utilizado

(Figura 3).

Figura 3 - Layout do posto de trabalho

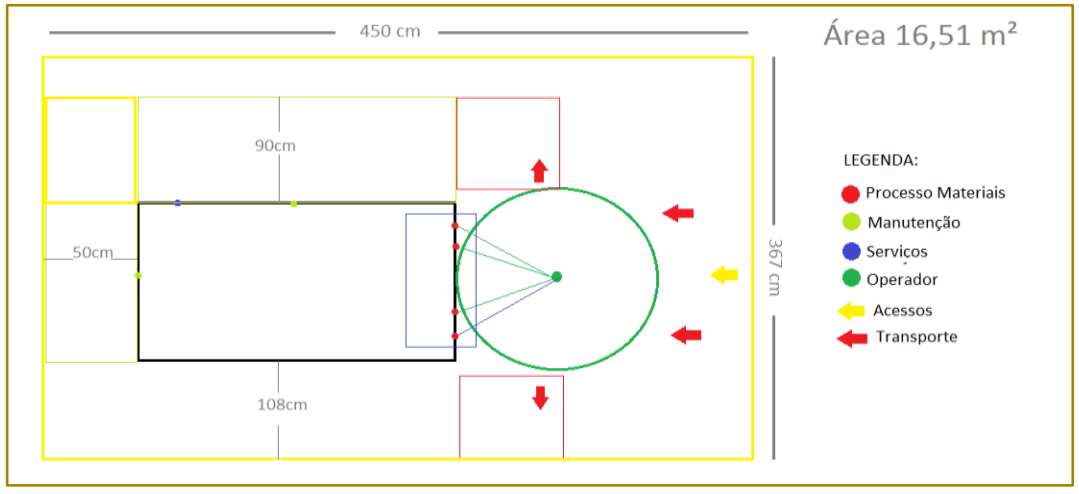

Fonte: Autoria Própria

Tais objetos foram utilizados para garantir que todas as atividades, equipamentos e áreas físicas que compreendem a atividade analisada estivessem contidos no projeto de trabalho.
$\mathrm{Na}$ segunda reunião, que contou com o proprietário, a gerente de produção e o grupo de pesquisa, foi discutida a relevância e prioridade dos problemas e dos pontos de melhoria identificados. Apresentou-se um 
forno (Figura 4) que poderia ser adquirido pela empresa para amenizar tal risco, assim como uma foto do tablado com as borrachas desgastadas (Figura 5). E ainda, foi discutida a viabilidade financeira da empresa em adotar as possíveis propostas.

Figura 4 - Forno Proposto

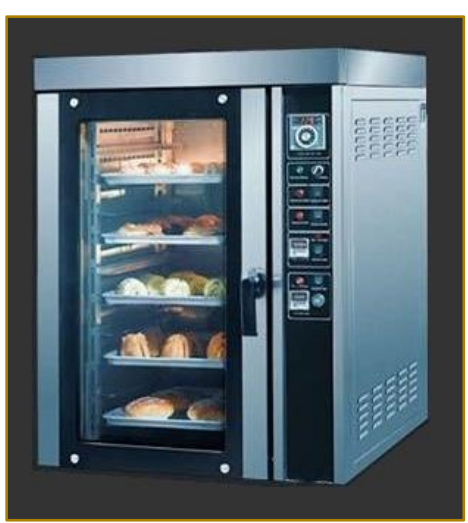

Fonte: Internet

Figura 5 - Tablado de Metal

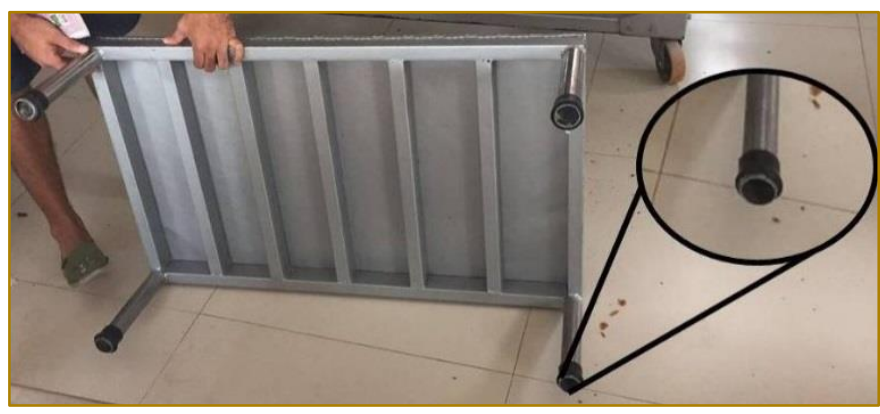

Fonte: Visita Técnica

\subsection{ESCOPO - TEMPO - RECURSOS}

Para a terceira reunião, foi feito o levantamento de propostas para melhoria da execução do trabalho e sua avaliação no que diz respeito a escopo, tempo e custo. No gráfico que relaciona escopo $\mathrm{x}$ tempo $\mathrm{x}$ custo, utilizou-se uma escala de 0 a 5 , onde 5 era a melhor situação e 0 a pior. Considerando que o valor do investimento total que a empresa definiu para o projeto foi de $\mathrm{R} \$ 500,00$, avaliava-se como 5 quando a proposta não tinha custo e 0 quando ela tinha custo de $\mathrm{R} \$ 500,00$ ou mais.

Para o risco "Exposição ao calor", apresentouse 3 soluções. Na primeira, um aumento do consumo de água durante a jornada de trabalho, sugeriu-se que consumo de água coincida com os intervalos em que o funcionário lava e higieniza as mãos, antes de entrar em contato com o forno, seria uma proposta que não possuía custos e poderia ser implementado de forma imediata. A segunda solução seria a utilização de um creme protetor específico para a exposição ao calor radiante, que possui a finalidade de manter a hidratação e reduzir os efeitos dos raios infravermelhos provenientes do calor radiante do forno. Tendo em vista os protetores analisados identificou-se o Protetor Solar Nutriex Profissional (FPS 30) - 1L como melhor solução, pois dentre as opções era a com melhor custo-benefício, possuindo um valor de $\mathrm{R} \$ 120,99$, e tendo uma demora de poucos dias para implementação pois 0 pedido seria realizado via internet. A terceira solução foi a utilização de um óculos protetor específico para a exposição ao calor radiante, esse possui a finalidade de proteger os olhos e a qualidade da visão do trabalhador. A sugestão levada foi o Óculos Hawk - MAS, que possui um custo de $R \$ 133,00$ e também é facilmente encontrado na internet, levando poucos dias para ser implementado. A Tabela 
Tabela 3 - Avaliação de propostas para exposição ao calor

\begin{tabular}{|cccc}
\hline & Água & Protetor & Óculos \\
\hline Tempo & 5 & 4 & 4 \\
Escopo & 2 & 3 & 3 \\
Custo & 5 & 3 & 3 \\
\hline
\end{tabular}

Fonte: Autoria Própria

Gráfico 1 - Avaliação de propostas para exposição ao calor

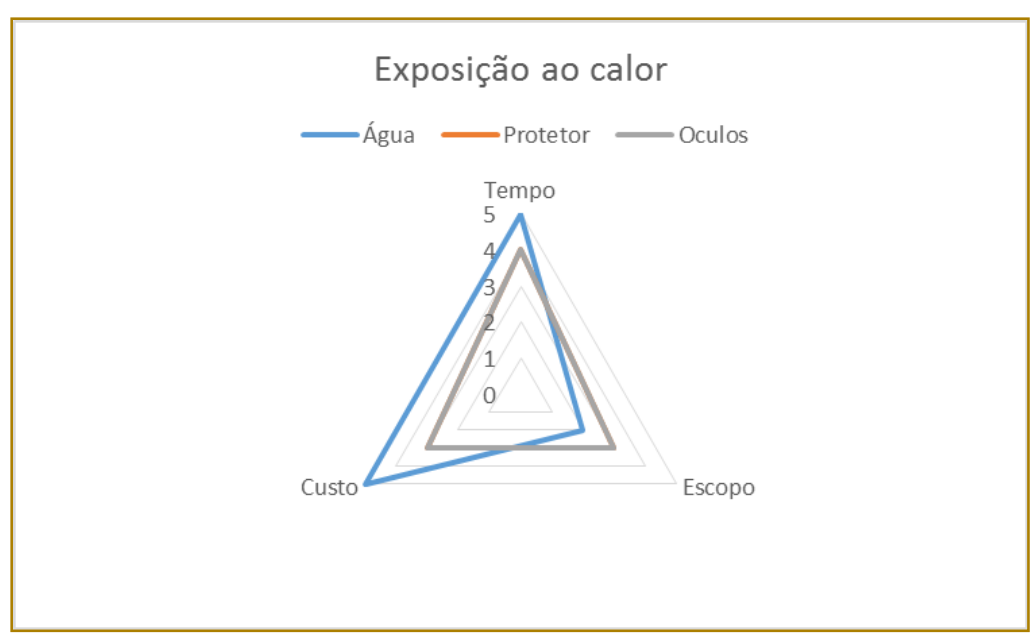

Fonte: Autoria Própria

Já com relação ao problema "Espera do elevador de", duas propostas foram apresentadas. A primeira seria a substituição do ramal por um interfone, com a finalidade de facilitar a solicitação. Essa proposta possuía um custo de $\mathrm{R} \$ 160,00$ e, por ser facilmente instalada, não possui problemas no que diz respeito a tempo de implementação. Porém, apesar de facilitar o trabalho, não solucionaria o problema em si. Uma segunda solução foi a substituição do ramal por um sistema com LEDs, que funcionaria com uma caixa que possui dois botões e seria acoplada na parede ou mesa, junto a um controlador de onde sairão os fios que vão até o andar de baixo. Na sala de embalagens ficam duas lâmpadas e a campainha. Essa implementação necessitaria de um pouco de tempo, uma vez que exige uma maior alteração na estrutura da empresa. Quanto ao custo, o sistema custaria $R \$ 100,00$, sendo necessária uma mão de obra para instalação, o que aumenta o custo. Essa solução, como a anterior, não atenderia o verdadeiro problema. A Tabela 4 e Gráfico 2 mostram a avaliação dessa proposta.

Tabela 4 - Avaliação de propostas para demora do elevador

\begin{tabular}{|ccc|}
\hline & Interfone & LED \\
\hline Tempo & 4 & 3 \\
Escopo & 1 & 1 \\
Custo & 3 & 2 \\
\hline
\end{tabular}

Fonte: Autoria Própria 
Gráfico 2 - Avaliação de propostas para demora do elevador

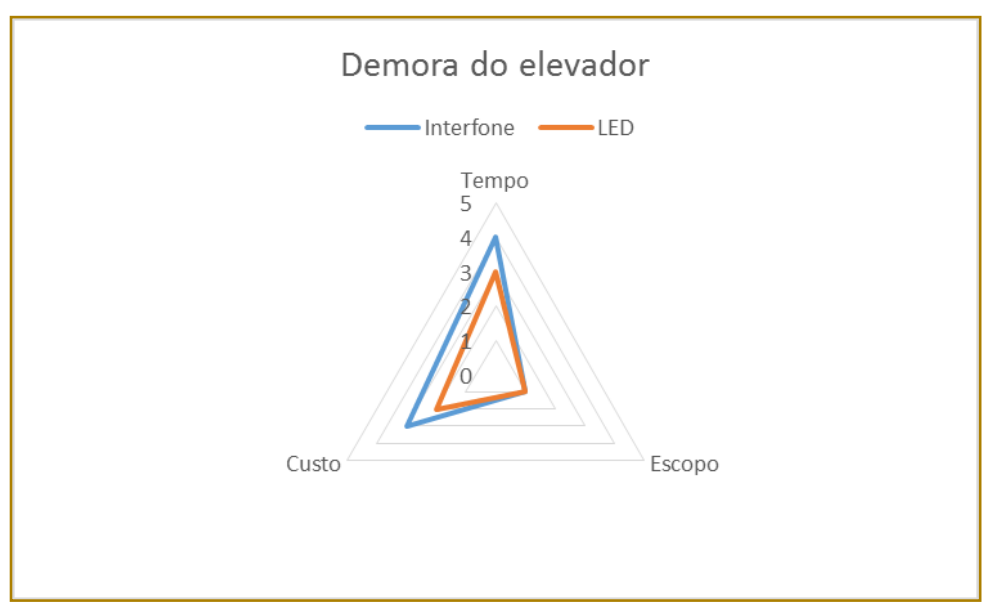

Fonte: Autoria Própria

Para o risco de lesões causadas por "Posturas Inadequadas", foi proposto a incorporação de ginástica laboral, ou seja, seriam realizados exercícios aplicados por um profissional da área. Com um custo de $\mathrm{R} \$$ 400,00 por mês, essa proposta se estenderia aos demais funcionários da empresa e possuiria um tempo de implementação curto, já que seria necessário apenas a contratação de um profissionall. A Tabela 5 e o Gráfico 3 mostram a avaliação dessa proposta.

Tabela 5 - Avaliação de propostas para lesões

\begin{tabular}{|ll|l|}
\hline \multicolumn{3}{|c|}{ Ginástica Laboral } \\
\hline Tempo & 5 \\
\hline Escopo & 3 \\
\hline Custo & & 1 \\
\hline
\end{tabular}

Gráfico 3 - Avaliação de propostas para lesões

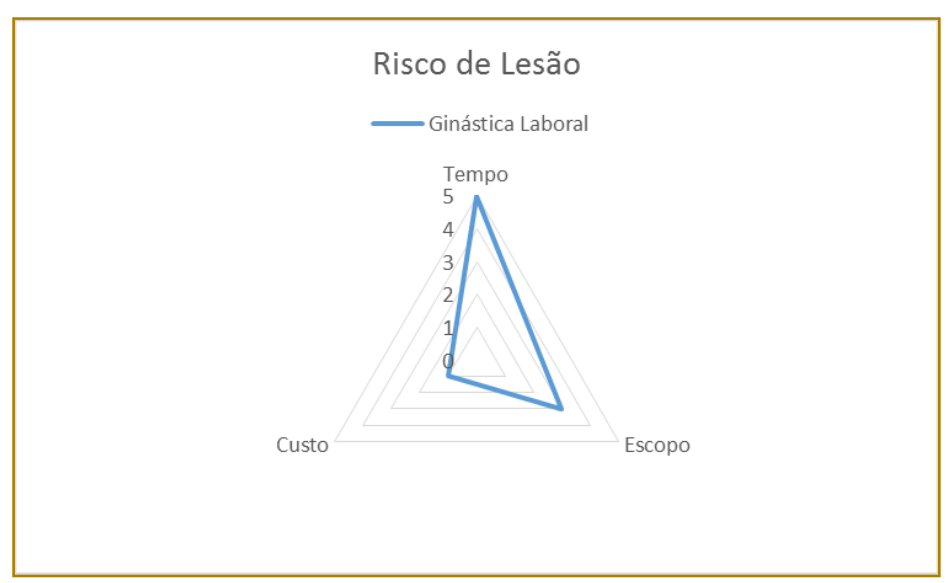

Fonte: Autoria Própria

A proposta para o problema "Desgaste da borracha do tablado" foi a troca periódica da ponteira de borracha, esta impede o deslizamento do tablado no chão, aumentando a segurança do forneiro na execução da tarefa. Seriam aquisições feitas por internet, não apresentando uma grande demora para implementação, pois as mesmas chegariam com cerca de 10 dias após a compra. O custo para implementação seria de $\mathrm{R} \$ 24,77$. A Tabela 6 e o Gráfico 4 mostram a avaliação dessa proposta. 
Tabela 6 - Avaliação de propostas para borracha desgastada

\begin{tabular}{|cc|}
\hline & Ponteiras de Borracha \\
\hline Tempo & 5 \\
Escopo & 3 \\
Custo & 1 \\
\hline
\end{tabular}

Fonte: Autoria Própria

Gráfico 4 - Avaliação de propostas para borracha desgastada

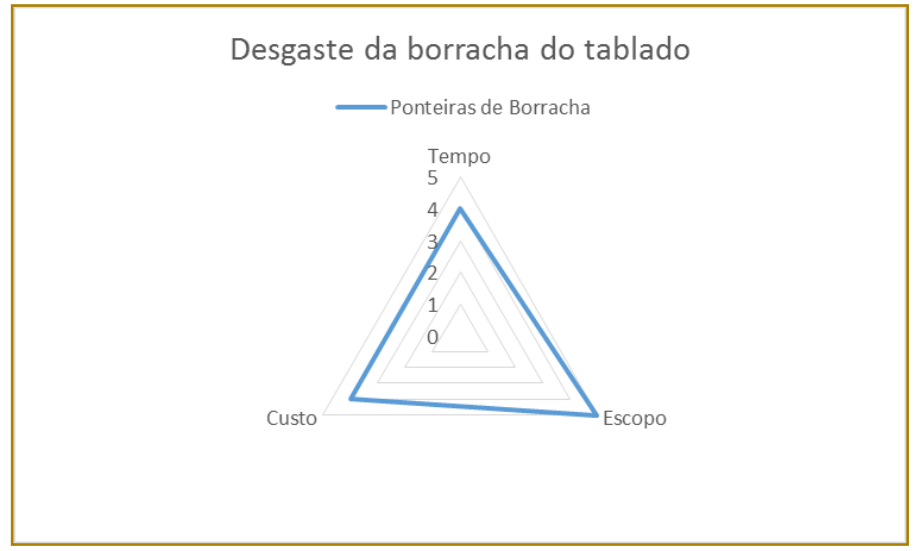

Fonte: Autoria Própria

No que diz respeito "Movimentação excessiva para alcançar materiais distantes", foi sugerido a aquisição de um gaveteiro móvel. Dentre os objetos analisados, foi-se sugerido o Gaveteiro Plástico 3 Gavetas 56×33×38cm, que possui um custo de $R \$ 49,90$, e sua implementação é quase que imediata tendo em vista que seria necessário apenas a compra. A Tabela 7 e oGráfico 5 mostram a avaliação dessa proposta.

Tabela 7 - Avaliação de propostas para movimentação desnecessária

\begin{tabular}{|cc|}
\hline & Gaveteiro \\
\hline Tempo & 4 \\
Escopo & 5 \\
Custo & 4 \\
\hline
\end{tabular}

Fonte: Autoria Própria 
Gráfico 5 - Avaliação de propostas para movimentação desnecessária

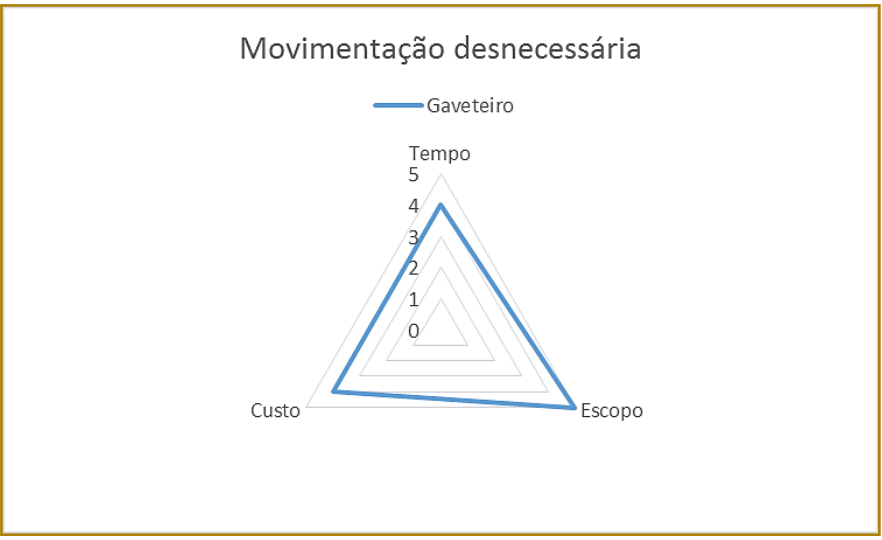

Fonte: Autoria Própria

Ao final da reunião foi apresentado o Orçamento Final (Tabela 8) dos de todas as propostas, considerando que todas as soluções fossem adotadas e observou-se que o valor estimado superaria o valor definido pela empresa como investimento. Dessa forma, todas as propostas foram entregues ao proprietário para avaliação.

Tabela 8 - Orçamento Final

\begin{tabular}{|lcr|}
\hline \multicolumn{1}{c}{ Item } & \multicolumn{2}{c|}{ Preço Unitário } \\
\hline Protetor Solar Nutriex Profissional (FPS 30) - 1L & R\$ & 120,99 \\
Óculos Hawk - MAS & R\$ & 133,00 \\
Ginástica Laboral/mês & R\$ & 400,00 \\
Ponteira de Borracha (Pacote c/ 4 und.) & R\$ & 24,77 \\
Gaveteiro & R\$ & 49,90 \\
\hline TOTAL & R\$ & 728,66 \\
\hline
\end{tabular}

Fonte: Autoria Própria

\subsection{SÍNTESE DE PROPOSTAS}

A seguir serão listados e descritos todos os conceitos de solução propostas, incluindo os que foram aprovados no projeto final e os que foram descartados ou modificados ao longo do desenvolvimento.

\subsubsection{REDUÇÃO DO NÍVEL DE EXPOSIÇÃO DO ROSTO E MEMBROS SUPERIORES DO FUNCIONÁRIO AO CALOR}

A inclusão desta proposta no escopo do projeto surgiu da necessidade de reduzir ao máximo a exposição do trabalhador ao agente de risco físico, no caso, o calor. A solução de tal proposta surgiu após a análise dos riscos do posto de trabalho e do PPRA disponibilizado pela organização.

Inicialmente, os projetistas propuseram a aquisição de um forno que possuísse uma estrutura que reduzisse a proximidade entre o corpo do funcionário e a parte interna do forno no momento de inserção e retirada dos bolos. Entretanto, tal proposta foi imediatamente recusada pelos gerentes devido a atual condição financeira da empresa.

Com isso, foi proposta a utilização de EPI's adicionais que pudessem atenuar o efeito do calor na saúde do trabalhador. A aquisição do creme protetor e óculos de proteção foi aceita pelo proprietário e gerente de produção, que se comprometeram a adotar tal medida de imediato.

\subsubsection{INCLUSÃO DE PAUSAS E INTERVALOS DE DESCANSO DURANTE A JORNADA DE TRABALHO}

Foi identificada na observação in loco, que o forneiro possui um ritmo de trabalho acelerado e embora execute diversas 
atividades durante sua jornada de trabalho, percebeu-se que tais ações obedecem a um ciclo de acontecimentos e podem ser consideradas repetitivas. Nesse contexto, tem-se que ele se encontra exposto à fadiga física e mental dos membros inferiores e superiores e a lesões por esforço repetitivo.

No início do projeto foram analisados e comparados os dados antropométricos do forneiro com a altura do nível inferior do forno. Tais informação mostraram-se incompatíveis e propensas a causar lesões e acidentes de trabalho.

Inicialmente, os projetistas propuseram a aquisição de um banco semi-sentado para que $\mathrm{o}$ trabalhador pudesse realizar pausas regulares durante a jornada de trabalho. Tal proposta foi descartada tanto pelo forneiro como pelo proprietário. Ambos alegaram que o banco iria interferir no ritmo de trabalho e nível de produtividade do trabalhador, gerando comodismo. Posteriormente, foi sugerida pelos autores a contratação de um profissional de educação física que pudesse realizar ginásticas laborais com toda a equipe de funcionários presente na sala de preparo da empresa, antes do início das atividades.

Embora a segunda proposta exija maior investimento e ultrapasse o limite de custo definido no projeto, esta foi aceita pela gerência, pois afirmou-se que a relação de custo-benefício para a organização seria maior do que a simples aquisição de um banco. A ginástica laboral seria útil para atenuar a fadiga física que poderia surgir ao longo da execução das atividades e reduziria o risco de lesões por esforço e repetitividade da tarefa. A longo prazo, esta proposta pode influenciar de forma positiva o nível de produtividade e satisfação dos trabalhadores.

\subsubsection{DESGASTE DA BORRACHA PRESENTE NOS PÉS DO TABLADO UTILIZADO PELO FUNCIONÁRIO}

A renovação das borrachas do tablado de alumínio foi proposta imediatamente pelos projetistas, a fim de eliminar o risco de escorregamentos, quedas e outros acidentes pela redução da aderência entre o metal e o chão da sala.

Tal proposta não sofreu evoluções ao longo do desenvolvimento do projeto e foi aceita pelo proprietário da empresa, que reconheceu a relevância do risco. Segundo ele, a mudança seria implementada o quanto antes.

\subsubsection{COMUNICAÇÃO DEFICIENTE SOBRE O ELEVADOR DE CARGA}

O tempo gasto na tentativa de comunicação entre o forneiro e o setor de embalagens chamou a atenção dos projetistas. Após preencher a estante móvel com os bolos desenformados, o funcionário desperdiça uma quantidade considerável de tempo para requisitar a presença do elevador de carga e de uma estante móvel desocupada.

No pré-projeto, a solução proposta para tal problema consistiu na mudança do equipamento de comunicação entre os setores. Entretanto, foi ressaltado na reunião de construção social que o problema não consiste no equipamento, e sim na disponibilidade da funcionária do setor de embalagens responsável também por atender o elevador de carga e realizar a reposição de uma estante desocupada. Nos momentos de maior fluxo de clientes na empresa, é requisitado pela empresa que a funcionária auxilie a balconista a atender os clientes, sendo esta a razão da sua indisponibilidade.

Sabendo disso, a solução encontrada pelos projetistas para sanar o problema seria a contratação de um novo colaborador que realizaria, de forma exclusiva, a comunicação entre o setor de produção e embalagens, sendo responsável por atender o elevador de carga, retirar as estantes ocupadas, retirar os bolos desenformados da mesma e depositar uma estante vazia no elevador. Entretanto, tal proposta foi recusada pelo proprietário, sendo ressaltado que o problema só ocorre em horários de pico de atendimento e os benefícios da contratação não compensariam com os gastos pela adição de mais um funcionário à empresa.

\subsubsection{POSTURAS INADEQUADAS DURANTE A EXECUÇÃO DO TRABALHO}

Durante a visita técnica ao ambiente de trabalho em questão, os projetistas puderam observar que o forneiro adota algumas posturas inadequadas enquanto executa suas atividades, um exemplo disso é a postura de apoiar-se nos joelhos e curvar a coluna para manusear a parte inferior do forno. Embora esteja em constante movimento, a atividade realizada pelo funcionário pode ser considerada repetitiva. 
Durante o projeto, a ferramenta OWAS foi aplicada, com o intuito de identificar as posturas adotadas em partes corporais críticas. Visto que a adoção de tais posturas possui baixa frequência, os projetistas propuseram, ainda no pré-projeto a inclusão de ginásticas laborais antes do início da jornada de trabalho. Esta proposta de solução foi de encontro ao problema da inexistência de pausas regulares para o descanso do funcionário, sendo considerada satisfatória pela gerência e aceita para a futura implementação.

\subsubsection{MOVIMENTAÇÃO EXCESSIVA REALIZADA PELO TRABALHADOR PARA ALCANÇAR DETERMINADOS MATERIAIS}

Além das atividades de inserir, retirar e organizar os bolos no forno. Os projetistas puderam observar que entre o forneiro também é responsável por desenformar os bolos, colocá-los em estantes móveis vazias e despachar os bolos para o setor de embalagens por meio do elevador de carga.

Foi identificado então a movimentação excessiva do funcionário no momento de utilizar o papel manteiga forra as bandejas que comportam os bolos desenformados.

O layout do posto de trabalho, a criação de um mapofluxograma e de um gráfico homem $x$ máquina, auxiliaram os projetistas a analisar as áreas, o tempo e as movimentações despendidas e necessárias para a execução do trabalho, além das limitações existentes.

Nesse sentido, desde o momento inicial da construção deste projeto de trabalho, foi proposta pelos projetistas a aquisição de um gaveteiro móvel que pudesse ser posicionado ao lado do elevador de carga e das estantes móveis, eliminando a necessidade do funcionário de transitar por todo o ambiente para alcançar o papel manteiga. Visto que a proposta é capaz de solucionar o problema e a escolha do gaveteiro manteve-se dentro do limite de custo imposto pela empresa, a proposta foi aceita e foi relatada que será de rápida implantação.

\subsection{DECISÃO FINAL}

Após a adequação das propostas levando em consideração as variáveis de tempo, escopo e custo, foi realizada uma última reunião, com o intuito de realizar uma análise final nas propostas de reestruturação e melhoria do posto de trabalho analisado. Em adição, definir quais delas, seriam, de fato, implementadas pela empresa. Essa reunião teve duração de meia hora e contou com a gerência da empresa, o forneiro e os projetistas. O resultado da reunião acerca da aceitação das propostas foi apresentado no item 4.3, intitulado Síntese de Propostas.

\section{CONCLUSÃO}

Para a construção, desenvolvimento e conclusão, o projeto foi dividido em três partes: registro, análise e execução. No registro levantaram-se todos os dados e informações necessárias do posto de trabalho. $\mathrm{Na}$ análise, utilizam-se os conhecimentos técnicos adquiridos a partir do curso de Engenharia de Produção como Custos da Produção Industrial, Segurança do Trabalho, Ergonomia, entre outros. E na execução, apresentaram-se soluções e intervenções que melhorariam a atividade do forneiro e o seu posto de trabalho. Essas soluções foram desenvolvidas pelo grupo de projetistas em parceria com o proprietário, gerente e forneiro. Houve aceitação de algumas propostas por parte do proprietário que as colocou em execução, enquanto que outras guardou para um momento mais oportuno na empresa.

A realização das reuniões de construção social com todos os envolvidos do projeto de melhoria do posto de trabalho foi de grande importância para sua elaboração, pois independentemente do nível hierárquico dentro da empresa todos puderam contribuir de forma positiva nas discussões, com observações e sugestões de melhorias, em um ambiente onde todos tinham conhecimento da importância do projeto e do papel desempenhado dentro do projeto, com destaque para o forneiro que soube com discernimento definir o que de fato era relevante para o escopo do projeto. Dessa forma, foi possível observar que ao fim do projeto todos os envolvidos estavam satisfeitos com as mudanças estabelecidas. 
[1] ABIP - Associação Brasileira da Indústria de Panificação e Confeitaria. A história do Pão. Brasília, 2015. Disponível em: < http://www.abip.org.br/site/699-2/>. Acesso: 10/05/2018.

[2] ABNT - Associação Brasileira de Normas Técnicas. ISO 10006: Gestão da qualidade Diretrizes para a qualidade no gerenciamento de Projetos. Rio de Janeiro, 2010. Disponível em:

[3] < http://licenciadorambiental.com.br/wpcontent/uploads/2015/01/NBR-10.006-

Gest\%C3\%A3o-da-Qualidadediretrizes-para-aqualidade-no-gerenciamento-de-projetos.pdf >. Acesso em 10/05/2018.

[4] Cordeiro, C. Entre o Projeto e o Uso: A Colaboração da Ergonomia na Etapa de Execução da Obra. Tese de Doutorado, Programa de Engenharia de Produção da COPPE/UFRJ. Rio de Janeiro, 2013.

[5] LANA, Sibelle Meyer . O arquiteto e o processo de projeto participativo: o caso do RSV. Dissertação (Mestrado em Arquitetura e Urbanismo)- Universidade Federal de Minas Gerais , Minas Gerais, 2007.

[6] PMBoK. Um guia do conhecimento em gerenciamento de projetos. Guia PMBok. EUA Project Management Institute (PMI), 2017. 6a Edição.

[7] SELL, I. Qualidade de vida e condições de trabalho. In: Medicina básica do trabalho. Curitiba: Gênesis, v. 5, p.158-175, 1995. 


\section{Gapítulo 18}

\section{IDENTIFICAÇÃO DO NÍVEL DE INOVAÇÃO DAS EMPRESAS DO APL DE CALÇADOS DA REGIÃO DO CARIRI-CE}

\section{Isis da Silva Vieira}

Isydorio Alves Donato

Maria Keyllyany Rodrigues da Silva

Resumo: As organizações atuais sejam elas de qualquer setor, se encontram em um ambiente competitivo onde necessitam buscar meios de se manterem no mercado mantendo a competitividade. Dessa forma as organizações são incentivadas a buscar estratégias para permanência, implementando métodos de inovação de melhoria constante de processos, aperfeiçoamento de produtos dentre outros métodos. Deste modo esta pesquisa teve como objetivo principal entender em que nível de inovação as empresas do setor de calçados da região do cariri se encontram a partir de um método de avaliação específico. O método de avaliação foi feito a partir de um questionário aplicado in loco em oito empresas selecionadas para a realização da pesquisa. A partir da aplicação do questionário constatou-se que apesar de existir um crescimento contínuo de empresas do setor de calçados na região do Cariri, as práticas de inovação ainda são pouco desenvolvidas ocasionando de certa forma um atraso competitivo em relação a outras regiões com empresas do mesmo setor. 


\section{INTRODUÇÃO}

A inovação apresenta um dos principais desafios enfrentados por diversas empresas que necessitam adaptar-se ao crescimento e surgimentos das tecnologias. A adaptação dessas empresas no investimento da inovação é primordial para um melhor desenvolvimento das mesmas.

O fator inovação nas organizações não é visto como algo diferencial, mas sim como uma necessidade para sobrevivência no mercado, uma empresa que não investe em inovação e novos métodos de processos e produtos não possui o mesmo poder de competitividade que uma empresa que busca constantemente formas de inovar. Dessa forma a permanência das empresas no mercado é na maioria das vezes determinada pela incorporação ou não da inovação.

As empresas na sua grande maioria não possuem maturidade suficiente ou conhecimento necessário para investir em inovação, assim permanecem exercendo sempre de mesma forma o seu funcionamento administrativo, gerencial e produtivo. A inovação nessas empresas pode ser habilitada por pequenas inciativas como mudança nos fatores de produção e a busca de resultados que aumentem a produção e desempenho comercial. O desafio da inovação a ser desenvolvida nessas empresas não se dá somente pelas inovações tecnológicas de produto e processos, sendo necessário uma estrutura mais abrangente implementando assim a inovação organizacional e de marketing.

Algumas teorias sobre a inovação são necessárias para entender como e porque se dá o processo de inovação. Sendo necessárias para Identificar os possíveis motivos e dificuldades para se inovar na empresa ou os tipos de inovações em que as mesma pode ser inserida. Tornando-se necessário entender por que as empresas inovam, já que a iniciativa da inovação nessas empresas aumenta o seu desempenho e consequentemente a sua capacidade de inovar.

Os processos de inovação diferenciam-se bastante de setor para setor em relação ao desenvolvimento, tecnologia, e estrutura organizacional. As inovações acontecem em velocidades diferentes em alguns setores. A adoção de medidas de inovação é essencial quando se trata de arranjos produtivos locais APL.
Na região do cariri o arranjo produtivo local de calçados encontra-se em crescimento continuo principalmente ao referir-se ao aumento do número de empresas que se instalam na região em busca de condições satisfatórias de mercado.

Para que essas empresas do ramo calçadista possam encontrar o destaque no mercado as mesmas devem buscar investir em formas de inovação. Dessa forma o presente trabalho tem como objetivo relacionado ao fator inovação identificar o nível de maturidade das empresas do setor de calçados da região do cariri.

\section{OBJETIVO}

\subsection{OBJETIVO GERAL}

Esta pesquisa tem como objetivo principal identificar como as empresas do setor de calçados da região do Cariri se encontram em relação ao fator inovação. Dessa forma mensurar o grau de inovação e como ocorre o a utilização dos processos de inovação.

\subsection{ESPECÍFICOS}

- Mensurar grau de inovação;

- Identificar quais tipos de inovação são utilizadas;

- Identificar os indicadores que influenciam o processo de inovação.

\section{INOVAÇÃO}

As empresas inovam para continuarem competitivas no mercado, assim aumenta crescentemente o processo de inovação nas empresas devido a essa competição. Como também para estarem a frente das vantagens do mercado.

Para se entender o que vem a ser inovação, tem-se como principal referência o manual de oslo desenvolvido pela OCDE (Organização Para a Cooperação e Desenvolvimento Econômico), o manual pode ser considerado um documento essencial de diretrizes sobre inovação e como ocorre o comportamento da inovação em diversos países membros da OCDE. Torna-se um alicerce para as empresas para que as mesmas possam utilizar seus conceitos, aderi-los ou incorporálos na iniciativa de inovação para que elas possam ser capazes de investir corretamente 
em inovação, usufruindo dos conceitos estabelecidos. Sendo uma das principais referências para as atividades de inovação tecnológica, o manual de Oslo busca padronizar conceitos definições e metodologias que possam ser utilizadas pelas empresas na busca de inovação tecnológica tornando possível conhecer como ocorre o processo de inovação.

De acordo com a OCDE - Manual de Oslo,

As empresas engajam-se em inovações em virtude de inúmeras razões. Seus objetivos podem envolver produtos, mercados, eficiência, qualidade ou capacidade de aprendizado e de implementação de mudanças. Identificar os motivos que levam as empresas a inovar e sua importância auxilia o exame das forças que conduzem as atividades de inovação, tais como a competição e as oportunidades de ingresso em novos mercados. (OCDE, 2005, p. 26).

Segundo (DOBNI; KLASSEN; NELSON, 2015), Inovação é um fenômeno considerado a mola propulsora do sistema capitalista e, com efeito, têm instigado diferentes estratos da sociedade a melhor compreender a inovação no tocante ao seu fomento, desenvolvimento e apropriação do seu resultado.

Peter Drucker (1987), por sua vez, afirma que a inovação é o ato que contempla os recursos com a nova capacidade de criar riqueza.

Dessa forma Pode-se entender então como Inovação a capacidade de criar e utilizar um recurso inexistente e obter como resultado a agregação de valor.

É notório que Inovação sempre esteve no processo de desenvolvimento humano, desde a criação de ferramentas, mudanças de hábitos, de alimentação, etc. No sistema capitalista em que nos encontramos, sua utilização é fundamental para melhorar processos e desenvolvê-los, trazendo assim sistemas que agregam mais valor econômico às firmas.

Para que tal política seja eficaz, devemos tratá-la como uma atividade que evolui constantemente, pois (...) a inovação como estratégia empresarial se tornou ainda mais crucial devido ao ambiente de profundas alterações e de acirramento da competição, que requerem transformações nas empresas, consumidores e políticas públicas (BOSCOLO; SBRAGIA, 2008), tratando-a também como um recurso que deve ser gerenciado, à fins organizacionais pois é necessário dá-la importância semelhante aos outros setores empresariais devido a (...) todas as atividades empresariais voltadas para a inovação demandam dispêndios que podem ser caracterizados contabilmente como investimentos (ativos) ou custos/despesas (resultados), dependendo do estágio ou característica do gasto. Nessa direção, esse recurso exige uma estrutura de financiamento que o viabilize e o sustente no curso do tempo (SANTOS et al., 2014).

Desse modo, temos que a Inovação utilizada como ferramenta, desempenha papel crucial para manter-se o desenvolvimento, lucratividade, economia em processos, evolução, qualidade e organização.

Gerenciar uma inovação é um dos maiores desafios e o grau de seu sucesso depende da elaboração de uma estratégia clara em que se define o propósito de assumir e investir em inovação (PERDIGÃO et al., 2012).

\section{ARRANJO PRODUTIVO LOCAL}

O termo Arranjo Produtivo Local (APL) pode ser definido como uma aglomeração territorial de agentes econômicos com foco em um setor específico, no qual há vínculos entre as empresas, geralmente, de pequeno ou de médio porte. Essas relações empresariais podem ser no sentido de viabilizar, diminuir custos ou melhorar a qualidade dos insumos, incrementar a escala de produção, solucionar coletivamente problemas de infraestruturas, como trafegabilidade de vias e aperfeiçoamento de serviços de energia elétrica e telecomunicações, entre outros benefícios (LASTRES \& CASSIOLATO, 2004).

Os arranjos produtivos locais (APL's) são essenciais para gerar competitividade para as pequenas e médias empresas, principalmente. Por meio do arranjo produtivo local, estas empresas tem a possibilidade de ter acesso a recursos, conhecimento, qualificação [...] (LIRA et al, 2013). Os arranjos desenvolvidos propiciam cooperação e aprendizagem entre os agentes envolvidos, proporcionando a inovação de produtos, interagindo com a comunidade e apresentando relações estreitas com agentes financeiros, podendo alcançar o mercado externo, além de possuir uma estrutura produtiva ampla e complexa (SEBRAE, 2014).

Os principais elementos que caracterizam um APL são: proximidade e concentração territorial como fonte de dinamismo local; 
diversidade de atividades e atores econômicos, políticos e sociais; especificidade geográfica, de indivíduos ou de organizações; interação entre as empresas no sentido de possibilitar aprendizado e inovação; governança entre os agentes econômicos e suas atividades; e comprometimento dos diferentes agentes com capacitações e até com o desempenho produtivo dos demais integrantes do aglomerado (CASSIOLATO et al., 2008).

Dentre os conceitos obtidos temos que os Arranjos Produtivos Locais são de importância enorme no desenvolvimento econômico e social, facilitando a cooperação entre os agentes da cadeia produtiva, corrigindo problemas de infraestruturas, aumentando o dinamismo entre os agentes envolvidos, garantindo a sobrevivência no mercado competitivo e crescimento, possibilitando uma série de vantagens competitivas e competências mais duradouras.

\section{O SETOR DE CALÇADOS}

O surgimento da indústria coureiro-calçadista brasileira iniciou no Rio Grande do Sul com a chegada dos primeiros imigrantes alemães, em junho de 1824. Instalados no Vale do Rio dos Sinos [...] (JAEGER, 2008).

Segundo a Agência Brasileira de promoção de exportação e investimentos APEX BRASIL (2013) a fabricação de calçado é uma atividade industrial muito presente no desenvolvimento econômico mundial e brasileiro. A indústria de calçados brasileira tem um importante papel econômico e social para o país, sendo de grande importância no contexto industrial brasileiro (ABICALÇADOS, 2014). Segundo Filho (2009), a importância do setor para o pais decorre de uma crescente exportação dos produtos deste setor como também pelo volume de produção e uma ampla geração de empregos. O setor de calçados é importante para o Brasil para a geração de emprego e de renda, tendo também impactos relevantes na balança comercial, isto é, representando com exportações superiores a US\$ 1 bilhão ao ano (APEX BRASIL, 2013).

As empresas calçadistas brasileiras de pequeno porte, em sua maioria estão localizadas em sete principais polos, distribuídos em 3 macrorregiões (Sul, Sudeste e Nordeste): Rio Grande do Sul, Santa Catarina, São Paulo, Minas Gerais, Bahia,
Paraíba e Ceará, onde se localizam importantes clusters calçadistas (VIEIRA; BARBOSA, 2012).

O setor de calçados é caracterizado por um baixo nível tecnológico como também do processo de inovação, devido ao retardo da evolução dos processos produtivos, isso ocorre pelo fato de que esse setor emprega uma quantidade considerável de trabalho artesanal nos processos o que ocasiona uma demanda elevada de mão de obra, devido a quantidade elevada de operações necessárias a produção do calçado. Isso ocorre também devido ao baixo custo do emprego da mão de obra e que dessa forma sustenta uma cultura direcionada ao lucro com baixos custos não atendo-se ao desenvolvimento tecnológico da empresa Dessa forma o setor de calçados ao decorrer dos anos tem buscado implementar adaptações operacionais e produtivas visando uma produtividade acima do padrão, redução dos gastos e tempo necessário para a confecção dos produtos.

Entende-se por polo calçadista as regiões onde há grande concentração de empresas produtoras, em locais próximos. Estados como a Bahia e Pernambuco possuem produção significativa de calçados, no entanto, há uma dispersão geográfica elevada dessa produção. Por isso, não são identificados polos, mas sim, a produção do estado como um todo (ABI CALÇADOS, 2017, p. 19).

Assim pode-se observar que o Setor Calçadista tem um papel fundamental como um dos pilares da economia brasileira, atuando fortemente nas importações e exportações em decorrência do seu nível elevado de produção.

A indústria de calçados possibilita o desenvolvimento do local em que está localizada. Segundo a APEX BRAIL (2013), "No país são mais de 800 mil estabelecimentos que fabricam calçados, gerando cerca de 330 mil postos de trabalho."

\section{METODOLOGIA}

Para início deste trabalho elaborou-se uma revisão bibliométrica de trabalhos de maior relevância e obter uma pesquisa estruturada, para isso foram utilizados como meio de pesquisa algumas bases de dados, podendo citar Scielo, Web of Science, Scopus. 
Após a realização de boa parte da fundamentação teórica, teve-se início a fase de identificação das potenciais empresas. A seleção foi feita com empresas que possivelmente poderiam aplicar métodos de inovação, pois empresas muito pequenas possivelmente não saberiam ao certo o que viria a ser inovação e como seria esse processo de inovação dentro da empresa.

No final da seleção obteve-se um total de 8 empresas escolhidas e que aparentemente estariam aptas a participar do método de avaliação que seria posteriormente aplicado nas mesmas. Logo após elaborou-se o método de avaliação.

O método de avaliação foi aplicado com indivíduos específicos ligados ao processo de decisão, pois o processo de inovação é decidido e controlado geralmente pelo setor de gerenciamento da empresa, ou por indivíduos que estão diretamente ligados a tomada de decisão dentro da empresa que possuem conhecimento técnico e prático do assunto em questão.

O método de avaliação foi determinado com a aplicação de um questionário estruturado, este questionário foi elaborado a partir do método estrutural "aprender a crescer" analisando as possíveis inovações que poderiam ser utilizadas na empresa. Foram elaboradas um total de vinte e cinco questões, essas questões foram divididas em quatro tópicos classificados em categorias que identificam qual tipo de inovação a empresa está inserida. Os tópicos foram definidos como fontes de inovação, indicadores de entrada, indicadores de saída e impacto das inovações.

O método de pergunte das questões foi elaborado de acordo com a escala Likert, onde se distribuiu de 1 a 5 e 1 a 4 o intervalo de respostas, utilizou-se esse método para que as respostas fossem adequadamente distribuídas possibilitando identificar os níveis de opinião corretamente.

\section{RESULTADOS}

A partir da aplicação do questionário foi possível identificar aproximadamente como se encontra o cenário de boa parte da indústria de calçados do Cariri. A seguir serão detalhados os resultados observados no Gráfico 1.

Ao observar-se o resultado do questionário constatou-se que em relação as fontes de inovação apresentaram um percentual de $24 \%$, um valor relativamente baixo indicando que as empresas não estão investindo o necessário em inovações de produtos, processos e P\&D que são considerados de grande importância no desenvolvimento da empresa.

Em relação ao segundo fator indicadores de entrada se obteve o mesmo percentual das fontes de inovação, as ações relacionadas a esse setor indicam como a empresa está se comportando com relação a utilização ou não de inovações do tipo organizacional. Como também identificar quais setores da empresa utilizam exclusivamente atividade de P\&D.

Observando o terceiro fator, indicadores de saída. Obteve-se uma diferença acentuada em relação aos dois anteriores, com um total de 54\%. Apesar de os indicadores de saída estarem diretamente relacionado aos indicadores de entrada, se obteve uma diferença considerável fazendo o comparativo das duas porcentagens, isso pode ser explicado ao entender-se o que vem a ser os indicadores de saída. Este indicador está relacionado a quais os tipos de melhorias aparente que foram realizadas identificadas a partir das inovações realizadas na empresa relacionados a tecnologias, produtos, processos dentre outros. Constatou-se que existe ainda um baixo investimento em inovações tecnológicas.

O quarto e último fator impacto das inovações busca analisar qual foi o impacto que as mudanças na empresa ocasionaram a partir das mudanças relacionadas a inovação, obtendo um valor relativamente alto com $74 \%$, com isso pode-se observar que apesar de as empresas apresentarem um baixo investimento em inovações as pequenas mudanças inovacionais realizadas ocasionam ganhos diretos e melhorias para a empresa. 
Gráfico 1 - Resultado questionário

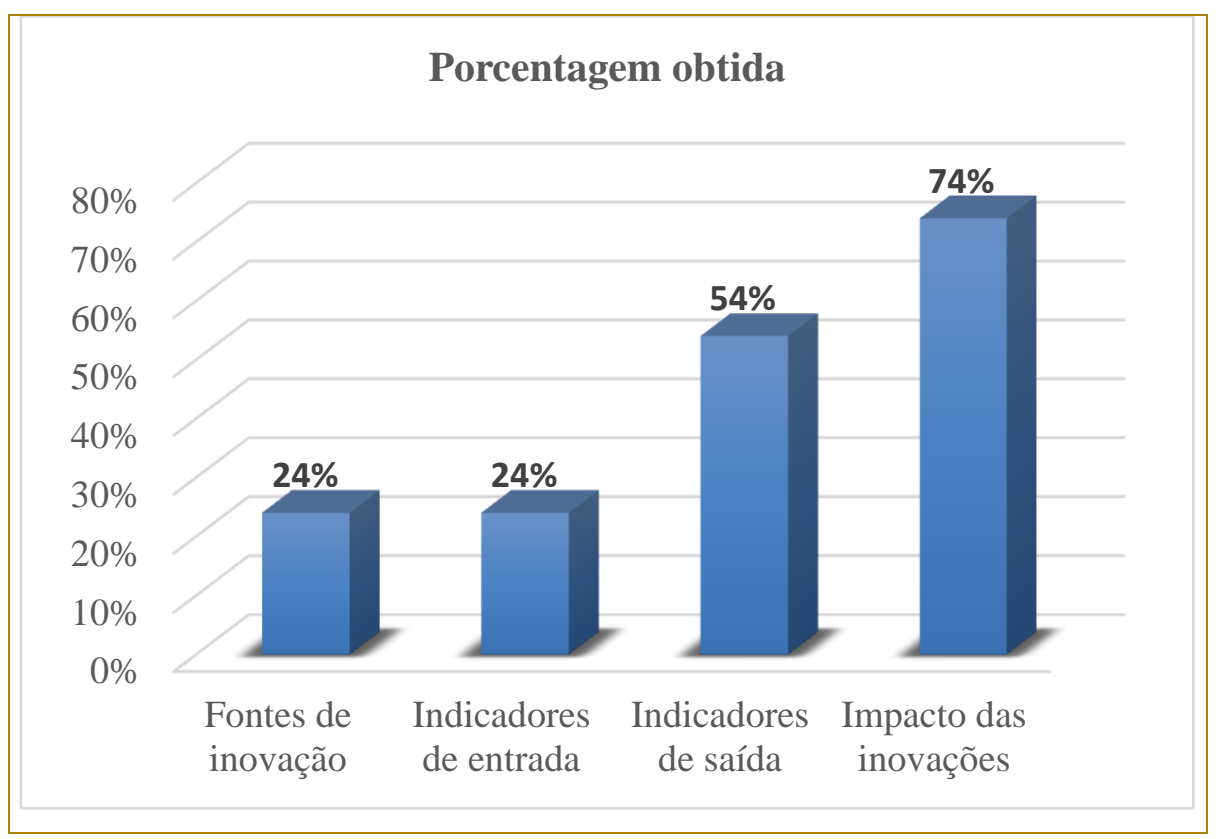

Fonte: Os próprios autores

\section{CONCLUSÃO}

É importante que a empresa questione-se em relação a quanto a mesma está investindo em inovação tecnológica, como está inovando, quais os tipos de inovação que estão sendo desenvolvidos, quais os resultados da inovação, e se são suficientes para a empresa. Assim a empresa realiza a coleta de dados de inovação e realmente passa a entender o que necessita ser feito no âmbito da empresa para que tenham indicadores de inovação significativos.
O desafio de inovar dentro de organizações pode ser um processo bastante complexo, pois essas organizações necessitam de um conhecimento aprofundado, não torna-se somente necessário compreender como ocorrem as medidas de entrada (investimentos financeiros em atividades que levam a inovação) e saídas (quantidade de produtos ou serviços inovadores lançados no mercado em um determinado período de tempo) desse processo, pois os indicadores de entrada e saída do processo são considerados insuficientes para identificar os elementos necessários a inovação.

[4] CASSIOLATO, J. E., MATOS, M. P. \& LASTRES, H. M. M. (2008). Arranjos produtivos locais: uma alternativa para o desenvolvimento, criatividade e cultura. Rio de Janeiro: E-papers.

[5] DOBNI, C. B.; KLASSEN, M.; NELSON, T. Innovation strategy in the US: top executives offer their views. Journal of Business Strategy, v. 36, n. 1, p. 3-13, 2015.

[6] DOBNI,C.B. "Measuring innovation culture in organizations: The development of a generalized innovation culture construct using exploratory factor analysis", European Journal of Innovation Management, Vol. 11 Issue: 4, pp.539-559, 2008.

[7] DRUCKER, P.F. Inovação e Espírito empreendedor. 2 ed. - São Paulo: Pioneira, 1987. 
[8] FILHO, M. G. Pesquisa em Gestão da Produção na indústria de calçados: revisão , classificação e análise. p. 163-186, 2009.

[9] JAEGER, Sílvio Aurélio. Medidas de minimização da geração de resíduos sólidos industriais em curtume - estudo de caso. 2008. 177f. Dissertação (Tese de mestrado) - Programa de Pós Graduação em Gestão Tecnológica. Centro Universitário Feevale, Novo Hamburgo, RS, 2008.

[10] LASTRES, H. M. M. \& CASSIOLATO, J. E. (2004). Glossário de arranjos e sistemas produtivos e inovativos locais. Rio de Janeiro: Rede de Pesquisa em Sistemas Produtivos e Inovativos Locais.

[11] OCDE. Organização para a Cooperação e Desenvolvimento Econômico. Manual de Oslo: diretrizes para coleta e interpretação de dados sobre inovação. Publicado pela FINEP (Financiadora de Estudos e Projetos), 3aㅡ Ed, 2005.

[12] PERDIGÃO et al Teoria e prática da pesquisa aplicada, Ed. Elsevier. Rio de Janeiro, 2012.

[13] SANTOS, D. F. L. et al. Innovation efforts and performances of Brazilian firms. Journal of Business Research, v. 67, n. 4, p. 527-535, 2014.

[14] SEBRAE - Serviço Brasileiro de Apoio às Micro e Pequenas Empresas. (2014). APL: Arranjo Produtivo Local. Brasília: SEBRAE.

[15] VIEIRA, E. A.; BARBOSA, A. D. S. Gestão dos resíduos e rejeitos sólidos industriais: a conjuntura dos pólos calçadistas brasileiros. Revista Monografias Ambientais, v. 10, n. 10, p. 2318-2325, out./dec. 2012. 


\section{Capítulo 19}

\section{ECOSSISTEMA DE INOVACÃO: UM ESTUDO ACERCA DO INCENTIVO AO DESENVOLVIMENTO DE STARTUPS NO MUNICIPIO DE SÃO CARLOS/SP}

\section{Aiquinis Kellen Rosalis Fantuce \\ Ana Rita Gallo \\ Maria Amélia Silva dos Reis \\ Suellen Cristina Balduino Lopes \\ Thiago Silva Polli Santos}

Resumo: Este estudo objetivou entender quais os mecanismos de fomento ao desenvolvimento de startups presentes na cidade, analisando as universidades renomadas, empresas multinacionais, além de centros de desenvolvimento, além de considerar quais os meios utilizados por estes para promover um ecossistema inovador eficiente para a cidade e para as startups.

O presente trabalho trata-se de pesquisa de natureza exploratória, com abordagem qualitativa, com dados coletados por meio de entrevistas em três organizações que compõem esse ecossistema. Desta forma, o presente estudo contribuiu de modo a identificar os mecanismos de fomento existentes no município de São Carlos/SP, discorrendo acerca de suas funções, objetivos,métodos e algumas limitações em relação ao apoio e incentivo ao desenvolvimento que são recebidos pelas startups. Sendo assim, considerando que São Carlos/SP é um potencial ecossistema de inovação, é preciso que a cidade invista em programas de desenvolvimento e fomento, criando condições favoráveis para que este ecossistema cresça, mostrando-se eficiente, no desenvolvimento de novas tecnologias nascidas com as startups.

Palavras chave: Startups; ecossistemas; inovação. 


\section{INTRODUÇÃO}

O mercado investidor tem cada vez mais voltado sua atenção para negócios inovadores, fazendo uso da tecnologia e do conhecimento do empreendedor, que a partir de uma ideia, desenvolve um produto ou serviço criando valor para a sociedade. Tais iniciativas dão origem às startups, empresas que tendem a formar um novo segmento de mercado, dadas suas características inovadoras que proporcionam maior proveito das oportunidades oferecidas pelo mercado globalizado (ABStartup, 2017).

Um alto potencial de inovação está atrelado às startups, o que gera a criação de empregos, renda e a colaboração, para o desenvolvimento socioeconômico na região onde estão inseridas. Da mesma forma que as startups influenciam o ambiente externo, o mesmo ambiente é capaz de influenciá-las, criando assim um ecossistema (CERNICCHIARO,2017, p.21).

Entende-se que ecossistema de startups é o ambiente no qual os indivíduos estão inseridos. Este é formado pela teia de relações entre todos que contribuem direta ou indiretamente para o desenvolvimento dos startups. "Dependendo da qualidade das conexões formadas entre esses atores, as startups têm maior ou menor facilidade para prosperar. " (SEBRAE, 2016, p.5)

São Carlos está localizada no interior do Estado de São Paulo, e é considerada a capital da tecnologia, pois além de sua alta taxa de atividade acadêmica dada pelas Universidades que abriga, o caráter de pólo de desenvolvimento é reforçado por instituições que fomentam o desenvolvimento científico e inovador como a Embrapa, o ParqTec e recentemente o ONOVOLAB, um coworking com características de centro de inovação e tecnologia (Prefeitura Municipal de São Carlos, 2018).

Tais circunstâncias concebe um ambiente favorável para o empreendedorismo, de modo que eleve a criação e o desenvolvimento de diversas startups. Segundo o jornal Estadão (2018), São Carlos/SP possui atualmente cerca de 150 startups em funcionamento, sendo estas, em sua maioria, lideradas por ex-alunos da USP e UFSCar, universidades localizadas na cidade (ESTADÃO, 2018).

Tendo em vista as tendências de que a cidade de São Carlos se torne um polo para acomodação e desenvolvimento de startups, torna-se viável e relevante o estudo apresentado nesta pesquisa, que tem como finalidade, entender qual a importância dos mecanismos de fomento para o processo de desenvolvimento e evolução das startups localizadas em São Carlos, o quanto é imprescindível às parcerias para alavancar esse novo nicho de mercado e quais os perfis desses investidores.

O presente artigo está estruturado em sessões, sendo que a primeira é destinada a introdução, apresentando o tema e questão de pesquisa, a segunda coloca a metodologia admitida pela pesquisa. A terceira sessão é composta pela fundamentação teórica que discorre acerca da criação de startups e dos critérios de desenvolvimento de um ecossistema favorável, expondo os resultados e sua discussão, seguida pela apresentação das considerações finais e referências bibliográficas utilizadas.

\section{METODOLOGIA}

A metodologia utilizada para a realização do presente trabalho trata-se de pesquisa de natureza exploratória, com abordagem qualitativa, que segundo Selltiz apud Gil et al (2002), tem o objetivo de possibilitar maior conhecimento sobre o problema, tornando-o compreensível e possibilitando a construção de hipóteses e o aprimoramento de ideias. Deste modo a priori realizou-se o levantamento bibliográfico, por meio de consulta a bancos digitais de trabalhos acadêmicos, seguida pela pesquisa de campo.

A coleta de dados para a construção desse trabalho deu-se por meio de pesquisa empírica de natureza exploratória e qualitativa, tendo como instrumento para realização a elaboração e aplicação de um questionário para entrevistas contendo 13 perguntas abertas.

Após a compreensão dos dados históricos da cidade, notou-se que esta possui grande potencial empreendedor, pois abriga universidades renomadas, empresas multinacionais, além de centros de desenvolvimento tecnológicos e acadêmicos que tem por finalidade incentivar 0 desenvolvimento de startups na cidade.

Dessa forma, deu-se início ao levantamento de informações realizando as entrevistas em setembro de 2018, em 3 diferentes instituições: uma startup (entrevistado A), uma 
empresa que fomenta startups (entrevistado B), e um centro de coworking e aceleração (entrevistado C). Sendo assim, a aplicação do questionário objetivou identificar os métodos de fomento dos quais estas instituições se utilizam para contribuir e incentivar o desenvolvimento do ecossistema de startup da cidade de São Carlos.

\section{CONTEXTUALIZAÇÃO DO TERMO STARTUP}

Para Blanck (2003, apud PINTO,2017, p. 25), startups podem ser definidas como organizações que tem por objetivo encontrar maneiras de tornar seu modelo de negócio escalável e replicável. Seguindo essa mesma vertente, Santos (2016), acrescenta que esse modelo de negócio é apenas um estágio, ambicionando tornar-se uma empresa consolidada. Contudo, ao se perceber que o modelo de negócio é insustentável, cabe então, ao gestor interrompê-lo com rapidez, findando assim as atividades, minimizando os prejuízos financeiros, e o desperdício de tempo de seus colaboradores.

Blank e Dorf (2014) apud Rocha (2016, p.33), destaca a necessidade de diferenciar o modelo de negócio startup das demais empresas. Para os autores, a startup não pode ser considerada uma empresa formal de pequeno porte, sequer a versão ínfima de uma grande corporação, como uma multinacional por exemplo. Tal fato ocorre, pelas características peculiares abrangentes das startups, e do ambiente no qual estas estão inseridas.

\section{ECOSSISTEMAS DE STARTUPS}

De acordo com a ABStartups (2017) um ecossistema é formado por todas as empresas ou órgãos, que de alguma forma contribuem para as empresas nascentes se desenvolverem. Dentre eles estão às universidades, que são responsáveis por colocar no mercado de trabalho, profissionais bem qualificados, por exemplo os coworkings, concebido através de uma união entre um grupo de pessoas que continuam trabalhando independentes umas das outras, e compartilham valores e buscam a sinergia que acontece quando pessoas talentosas dividem o mesmo espaço, gerando um fluxo de troca de ideias e experiências.
As organizações aceleradoras são para startups que estão em busca de uma inovação radical ou de um modelo de negócios escalável e repetível. Entretanto, se - modelo de negócios é baseado na economia tradicional, as incubadoras estarão mais aptas a atender as startups durante o processo de iniciação. Tanto as organizações aceleradoras e quanto as incubadoras estão presentes para dar todas as instruções necessárias para o sucesso do negócio.

A imprensa, também faz parte do ecossistema das startups, visto que, é ela quem dá a visibilidade necessária para o novo negócio, porém cabe a todos os integrantes (stakeholders) do ecossistema colaborar com a troca de informações e experiências, de maneira a estabelecer parcerias visando as alterações e necessidades para o próprio ecossistema. Tais características citadas anteriormente são primordiais para se dizer que uma determinada região é um ecossistema. No Brasil, Belo Horizonte - MG e Florianópolis - SC são cidades que vem destacando-se e se expandindo como ecossistemas das startups (ASAS.com, 2017).

Para a sobrevivência de um ecossistema é necessário que haja um engajamento entre os integrantes, devido a um mercado atual competitivo. É necessária essa relação, visto que é improvável a sobrevivência de um negócio em um mercado sem essa integração. Embora busquem objetivos individuais, "a formação de um ecossistema de inovação está pautada na necessidade de ajuda fornecida pelos outros elementos do ecossistema " (TORRES, 2016, p. 26).

\subsection{ECOSSISTEMA DE SÃO CARLOS/SP}

O ecossistema empreendedor de São Carlos é muito rico e diversificado. A cidade conta com inúmeras iniciativas de diferentes Stakeholders (Startups, Aceleradoras, Espaços de Coworkings, Institutos, Universidades, universitários e diversos outros).

O Sanca Hub, refere-se à região geográfica de São Carlos, como um ecossistema de tecnologia e inovação. Segundo Anderson Criativo, CEO do ONOVOLAB, o Sanca Hub é um apelido para São Carlos, da mesma forma que Silicon Valley é para a região da Califórnia. Criativo (2017) afirma que:

"Estabelecer um ecossistema empreendedor é basicamente um processo que envolve um 
esforço absurdo de poucos pioneiros no começo, que parece que não está dando resultado nenhum durante anos e anos. Até que chega o momento onde o Movimento começa a exercer um poder de atração que faz a roda girar. É isso que acontece no Sanca Hub nesse exato momento. (CRIATIVO, 2017)

Vanderlei Bagnato renomado cientista da cidade (2014), cita em sua entrevista à revista ICMCotidi@ (2014), que a cidade de São Carlos superou as iniciativas de inovação tecnológica em seu ambiente acadêmico. No campus da USP em São Carlos, há 30 anos, já se formavam empresas, em sua maioria dentro do Instituto de Física, local onde nasceu a primeira fundação de apoio a tecnologia, o ParqTec. Tal fato ocorreu bem antes do governo ou das agências de fomento começarem a incentivar e se preocupar com a inovação. Como São Carlos foi uma cidade precursora nesse quesito, teve que aprender com suas próprias experiências que algumas coisas dariam certo e outras não funcionam.

\section{PROGRAMAS DE INCENTIVO AO DESENVOLVIMENTO DE STARTUPS}

Esta parte tem como finalidade, analisar as iniciativas de incentivo, que têm como foco o desenvolvimento de startups.

"As iniciativas e os instrumentos de incentivo a startups usualmente levam em conta suas diferentes fases de maturação. O processo de estabelecimento de um novo negócio costuma ser dividido em quatro estágios, cada um com desafios específicos" (RONCARATTI, 2017, p.217).

O primeiro estágio é o da fase inicial, que é o momento em que os empresários identificam as oportunidades e decidem começar uma atividade empresarial. Seguido da fase semente, na qual os empresários fazem uma avaliação de mercado, a fim de desenvolver um modelo de negócio e quais os aspectos necessários para sua execução. Por conseguinte, chega-se a fase startup, no qual o negócio é estabelecido com a criação oficial do empreendimento. E por último chega-se ao estágio da fase de expansão, que é o período que sucede o lançamento do produto e ocorre uma elevação na escala de produção. (RONCARATTI, 2017, p.217).

O modelo de empresas nascentes conhecido como startup, existente no Brasil, se amplia devido aos programas de novos fundos de investimento criados a partir do ano de 1999. Tais programas englobam diferentes tipos de investidores, que podem ser denominados como: sócio, empréstimo, crowdfunding (financiamento coletivo), aceleradoras, incubadoras, investidores anjo, private equity (capital privado). No entanto, as startups se potencializaram a partir de 2010, tornando o mercado dinâmico, e, assim, trazendo o desenvolvimento científico e tecnológico, aplicados em produtos e serviços que, anteriormente, só eram dispostos no mercado por empresas de grande porte (SANTOS,2016).

Segundo o Sebrae (2017), apoiar o crescimento das startups por meio de parcerias com as grandes empresas tem sido um de seus focos de atuação, Heloisa Mendes - Diretora do Sebrae completa a afirmação com a seguinte frase:

\begin{abstract}
"Vimos vários exemplos neste Congresso de Inovação que comprovam a importância dessa relação. Esse é um jogo de ganha/ganha, onde as startups podem oferecer agilidade na solução de problemas e as grandes empresas podem proporcionar aos pequenos negócios o ganho de escala, o acesso a recursos, a experiência em gestão e logística" (MENDES, 2017)
\end{abstract}

De acordo com o MCTIC, 2017 (Ministério da Ciência, Tecnologia, Inovações e Comunicações) a maior parte das incubadoras brasileiras encontram-se próximas às universidades e centros de pesquisas. Esse fato, faz com que haja estímulo e interesse dos alunos e professores no empreendedorismo. As incubadoras oferecem espaço físico de qualidade e baixo custo, além de ofertar serviços como consultoria tecnológica, financeira, jurídica, desenvolvimento de plano de negócios, mentorias, gestão de negócios, entre outros.

Álvaro Prata, secretário de Desenvolvimento Tecnológico e Inovação do MCTIC (Ministério da Ciência, Tecnologia, Inovações e Comunicações), afirma que o Startup Brasil, um dos programas de fomento às startups, contribui de forma a atrair o investimento privado com recursos públicos para pesquisa. Segundo ele, a cada real investido pelo governo, o setor privado investiu outros três reais (CNPq, 2017).

A seguir discorreu-se sobre os principais responsáveis do Programa Startup Brasil e suas respectivas funções. ( SOUZA, 2017, p.18/19) 
MCTIC - Desenha e realiza o planejamento estratégico do programa. Trabalha em negociações para aquisição de recursos para apoiar as Startups. Seleção Aceleradoras.

SOFTEX - Apresentação para investidores; participa da seleção das Startups; comunicação referente ao programa; negociação de parcerias; acompanhamento de todos os projetos; e realização evento Welcome Aboard.

CNPq - Seleção e distribuição de bolsas para as Startups.

APEX - Seleciona Startups internacionais e organiza o evento Demo Day Internacional no Vale do Silício.

ACELERADORAS - São responsáveis pela capacitação das Startups selecionadas e pela adequação do seu produto ao mercado por 12 meses. Investem nas Startups em troca de participação no capital da empresa.

STARTUPS - São beneficiárias e trabalham juntamente com as aceleradoras para atingir métricas de crescimento durante a participação no programa.

Outro programa de incentivo, no Brasil, é o Anprotec (Associação Nacional de Entidades Promotoras de Empreendimentos Inovadores) que em parceria com o SEBRAE (Serviço Brasileiro de Apoio à Micro e Pequena Empresa) tem como objetivo motivar as aceleradoras e incubadoras a traçarem estratégias para atrair, selecionar e acompanhar a organização de negócios de impacto social em seu portfólio. O Anprotec cita que as incubadoras e aceleradoras no Brasil tem a competência de influenciar o empreendedorismo no país. Levando o conceito de negócios de impacto em escala nacional, e também contribui para que haja uma rápida solução dos problemas encontrados. (ANPROTEC, 2018).

\section{FOMENTO ÀS STARTUPS DA CIDADE DE SÃO CARLOS/SP}

A seguir serão expostos alguns meios de fomento que beneficiam a cidade de São Carlos/SP, são eles:

O ParqTec, que é uma incubadora de empresas, pioneira, privada e sem fins lucrativos foi criada pelo Conselho Nacional de Desenvolvimento Científico e Tecnológico (CNPq) em 17 de dezembro de 1984 e tem o objetivo de "promover o desenvolvimento regional otimizando o custo da transação inovação tecnológica - mercado e valorizando o empreendedorismo" (ParqTec, 2018).

No ParqTec o processo de incubação é feito através de cinco etapas. A primeira etapa é a seleção, que é feita através da análise do estudo

viabilidade/técnica/econômico/financeira do projeto. A segunda, consiste na Préincubação, onde é oferecido uma assessoria e consultoria para que o empreendedor possa aprimorar a viabilidade e desenvolver protótipos de produtos ou serviços para o início do negócio. A etapa seguinte é a incubação, nesse período o empreendedor recebe o apoio da incubadora, podendo usar as instalações físicas individuais e comuns, por exemplo, salas empresariais, recepção, salas para reuniões e treinamentos, auditório e cafeteria. Nessa etapa, podem candidatarse empreendedores com plano de negócios aprovados; em desenvolvimento ou empresas existentes em outras localidades que queiram transferir-se para a incubadora. $\mathrm{Na}$ quarta etapa, a graduação e aceleração, o empreendedor recebe toda a preparação para a sua graduação. Realizada através de consultorias e assessorias específicas e individuais. $\mathrm{Na}$ última etapa, empresas graduadas, as empresas que já passaram pela incubadora, podem continuar recebendo o apoio no processo de renovação e adequação dos planos de negócios. (ParqTec, 2018).

São Carlos também conta com o Parque Ecotec Damha que "é um empreendimento voltado à geração de negócios com valor agregado, promoção da ciência, tecnologia e inovação" (INSTITUTO INOVA, 2018). Um espaço localizado em uma área estratégica, responsável por oferecer oportunidades para as empresas transformarem suas pesquisas em produtos, além de aproximar os centros de conhecimentos, como por exemplo, universidades, escolas e centros de pesquisas dos empreendimentos.

O mais recente empreendimento de fomento à inovação presente na cidade de São Carlos é o ONOVOLAB. Este encontrou nas estruturas da antiga "Companhia de Fiação Tecidos São Carlos" base para construir um novo modo de empreender, O ONOVOLAB é um espaço de coworking direcionado às startups, tornandose uma plataforma de apoio ao desenvolvimento de projetos que tenham em 
sua essência a inovação (Revista Pequenas Empresas \& grandes Negócios, 2018).

Segundo conteúdo publicado na revista eletrônica "Pequenas Empresas \& Grandes Negócios" (2018), atualmente o ONOVOLAB acomoda 12 startups, com a intenção de que em 2019 o espaço da antiga "Companhia de Fiação Tecidos São Carlos", seja totalmente ocupado. Para tal, o empreendimento investe em eventos com intuito de tornar as relações entre empreendedores, universidades e startups mais interativas, proporcionando também possíveis parcerias com grandes empresas, como a Elo, que contratou o espaço, com intuito de desenvolver soluções para novos produtos por meio das equipes formadas pelo ONOVOLAB (Revista Pequenas Empresas \& grandes Negócios, 2018).

Vale salientar que existem inúmeras startups não estão nesses centros, e dependem de capital privado para conseguir ganhar escalabilidade e tornar-se replicável. Um exemplo de tal fato é a startup que contribuiu para esta pesquisa, a Gryfo está acoplada a Monitora, uma empresa voltada para a disponibilização de serviços tecnológicos, inovação e processos necessários para viabilizar o desenvolvimento destas startups no ecossistema empreendedor.

\section{APRESENTAÇÃO DOS DADOS COLETADOS:}

Segundo Pinto (2017, apud BIANCK,2003,p. 25), startups podem ser definidas como organizações que tem por objetivo encontrar maneiras de tornar seu modelo de negócio escalável e replicável. Seguindo essa mesma vertente, Santos (2016), acrescenta que esse modelo de negócio é apenas um estágio, ambicionando tornar-se uma empresa consolidada. Tais afirmações foram comprovadas com a aplicação do questionário. Assim, para o representante da Monitoratec (empresa de tecnologia), entrevistado B, a empresa, mesmo que em seu início, não se caracterizava como startup, pois tinha como modelo de negócios a comercialização de serviços de softwares terceirizados Alt Service. Deste modo, o representante da Gryfo, entrevistado A, entende que esta apesar de ser um Spin Off da Monitoratec, ainda se encontra no estágio de startup, pois não encontrou seu modelo de negócio.
Assim, a Monitoratec assume o papel de investidor, considerando que fomenta o desenvolvimento da startup Gryfo, que desenvolve suas atividades nas mediações da Monitora, partilhando de sua infraestrutura e conhecimento de negócios.

Segundo o representante da Gryfo, o papel da monitora é majoritariamente de investidor do que de acelerador, pois o fomento recebido é principalmente financeiro e em infraestrutura.

O CEO e representante do espaço de coworking e centro de co-inovação, entrevistado C, expõe seu ponto de vista, quando questionado sobre fomentos recebidos pelo governo, no trecho a seguir:

"...a gente não tem nenhum incentivo do governo, a gente não utiliza nenhuma linha do dinheiro público e a gente não tem nenhuma parceria, nem com governo, nem com prefeitura, mas isso é uma opção nossa né, existem alguns tipos de centro de inovação. Existe o centro de inovação que ele recebe dinheiro público, ele tem ligação governamental, existe o centro de inovação que é subsidiada por alguma grande empresa, então você pega os grandes bancos, hoje eles tenham centro de inovação próprio deles mas aí desenvolvendo coisas para interesse deles. Existe centro de inovação de origem Universitário de universidades que criam centro de inovação né. Nosso caso a gente optou ir para uma linha onde não fosse de uma empresa específico, não utilizasse dinheiro público e não estivesse travada uma universidade específica né. Então a gente fez um centro de inovação Independente com capital privado né. $E$ que é subsidiado por patrocínios por locação de espaço, por serviços, né, de forma bem orgânica como uma empresa qualquer".

De acordo com o entrevistado C, seria ideal que as startups de São Carlos e região recebessem algum tipo de fomento do governo, visto que empreender no Brasil tem sido dificultoso. Segundo ele, deveriam haver incentivos financeiros por parte do governo e prefeitura, para estimular o empreendedorismo.

O entrevistado C, salienta que, sempre recebeu incentivos do setor privado, e que além de receber os patrocínios, também vende o patrocínio do seu espaço de coworking. 
Quando se considera os fatores que dizem respeito ao ecossistema empreendedor de São Carlos/SP, encontra-se um consenso entre os entrevistados. Para eles a cidade ainda precisa evoluir em questões de infraestrutura, avaliando itens como: transporte público, saúde e educação(pública e privada), oferecendo maior qualidade de vida para atrair atenção dos talentos e investidores internacionais. No entanto, todos acreditam que o ecossistema possui características e tecnologia favoráveis para o seu rápido desenvolvimento, por meio de trabalho, projetos e até mesmo do desenvolvimento do marketing da cidade, o que pode torná-la visível e cobiçada para os grandes centros e mercados investidores.

\section{CONSIDERAÇÕES FINAIS}

Este estudo objetivou analisar quais os mecanismos de fomento existem para o desenvolvimento de startups presentes na cidade de São Carlos/SP, e quais os meios utilizados por estes para promover um ecossistema inovador eficiente para a cidade e para as startups.

Mediante a revisão bibliográfica realizada com o intuito de conceituar e entender o termo startup e o funcionamento de ecossistemas de inovação, foi possível compreender que para que uma startup encontre seu modelo de negócios escalável e replicável, esta precisa de fomento e parcerias que influenciam de modo positivo no seu crescimento.

Deste modo, por meio artigos e matérias publicadas em diferentes mídias, observou-se que a cidade de São Carlos/SP tem se destacado, mostrando-se um potencial núcleo de desenvolvimento de tecnologia e inovação, sendo comparada até mesmo com o Vale do Silício, devido ao crescente número de startups e mecanismos de fomento criados na cidade.

Seguindo essa linhagem, a pesquisa de campo possibilitou maior compreensão do

\section{REFERÊNCIAS}

[1] ABSTARTUPS. Ecossistema de startups! O que é, como funciona, o que já sabemos sobre ele?. $2017 . \quad$ Disponível em: <https://abstartups.com.br/2017/11/10/ecossistema termo e conhecimento a respeito do ecossistema de startup do município de São Carlos/SP. No decorrer da construção deste trabalho, observou-se que apesar do grande potencial de desenvolvimento a cidade ainda enfrenta alguns problemas de organização e, principalmente, de integração dos organismos que compõem seu ecossistema.

Um exemplo de tal fato, se dá na dificuldade de encontrar dados concretos sobre o número de startups e quais investimentos disponíveis há na cidade, pelo fato de até o momento desta pesquisa, ainda não ter sido realizado um levantamento oficial de tais dados pela Prefeitura. É de senso comum entre os entrevistados, que parcerias com órgãos públicos e a promoção dos programas de fomento por parte destes é restrito, gerando, assim, a impressão de apatia do órgão público perante o quesito inovação.

Segundo a revista eletrônica Pequenas Empresas \& Grandes Negócios (2018), a cidade conta com poucas formas de fomento. As aceleradoras, incubadoras e os espaços de coworkings ainda não são suficientes para atender a demanda crescente de startups criadas em São Carlos, sendo que muitos empreendedores necessitam buscar investimento de outras localidades.

Desta forma, o presente estudo contribuiu de modo a identificar os mecanismos de fomento existentes no município de São Carlos/SP, discorrendo acerca de suas funções, objetivos, métodos e algumas limitações em relação ao apoio e incentivo ao desenvolvimento recebidos pelas startups.

Em virtude dos aspectos observados neste estudo, e considerando que São Carlos/SP é um potencial ecossistema de inovação, é preciso que a cidade invista em programas de desenvolvimento e fomento, criando condições favoráveis para que este ecossistema cresça, mostrando-se eficiente, no desenvolvimento de novas tecnologias nascidas com as startups.

-de-startups-o-que-e-como-funciona-o-que-jasabemos-sobre-ele/>. Acesso em: 17 mai 2018.

[2] ANPROTEC. Programa de Incubação e Aceleração de Impacto. Disponível em: 
<http://www.anprotec.org.br/negociosdeimpacto/\# oprograma>. Acesso em: 16 jul. 2018.

[3] ASAAS. Você conhece os incríveis ecossistemas de startups? 2017. Disponível em: $<$ https://www.asaas.com/blog/voce-conhece-osincriveis-ecossistemas-de-startups/> Acesso em: 17 mai 2018. 7

[4] CERNICCHIARO, Bernardo Flores. A percepção das startups quanto ao ecossistema de empreendedorismo de Porto Alegre. 2017. p.21. Disponível em: <http://www.lume.ufrgs.br/handle/10183/169932>. Acesso em: 18 mai 2018

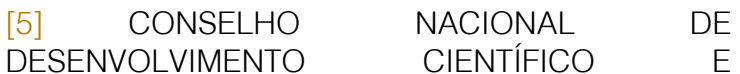
TECNOLÓGICO. Ministro anuncia R\$ 9,7 milhões para Start-Up Brasil e defende investimentos em inovação. $2017 . \quad$ Disponível em: <http://cnpq.br/web/guest/noticiasviews//journal_content/56_INSTANCE_a6MO/10157/5804 003 >. Acesso em: 05 abr. 2018.

[6] CRIATIVO, Anderson. Se liga no SANCA HUB! 2017. Disponível em: < https://medium.com/@onovolab/se-liga-no-sancahub-de15aa0c5e50> Acesso em: 20 mai 2018.

[7] ESTADÃO DE SÃO PAULO. O empreendedorismo que move o Brasil. $30 \mathrm{abr}$ 2012 Disponivel em: <http://economia.estadao.com.br/noticias/geral,oempreendedorismo-que-move-o-brasil-imp,867104> Acesso em: 09 mar 2018.

[8] GIL, Antonio Carlos. Como elaborar projetos de pesquisa. 4. ed. São Paulo: Atlas, 2002. 11 p. Disponível em: <https://professores.faccat.br/.../como_elaborar_pr ojeto_de_pesquisa_-_antonio_carlos...>. Acesso em: 03 abr. 2018.

[9] IMC Cotidi@ano. O boom das startups na capital da tecnologia. 2014. Disponível em: <http://conteudo.icmc.usp.br/CMS/Arquivos/arquiv os_enviados/ADMINISTRADOR_17_cotidiano104.p df $>$. Acesso em: 22 mai 2018.

[10] INSTITUTO INOVA. Parque Ecotec Damha. 2018. Disponível em: < http://institutoinova.org.br/parque-ecotecdamha/\#> Acesso em: 16 jul. 18

[11] PARQTEC. A instituição.2018. Disponível em: $\quad<\quad$ http://parqtec.com.br/quemsomos/instituicao/>.Acesso em: 20 mai 2018.

[12] PEQUENAS EMPRESAS \& GRANDES NEGÓCIOS. São Carlos: Cidade Paulista vira berço de startups e negócios inovadores.Disponível em: $<$ https://revistapegn.globo.com/Startups/noticia/20 18/02/sao-carlos-cidade-paulista-vira-berco-destartups-e-negocios-inovadores.html>. Acesso em: 12 jul 2018.

[13] PINTO, Felipe de Matos Sardinha. A construção de um modelo de acompanhamento da evolução de startups digitais em contexto de aceleração: o caso Start-Up Brasil. 2017. Dissertação (Mestrado em Empreendedorismo) Faculdade de Economia, Administração e Contabilidade, Universidade de São Paulo, São Paulo, 2017. Disponível em: <http://www.teses.usp.br/teses/disponiveis/12/1214 2/tde-21022018-110337/>. Acesso em: 2018-07-17.

[14] PREFEITURA MUNICIPAL de São Carlos. A Cidade de São Carlos. Disponível em: $<$ http://www.saocarlos.sp.gov.br/index.php/conhec a-sao-carlos/115268-a-cidade-de-sao-carlos.html> Acesso em: 01 jul 2018.

[15] ROCHA, Renata Malagoli. Empreendedorismo e inovação na jornada da startup: um framework da sintonia entre os processos. 2016.Dissertação (Mestrado em Empreendedorismo) - Faculdade de Economia, Administração e Contabilidade, Universidad de São Paulo, São Paulo, 2016. doi:10.11606/D.12.2017.tde-12012017-153034.

Acesso em: 2018-05-17.

[16] RONCARATTI, Luanna Sant'Anna. INCENTIVOS A STARTUPS NO BRASIL: os casos do Startup Brasil, InovAtiva e InovApps. 2017. p. $217 . \quad$ Disponível em: <http://www.ipea.gov.br/portal/images/stories/PDFs /livros/livros/171002_inovacao_no_setor_publico.pd $\mathrm{f}>$. Acesso em: 13 jul 2018.

[17] SANTOS, Monna Cleide Fonsêca Rodrigues dos. O ecossistema de startups de software da cidade de São Paulo. 2015. Dissertação (Mestrado em Ciência da Computação) - Instituto de Matemática e Estatística, Universidade de São Paulo, São Paulo, 2015. doi:10.11606/D.45.2016.tde-23022016204626. Acesso em: 2018-05-17.

[18] SEBRAE. Estudo sobre o Ecossistema Baiano de Startups. 2016. p.5. Disponível em: <http://www.sebrae.com.br/Sebrae/Portal\%20Sebra e/UFs/BA/Anexos/Estudo\%20sobre\%20o\%20Ecoss istema\%20Baiano\%20de\%20Startups.pdf>.

Acesso em: 20 mai 2018.

[19] SOUZA, Thais Mundim Baesse de. Programa Startup Brasil: análise da atuação em rede na implementação do programa. 2017. 40 f., il. Trabalho de conclusão de curso (Bacharelado em Gestão de Políticas Públicas)_Universidade de Brasília, Brasília, 2017.

[20] TORRES, NÁGILA NATÁLIA DE JESUS. MAPEAMENTO DO ECOSSISTEMA DE STARTUPS DE TECNOLOGIA DE BELÉM-PA. 2016. p. 17, 18, 26. Dissertação (Mestrado em Ciências da Computação) - Universidade Federal do Pará, Belém, 2016. Disponível em: <http://ppgcc.propesp.ufpa.br/Disserta\%C3\%A7\% C3\%B5es_2016/N\%C3\%A1gila\%20Nat\%C3\%A1lia \%20de\%20Jesus\%20Torres_Disserta\%C3\%A7\%C 3\%A3o.pdf> Acesso em: 17 mai 2018. 


\section{Capítulo 20}

\section{A APRENDIZAGEM E O CONHECIMENTO COMO FERRAMENTAS PARA \\ MULHERES: RELATO DE CASOS}

\section{Irlanda Mayra Medeiros da Silva}

Suellen Karolyne Silva Correia

Luana Kelly de Mendonça

Ricardo Moreira da Silva

Josilene Aires Moreira

Resumo: Uma das metas do milênio da ONU é o empoderamento de mulheres e uma forma delas conseguirem isso é através da aquisição do conhecimento. Dessa forma, o objetivo desse artigo é utilizar as tipologias de exploration e exploitation, ferramentas da aprendizagem organizacional desenvolvidas por March (1991) para demonstrar como as mulheres foram empoderadas ao longo do tempo, comprovando que partir da aquisição e gestão do conhecimento há a possibilidade real de avanço na sociedade, no espaço do trabalho e na vida, em prol de reduzir as diferenças e discriminação criadas culturalmente. Tal procedimento foi demonstrado metodologicamente a partir do uso do exploration nas vertentes da pesquisa, descoberta e experimentação e da exploitation no refinamento, escolha, produção, eficiência, seleção, implementação e execução. A escolha dos casos foi a partir da análise da história de mulheres com execução de feitos através do conhecimento, das organizações e das vertentes que cada uma estudou. A pesquisa enquadra-se em qualitativa e o método utilizado foi de dedução partindo de premissas da aprendizagem organizacional. Concluiu-se que a utilização na prática das variáveis do modelo de March(1991) já acontecem desde muito tempo, ao longo da história por algumas mulheres para se inserir no mercado de trabalho, alcançar cargos, diminuir diferenças socioculturais, alcançando empoderamento. 


\section{INTRODUÇÃO}

Conhecimento é um fator crucial para o desenvolvimento de algo ou alguém, numa organização ou na sociedade em si. Em uma instituição não é diferente, um dos pontos chaves que faz parte de um plano estratégico ou mesmo o que tem por trás de algo a mais que a empresa possui é o desenvolvimento e a detenção de seus conhecimentos, participando ativamente das entradas, transformações e saídas de uma empresa, ou seja, de todo seu universo.

A gestão do conhecimento vem acompanhada da vantagem competitiva entre empresas, algo primordial nos tempos atuais tendo em vista a alta concorrência e necessidade de diferenciação das demais. Gestão do conhecimento evolve criar, captar, disseminar, armazenar, disponibilizar e incorporar os conhecimentos individuais, transformando-os em conhecimento organizacional disseminado dentro e fora da organização (NONAKA e TACKEUCHI, 1997).

Pesquisas demonstram que em diversos cargos há a discriminação da mulher, sobretudo no papel que desempenham, seja na área de atuação, na conciliação de tarefas, do lar e corporativas, na dificuldade de ascensão de funções e nas diferenças salarial. Pesquisa realizada pelo site de empregos Catho neste ano com quase $8 \mathrm{mil}$ profissionais mostra que as mulheres ganham menos que os colegas do sexo oposto em todos os cargos, áreas de atuação e níveis de escolaridade pesquisados - a diferença salarial chega a quase 53\% (CAVALLINI, 2018).

Garcia (2018), destaca que o fato de a mulher ter entrado no mercado mais tarde, ter tido acesso a escolaridade mais tarde, ter atribuição principal sobre a maternidade, tudo isso contribui para que o processo de carreira seja mais lento e existam essas diferenças. Já em relação à distribuição das mulheres entre cargos de gestão pesquisados, houve uma pequena melhora desde 2011, mas as desigualdades ainda aparecem e aumentam à medida que o nível hierárquico sobe.

Cavallini (2018) cita que o cargo de presidente é o que tem a menor proporção de mulheres - 25,85\% em 2017 - e apresenta o menor crescimento em comparação a 2011 aumento de 2,94 pontos percentuais. Já o cargo de encarregado, o mais baixo entre os pesquisados em nível de gestão, tem a maior proporção de mulheres - 61,57\%. considera que a questão da maternidade pode desacelerar a carreira das mulheres, o que pode explicar tamanha desproporção e o fato de elas terem maior participação nos cargos mais baixos da hierarquia.

No presente artigo há o objetivo de utilizar as tipologias de exploration e exploitation, ferramentas da aprendizagem organizacional desenvolvidas por March (1991) para mostrar como a aquisição e a gestão do conhecimento permitiu a ascensão de mulheres no espaço de trabalho em prol de reduzir as diferenças e discriminação socioculturalmente desenvolvidas.

\section{METODOLOGIA}

Para relato dos casos de empoderamento de mulheres via a gestão do conhecimento será utilizado a abordagem de March (1991) que trabalha com o desenvolvimento e absorção de conhecimento em organizações. O autor utiliza com base as premissas exploration e exploitation. Assim, seu Modelo proposto partiu da criação de um contexto de aprendizagem organizacional que estimula $o$ desenvolvimento de novos conhecimentos, por meio da aprendizagem exploration e exploitation. Onde o de exploration implica em um comportamento da firma voltado à pesquisa, descoberta e experimentação; enquanto exploitation caracteriza-se pelo refinamento, escolha, produção, eficiência, seleção, implementação e execução a saber: 
Tabela 1 - Correlação das premissas exploration e exploitation e suas características

\begin{tabular}{|c|c|}
\hline \multicolumn{2}{|r|}{ Exploration } \\
\hline Pesquisa & Estudo de fatos com base em investigações visando novas descobertas cientificas. \\
\hline Descoberta & Conceber novo feito. \\
\hline Experimentação & $\begin{array}{l}\text { Testes por meio de pressupostos científicos. Abordagem pela qual a empresa } \\
\text { busca novas oportunidades e aprendizagem (DUBRIN, 2003). }\end{array}$ \\
\hline \multicolumn{2}{|r|}{ Exploitation } \\
\hline Refinamento & Aprimoramento de experiências anteriores. \\
\hline Escolha & Decisão entre determinadas opções. \\
\hline Produção & $\begin{array}{l}\text { Fenômeno econômico que consiste na atuação do Homem sobre a Natureza com o } \\
\text { objetivo de obter, através de um determinado processo produtivo, bens (incluindo } \\
\text { produtos e serviços) necessários para a satisfação das suas necessidades (NUNES, } \\
\text { 2017). }\end{array}$ \\
\hline Eficiência & Excelência na execução dessa atividade visando a obtenção de bons resultados. \\
\hline Seleção & $\begin{array}{l}\text { Recrutamento de pessoas tendo em vista um perfil profissional e a adequação do } \\
\text { indivíduo ao mesmo. }\end{array}$ \\
\hline Implementação & Aplicação de mudança ou modelo criado/existente. \\
\hline Execução & Colocar em prática ações anteriormente planejadas. \\
\hline
\end{tabular}

Fonte: Autoria própria

O conhecimento é gerido e há a descoberta de novos sistemas através de pesquisas (exploration) e a implementação de conhecimentos e manutenção dos mesmos (exploitation) em diversas gestões e automaticamente em suas organizações, seja no ensino, empreendendo, executando gerência, diretoria ou presidência em corporações e grandes instituições.

Assim, cada relato de caso de sucesso de empoderamento estará associado a um ou mais dessas variáveis de aprendizagem. A escolha das mulheres seguiu o critério de possuírem destaque na mídia e com exceção de Magareth Diniz, onde houve entrevista não estruturada, com a fala gravada, e depois transcrita, todas as outras biografias das outras mulheres foram captadas através de pesquisa bibliográfica ou jornalística, referenciada e de domínio público.

\section{DIFICULDADE NATURALIZADAS AO EMPODERAMENTO DE MULHERES}

Algumas profissões são associadas ao sexo masculino e em seu bojo de funcionamento trás uma dominação masculina pré-existente desde antes de consolidar profissões, ou seja, desde o ensino colegial.
Bourdieu (2007) explica esse estabelecimento de profissões masculinas e femininas quando argumenta expondo o funcionamento da divisão sexual do trabalho assim a ordem social funciona como uma imensa máquina simbólica que tende a ratificar a dominação masculina sobre a qual se alicerça: é a divisão social do trabalho.

Essa distribuição é bastante estrita das atividades atribuídas a cada um dos dois sexos, de seu local, seu momento, seus instrumentos; é a estrutura do espaço, opondo o lugar de assembleia ou de mercado, reservados aos homens, e a casa, reservada às mulheres; ou, no interior desta, entre a parte masculina, com o salão, e a parte feminina, com o estábulo, a água e os vegetais; é a estrutura do tempo, a jornada, o ano agrário, ou o ciclo de vida, com momentos de ruptura, masculinos, e longos períodos de gestação, femininos (BOURDIEU, 2007).

Logo, observamos que a dominação masculina perpetua o estabelecer de o cuidar ser destinado às mulheres e o trabalho aos homens, situação estabelecida por uma violência simbólica culturalmente construída, que reflete na dupla jornada de trabalho que mulheres enfrentam ao encarar uma profissão, pois além de profissional o cuidar da casa e 
do lar não deixam de ser prioridade da maioria das mulheres.

A desconstrução dos paradigmas préexistentes na atualidade parte do empoderar. O empoderamento feminino de acordo com a ONU mulheres busca a igualdade de gênero no âmbito político, social e econômico. Uma série de estudos da ONG americana Catalyst8, que desenvolve diferentes frentes de trabalho em prol da criação de ambientes de trabalho inclusivos para homens $e$ mulheres, aponta o impacto positivo que a presença de mulheres na alta liderança pode gerar nos resultados de negócios (ONU MULHERES, 2016).

A inserção da mulher no mercado de trabalho em grandes cargos de liderança necessita de competências e qualificação. Os dados do Censo da Educação Superior Brasileira de 2016, última edição do levantamento, revela que as mulheres representam $57,2 \%$ dos estudantes matriculados em cursos de graduação (INEP, 2018), buscando capacitação e conhecimento para prosperar no mercado de trabalho.

Uma das causas do empoderamento feminino e a busca de igualdade de gênero é a necessidade da equidade entre salários. Mulheres exercem o mesmo cargo que homens e ganham inferior, pesquisa do site Catho mostra que as maiores diferenças salariais se dão entre os profissionais de nível superior e com MBA - as mulheres ganham quase a metade do salário dos homens. O percentual é atenuado conforme a escolaridade vai diminuindo, mas o salário dos homens é superior em todos os níveis de escolaridade. Diz que essa diferença pode ser explicada pelo fato de as profissionais interromperem a vida profissional por causa da maternidade ou por mudarem de carreira e começarem do zero em outra com mais frequência que os homens. O levantamento mostra que quando as mulheres ocupam cargos de presidente e diretor recebem em média $32 \%$ a menos que os homens (CAVALLINI, 2018).

As dificuldades de salários desigual, dupla jornada de trabalho, "pré-conceitos" e diversas barreiras que mulheres enfrentam, demostram que essas violências simbólicas, necessitam da causa ao empoderamento e busca de direitos iguais em todas vertentes.
4 A APRENDIZAGEM ORGANIZACIONAL E O CONHECIMENTO COMO ALAVANCADORES DE EMPODERAMENTO

A gestão do conhecimento voltada ao empoderamento feminino dispõe de ferramentas que auxiliam e modificam modelos de administrar que é peça crucial em boas gestões para a obtenção de sucesso. A identificação dessas ferramentas em gestões bem-sucedidas faz assim valorizar as variáveis da GC e seu valor, pois auxilia no enfrentamento de possibilidades e desafios, as utilizando conscientemente o quanto antes para agregar valor ao seu ofício e instituição de trabalho.

Fator chave em uma organização, a aprendizagem e a gestão do conhecimento têm a capacidade de alavancar empoderamento, pois capacita e dispõe de segurança para os trabalhadores na execução de suas funções. A ascensão em cargos mais altos vem acompanhada de uma aprendizagem extensa e da detenção com excelência da gestão do conhecimento, automaticamente empoderando seu possuidor.

Dentro de uma instituição a sinergia que se cria em um grupo é fundamental para que a organização promova a aprendizagem individual, seguida da coletiva e, então, a aprendizagem organizacional, seja mais forte e duradoura (NAKATA, 2010). Em relação a gestão do conhecimento, a dinâmica da criação do conhecimento organizacional é um processo em espiral, que começa no nível individual e vai subindo, ampliando comunidades de interação que cruzam fronteiras entre seções, departamentos, divisões e organizações (NONAKA; TAKEUCHI, 1997).

Antonello (2005) descreve que a aprendizagem surge da tensão entre o novo e o velho conhecimento, e da transformação do conhecimento presente na memória de um indivíduo, preceitua que o entendimento da Aprendizagem Organizacional (AO) e a conexão com a gestão do conhecimento organizacional ainda não está esclarecida, especialmente porque, as teorias sobre $\mathrm{AO}$ não contemplam $O$ desenvolvimento do conhecimento como fator determinante para a aprendizagem. Nonaka e Takeuchi (1997) justifica o pensamento de Antonello ao diferenciar a aprendizagem da noção de conhecimento, ao afirmar que a aprendizagem está relacionada à apreensão 
de conhecimento tácito, conhecimento adquiridos através de experiências na prática.

Assim, o ato de conhecer e aprender nas organizações deve conectar -se aos seus objetivos, ou seja, tornar-se parte da gestão. Por esse motivo, detectar os melhores caminhos para o desenvolvimento de processos de disseminação e criação de conhecimento e aprendizagem encontra-se entre as prioridades das preocupações das organizações (AMORIM; FISCHER, 2013). Essas oportunidades e aprendizagem são ativos intangíveis correspondentes a uma grande competência na estratégia e sucesso de uma organização.

Atrelamos o conhecimento tácito a aprendizagem e a gestão do conhecimento o englobamento de gerir o conhecimento tácito associado ao explícito. A busca de novos conhecimentos é dada por pesquisas, experimentação, e assim descobertas, trazendo resultados a longo prazo (exploration) e por meio do uso do conhecimento que a empresa tem é aplicado o refinamento, escolha, produção, implementação, eficiência e seleção e execução obtendo resultados em curto prazo (exploitation). Portanto se uma organização tem um constante esforço para a aprendizagem, mediante uma capacitação e valorização de seu conhecimento interno, isso estaria um tanto relacionado com o processo. Mas, se além disso a organização está um tanto aberta para absorver o que acontece fora de seus domínios, ela estaria procurando a orientação em direção como no caso da utilização de pesquisas, experimentação e descobertas (POPADIUK, 2010).

Portanto, apenas através do investimento em pesquisas e desenvolvimento (inovação), ou aprimoramento de fatores e conhecimentos e compartilhamento que a pessoa ou empresa já possui é possível alavancar o empoderamento e formar grandes gestoras disparando em vantagem competitiva no mercado.

\section{AS MULHERES EMPODERADAS PELO CONHECIMENTO, SEGUNDO EXPLORATION E EXPLOITATION}

Na correlação dos artigos em estudo observase que na vertente evidenciada por March (1991); de desenvolver e reter o conhecimento nos desenvolvimentos de sete mulheres e suas profissões, que obtém ou já obtiveram destaque no expansão e aprimoramento de negócios, sendo atrelados como estudo as variáveis exploration e exploitation e suas dimensões, assim conhecendo a trajetória e contribuição de grandes mulheres a sociedade.

\subsection{EXPLORATION - USO DA PESQUISA, DESCOBERTA E EXPERIMENTAÇÃO:}

Maria Salomea Skłodowska: (Pesquisa, descoberta) mais conhecida por Marie Curie foi empoderada em uma época em que a ciência era dominada pelos homens. Ela fez uma revolução no meio científico ao ser a primeira pessoa e mulher a ganhar dois Prêmio Nobel (física e química). Sua maior contribuição foi a descoberta da radioatividade em sais de Urânio e de novos elementos químicos (Radio e Polônio, mesmo após o falecimento de seu companheiro Pierre Curie). No ensino superior enfrentou a primeira barreira ao nenhuma das instituições universitárias de Varsóvia aceitarem meninas na época (NOGUEIRA, 2018). Ensinou na Universidade de Sourbonne, onde obteve graduação em Física e Matemática. (CANAL CIENCIA, 2018).

Katherine Johnson: (Experimentação) Foi a primeira mulher negra a ser selecionada para fazer parte do curso de pós-graduação na West Virginia State University. Demartini (2017) conta que a afro-africana, elencou a equipe de "computadores humanos" da Nasa, onde fez os cálculos experimentais responsáveis pela primeira possibilidade de um astronauta norte-americano orbitasse a Terra. Calculou também a trajetória do Apolo 11 , foguete que levou o homem a lua pela primeira vez, em 1969. Ao saber que mulheres não podiam participar de reuniões, ela argumentou se havia uma lei contra isso. Como a resposta era não, ela passou a participar dos encontros. Também era praxe que só engenheiros assinassem a autoria de pesquisas e cálculos, mesmo que houvesse a colaboração de mulheres. Em 1960, Johnson se tornou a primeira mulher de sua divisão a receber crédito por um relatório de pesquisa. Ao longo de sua carreira, ela assinou 26 relatórios (MARISCIULO,2018). Johnson recebeu a Medalha Presidencial da Liberdade em 2015, a maior condecoração civil dos Estados Unidos pelas mãos do então presidente Barack Obama (DEMARTINI, 2017) 


\subsection{EXPLOITATION - REFINAMENTO, ESCOLHA, PRODUÇÃO, EFICIÊNCIA, SELEÇÃO, IMPLEMENTAÇÃO E EXECUÇÃO:}

Cristina Junqueira: (refinamento e escolha) Engenharia de produção, cursou MBA em finanças e marketing na Kellogg School of Management (Chicago). Ao voltar ao Brasil, foi a co-fundadora da startup Nubank, e a única mulher entre três sócios, o banco com o maior número de solicitações por cartões. De acordo com Prata (2017) a Nubank é uma fintech, nome dado às empresas de tecnologia com foco em serviços financeiros que trabalha com cartões de crédito, que de maneira revolucionaria, aprimorou os serviços de bancos via cartões, trazendo menos constrangimentos em esperas, sem taxa de anuidade e gerido pelo usuário através de um aplicativo no celular (DESIDÉRIO, 2018). Um dos maiores desafios do Nubank, tem sido em, como contratar os melhores, apelidados de "heróis", onde 300 a 400 funcionários falam com os clientes todos os dias. Precisou reinventar a maneira de atrair, contratar e selecionar essas pessoas implantando novo sistema de contratação, onde o candidato tira uma selfie, ajudando a entender mais o potencial funcionário. "Fomos criando etapas diferentes, que ninguém nunca tinha testado, mas nos ajudou demais a conferir se a pessoa tinha um fit cultural conosco ou não".

Claudia Sender: (Produção e eficiência) filha de pais médicos optou pela carreira de engenharia, tem MBA em Harvard, a ex presidente da LATAM e atual diretora executiva da holding Latam no Brasil, é a responsável pelo lançamento da marca Latam (GAZZONI, 2017). Acredita que baseado no seu histórico de resultados e estratégias a longo prazo que implementou durante sua carreira, possibilitou chegar a esse cargo, assim como a habilidade de trabalhar com tantas pessoas diferentes. Empodera-se visando o diferencial feminino no mercado para a tomada de decisões de empresas (BIGARELLI, 2014).

Margareth Diniz: (eficiência e seleção) nascida no interior da Paraíba, onde as oportunidades eram restritas, queria seguir a carreira da saúde, mas teria que mudar para conseguir estudar (1 $\underline{a}$ barreira a ser vencida) onde teve motivação familiar na mudança de cidade. Teve na busca do conhecimento a $2^{\text {a }}$ barreira quando terminou farmácia e medicina. Foi convidada para exercer cargo no governo do Estado, mas por ter foco na Universidade, sempre eficiente nos seus projetos, e seletiva nas escolhas, optou por ficar na UFPB quando decide trilhar por uma carreira docente (quando torna-se pesquisadora do CNPq e desenvolveu o Programa da Educação Tutorial na pósgraduação em Farmácia) e carreira política universitária assume a diretoria técnica do hospital universitário, depois a diretoria do centro da saúde por 8 anos, até chegar a ser a primeira reitora da Universidade UFPB, depois de 14 reitores homens. Nessa dupla carreira sofreu várias discriminações e barreiras pois assumiu cargos que anteriormente eram predominantemente masculinos, com homens mais velhos e que tinham tradição familiar, ainda mais, teve que conciliar a maternidade e amor a uma filha com necessidades especiais e a carreira.

Luiza Helena Trajano: (Implementação) Desde os 12 anos aproveitava as férias escolares para cuidar do balcão da loja de sua família. Mas, oficialmente, começou a trabalhar na rede de varejo somente aos 18 anos, na empresa dos tios, a partir daí, passou a conhecer todas as áreas da empresa até chegar ao topo do comando - onde está até hoje (ENDEAVOR, 2015). Fundadora do Magazine Luiza, e presidente é gestora de varejo, de pessoas, finanças e tecnologia (SIMPLIQUE RH, 2015). A empresa de venda de móveis, eletroeletrônicos, presentes, brinquedos, lazer, informática, Magazine Luiza, cresceu muito e tornou-se referência em gestão empresarial nacionalmente e internacionalmente quando Luiza Trajano implementou o e-commerce, impulsionando o desempenho da organização. A implementação do e-commerce como base a venda por meio de computadores e celulares, assim as vendas avançaram 30,6\% e somaram $R \$ 4,4$ bilhões. A adesão do aplicativo como meio de vendas e alcançou 10 milhões de downloads (ARROYO, 2018).

Paula Bellizia: (Execução) Angolana e filha de país portugueses, formada em tecnologia da informação, já trabalhou no Facebook e Apple mas atualmente é a presidente da Microsoft brasileira. Ao assumir o comando da Microsoft como presidente, executou o conceito de Growth Mindset: não sabemos tudo e podemos aprender sempre, todo os dias (MAKHLOUF, 2017) que é um dos lemas da empresa, ainda não desenvolvido na filial brasileira até então. Luta pelo empoderamento na sua empresa, engajada para criar uma companhia que busca a representação de 50\% homens e 50\% 
mulheres. Enxerga como a inserção da mulher nessa área como representação social que é um diferencial competitivo e uma questão de negócios, pois diversidade gera inovação (IDEIA SUSTENTAVEL, 2016).

\section{CONCLUSÃO}

Marie Curie, Katherine Johnson, Cristina Junqueira, Claudia Sender, Margareth Diniz, Luiza Helena Trajano e Paula Bellizia serviram como exemplo de mulheres empoderadas e conseguiram tal feito através de determinação, oportunidades não descartadas, foco, dedicação, lutas e com certeza sofreram constrangimentos, discriminações que nem conseguimos avaliar.

Entretanto, através das variáveis propostas por March(1991) exploration e exploitation que se subdividem em pesquisa, descoberta e experimentação; e refinamento, escolha, produção, eficiência, seleção, implementação

\section{REFERÊNCIAS}

[1] ANTONELLO, Claudia S. A metamorfose da aprendizagem organizacional. In: RUAS, R.; ANTONELLO, C. S.; BOFF, L. H. (Org.). Os novos horizontes da gestão: aprendizagem organizacional e competências. Porto Alegre: Bookman, 2005.

[2] ARROYO, Priscilla. E-commerce impulsiona desempenho do Magazine Luiza. Disponível em:< https://www.istoedinheiro.com.br/e-commerceimpulsiona-desempenho-do-magazine-luiza/> Acesso em: 18 de abril de 2018.

[3] BOURDIEU, P. A dominação masculina. Tradução Maria Helena Kühner. 5. ed. Rio de Janeiro: Bertrand Brasil, 2007.

[4] BIGARELLI, Barbara. Como Claudia Sender, presidente da TAM, chegou lá. Disponível em:

https://epocanegocios.globo.com/Inspiracao/Vida/n oticia/2014/08/como-claudia-sender-presidente-datam-chegou-la.html>. Acesso em: 12 de maio de 2018 .

[5] CANAL CIENCIA. Marie Curie: vida, obra e descobertas. Disponível em: $<$ http://www.canalciencia.ibict.br/personalidades_ci encia/Marie_Curie.html> Acesso em: 02 de maio de 2018

[6] CAVALLINI, Marta. Mulheres ganham menos que os homens em todos os cargos e áreas, diz pesquisa. Disponível em: $<$ https://g1.globo.com/economia/concursos-e- e execução respectivamente, foi possível tatear aonde cada uma conseguiu sair de uma condição discriminante para uma mulher empoderada, ainda que a tentativa foi classificar uma mulher a apenas uma ou duas vertentes, quando se sabe que, na prática elas tiveram que caminhar em todas vertentes.

Portanto o conhecimento, aprendizagem e gestão são primordiais e talvez o principal canal para a ascensão de mulheres à gerência, diretoria, reitoria, presidência, desenvolvimento de grandes empresas e destaque na história através de grandes contribuições.

A exploração das ferramentas organizacionais: exploration e exploitation observou-se que podem ser utilizadas independentes, porém é mister que o uso de todas em conjunto refletirá em melhores resultados e excelência organizacional, fruto de trabalhos futuros.

emprego/noticia/mulheres-ganham-menos-que-oshomens-em-todos-os-cargos-e-areas-dizpesquisa.ghtml> Acesso em: 02 de maio de 2018.

[7] DESIDÉRIO, Mariana. Nubank é eleito a $3^{\text {a }}$ empresa mais inovadora da América Latina. Disponível em: <https://exame.abril.com.br/negocios/nubank-eeleito-a-3a-empresa-mais-inovadora-da-americalatina/> Acesso em: 02 de maio de 2018.

[8] DUBRIN, Andrew J. Fundamentos do comportamento organizacional. São Paulo: Pioneira Thomson Learning, 2003

[9] ENDEAVOR. Conheça um pouco mais sobre Luiza Helena Trajano, a grande mulher por trás da gestão do Magazine Luiza e duas grandes lições de empreendedorismo. Disponível em <https://endeavor.org.br/luiza-helena-trajano/>. Acesso em: 18 de abril de 2018.

[10] EPOCA NEGOCIOS. Conheça a história do fundador do Ikea, que faleceu neste domingo. Disponível

em:<https://epocanegocios.globo.com/Dinheiro/not icia/2018/01/conheca-historia-do-fundador-do-ikeaque-faleceu-neste-domingo.html> Acesso em: 01 de maio de 2018.

[11] AMORIM, Wilson Aparecido Costa de; FISCHER, André Luiz. A aprendizagem organizacional e suas bases econômicas. Nova econ., Belo Horizonte, v. 23, n. 2, ago. 2013. Disponível em $<$ http://www.scielo.br/scielo.php?script=sci_arttext 
\&pid=S0103-

$63512013000200004 \& \mathrm{lng}=p t \& n r m=i s o>$. Acesso em: 18 de abril de 2018.

[12] IDEIA SUSTENTAVEL. Paula Bellizia Microsoft. Disponível em: <http://www.ideiasustentavel.com.br/paula-belliziamicrosoft/>. Acesso em 15 de maio de 2018.

[13] INEP. Mulheres são maioria na Educação Superior brasileira. Disponível em: $<$ http://portal.inep.gov.br/artigo/-

/asset_publisher/B4AQV9zFY7Bv/content/mulheressao-maioria-na-educacao-superior-

brasileira/21206 > . Acesso em: 02 de maio de 2018

[14] FONSECA, Mariana. O desafio que tira o sono de Cristina Junqueira, do Nubank. Disponível em:<https://exame.abril.com.br/pme/o-desafio-quetira-o-sono-de-cristina-junqueira-donubank/>Acesso em: 02 de maio de 2018.

[15] GAZZONI, Marina. Claudia Sender deixa presidência da Latam Brasil e assume aérea de cliente do grupo. Disponível em: <https://g1.globo.com/economia/negocios/noticia/c laudia-sender-deixa-presidencia-da-latam-brasil-eassume-aerea-de-cliente-do-grupo.ghtml>. Acesso em: 02 de maio de 2018.

[16] MARCH, J. G. Exploration and exploitation in organizational learning. Organizational Science, v.2, n.1, February, p.71-87, 1991.

[17] MAKHLOUF, Alexandre. Na Real: Paula Bellizia, CEO da Microsoft Brasil, fala sobre carreira e representatividade feminina. Disponível em: < https://revistaglamour.globo.com/Lifestyle/Carreirae-dinheiro/noticia/2017/06/na-real-paula-belliziaceo-da-microsoft-brasil-fala-sobre-carreira-erepresentatividade-feminina.html >. Acesso em: 02 de maio de 2018.

[18] MARISCIULO, Marilia. KATHERINE JOHNSON: 5 LIÇÕES INSPIRADORAS QUE APRENDEMOS COM A MATEMÁTICA. Disponível em:

$<$ https://revistagalileu.globo.com/Ciencia/noticia/20 18/03/katherine-johnson-5-licoes-inspiradoras-queaprendemos-com-matematica.html>. Acesso em: 12 de maio de 2018.
[19] NAKATA, L. E. As expectativas de aprendizagem nas organizações atuantes no Brasil. In: ENCONTRO DA ASSOCIAÇÃO NACIONAL DE PÓS-GRADUAÇÃO E PESQUISA EM ADMINISTRAÇÃO, 34., 2010. Rio de Janeiro. Anais... Rio de Janeiro: Anpad, 2010.

[20] NOGUEIRA, Salvador 2018. Marie Curie, a polonesa mais brilhante da história. Disponível em: $<$ https://super.abril.com.br/historia/marie-curie-apolonesa-mais-brilhante-do-mundo/>. Acesso em: 12 de maio de 2018.

[21] NONAKA, Ikujiro e TAKEUCHI, Hirotaka. Criação do Conhecimento na Empresa: como as empresas geram a dinâmica da inovação. Rio de Janeiro: Campus, 1997.

[22] NUNES, Paulo. Produção. Disponível em: $<$ http://knoow.net/cienceconempr/economia/produ cao/> Acesso em: 12 de maio de 2018.

[23] ONU MULHERES. PRINCÍPIOS DE EMPODERAMENTO DAS MULHERES. Disponível em: < www.onumulheres.org.br/wpcontent/uploads/2016/04/cartilha_WEPs_2016.pdf> . Acesso em 12 de abril de 2018.

[24] POPADIUK, Silvio. Escala de Orientação para Exploration-Exploitation do Conhecimento em Empresas Brasileiras. In: XXXXIV ENCONTRO DA ANPAD, 2010, Rio de Janeiro. Anais... Rio de Janeiro: Rio de Janeiro, 2010.

[25] PRATA, Maria. Vogue Business: conheça a empresária Cristina Junqueira, da Nubank. Disponível em: <https://vogue.globo.com/lifestyle/noticia/2017/01/v ogue-business-conheca-empresaria-cristinajunqueira-da-nubank.html>. Acesso em: 12 de maio de 2018

[26] SIMPLIFIQUE RH. Uma rápida lição de Gestão de Pessoas com Luiza Helena Trajano. Disponível <http://simplifiquerh.com.br/2015/05/11/umarapida-licao-de-gestao-de-pessoas-com-luizahelena-trajano/>. Acesso em: 18 de abril de 2018. 


$$
\text { Alutary }
$$




\section{ADONILDO MARQUES DA SILVA NETO}

Engenheiro de Produção pela Universidade Federal da Paraíba (2018). Graduação Sanduíche pela Gábor Dénes Főiskola (Hungria, 2014-2015). Atuação em Gestão de Projetos e Planejamento Estratégico no setor de Tecnologia da Informação em uma empresa de Desenvolvimento de Software.

\section{ADRIANA BARBOSA SANTOS}

Graduada e Mestre em Estatística pela Unicamp, Doutora em Engenharia de Produção pela UFSCar. Docente da Universidade Estadual Paulista "Júlio de Mesquita Filho" (UNESP), onde ministra disciplinas de Probabilidade e Inferência Estatística para cursos de graduação e Métodos Estatísticos para cursos de Pós graduação. Desenvolve projetos de pesquisa relacionados ao uso da abordagem estatística na gestão da qualidade. Tem experiência em assessoria estatística e orientação de pesquisadores de diversas áreas na aplicação de métodos estatísticos voltados ao planejamento de experimentos, pesquisas de opinião, planos de amostragem e, sobretudo, análise de dados.

\section{AIQUINIS KELLEN ROSALIS FANTUCE}

Graduada em Administração no Centro Universitário Central Paulista (2018)

\section{ALISSON MARCELO LAURINDO}

Doutorando em Engenharia de Produção e sistemas (PUCPR), Mestre em Engenharia de Produção (UFPR), MBA em planejamento e gestão de negócios pela FAE Business School, especialista em gerenciamento de projetos (PUC Minas) e graduação em Administração de Empresas pela Universidade Positivo (UP). Possui diversos cursos realizados nas áreas de Projetos, projetos de inovação tecnológica, Inovação e criatividade, Processos, análise de dados, estratégias, propriedade intelectual e marketing com experiência de 12 anos nestes temas. Atualmente trabalha com tecnologia e inovaçãoe presta serviços para modelagem de negócios e projetos (metalmecanica, gestão, logística, alimentos, celulose e papel e química).

\section{ANA CAROLINA KIENER}

Possui Graduação em Engenharia de Produção pela Universidade de Sorocaba (2018). Atualmente é Micro Empreendedor Individual.

\section{ANA CAROLINA LUCENA CHRISTIANO}

É Mestre em Engenharia de Produção pela Universidade Federal da Paraíba (UFPB) (2014), Especialista em Gestão e Política Ambiental pela Universidade Federal Rural de Pernambuco (UFRPE) (2011) e possui Graduação em Engenharia de Produção Mecânica pela Universidade Federal da Paraíba (UFPB) (2007). É Professora do Magistério Superior, em regime de dedicação exclusiva, no Curso de Engenharia de Produção, Campus Arapiraca, Unidade Educacional Penedo/Alagoas, da Universidade Federal de Alagoas (UFAL). Atualmente é Coordenadora do Curso de Engenharia de Produção, Coordenadora do Colegiado do Curso de Engenharia de Produção, Membro do Núcleo Docente Estruturante do Curso e participa de Comissões relacionadas à Unidade Penedo, bem como ao Campus Arapiraca.

\section{ANA LAURA DOS REIS}

Graduada em Engenharia Civil pela Universidade José do Rosário Vellano (2018). Desenvolve pesquisas na área de ergonômica associando este fator a produtividade. 


\section{ANA REGINA DE AGUIAR DUTRA}

Possui graduação em Matemática, mestrado e doutorado em Engenharia de Produção pela Universidade Federal de Santa Catarina. Doutorado na área de concentração em "Ergonomia". Atualmente é professor titular da Universidade do Sul de Santa Catarina. Tem experiência na área de Engenharia de Produção, com ênfase em Ergonomia, atuando principalmente nos seguintes temas: ergonomia, produtos e processos produtivos sustentáveis e saudáveis e educação. Faz parte dos quadros docentes dos Cursos de Graduação: Engenharia de Produção, Bacharelado em Matemática, Tecnólogo em Gestão da Produção Industria, Tecnólogo em Gestão de Recursos Humanos, da Pós-graduação lato sensu em Engenharia de Segurança do Trabalho e do Mestrado em Ciências Ambientais (PPGCA/UNISUL).

\section{ANA RITA GALLO}

Graduada em Ciências Sociais pela Universidade Federal de São Carlos (1995), mestre em Engenharia de Produção pela Escola de Engenharia de São Carlos - Usp (1999) e doutora em Engenharia de Produção pela Universidade Federal de São Carlos (2003). Em 2008 concluiu sua segunda graduação em Administração no Centro Universitário Central Paulista (UNICEP). Atualmente é professora titular do Centro Universitário Central Paulista e responsável pela Coordenação do CST em Gestão de Recursos Humanos desde o início de 2014. Tem experiência na área de Administração, principalmente nas seguintes disciplinas: Gestão de Pessoas, Metodologia Científica, Trabalho de Conclusão de Curso e Projeto Multidisciplinar Integrado. Atua na Comissão ENADE do Centro Universitário Central Paulista. (Fonte: Currículo Lattes)

\section{ANDERSON CASTAGNA}

Atua na área de Engenharia de Produção, com ênfase na Gestão de Projetos voltados a melhorias nos Sistemas Produtivos, Supply Chain, Planejamento e Controle de Produção (PCP) e Logística. Graduado em Engenharia de Produção pela Faculdade Empresarial de Chapecó - UCEFF (2018).

\section{ANDERSON COSTA}

Graduando em Engenharia de Produção pela Universidade Federal de Alagoas, Técnico em Informática, ex membro do CA onde exercia o cargo de diretor de esportes e membro atual da primeira empresa júnior do curso de Engenharia de Produção onde exerce o cargo de diretor de finanças. Se interessa pelas áreas de Pesquisa Operacional e Engenharia de Métodos.

\section{ANDRÉ DE LIMA}

Atualmente Professor Titular na Escola de Engenharia de Piracicaba - EEP, nos cursos de Administração, Engenharia Mecânica, Engenharia Mecatrônica e Engenharia de Produção e neste ultimo ocupa desde 2014 o cargo de Coordenador do Curso, Coordenador da Equipe EEP Baja SAE/Brasil desde de 2014; Professor Titular da FATEC Piracicaba e Fatec Americana das disciplinas de Logística e Tecnologia de Transportes; Professor dos cursos de Engenharia Mecânica e de Produção das Faculdades Integradas Einstein de Limeira - FIEL. Membro do corpo de avaliadores do INEP-MEC e do CEE. Formação de Engenharia de Produção Mecânica pela Universidade Metodista de Piracicaba (1999), com Mestrado e Doutorado em Engenharia de Produção pelo PPGEP-UNIMEP (2002 e 2008); Experiência docente desde 2001 em Gestão da Produção, Lean Manufacturing, PCP, 6 Sigma, Gestão de Materiais, Pesquisa Operacional e Logística. Experiência acadêmica tecnológica na área de Engenharia de Materiais e Metalúrgica, com ênfase em Usinagem, atuando principalmente nos seguintes temas: Integridade Superficial, Camada Afetada pelo Calor (CAC), Análise de Imagens, Dry Cutting e HSM. 


\section{CAMILLA HENRIQUE DE ARAÚJO}

Engenheira de Produção pela Universidade Federal da Paraíba (2018). Graduação Sanduíche em BSc Mechanical Engineering pela Kingston University (Reino Unido, 20142015). Atuação em Gestão de Projetos e Gestão de Consultorias no setor de Tecnologia da Informação numa empresa de varejo.

\section{CARLOS FRANCISCO SIMÕES GOMES}

Foi gerente de projetos, pesquisador no Centro de Análises de Sistemas Navais (CASNAV) de 1997 a 2007 (trabalhando durante 10 anos atividades de desenvolvimento tecnológico, nas áreas de TI, software, usabilidade interface entre outros), em 2007 foi Chefe do Departamento de Engenharia de Sistemas do, CASNAV. Posteriormente Vice-Diretor deste Centro (última função que assumiu) até 2008, quando se desligou do serviço ativo da Marinha. Tem experiência na área de Administraçãolnformação (TI) e Arquitetura da Informação, com ênfase em Gestão de Risco, atuando principalmente em Decisão Multicritério, Pesquisa Operacional e Engenharia de Produção. Foi vice-presidente da Sociedade Brasileira de Pesquisa Operacional de 2006 até 2012, exerceu anteriormente por Quatro anos a função de Diretor Tesoureiro. Ocupa a função de professor Associado da Universidade Federal Fluminense. Foi professor horista do Ibmec (oito anos) e da Universidade Veiga de Almeida (13 anos). Foi coordenador do MBA de Governança e Tecnologia da Informação, e da Graduação de Gestão do INFNET de Janeiro a Outubro de 2010. Participou de 125 bancas de conclusão de Graduação, Mestrado, Doutorado e Exame de Qualificação para Mestrado ou Doutorado. Participou de 110 congressos e/ou simpósios, eventos nacionais e/ou internacionais. Possui 98 artigos publicados em periódicos nacionais e internacionais, e 220 artigos publicados em congressos, simpósios, eventos nacionais e internacionais. Orientou 39 monografias de graduação, 25 dissertações de mestrado, e três monografias de especialização/aperfeiçoamento e três Teses de Doutorado e um PBIC. Autor dos Livros Gestão da Cadeia de Suprimentos Integrada à Tecnologia da Informação, pela Editora CENGAGE LEARNING, (segunda Edição em 2014); e Tomada de Decisão Gerencial Enfoque Multicritério (quinta Edição em 2014); pela Editora Atlas; BIG DATA um Panorama Global Através de Análise da Literatura e Survey; e Liderança Aplicada a Gerencia de Projetos de Tecnologia da Informação, ambos pela Editora Prismas. Participou como membro da delegação brasileira junto a International Maritime Organization (orgão da ONU para Oceanos com sede em Londres) nas negociações do acordo de Água de Lastro e Casco Duplo, sendo em ambas as reuniões autor do trabalho que balizou a posição brasileira. É revisor técnico dos periódicos: European Journal of Operational Research (EJOR); Pesquisa Operacional; Gestão e Produção; Revista Produção; Brazilian Journal of Operations and Production Management, Annals of Operations Research e Engevista. Atua na área de Logística, Gerenciamento de Projetos, Sistemas de Informação com foco em Acessibilidade e Usabilidade, Análise de Decisões, Métodos Analíticos aplicados à solução de problemas empresariais Brasileiros e Planejamento Estratégico com uso de TI. Foi professor/palestrante de cursos de pós-graduação nas instituições UFRJ, UFPE, Candido Mendes, Uff - Volta Redonda, UVA e FGV. Foi palestrante na Escola de Guerra Naval e Escola Superior de Guerra.

\section{CAROLINA BARBOSA GOMES}

Graduanda em Engenharia de Alimentos pela Universidade Estadual Paulista "Júlio de Mesquita Filho" (UNESP), realiza iniciação científica no Departamento de Ciências da Computação e Estatística (DCCE). No projeto desenvolvido, utiliza conhecimentos de pensamento estatístico e pesquisa de marketing para compreender o mercado de cervejarias artesanais e as dificuldades dos empreendedores da área. Os conhecimentos de gestão desenvolvidos na iniciação são aplicados na empresa júnior, onde trabalha com administração, gestão de pessoas e planejamento estratégico. 


\section{CÁSSIA GARCIA RENÓ}

Possui graduação em Engenharia de Produção pela Universidade de Sorocaba (2018). Tem experiência na área de Engenharia de Produção, com ênfase em Supply Chain, PCP, Qualidade e Desenvolvimento de Produto na área de confecção e em áreas correlatas.

\section{CINTIA CASTELO BRANCO}

Graduanda em Engenharia de Produção Civil pelo Instituto Federal do Ceará. Trabalhou na Companhia de Água e Esgoto do Ceará (Cagece) no programa Jovem Aprendiz - Trabalhou na Morefácil Construtora e Incorporadora - Ltda no programa Jovem Aprendiz.

\section{CLEUSA TERESINHA ANSCHAU}

Economista; especialista em Gestão do Agronegócio e Mestre em Ciências Ambientais (foco em economia ecológica), atua no docência nos cursos de Engenharia de Produção, Administração, Ciências Contábeis e Engenharia Civil. Com as disciplinas de Economia, Engenharia econômica e Finanças; Avaliação de projetos de Investimentos. Membro integrante do Corpo Editorial da Revista Tecnológica da UCEFF e Coordenadora do Comitê de Ética da UCEFF.

\section{DAVIDSON DE ALMEIDA SANTOS}

Doutorando em Engenharia de Produção na Universidade Federal Fluminense, possui mestrado em Engenharia de Produção (área de Concentração; Sistemas de Apoio a Decisão e Logística) pela Universidade Federal Fluminense, MBA em logística empresarial (Ênfase em Gestão de Cadeia de Suprimentos) pela Universidade Federal Fluminense e graduação em Administração com ênfase em Logística pela Universidade Federal do Rio de Janeiro. Experiência profissional em empresas multinacionais como a Ambev; SHV GAS Brasil (Supergasbrás) e Loreal Brasil, tendo atuado nas áreas de administração com ênfase em Supply Chain Management, análise de indicadores de produtividade logística, softwares de roteamento, modelos econométricos aplicados à distribuição urbana/previsão de vendas, administração da produção e de material e pesquisa Operacional aplicada à Logística. Atualmente é docente, ministrando disciplinas nas áreas de administração geral, engenharia de produção e logística / operações para a graduação e pós-graduação.

\section{DELLANO JATOBÁ BEZERRA TINOCO}

Engenheiro de Produção com carreira desenvolvida em Gestão de Projetos, certificação PMP, com ampla experiência na gestão de plantas/processos industriais e gerenciamento de projetos, tendo atuado em multinacionais nos estados do Rio Grande do Norte, Amazonas e Rio Grande do Sul. Atuação como palestrante e professor pela UFERSA, UNP e SENAI. Profissional com habilidade de planejar e mobilizar recursos em prol de um objetivo comum, potencializando a criatividade, a inovação e a velocidade de entregas e principais soft skills desenvolvidas.

\section{DÉLVIO VENANZI}

Possui graduação em Engenharia Elétrica pela Universidade de Mogi das Cruzes (1986), Mestrado em Administração de Empresas pelo Centro Universitário Santana (2000), Mestrado em Engenharia de Produção pela Universidade Estadual Paulista Júlio de Mesquita Filho (2009) e Doutorado em Educação pela Universidade de Sorocaba (2016). Atualmente é Professor Titular da Faculdade de Tecnologia de Sorocaba-Logística, Professor visitante da Faculdade de Tecnologia de Piracicaba (Latu Sensu). Tem experiência na área de Engenharia de Produção, com ênfase em Engenharia de Produção, atuando principalmente nos seguintes temas: Supply Chain, Estratégia de Manufatura, PCP, Modelos de Condomínios e Consórcio Modular na Indústria Automobilística. 


\section{EDUARDO LOURES}

Professor Titular vinculado ao curso de Engenharia de Controle e Automação e Engenharia de Produção da Escola Politécnica da Pontifícia Universidade Católica do Paraná - PUCPR. Atualmente é pesquisador permanente do Programa de Pós-Graduação em Engenharia de Produção e Sistemas PPGEPS, PUCPR. Diretor da ISA (International Society of Automation), Distrito 4 América do Sul, Seção Curitiba. Bolsista de Produtividade Desenvolvimento Tecnológico e Extensão Inovadora do CNPq. Coordenador de diferentes projetos PD\&I com iniciativa privada e pública em temáticas como a Indústria 4.0, Gerenciamento de Ativos e Manutenção, Interoperabilidade e Engenharia Organizacional.

\section{ERICK CARDOSO COSTA}

Possui graduação em Engenharia de Produção ênfase Mecânica pela Universidade Federal do Amazonas (2016). Mestrando em Engenharia Mecânica na área de Fabricação pela Universidade Federal de Santa Catarina. Tem experiência na área de Projeto Mecânico e Automação, Usinagem de Materiais Frágeis e Análise de Superfícies Usinadas.

\section{FRANCISCO RENNAN MOTA UCHOA}

Graduando em Engenharia de Produção Civil no Instituto Federal do Ceará (IFCE). Graduado em Publicidade e Propaganda pela Universidade Federal do Ceará (UFC), pesquisador nas áreas de Gestão de Produção, Marketing, Construção civil e Comportamento do Consumidor. Participou do programa de extensão Enactus que versa sobre empreendedorismo social e atuou em agências de publicidade na área de marketing.

\section{GABRIELA MORAES SIMÕES EVANGELISTA}

Graduanda em Engenharia de Produção pelas Faculdades Integradas Einstein de Limeira

\section{GERÔNIMO GUERREIRO NETO}

Engenheiro Agrônomo (1992), pela Faculdade de Engenharia de Ilha Solteira (Unesp) Experiência de trabalho em Cooperativas Agrícolas e Empresas de Alimentos ( Suco de Laranja). Mestrando em Administração de FCAVJ (Unesp)

\section{GILBERTO MILLER DEVÓS GANGA}

Professor Associado no Departamento de Engenharia de Produção da Universidade Federal de São Carlos (UFScar). Possui Mestrado e Doutorado em Engenharia de Produção pela Escola de Engenharia de São Carlos (EESC), Universidade de São Paulo (USP). Professor Ganga tem publicado artigos em periódicos com seletiva política editorial como, por exemplo, International Journal of Production Economics, International Journal Production Research, Journal of Cleaner Production e Quality and Reliability Engineering International.

\section{GLAUCO HENRIQUE DE SOUSA MENDES}

Possui graduação em Administração pela Universidade Estadual Paulista Júlio de Mesquita Filho (1994), mestrado em Engenharia de Produção pela Universidade Federal de São Carlos (1999) e Doutorado em Engenharia de Produção pela Universidade Federal de São Carlos (2008). Realizou pós-doutorados na Universidade de São Paulo (2015) e na Denmark Technical University - DTU (2016) . É professor do Departamento de Engenharia de Produção da Universidade Federal de São Carlos. É docente permanente do Programa de PósGraduação em Engenharia de Produção (PPGEP - UFSCar) e do Mestrado Profissional em Gestão de Organizações Públicas (PPGOSP - UFSCar). Coordenador do Grupo de Pesquisa e Estudo em Serviços (GEPS). 


\section{HAROLDO LHOU HASEGAWA}

Possui graduação em Engenharia de Materiais pela Universidade Federal de São Carlos (2000), Mestrado em Ciência e Engenharia dos Materiais pela Universidade Federal de São Carlos (2004) e Doutorado em Programa de Pós Graduação em Ciência e Engenharia de Materiais pela Universidade Federal de São Carlos (2007) também é especialista em Engenharia de Produção pelo Curso de Especialização em Engenharia de Produção pela UNESP (2010). Atualmente é professor adjunto-Aa da Universidade Federal de Itajubá.

\section{IRLANDA MAYRA MEDEIROS FEMININO SILVA}

Graduanda em Engenharia de Produção, pela Universidade Federal da Paraíba. Pesquisadora pelo CNPq - Conselho Nacional de Desenvolvimento Científico e Tecnológico. Competências em gestão do conhecimento, aprendizagem organizacional e gestão de projetos. Em andamento com os projetos intitulados de: Análise da diferença da produtividade de homens e de mulheres sob excesso de calor em um abatedouro de frangos pelo PIBIC eTIPOS DE VIOLÊNCIA CONTRA MULHER: (da simbólica à física, qual machuca mais?): Uma análise em escolas de nível médio na Paraíba e Pernambuco) pelo PROBEX.

\section{ISIS DA SILVA VIEIRA}

Formada em Técnico em eletrotécnica pelo Instituto Federal de Educação Ciência e Tecnologia do Ceará - IFCE. Graduanda em Engenharia de Produção mecânica pela Universidade Regional do Cariri - URCA

\section{ISYDORIO ALVES DONATO}

Engenheiro de Produção pela Universidade Regional do Cariri - URCA. Mestre em Engenharia de Software pelo Centro de Estudos e Sistemas Avançados do Recife - CESAR. Professor Efetivo do Departamento de Engenharia de Produção - URCA

\section{IVAN CORRER}

Formado em Engenharia de Controle e Automação pela Universidade Metodista de Piracicaba (2004), Mestrado em Gerência da Produção pela Universidade Metodista de Piracicaba (2006), Doutorando em Gerência da Produção pela Universidade Metodista de Piracicaba (desde 2017). Atualmente é sócio/proprietário da empresa GeoTecno Soluções em Automação. Tem experiência na área de Engenharia de Produção, Engenharia de Controle e Automação e Gestão Empresarial, com ênfase em Automação da Manufatura, Gestão da Produção, Administração, atuando principalmente nos seguintes temas: P\&D de Novos Produtos, Controle de Processos, Controle da Produção, Sistemas de Monitoramento, Redução de tempos de Setup.

\section{IVETE DE FÁTIMA ROSSATO}

Possui graduação em Engenharia Química pela Universidade Federal de Santa Maria (1993), graduação em Química Licenciatura pela Universidade Federal de Santa Maria (1987), mestrado em Engenharia de Produção pela Universidade Federal de Santa Catarina (1996) e doutorado em Engenharia de Produção pela Universidade Federal de Santa Catarina (2002). Atualmente é professor titular da Universidade do Sul de Santa Catarina e Coordenadora do curso de Engenharia Química, Gestão da Produção Industrial (UnisulVirtual) e coordenadora do curso Logística. Tem experiência na área de Engenharia de Produção e Engenharia Ambiental, com ênfase nos seguintes temas: Gerenciamento de Processo, Gestão Ambiental, Educação Ambiental , ISO 14000 e Analise do Ciclo de Vida -ACV. 


\section{JORGE ALBERTO ACHCAR}

Possui graduação em matemática pela UNESP em 1971, mestrado em estatistica pelo IMEUSP, Sao Paulo em 1976, doutorado (PhD) em estatística pela Universidade de WisconsinMadison - Estados Unidos em 1982.Professor livre-docente pelo ICMC-USP em 1990. Possui pos-doutorado pelas Universidades de Nottingham,Inglaterra; de Connecticut,EUA e Carnegie-Mellon, EUA. Professor visitante em diversas universidades brasileiras e estrangeiras.Atua como docente na UNESP, UFSCAR e USP desde 1974 na área de estatistica.

\section{JORGE HENRIQUE DE OLIVEIRA SILVA}

Possui Mestrado em Gestão de Organizações e Sistemas Públicos pela Universidade Federal de São Carlos (2017) e Bacharelado em Administração Pública pela Universidade Estadual Paulista (2014). É doutorando em Engenharia de Produção pela Universidade Federal de São Carlos e pesquisador do Grupo de Estudo e Pesquisa em Serviços (GEPS).

\section{JOSILENE AIRES}

Especialista em Redes de Computadores pela UFPB (1998), Mestre em Redes de Computadores e Sistemas Distribuídos pela Universidade Federal de Campina Grande (2003) e Doutora em Redes de Computadores e Sistemas Distribuídos pela Universidade Federal de Pernambuco (2011), conceito 6 da CAPES. Atua como professora adjunta e pesquisadora na Universidade Federal da Paraíba, onde coordena projetos de Pesquisa e Extensão em Gênero na Ciência e Tecnologia, com foco na Ciência da Computação

\section{JULIANO MAZUTE}

Professor das Engenharias da Universidade do Sul de SC (UNISUL), conselheiro do comitê de Engenharia Mecânica e Industrial do CREA-SC, com mestrado em Engenharia Mecânica (2014) pela Universidade Federal de Santa Catarina (UFSC), na área de projeto de sistemas mecânicos, com ênfase no Desenvolvimento de produtos e graduação em Engenharia mecânica pela Universidade de Passo Fundo (2009), além de Técnico em Eletromecânica pelo SENAI (2003). Apaixonado pelo desenvolvimento sistêmico de produtos, sempre esteve envolvido profissionalmente com Inovação tecnológica e mercadológica, tendo atuado em Multinacional, Instituto de Inovação, laboratórios de pesquisas e empresas Nascentes. Com cursos em Marketing, Design Estratégico e Governança de Startups.

\section{LAÍS GABRIEL LEANDRO MARILENE SOUZA GABRIEL}

Graduada em Engenharia de Produção pela Universidade do Sul de Santa Catarina (UNISUL) e Técnica em Plástico pela Instituição SATC. 11 anos de experiência na área de qualidade, com forte atuação em todos os seus aspectos, como: gestão da qualidade, mapeamento de processos, auditorias, desenvolvimento de fornecedores, implementação de programas de qualidade, BPF, normas ISO 9001 e 22716 ,e treinamentos.

\section{LAÍSA CRISTINA CARVALHO}

Possui graduação em Engenharia Civil pela Universidade Estadual de Minas Gerais (2013), mestrado em Estruturas e Construção Civil pela Universidade Federal de São Carlos (2016) e doutoranda em Estruturas e Construção Civil pela Universidade Federal de São Carlos. Desenvolve pesquisas relativas ao esforço despendido pelos trabalhadores nas diversas tarefas da construção civil. Atuando principalmente nos seguintes temas: ergonomia, produtividade e gestão do canteiro de obras. Coordenadora e Professora do curso de Engenharia Civil EaD do Centro Universitário do Sul de Minas - Minas. 


\section{LAURA KEIKO ARIMITSU}

Graduanda em Engenharia de Produção pelas Faculdades Integradas Einstein de Limeira

\section{LEONARDO REZENDE MARTINS}

Agrônomo pela Universidade Federal Rural do Rio de Janeiro (2005) e Mestrando pela UNESP Jaboticabal (previsto 2019). Atualmente é consultor de risco rural e agrônomo da Prefeitura Municipal de Frutal (MG)

\section{LETÍCIA SAGGIORATTO}

Graduanda em Engenharia de Alimentos pela Universidade Estadual Paulista "Júlio de Mesquita Filho" (UNESP), onde realizou iniciação científica no Departamento de Ciências da Computação e Estatística (DCCE). Nessa iniciação foi possível aprofundar os conhecimentos relacionados a estatística e condução de um projeto baseado em survey. Possui conhecimento na metodologia Seis Sigma e no uso de Excel para a realização de análise de dados e planejamento e condução de projetos. Esses conhecimentos foram provenientes de cursos e puderam ser vivenciados na prática na empresa júnior durante a graduação e atualmente no estágio realizado na empresa TEREOS AÇÚCAR E ENERGIA BRASIL.

\section{LORENA SANTOS DE JESUS}

Especialista em Logística pela Universidade Jorge Amado, graduada em Engenharia de Produção e Tecnóloga em Gestão Comercial pela Universidade Salvador.

\section{LUANA DE MENDONÇA}

Graduanda em Engenharia de Produção pela Universidade Federal da Paraíba. Pesquisadora PROBEX - Programa de Bolsas de Extensão/UFPB do projeto intitulado Tipos de Violência contra mulher (da simbólica a física, qual machuca mais?): Uma análise em escolas de nível médio na Paraíba e em Pernambuco.

\section{MARA LUCIA GRANDO}

Coordenadora do curso de Engenharia de Produção da Uceff Faculdades. Coordenadora da CPA - Comissão Própria de Avaliação. Mestre em Engenharia de Produção pela Universidade Federal do Rio Grande do Sul (UFRGS). Professora de Pesquisa Operacional I, II e III, Supply Chain, PCP, Gestão Estratégica da Produção, Gestão da Produção, Logística Industrial, Metodologia Científica.

\section{MARA REGINA DOS SANTOS BARCELOS}

Doutoranda em Engenharia de Produção (Universidade Federal Fluminense), Mestre em Engenharia de Produção (Universidade Estadual do Norte Fluminense - UENF, 2013), Especialista em Educação a Distância (Faculdades Integradas de Jacarepaguá-FIJ, 2011) e Graduada em Tecnologia em Desenvolvimento de Software (Instituto Federal Fluminense, 2009).

\section{MARIA AMELIA DA SILVA DOS REIS}

Graduada em Administração pelo Centro Universitário Central Paulista (2018) 


\section{MARIA EDUARDA NUNES}

Graduanda em Engenharia de Produção pela Universidade Federal de Alagoas - UFAL. Atua no grupo de pesquisa Microssistemas de Análises, nas linhas de pesquisas de desenvolvimento tecnológico de metodologias e materiais, com ênfase processos de adsorção utilizando bioadsorventes e Sistemas micro fluídicos e na diretoria de planejamento de projetos da primeira empresa júnior do curso de Engenharia de Produção, Campus Arapiraca - Unidade de ensino Penedo. Se interessa pelas áreas de processos produtivos e estudo de tempos e movimentos.

\section{MARIA KEYLLYANY RODRIGUES DA SILVA}

Graduanda em Engenharia de Produção mecânica pela Universidade Regional do Cariri URCA

\section{MAX ADILSON LIMA COSTA}

Possui graduação em Licenciatura Plena em Química pela Universidade do Estado do Amazonas (2008), Mestrado (2011) e Doutorado (2016) em Engenharia Química pela Universidade Estadual de Campinas. Tem experiência na área de material lignocelulósico, fermentação em estado sólido, fermentação submersa, enzimas, xilanase, preciptação de proteínas, extratos, Senna reticulata, fungos xilófagos, extração supercrítica, antifúngico.

\section{NICOLAS BOMFIM}

Graduando em Engenharia de Produção na UFAL (Universidade Federal de Alagoas) Unidade de Ensino Penedo, bolsista do PET (Programa de Educação Tutorial) - Conexões de Saberes Penedo. Atua no grupo de pesquisa Microssistemas de Análises, nas linhas de pesquisas de desenvolvimento tecnológico de metodologias e materiais, com ênfase processos de adsorção utilizando bioadsorventes e Sistemas microfluidicos. Desenvolve ações de ensino e extensão com ênfase no ensino da matemática aplicada e línguas estrangeiras. Foi monitor das disciplinas de Espanhol e Matemática no Curso Pré-ENEM comunitário, no curso de Graduação em Engenharia De Produção das disciplinas de Metodologia Científica e Química Tecnológica, e, no curso de Sistema de Informação da disciplina de Matemática 1.

\section{OSVALDO LUIZ GONÇALVES QUELHAS}

Eu sou Engenheiro Civil (1978), Mestre na Engenharia Civil (1984) e Doutor em Engenharia de Produção (1994), sendo meus títulos de Graduação e Mestrado pela Universidade Federal Fluminense e Doutorado com foco em processo decisório para escolhas de fornecedores na cadeia produtiva, pela Universidade Federal do Rio de Janeiro, COPPE. Desenvolvo pesquisas em Associação com professores da UNICAMP, Universidade de Hamburgo (Alemanha); University at Sherbrooke (Canadá); Faculty of Education at North-West University (South Africa); Universitá Politecnica de Catalunya (Barcelona, Spain); Manchester Metropolitana University (South Africa); Department of Environment and Planning, Faculty of Architecture - Damascus University (República Árabe, Síria); Department of Environmental Science, University of Latvia, (Raina, Latvia); Faculty of Philosophy, University of Belgrade, (Belgrade, Serbia). Experiência na área de Planejamento e Controle da Produção e Sistemas de Gestão integrados (Qualidade, Meio Ambiente, Responsabilidade Social e Segurança e Saúde do Trabalho). Com 22 anos de experiência profissional: indústria do petróleo e gás e em empresas de projeto e execução de engenharia. Possuo vivência internacional em capacitações na Espanha e Itália; Professor Titular da Universidade Federal Fluminense na Escola de Engenharia, UFF. Participa como docente e orientador de Mestrado e Doutorado do Programa de Pós Graduação em Engenharia de Produção, Coordena o LATEC / UFF (Laboratório de Tecnologia, Gestão de Negócios e Meio Ambiente), Coordenador do Doutorado em Sistemas de Gestão Sustentáveis, Vice Coordenador do Mestrado Profissional em Sistemas de Gestão do departamento de Engenharia de Produção, UFF. Consultor Ad 
Hoc em Projetos P\&D, CAPES, CNPq e FAPERJ; Autor e Avaliador em periódicos nacionais e internacionais. Editor da Revista BJO\&PM - Brazilian Journal of Operations and Production Management (ISSN:2237-8960) / ABEPRO (DESDE 2015), Presidente da ABEPRO (Associação de Engenharia de Produção) nos mandatos 2006-2007 e 2008-2009.

\section{PAULO ROGÉRIO FREITAS DE MATOS}

Graduado em Engenharia Civil pela Universidade Federal do Ceará (2010) e Especialista em Gestão de Projetos pela Instituição Stella Maris (2016). Atualmente professor substituto do Instituto Federal do Ceará (IFCE-Quixadá) e professor da Universidade Paulista (UNIP Fortaleza), ministrando aulas para nível Técnico e Superior na área de Edificações, Engenharia Civil e Engenharia de Produção. Atuou como Engenheiro Civil em construtoras de grande porte em Fortaleza-CE, gerenciando obras de alto padrão e projetos de engenharia do padrão Minha Casa Minha Vida.

\section{PEDRO MATHEUS VIEIRA PINHEIRO}

Graduação em andamento Engenharia de Produção Civil pelo Instituto Federal do Ceará. Possui o Técnico em Edificações pela E.E.E.P Dr. José Alves da Silveira (2016). Cursando o Técnico em Meio Ambiente pelo Instituto Federal do Ceará. Participou do Programa MiniEmpresa da Junior Achievement Ceará como Diretor de Produção (2015). Atualmente. é Bolsista do Núcleo de Pesquisas e Experimentos Audiovisuais do IFCE, campus Quixadá.

\section{RANNA MARQUES FELIPE}

Graduanda em Engenharia de Produção Civil no Instituto Federal do Ceará. Diretora financeira do time Enactus IFCE Quixadá.

\section{REINALDO JOSÉ TONETE}

Possui graduação em Engenharia de Segurança do Trabalho pela Universidade Braz Cubas (1975), graduação em Engenharia Mecânica pela Universidade Braz Cubas (1975) e mestrado em Engenharia de Produção pela Universidade Federal do Amazonas (2009). Atualmente é professor da Universidade Federal do Amazonas. Tem experiência na área de Engenharia Mecânica, com ênfase em Projetos de Máquinas.

\section{RICARDO MOREIRA DA SILVA}

Pós-Doutor (KTH-Suécia 2012) na área de Energia e Sustentabilidade; Doutor em Administração (PROPAD/UFPE 2011) na área de Gestão ambiental e energética; Doutor e Mestre em Engenharia de Produção (UFPB, 2004, 1998) na área de Gestão da Produção e Engenheiro Elétrico (UFCG 1985). É docente e pesquisador ligado a Pós-Graduação em Engenharia de Produção da UFPB atuando nas áreas de "Gestão ambiental, do conhecimento" e "Gestão Energética e Sustentabilidade"

\section{RODRIGO BÍSCARO NOGUEIRA}

Professor do Instituto de Ciências Exatas e Tecnologia da Universidade Federal do Amazonas, Engenheiro de Materiais pela Universidade Federal de São Carlos e doutor em Ciências pela Universidade de São Paulo. Atua na área de materiais poliméricos e no desenvolvimento de produtos e equipamentos. 


\section{RODRIGO DE CARVALHO PAES LOUREIRO}

Possui graduação em Engenharia de Produção com ênfase em Mecânica pela Universidade Federal do Amazonas (2017). Atualmente é mestrando em Ciência e Engenharia de Materiais pela Universidade Federal do Ceará, atuando na área de Propriedades Físicas e Mecânicas dos Materiais, trabalhando com a caracterização de aço Maraging.

\section{RODRIGO RIBEIRO MONTEIRO GOMES}

Graduando em Engenharia de Produção pela Universidade Federal da Paraíba. Certificado de Estudo de Proficiência de Estudo no Exterior pela Massey University (Nova Zelândia, 20142015). Atuação em Gestão do Planejamento Estratégico no setor de Serviços Comerciais em uma Distribuidora de Energia Elétrica.

\section{SAMANTHA NASCIMENTO SANTANA}

Engenheira da Qualidade em uma indústria multinacional do setor automotivo, graduada em Engenharia de Produção pela Universidade Salvador e Técnica em Química pelo Instituto Federal da Bahia.

\section{SÉRGIO RANGEL FERNANDES FIGUEIRA}

Professor assistente doutor - FCAV-UNESP-Jaboticabal. Possui graduação em Economia pela Universidade de São Paulo (1993), mestrado em Ciência Econômica pela Universidade Estadual de Campinas (1999) e doutorado em Ciências (Economia Aplicada) pela Universidade de São Paulo (2005). Integra também, o corpo docente do curso de Mestrado Profissional em Administração, lecionando a disciplina de Análise Setorial e Competitividade.

\section{SHEILA DA SILVA CARVALHO SANTOS}

Mestre em Administração e Desenvolvimento Empresarial do Programa de Pós-Graduação da UNESA. Possui MBA em Gestão de Recursos Humanos pela Universidade Veiga de Almeida (2012) e graduação em Administração com ênfase em Gestão de Pessoas pela Universidade Federal do Rio de Janeiro (2005). Possui experiência na área de Gestão de Pessoas desde 2010. Atualmente é Administradora na Divisão de Capacitação, Desenvolvimento e Avaliação de Desempenho do Centro Federal de Educação Tecnológica Celso Suckow da Fonseca (Cefet/RJ). Na Nuclebrás Equipamentos Pesados S.A. - Nuclep (Empresa de Economia Mista do Governo Federal) coordenava o processo de avaliação de desempenho da empresa e de integração/ambientação de novos empregados, além de corresponsável pelos treinamentos corporativos.

\section{SOLANGE APARECIDA DE SOUZA MONTEIRO}

Mestra em Processos de Ensino, Gestão e Inovação pela Universidade de Araraquara UNIARA (2018). Possui graduação em Pedagogia pela Faculdade de Educação, Ciências e Letras Urubupunga (1989). Possui Especialização em Metodologia do Ensino pela Faculdade de Educação, Ciências e Letras Urubupunga (1992). Trabalha como pedagoga do Instituto Federal de São Paulo Campus Araraquara.

\section{STEFAN ANTONIO BUENO}

Professor na UCEFF Faculdades de Chapecó, atuando nas disciplinas de PCPI, PCPII, Logística, Gestão de Projetos, Sistemas produtivos e orientações de trabalhos de conclusão de curso. Mestrando em Tecnologia e Gestão da Inovação pela Unochapecó (2019). Especialista em Gerenciamento de Projetos pela Fundação Getulio Vargas - FGV (2015). Graduado em Engenharia de Produção pela Faculdade Empresarial de Chapecó - UCEFF 
(2013). Tem experiência na área de Engenharia de Produção, com ênfase em Logística e Programação e Controle da Produção (PCP), Gestão de Projetos e Sistemas produtivos.

\section{SUELLEN CRISTINA BALDUINO LOPES}

Graduada em Administração pelo Centro Universitário Central Paulista (2018)

\section{SUELLEN KAROLYNE SILVA CORREIA}

Graduanda em Engenharia de Produção, pela Universidade Federal da Paraíba. Pesquisadora na CNPq- Conselho Nacional de Desenvolvimento Cientifico e Tecnológico. Competências em Gerenciamento de Projetos, Planejamento Estratégico, projeto concluído sobre gestão do conhecimento, voltada para inserção feminina na Engenharia de produção aprovado pelo $\mathrm{CNPQ}$, um projeto PIBIC e PROBEX sobre as barreiras ao Empoderamento Feminino. Em andamento com o projeto PIBIC, intitulado "Análise da diferença de produtividade de homens e de mulheres sob excesso de calor em um abatedouro de frangos"

\section{THIAGO SILVA POLLI SANTOS}

Graduado em Administração pelo Centro Universitário Central Paulista

\section{VALNEI CARLOS DENARDIN}

Possui graduação em Ciências Agrárias pela Universidade Federal de Santa Catarina (1989) e mestrado em Ciências dos Alimentos pela Universidade Federal de Santa Catarina (1993). Concluiu os créditos de Doutorado em Engenharia de Produção. Atualmente é professor da Universidade do Sul de Santa Catarina. Tem experiência na área de Agronomia e Engenharia de Produção, com ênfase em Matérias Primas Alimentares, processos produtivos; atuando principalmente nos seguintes temas: controle de qualidade, logística, estatística, plano de negócios, rastreabilidade; alimentos e gastronomia. Atua também como professor nos cursos de pós-graduação na área de logística na UNISUL e SENAC.

\section{VIDAL DIAS DA MOTA JUNIOR}

Possui graduação em Ciências Sociais (UNESP), Especialista em Gestão Pública e Gerência de Cidades (UNESP), Mestre em Ciências Sociais pela Universidade Federal de São Carlos (UFSCar) e Doutor em Ciências Sociais pela Universidade Estadual de Campinas (UNICAMP). Pós Doutor em Ciências Ambientais (UNESP). Professor Titular da Universidade de Sorocaba (Uniso).

\section{WALTHER AZZOLINI JÚNIOR}

Engenheiro de Produção Mecânica (Bachelor of Engineering (B.E.)) pela Universidade Metodista de Piracicaba (UNIMEP) (período: 06/1987 a 12/1991), Mestre em Engenharia Mecânica pela Universidade Estadual de Campinas (UNICAMP) (1994 a 1996 - Conceito CAPES 7) e Doutor (PhD Degree in Engineering/Applied Sciences) em Engenharia Mecânica pela Universidade de São Paulo (Escola de Engenharia de São Carlos (EESC) (2000 a 2004 Conceito - CAPES 6). Cursou os cursos de Extensão Universitária ministrados por docentes da University of Califórnia, Berkeley: Project Management/Logistics and Distribution Channels. 


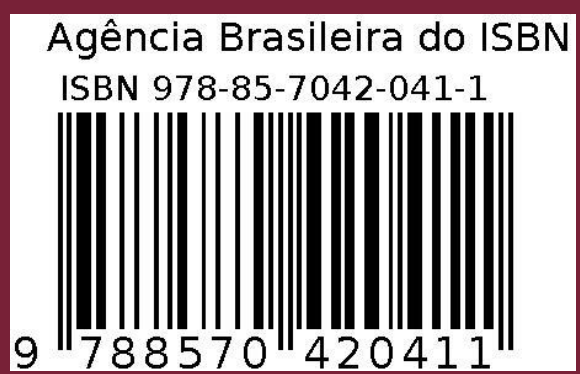

